Universidad Nacional de LA Plata

FACUltad DE Ciencias Naturales y Museo

TESIS DOCTORAL:

\title{
GEOARQUEOLOGÍA DE LOS ZANJONES BLANCO Y ROJO, MACIZO DEL DESEADO, PROVINCIA DE SANTA CRUZ
}

LIC. BRUNO MOSQUERA

TESIS PARA OPTAR AL GRADO ACADÉMICO DE

Doctor EN Ciencias NATURALeS

Dirigido por:

DRA. ADRIANA MÓNICA BLASI \& DR. DARÍO OMAR HERMO 

A mi familia, por estar siempre.

A Pau por estar a mi lado construyendo futuro. 


\section{AGRADECIMIENTOS}

Algo verdaderamente injusto es tener que agradecer a personas cuyos nombres deberían ir junto al mío en la tapa de este trabajo, ya sea por sus aportes en cuanto a discusiones, métodos y contenido, como a su apoyo y aguante durante todo este proceso.

La "Tesis", es en los papeles la culminación de una etapa de mi vida como arqueólogo, pero también he descubierto que es un estado de ánimo. En cualquiera de sus dos facetas, tuve la suerte de estar rodeado de las mejores personas... A ellos les va este agradecimiento.

Adriana Blasi y Fisu (también conocido como Darío Hermo), directores de esta tesis, grandes profesionales y sobre todo amigos. Adriana me aceptó como tesista al momento en que toque la puerta de su laboratorio. Ella sabe de todo, literalmente hablando. Me hizo entender de geología y al escucharla, también supe que" no se nada"... espero haber cumplido sus expectativas. Fisu por otro lado, me conoció siendo un pibe cuando entré por primera vez al laboratorio de arqueología. Aprendí mucho de él desde tecnología lítica, hasta Frank Zappa. Hemos sido compinches de muchas cosas y es un gran amigo. Que haya dirigido este trabajo no es más que una cuestión de justicia. Ambos soportaron estoicamente mis embates de desconcentración, cuelgues y destrucción de cualquier momento de tranquilidad. Tuvieron paciencia para dedicarme momentos de explicación, discusión y lectura, sea en verano, invierno y sin distinción de días hábiles, fines de semana o vacaciones.

En el año 2003, Laura Miotti me permitió ser parte de su equipo de trabajo, me abrió las puertas del laboratorio en el Museo de la Plata y por extensión, las del mundo arqueológico y, con el correr del tiempo, fue la directora de todas las becas que tuve. Me enseño a disfrutar de los viajes de campo, se tomó su tiempo para discutir y enseñarme diferentes temas. Supe ser entre otras cosas, su sobrino ante los ojos del Ing. Cardich, un "desacatado" 
ante su autoridad y un ladero en muchas aventuras. Sobre todas estas cosas la aprecio y le agradezco dejarme formar parte de su gran equipo, sin su apoyo yo no habría llegado hasta aquí.

Ese equipo, no son ni más ni menos que los "chicos del laboratorio", los que compartimos el día a día en el trabajo, los viajes de campo, juntadas, brindis y tantísimas cosas más. Todos ellos merecen mi más sentido agradecimiento ya que contribuyeron para que este trabajo llegue a un buen puerto. A Laurita Marchionni, "huesóloga” de las buenas, por las discusiones y aportes sobre zooarqueología. A Rocío Blanco, porque su cabeza memoriosa es fuente de bibliografía y datos importantísimos y porque los viernes a la mañana se transformaron en una institución de la descontractura. Eloisa García Aniño parte integrante de los viernes a la mañana, fue de gran aliento en más de una ocasión (debe ser porque somos los más jóvenes) y contribuyó en los antecedentes. A Quique Terranova, leyó partes del manuscrito y realizó sugerencias, tiene suficientes cosas positivas como para soslayar el hecho de que es pincha. A Virginia Lynch, por su aporte sobre la discusión de la tecnología lítica, siempre fue una voz de aliento. A Lucía Magnín, que me ayudo con algunas figuras y con quien hemos recorrido muchos kilómetros de meseta que me sirvieron para entender mejor el espacio de nuestra región de estudio. A Natalia Carden, compañera de las primeras épocas, con quien compartimos muchos momentos y viajes de campo. A todos ellos les debo un agradecimiento gigante, no solo por lo mencionado, sino por el placer de trabajar con amigos.

Un agradecimiento especial le corresponde a Diego Gonnet, quien con la mejor predisposición vino de campaña cuando el recurso humano escaseaba, y necesité un par de manos más en el barreno.

En la división mineralogía, la conocí a Carola Castiñeira con quien compartimos la geoarqueología, los mates y discusiones de todos los temas habidos y por haber. Ahora es mi amiga charrúa "puro corazón y garra..." de lo mejor que me dejó este proceso tesístico.

Les agradezco a mis compañeros y compañeras de carrera, Leo Zilio, Heidi Hammond, Eugenia Mellado, Mariana Saez, Laura Palermo y Romina Vázquez con quienes recorrimos un largo camino juntos y hoy compartimos las inquietudes propias de este trabajo.

Heidi y Leo merecen un párrafo aparte. Con cada uno de ellos preparamos finales juntos desde primer año, fuimos compañeros de estudio, somos 
amigos de la vida y por último, editaron de esta tesis y Leo aportó con sus mapas y figuras. Su ayuda y aliento fueron fundamentales para hacerme la carga más liviana y motivarme a terminar. Por eso ¡Gracias!

A mis amigos, los de siempre con los que he compartido todo, les agradezco los momentos el aguante y el aliento. Entre asados, viajes y fútbol siempre estuvieron.

Comenzar a trabajar con Adriana significó mi ingreso en la División Mineralogía, Petrología y Sedimentología del Museo de La Plata, donde conocí grandes personas y profesionales como Silvia Ametrano y Claudia Di Lello que siempre se prestaron a contestar mis preguntas mineralógicas y geoquímicas. También debo agradecer a Florencia Mari del LATYR, a quien interrumpí en más de una ocasión con dudas sobre cronología, calibración y otras yerbas y, con toda su paciencia, se hizo un momento para ayudarme.

A Mariano Del Papa, quien fue consulta y compañero de charlas a dos puertas de distancia.

María Virginia Mancini y su equipo aportaron conocimiento y buena predisposición para poder llevar adelante un análisis polínico en nuestra región de estudio.

A Margarita Osterrieth, Mariana Fernández Honaine y Georgina Erra, les debo el análisis de fitolitos que permitió incluirlo como vía de análisis. Margarita y Mariana se prestaron a un ida y vuelta de mails compartiendo ideas. Georgina siempre estuvo pendiente de mis dudas y me dio aliento para que terminara.

Charles Stern realizó la caracterización geoquímica de las muestras de tefra, siempre tuvo la mejor predisposición para realizar los análisis y para discutir otros temas. Los análisis de Difracción de rayos $\mathrm{X}$ fueron realizados en el CIG y en el Museo de La Plata, por lo que agradezco profundamente a Cecilia Genazzini y María Eugenia del Valle.

Estoy más que agradecido a la Universidad Nacional de La Plata y a la Facultad de Ciencias Naturales y Museo, por el privilegio de haber recibido una educación universitaria pública, gratuita y de calidad. Además, la realización de esta tesis fue posible gracias a la asignación de Becas Tipo A y B de Postgrado de la UNLP.

Mis viejos Quino y Graciela, fueron, son y serán los más grandes. Siempre estuvieron para bancar mis decisiones, incluida la de ser arqueólogo, me dieron libertad y aliento para ser y hacer lo que yo quiera en todo momen- 
to. Lo mismo corre para mis hermanos, los de sangre, Vanina y Mauro, y los políticos Romina y Fabricio (las categorías formales dicen que es mi cuñado, la realidad es que es mi hermano), con quienes somos superficialmente diferentes pero profundamente iguales. Han sido mi modelo a seguir desde siempre, me dieron el lujo de ser tío de Gena, Mate y Manu, tres genios que me hacen revivir las cosas desde otro lado. Por el simple hecho de ser parte de mi vida y darme el lujo de una tener una familia maravillosa: ¡Gracias siempre!

Para terminar, debo recordar que comencé diciendo que la Tesis es un estado de ánimo. En mi caso, quien tiene eso más claro que cualquiera es Pau, el amor de mi vida. Ella estuvo a mi lado todo el proceso de tesis incluso antes de ser siquiera un becario. Ella soportó mis bajones y disfrutó mis alegrías. Fue un aliento y me mantuvo a flote sabiendo que este no es más que solo un paso en el largo camino que emprendimos juntos.

¡Gracias a todos! 


\section{Índice general}

I Presentación 1

1. Introducción 3

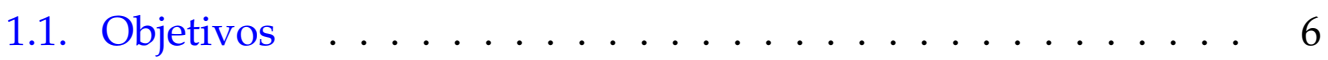

1.2. Hipótesis . . . . . . . . . . . . . . 6

1.3. Organización de la tesis ............. 7

2. Área de Estudio $\quad 11$

2.1. Geología ... . . . . . . . . . . . . . 12

2.2. Geormorfología . . . . . . . . . . . . . . . . 17

2.3. Hidrografía . . . . . . . . . . . . . . . . . . . 19

2.3.1. Mallines .................. 22

2.4. Clima ....................... 25

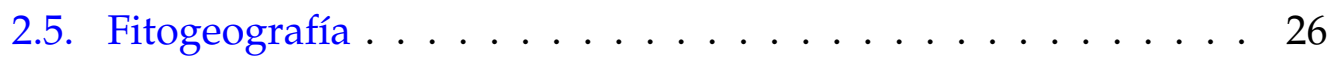

2.6. Zoogeografía .................... 28

3. Evolución Paleoambiental y Paleoclimática 31

3.1. Esquema crono-estratigráfico . . . . . . . . . . . . 32

3.2. Glaciaciones y líneas de costa . . . . . . . . . . . . . . . . 34

3.3. Información Polínica . . . . . . . . . . . . . . . 37

3.4. Estructura faunística . . . . . . . . . . . . . . . . 42

3.5. Vientos y precipitaciones . . . . . . . . . . . . . . . 44

3.6. Erupciones volcánicas . . . . . . . . . . . . . . 45

4. Antecedentes 49

4.1. El desarrollo de la Geoarqueología . . . . . . . . . . . . . . . 49

4.2. Los trabajos geoarqueológicos en la región patagónica ....................... 53

4.3. El estudio geoarqueológico de sitios en cuevas y abrigos rocosos . . . . . . . . . . . . . . 54 
4.4. Modelos de poblamiento . . . . . . . . . . . . . . . . 55

4.5. Los conjuntos arqueológicos del Macizo del Deseado . . . . . 57

4.6. Sitios estudiados en esta tesis . . . . . . . . . . . . . . 60

4.6.1. Anecedentes - Sitio Cueva Maripe . . . . . . . . . . . 60

4.6.2. Antecedentes - Tito del Valle . . . . . . . . . . . 72

4.6.3. Antecedentes - Alero el Puesto $1 \ldots$. . . . . . . . . 73

5. Marco teórico metodológico $\quad 89$

5.1. Escalas de análisis . . . . . . . . . . . . . . . . . . . 91

5.2. Diseño de muestreo . . . . . . . . . . . . . . . . . . . 93

5.3. Perfiles estratigráficos _ . . . . . . . . . . . . . . 997

5.4. Análisis sedimentológico . . . . . . . . . . . . . . . . . 98

5.4.1. Granulométrico . . . . . . . . . . . . . . . . 98

5.4.2. Composición y Forma . . . . . . . . . . . . . . . . . 102

5.4.3. Análisis geoquímicos . . . . . . . . . . . . . . 105

5.4.4. Información cronológica . . . . . . . . . . . . 106

5.4.5. Cálculo de tasas de depositación . . . . . . . . . . 108

5.4.6. Los datos tafonómicos como indicadores indirectos de tasas de depositación y procesos postdepositacionales 109

5.4.7. Proxies Ambientales Biológicos . . . . . . . . . . . . . 111

II Resultados 115

6. Cuenca Alta 117

6.1. Cueva Maripe . . . . . . . . . . . . . . . . . . . . 118

6.1.1. Tipos de aportes sedimentarios: Endógenos y Exógenos . . . . . . . . . . . . . . . 118

6.1.2. Cámara Norte $(\mathrm{CN})$. . . . . . . . . . . . . . . . 120

6.1.3. Análisis sedimentológico . . . . . . . . . . . . . . 121

6.1.4. Cálculo de tasas de acumulación sedimentaria (TAS) . 131

6.1.5. Valoración de los resultados de CN . . . . . . . . . 133

6.1.6. Cámara Sur (CS) . . . . . . . . . . . . . . . . . . 136

6.1.7. Análisis sedimentológico . . . . . . . . . . . . 136

6.1.8. Cálculo de tasas de acumulación sedimentaria (TAS) . 144

6.1.9. Valoración de los resultados de CS . . . . . . . . . . . . 145

6.1.10. Integración de resultados de Cueva Maripe . . . . . 147

6.2. Mallín La Primavera . . . . . . . . . . . . . . . . . . . . . . . 152 
6.2.1. MLP-1 . . . . . . . . . . . . . . . . . . . . 154

6.2.2. MLP-2 . . . . . . . . . . . . . . . . . . . . . . 154

6.2.3. $\quad$ MLP-3 . . . . . . . . . . . . . . . . . 156

6.2.4. $\quad$ MLP-5 . . . . . . . . . . . . . . . . . 158

6.2.5. MLP-6 . . . . . . . . . . . . . . . . . . . . 161

6.2.6. Valoración de resultados . . . . . . . . . . . . . 162

6.3. Análisis de proxies ambientales . . . . . . . . . . . . . . 164

6.3.1. Polen . . . . . . . . . . . . . . . . . . . . . . . 164

6.3.2. Fitolitos . . . . . . . . . . . . . . . 167

6.3.3. Cámara Norte . . . . . . . . . . . . . . . . . . . 171

6.3.4. Mallín La Primavera . . . . . . . . . . . . . . . . . 174

6.3.5. Valoración de resultados . . . . . . . . . . . . . . . 174

7. Cuenca Media 179

7.1. Sitio Tito del Valle . . . . . . . . . . . . . . . . . . . . . . 179

7.1.1. Análisis sedimentológico . . . . . . . . . . . . . . 181

7.1.2. Cauce Sin Nombre de Tito del Valle . . . . . . . . . . . 184

7.2. Valoración de resultados . . . . . . . . . . . . . . . . . 195

8. Cuenca Baja 201

8.1. Sitio AEP-1 . . . . . . . . . . . . . . . . . . . . . . . . 201

8.1.1. Tipos de aportes sedimentarios: Endógenos y Exógenos . . . . . . . . . . . . . . . . . 202

8.1.2. Análisis sedimentológico . . . . . . . . . . . . . 204

8.1.3. Calculo de tasas de acumulación sedimentaria (TAS) . 211

8.2. Paleolago de Piedra Museo . . . . . . . . . . . . . . . . . 213

8.3. Valoración de los resultados de la Cuenca Baja . . . . . . . . . . . . . . . . . . 216

9. Marco cronológico de las ocupaciones humanas 225

9.1. Cuenca de los Zanjones Blanco y Rojo . . . . . . . . . . . 226

9.2. Macizo del Deseado . . . . . . . . . . . . . . . . . . . . 230

9.3. Escala extra-regional: Sectores de costa y cordillera . . . . . . . . . . . . . . . . . . . . 232

9.4. Valoración de los resultados del análisis de... . . . . . . . . 237 


\section{Discusión y Conclusiones}

10. Discusión

10.1. Consideraciones sobre los sitios

arqueológicos estudiados en la cuenca

de los zanjones Blanco y Rojo . . . . . . . . . . . . . . . 249

10.2. Pleistoceno final . . . . . . . . . . . . . . . . . . . 250

10.3. Holoceno Temprano . . . . . . . . . . . . . . . . 256

10.4. Holoceno Medio . . . . . . . . . . . . . . . . . . . . . . 261

10.5. Holoceno Tardío . . . . . . . . . . . . . . . . . . . . . . 269

11. Conclusiones

Bibliografía

286 


\section{Índice de figuras}

2.1. Ubicación del área de estudio y sitios en análisis. CM: Cueva Maripe, TDV: Tito del Valle, PM: Piedra Museo. . . . . . . . 12

2.2. Cuenca del Zanjón Blanco y Rojo, y sitios analizados. . . . . . 13

2.3. Geología del área de estudio. Tomado de Panza (2001). . . . . 15

2.4. Formaciones Geológicas y cuadro estratigráfico del Área de Estudio. Tomado de Panza 2001. . . . . . . . . . . . . . . . . 16

2.5. Paisaje en diferentes sectores del área de estudio. A) Cuenca alta, sector de cabecera del Mallín La Primavera, nótese como se distinguen los sectores más húmedos del mallín B) Cuenca media, tramo del Zanjón Blanco, C) Cuenca Baja, Laguna Grande del Bosque Petrificado. . . . . . . . . . . . . . . 18

2.6. Perfil longitudinal de la Cuenca del Zanjón Blanco y desembocadura del Zanjón Rojo. Los puntos rojos son los que han sido incluidos en el gráfico de altitud de la cuenca. CLP: Cañadón La Primavera, CM: Cueva Maripe, TDV: Tito del Valle, PM: Piedra Museo. Los puntos sin nombre son los asignados a las intersecciones. . . . . . . . . . . . . . . . . . . . . 19

2.7. Barranca Zanjón Blanco. Perfiles estratigráficos de la Cuenca Media del Zanjón Blanco A. Paredón de rocas pre-cuaternarias B. Perfil de la margen opuesta donde se observa un a sección inferior pre-cuaternaria siendo asignable al cuaternario solo el extremo superior (aprox. $1 \mathrm{~m}$ de potencia). . . . . . . . . . 20

2.8. Cuencas hidrográficas principales de la Provincia de Santa Cruz. Ref.: 1. Sitio Cueva Maripe; 2. Sitio Tito del Valle; 3. Sitio AEP-1 . . . . . . . . . . . . . . . . . . . 22

2.9. Ejemplos de barras de grava. . . . . . . . . . . . . 23

2.10. Modelo hidrológico de un área hipotética de meseta basáltica (tomado de Mazzoni y Vázquez 2004). . . . . . . . . . . . . . . 24 
2.11. Tipos de mallines desarrollados en las laderas de mesetas volcánicas (tomado de Mazzoni y Vázquez 2004). . . . . . . . . . 25

2.12. Cuencas hidrográficas del área de estudio. El recorte responde a la cuenca del Zanjón Blanco (Área de Estudio). . . . . . . 26

2.13. Temperatura y precipitación Media Anual de la Provincia de Santa Cruz. Los recuadros negros marcan la ubicación del área de estudio (Tomado de Soto 2004 en Cruzate et al. 2007). . 27

3.1. Evolución de las líneas de costa de Patagonia desde el Último Máximo Glacial hasta el presente. Tomado de Ponce et al. 2011. 36

3.2. Extensión de la línea de glaciares patagónicos en los momentos iniciales de la ocupación humana de la región. Tomado de Coronatto et al. 1999. . . . . . . . . . . . . . . . . . . . . . . 37

3.3. Localidades arqueológicas del Macizo del Deseado con información palinológica. AC: Alero Cárdenas, LT: Los Toldos, PM: Piedra Museo, LMC4: La Martita Cueva 4, LM: La María, LG: La Gruta 1 y $2 . . . . . . . . . . .39$

3.4. Asociaciones polínicas del Macizo del Deseado reconstruidas a partir de sitios arqueológicos en cuevas. (Borromei 2003; De Porras 2010; De Porras et al. 2009; Mancini y Trivi de Mandri 1994; Mancini 1998; Mancini et al. 2008; 2013; Páez et al. 1999).

3.5. Cuadro de síntesis paleoambiental. En Estructura faúnistica, se muestran en rojo las especies extintas y en verde las que ya no habitan la región. . . . . . . . . . . . . . . . . . .

4.1. Vista general del Cañadón La Primavera y la Cueva Maripe al borde del mallín . . . . . . . . . . . . . . . . . . . . . . . 61

4.2. Planta del sitio Cueva Maripe. A) Estratigrafía de Cámara Norte. B) Estratigrafía de CS. C) Cámara Sur, la línea punteada marca el derrumbe mencionado. D) Fondo de Cámara Norte. E) Fondo de Cámara Sur donde surge el manantial mencionado. . . . . . . . . . . . . . . . . . . 62

4.3. Localidad arqueológica Piedra Museo. A. Vista del sitio Alero El Puesto 1 (AEP-1) B. Vista panorámica del paleolago de Piedra Museo (foto tomada desde la cima del afloramiento en el que se emplaza el sitio) . . . . . . . . . . . . . . . . . 74 
4.4. Planta de excavación del sitio AEP-1 de Piedra Museo. Tomado de Marchionni 2013 . . . . . . . . . . . . . . . 75

4.5. Perfil estratigráfico del sitio AEP-1 Tomado de Miotti et al.

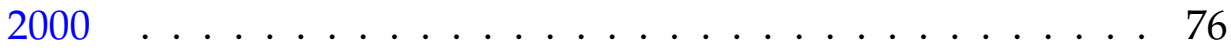

5.1. División del área de estudio en tres subcuencas. CM: Cueva Maripe, TDV: Tito del Valle, PM: Piedra Museo. . . . . . . . . 91

5.2. Extracción de muestras mediante barreno helicoidal en el Mallín La Primavera. La foto corresponde al muestreo MLP1. . 95

5.3. Escala granulométrica de Udden-Wentworth. . . . . . . . . . . 100

5.4. Cálculo y valoración de parámetros estadísticos. A. Fórmulas para la obtención de los parámetros estadísticos mediante el método gráfico. B. Valores límites de las categorías de selección, curtosis y asimetría. . . . . . . . . . . . . . . . 102

5.5. Escala de redondeamiento de granos. Tomado de Powers 1953. 104

5.6. A. Extracción de testigos sin disturbar de un sector húmedo del mallín. B. Empaquetamiento de la columna para su transporte al laboratorio. . . . . . . . . . . . . . . . 113

6.1. Resultado de las difractometrías de rayos $\mathrm{X}$ realizadas sobre una muestra de roca de caja. . . . . . . . . . . . . . . . 119

6.2. Ejemplos de observación y conteo de granos con lupa. A. Capa 3a, fracción $-1 \varphi$. B. Capa 4b, fracción $1 \varphi$. C. Capa 6b, fracción $2 \varphi$. Referencias: RC-Roca de Caja; LO - Lítoclasto oscuro; E - Estiércol; Qz - Cuarzo; C - Carbón; H - Hueso; CR - Clasto Redondeado. . . . . . . . . . . . . . . . . . . . . . 120

6.3. Perfil estratigráfico de Cámara Norte. . . . . . . . . . . . . . . 121

6.4. Resultados de los análisis textural-granulométricos de Cámara Norte: Histogramas de distribución granulométrica, triangulo de clases texturales y cálculo de coeficientes estadísticos. 123 
6.5. Resultados de los análisis de composición sedimentaria de Cámara Norte. A) Porcentajes de componentes reconocidos en las fracciones grava y arena a partir de conteo con lupa binocular. B) Relación de sedimento exógeno y endógeno de cada fracción. C) Relación entre sedimento exógeno y endógeno de la muestra total a partir de la ponderación de los porcentajes de A. D) Composición argilomineral de la fracción arcilla de cada muestra. (Continúa en la siguiente página) . . . . . . . . 125

6.6. Detalle de acumulaciones lentiformes de grava clasto sostén incluidas en la Capa 5a. . . . . . . . . . . . . . . . . . 128

6.7. Suma de probabilidades de las dataciones radiocarbónicas obtenidas en CS. . . . . . . . . . . . . . . . . . . 128

6.8. Distribución de todos los fechados y cálculo de tasa de acumulación general de la Cámara Norte. . . . . . . . . . . . . . 132

6.9. Cálculo de tasas de acumulación por unidad estratigráfica de Cámara Norte. Las tablas muestran los cálculos por pares y debajo de ellas se incluye el resultado obtenido a partir de la ecuación de regresión (en cm/año). . . . . . . . . . . . . . . 134

6.10. Perfil estratigráfico de Cámara Sur. . . . . . . . . . . . . . . . . 138

6.11. Resultados de los análisis textural-granulométricos de Cámara Sur: Histogramas de distribución granulométrica, triangulo de clases texturales y cálculo de coeficientes estadísticos. . . 139

6.12. Resultados de los análisis de composición sedimentaria de Cámara Sur. A) Porcentajes de componentes reconocidos en las fracciones grava y arena a partir de conteo con lupa binocular. B) Relación de sedimento exógeno y endógeno de cada fracción. C) Relación entre sedimento exógeno y endógeno de la muestra total a partir de la ponderación de los porcentajes de A. D) Composición argilomineral de la fracción arcilla de cada muestra. (Continúa en la siguiente página) . . . . . . . . . . 141

6.13. Suma de probabilidades de las dataciones radiocarbónicas obtenidas en CS. Las dos curvas pintadas de rojo corresponden a los fechados que presentan valores anómalos. . . . . . . 142

6.14. Distribución de todos los fechados y cálculo de tasa de acumulación general de la Cámara Sur. . . . . . . . . . . . . . 144 
6.15. Cálculo de tasas de acumulación por unidad estratigráfica de Cámara Sur. Las tablas muestran los cálculos por pares y debajo de ellas se incluye el resultado obtenido a partir de la ecuación de regresión. . . . . . . . . . . . . . . . . . . . 145

6.16. Fechados calibrados y suma de probabilidades de Cueva Maripe. . . . . . . . . . . . . . . . . 148

6.17. Correlación estratigráfica entre las dos cámaras de Cueva Maripe. Los colores asigados a las capas responden a diferencias colorimétricas comparadas con la Munsell Color Chart . . . . 151

6.18. Ubicación de los muestreos realizados a lo largo del Mallín La Primavera. . . . . . . . . . . . . . . . . . . . . 153

6.19. Caracterización sedimentaria de las muestras del testigo MLP1. . . . . . . . . . . . . . . . . . . 155

6.20. Imagen del entorno del que se obtuvo el testigo MLP-2 dentro del Mallín La Primavera. . . . . . . . . . . . . . . . . . 156

6.21. Caracterización sedimentaria de las muestras del testigo MLP2. . . . . . . . . . . . . . . . . . 157

6.22. Sector de la extracción del testigo MLP-3 en relación con los muestreos polínico y MLP-2. . . . . . . . . . . . . . . . 159

6.23. Caracterización sedimentaria de las muestras del testigo MLP3. . . . . . . . . . . . . . . . . 160

6.24. Extracción del testigo MLP-6 sobre el Mallín La Primavera. En el fondo se observa la Cueva Maripe. . . . . . . . . . . . . 161

6.25. Caracterización sedimentaria de las muestras del testigo MLP-

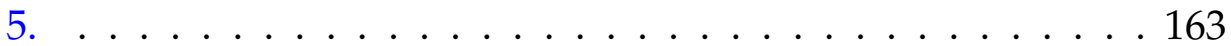

6.26. Columnas estratigráficas de los barrenos realizados en el Ma1 lín La Primavera y sectores aledaños. . . . . . . . . . . . . 165

6.27. Vista del Mallín La Primavera mostrando la ubicación del muestreo polínico y su relación con el Cueva Maripe. La foto está tomada desde las cabeceras del cañadón en dirección NE pudiendo observar, en el fondo de la misma, el bajo en el que corre el Zanjón Blanco. . . . . . . . . . . . . . . . . . . . . 166

6.28. Resultados del análisis sedimentológico de las muestras del testigo MLP-6. . . . . . . . . . . . . . . . . . . 168

6.29. Diagrama polínico del testigo extraído del Mallín La Primavera. 169 
6.30. Perfiles esquemáticos de Cámara Norte y Cámara Sur que señalan el lugar de procedencia de las muestras. . . . . . . . . 170

6.31. Diagrama porcentual de fitolitos de las muestras de Cámara Norte. . . . . . . . . . . . . . . . . . . . 172

6.32. Diagrama porcentual de fitolitos de las muestras de Cámara Sur. . . . . . . . . . . . . . . . . . . . . . . . . . 173

6.33. Diagrama porcentual de fitolitos de las muestras de MLP6. . . 175

7.1. Planta de la cueva Tito del Valle. . . . . . . . . . . . . . . . . 180

7.2. Estratigrafía del sondeo de la cueva Tito del Valle. . . . . . . . 181

7.3. Histogramas de distribución granulométrica, triángulo de clasificación y coeficientes estadísticos de las capas que conforman el depósito sedimentario de la cueva Tito del Valle. . . . 183

7.4. Sector del cauce sin nombre relevado en el sector Cuenca Media. Se señalan diferentes sectores del recorrido que muestran diferentes secciones estratigráficas a lo largo del cauce. . . . . 185

7.5. Imagen de la sección muestreada y columna estratigráfica. . . 186

7.6. Histogramas de distribución granulométrica, triángulo de clasificación sedimentaria y parámetros estadísticos de las capas que conforman el Perfil 5. . . . . . . . . . . . . . . . . 187

7.7. Estratigrafía del perfil 4. . . . . . . . . . . . . . . . . . 188

7.8. Histogramas de distribución granulométrica, triángulo de clasificación sedimentaria y parámetros estadísticos de las capas que conforman el Perfil 4. . . . . . . . . . . . . . . . . . . . 189

7.9. Imágenes de la estratigrafía del perfil 3. En la foto A se puede observar la capa clara de ceniza volcánica la cual en el análisis sedimentológico se denomina Capa V. En la foto B, se ve con claridad la capa oscura que conforma la Capa III. . . . . . . . . 191

7.10. Relación Ti-RB y Sr-Rb de la muestra de ceniza recuperada en el perfil 3 en relación con otras muestras de la región de procedencia conocida. Se grafican las erupciones H1, H2 y 1991 del volcán Hudson. Los datos comparativos fueron extraídos de Naranjo y Stern 1998 y Kratzmann et al. 2010. . . . . . . . . 193

7.11. Histogramas de distribución granulométrica, triángulo de clasificación sedimentaria y coeficientes estadísticos de las capas que conforman el Perfil 5. . . . . . . . . . . . . . . . . . . 194 
7.12. Ejemplo de afloramiento del nivel freático en la base de los cauces de los zanjones secos. . . . . . . . . . . . . . . 197

7.13. Ejemplo de un cuerpo de agua formado en una depresión en un cauce efímero. . . . . . . . . . . . . . . . . . . . . . 198

8.1. A. Imagen satelital de la localidad arqueológica Piedra Museo. B. Panorama visual del paleolago desde el techo del afloramiento de la Formación Puesto el Museo. Referencias: 1. Lugar de extracción del testigo sedimentario del paleolago.

2. Manantial. . . . . . . . . . . . . . . . . . . . . . . . 202

8.2. Imágenes de muestras de roca de caja y de sediemento del sitio AEP-1 . A) Concentración de valvas en la roca de caja. B) Detalle de componentes de la roca, una valva cementada junto a un grano redondeado de cuarzo C) Muestra de roca de caja molida y reconocimiento de sus componentes D) Muestra sedimetaria de Capa 6. Referencias: RC-Roca de caja; CR-Clasto redondeado; CC-Clasto carbonático; Qz-Cuarzo 203

8.3. Histogramas de distribución granulométrica, triángulo de clasificación y coeficientes estadísticos de las capas que conforman el depósito sedimentario de AEP-1. . . . . . . . . . . . . 208

8.4. Resultados de los análisis de composición sedimentaria de AEP-1. A) Porcentajes de componentes reconocidos en las fracciones grava y arena a partir de conteo con lupa binocular. B) Relación de sedimento exógeno y endógeno de cada fracción. C) Relación entre sedimento exógeno y endógeno de la muestra total a partir de la ponderación de los porcentajes de A. . . 210

8.5. Calibración y suma de probabilidades las dataciones provenientes de AEP-1. Nótese que hay una superposición cronológica de dataciones provenientes de Capa 5 y Capa $6 . \quad$. . . . 211

8.6. Distribución de todos los fechados y cálculo de tasa de acumulación general del sitio AEP-1. . . . . . . . . . . . . . . 212

8.7. Cálculo de tasas de acumulación por unidad de excavación de AEP-1. Las tablas muestran los cálculos por pares y debajo de ellas se incluye el resultado obtenido a partir de la ecuación de regresión (en cm/año). . . . . . . . . . . . . . 214 
8.8. Sector de extracción del testigo del Paleolago de Piedra Museo. Al fondo se puede observar el afloramiento de la Fm. El Museo en el que se ubica el sitio AEP-1. . . . . . . . . . . . . 215

8.9. Histogramas de distribución granulométrica, triángulo de clasificación y coeficientes estadísticos del registro sedimentario de un testigo del Paleolago de Piedra Museo. . . . . . . . . . 217

8.10. Techo de Capa 2 de AEP-1. Superficie ondulada que marca la discordancia observada en la estratigrafía (fotografía, Miotti y Marchionni 2011). . . . . . . . . . . . . . . . . . . . . . . . 221

8.11. Estratigrafía de AEP-1 con caracterización general de los aportes sedimentarios y modificaciones postdepositacionales (modificado de Zárate et al. 2000) . . . . . . . . . . . . . . . . . . 222

9.1. Suma de probabilidades de los fechados de la cuenca del Zanjón Blanco y cuenca baja del Zanjón Rojo. Las sombras rectangulares grises marcan los vacíos cronológicos mencionados en el texto. . . . . . . . . . . . . . . . . . . . . . 227

9.2. Suma de probabilidades de los fechados provenientes de diferentes contextos arqueológicos del Macizo del Deseado. Las sombras rectangulares grises marcan los vacíos cronológicos mencionados en el texto. . . . . . . . . . . . . . . . . . . . . . 231

9.3. Suma de probabilidades de los fechados de la costa atlántica entre los paralelos $47^{\circ}$ y $49^{\circ} \mathrm{S}$. Las sombras grises marcan los vacíos cronológicos reconocidos en el Macizo del Deseado. . . 234

9.4. Suma de probabilidades de los fechados del sector Cordillerano entre los paralelos $47^{\circ}$ y $49^{\circ} \mathrm{S}$. Las sombras grises marcan los vacíos cronológicos reconocidos en el Macizo del Deseado. . . . . . . . . . . . . . . . . . 235

9.5. Sumas de probabilidades de las dataciones radiocarbónicas obtenidas en cada área. Las sombras grises marcan los hiatos reconocidos en el Macizo del Deseado. . . . . . . . . . . . . . . 244

10.1. Cuadro comparativo de las tasas de acumulación sedimentaria de AEP-1 y Cueva Maripe. Los valores que acompañan a las rectas responden al valor calculado en cm/100 años presentado en el Capítulo 6. . . . . . . . . . . . . . . . . . 253 
10.2. Cuadro de síntesis de información generada y recopilada tratada en esta tesis. . . . . . . . . . . . . . . . . . 276 


\section{Índice de tablas}

2.1. Categorías de mallines de acuerdo a proporción de humedad (Realizado a partir de Mazzoni y Vazquez 2004). . . . . . . . . 28

4.1. Fechados radiocarbónicos de $\mathrm{CN}$ de Cueva Maripe (Tomados de Miotti et al. 2007; 2014) _ . . . . . . . . . . . . . . . . . 63

4.2. Fechados radiocarbónicos de CS de Cueva Maripe (Tomados de Miotti et al. 2007; 2014) _ . . . . . . . . . . . . . . . . . 64

4.3. Dataciones radiocarbónicas de AEP-1 (Tomadas de Miotti et al. 2003) . . . . . . . . . . . . . . . . . 77

4.4. Características sedimentarias y estratigráficas obtenidas en AEP-1, extraídas de Zárate et al. 2000. . . . . . . . . . . . . 78

5.1. Escalas de análisis seleccionadas en esta tesis. Adaptación a la propuesta de Dincauze (2000). . . . . . . . . . . . . . . . 94

5.2. Testigos sedimentarios obtenidos en el Mallín La Primavera mediante barreno helicoidal. . . . . . . . . . . . . . . . 96

5.3. Perfiles y muestras relevados en el cauce de Tito del Valle. . . 97

6.1. Resultados del análisis sedimentológico de Cámara Norte de Cueva Maripe. Características de color, granulometrías y de porcentajes de materia orgánica y carbonatos de calcio. Referencias: Psef.: psefitas, Amg: Arena muy gruesa, Ag: Arena gruesa, Am: Arena mediana, Af: Arena fina, Amf: Arena muy fina. . . . . . . . . . . . . . . . . . . . . . . . 124

6.2. Resultados del análisis sedimentológico de Cámara Sur de Cueva Maripe. Características de color, granulometrías y de porcentajes de materia orgánica y carbonatos de calcio. Referencias: Psef.: psefitas, Amg: Arena muy gruesa, Ag: Arena gruesa, Am: Arena mediana, Af: Arena fina, Amf: Arena muy fina . . . . . . . . . . . . . . . . 137 
6.3. Datación radiocarbónica obtenida en el testigo MLP6. . . . . . 162

6.4. Dataciones radiocarbónicas del testigo polínico obtenido en el Mallín La Primavera. . . . . . . . . . . . . . . . . . . . . . . . 166

7.1. Resultado del análisis ICP-MS realizado sobre la muestra de tefra que conforma el depósito de capa V del perfil 3. . . . . . 192

8.1. Resultados del análisis sedimentológico de AEP-1. . . . . . . 206

9.1. Fechados radiocarbónicos de sitios arqueológicos en Cuevas del Macizo del Deseado. En la tabla se incluyen los sitios ubicados en la Cuenca de los zanjones Blanco y Rojo. . . . . . . . 227

9.2. Fechados de sitios a cielo abierto de la cuenca de los zanjones Blanco y Rojo. . . . . . . . . . . . . . . . . . . . . . . 230

9.3. Fechados de entierros humanos del Macizo del Deseado. . . . 232

9.4. Fechados radiocarbónicos de las Cuevas de la Costa Norte de Santa Cruz. . . . . . . . . . . . . . . . . . 233

9.5. Fechados radiocarbónicos de sitios tipo concheros de la Costa Norte de Santa Cruz. . . . . . . . . . . . . . . . . . . . . . . . 236

9.6. Fechados radiocarbónicos de entierros humanos de la Costa Norte de Santa Cruz. . . . . . . . . . . . . . . . . . . . . 237

9.7. Fechados radiocarbónicos de sitios arqueológicos en cuevas del sector cordillerano seleccionado. . . . . . . . . . . . . . . . 239

9.8. Fechados radiocarbónicos de sitios arqueológicos a cielo abierto del sector cordillerano seleccionado. . . . . . . . . . . . . . . 241

9.9. Fechados radiocarbónicos de entierros humanos del sector cordillerano seleccionado. . . . . . . . . . . . . . . . . . 242 


\section{RESUMEN}

Esta tesis aborda el estudio geoarqueológico de sitios arqueológicos en cuevas y de geoformas asociadas con la finalidad de aportar nuevos enfoques a la problemática del poblamiento de la región y las decisiones culturales de los cazadores recolectores que habitaron el área de estudio. Consideramos a la geoarqueología como un marco que nos permite abordar tres temáticas principales: cronología, procesos de formación de sitio y reconstrucción paleoambiental.

El objetivo principal de esta Tesis consiste en analizar los ambientes de depositación y los procesos de formación que influyeron a los sitios en cuevas del Macizo del Deseado y al entorno de los mismos, con el fin de discutir los cambios y discontinuidades en el registro arqueológico, en las dinámicas sociales del pasado y en los ambientes de la región a través el tiempo.

El ámbito geográfico seleccionado corresponde al Macizo del Deseado que es una provincia geológica que abarca una superficie de $60.000 \mathrm{~km} 2$, ubicada en el área de la Patagonia extra-andina de la Provincia de Santa Cruz. Dentro de esta macro área de estudio, se reconocen numerosas cuencas endorreicas de diferentes tamaños. Para la realización de este trabajo, el área de estudio seleccionada corresponde a la cuenca del Zanjón Blanco que corre a lo largo de $100 \mathrm{~km}$ en sentido E-O, y que comparte su cuenca baja con el Zanjón Rojo. Los sitios que se analizan son Cueva Maripe ubicada en la cuenca alta, la cueva Tito del Valle en el sector de cuenca media y Alero El Puesto 1 (AEP-1) en el sector de la cuenca baja. Por otro lado, se tomaron como base los fechados radiocarbónicos publicados para la región con el fin de establecer el marco cronológico de análisis. Esto permitió ordenar los datos y las discusiones en cuatro bloques temporales: Pleistoceno final, Holoceno temprano, Holoceno medio y Holoceno tardío.

La mayor parte de los conjuntos arqueológicos en estratigrafía y las secuencias ocupacionales más amplias de la región provienen de sitios en cue- 
vas y abrigos rocosos. A partir de este estado del arte es que aportamos información sobre la conformación sedimentológica de estos sitios, evaluando su capacidad de contener registros de cambios ambientales y el rol de los humanos que los habitaron como agente geomorfológico. Asimismo, hemos realizado estudios sedimentológicos y de otros proxies ambientales (polen y fitolitos) de geoformas asociadas a las cuevas seleccionadas, como son mallines, cauces secos y paleolagos.

Los resultados obtenidos dieron cuenta de la variabilidad estratigráfica de los sitios en cuevas de la región, así como también de los procesos postdepositacionales que los han afectado. También pudimos por un lado conocer la conformación sedimentaria de las geoformas mencionadas que han sido poco estudiadas como fuente de información paleoambiental en el Macizo del Deseado. Mediante el análisis sedimentológico y estratigráfico hemos reconocido que algunos cambios ambientales y climáticos de escala regional y suprarregional tienen su correlato en los depósitos sedimentarios de las cuevas analizadas, y han influido en las tasas de acumulación sedimentaria calculadas para diferentes momentos desde el Pleistoceno.

Además, a partir del análisis de dataciones radiocarbónicas recuperadas en nuestra área de estudio y en escalas mayores hemos definido la presencia de un hiato de casi 1400 años calendáricos en cuanto a las dataciones cronológicas de sitios arqueológicos durante el Holoceno medio, lo que marca una discontinuidad en el uso del área. En este sentido nuestros registros polínicos muestran un momento de disminución en la húmedad en los mallines dentro del periodo abarcado por el hiato cronológico. Asimismo, hay casos de estudio que aportan información en la dirección de un sesgo metodológico que contribuiría a la conformación de esa falta de dataciones en nuestra área de estudio.

La combinación de nuestros datos con los provenientes de los conjuntos arqueológicos de la región nos ha permitido relacionar aspectos de índole paleoambiental con subsistencia y dinámica de los cazadores-recolectores. Este nuevo estado del conocimientos, abre muchas líneas de investigación nuevas, como son la importancia de los mallines como fuente de agua y recursos vegetales, su importancia como reservorio de información paleoambiental, la discontinuidad de uso del espacio estudiado durante el Holoceno medio, y las estrategias utilizadas por los cazadores recolectores de la región ante situaciones climático/ambientales cambiantes. 


\section{ABSTRACT}

This thesis deals with the geoarchaeological study of archaeological caves sites and its associated landforms in order to bring new approaches to the problems of the region peopling and hunter-gatherers cultural decisions who inhabited the study area. Geoarchaeology is considered here as a framework that allows us to address three main themes: chronology, site formation processes and paleoenvironmental reconstruction.

The main objective of this work is to analyze the depositional environments and site formation processes that influenced the Deseado Massif cave sites and the environment near them, in order to discuss changes and discontinuities in the archaeological record, in the social dynamics of the past and in the environments of the region throughout time.

The Deseado Massif geological province covers an area of $60,000 \mathrm{~km} 2$, located in the area of extra-Andean Patagonia Province of Santa Cruz. Within this macro study area, many endorheic basins of different sizes are recognized. To carry out this work, the selected study area is the basin of Zanjón Blanco running along $100 \mathrm{~km}$ in direction E-W, and shares its basin floor with the Zanjón Rojo. The sites analyzed are Cueva Maripe located in the upper basin, Tito del Valle cave in the sector of middle basin and Alero El Puesto 1 (AEP-1) in the downstream sector. On the other hand, we analysed radiocarbon dates published for the region in order to establish the chronological frame for our analysis. This allowed us to sort data and discussions in four time blocks: Late Pleistocene, Early, Middle and Late Holocene.

Most of the archaeological assemblages with broader occupational sequences of this region come from sites in caves and rock shelters. We provide information about the sedimentological conformation of these sites, assessing their ability to contain environmental change records and the human role in its conformation. We have also made sedimentological and proxy data (pollen and phytoliths) analysis of landforms associated with the selec- 
ted caves, such as mallines, ephemeral streams and paleolakes.

The results show stratigraphic variability between the caves, as well as the postdepositational processes that have affected them. Also, we could know the sedimentary deposits of the landforms that have been little studied as a source of paleoenvironmental information in the Deseado Massif. By sedimentological and stratigraphic analysis we found changes in sedimentary deposits of the caves as counterpart of environmental and climatic changes since the Pleistocene.

In addition, using radiocarbon dates analysis we have defined the presence of a hiatus of 1400 calendar years long during the middle Holocene, that shows a discontinuity in the use of the area. In this sense our pollen records shows in the hiatus period, a decrease in humidity in the mallines. There are also local evidences that suggest a geomorphological bias for lack of datings in our study area.

The combination of our data with those from the archaeological assemblages allowed us to relate paleoenvironmental aspects with dynamic huntergatherers subsistence. This new state of knowledge, opens up new lines of research, such as the importance of the mallines as a source of water and plant resources and its importance as paleoenvironmental information reservoir, occupational discontinuity during the middle Holocene, and huntergatherers subsistence strategies applied in changing environmental situations. 


\section{Parte I}

\section{Presentación}





\section{Capítulo 1}

\section{Introducción}

Cuando excavamos un sitio arqueológico, lo que estamos removiendo es "tierra", sedimento. Este sedimento conforma la matriz hospedante de los materiales arqueológicos que estudiamos los arqueólogos, pero también es un reservorio de información paleoambiental y paleoecológica. En el Macizo del Deseado, Patagonia Argentina, los sitios en cuevas y abrigos rocosos son los que hasta el momento, han permitido obtener la mayoría de los contextos arqueológicos en estratigrafía de la región. Sin embargo, el estudio de los depósitos sedimentarios que se acumulan en estas formas erosivas como en su entorno más cercano, así como su vinculación con el registro arqueológico que alojan, no ha sido abordado sistemáticamente en dicha región.

Esta tesis indaga sobre los aspectos geoarqueológicos de sitios arqueológicos en cuevas y su entorno, en un sector particular del Macizo del Deseado, provincia de Santa Cruz, desde la Transición Pleistoceno Holoceno hasta tiempos históricos. Para este fin se adopta un abordaje desde la geoarqueología entendiendo a la misma como una "investigación arqueológica que utiliza métodos y conceptos de las ciencias de la tierra" (Butzer 1982) siendo una herramienta fundamental para la reconstrucción del entorno medioambiental que conformó al paisaje en diferentes momentos del pasado (Rapp y Hill 1998).

De acuerdo con Waters (1992), esta disciplina tiene tres grandes objetivos: 1) la contextualización temporal absoluta o relativa de los sitios arqueológicos y su contenido, 2) la comprensión de los procesos de formación de sitios y, 3) la reconstrucción de los ambientes del pasado de los sitios arqueológicos y su entorno. Estos objetivos generales son los que, en mayor o menor medida, guían nuestro análisis en el área de estudio escogida. A 
partir de lo dicho, aquí consideramos que la investigación geoarqueologíca aporta conocimientos insoslayables para conectar el registro arqueológico con los diferentes escenarios naturales en los que se desenvolvieron las sociedades del pasado.

En este sentido, la matriz de un sitio arqueológico, entendida como el medio físico que hospeda a los materiales arqueológicos, está constituida por dos componentes principales, el sedimento y/o el suelo (Waters 1992). Estos componentes son un proxy data ambiental en sí mismos. Los sedimentos por su parte, pueden tener diferentes orígenes, siendo acumulados por agentes naturales como resultado de la actividad humana. Asimismo, los sedimentos con o sin reorganización pedológica contienen otros registros materiales de gran importancia para la reconstrucción paleoambiental como el polen, los fitolitos y las diatomeas (entre otros). En este marco, el trabajo que aquí se propone toma como principal material de análisis a los sedimentos que conforman los sitios arqueológicos y los depósitos de diferentes geoformas del área que los circunda, ya que estos constituyen la columna vertebral del trabajo geoarqueológico (Goldberg y Macphail 2006), y se analiza su ubicación espacio-temporal a escala de sitio y dentro de la gran cuenca de los zanjones Blanco y Rojo (escala macroregional).

Las investigaciones geoarqueológicas en la región patagónica son relativamente escasas, y en muchos casos responde a abordajes desde la que ha sido denominada geología arqueológica entendida como "la aplicación rutinaria de conceptos y técnicas geológicas a los estudios arqueológicos con poca integración de esta información a las interpretaciones del pasado humano" (Favier Dubois 2014). A diferencia de ese tipo de abordaje, la geoarqueología es una aproximación conceptual que contribuye a la integración de datos desde un acercamiento contextual (Butzer 1982; Favier Dubois 2001).

Específicamente, en la provincia de Santa Cruz son pocos los trabajos geoarqueológicos realizados de modo sistemático. Entre estos se encuentran las investigaciones realizadas por Cristian Favier Dubois en Punta Dungeness/Cabo Vírgenes y Lago Argentino (Favier Dubois 2001) donde el interés se centró en la reconstrucción paleoambiental, al estudio de procesos de formación de sitio y al establecimiento de relaciones cronológicas y estratigráficas a escala regional (Favier Dubois 2003; 2004). Por otro lado, las investigaciones recientes llevadas a cabo en el Campo Volcánico Pali Aike 
por Ramiro Barberena (2008), han puesto gran interés en la geoarqueología tanto a escala regional como de sitio desde una perspectiva biogeográfica (Barberena et al. 2006; 2007).

Las tareas que aquí se desarrollan se enmarcan en un proyecto dirigido por la Dra. Laura Miotti que apunta al estudio del poblamiento de la región y la evolución en tiempo y espacio de las sociedades cazadoras-recolectoras que la habitaron, a partir de diferentes líneas de evidencia como son el arte rupestre, el análisis tecno-morfológico y funcional de artefactos líticos, la zooarqueología, el estudio de sistemas de información geográfica y diatomeas (Blanco y Lynch 2011; Carden 2008; Fernández 2013, Hermo 2008; Lynch 2014; Magnin 2010; Marchionni et al. 2010; Miotti 1992; 1998; Miotti et al. 1999; 2014; Mosquera 2014; entre otros) (Fig. ).

El área de estudio que conforma nuestra mesoescala de trabajo (Dincauze 2000) se enmarca en la cuenca de los zanjones Blanco y Rojo (Panza 2001), la cual fue dividida en tres sectores: Cuenca Alta, Media y Baja según los criterios propuestos por Schumm (1977). Los sitios arqueológicos escogidos para su análisis son Cueva Maripe ubicado en la cuenca alta (Miotti et al. 2007; Hermo y Magnin 2012; Marchionni et al. 2012; entre otros), Tito del Valle en la cuenca media (Carden 2008) y AEP-1 de Piedra Museo en la cuenca baja (Miotti 1992; 1996; Miotti et al. 1999; 2003; entre otros).

En el caso particular de la cuenca de los zanjones Blanco y Rojo y sectores aledaños, la investigación geoarqueológica cuenta con escasos trabajos. Ellos se reducen a unos pocos aportes realizados por geólogos que contribuyeron al conocimiento en casos de estudio particulares (Spalletti y Mazzoni 1975; Blasi et al. 1997; Zárate et al. 2000; Paunero y Blasi 2009). Estos consisten fundamentalmente en el análisis sedimentológico de sitios en cuevas y abrigos rocosos de las localidades arqueológicas de Los Toldos y Piedra Museo, y apuntaron a la descripción estratigráfica y a la inferencia de paleoambientes a partir de indicadores geológicos.

En este contexto, y a partir de la naturaleza de los estudios que se desarrollan en la presente Tesis Doctoral, no sólo se espera contribuir con información inédita proveniente de líneas de evidencia poco abordadas en la región, sino aportar a los resultados de investigaciones previas, dentro de un marco que engloba al ambiente, la geología y el registro arqueológico y al avance del conocimiento científico de la región. 


\subsection{Objetivos}

El objetivo principal de esta Tesis es analizar los ambientes de depositación y los procesos de formación que influyeron a los sitios en cuevas seleccionados y al entorno de los mismos, para discutir los cambios en el registro arqueológico, en las dinámicas sociales del pasado y en los ambientes de la región a lo largo del tiempo.

Dicho objetivo general fue instrumentado siguiendo los siguientes objetivos específicos:

1. Evaluar la conformación y la variación intra e intersitio los depósitos sedimentarios de cuevas.

2. Reconocer e identificar la conformación sedimentaria de geoformas relevantes emplazadas en las adyacencias de los sitios estudiados escogidos a lo largo de la cuenca de los zanjones Blanco y Rojo.

3. Determinar el rol de los humanos en el proceso de acreción sedimentaria dentro de las cuevas estudiadas a lo largo del tiempo.

4. Definir procesos de depositación a partir del estudio estratigráfico/ sedimentológico de los depósitos de cuevas y de geoformas externas asociadas al sitio.

5. Sintetizar y relacionar la información radiocarbónica de sitios arqueológicos a escala regional y macro regional, con los datos paleoambientales disponibles y generados en esta tesis.

6. Discutir las continuidades y discontinuidades del registro arqueológico y cronológico en relación con la dinámica sedimentaria/ geomorfológica y ambiental del área de estudio.

\subsection{Hipótesis}

Las hipótesis de trabajo a contrastar están referidas a los objetivos planteados y se enumeran a continuación:

1. Las estratigrafías de los sitios arqueológicos en cuevas analizados, reflejan los cambios ambientales ocurridos desde el Pleistoceno Tardío hasta la actualidad, debido a su cualidad de ser trampas sedimentarias efectivas. 
2. Las variabilidad arqueológica y tafonómica entre los sitios en cuevas abrigos rocosos en los tres sectores seleccionados de la cuenca son resultado de diferencias paleoambientales locales.

3. La presencia de hiatos arqueológicos y cronológicos en distintos momentos del pasado, tanto en cuevas como en sitios a cielo abierto, se debe a la acción de procesos geomorfológicos actuantes a diferentes escalas, los cuales impidieron su preservación de los conjuntos arqueológicos.

4. La dinámica social de los cazadores recolectores de la región se vio afectada por cambios ambientales ocurridos desde el Pleistoceno final, generando modificaciones en la presencia y características del registro arqueológico recuperado en las cuevas.

\subsection{Organización de la tesis}

Esta tesis se encuentra estructurada en 11 capítulos. En el Capítulo 1, presentamos el problema de investigación y exponemos los objetivos de la misma y las hipótesis a comprobar, así como también los lineamientos que organizaron los procedimientos de campo y de laboratorio. En el Capítulo 2: Área de estudio, definimos el área de estudio seleccionada (cuenca de los zanjones Blanco y Rojo) y sus sectores (Cuenca Alta, Media y Baja), y sintetizamos sus características geográficas, geológicas y ambientales actuales. Asimismo, detallamos la información disponible sobre mallines que son geoformas particularmente interesantes para esta tesis. En el Capítulo 3: Paleoambiente, presentamos las características paleoambientales de la región inferidas desde diferentes líneas de evidencia en un marco cronológico que abarca los últimos 15000 años cal AP, que es la cronología en la que se enmarcan los sitios estudiados. Esta información muestra el panorama ambiental en escalas amplias, que luego nos servirá para reconocer la incidencia de tales cambios en nuestra región. En el Capítulo 4: Antecedentes, realizamos un análisis del contexto histórico de la geoarqueología en general $y$, particularmente de los casos de estudio abordados desde esta disciplina en la región patagónica. Asimismo, se exponen los modelos de poblamiento planteados para la región; las características de los conjuntos arqueológicos provenientes de los sitios estudiados en esta Tesis, y sus relaciones con otros 
conjuntos de la región. Finalmente, brindamos un panorama del aporte de los estudios sobre los proxy data ambientales en nuestra área de estudio. El anclaje teórico-metodológico que utilizaremos se detalla en el Capítulo 5: Marco Teórico-Metodológico, en el que además definimos los sectores de la cuenca, sitios y geoformas que definen el corpus empírico que sustenta esta Tesis. En este capítulo explicamos la metodología de campo y laboratorio aplicada en los diferentes sitios y contextos geomorfológicos, con especial énfasis en el estudio sedimentológico que fue la columna vertebral de este trabajo.

Los capítulos en los que se presentan los resultados de los estudios sedimentológicos y de proxies ambientales son tres (Capítulos 6,7 y 8) y en cada capitulo se presenta el desarrollo de cada sector de la cuenca: la Cuenca Alta, con el sitio Cueva Maripe y el Mallín La Primavera; la Cuenca Media con el Sitio Tito del Valle y el cauce sin nombre y; la Cuenca Baja, con el sitio AEP-1 de Piedra Museo y el paleolago de Piedra Museo. En Cueva Maripe y AEP-1, que presentan secuencias amplias de ocupación humana, se realizaron los estudios texturales y de composición para evaluar ambientes sedimentarios y el rol de los humanos en la conformación del relleno sedimentario. Por su parte, la cueva Tito del Valle fue excavada en el marco de esta tesis, pero debido a que no se recuperaron materiales en estratigrafía, sólo se realizaron estudios texturales. En cuanto a los muestreos realizados para análisis de polen, cabe destacar que fue necesario generar este tipo de información para la Cuenca Alta, en pos de complementarlos con los datos previamente generados para el sector de Cuenca Baja (Borromei 2003). En el Capítulo 9 se presentan los resultados de la revision bibliográfica que permitió recopilar la información radiocarbónica de nuestra región de estudio y de zonas aledañas. A partir del análisis y calibración de estos fechados pudimos vislumbrar la presencia de un vacío cronológico de casi 1400 años cal. AP durante el Holoceno Medio que abre interrogantes con respecto a los modelos de poblamiento del sector para ese momento.

Finalmente, los resultados sedimentológicos, de proxies ambientales y cronológicos son interpretados, discutidos en relación con el registro arqueológico presente en las diferentes escalas espacio-temporales analizadas durante los capítulos previos (Capítulo 10: Discusión), lo que permitirá relacionar las variaciones ambientales con los cambios en la evidencia arqueológica y los hiatos cronológicos/ocupacionales registrados en el norte santa- 
cruceño. Así, en el Capítulo 11: Conclusiones, expondremos los lineamientos y tendencias generales que surgen de nuestra investigación, así como las nuevas interrogantes que se nos presentaron y que permitirán orientar las investigaciones futuras. 


\section{Capítulo 2}

\section{Área de Estudio}

En este capítulo se define y describe el área de estudio donde tuvieron lugar los trabajos realizados en esta tesis. Aquí se resume la información geológica y geomorfológica disponible, así como también, las características ambientales de la región y la macro región de estudio. Se describen además las características fisiográficas y ecológicas que servirán para contextualizar los análisis realizados y los resultados obtenidos. Por último, este marco de referencia actual del área, servirá de base para referir las discusiones y conclusiones que surgen del análisis y evolución de las condiciones ambientales en esta área de estudio.

La provincia de Santa Cruz, así como el resto de la Patagonia puede dividirse geológica y geomorfológicamente en dos regiones principales: sector de la cordillera Andina o sistema andino, que es una franja montañosa con una orientación general N-S ubicada al oeste, y la meseta o Patagonia extraandina, que se extiende entre la cordillera y el litoral atlántico y comprende una serie de planicies escalonadas que descienden en altura de oeste a este (Feruglio 1949).

La región de estudio se incluye en el ámbito de la Patagonia extra-andina, dentro del Macizo del Deseado (De Giusto et al. 1980) el cual será considerado como la macro-área de estudio (Dincauze 2000) (Figura 2.1). Dentro de la Hoja Geológica 4769-IV Monumento Natural Bosque Petrificado, Provincia de Santa Cruz, 1:250.000 (Panza 2001) se puede individualizar el área de trabajo que compete a esta tesis y que corresponde a la cuenca del Zanjón Blanco y la cuenca baja del Zanjón Rojo (Figura 2.2). En esta cuenca se han desarrollado gran parte de los trabajos arqueológicos del equipo de trabajo de la Dra. Miotti y se cuenta con dos sitios excavados hasta la roca de base 


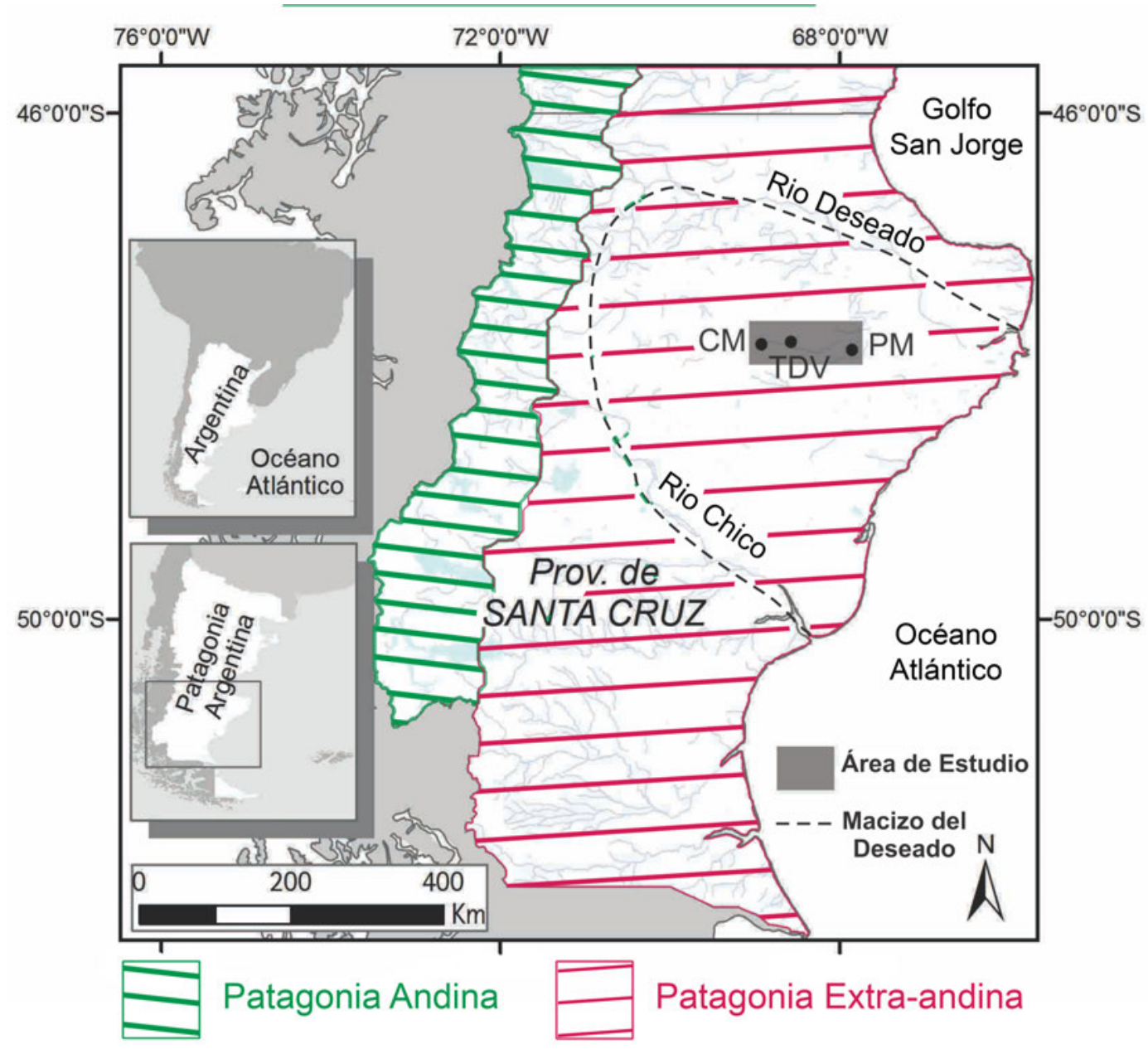

Figura 2.1: Ubicación del área de estudio y sitios en análisis. CM: Cueva Maripe, TDV: Tito del Valle, PM: Piedra Museo.

con secuencias de ocupación amplias como Cueva Maripe en la cuenca alta del Zanjón Banco (Miotti et al. 2007; 2014) y AEP-1 de Piedra Museo en la cuenca baja de los Zanjones Blanco y Rojo (Miotti 1992; Miotti et al. 1999; 2003). Además, para esta tesis se realizó una excavación en el sitio Tito del Valle ubicado en la Cuenca Media del Zanjón Blanco.

\subsection{Geología}

El Macizo o Nesocratón del Deseado es una provincia geológica argentina (De Giusto et al. 1980) limitada al norte por el Río Deseado, al sur por el Río Chico, al este por la costa atlántica y al oeste por la dorsal del Río Mayo limitando con la Cordillera Patagónica Austral (Figura 2.1). Este macizo o 


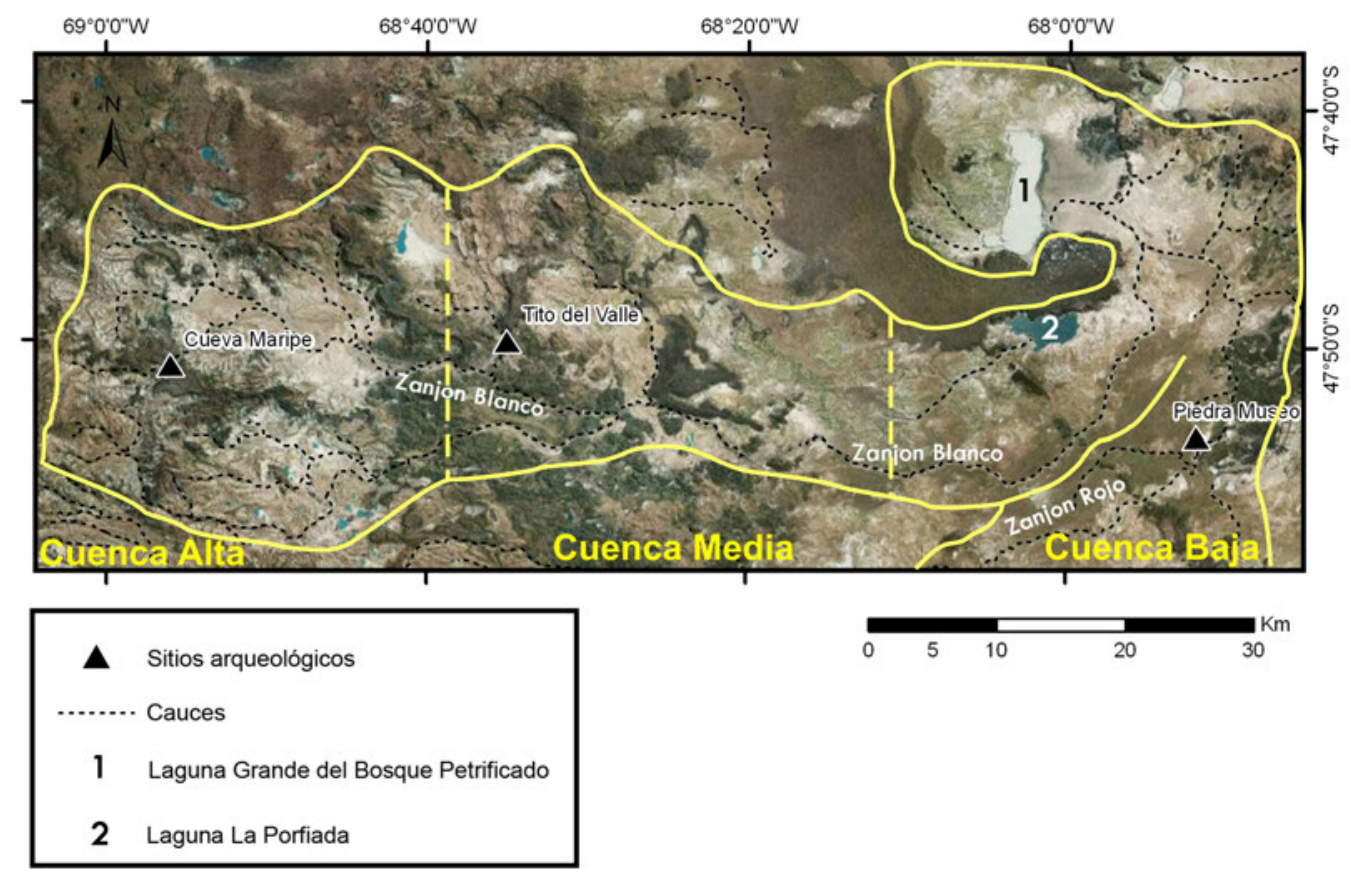

Figura 2.2: Cuenca del Zanjón Blanco y Rojo, y sitios analizados.

nesocratón, se caracteriza por un comportamiento temporalmente positivo y rígido con respecto a regiones vecinas con la subsidencia característica de la cordillera al oeste y las cuencas pericratónicas del Golfo San Jorge al norte y la cuenca Austral al sur (De Giusto et al. 1980).

El Macizo del Deseado es resultado de diferentes ciclos diastróficos, cuyos rasgos estructurales están principalmente ligados a la orogenia de la Cordillera Patagónica Austral en conjunción con la evolución de la dorsal meso-atlántica durante el Mesozoico y Cenozoico (Panza 2001). En cuanto a la estructura del área, es notoria la presencia de fallamiento en bloques, los cuales responden a dos sistemas de fracturación principales denominados El Tranquilo (dirección principal $\mathrm{N} 35^{\circ} \mathrm{O}$, conjugada N60 ${ }^{\circ}$ ) y Bajo Grande $\left(\mathrm{N} 64^{\circ} \mathrm{O}\right.$ y $\mathrm{N} 35^{\circ} \mathrm{E}$, respectivamente) quedando subordinadas a éstos, las estructuras de plegamiento (Panza 2001).

La secuencia geológica aflorante (Figura 2.1 y 2.4) se compone en primer lugar por rocas jurásicas de origen lávico-piroclástico, representadas por las formaciones Roca Blanca (Liásico) y Bajo Pobre (Dogger Inferior) (Guido et al. 2006). Sobre éstas se dispone el complejo lávico-piroclástico Bahía Laura (Dogger superior- Malm inferior), conformado por dos formaciones de las más importantes del macizo: Fm. Chon Aike y Fm. La Matilde. Las ig- 
nimbritas y tobas de Chon Aike albergan una gran cantidad de cuevas con sitios arqueológicos, entre ellas Cueva Maripe que es estudiada en esta tesis y las tobas de la Fm. La Matilde contienen bosques petrificados de araucaria (Figura 2.3).

A finales del Jurásico e inicios del Cretácico un acontecimiento diastrófico desarrolló una estructura de bloques por fracturación que generaron cuencas en las que se registran, posteriormente, episodios de sedimentación continental. Los depósitos sedimentarios se asignaron a la la Fm. Bajo Grande (Kimmeridgiano superior-Hauteriviano) compuesta por areniscas tobáceas, tobas y chonitas que apoya en discordancia angular sobre el grupo Bahía Laura y la Fm. Baqueró (Barremiano-Aptiano) que incluye tobas, cineritas, pelitas y areniscas gruesas a conglomerados (Panza 2001).

A continuación se produjo la emisión de lavas básicas agrupadas bajo el nombre Basalto Las Mercedes (Cretácico superior). En algunos sectores acotados de la hoja, las unidades jurásicas y cretácicas han sido cubiertas por sedimentitas psamo-pelíticas de la Fm. Salamanca, que apoya en discordancia sobre las anteriores. Por encima, apoya el Basalto La Levadura y sedimentitas continentales del paleoceno incluidas en la Fm. Rio Chico (Panza 2001).

Luego, en el Cenozoinco, durante el Eoceno tuvieron lugar las efusiones volcánicas que dieron lugar al Basalto Cerro del Doce y durante el eoceno medio a superior se depositaron las sedimentitas coquinoides de la Fm. Puesto El Museo, en la cual se emplaza el sitio Piedra Museo que analizamos en esta tesis (Panza et al. 1996).

Para el Oligoceno se reconoce en algunos sectores a las bentonitas de la Fm. Sarmiento y al Basalto Alma Gaucha que cubre varias de las unidades antes mencionadas. Sobre estas, en discordancia angular regional apoyan las sedimentitas marinas de la Fm. Monte León.

Durante el Neógeno se registran ciclos basálticos y niveles de terrazas de gravas asociadas al Rio Deseado. Los basaltos neógenos se denominan El Pedrero, Madre e Hija y Cerro El Mojón. Hacia fines del Neógeno en inicios del Cuaternario (Plioceno-Pleistoceno) se reconoce el último episodio basáltico de la región: el Basalto La Angelita.

En cuanto a los depósitos que tuvieron lugar durante el Pleistoceno tardío y el Holoceno descriptos en la hoja geológica, se reconocen para este intervalo los depósitos que forman los dos últimos niveles de terrazas flu- 


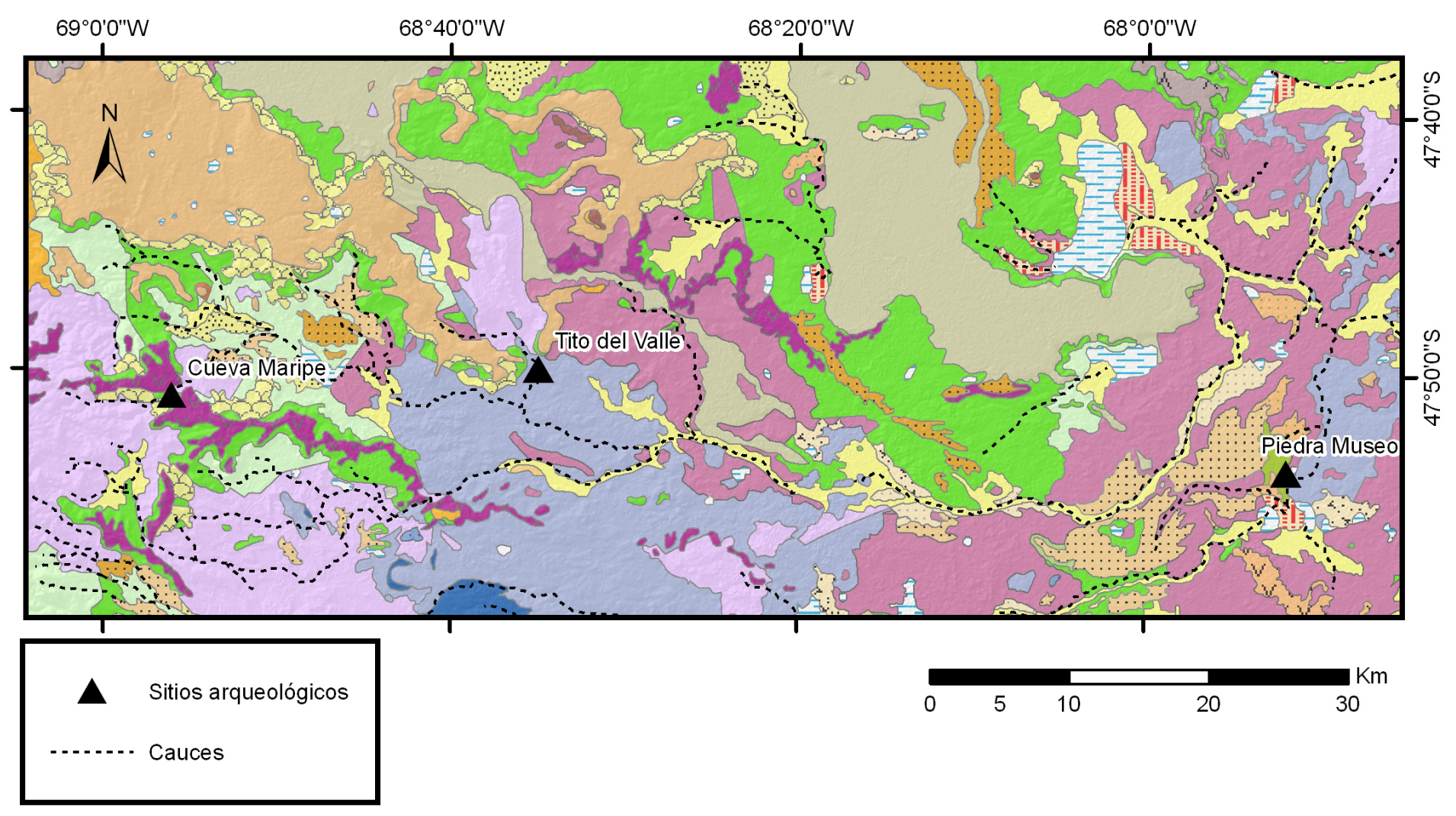

:

Referencias

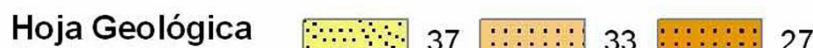

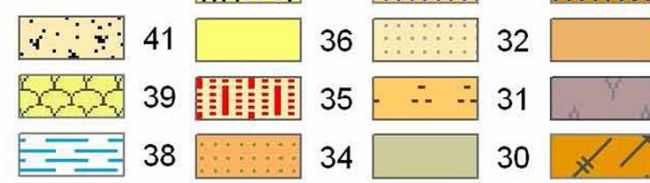
26 25 $2 1 \longdiv { V W }$

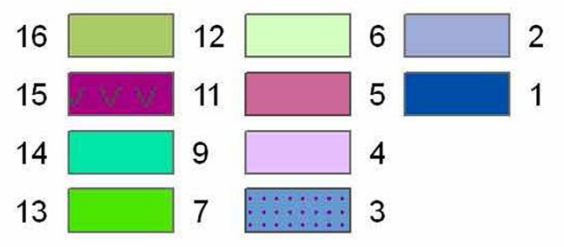

Figura 2.3: Geología del área de estudio. Tomado de Panza (2001). 


\section{CUADRO ESTRATIGRAFICO}

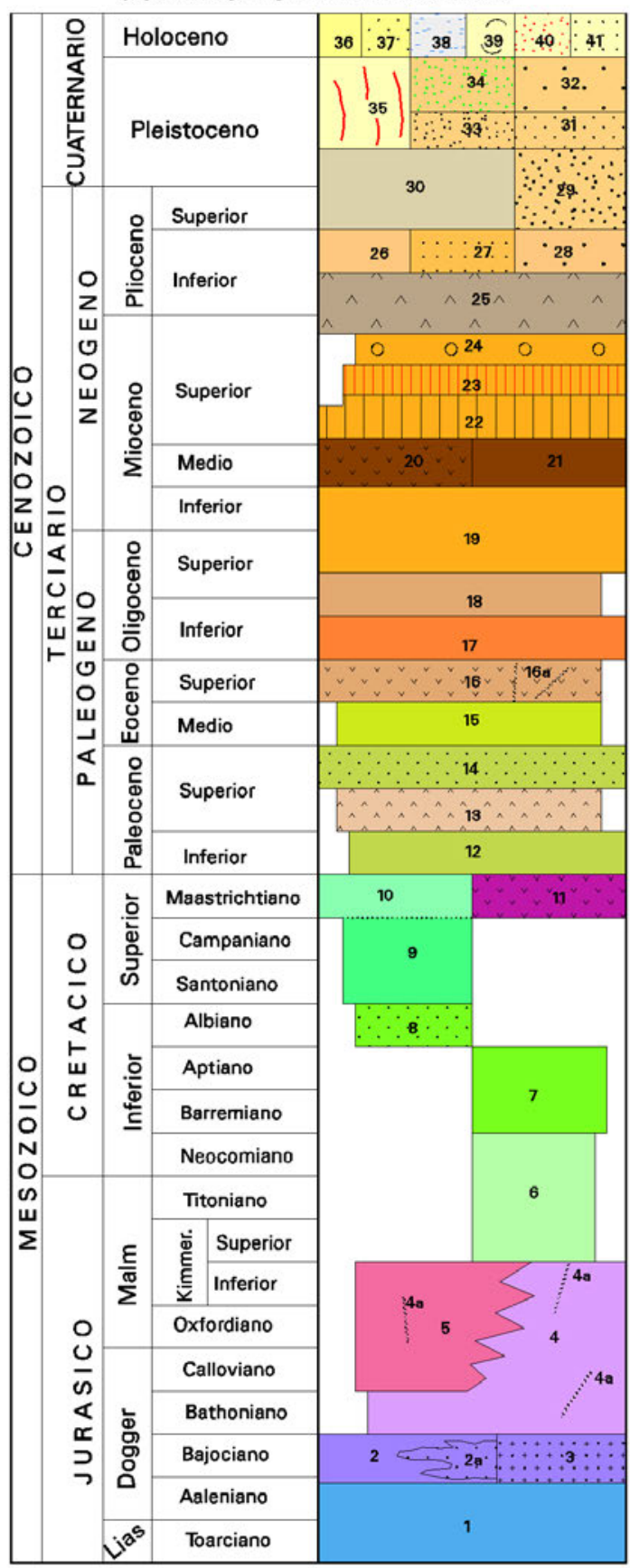

41 DEPOSTTOS ALUVIALES Y COLUVIALES INDIFERENCIADOS. Arenas finas a medianas, limos y arcillas subordinados; rodados diepersos. 40 DEPOSTrOS EOLICOS. Arenas finas a medianas.

39 MATERIAL DE DERRUMBES Y DESLIZAMIENTOS. Bloquos.

38 SEDIMENTOS FINOS DE BANOS Y LAGUNAS. Limos $y$ arcillas.

37 DEPOSITOS DE CONOS ALUVIALES. Arenas y gravas; limos y arcillas subordinados.

36 DEPOSTOS DE PLANICIES ALUVIALES. Arenas finas a gruesas, gravas, limos y arcillas.

35 DEPOSTOS DE ANTIGUAS PLAYAS Y CORDONES LTTORALES LACUSTRES. Aronas

finas, limos y aroillas; cordones de gravas finas con matriz arenosa.

34 , 33 DEPOSITOS QUE CUBREN NIVELES DE PEDIMENTOS. (Niveles 11 y III).

Gravas con matriz arenosa y limosa, y arenas.

32, 31 DEPOSITOS DE TERRAZAS FLUVIALES DEL RIO DESEADO. (Niveles VI y VII).

Gravas arenosas, arenas finas a gruesas subordinadas, escasos limos y

30 BASALTO LA ANGELTA. (Continemtal). Bagaltos OlMinicos.

29, 28 DEPOSITOS DE TERRAZAS FLUVIALES DEL RIO DESEADO (Niveles N y V).

Gravas con matriz arenosa y arenas.

27 DEPOSTTOS QUE CUBREN NIVELES DE PEDIMENTOS. (Nivel I). Gravas con matriz arenosa, arenas.

26 FOPMACION LA AVENIDA (Continental). Gravas medianas a grueses con matriz

arenosa.

25 BASALTO CERRO MOJON. (Continental). Basaltos olivinioos.

24, 23, 22 DEPOSITOS DE TERRAZAS FLUVIALES DEL RIO DESEADO (Niveles 1, 11

21 FOPMACION MADRE E HWA. Foiditas (analoimicas, nefelinitas y fonolitas).

20 BASALTO EL PEDRERO (Continental). Basaltos olivínicos.

19 FOFMACION MONTE LEON. (Marina). Aroilitas, tobas, coquinas y areniscas.

18 BASALTO ALMA GAUCHA. (Continental). Basaltos olivinicos y basanitas.

17 FOPMACION (GRUPO) SARMIENTO. (Continental). Tobes, cineritas, arcilites

tobáceas y bentonitas.

16 BASALTO CERRO DEL DOCE. (Continental). Basaltos olivínicos. 16a Chimeneas

y diques.
15 FOPMACION PUESTO DEL MUSEO. (Marina). Areniscas coquinoides.

14 FOPMACION RIO CHICO. (Continental). Tobas, chonitas, areniscas finas a

medianas, arcilitas.

13 BASALTO LA LEVADURA. (Continental). Basaltog olivinicos.

12 FOPMACION SALAMANCA. (Marina). Areniscas fines a medianes, aroilthas, areniscas ooquinoides.

11 BASALTO LAS MERCEDES (Continental). Basaltos olivinicos.

$10,9,8$, GRUPO CHUBUT

10 FORMACION LAGUNA PALACIOS. (Continenta). Tobas, oineritas;

tufftas subordinadas.

9 FORMACION BAJO BARREAL.(Continental). Chonitas, arcilitas y

limolitas tobaceas; escasas areniscas y conglomerados tobáceos.

8 FORMACION CASTILLO. (Cortinental). Tobas, tobas finas y tufftas.

7 FOPMACION BAQUERO. (Continenta)). Tobas, oineritas, pelitas, areniscas

gruesas a conglomerados.

6 FOPMACION BAJO GRANDE (Comtinenta). tobes, tufitas, arenisces y

onglomerados; escasas calizas laminadas.

5, 4, 4a GRUPO BAHIA LAURA

5 FORMACION LA MATILDE. (Continemta). tobas, ohonitas, lapillitas

y tufitas; delgadas intercalaciones de ignimbritas rioliticas.

4 FORMACION CHON AIKE. (Continenta)). Ignimbritas, aglomerados y

tobes rioliticas; escasas tufitas y pórfiros rioliticos.

tobas rioliticas; escasas tufitas y por

4a filones epitermales de ouarzo.

3 FOPMACION CERRO LEON. (Continental). Pórfiros andesiticos, diabasas.

voloánicos. 2a Intercalación piro-sedimentaria.

1 FOFMACION ROCA BLANCA. (Continental). Tobas, arenisoas, tufitas y pelitas.

Figura 2.4: Formaciones Geológicas y cuadro estratigráfico del Área de Estudio. Tomado de Panza 2001. 
viales del Rio Deseado y otros depósitos que cubren superficies de pedimentos, antiguas playas y cordones litorales lacustres, de planicies y conos aluviales, eólicos, de bajos sin salida y productos de remoción en masa. La información que se puede obtener de estas cartas geológicas para tiempos recientes es prácticamente nula a los fines de un estudio arqueológico, ya que no tienen el grado de detalle necesario para alinearse con la información arqueológica por lo que se necesitan estudios de ajuste en este sentido (Zárate 1993, Blasi 2008).

En términos generales, la geología de la región está compuesta principalmente por los depósitos volcánicos del Jurásico medio y superior (Fm. Bajo Pobre, Chon Aike, La Matilde, Bajo Grande) que conforman un extenso plateau que cubre más de la mitad de la superficie del Macizo. En muchas de estas Formaciones se generaron cuevas que han sido estudiadas por su contenido arqueológico como en el caso de Cueva Maripe, Cueva de las Manos, Localidad La María (Chon Aike) entre otras, o Tito del Valle (Bajo Pobre). Además cabe destacar que muchas de esas formaciones rocosas poseen litologías que han sido utilizadas por los grupos cazadores-recolectores durante todo el Holoceno para la manufactura de artefactos (véase síntesis de la importancia tecnológica de estas rocas en Hermo 2008, Hermo et al. 2015 y Magnin 2015), así como para soporte de manifestaciones rupestres (Carden 2008).

\subsection{Geormorfología}

Desde el punto de vista geomorfológico, las formas del paisaje son producto tanto de la actividad volcánica efusiva (campos de lava), como de la acción de varios agentes modeladores del paisaje, dentro de los cuales predomina la acción fluvial, la acción eólica y los procesos de remoción en masa. En este sentido, el intemperismo es un factor esencial en los procesos de erosión y generación de detritos. El área de estudio presenta dos grandes tipos de paisaje característicos: las serranías, y las mesetas basálticas con procesos de remoción en masa asociados (Oliva et al. 2001). En muchos sectores del área, grandes mesetas volcánicas cubren y protegen de la erosión a formaciones de tobas, ignimbritas y sedimentitas friables sobre las cuales la erosión ha labrado valles y cañadones, como por ejemplo el Cañadón La Primavera. En la Figura 2.5 se pueden observar ejemplos de diferentes 
paisajes dentro de la cuenca estudiada.

La pendiente general de la región disminuye en sentido W-E, registrándose elevaciones máximas de 850 m.s.n.m en el oeste sobre la meseta que marca el límite de la cuenca del Zanjón Blanco (Figura 2.12) y 40 m.s.n.m en la Laguna Grande que funciona como nivel de base de la cuenca endorreica del cañadón mencionado (Figura 2.6).

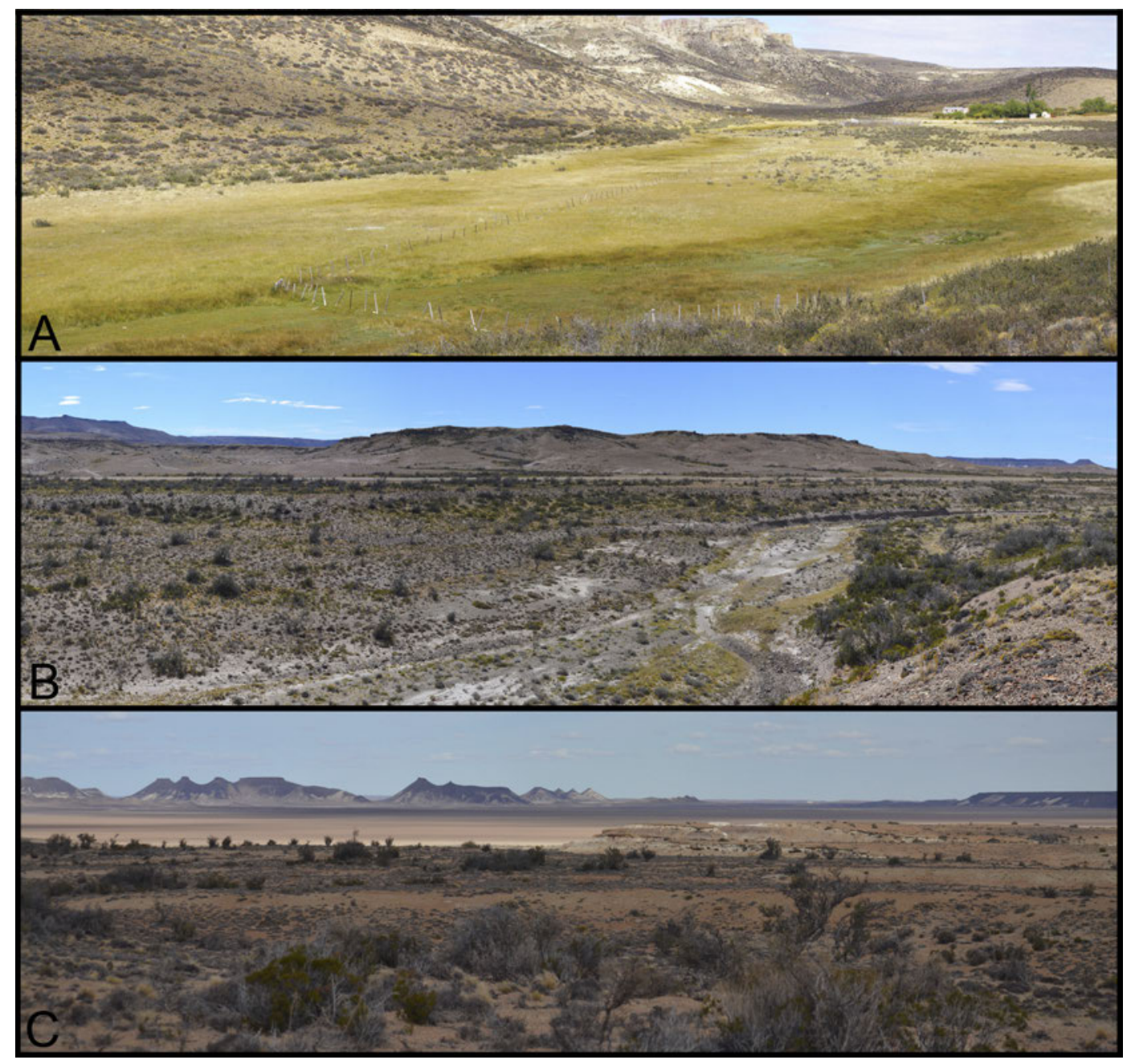

Figura 2.5: Paisaje en diferentes sectores del área de estudio. A) Cuenca alta, sector de cabecera del Mallín La Primavera, nótese como se distinguen los sectores más húmedos del mallín B) Cuenca media, tramo del Zanjón Blanco, C) Cuenca Baja, Laguna Grande del Bosque Petrificado. 


\subsection{Hidrografía}

La región abarcada por la Hoja 4769-IV presenta como principal curso hídrico en su extremo NE al Rio Deseado, el cual es un curso efímero que nace en el Lago Buenos Aires al NW de la provincia de Santa Cruz y desemboca en el océano Atlántico en la localidad de Puerto Deseado al sur del Golfo San Jorge.
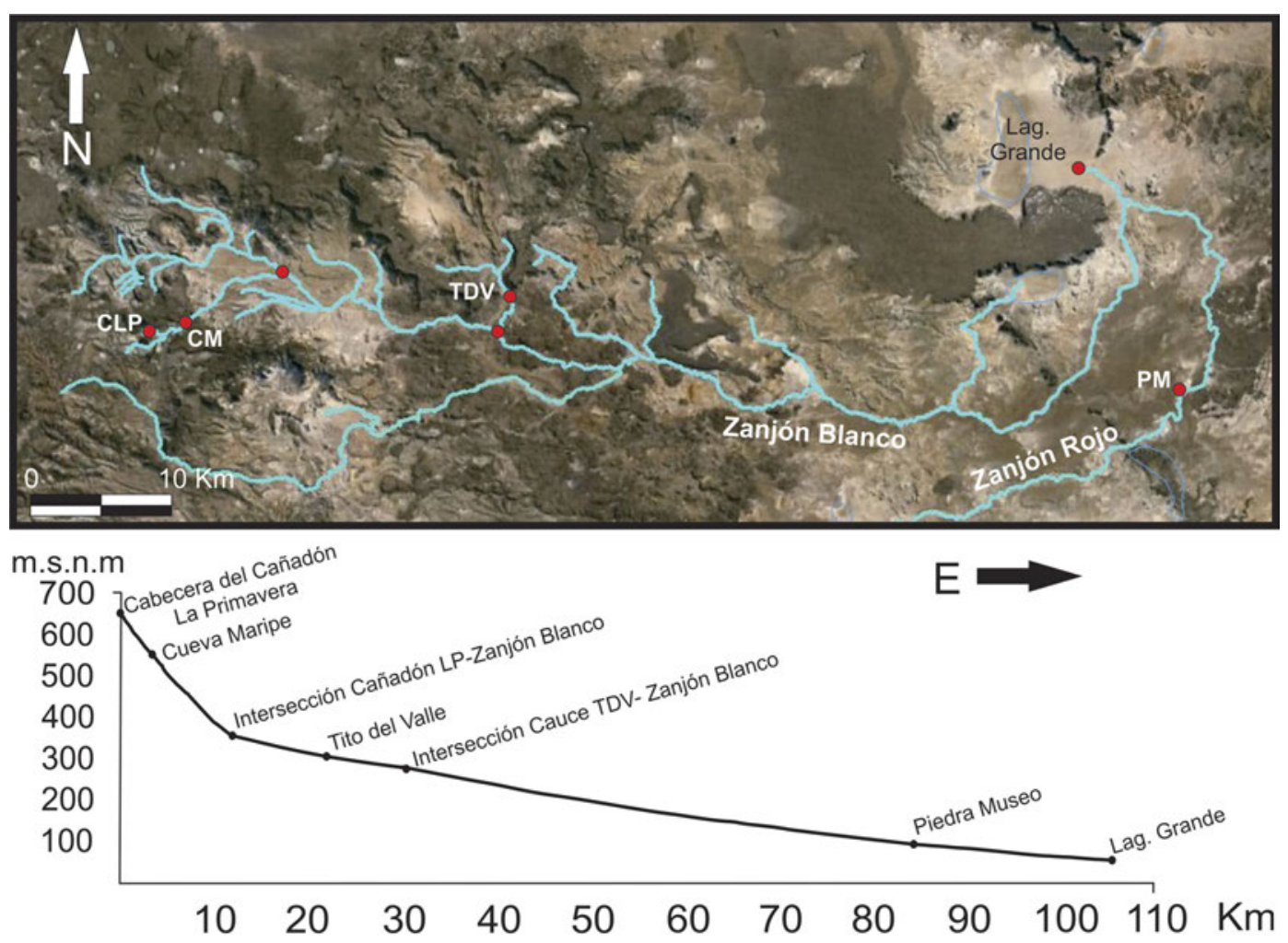

Figura 2.6: Perfil longitudinal de la Cuenca del Zanjón Blanco y desembocadura del Zanjón Rojo. Los puntos rojos son los que han sido incluidos en el gráfico de altitud de la cuenca. CLP: Cañadón La Primavera, CM: Cueva Maripe, TDV: Tito del Valle, PM: Piedra Museo. Los puntos sin nombre son los asignados a las intersecciones.

Con excepción del Río Deseado y el Río Chico que delimitan al Macizo del Deseado al norte y sur respectivamente (Figura 2.8), la hidrografía de la región se compone de cuencas endorreicas de distinto tamaño formadas por cursos efímeros, lagunas secas y bajos sin salida. Estos cauces efímeros transportan agua principalmente en invierno que coincide con la época de lluvias. Una de las mayores cuencas endorreicas es la de los zanjones Blanco y Rojo, dos cauces que corren casi paralelamente en dirección E-O y que 
desembocan en la Laguna Grande del Bosque Petrificado (Figura 2.6). Por lo tanto, nuestra área de estudio queda definida por la cuenca del Zanjón Blanco y la desembocadura del Zanjón Rojo (Figura 2.6).

El Zanjón Blanco nace en las mesetas basálticas de Los Navarro y a lo largo de su trayecto recibe a numerosos cursos tributarios entre los que se pueden mencionar al Cañadón La Primavera en las cabeceras de su cuenca, donde se emplaza Cueva Maripe; un cauce sin nombre en la cuenca media sobre el que se emplaza Tito del Valle, mientras que en la cuenca baja, en los márgenes de un paleolago sobre el Zanjón Rojo, se emplaza Piedra Museo, el tercer sitio arqueológico estudiado. El Zanjón Blanco se extiende a lo largo de aproximadamente $110 \mathrm{~km}$ comenzando a una altura cercana a los 670 m.s.n.m. hasta su desembocadura en la Laguna Grande del Bosque Petrificado a 45 m.s.n.m (Figura 2.6).

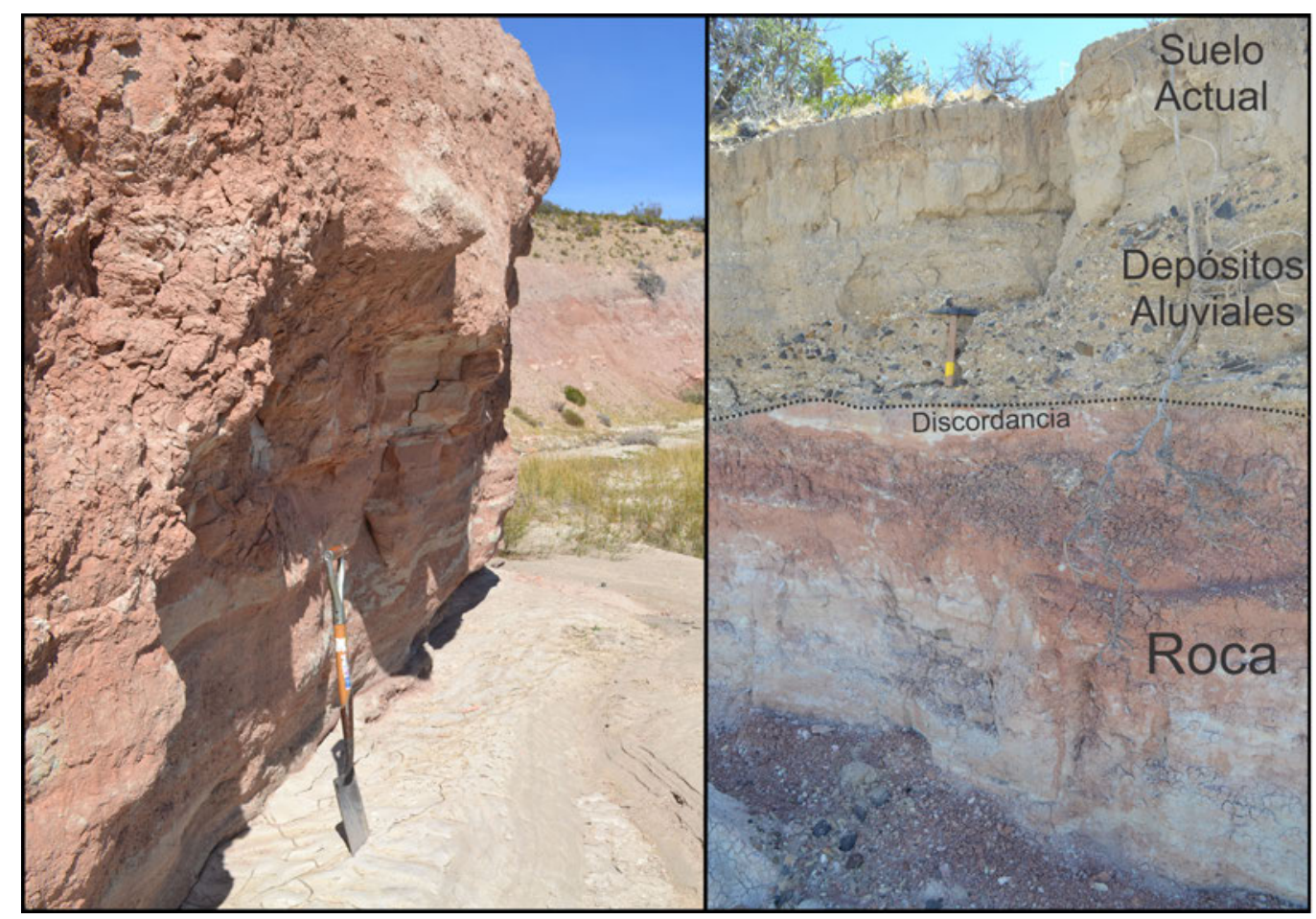

Figura 2.7: Barranca Zanjón Blanco. Perfiles estratigráficos de la Cuenca Media del Zanjón Blanco A. Paredón de rocas pre-cuaternarias B. Perfil de la margen opuesta donde se observa un a sección inferior pre-cuaternaria siendo asignable al cuaternario solo el extremo superior (aprox. $1 \mathrm{~m}$ de potencia).

En general, la red de drenaje presenta un diseño rectangular-angular debido al fuerte control estructural ejercido sobre los cursos de agua por dia- 
clasas y fracturas. Estos cauces pueden definirse como subsecuentes ya que en gran parte se ajustan a fallas y fracturas (Panza 2001). Esta característica es notoria sobre todo en los cauces principales como los zanjones Blanco y Rojo. En estos casos no desarrollan planicies aluviales amplias por lo que se generan cauces profundos labrados en rocas sedimentarias, con valles angostos de paredes abruptas y elevadas (Figura 2.7). En algunos sectores del recorrido del zanjón coincidentes con sectores de fallas, se observan cauces encajonados $y$, en sectores sin confinamiento adoptan un diseño meandroso reconociéndose en algunos casos meandros abandonados.

La falta de estaciones de aforo o de mediciones periódicas en estos cursos temporarios no permite conocer los caudales medios anuales o velocidad de escorrentia de los mismos. Sin embargo, la carga sólida reconocida en las geoformas internas a los cauces y en los perfiles de los mismos, permiten inferir que en momentos de máximo caudal se forman barras psefíticas de guijas a guijones, por lo que se estima una alta competencia. En tanto, en momentos en los que los cauces estan secos, adquiere importancia la actividad eólica tanto en la deflación como en la generación de formas de lecho eólicas en el mismo (ie. sombras de arena, protodunas, pavimentos del desierto -lag deposits-, ondas de arena) (Figura 2.9). 


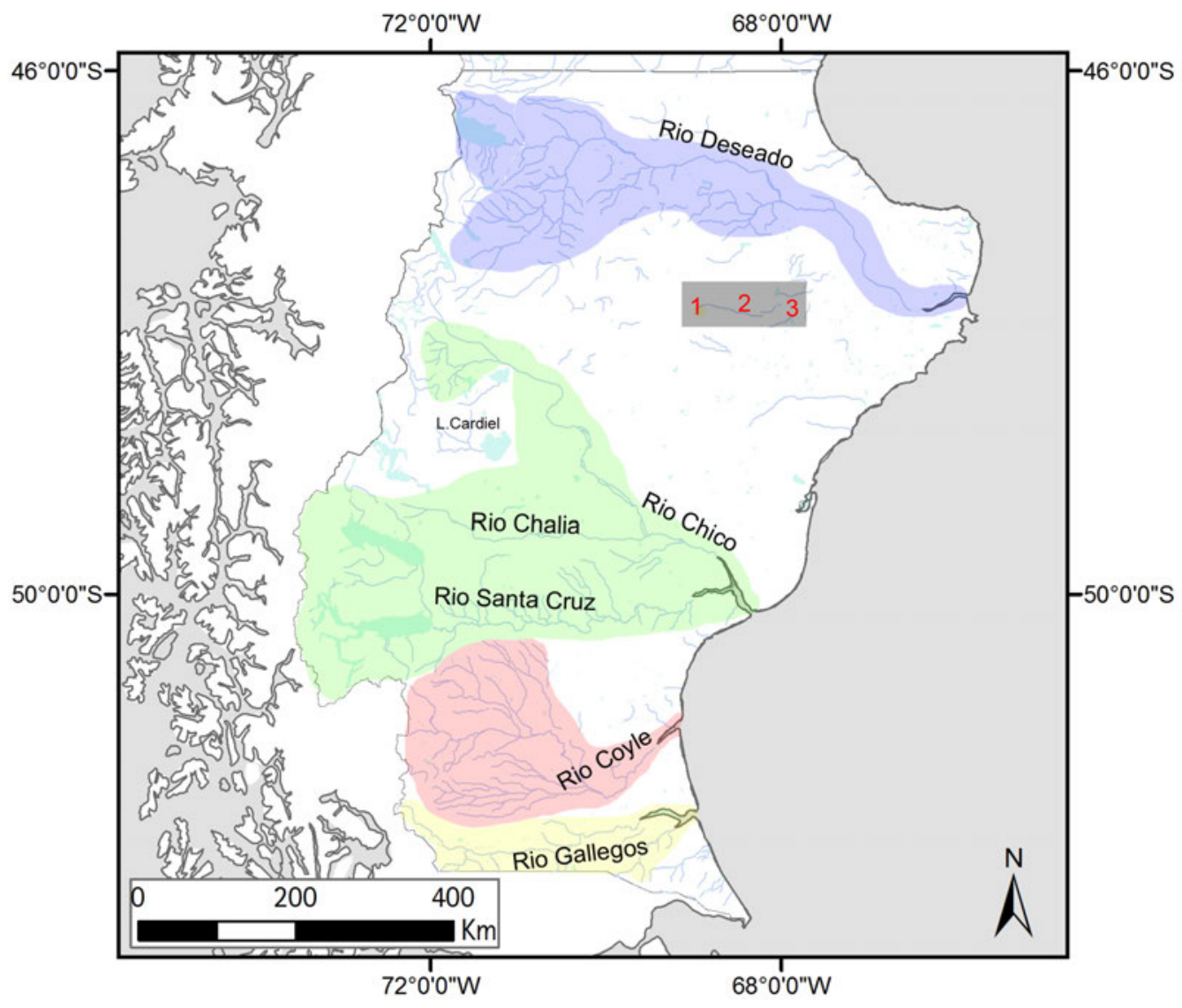

Figura 2.8: Cuencas hidrográficas principales de la Provincia de Santa Cruz. Ref.: 1. Sitio Cueva Maripe; 2. Sitio Tito del Valle; 3. Sitio AEP-1

\subsubsection{Mallines}

Algunos de los cauces mencionados son de naturaleza efluente, ya que se originan por aportes de las aguas freáticas superficiales. La surgencia de estas aguas también dan lugar a ecosistemas como los mallines, que son humedales que ofrecen recursos hídricos, vegetales y paisajísticos (Mazzoni y Vazquez 2004) como ocurre en el caso del Cañadón La Primavera.

Los mallines se generan en lugares donde el aporte de agua es permanente, la cual en sectores áridos como la Patagonia extra andina generalmente proviene de acuíferos subterráneos (Figura 2.10). Debido a esto, su ubicación se da en sectores deprimidos del paisaje como en fondos de va- 


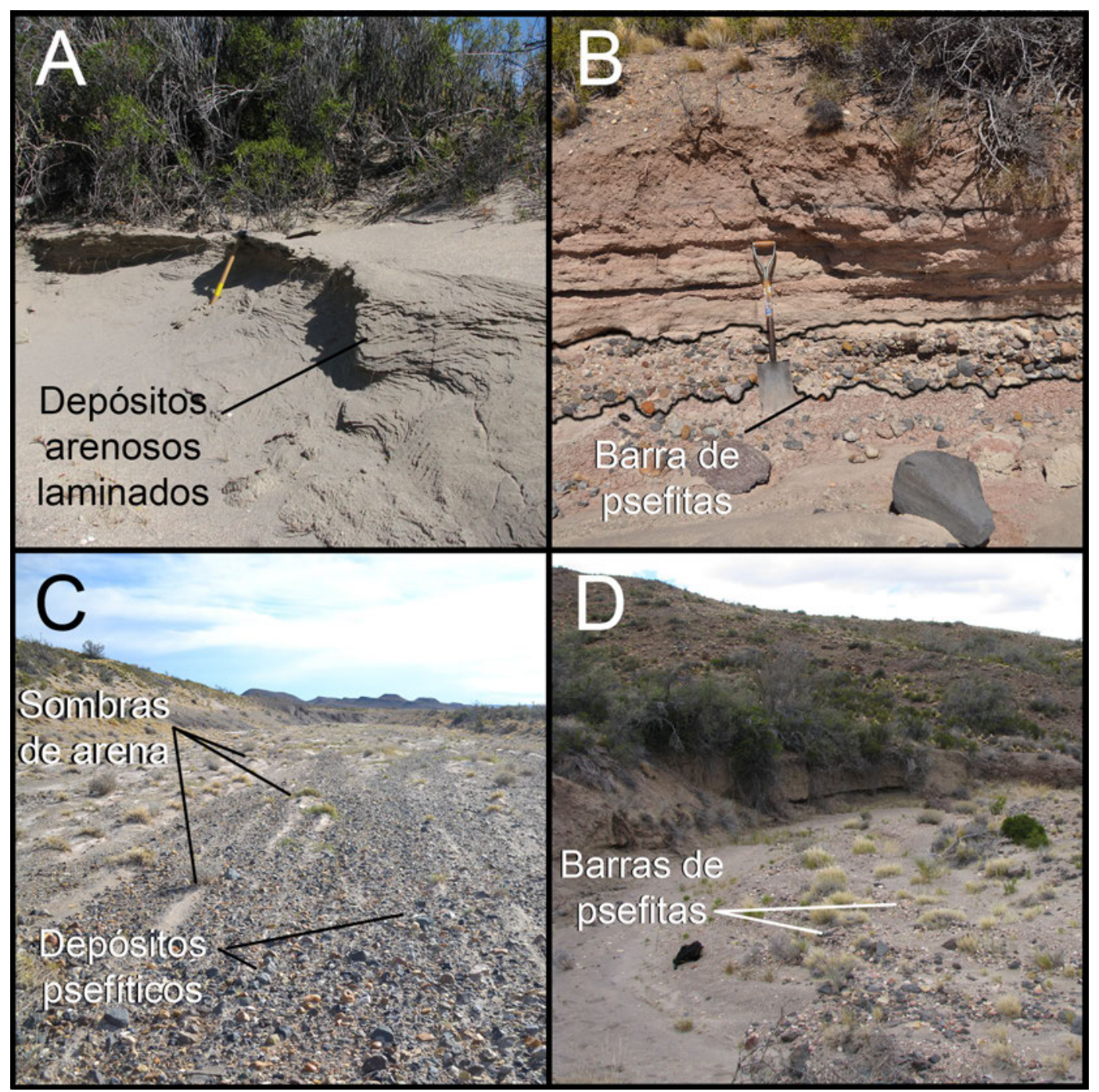

Figura 2.9: Ejemplos de barras de grava.

lles, en "bajos sin salida", así como también en las laderas de mesetas basálticas donde el nivel de aguas subterraneas toca la superficie del terreno. De acuerdo a su posición con relación a las mesetas, los mallines pueden clasificarse en cuatro tipos básicos (Figura 2.11):

- $a$. De llano aluvial y cauces fluviales (cauces principales).

- $b$. En rosario o de valles pequeños (a lo largo de cursos secundarios).

- c. De ladera (mallines colgados).

$-d$. Entre lóbulos de desmoronamiento.

El Mallín La Primavera, que corre dentro del cañadón homónimo tiene una extensión cercana a los $6 \mathrm{~km}$. A lo largo de su recorrido presenta variacio- 
nes en cuanto a humedad y vegetación pudiendo reconocerse sectores desde muy húmedos a anegados, hasta sectores semihúmedos con pastizal (Tabla 2.1). Los orígenes de esa humedad pueden ser variados, ya que se observan vertientes en las laderas de las mesetas volcánicas así como también surgentes en los fondos de valle. Teniendo en cuenta esto, el Mallín La Primavera es un mallín en rosario que en su recorrido presenta angostamientos y sectores abiertos que dan lugar a variaciones en la extensión y forma de la zona húmeda.

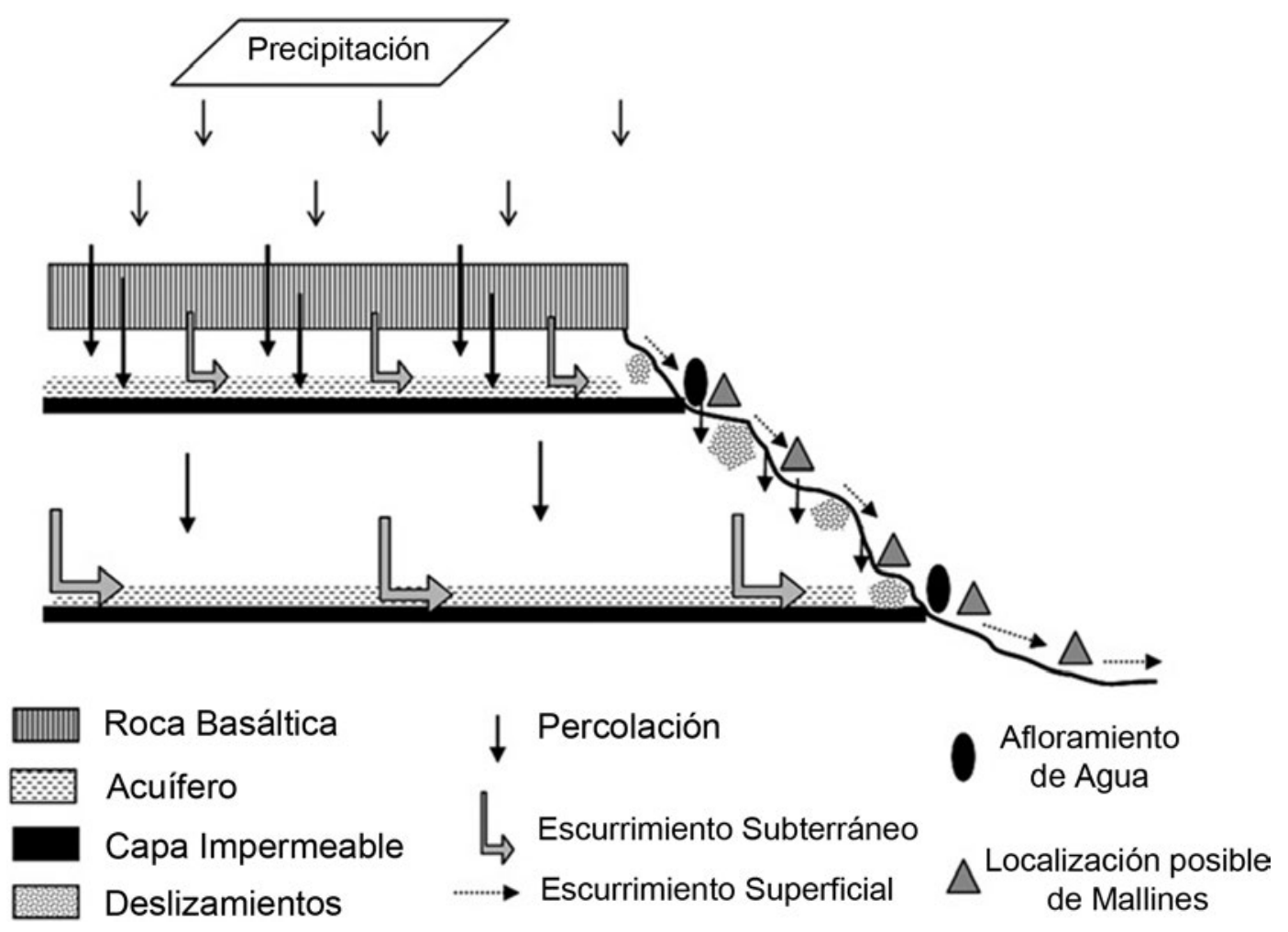

Figura 2.10: Modelo hidrológico de un área hipotética de meseta basáltica (tomado de Mazzoni y Vázquez 2004).

Los mallines se configuran como una fuente de agua y recursos muy importante para sectores áridos y semiáridos como el Macizo del Deseado donde los pastizales presentes se ven muy afectados por eventos de sequía y catástrofes naturales. Un ejemplo de esto es el caso de la erupción del volcán Hudson de 1991 donde estos ecosistemas se convirtieron prácticamente en la única fuente de sustento de los pobladores locales.

Otras cuencas endorreicas de la región están representadas por los "bajos sin salida", que son depresiones en las mesetas basálticas que funcionan como concentradoras de agua (Mazzoni 2001). Estas geoformas albergan 


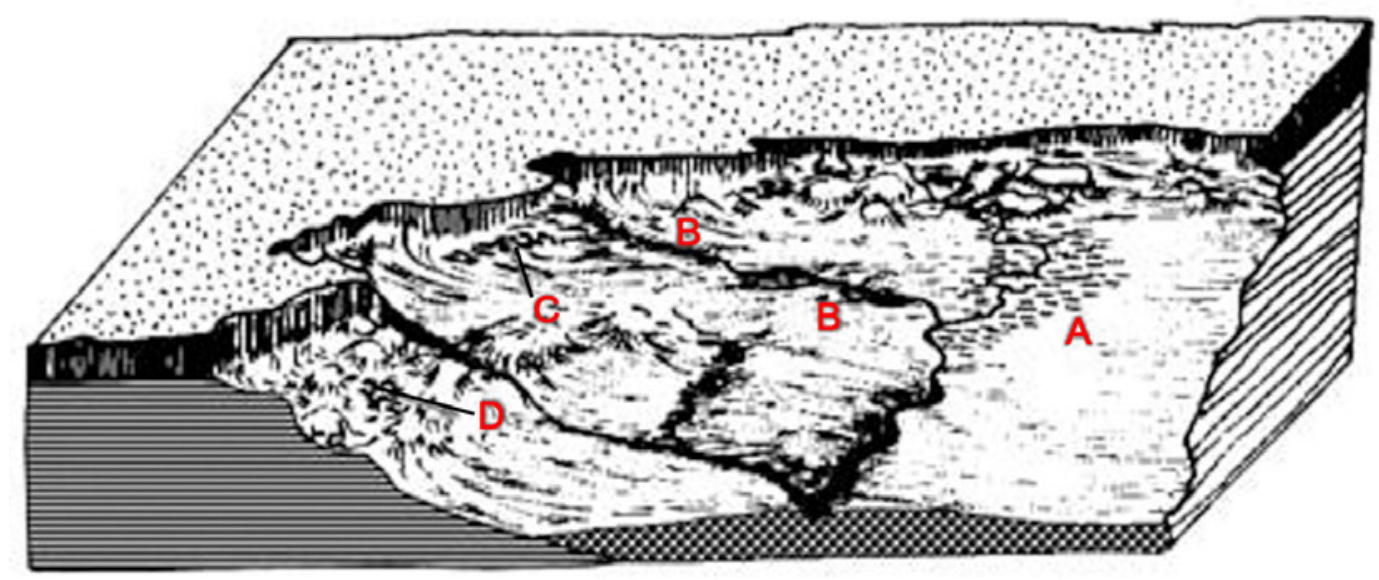

\section{$\underline{\text { Referencias }}$}

\section{Basaltos}

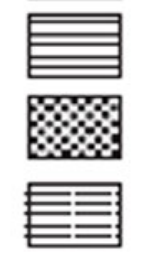

Mallines
Sustratos prebasálticos

Depósitos recientes
Tipos de mallines

A. De llano aluvial (cursos principales)

B. En "rosario" (a lo largo de cursos secundarios)

C. De laderas (Mallines "colgados")

D. Entre lóbulos de desmoronamiento

Figura 2.11: Tipos de mallines desarrollados en las laderas de mesetas volcánicas (tomado de Mazzoni y Vázquez 2004).

lagunas de régimen temporario que fluctúan de acuerdo a las variaciones pluvio-nivales y, que en períodos de desecación, aportan el sedimento para una intensa deflación eólica que generan las geoformas denominadas "plumas eólicas" (Mazzoni et al. 2002).

\subsection{Clima}

El clima de la Patagonia está dominado por las masas de aire del Pacífico y por los fuertes vientos del oeste (Westerlies). Asimismo, la presencia de la Cordillera de los Andes funciona como una barrera para las masas de viento húmedo provenientes del pacífico que genera precipitaciones en la ladera occidental, y que al descender en el sector oriental se calientan y se secan dando lugar a un gradiente de precipitación que decrece hacia el este (Paruelo et al. 2005). Según los datos discontinuos recuperados por Panza (1982) en la estancia La Reconquista para el lapso 1965-1980, en el área de estudio el promedio anual de precipitaciones oscila entre 180-300 mm (Figura 


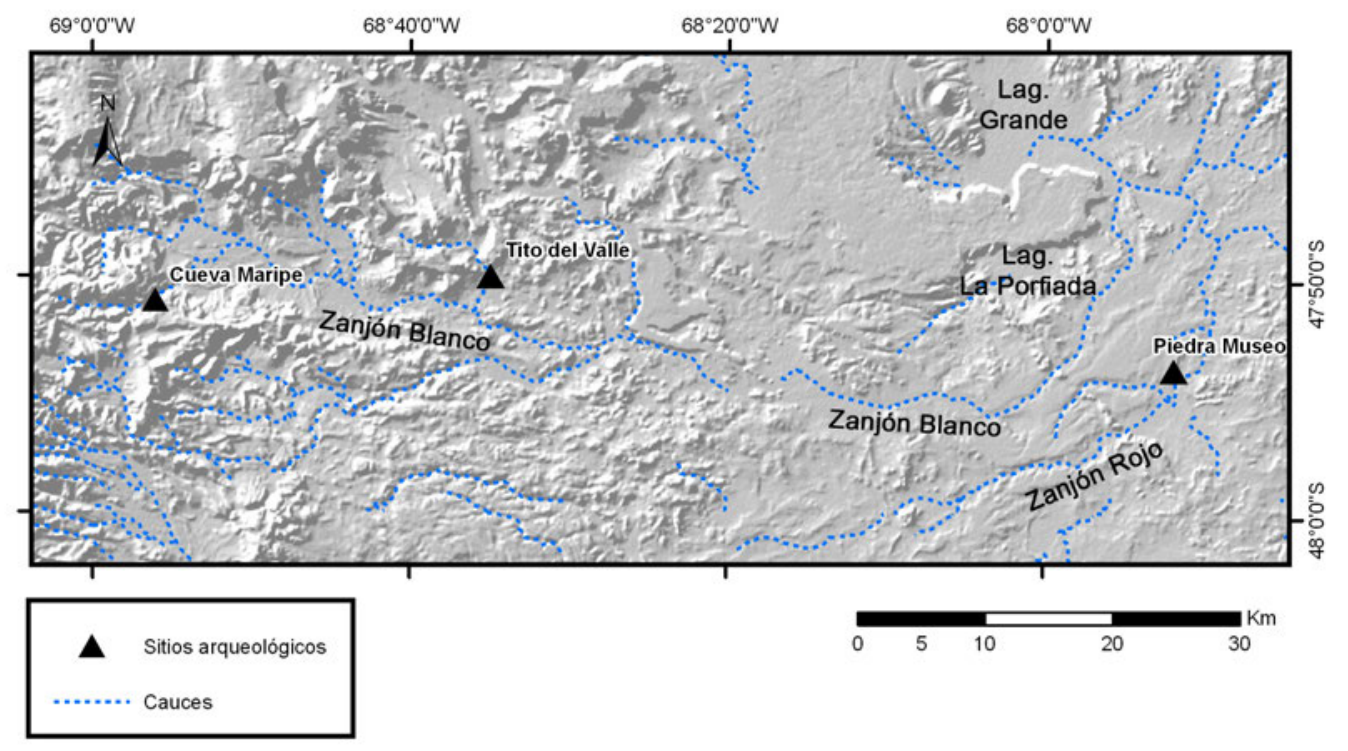

Figura 2.12: Cuencas hidrográficas del área de estudio. El recorte responde a la cuenca del Zanjón Blanco (Área de Estudio).

2.13), aunque observa valores de 100 (1968) y $400 \mathrm{~mm}$ anuales (1981), para años muy secos o muy lluviosos, respectivamente. Algo similar se observa en el registro de la estación meteorológica Gobernador Gregores activa durante el lapso 1971-1980 (Panza 1982)

Por su parte, el gradiente de temperatura en la provincia de Santa Cruz, aumenta en un eje SO-NE, reconociéndose en el área de estudio una temperatura media anual de $8-10^{\circ} \mathrm{C}$ (Figura 2.13). Sobre la base de estos valores de temperatura media, la región de la meseta patagónica es considerada como un área templada-fría, en la cual predomina la aridez como resultado de las bajas precipitaciones y los fuertes vientos del oeste que producen tasas de evaporación altas (Roig 1998; Soriano et al. 1983). De esta manera, en el área se registra heterogeneidad de paisajes mientras que la variabilidad climática es baja (De Porras 2010).

\subsection{Fitogeografía}

Desde el punto de vista florístico en la provincia de Santa Cruz se incluyen dos regiones fitogeográficas: la Antártica que abarca la región de la cordillera y la Neotropical que abarca prácticamente el resto de la provincia, dentro del denominado Dominio Andino Patagónico, Provincia Patagónica 
TEMPERATURA MEDIA ANUAL $\left({ }^{\circ} \mathrm{C}\right)$

PRECIPITACIÓN MEDIA ANUAL (mm)
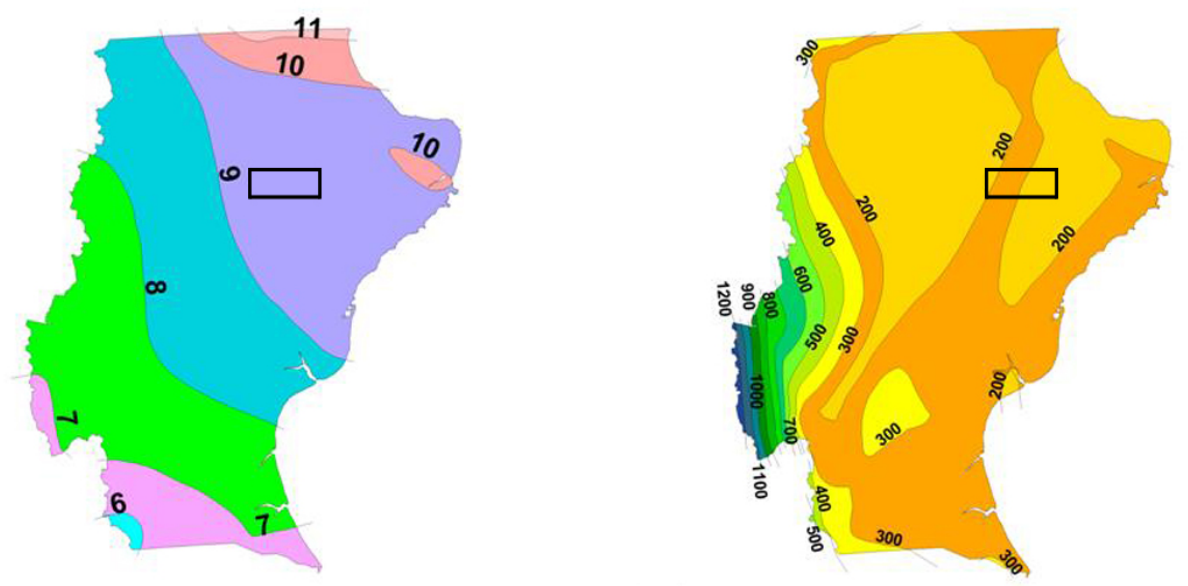

Figura 2.13: Temperatura y precipitación Media Anual de la Provincia de Santa Cruz. Los recuadros negros marcan la ubicación del área de estudio (Tomado de Soto 2004 en Cruzate et al. 2007).

(Cabrera 1976).

Las unidades de vegetación se distribuyen de acuerdo al gradiente de precipitación E-O. De esta manera, sobre la cordillera se reconoce una franja de bosque de Nothofagus sp. (Provincia Subantártica, Distrito del Bosque Caducifolio y Distrito Magallánico) que linda con una estepa de Festuca pallescens ubicada en las laderas orientales y mesetas más elevadas (Provincia Patagónica, Distrito Subandino).

Entre los paralelos $51^{\circ}$ y $52^{\circ}$ de latitud sur se desarrolla una estepa graminosa de Festuca gracillima desde la cordillera al mar. Hacia el este, se reconocen comunidades de estepas arbustivas y subarbustivas de composición variada hasta llegar a la costa del mar donde se observan comunidades de plantas halófitas dominadas por Lepidophyllum cupresiforme (Provincia Patagónica, Distrito Central, Subdistrito Santacrucence (Cabrera 1976; León et al. 1998; Roig 1998; Soriano et al. 1983).

La mayor parte de la meseta patagónica está dominada por estas estepas arbustivas y subarbustivas las cuales están distribuidas heterogéneamente, encontrándose vegetación de tipo xerófila de arbustos bajos y achaparrados, plantas en cojín de hojas pequeñas y espinas y, en las zonas húmedas y con protección del viento, predominan las estepas graminosas (Cabrera y Willink 1980).

Dentro de esta estructura florística, los ecosistemas de humedales mese- 
tarios como son los mallines, se presentan como parches verdes de gramíneas y juncáceas. Los mallines varían su frecuencia de diferentes especies de acuerdo a la humedad y características del suelo como se detalla en la Tabla 2.1.

\begin{tabular}{|c|c|c|c|c|}
\hline & Humedad & Suelo & Cobertura vegetal & Especies \\
\hline $\begin{array}{l}\text { Mallines muy húmedos o } \\
\text { anegados }\end{array}$ & $\begin{array}{c}\text { Superficie anegada o } \\
\text { saturada }\end{array}$ & $\begin{array}{l}\text { Hidromórfico con } \\
\text { horizonte gley }\end{array}$ & Densa. & Ciperáceas y Juncáceas \\
\hline Mallines húmedos & Abundante & Hidromórfico & $75-100 \%$ & $\begin{array}{c}\text { Juncos y gramíneas. Juncus bálticus y Festuca } \\
\text { pallescens }\end{array}$ \\
\hline $\begin{array}{l}\text { Mallines semihúmedos con } \\
\text { pastizal }\end{array}$ & $\begin{array}{c}\text { Media. La napa freática } \\
\text { no aflora en la superficie }\end{array}$ & Textura franca a gruesa & $50-75 \%$ & Festuca sp y ytipa gracillima \\
\hline $\begin{array}{c}\text { Mallines semihúmedos con } \\
\text { pastizal y arbustos }\end{array}$ & $\begin{array}{l}\text { Media. La napa freática } \\
\text { no aflora en la superficie }\end{array}$ & Arenoso & $50-75 \%$ & $\begin{array}{l}\text { Junella tridens/Verbena tridens con suelo arenoso; } \\
\text { Lepidofhyllum cupressiforme con suelos salinos. }\end{array}$ \\
\hline Mallines secos o degradados & Baja & $\begin{array}{c}\text { Peladales y " pavimentos } \\
\text { de desierto". }\end{array}$ & menos de $50 \%$ & $\begin{array}{l}\text { No hay juncos. Parches de gramíneas y arbustos. } \\
\text { Chuquiraga aurea, Azorella caespitosa, Lycium } \\
\text { repens y Nitrophila australis. Cuando el suelos es } \\
\text { salino aparecen gramineas del genero Distichlis }\end{array}$ \\
\hline
\end{tabular}

Tabla 2.1: Categorías de mallines de acuerdo a proporción de humedad (Realizado a partir de Mazzoni y Vazquez 2004).

Los ambientes mesetarios permiten que se formen estos ecosistemas fértiles como resultado de la captación de agua en la parte alta de la meseta y la percolación a traves de fisuras, formando acuíferos sobre capas impermeables que, al cortar las laderas, generan manantiales (afloramientos de agua). Estas surgentes de agua son las que aumentan la humedad de un determinado sector, el cual está determinado por las características geomorfológicas del lugar en el que actúa y que puede, como se mencionó anteriormente, generar diferentes tipos de mallines (Figura 2.12).

\subsection{Zoogeografía}

La provincia de Santa Cruz corresponde a la Subregión Patagónica de la Región Neotropical (Cabrera y Yepes 1940; Cabrera y Willink 1980). Dentro de ella, el Macizo del Deseado forma parte de la estepa patagónica incluida del Dominio andino-patagónico. La fauna de este dominio se distingue por sus adaptaciones a condiciones extremas de vida, en general de gran aridez y gran amplitud térmica entre el día y la noche. Debido a ello, muchos animales son de hábitos nocturnos, protegiéndose o adquiriendo hábitos o adaptaciones fisiológicas que les permiten resistir las condiciones adversas del medio.

Entre los animales más sobresalientes de este dominio, se destaca la presencia de abundantes roedores, camélidos y numerosas aves. Una especie 
característica de la región es el guanaco (Lama guanicoe), el ungulado silvestre de mayor talla y rango de distribución en Sud América (Raedecke 1978). Entre los géneros y especies más comunes encontramos: la comadreja overa (Didelphis), lestodelfo patagónico (Lestodelphis), murciélagos (Lasiurus y Tadarida), la mara o liebre patagónica (Dolichotis patagonum) y la vizcacha de la sierra (Lagidium). Los tuco-tucos (Ctenomys) son muy abundantes, también los Cricetidae y, en menor frecuencia, se registran los Caviidae. Los armadillos o edentados están representados por dos especies: el piche (Zaedyus pichi) y el peludo (Chaetophractus villosus). En el área de estudio se encuentran distintos carnívoros, entre ellos especies dos especies de zorros Pseudalopex culpaeus y Pseudalopex griseus. Entre los félidos, el puma (Felis concolor) es una especie de amplia distribución, y es el mayor depredador de la región. También se encuentran el huroncito patagónico (Lyncodon) y el zorrino (Conepatus humboldtii).

El ave más representativa del área es el ñandú petiso o choique (Pterocnemia pennata) y en el área se registra variedad de avifauna, la cual se encuentra integrada por patos y macaes, cauquenes o avutardas (Chloephaga), cisnes de cuello negro (Cygnus), gaviotas (Larus), martineta (Eudromia elegans); entre las rapaces más frecuentes se encuentran el águila escudada o mora (Geranoaetus melanoleucus), el carancho (Polyborus), el chimango (Milvago) y la lechuza del campanario (Tito alba). 


\section{Capítulo 3}

\section{Evolución Paleoambiental y Paleoclimática del Pleistoceno Tardío-Holoceno}

De acuerdo con los objetivos de esta tesis, para comprender e interpretar los depósitos sedimentarios estudiados de abrigos rocosos y su entorno, resulta necesaria la comprensión de los procesos ambientales a diferente escala (Dincauze 2000). La información paleoclimática disponible de alcance global y regional, servirá como esquema base para reconocer y la dinámica propia del área estudiada y si tal dinámica se corresponde o no con escalas mayores. En este capítulo se hace una breve reseña de los eventos paleoambientales y paleoclimáticos inferidos desde diferentes registros proxy, de escala global primero y luego a escala regional, para fines del Pleistoceno y el Holoceno.

Desde un enfoque geológico, el Holoceno se presenta como un momento de condiciones sub-actuales (Zárate 1993), donde los procesos imperantes están aún activos o lo estuvieron hasta hace relativamente poco tiempo, por lo que la aplicación de modelos analógicos actuales resulta más útil para este período que para cualquier otro. Es así que la mayoría de los trabajos citados en este capítulo han obtenido sus datos geológicos o de proxies ambientales utilizando modelos comparativos actuales. 


\subsection{Esquema crono-estratigráfico}

El Cuaternario (2.58 Ma. - actualidad) es un periodo geológico caracterizado por las grandes fluctuaciones climáticas signadas por sucesivos ciclos glaciales a nivel global. Esta configuración climática planteó el escenario para la evolución de la especie humana desde su aparición hasta la actualidad. Si bien en el denominado "Viejo Mundo" (África, Asia y Europa), la evidencia arqueológica abarca gran parte del periodo, en América el poblamiento comienza hace unos $14.5 \mathrm{ka}$ cal AP. (véase Borrero 2015 y comentarios alli realizados) siendo el último continente en ser ocupado por los humanos.

Los periodos geológicos que conforman al cuaternario son dos: el Pleistoceno y el Holoceno. De acuerdo con la International Commission on Stratigraphy, el límite entre ambos se ubica en el 11.7 ka cal AP (ca. 10 ka AP), momento en el cual se reconoce en los testigos de hielo de Groenlandia (NGRIP) un desplazamiento abrupto en los valores de deuterio, seguido por cambios graduales del isótopo $\delta^{18} \mathrm{O}$, en la concentración de polvo, en un rango de especies químicas y en el espesor de las capas anuales (Ogg 2008).

Para analizar el momento de cambio entre estos periodos geológicos, en arqueología se utiliza el lapso denominado Transición Pleistoceno/Holoceno, que incluye el final del Pleistoceno y parte o todo el Holoceno Temprano. Esta categoría abarca en el caso de nuestra área de estudio y en el continente americano en general, el lapso correspondiente entre los ca. 13 y $8 \mathrm{ka}{ }^{14} \mathrm{C} \mathrm{AP}$ que incluye desde el poblamiento inicial del continente hasta el Holoceno Temprano.

Por su parte, el Holoceno carece de consenso en cuanto a las subdivisiones que habitualmente se utilizan para analizarlo, en especial en arqueología. Las divisiones utilizadas son informales y generalmente se denominan con los términos Temprano, Medio y Tardío aunque también hay casos en los que se utiliza una división de dos bloques temporales en un Holoceno Temprano (10000-5000 años ${ }^{14} \mathrm{C}$ AP) y uno Tardío (5000-actualidad) (Borrero 2001). Si bien la división tripartita es la más utilizada, presenta variaciones en la posición cronológica de los límites. Como ejemplo de esto se pueden mencionar dos volúmenes de Quaternary International en los que se exponen casos arqueológicos del Holoceno medio de Argentina y Sudamérica: Zárate, Neme y Gil (2005) y Hoguin y Restifo (2012). En el primero, la mayoría de los trabajos considera que el Holoceno medio se incluye entre los 
8 y los $4 \mathrm{ka}{ }^{14} \mathrm{C} \mathrm{AP}$, con algunas variaciones en la fecha de finalización que puede llegar a $3 \mathrm{ka}{ }^{14} \mathrm{C} \mathrm{AP}$, mientras que en el segundo volumen la variación de los límites entre los trabajos ubican al inicio del Holoceno medio entre 8 y 6 ka ${ }^{14} \mathrm{C}$ AP y el final entre 5 y $2,5 \mathrm{ka}{ }^{14} \mathrm{C}$ AP. La falta de convención estratigráfica para dividir los últimos $11.7 \mathrm{ka} \mathrm{cal} \mathrm{AP,} \mathrm{genera} \mathrm{este} \mathrm{tipo} \mathrm{de}$ inconsistencias ya que cada investigador utiliza categorías propias acordes a las características de cada zona, y que pueden tener que ver con variaciones climáticas globales o locales inferidas a partir de proxies ambientales de alcance regional y/o a cambios en los patrones arqueológicos (Goñi 2010, Mancini et al. 2013, Miotti y Salemme 2004).

En un trabajo reciente realizado por el grupo de trabajo INTIMATE (Integration of ice-core, marine and terrestrial records) y la Subcommision on Quaternary Stratigraphy (SQS) de la International Commission on Stratigraphy (ICS) (Walker et al. 2012), se consideran las perspectivas para definir una subdivisión formal para el Holoceno. En dicho trabajo, se propone una subdivisión tripartita respetando las categorías informales mencionadas (Temprano, Medio y Tardío), a partir de eventos climáticos reconocidos en testigos de hielo del casquete polar ártico. Teniendo en cuenta estos eventos, los autores ubican el límite Holoceno temprano/medio en el evento 8.2 ka cal. AP (ca.7.4 $\left.{ }^{14} \mathrm{C} \mathrm{AP}\right)$ que es un episodio de enfriamiento de corta duración que se refleja claramente en la señal isotópica en los núcleos de hielo de Groenlandia, y que tiene correlatos Sudamérica, Asia y Africa (ver Walker et al. 2012 y bibliografía allí citada). Por su parte, el límite Holoceno medio/tardío se estipula en coincidencia con el evento 4.2 cal. AP (ca. $3.8 \mathrm{ka}$ ${ }^{14} \mathrm{C} \mathrm{AP}$ ) que fue un fenómeno climático generalizado que provoco una aridización en latitudes medias y bajas, y que se refleja en los registros de de América del Norte, Oriente Medio, China, África, partes de América del Sur y la Antártida (ver Walker et al. 2012 y bibliografía allí citada).

Tomando en consideración a estas variaciones, a continuación reseñaremos las variaciones climáticas reconocidas en el periodo estudiado ya que nos servirán de esquema base para interpretar la evidencia estratigráfica y arqueológica estudiada. 


\subsection{Glaciaciones y líneas de costa}

Los ciclos glaciares ocurridos durante el Cuaternario llegaron a su final durante el Ultimo Máximo Glacial (LGM) que se desarrolló entre los 25 y 18 ka cal. AP. Luego de esta máxima expansión comienza el Tardiglaciar que es el inicio del intervalo climático interglaciar que estamos viviendo actualmente. Conjuntamente con el aumento de la temperatura global, las grandes plataformas de hielo polar así como los hielos continentales comenzaron un proceso de retracción de manera fluctuante hasta que hacia los $11.7 \mathrm{ka}$ cal. $\mathrm{AP}\left(10 \mathrm{ka}{ }^{14} \mathrm{C}\right)$ retroceden definitivamente.

Entre el LGM y comienzo del Holoceno, se dieron al menos dos avances glaciarios en coincidencia con Episodio Frío Reverso Antártico -EFRA- (o ACR por su nombre en inglés) entre 14.6 y $12.8 \mathrm{ka}$ cal. AP $\left(12.5\right.$ y $11 \mathrm{ka}{ }^{14} \mathrm{C}$ AP) y el Younger Dryas (YD) entre 12.8 y 11.7 ka cal. AP (11000 y 10000 años ${ }^{14}$ C AP) (Blunier et al. 1997; Coronato y Rabassa 2007; Brook et al. 2013). El ACR, como su nombre lo dice, es un episodio frío que ha sido reconocido en el hemisferio sur siendo contemporáneo con el periodo cálido BøllingAllerød del hemisferio norte.

El Younger Dryas, por su parte, se reconoce a nivel mundial pero con características y cronologías diferentes: mientras que en el hemisferio norte se expresa como un momento frío y seco, en el hemisferio sur adopta característica de climas más cálidos y húmedos (Brook et al. 2013; Shakun y Carlson 2010) y se plantea que los cambios referidos a este evento en el hemisferio sur comienzan entre 500 y 1000 años antes. De esta manera se reconoce un comportamiento en "anti-fase" entre ambos hemisferios para los dos periodos mencionados (Blunier et al. 1997; McCulloch et al. 2005). Sin embargo, la información proveniente de los glaciares patagónicos muestran avances de los frentes en coincidencia con el ACR como en el caso de Magallanes (Sugden et al. 2005) mientras que en la Patagonia norte, Hajdas y colaboradores (2003) reconocen un avance glaciario en coincidencia con la cronozona YD a la que denominan "Reversión fría Huelmo/Mascardi" (11.4 - 10.2 ka ${ }^{14} \mathrm{C}$ $\mathrm{AP})$.

El derretimiento de los hielos generó cambios fisiográficos importantes. Además de la superficie liberada de hielos en los sectores previamente cubiertos, la costa atlántica presentó una tendencia transgresiva desde el LGM cuando su cota estaba $120 \mathrm{~m}$ por debajo del nivel actual del mar, hasta su pico máximo ca. 6.5 - 4 ka AP cuando alcanzó los 8 msnm, para luego estabi- 
lizarse en las cotas actuales (Figura 3.1) (Codignotto et al. 1992, Codignotto 1997, Ponce et al. 2011). Esta dinámica de la linea de costa tiene una clara repercusión en la distribución del registro arqueológico, ya que mucha de la evidencia arqueológica costera de cronologías tempranas actualmente se encuentra sumergida . Lo mismo sucede en el caso de algunos sectores cordilleranos que a durante el Tardiglaciar se encontraban cubiertos de hielo, por lo que la ocupación humana no era factible (Figura 3.2) (Miotti 2006a). 

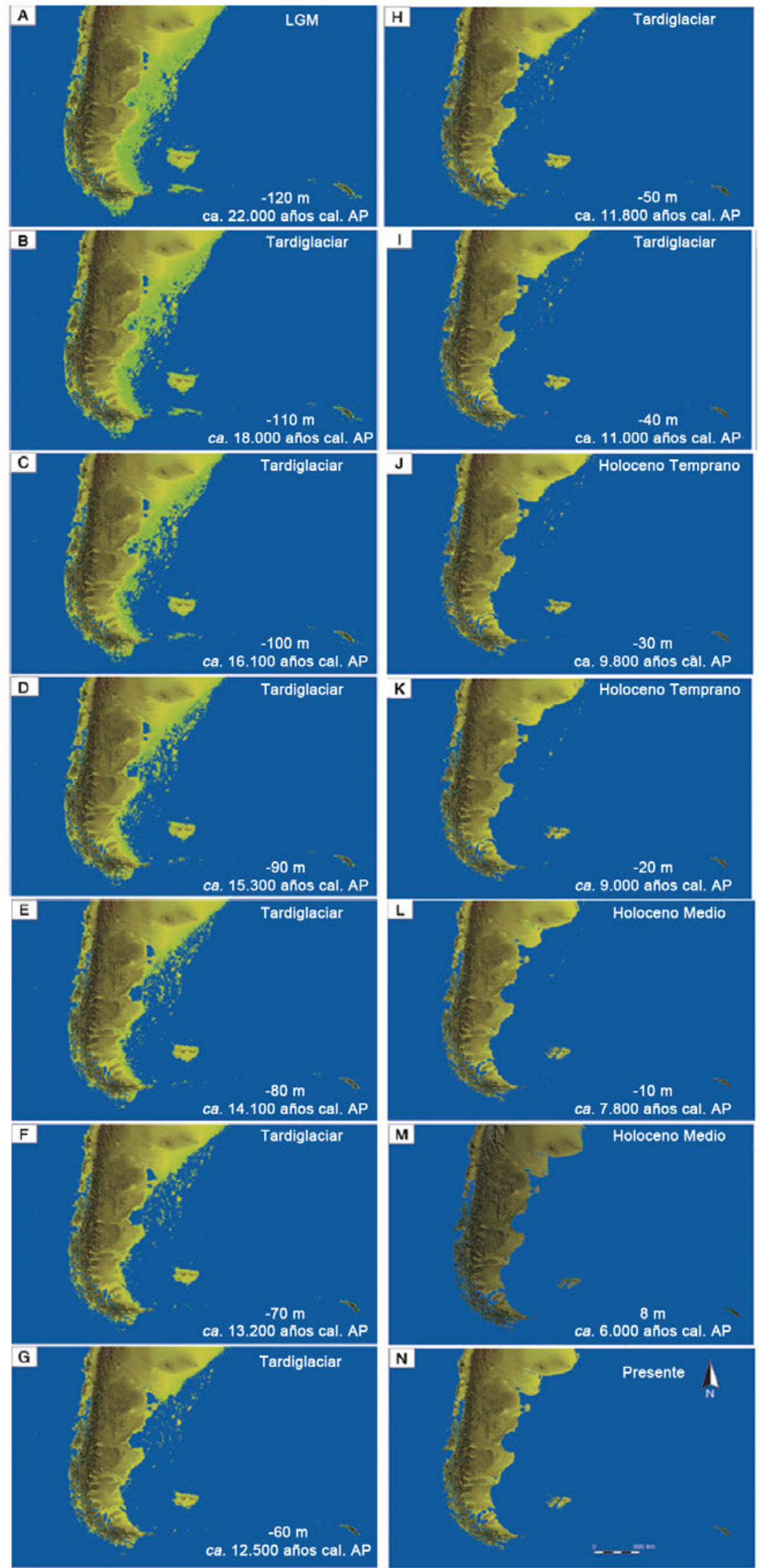

Figura 3.1: Evolución de las líneas de costa de Patagonia desde el Último Máximo Glacial hasta el presente. Tomado de Ponce et al. 2011. 


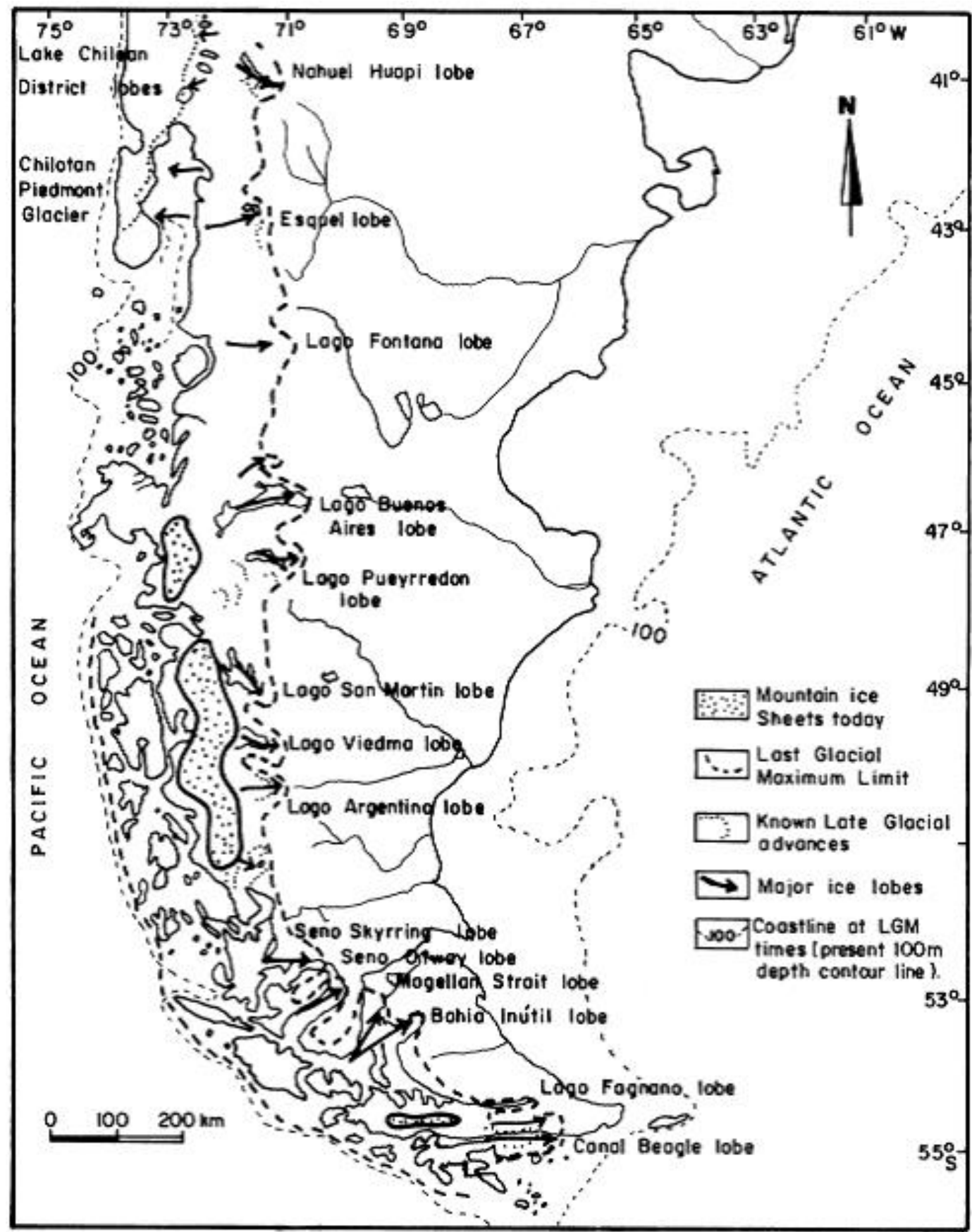

Figura 3.2: Extensión de la línea de glaciares patagónicos en los momentos iniciales de la ocupación humana de la región. Tomado de Coronatto et al. 1999.

\subsection{Información Polínica}

Dentro de las vías de análisis para abordar la reconstrucción de los ambientes dentro de nuestra región de estudio, la que ha proporcionado más 
información a lo largo del tiempo es la palinología. Gran parte de estos estudios se concentraron en la región cordillerana de ecotono bosque-estepa (Bamonte y Mancini 2009; Haberzettl el al. 2007; Mancini 2009; Markgraf et al. 2003; Schabitz et al. 2003; entre otros) quedando las regiones áridas y semiáridas de la Patagonia extrandina que son las de mayor extensión superficial, en un lugar subordinado. La información palinológica generada en el Macizo del Deseado, proviene principalmente de sitios arqueológicos en cuevas y abrigos rocosos (Borromei 2003; Paez et al. 1999; Mancini et al. 2008; 2013; De Porras 2010; De Porras et al. 2009), los cuales si bien son trampas sedimentarias con registros temporales amplios, conforman depósitos sedimentarios discontinuos y por lo tanto con "gaps" o vacíos en cuanto al tiempo representado (Colcutt 1979; Farrand 1993). Además, en el caso de los sitios con registro de ocupaciones humanas, se trata de lugares que han sufrido algun tipo de modificación como puede ser el ingreso de vegetales, los cuales pueden modificar los registros polínicos. A diferencia de la zona cordillerana, donde un gran corpus de información polínica se obtuvo de lagos, humedales y mallines, este tipo de ecosistemas ha sido poco analizado en nuestra región de estudio.

En función de sintetizar la información palinológica publicada por los autores previamente mencionados para el Macizo del Deseado, se detallan los resultados obtenidos en diferentes localidades y sitios arqueológicos en cuevas y abrigos rocosos (Los Toldos, AEP-1 de Piedra Museo, La Martita Cueva 4, La Gruta 1 y 2, La María y Río Pinturas) (Figura 3.3) (Mancini 1998; Páez et al. 1999; Borromei 2003; Mancini et al. 2009; De Porras 2010; Mancini et al. 2013).

La reconstrucción de comunidades vegetales a partir del polen de sitios arqueológicos en cuevas, muestra que entre los 12,6 y $11 \mathrm{ka}$ AP en el caso de Los Toldos, predominó la estepa arbustiva con alto porcentaje de Ephedra frustillata que no tiene análogos actuales (Mancini 1998), pero por la alta frecuencia de esta especie en relación con otros sectores de Patagonia se asume un ambiente de extrema aridez (Páez et al. 1999). Algo similar ocurre en La María, donde la frecuencia de E. frustillata para estos momentos es alta, pero presenta menor cantidad de Poaceae, lo cual se interpreta como una distribución en mosaico de estas comunidades vegetales como sucede en la actualidad en el Macizo de Deseado (De Porras 2010). Por su parte en AEP-1 de Piedra Museo, que se encuentra dentro del área de estudio de 


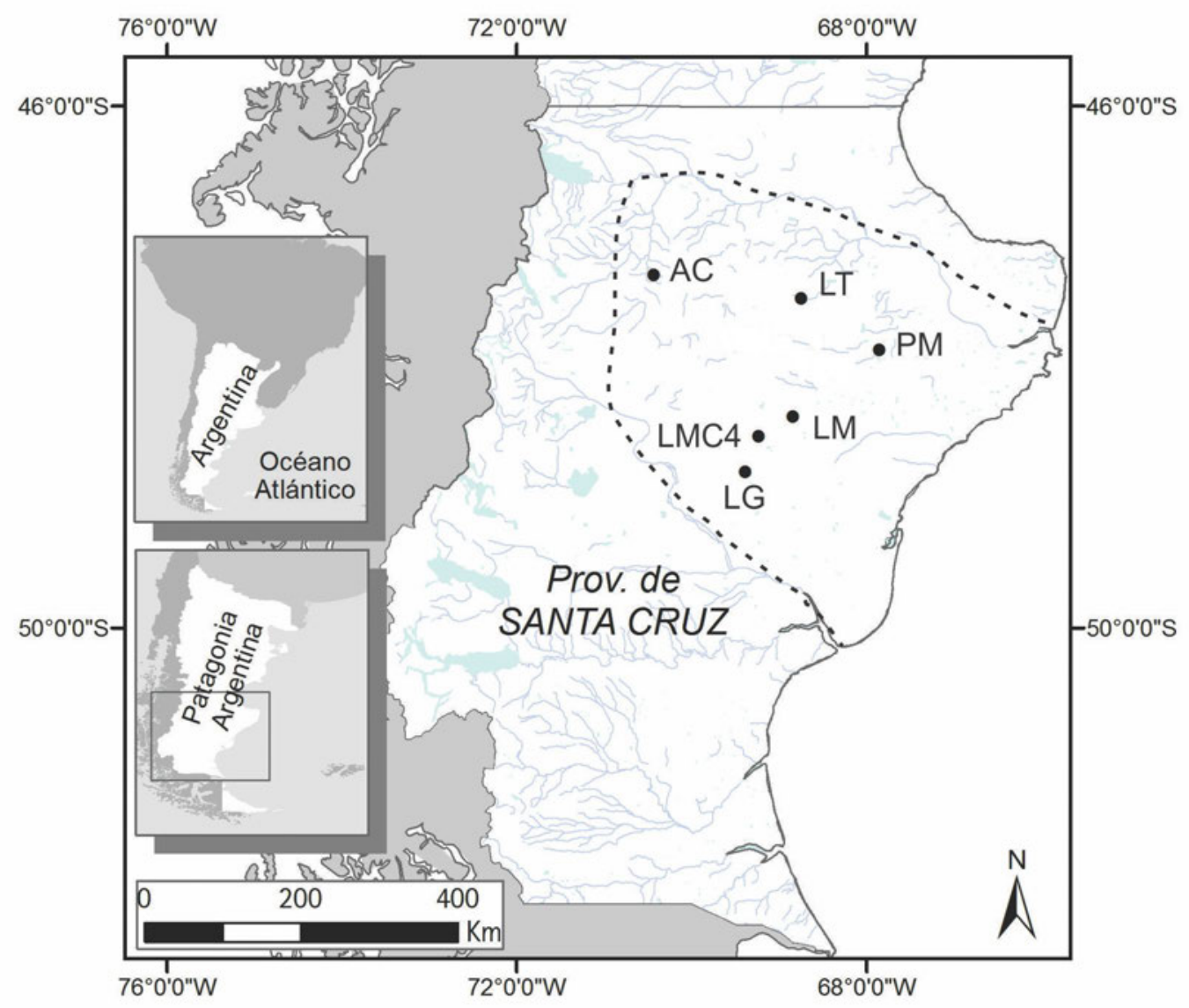

Figura 3.3: Localidades arqueológicas del Macizo del Deseado con información palinológica. AC: Alero Cárdenas, LT: Los Toldos, PM: Piedra Museo, LMC4: La Martita Cueva 4, LM: La María, LG: La Gruta 1 y 2.

esta tesis, la asociación polínica varía en los momentos iniciales con respecto a las de Los Toldos y La María, habiéndose reconocido estepa arbustiva de Asteroidea. Sin embargo las inferencias climáticas al respecto son similares, correspondiendo a un ambiente de condiciones frías y áridas (Borromei 2003). Las tres localidades arqueológicas mencionadas son las únicas que proporcionan información paleoambiental previa a los 11 ka AP dentro del Macizo del Deseado.

Para momentos posteriores a los $11 \mathrm{ka} \mathrm{AP} \mathrm{(ca.} 12.8 \mathrm{ka}$ cal. AP), se incrementa la cantidad de sitios con información palinológica y arqueológica incluyendo a Los Toldos, AEP-1 de Piedra Museo, La María, La Martita Cueva 4, La Gruta 1 y 3, y Río Pinturas. Las asociaciones polínicas de Los 
Toldos, AEP-1, La Gruta y La Maria, muestran ambientes de estepas graminosas, con bajas frecuencias de arbustos (e.g Nassauvia, Asteroidea, Ephedra) luego de los $11 \mathrm{ka}$ AP (12.8 ka cal. AP) hasta los $9.5 \mathrm{ka} \mathrm{AP} \mathrm{(10.9} \mathrm{ka} \mathrm{cal.} \mathrm{AP)}$ en AEP-1 y hasta los $10 \mathrm{ka}$ AP (11.7 ka cal. AP) en Los Toldos y La Gruta. De acuerdo, a estos datos se interpreta un incremento de la humedad efectiva por un aumento en las precipitaciones bajo condiciones de temperaturas frías, probablemente mas frías que las actuales (Mancini 1998; Mancini et al. 2013; De Porras 2010). Luego de los $10 \mathrm{ka} \mathrm{AP,} \mathrm{las} \mathrm{estepas} \mathrm{arbustivas} \mathrm{de} \mathrm{Aste-}$ raceae reconocida en Los Toldos (Páez et al. 1999), La María (De Porras 2010) y La Gruta 1 (Mancini et al. 2013), de Ephedra y Asteroideae en asociación con Chenopodiaceae en AEP-1 (Borromei 2003), dan la pauta de una tendencia al aumento de temperatura que influyó en una disminución de la humedad efectiva (Mancini et al. 2008; Páez et al. 1999; Borromei 2003).

De Porras (2010) observa en las localidades de Los Toldos y La María que con anterioridad a los $7.26 \mathrm{ka} \mathrm{AP}$, las comunidades vegetales estaban dominadas por arbustos enanos y en cojín como Nassauvia y E. frustillata y, luego de esta fecha toman protagonismo los arbustos medianos y altos, lo que la autora interpreta como resultado de un aumento paulatino de temperatura hacia el Holoceno medio y de un mayor relleno sedimentario de los cañadones que permitió sostener especies de mayor tamaño con sistemas radiculares axonomorfos. Estas señales de aumento de temperatura durante el Holoceno medio también se observan en La Martita (Mancini 1998). Mientras que en la zona del Río Pinturas, en el límite noroeste del Macizo, el análisis polínico del Alero Cárdenas muestra que entre los 7.3 y $2.5 \mathrm{ka}$ AP presenta características semidesérticas con asociaciones de comunidad arbustiva de Verbena y Nassauvia sumadas a gramíneas lo que da la pauta de un clima seco (Mancini y Trivi de Mandri 1994).

En Los Toldos entre los 5 y los $3.75 \mathrm{ka} \mathrm{AP}$, se reconoce un ambiente de estepa arbustiva-subarbustiva con diversos componentes dominada por Asteracea subf. Asteroidea, con una variedad de arbustos medianos y altos como C. intergerrima, Schinus y Lycium, arbustos enanos y en cojín como Nassauvia y E. frustillata y una alta proporción de pastos. Esta asociación polínica muestra el momento de mayor variabilidad de arbustos (De Porras 2010). Por su parte en La Maria (Sitio Casa del Minero 1), se reconoce una comunidad arbustiva de Asteracea subf. Asteroidea, similar a la actual establecida hacia el 5 ka AP. Sin embargo, tanto en Los Toldos como en La Maria, hacia 


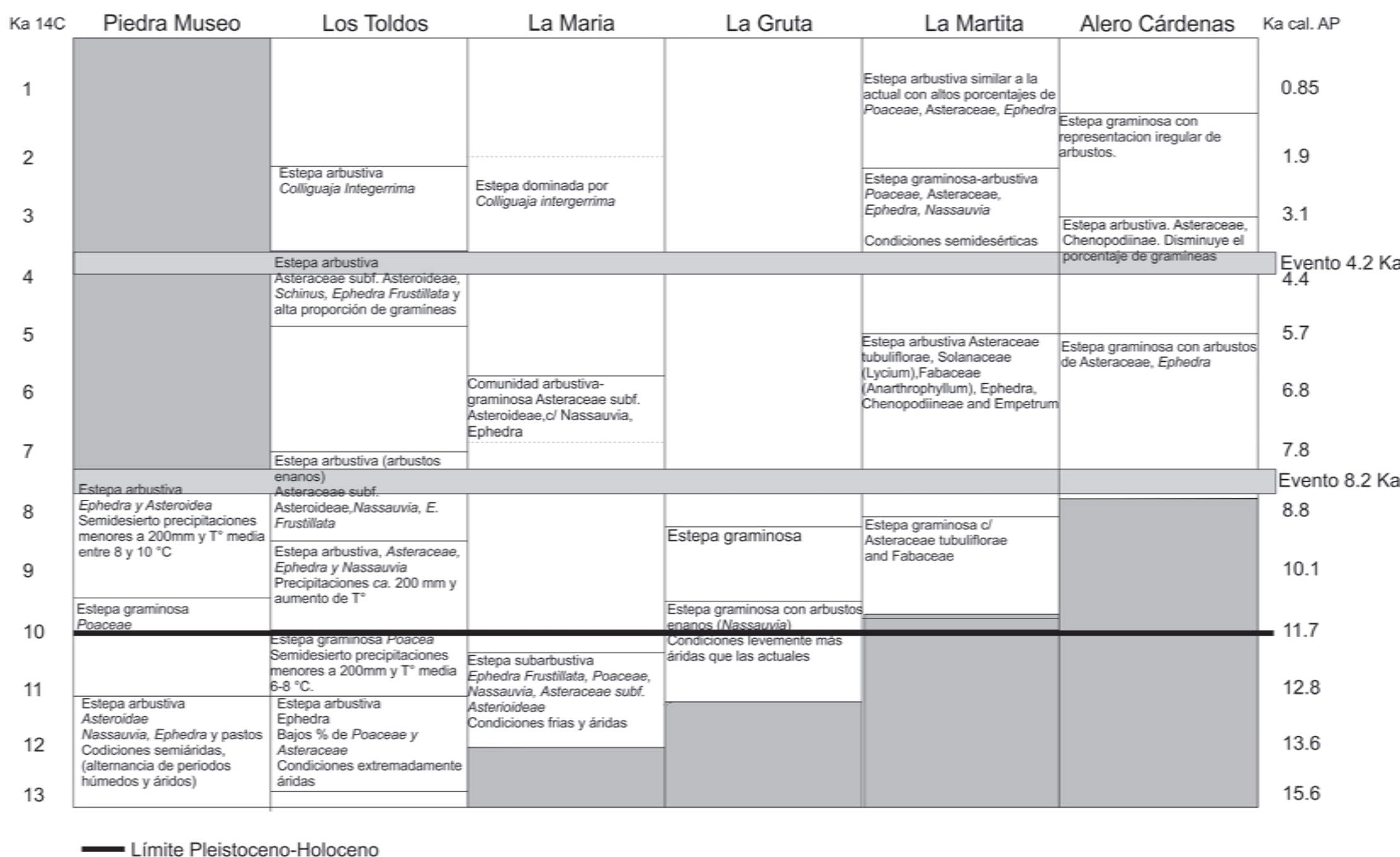

Figura 3.4: Asociaciones polínicas del Macizo del Deseado reconstruidas a partir de sitios arqueológicos en cuevas. (Borromei 2003; De Porras 2010; De Porras et al. 2009; Mancini y Trivi de Mandri 1994; Mancini 1998; Mancini et al. 2008; 2013; Páez et al. 1999). 
el $3.75 \mathrm{ka}$ AP se da un cambio en la estructura florística reconociéndose un aumento en la frecuencia de Colliguaja intergerrima, cuyo aumento se puede relacionar con los depósitos de ceniza volcánica de la erupción H2 del Hudson (Stern 2008). En este sentido, el cambio en la frecuencia de especies podría explicarse por una mayor capacidad colonizadora de $C$. intergerrima que es un "arbusto invasor" luego de la caída de cenizas, o por un crecimiento de estos arbustos en las entradas de las cuevas y no por un cambio de condiciones climáticas (De Porras et al. 2009; De Porras 2010).

A partir de $3.75 \mathrm{ka}$ AP se establecen condiciones ambientales similares a las actuales en Los Toldos, mientras que para el Rio Pinturas durante los últimos $2 \mathrm{ka}$ AP se observa una intercalación de períodos húmedos y secos (Mancini y Trivi de Mandri 1994), que coinciden con periodos de transgresión y regresión del Lago Cardiel (Stine y Stine 1990).

\subsection{Estructura faunística}

Diversos trabajos han planteado que los diferentes cambios ambientales trajeron aparejados cambios en la estructura faunística (Miotti 1996; 1998; Miotti y Salemme 1999; 2005; Miotti et al. 1988; Paunero 2009; 2010). La tendencia registrada indica que la diversidad faunística disminuye desde el Pleistoceno final hacia el Holoceno en el sur de Patagonia (Miotti 1996; 1998; Miotti y Salemme 1999).

Durante Pleistoceno final se registran una gran variedad de familias taxonómicas entre las que se pueden incluir camélidos, équidos, rheidos, felinos y cánidos entre otras. Entre los camélidos además de L. guanicoe, especie actualmente representada en el área, se registra la presencia de L. gracilis únicamente en depósitos del último episodio glaciario y del Holoceno temprano (Miotti y Salemme 1999). Su presencia ha sido determinada en algunos sitios arqueológicos de la región como son en la Cueva 3 de Los Toldos (Cardich et al. 1973; Miotti 1998), Cueva 7 de El Ceibo (Miotti 1998), Casa del Minero 1 (Paunero 2003; Paunero et al. 2007), Cueva Túnel (Frank 2011) y en Piedra Museo (Miotti et al. 1999; Miotti y Salemme 1999). Por su parte, los registros en el área de Hemiauchenia paradoxa provienen del sitio Casa del Minero 1 (Paunero et al. 2007) y Cueva Túnel (Frank 2011).

La presencia de Hippidion saldiasi está geográfica y estratigráficamente restringida a este período en la región Patagónica hasta los 8.5 ka AP (Al- 
berdi y Prado 1993; Alberdi et al. 2001). Dentro del área de estudio se registraron restos de estos caballos en los sitios arqueológicos Cueva 2 (Mengoni Goñalons 1976) y 3 de Los Toldos (Cardich et al. 1973; Miotti 1998), en Cueva 7 de El Ceibo (Miotti 1998), en Cueva Túnel (Frank 2011) y en Piedra Museo (Miotti et al. 1999), asi como también en el sitio paleontológico Cerro Bombero (Paunero 2010; Paunero et al. 2008).

Durante este lapso temporal en la región, ambas especies de Rheidos $(R$. americana y $P$. pennata) habrían sido recursos disponibles. $R$. americana habría estado presente hasta ca. $9 \mathrm{ka} \mathrm{AP}$ (como especies simpátricas) momento en que se da su último registro en el área. Su desplazamiento hacia el norte en busca de condiciones menos erémicas se produjo debido a cambios ambientales (Cardich y Miotti 1983; Miotti y Salemme 1999; Salemme y Miotti 1987; Tambussi y Tonni 1985). A partir de ese momento Pterocnemia pennata habría ocupado el nicho ecológico dejado por R. americana. La presencia de estos rheidos fue determinada en la Cueva 3 de Los Toldos (Cardich et al. 1973; Miotti 1998), en la Cueva 7 de El Ceibo (Miotti 1998), Casa del Minero 1 (Paunero et al. 2007), Cueva Túnel (Frank 2011) y Piedra Museo (Miotti et al. 1999).

Otras categorías taxonómicas que también aparecen representadas en sitios arqueológicos del área para este momento son los cánidos, entre los que fue determinada la presencia de Pseudalopex sp. (Miotti 1998), Dusicyon sp. (Frank 2011). Mientras que félidos además del Puma (Felis concolor), se han hallado restos de Panthera sp. (Frank 2011).

Para el Holoceno medio se registran variaciones en el nivel del mar (Rabassa 1987; Rabassa et al. 1989), con aumento de la temperatura y disminución de la humedad (hipsitermal) pero que en la región extra andina no produjeron cambios en la estructura faunística (Miotti 1998). Resulta excepcional el registro zooarqueológico de lobito de río (Lutra sp.) como evidencia aumento de humedad ( $c a .8 \mathrm{ka}$ AP) en el sector sur del Macizo del Deseado (Miotti 1998; Horovitz 2003). El registro zooarqueológico del área se encuentra dominado por la presencia de L. guanicoe y no se registra la presencia de la fauna pleistocénica que se reconoce en el período anterior. Respecto de este punto, para el Holoceno medio los índices indican menor diversidad taxonómica que para el Pleistoceno final- Holoceno temprano (Miotti y Salemme 1999).

Las variaciones en la estructura faunística registradas en el área para 
el Holoceno tardío se relacionan con la introducción de ganado ovino el cual produce un retroceso numérico de especies nativas produciendo casi la extinción de algunas de ellas. Un ejemplo lo constituye la retracción del huemul (Hippocamelus bisulcus) hacia el bosque cordillerano (Miotti 1998).

\subsection{Vientos y precipitaciones}

El clima de la región patagónica está fuertemente influenciado por los vientos del oeste (Southern Westerlies Winds - SWW de aquí en adelante-). La combinación de los patrones generales de circulación atmosférica, sumados a la influencia de masas de aire del Pacífico y a la barrera topográfica que conforma la cordillera de Los Andes, dan como resultado un gradiente de precipitaciones oeste-este (Paruelo et al. 1998). Las fluctuaciones en los patrones de precipitación de la región están directamente relacionadas con la intensidad de estos vientos que son los que traen humedad desde el oeste y que generan diferentes efectos en franjas latitudinales distintas (ie. cambios en la humedad) (Gili et al. 2001; Gilli 2003; Markgraf et al. 2003). A su vez, los SWW están condicionados por la posición del anticiclón del Pacífico, el cual ha experimentado desplazamientos a lo largo del tiempo modificando la intensidad de los mismos (Gilli et al. 2005). Dichos cambios en la intensidad los SWW repercuten en la ubicación de la Diagonal Árida que es una franja del territorio sudamericano de escasas precipitaciones que se forma en el límite de las influencias de los anticiclones semipermanentes de los océanos Atlántico y Pacífico sobre Los Andes (González Loyarte 1995; Mancini 1998).

Se ha planteado que para el hemisferio sur los SWW han tenido un comportamiento simétrico entre las diferentes zonas del mismo (Oceanía, Sudáfrica y Sudamérica) para el lapso 14 y $5 \mathrm{ka} \mathrm{AP}$, con un alto grado de sincronía y co-variabilidad que refleja claramente la relación moderna entre la velocidad del viento del oeste y las precipitación a través del hemisferio sur. Pero a partir de los $6.5 \mathrm{ka}$ AP se rompe tal simetría coincidiendo con el inicio de la variabilidad propia del fenómeno de El Niño (El Niño Southern Oscilation -ENSO-) (Fletcher y Moreno 2012).

Para reconstruir la dinámica de los SWW en el pasado, se dispone de información sedimentológica del Lago Cardiel así como también de diferentes sectores de Chile. En el Lago Cardiel se realizaron análisis sedimentológicos 
y de susceptibilidad magnética que demuestran una intensificación de los SWW que coinciden con un evento de crecimiento del nivel del lago (Stine y Stine 1990) y con el registro de altas proporciones de polen de larga distancia perteneciente a los bosques andinos del oeste (Markgraf et al. 2003).

Markgraf y colaboradores (2003) exponen como las diferencias en cuanto a la humedad ambiental se relacionan con la ubicación latitudinal de los SWW. Estos autores plantean que, durante el Holoceno temprano entre 10 y $8.5 \mathrm{ka} \mathrm{AP}$ las bandas latitudinales norte $\left(36^{\circ}\right.$ a $\left.43^{\circ} \mathrm{S}\right)$ y sur $\left(52^{\circ}\right.$ a $\left.56^{\circ} \mathrm{S}\right)$ se caracterizan por ambientes más secos mientras que en las latitudes intermedias $\left(43^{\circ}\right.$ a $\left.52^{\circ} \mathrm{S}\right)$ que incluyen al Lago Cardiel y a nuestra área de estudio, muestran altos niveles de humedad. Luego de los $8.5 \mathrm{ka}$ AP la humedad se incrementa en las bandas latitudinales norte y sur mientras que el sector intermedio se torna más cálido y árido. Esta variación se corrobora en la evidencia obtenida en Lago Cardiel que muestra un descenso de su nivel (Stine y Stine 1990; Gilli et al. 2001). En el lapso 6-5 ka AP, como resultado de una intensificación del anticiclón del Pacífico Sudeste con un incremento en el gradiente de temperaturas polo-ecuador se genera un reacomodamiento de los SWW hacia latitudes más meridionales con una intensificación de los mismos en la franja de $49^{\circ}$ (Gilli 2003; Markgraf et al. 2003) En la región del Lago Cardiel se registra como un momento de marcada aridez que tiene su correlato en diferentes sectores del continente como el norte de Sudamérica, América Central y en algunos sectores de América del Norte (Grimm et al. 2001). Ya en el Holoceno tardío, se registra otro periodo de gran actividad eólica entre 1.8 y $1.2 \mathrm{ka} \mathrm{cal}$. AP (Gilli 2003).

En la Figura 3.5 se resumen los datos paleoambientales recopilados a partir de la bibliografía disponible para el Macizo del Deseado y sectores aledaños.

\subsection{Erupciones volcánicas}

La región patagónica en general ha sido testigo de diferentes erupciones volcánicas desde momentos previos a su ocupación humana. Estas manifestaciones ocacionaron condiciones particulares para el desarrollo de la vida y en el ambiente, por lo que se incluyen en este capítulo.

Los focos de erupción principales pertenecen a la Zona Volcánica Andina Austral donde se encuentran los volcanes Mt. Burney y Aguilera, y a la Zona 
Volcánica Andina Sur $\left(46^{\circ}-33^{\circ} \mathrm{S}\right)$ en la cual se incluye el volcán Hudson que es el que para nuestro caso cobra mayor relevancia ya que se han reconocido depósitos de ceniza en nuestra región (Stern 2004; 2008).

El caso del volcán Hudson es particularmente interesante ya que se han reconocido tres erupciones grandes a lo largo del Holoceno: la primera (denominada H1) ocurrió ca. 7750 años cal. AP; la segunda (H2) ca. 4050 años cal. AP y la última ocurrió en el año 1991 (Naranjo y Stern 1998). De estas tres erupciones la $\mathrm{H} 1$ es considerada la más importante de este volcán y una de las más grandes de entre los volcanes de la región (Stern 2008).

Si bien el registro de estas erupciones en los sitios arqueológicos mencionados en este trabajo no es ubicuo, aparece en diferentes contextos marcando la pauta de que la conservación de estos depósitos es diferencial (H1 solo se reconoce en el Lago Cardiel y H2 en Cerro Tres Tetas y Los Toldos- ver Capítulo Resultados para nueva evidencia de esta erupción-). Por lo tanto, se puede pensar que la presencia de un depósito de tefra en un sitio es suficiente para al menos, considerar que en mayor o menor medida la región fue afectada por dicha erupción.

Para tener un parámetro actualístico sobre los problemas que genera una erupción volcánica en la región que analizamos, enumeramos aquellos registrados luego de la erupción de 1991: irritación de la vista y de las vías respiratorias y digestivas, muerte de ganado ovino por falta de alimentación y agua potable, disminución de las pasturas por la saturación de cenizas en la tierra y la contaminación de las aguas (Triveri 2008). Efectos de este tipo sobre el ambiente y las personas pueden generar el abandono de lugares afectados y un grave desequilibrio ambiental en un breve lapso de tiempo, que luego necesita un periodo de recuperación para retornar a un estado similar al que prevalecía con anterioridad a la catástrofe. En este sentido, pobladores locales nos informaron en el año 2012, que recién en ese momento (21 años después de la erupción), estaban alcanzando los niveles de productividad ganadera que tenían previo a la erupción. 


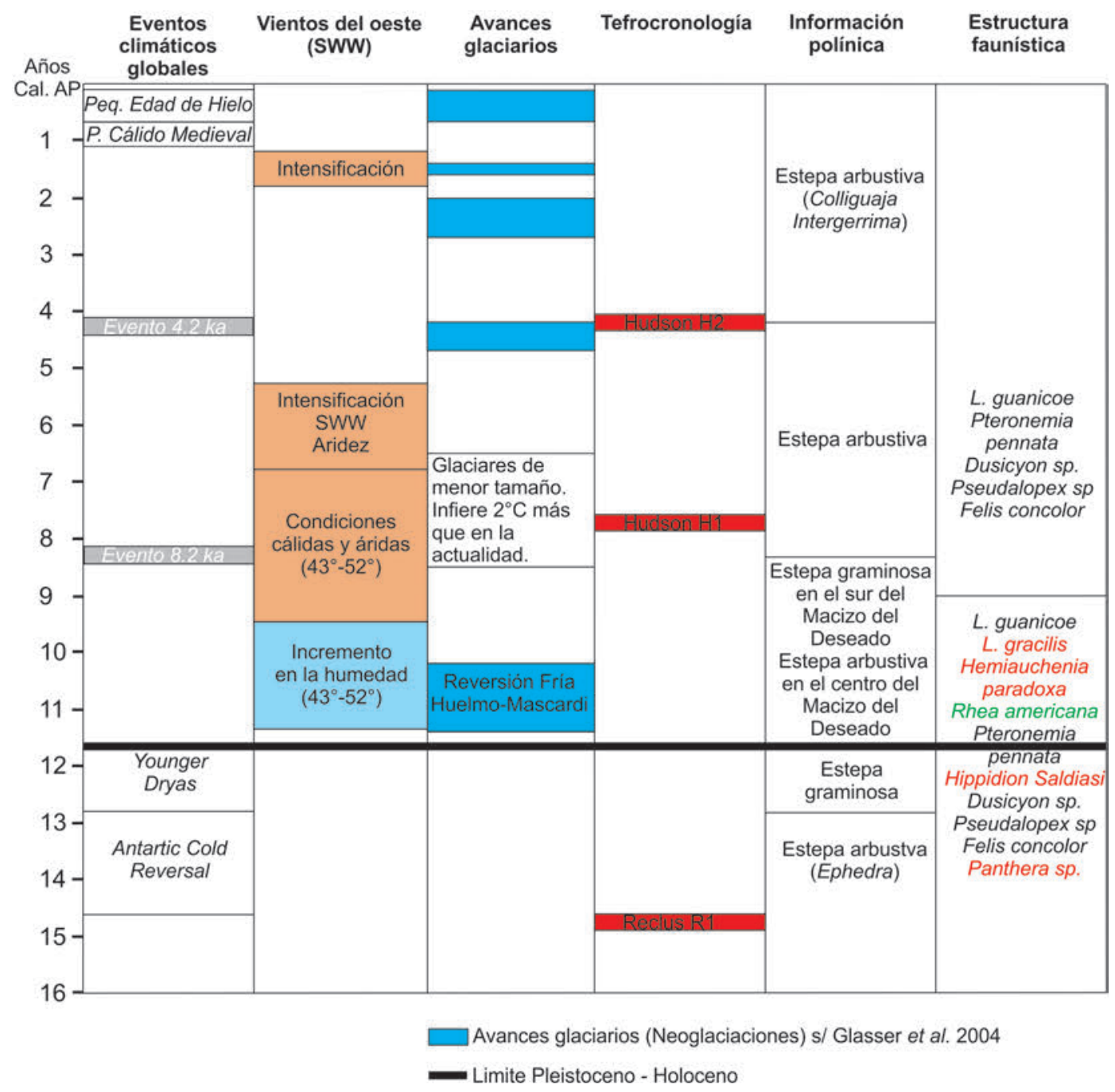

Figura 3.5: Cuadro de síntesis paleoambiental. En Estructura faúnistica, se muestran en rojo las especies extintas y en verde las que ya no habitan la región. 
48CAPÍTULO 3. EVOLUCIÓN PALEOAMBIENTAL Y PALEOCLIMÁTICA 


\section{Capítulo 4}

\section{Antecedentes}

Los antecedentes arqueológicos de nuestra área de estudio en particular y, de la región patagónica en general, son muchos y muy variados. En este capítulo nos focalizaremos principalmente en los antecedentes geoarquelógicos de la región y, en segundo lugar haremos una revisión de los antecedentes arqueológicos generados en el área de estudio, de los sitios analizados en esta tesis y de los modelos arqueológicos de poblamiento vigentes en la arqueología patagónica.

En caso de requerir mayor detalle en los antecedentes arqueológicos de nuestra área de estudio y de la Patagonia en general, recomendamos remitirse a las tesis generadas en nuestro grupo de trabajo (Blanco 2014; Carden 2008; Hermo 2008; Lynch 2014; Magnin 2010; Marchionni 2013; Miotti 1998).

\subsection{El desarrollo de la Geoarqueología}

La historia de la geoarqueología transitó por diferentes momentos hasta establecerse como un campo disciplinar. Durante el siglo XX, tanto en nuestro país como en el hemisferio norte, la inclusión del enfoque geológico en las investigaciones arqueológicas se fue dando de forma paulatina y algunos autores consideran que en tal proceso pueden reconocerse etapas o fases (Stein y Farrand 1985; Rapp y Hill 1998; Zárate 1994; 1997).

Stein y Farrand (1985), reconocen tres etapas: una primera que comienza en la década del 1930, en donde los arqueólogos enviaban muestras de sedimento o materias primas a geólogos para su análisis y caracterización. En esta etapa los resultados de esta interacción eran publicados en apéndices separados. 
En una segunda etapa, incluida en los años 1940 y 1950, los especialistas en Ciencias de la Tierra (pedólogos, geógrafos, etc.) eran incorporados en los trabajos de campo arqueológicos para aportar a la caracterización paisajística y cronológica del sitio y su entorno. Por último, luego de 1950, se incorporan geólogos a los trabajos de campo desarrollando análisis estratigráficos y muestreos en conjunto con los arqueólogos.

Por su parte Rapp y Hill (1998) llevan el comienzo de la disciplina al siglo XIX, definiendo también tres fases en el desarrollo de la misma: una Fase Fundacional (antes de 1900), seguida por la Fase Colaborativa (entre 1900 y 1950) y por último, la Fase Integradora (después de 1950). Las características de cada una son similares a las planteadas por Stein y Farrand (1985) variando básicamente la profundidad temporal de cada una.

Butzer (1982) opta por utilizar la denominación de Geología Arqueológica para las etapas posteriores a 1940, considerando que son "aplicaciones rutinarias de técnicas geológicas a casos arqueológicos", sin llegar a un resultado común integrado, sino más bien, a datos separados de los objetivos arqueológicos (Butzer 1982; Rapp y Hill 1998 y Waters 1992).

Las primeras definiciones de Geoarqueología aparecen en la década de los `70, algunas con una mirada más cercana a las Ciencias de la Tierra, planteándola como una contribución metodológica a la arqueología (Renfrew 1976; Gladfelter 1977) y otras con un mayor énfasis en la interdisciplinaridad (Butzer 1982).

La definición de Butzer (1982) es de las más aceptadas en la actualidad y la que hemos tomado en este trabajo. El autor, en el marco de una Arqueología Contextual, plantea que la geoarqueología es "investigación arqueológica que utiliza métodos y conceptos de las Ciencias de la Tierra". El autor afirma que esta disciplina es, ante todo, un enfoque conceptual y no un simple repertorio de técnicas. Es por esto que "la discusión sobre los objetivos básicos girará en torno a los componentes, procedimientos y fines interdisciplinarios del estudio" (Butzer 1982:64).

En nuestro país el desarrollo de la geoarqueología como disciplina tuvo un camino similar en cuanto a la trayectoria que se describió para el hemisferio norte. Según el Dr. Marcelo Zárate las etapas de geología arqueológica y de geoarqueología coexisten en las investigaciones actuales (Zárate 1994; 1997). De hecho, la geoarqueología, aparece en nuestro país recientemente (en la década de 1990) y en las últimas décadas ha ganado protagonismo en 
la escena científica en el marco de una labor interdisciplinaria. Fue recién en el año 2001 cuando se presentó en nuestro país la primer tesis doctoral en geoarqueología (Favier Dubois 2001) en la que el autor, egresado de la carrera de Arqueología, direccionó su especialización de posgrado hacia conocimientos teórico-metodológicos provenientes de las Ciencias de la Tierra, para aplicarlos en sus investigaciones de cazadores recolectores de fuego-patagonia.

En relación al establecimiento de la disciplina en nuestro país, en una mesa de redonda del XII Congreso Nacional de Arqueología Argentina (Blasi y Zárate 2002) se trató el tema de la interdisciplina en Arqueología. En dicha reunión se caracterizaron las dificultades para llevar adelante un trabajo interdisciplinario entre la arqueología y otras disciplinas incluida la geología. Los autores acuerdan con un trabajo precursor (Zárate 1993) en que hay tres condicionantes que dificultan el trabajo interdisciplinario, estos son: el lenguaje, las escalas de trabajo y el conocimiento básico.

Teniendo en cuenta tales dificultades, el trabajo geoarqueológico ha tenido una inserción diferencial en los proyectos de investigación desarrollados en nuestro país y los trabajos geoarqueológicos redundan muchas veces en trabajos multidisciplinarios en detrimento de los interdisciplinarios (Blasi 2008).

Recientemente, realizamos un trabajo de revisión de actas de Congresos Nacionales de Arqueología Argentina y de Congresos de Geología y Geomorfología del Cuaternario para evaluar el estado de las investigaciones geoarqueológicas durante los últimos 20 años (Mosquera y Castiñeira 2014). Los resultados indican que hay un incremento en la presentación de trabajos con objetivos geoarqueológicos, aunque también se reconoce una alta recurrencia a científicos de las Ciencias de la Tierra, para responder a cuestiones particulares o aplicar análisis específicos.

Hacia la década del 2000 se observa una recurrente inclusión de mesas exclusivas de Geoarqueología o temáticas afines en congresos de arqueología, así como también se incluyen mesas de arqueología en congresos de geología del cuaternario. Esto, ha contribuido a incrementar el interés en esta disciplina y el número de trabajos publicados dentro de esta temática, sin embargo, lograr el que los alumnos egresados de arqueología se interesen $\mathrm{y}$ trabajen en temas relacionados a las Geociencias sigue siendo dificultoso (Rubin de Rubin 2013). 
Como mencionamos al inicio del capítulo, nuestra intención es centrar la revisión de antecedentes en nuestra región de competencia. Por supuesto que esto no significa un desconocimiento o falta de trabajo geoarqueológico en otras regiones del país. De hecho, en la actualidad, en diferentes sectores de nuestro país hay investigadores especializados en geoarqueología realizando sus labores en diferentes temáticas. Ejemplo de esto son los trabajos de María Marta Sampietro y equipo (ej. Maldonado et al. 2009; Sampietro 2001; 2010; Sampietro et al. 1996), abordando distintos temas como la geomorfología, cambios ambientales y climáticos en relación al desarrollo de sociedades agrícolas, la distribución y los procesos de formación de sitios en el NOA.

Otro abordaje geoarqueológico importante se da en el área deltaica superior del río Paraná, donde se abordan los distintos patrones de asentamientos y subsistencia en los diferentes ambientes sometidos a una intensa dinámica fluvial e hidrometerológica vulnerable (Castiñeira et al. 2014).

Entre los sitios abordados se destacan las estructuras en tierra regionalmente reconocidas como "cerritos", en los cuales a partir de diferentes análisis que incluyen: sedimentología, micromorfología, paleobotánica y proxies ambientales se discute su génesis antrópica, su evolución, funcionalidad y rol en la dinámica social (Castiñeira et al. 2012; Blasi et al. 2013a).

En la región pampeana, se han desarrollado numerosos trabajos de geoarqueología a partir de la inclusión de geólogos en proyectos arqueológicos. Dentro de estos trabajos se incluyen el análisis de sitios ubicados en ambientes fluviales del área interserrana bonaerense (Favier Dubois 2006; Favier Dubois y Bonomo 2008; Johnson et al. 2012) así como en la costa marina de dicha provincia (Blasi et al. 2013b). También se han realizado estudios geoarqueológicos de cuevas en el este del sistema serrano de Tandilia. Estos trabajos están caracterizados por un enfoque interdisciplinario que sintetiza diferentes líneas de evidencia (Martinez et al. 2013; Mazzanti et al. 2013; 2015). A partir de ellos se han planteado algunas generalidades sobre las secuencias estratigráficas de las cuevas de la región pampeana, como por ejemplo un cambio sedimentario que se da hacia los 10500 años ${ }^{14} \mathrm{C}$ AP, cuando se registra a partir de los proxies ambientales un mejoramiento climático luego de las condiciones secas y áridas del Último Máximo Glacial. A nivel sedimentológico se observa una discordancia estratigráfica que separa sedimentos de diferente color, textura y compactación y que se ubica por debajo se las 
primeras ocupaciones arqueológicas registradas en la zona.

\subsection{Los trabajos geoarqueológicos en la región patagónica}

Como mencionamos anteriormente, en la década de 1990 se establece la "geoarqueología" dentro de la escena científica de nuestro país en un contexto donde convivían (y continúan conviviendo) los trabajos geoarqueológicos propiamente dichos y aquellos que eran aportes de geólogos a estudios arqueológicos.

Específicamente en la región patagónica los temas abordados desde entonces son variados incluyendo sedimentología, geomorfología, pedología, petrografía, paleomagnetismo, y cronología entre otros (ej. Andreis 2007; Barberena et al. 2006; Barberena 2014; Blasi y Zárate 2002; Brook et al. 2014; Eugenio 1999; Favier Dubois 1998; 2003; Mehl y Franco 2009; Paunero y Blasi 2009; Scasso y Eugenio 1999; Skarbun y Páez 2012; Zárate et al. 2000).

Los estudios geoarqueológicos; desarrollados de manera sistemática en la región son pocos y entre ellos podemos mencionar aquellos llevados a cabo por Favier Dubois en el norte de Tierra del Fuego y la región de Magallanes (Favier Dubois 1998; 2003; 2008) y luego en la costa Norte de Patagonia (Favier Dubois 2009; Favier Dubois y Borella 2007; Favier Dubois y Kokot 2011; Favier Dubois y Scartacini 2012). Este autor abordó diferentes temáticas dentro de la geoarqueología de la región como son la geomorfología de costas y su relación con sitios arqueológicos, aspectos metodológicos de las dataciones radiocarbónicas, cronología, paleoambientes, pedogénesis, procesos de formación del registro arqueológico así como también la dinámica sedimentaria de sitios en cuevas.

Otro aporte interesante ha sido el de Ramiro Barberena en el campo volcánico Pali Aike donde desde una perspectiva biogeográfica analiza los depósitos sedimentarios de la cueva Orejas de Burro 1, en la que evalúa las implicancias tafonómicas del depósito y el uso de diferentes sectores de la cueva (Barberena 2008), y Cueva Condor 1 en la cual a partir del análisis geoarqueológico discute las implicancias cronológicas, paleoambientales y de formación de sitio (Barberena et al. 2006). 


\subsection{El estudio geoarqueológico de sitios en cuevas y abrigos rocosos}

En esta tesis tienen un lugar preponderante los sitios arqueológicos emplazados en cuevas y abrigos rocosos los cuales actúan como trampas sedimentarias naturales (Colcutt 1979; Farrand 1985). Este tipo de sitio ha tenido una importancia mayúscula en la arqueología de la Patagonia ya que a partir de ellos se obtuvieron las secuencias arqueológicas más antiguas y prolongadas de la región. Los resultados obtenidos permitieron discutir numerosos temas de gran importancia para la arqueología, como el poblamiento de América (Borrero 1994-95, Cardich et al. 1973, Miotti 2006a), la coexistencia del hombre con la megafauna (Borrero 2001; Miotti y Salemme 1999; entre otros), el rol del arte rupestre (Aschero 1987; Menghin 1957; Carden 2008; Gradín et al. 1976b; entre muchos otros) y el uso del espacio por parte de poblaciones cazadoras recolectoras desde la transición PleistocenoHoloceno hasta tiempos históricos (Barberena et al. 2006; Miotti 2008; Skarbun y Frank 2011).

El enfoque geoarqueológico del estudio en cuevas y abrigos rocosos de la Patagonia ha cambiado a través del tiempo y ha sido reflejo de las etapas históricas de la disciplina mencionadas anteriormente. Los primeros trabajos sobre formación de depósitos sedimentarios en cuevas fueron publicaciones de índole geológica que a veces se presentaban como informes o apéndices de trabajos arqueológicos (Etchichury 1976; Mazzoni y Spalletti 1975; Scasso y Eugenio 1999) mientras que en la actualidad se reconocen en la literatura estudios geoarqueológicos con integración de información arqueológica (Brook et al. 2014; Barberena et al. 2006; Barberena 2014; Favier Dubois 1998; Miotti et al. 2014; entre otros).

Dentro de los primeros, hay un énfasis en la reconstrucción paleoambiental a partir de indicadores sedimentológicos como la textura de los sedimentos y los porcentajes de carbonato y materia orgánica. En estos estudios aplican los análisis texturales clásicos (Folk 1954; Folk y Ward 1957) sin tener en cuenta el rol de los cazadores-recolectores como agentes geomórficos (Butzer 1982). Con el paso del tiempo las observaciones geológicas de los sitios han ido incluyendo al material arqueológico para responder a preguntas de índole tafonómica y cronológica, así como también de impacto humano en los procesos de formación de sitios. 


\subsection{Modelos de poblamiento}

La Patagonia Argentina se inscribe tempranamente en la historia continental del poblamiento humano con registro de la presencia humana desde el Pleistoceno tardío en diferentes áreas (Norpatagonia, el Macizo del Deseado y la cuenca Magallánica). A partir de ese lapso, fueron puestas en marcha diversas estrategias tecnológicas que permitieron ocupar progresivamente distintos espacios haciendo frente a los cambios ambientales y a la variabilidad ecológica de la región.

Uno de los modelos con mayor difusión es el planteado por Borrero (1989-1990, 1994-95) en el que se proponen diferentes etapas del poblamiento de una región, estas son: Exploración inicial, su Colonización y Ocupación efectiva del espacio. Se basa en un marco ecológico y plantea diferentes expectativas arqueológicas en relación con las estrategias de subsistencia plausibles de haber sido desarrolladas en cada etapa.

Por su parte, Miotti y Salemme $(1999 ; 2004)$ plantean un modelo de poblamiento de Pampa y Patagonia que consta de dos etapas denominadas Fase de Colonización la cual se desarrolla temporalmente entre 13.5 y $8.5 \mathrm{ka}$ ${ }^{14} \mathrm{C}$ AP y Fase de Consolidación Territorial entre 8.5 y $4.5 \mathrm{ka}{ }^{14} \mathrm{C}$ AP. Según las autoras, a partir del análisis de taxa faunísticos explotados durante la Fase de Colonización, plantean que las estrategias de movilidad y explotación de recursos se asemejarían al tipo forager (Binford 1980) o generalista en cuanto al manejo de los recursos faunísticos. Posteriormente, en la Fase de Consolidación (8.5-4.5 ka ${ }^{14} \mathrm{C}$ AP) cuando las especies de megamamiferos se extinguen por completo, la diversidad taxonómica se reduce y las estrategias de explotación muestran una tendencia a la especificación, con una marcada reducción de los taxa utilizados. En ambos momentos el guanaco (Lama guanicoe) es el recurso principal.

En un trabajo posterior basándose en el modelo de adaptaciones acuáticas (Erlandson 2001) Miotti (2006b) propone que las vías de ingreso al continente sudamericano habrían sido los litorales marinos. La autora postula que los litorales son sectores que proveen vías de tránsito claras entre la tierra y el mar, y permiten acceder hacia el interior del continente siguiendo las cuencas de los grandes ríos que desembocan en el océano tales como el Magdalena-Cauca, Orinoco, Amazonas, de la Plata, y específicamente en la Patagonia, el Negro, Colorado, Chubut, Deseado, Chalía, Santa Cruz y Chico. 
Los diferentes sectores patagónicos fueron incorporados a los espacios de vida de las poblaciones cazadoras-recolectoras de la región de manera creciente desde fines del Pleistoceno y a lo largo del Holoceno. La sucesión de las diferentes etapas en la ocupación de los ambientes patagónicos no implica que ésta haya sido siempre continua, ni unilineal (Borrero 2001). Esta larga historia ocupacional puede ser entendida como una sucesión de ocupaciones, abandonos, reocupaciones de espacios y de los usos dados a los recursos presentes en cada sector.

Teniendo en cuenta que las formas de subsistencia fueron cazadorasrecolectoras con exclusividad, es esperable que dicha historia haya sido desarrollada mediante tecnologías y mecanismos sociales de aprovisionamiento y circulación de bienes a diferentes escalas (Fitzhugh et al. 2011; Mc Donald y Veth 2011).

En los modelos planteados para Patagonia, se ha propuesto que para la exploración inicial de zonas deshabitadas se espera una baja depositación de materiales, que sean funcionalmente poco específicos y que se acumulen en localizaciones no óptimas (Borrero 1994-95:10). Los conjuntos líticos estarían conformados principalmente por artefactos formatizados expeditivamente, y en menor medida por artefactos conservados (quebrados o agotados) y desechos correspondientes a las etapas finales (ej. mantenimiento, reciclaje) de artefactos transportados (Borrero y Franco 1997).

El proceso de colonización o consolidación inicial de grupos humanos en sectores determinados del espacio (Borrero 1989-1990), se asocia a una mayor reocupación de sitios localizados óptimamente, generando registros con alta visibilidad y buena resolución. En esta etapa es posible una ampliación en la variabilidad de la cultura material como resultado de adaptaciones a condiciones locales y se espera la presencia de hiatos ocupacionales entre las etapas de exploración y colonización de sectores (Borrero 1994-95).

En el modelo propuesto por Miotti y Salemme (1999), estas dos primeras etapas son integradas en la de Colonización Inicial, ya que según estas autoras no es posible discriminar la exploración de la colonización inicial en el registro arqueológico.

Finalmente, la tercera etapa del modelo es la ocupación efectiva del espacio (sensu Borrero 1989-1990) o de consolidación territorial (Miotti y Salemme 1999); definida por la ocupación de todo el espacio deseable y caracterizada por una densidad poblacional y una territorialidad relativamente 
altas. Las expectativas arqueológicas implican una alta visibilidad pero una baja resolución producida por la superposición de rangos de acción, en ocupaciones continuas o separadas por hiatos pequeños y de amplitud comparable.

Por otro lado, recientemente se ha generado una propuesta basada en los conceptos de aprendizaje del paisaje, ecorrefugios y espacios de vida para comprender las formas en que los espacios deshabitados fueron convertidos en lugares ocupados. Este modelo no tiene anclaje en la cronología, ya que busca conocer qué rol jugó cada sitio en el proceso de inclusión de nuevos espacios de vida en el poblamiento de Patagonia. Se presenta en tres pasos: el primer paso corresponde al scouting o exploración (reconocimiento y ubicación de los recursos se convierte en el aprendizaje locacional); el segundo paso está dado por los eventos ocupacionales que representan un retorno a lugares conocidos durante la exploración (puntos que muestran señales de haber sido incorporados a los espacios de vida humanos a escala regional); y el tercer paso en esta cadena de aprendizaje y transformación de los paisajes es lo que se denominó conocimiento social del ambiente (los paisajes se encuentran configurados a partir de las marcaciones territoriales y las prácticas sociales para transitar y habitar lugares) (Miotti et al. 2015).

\subsection{Los conjuntos arqueológicos del Macizo del Deseado}

En el Macizo del Deseado para el momento de la transición PleistocenoHoloceno y Holoceno temprano han sido registradas ocupaciones cuyos conjuntos líticos pueden caracterizarse por la presencia de artefactos elaborados sobre lascas grandes, generalmente espesas y formatizados mediante retoque marginal [Los Toldos (Cardich et al. 1973), Piedra Museo (Miotti 1995; Miotti et al. 1999; Lynch 2014), El Ceibo (Cardich 1987; Mansur 1983), Cerro Tres Tetas (Paunero 2000; 2003), Cueva Casa del Minero (Paunero 2000; 2003; Skarbun y Frank 2011), La Mesada (Skarbun 2011), La Martita (Aguerre 1987; 2003) y El Verano (Durán et al. 2003), como así también en el noroeste santacruceño (Civalero 2000, Civalero y Franco 2003)]. La tecnología de puntas de proyectil presenta mejor definición hacia el Holoceno temprano, lapso para el que se registran dos morfologías bien diferenciadas: puntas cola de pescado en el Componente Inferior de Piedra Museo (Miotti 
1995); y puntas triangulares apedunculadas (denominadas Toldenses sensu Cardich et al. 1973, Río Pinturas I sensu Gradín et al. 1987 o Fell III sensu Bird 1938) en los sitios arqueológicos de Los Toldos (Cardich et al. 1973), La Martita (Aguerre 2003), El Verano (Durán 1990, Durán et al. 2003), Cueva La Mesada, y el Componente Superior de Piedra Museo.

Cabe destacar que las puntas cola de pescado son reconocidas como artefactos de las primeras ocupaciones humanas desde México hasta Tierra del Fuego y poseen una amplia distribución temporal (Castiñeira et al. 2012; Flegenheimer et al. 2013; Miotti y Terranova 2015). No obstante, en el sector en estudio los fechado radiocarbónicos de Piedra Museo ubican a estos artefactos en los comienzos del Holoceno temprano.

En cuanto al aprovechamiento de la fauna, para este período se propuso que los grupos humanos que colonizaron la región implementaron una estrategia generalista basada en la caza del guanaco utilizando un amplio rango de recursos faunísticos - ej. équidos, camélidos, perezosos gigantes y aves corredoras- (Borrero 1994-95; Miotti 1998; Miotti y Salemme 1999).

Son varios los autores que sostienen un uso complementario y ocasional de la megafauna en relación al guanaco (Borrero 1984; 2009; Cardich y Miotti 1983; Gutiérrez y Martínez 2008; Mengoni Goñalons 1983; Miotti 1998; Miotti et al. 1988; Politis 1984; Politis y Messineo 2008). Para este momento, se propone que las redes de comunicación y los rangos de movilidad habrían sido amplios, lo que permitía conocer el territorio y los lugares aptos para su ocupación (Miotti 1995; 2003; Miotti y Salemme 1999). Esto contrasta con lo planteado por Borrero, que para esta etapa propone que los lugares de asentamiento debieron ser locaciones no óptimas.

Hacia el Holoceno medio (ca.7500-3500 años ${ }^{14} \mathrm{C}$ AP; 8.2-4.2 ka cal AP) se dieron condiciones climáticas de aumento de temperaturas y de expansión de bosques y gramíneas; y en el Macizo del Deseado proliferan las estepas arbustivas (De Porras 2010; Mancini 2009; Miotti y Salemme 2004; Páez et al. 1999).

En este periodo se desarrolla la Fase de Consolidación Territorial (Miotti y Salemme 1999), donde la estrategia de apropiación de fauna se torna especializada en el guanaco luego de la desaparición de la megafauna. Además se habrían establecido alianzas e intercambios entre la meseta, la cordillera y la costa, en concordancia con un aumento poblacional y la ocupación de nichos previamente vacantes (Miotti y Salemme 2004). 
En este sentido, la propuesta de Borrero (1989-1990; 1994-95) plantea que comienza la etapa denominada de Ocupación efectiva del espacio en la cual se llegan a utilizar todos los espacios deseables. Según este autor, se emplean dos estrategias de ocupación, la Ocupación estable y la Saturación del espacio. La primera podría implicar una territorialidad bajo ciertas condiciones específicas, la segunda implicaría la aparición masiva de mecanismos dependientes de la densidad poblacional (Borrero 1994-95). Las expectativas de dicho modelo para este proceso son una alta visibilidad arqueológica con baja resolución debida a la superposición de rangos de acción de los distintos grupos.

Los fechados radiocarbónicos del Holoceno medio son escasos tanto para el Macizo del Deseado (Hermo y Magnin 2012) como para otras regiones del país (ver listado de los mismos en Zárate et al. 2000). La tecnología de los conjuntos del Holoceno medio de la región muestran una preponderancia en la producción de hojas y su uso como formas base, la ausencia de registro de puntas de proyectil en el Macizo del Deseado (no así en la zona cordillerana donde las puntas triangulares apedunculadas continúan presentes hasta ca. 4000 años AP, Gradín et al. 1987) y la aparición de bolas de boleadora (véase discusión en Hermo y Magnín 2012; Lynch 2013; Lynch y Hermo 2015).

Otras evidencias materiales destacables son la presencia de valvas de moluscos marinos provenientes de la costa atlántica en el Macizo del Deseado (distante a $200 \mathrm{~km}$ aproximadamente en línea recta), al igual que de una materia prima alóctona (obsidiana) proveniente de Pampa del asador, ubicada en el sector cordillerano andino (Cardich et al. 1994; Stern 1999; Miotti 1998; 2006a; Miotti y Salemme 2004; Hermo 2008). Dichos objetos han sido interpretados como bienes circulantes en redes de comunicación/información que conectaban estos diferentes ambientes (Miotti 2006a; Hermo y Miotti 2011; Hermo y Magnin 2012). Recientemente, se ha publicado el hallazgo de una fuente de secundaria de aprovisionamiento de guijarros de obsidiana de tamaño muy pequeño en el sur del macizo, geoquímicamente indistinguible de la de Pampa del Asador (Franco et al. 2015a, Franco et al. 2015b). Esto permite relativizar la extensión de los rangos de acción en el caso de instrumentos pequeños.

Es durante este bloque temporal que se registra la incorporación de determinadas áreas a los espacios de vida humanos, en ambientes bien dife- 
rentes de Patagonia como la costa chubutense (Castro et al. 2007; Gómez Otero y Stern 2005), el bosque Nordpatagónico (Fernández et al. 2013), la cuenca alta del río Chubut (Aschero et al. 1983; Bellelli 1991) y las ocupaciones en determinados sectores de las cuencas de los lagos del noroeste de Santa Cruz (Aschero et al. 2009); pese que en algunos sectores se registraron pulsos ocupacionales previos (véase asimismo Miotti y Salemme 2004).

Hacia fines del Holoceno medio se habría desarrollado el proceso de consolidación territorial de los grupos humanos en el sector, caracterizado por alianzas e intercambios con una alta movilidad, viéndose favorecido por mayor disponibilidad de microambientes (Miotti y Salemme 1999; Miotti $2006 a$; 2012). A medida que fue avanzando este proceso de consolidación territorial en conjunto con un incremento poblacional, muchos sectores nuevos habrían sido ocupados hacia el Holoceno tardío (véase Borrero 1994-95; Goñi 2010; Bozzuto 2011), continuando asimismo la utilización de las cuevas y aleros como loci para diferentes actividades dentro del Macizo del Deseado (Goñi y Barrientos 2004; Cassiodoro et al. 2004; Miotti 2006a; Magnin 2010; Lynch 2014).

Para este lapso se han propuesto algunos cambios en los conjuntos líticos, tales como la aparición de puntas triangulares con pedúnculo y aletas, y una tendencia hacia la reducción de tamaño y del módulo de longitudanchura de las hojas y de los instrumentos elaborados sobre hojas (ej. raspadores) (Aschero 1987; Orquera 1984-85; Lynch 2014).

\subsection{Sitios estudiados en esta tesis}

\subsubsection{Anecedentes - Sitio Cueva Maripe}

La cueva Maripe, ubicada en el Macizo del Deseado, provincia de Santa

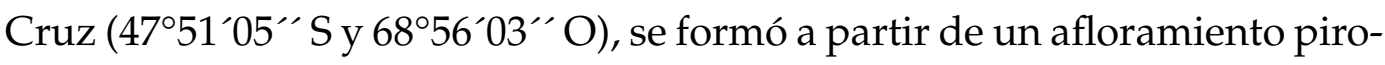
clástico, correspondiente a una toba lapillítica de la Fm. Chön Aike (Panza 2001). Dicha formación forma parte del grupo Bahía Laura integrado por las Formaciones Chön Aike y La Matilde del Jurásico medio a superior que conforman un complejo volcano-piro-sedimentario de carácter ácido a mesosilícico. Estas rocas conforman un gran plateau ignimbrítico (De Barrio 1993; Pankhurst et al. 1993) de gran importancia en la conformación geológica del Macizo del Deseado, debido a la extensa superficie que ocupa. 
La cueva se emplaza en el margen este del Cañadón La Primavera dentro del cual corre el mallín homónimo (Figura 4.1). Este sitio presenta un área de $624 \mathrm{~m} 2(26 \mathrm{~m} \times 24 \mathrm{~m}$ ) y se encuentra dividido por un tabique rocoso en dos cámaras, las que fueron denominadas como: Cámara Norte $(\mathrm{CN})$ y Cámara Sur (CS) (Miotti et al. 2007) (Figura 4.2). El tabique además de dividir el espacio interno de la cueva, marca una diferenciación de tipo microambiental (Miotti et al. 2007).

La $\mathrm{CN}$ es un área más seca y de mayores dimensiones areales en la que tuvo lugar la mayor depositación de sedimentos dentro del sitio (Miotti et al. 2007), mientras que CS es más húmeda debido a una filtración intermitente de agua desde las paredes del fondo de la misma, más luminosa por la incidencia de luz solar durante gran parte del día y presenta una acumulación de sedimentos menos potente que CN (Figura 4.2).

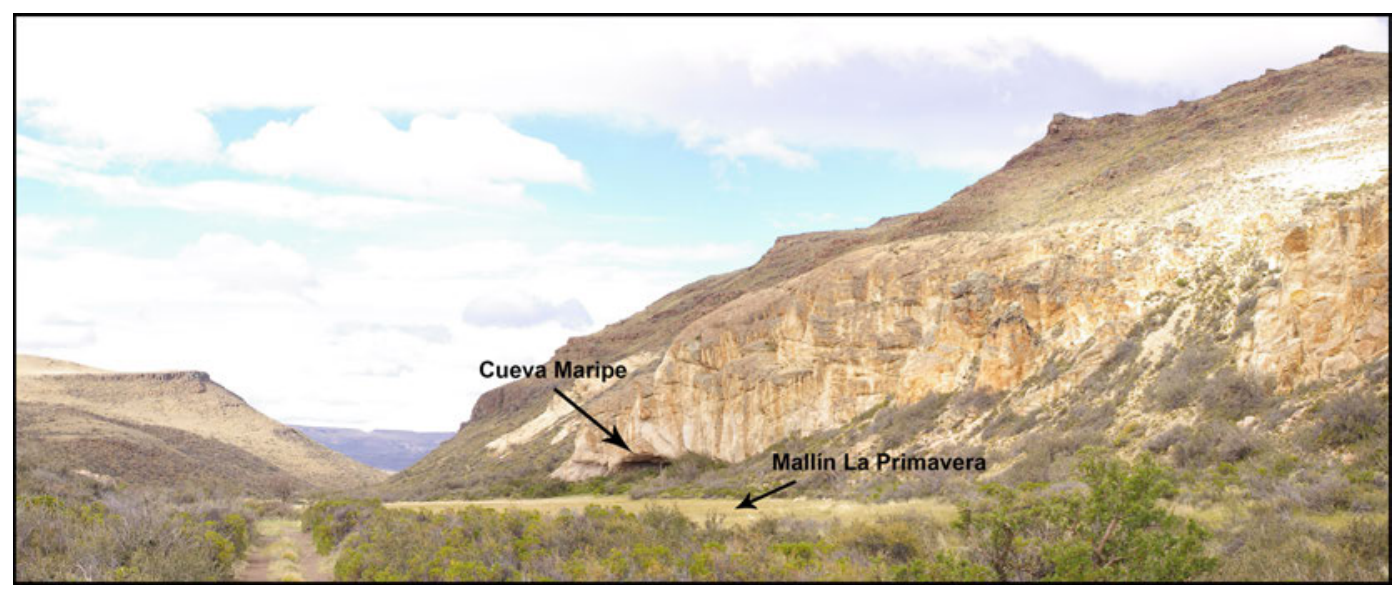

Figura 4.1: Vista general del Cañadón La Primavera y la Cueva Maripe al borde del mallín

El análisis de los conjuntos arqueológicos recuperados, permitió reconocer diferencias entre estos sectores a partir de la tecnología lítica (Hermo 2008), el arte rupestre (Carden 2008) y la zooarqueología y tafonomía (Marchionni et al. 2012). A partir de las dataciones radiocarbónicas realizadas en el sitio, se ha reconocido un lapso similar de ocupación en ambas cámaras, llegando a los ca. 9500 años AP en CS y ca. 9200 años AP en CN.

En un trabajo previo a partir de los datos radiocarbónicos disponibles en ese entonces se calcularon dos valores de tasas de acumulación (Miotti et al. 2007). Los mismos permitieron estimar una clara diferencia depositacional entre sectores, con una estratigrafía de menos de $1 \mathrm{~m}$ de potencia en CS con una tasa promedio de depositación (considerando acumulación continua) 


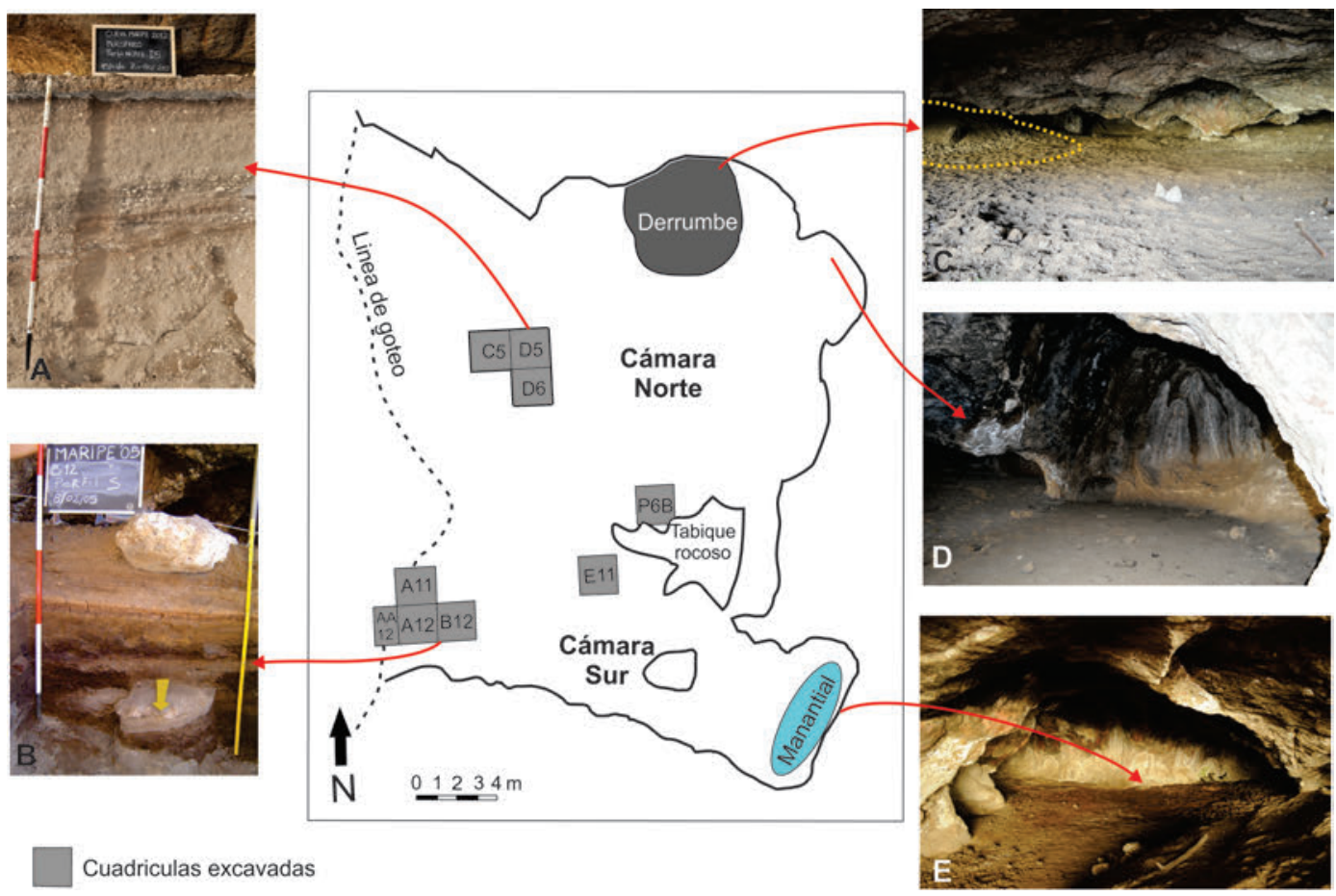

Figura 4.2: Planta del sitio Cueva Maripe. A) Estratigrafía de Cámara Norte. B) Estratigrafía de CS. C) Cámara Sur, la línea punteada marca el derrumbe mencionado. D) Fondo de Cámara Norte. E) Fondo de Cámara Sur donde surge el manantial mencionado.

de 0,004 cm/años, mientras que en $\mathrm{CN}$ esta tasa (considerada de igual manera) es de $0,015 \mathrm{~cm} /$ años alcanzando los $2 \mathrm{~m}$ de potencia, lo que a priori, resulta en una mayor resolución para el estudio del registro de este último sector (Marchionni et al. 2012; Miotti et al. 2007). Debido a su conexión con el exterior, puede decirse que Maripe es una cueva externa (Miotti 2010) y su superficie actual se ubica alrededor de $4 \mathrm{~m}$ sobre la superficie actual del mallín La Primavera.

Los trabajos de excavación en este sitio comenzaron en el año 2003 y se continuaron hasta el año 2012. Se utilizaron unidades de excavación de $2 \times 2 \mathrm{~m}$, con excepción de la cuadricula AA12 de CS en la cual se excavó una extensión de $2 \times 1 \mathrm{~m}$. En total la superficie excavada es de $34 \mathrm{~m}^{2}$, de los cuales $16 \mathrm{~m}^{2}$ corresponden a CN -cuadrículas C5, D5, D6 y P6B- y $18 \mathrm{~m}^{2}$ fueron excavados en CS - cuadriculas A11, A12, AA12, B12 y E11- por lo que las superficies excavadas en ambos sectores son similares.

A lo largo de las investigaciones desarrolladas en el sitio se han realizado un total de 22 dataciones radiocarbónicas, 14 provenientes de CN y 8 de CS (Miotti et al. 2007; 2014) (Tablas 4.1 y 4.2). Todas ellas fueron realizadas me- 


\begin{tabular}{ccccccc}
\hline Código Lab. & Años ${ }^{14}$ C AP & Años cal AP & Material & Cuadr. & Sector & Capa \\
\hline AA95129 & $9177 \pm 56$ & $10496-10234$ & Carbón & D6 & SW & 5 \\
\hline AA65179 & $8992 \pm 65$ & $10249-9912$ & Carbón & D5 & NW & 5 \\
\hline AA95127 & $8827 \pm 87$ & $10181-6909$ & Hueso & C5 & NW & 5 \\
\hline AA95126 & $8012 \pm 80$ & $9091-8608$ & Hueso & D5 & SE & 5 \\
\hline AA65178 & $8762 \pm 50$ & $10115-9556$ & Carbón & C5 & SE & 5 \\
\hline AA99069 & $7153 \pm 50$ & $8152-7858$ & Carbón & C5 & NW & 5 \\
\hline AA99071 & $5376 \pm 45$ & $6284-6004$ & Carbón & D5 & SE & 4 \\
\hline AA99070 & $5137 \pm 45$ & $5990-5749$ & Carbón & D5 & SE & 4 \\
\hline AA65173 & $5084 \pm 49$ & $5928-5716$ & Carbón & D6 & SE & 4 \\
\hline AA99067 & $4002 \pm 43$ & $4782-4300$ & Carbón & C5 & NE & 4 \\
\hline AA99068 & $3791 \pm 42$ & $4383-3992$ & Carbón & C5 & NW & 4 \\
\hline LP-1497 & $3210 \pm 60$ & $3579-3272$ & Carbón & C5 & NE & 4 \\
\hline AA95123 & $3535 \pm 62$ & $3980-3642$ & Hueso & P6B & SE & - \\
\hline AA95124 & $1907 \pm 48$ & $1949-1719$ & Hueso & P6B & SW & - \\
\hline
\end{tabular}

Tabla 4.1: Fechados radiocarbónicos de CN de Cueva Maripe (Tomados de Miotti et al. 2007; 2014)

diante AMS en el laboratorio de la Universidad de Arizona con excepción de una (LP-1497) que se hizo mediante técnica estándar en el Laboratorio de Tritio y Radiocarbono (LATyR) del Museo de Ciencias Naturales de La Plata. Estas dataciones permitieron reconocer que la cueva estuvo ocupada desde hace $c a .9,500$ años ${ }^{14} \mathrm{C}$ AP (11102-10594 años cal AP) hasta tiempos históricos.

En relación a los conjuntos arqueológicos del Macizo del Deseado, los estudios realizados sobre los materiales de Cueva Maripe permitieron conocer algunas tendencias y cambios a lo largo de la secuencia ocupacional, tanto en la tecnología lítica como en el análisis zooarqueológico y en el uso del espacio a diferentes escalas. 


\begin{tabular}{ccccccc}
\hline Código Lab. & Años ${ }^{14}$ C AP & Años cal AP & Material & Cuadr. & Sector & Capa \\
\hline AA65175 & $9518 \pm 64$ & $11102-10594$ & Carbón & A12 & SW & 4 \\
\hline AA65174 & $8333 \pm 63$ & $9479-9136$ & Carbón & A12 & SE & 4 \\
\hline AA65177 & $7703 \pm 47$ & $8584-8411$ & Carbón & B12 & SW & 3 \\
\hline AA65181 & $4113 \pm 39$ & $4821-4522$ & Carbón & A12 & SE & 3 \\
\hline AA95122 & $2655 \pm 39$ & $2849-2736$ & Carbón & B12 & SW & 4 \\
\hline AA95118 & $1403 \pm 46$ & $1394-1264$ & Hueso & A11 & NW & 2 \\
\hline AA65176 & $1078 \pm 40$ & $1061-928$ & Carbón & B12 & SW & 2 \\
\hline AA95121 & $155 \pm 35$ & $285-(-2)$ & Carbón & A12 & SE & 3 \\
\hline
\end{tabular}

Tabla 4.2: Fechados radiocarbónicos de CS de Cueva Maripe (Tomados de Miotti et al. 2007; 2014)

Debemos remarcar que Cueva Maripe fue un espacio recurrentemente ocupado desde la colonización inicial de Patagonia y las evidencias de estas ocupaciones han sido agrupadas en tres componentes que se corresponden a los siguientes bloques temporales: Transición Pleistoceno/Holoceno temprano con fechados entre ca. 9100 y 9500 años ${ }^{14} \mathrm{C}$ AP, Holoceno medio con fechados entre $c a .7700$ y 3500 años ${ }^{14} \mathrm{C}$ AP, y Holoceno tardío con dataciones entre ca. 4100 y 1100 años ${ }^{14} \mathrm{C}$ AP. Esta definición fue lograda mediante la confluencia de distintas líneas de evidencia: Sistemas de Información Geográfica (SIG), tecnología lítica, zooarqueología, sedimentología y fechados radiocarbónicos (Miotti et al. 2014).

\section{Tecnología lítica en Cueva Maripe}

\section{Transición Pleistoceno/Holoceno Temprano: Componente 1}

Las ocupaciones del Componente 1 de Cueva Maripe se adecuan a algunas de las expectativas teóricas formuladas para momentos de exploración/ colonización inicial de espacios (ej. baja frecuencia artefactual, uso de materias primas preferentemente locales y módulos muy espesos). En este caso se reconoce una tecnología preponderantemente unifacial sobre lascas en la que abundan los filos largos. Entre los grupos tipológicos más diagnósticos se encuentran puntas de proyectil, cepillos y raederas.

Las puntas de proyectil corresponden tecnomorfológicamente a las denominadas Magallanes III, Toldenses o "puntas triangulares apedunculadas" (Bird 1946: Cardich et al. 1973; Aschero 1987; Gradin y Aguerre 1994; 
Aguerre 2003; entre otros) presentes en diferentes conjuntos del Holoceno temprano del norte de la provincia de Santa Cruz (véase Cardich et al. 1973; Gradin y Aguerre 1994; Aguerre 2003; Cattáneo 2002; Civalero y De Nigris 2005).

Las materias primas corresponden en general a fuentes locales de un radio de $15 \mathrm{~km}$, a excepción de la obsidiana, de la cual se registran solo dos AF que sugieren un aprovisionamiento a escala regional, ya que las fuentes conocidas se sitúan en la cordillera (véase Espinosa y Goñi 1999; Stern 2004; Miotti 2008; Hermo y Miotti 2011 y bibliografía allí citada). Los análisis de los núcleos abandonados en Cueva Maripe durante este lapso indican principalmente estrategias de aprovisionamiento de personas (sensu Kuhn 2004).

Los fechados radiocarbónicos ubican estos eventos en momentos en los que el área ya se encontraba poblada, por lo que Cueva Maripe habría sido ocupada inicialmente durante la ampliación de los espacios de vida y la incorporación de nuevos lugares entre los cazadores-recolectores del Holoceno temprano de Patagonia (Hermo y Lynch 2015).

- $\quad$ Holoceno Medio: Componente 2

El Componente 2, correspondiente al Holoceno medio, presenta mayor frecuencia y diversidad morfológica de artefactos formatizados, representando un uso del espacio para actividades múltiples. Si bien las materias primas locales son predominantes, se ha observado incremento en el uso de xilópalo y de obsidiana.

Es importante destacar que en esta capa se hallaron evidencias de manufactura de bolas de boleadora (Hermo 2008), tecnología de armas que hace su aparición en la región hacia el Holoceno medio, lo que constituye no sólo una innovación a nivel tecnológico sino también nuevas necesidades (rocas más duras) y diferentes formas de relacionarse con el entorno (uso de topografías específicas para emboscar a las presas). No obstante, en este componente también se registraron puntas triangulares apedunculadas, lo que marcaría una continuidad de los sistemas de armas utilizados durante el Holoceno temprano, en concordancia con lo que muestra la secuencia cultural del área Río Pinturas (véase Gradin y Aguerre 1994).

Durante el Holoceno medio, los núcleos de Cueva Maripe muestran extracciones de hojas y uso de materias primas de larga distancia, descartados con utilidad potencial restante. Hermo y Lynch (2015) propusieron que 
los núcleos correspondientes a este lapso resultaron, al menos en parte, de estrategias de aprovisionamiento de lugar (sensu Kuhn 2004) lo que se relacionaría con el uso recurrente de la cueva (ej. retorno al lugar). A su vez, Lynch y Hermo (2015) estudiaron la cadena operativa de las hojas y de los artefactos formatizados cuyas formas base fueran hojas presentes en Cueva Maripe, como forma de aportar al conocimiento de esta tecnología que se encuentra presente en muchos contextos del norte santacruceño con posterioridad al Holoceno temprano.

Los resultados alcanzados indicaron que la producción de hojas, al menos durante el Holoceno medio, fue empleada para la manufactura de artefactos que fueron utilizados sobre diferentes materiales (de origen animales y/o vegetal) y en diferentes estados, pudiendo incluso haber sido manipulados a partir de diferentes dispositivos de enmangue (Lynch 2014; Hermo y Lynch 2015). Estos resultados complementan hipótesis planteadas con anterioridad sobre la producción de la tecnología lítica en el Macizo del Deseado (Hermo 2008).

Por otro lado, el uso más frecuente de obsidiana indica abastecimiento en otros tipos de ambientes (ej. región cordillerana), lo que podría haberse efectuado por aprovisionamiento directo y/o por intercambio (Miotti y Salemme 2004; Miotti 2006a; Hermo y Magnin 2012; Hermo y Lynch 2015; Magnin 2010), lo mismo sucedería con el xilópalo, aunque a distancias mucho menores. Estas consideraciones avalan postulados anteriores que proponen procesos de consolidación territorial para este lapso del Holoceno (Miotti 2006a; Miotti y Salemme 2004; Hermo 2008; Hermo y Magnin 2012; Lynch 2014).

Finales del Holoceno Medio y Holoceno Tardío: Componente 3

Por último, el Componente 3 con cronologías que incluyen finales del Holoceno medio y Holoceno tardío, evidencian una mayor utilización de recursos líticos de procedencias lejanas (obsidiana y xilópalo), así como el desarrollo de diferentes actividades dentro de Cámara Norte, marcado por la baja variabilidad de grupos tipológicos representados en esta muestra y por la presencia de núcleos empleados, casi en su totalidad, para la extracción de hojas (Hermo 2008; Miotti et al. 2014). Esta utilización del sector resulta coincidente con lo planteado por Miotti (2006a; 2012) para el Holoceno tardío como parte del proceso de expansión territorial de los grupos cazadoresrecolectores. 
En síntesis, los cambios tecnológicos en la secuencia cultural de Cueva Maripe fueron abordados desde las estrategias de producción correspondientes a los diferentes períodos de ocupación identificados en la cueva. Los resultados obtenidos evidencian diferencias en relación a estos tópicos para los distintos bloques temporales registrados en Cueva Maripe. Desde el comienzo de la secuencia (Componente 1) se observa la utilización de una elevada proporción de materias primas, casi la misma en términos numéricos que a lo largo de toda la secuencia.

Sin embargo, el aumento en las proporciones de obsidiana y xilópalo hacia el Holoceno medio y tardío indicarían una ampliación de los circuitos de movilidad (Hermo y Lynch 2015; Lynch 2014; Lynch y Hermo 2015; Lynch y Miotti 2015).

Por otra parte, también se observaron elecciones en la manufactura de los artefactos que indican tendencias hacia la reducción en volumen de los mismos. En cada componente, los artefactos formatizados tienden a ser de menor tamaño, y esto no se debe al grado de reactivación de los instrumentos, sino a elecciones culturales y modos de uso específicos (prensión manual o mediante distintos dispositivos de enmangues) a los cuales estuvieron destinados estos artefactos a nivel regional (Lynch 2014; Lynch y Hermo 2015).

Estas tendencias son concordantes con los estudios tecnológicos desarrollados por nuestro equipo de trabajo en otras localidades arqueológicas, como Piedra Museo (Miotti 1995; Cattáneo 2002; 2005; Lynch 2014), Cueva Moreno y Cueva de La Hacienda (Miotti 2006a; Hermo 2008), así como los generados por otros autores del Macizo del Deseado (Paunero 2000; 2003; Skarbun y Frank 2011; Skarbun 2011, entre muchos otros).

\section{Tafonomía y Zooarqueología}

Los estudios zooarqueológicos realizados en los conjuntos de Cueva Maripe indican que la especie más representada en los tres componentes ha sido Lama guanicoe (guanaco). En todos los conjuntos luego de los guanacos, la mayor frecuencia relativa corresponde a Mamífero grande y Mamífero indeterminado, debido al alto grado de fragmentación.A continuación se caracteriza cada uno de los componentes en base a las diferentes variables tafonómicas y zooarqueológicas consideradas en su estudio (Marchionni 2013; 2015; Marchionni et al. 2012). 
Los resultados obtenidos a partir de ésta línea de investigación confirman que en los distintos momentos de la ocupación de Cueva Maripe, en el sitio se llevaron a cabo actividades domésticas (Miotti et al. 2007), posiblemente con un uso de los distintos sectores de la cueva para el desarrollo de actividades más específicas (Marchionni 2013; Miotti et al. 2014).

\section{Transición Pleistoceno/Holoceno Temprano: Componente 1}

El guanaco es sin dudas el taxón principal de la subsistencia de las primeras sociedades que habitaron el sitio. Este patrón de uso de la fauna, totalmente centrado en el aprovechamiento este recurso, se mantiene a lo largo de las ocupaciones del Holoceno (Marchionni 2013). Los conjuntos óseos correspondientes a este componente registran estadios bajos de meteorización indicando un breve tiempo de exposición y buena preservación de los conjuntos.

Entre las modificaciones naturales registradas por Marchionni (2013) en estos conjuntos tempranos, las manchas de manganeso y los depósitos de carbonato de calcio que indican condiciones postdepositacionales de humedad parecen haber sido las modificaciones más recurrentes.

En relación a la mayor frecuencia de especímenes óseos con manganeso (28\%) y carbonato (ca. $5 \%$ ) en CN es que Marchionni $(2013 ; 2015)$ propuso que éstos procesos de humedad habrían sido más generalizados o intensos en CN que en CS ( $c a .8 \%$ de los especímenes con depósitos de carbonatos). Otras modificaciones naturales no fueron reconocidas sobre los especímenes de éste componente excepto por un bajísimo porcentaje de marcas de raíces $(<2 \%)$ y roedores $(<1 \%)$.

Por el contrario, en estos conjuntos se registró una abundante frecuencia de modificaciones culturales (fracturas, huellas de corte, puntos de impacto, marcas de raspado, etc.) que indican que el principal agente responsable de la formación habría sido el humano. Las distintas marcas de procesamiento registradas evidencias las diversas etapas vinculadas a la reducción, preparación y consumo de los guanacos en el sitio.

Holoceno Medio: Componente 2

Tal como se mencionó anteriormente, el guanaco continúa siendo la principal especie utilizada a lo largo de todo el Holoceno medio, sin embargo, y a diferencia de lo que se observa en el Componente 1, aquí se produce un incremento de la representación relativa de los rheidos, principalmente 
a partir del registro de numerosos fragmentos de cáscaras de huevos (Marchionni 2013).

Si bien las superficies óseas de los especímenes muestran estadios que indican una baja meteorización de los conjuntos, Marchionni (2013) observa que los materiales procedentes de CS presentan una preservación levemente menor que la observada en CN. Las superficies óseas de los especímenes correspondientes al Holoceno medio muestran que, tal como sucede en los conjuntos del Componente 1 , los principales procesos naturales vinculados a la formación de estos conjuntos serían las condiciones de humedad posdepositacional, seguidas por la acción del los roedores.

La existencia de humedad se hace evidente por la presencia principalmente de depósitos de manganeso sobre los especímenes, que en este componente son más frecuentes en CS (ca. 10\%) que en CN (6\%), y la muy baja presencia de depósitos de carbonatos $(<2 \%)$, solamente presente en especímenes de CS. Las improntas de raíces solamente fueron observadas en menos del $2 \%$ de los especímenes en ambas cámaras.

Sobre la base del numeroso y variado registro de modificaciones culturales registradas en estos conjuntos Marchionni (2013) sostiene un indudable origen humano para este contexto, el cual estaría reflejando el desarrollo de actividades no solamente vinculadas al procesamiento de las presas (huellas de corte, fracturas intencionales, puntos de impacto, alteración térmica) que serían más numerosas en $\mathrm{CN}$, sino además la presencia de aserrado perimetral, que podría estar vinculado con la producción de artefactos óseos registrados en ambos sectores del sitio junto con fragmentos de huesos decorados. Este registro material estaría evidenciando un uso significativo del hueso como materia prima durante el Holoceno medio (Marchionni 2013; Miotti y Marchionni 2011).

Finales del Holoceno Medio y Holoceno Tardío: Componente 3

Los análisis zooarqueológicos indican que para este componente se mantiene la tendencia observada a lo largo de toda la secuencia del sitio, centrada en el aprovechamiento de los guanacos. No obstante, se registra, además de los guanacos y los rheidos, la presencia de aves medianas y moluscos, ambos en muy baja frecuencia, este panorama se completa con el registro, en la porción superficial de este componente, de Ovis aries, especie que solamente fue identificada en CS y seguramente su presencia esté vinculada con la ocupación histórica registrada en la cueva a mediados del siglo XX. 
La meteorización registrada por Marchionni (2013; 2015) indica una mayor preservación de los especímenes de $\mathrm{CN}$ respecto de los de $\mathrm{CS}$ aunque la tendencia general es a una mayor representación de estadios bajos, que indican un enterramiento relativamente rápido de los materiales.

Las modificaciones naturales se registran en muy bajas frecuencia, siendo tal como sucede en el resto de la secuencia del sitio los depósitos de manganeso y las marcas de roedores (ca. 10\%), las más representativas en estos conjuntos, encontrándose ambas más representadas en CS. La información presentada por Marchionni muestra que la principal modificación antrópica de estos conjuntos responde a la alteración térmica registrada en ambos conjuntos aunque en frecuencias más elevadas en CS (ca. $20 \%$ ). No obstante, la autora destaca un elevado porcentaje de fracturas antrópicas, la presencia de huellas de corte, puntos de impacto, marcas de percusión, surco perimetral y otras tantas que, presentes en mayor frecuencia en $\mathrm{CN}$ evidencian el origen cultural de estos conjuntos tardíos.

En términos generales, en Cueva Maripe se observa que la meteorización en todos los conjuntos ha sido baja, registrándose la mayoría de los especímenes de cada capa en estadios iguales o menores a 2 (Behrensmeyer 1978). Se observa una tendencia hacia una meteorización levemente mayor en los conjuntos de CS con un incremento del deterioro hacia las unidades superiores. Marchionni (2015) sostiene que esta diferencia en la preservación de los conjuntos entre una y otra cámara podría estar relacionada a la tasa de sedimentación diferencial que se registran entre ambos sectores (Miotti et al. 2007).

Las modificaciones naturales más relevantes, registradas en los conjuntos óseos y que guardan relación con los procesos de formación del sitio corresponden a los depósitos de manganeso, presentes en los conjuntos de toda la secuencia y en ambas cámaras (Marchionni 2013; Marchionni et al. 2012). En este contexto es interesante destacar la gran cantidad de especímenes con manganeso en el conjunto de capa 5 de $\mathrm{CN}$ (Componente 1), que pondría en evidencia procesos de humedad más generalizados o intensos en ese sector del sitio. Con claridad se observa que los procesos de humedad habrían afectado en mayor medida a los conjuntos de CS, excepto en lo que corresponde al Componente 1 .

Los conjuntos estudiados por Marchionni reúnen características suficientes para sostener su origen cultural. No obstante, existe un registro más 
variado y abundante de modificaciones antrópicas sobre los especímenes provenientes de $\mathrm{CN}$, que lleva a la autora a proponer el desarrollo de actividades diferentes en un sector y otro del sitio. Mientras en CS parecen haber sido más recurrente las prácticas vinculadas a la preparación y consumo de los recursos, en $\mathrm{CN}$, además de estas actividades, parecen haber tenido un lugar otras relacionadas a la manufactura y uso de artefactos, que podría estar indicando el desarrollo de actividades específicas intra-sitio.

\section{Arte Rupestre}

El sitio presenta una alta concentración de pinturas rupestres $(n=225)$ entre las cuales predominan las manos negativas, con una escasa proporción de motivos zoomorfos, círculos, líneas conjuntos de puntos. Estos motivos se distribuyen en distintos sectores dentro las dos cámaras. Aunque el estado preservación de las pinturas es en general de regular a malo, el proceso de deterioro del arte rupestre se ha producido diferencialmente en distintos sectores de la cueva.

El área de la entrada, abarca aproximadamente los primeros seis metros desde la actual línea de goteo, es la única recibe la luz directa del sol. En esta solo se registraron dos motivos, aunque se estima que la superficie pintada debió haber sido mayor y ha desaparecido como consecuencia de los efectos la insolación directa. Hacia el fondo de la cueva la humedad es más alta, especialmente en cámara sur donde se registró la infiltración de agua proveniente de un manantial. Debido a la mayor oscuridad, los colores de los motivos del fondo presentan una mejor preservación, aunque pinturas se encuentran en un proceso avanzado de exfoliación causado, entre otros factores, la acción de los carbonatos (Carden 2008).

A partir del relevamiento de las pinturas y de su sectorización se detectaron algunas tendencias en cuanto a la localización de los distintos motivos y a los colores empleados (Carden 2008). El área intermedia de la cueva (entre la entrada y el fondo), donde se encuentran los paneles con mayor visibilidad, se caracteriza por paredes pintadas de rojo sobre el cual se aplicaron manos negativas blancas. Debido al mal estado de conservación de la pintura, no se ha podido comprobar si dichos fondos fueron intencionalmente preparados o si en realidad, se trata de coloración a partir de motivos previos que actualmente no son distinguibles.

La presencia de gruesas capas de pintura roja en las paredes del tabique 
rocoso del lado de CS y, el hecho de no haber podido distinguir motivos favorecen, sin embargo, la idea de fondos preparados. La tonalidad del rojo subyacente a las manos negativas varía entre los sectores así como dentro de un mismo sector, aunque en general es pálida, entre rosado y anaranjado. Sobre las manos negativas blancas se superponen motivos puntiformes naranjas en un mejor estado de conservación y, en la pared del tabique rocoso de $\mathrm{CN}$, restos de pintura amarilla estarcida.

\section{Proxies Ambientales Biológicos}

Hasta el momento, en este sitio fueron analizados dos proxies ambientales: las diatomeas como parte de la tesis doctoral de Marilen Fernández (2013) y los fitolitos, de los cuales solo se realizaron estudios preliminares que permitieron aseverar la predominancia de fitolitos asignables a gramíneas y una mayor frecuencia de fitolitos en estructuras de fogon dentro de la cueva (Miotti et al. 2008).

Los análisis de diatomeas realizados en Cueva Maripe por la Dra. Marilén Fernández, mostraron un alto grado de fragmentación de las valvas, lo que dificultó la caracterización de los micro ambientes de cada cámara. En relación a esto, no se pudieron generar datos paleoambientales claros para momentos de ocupación arqueológica. Sin embargo, en las capas basales, arqueológicamente estériles, se pudieron observar frústulos mejor preservados y una mayor variedad morfológica, lo que permitió realizar inferencias para esos momentos. Al respecto, la asociación diatomológica muestra un gran porcentaje de especies perifíticas asociadas a vegetación palustre, lo que podría indicar que la CN de la cueva habría estado inundada por aguas someras y quietas antes de su primera ocupación (Fernández 2013).

Por otro lado, en un muestreo realizado en una locación denominada la cárcava ubicada a 1,5 km de Cueva Maripe, no se pudo realizar ningún tipo de inferencia ambiental sobre las muestras recolectadas ya que el grado de fragmentación era muy alto.

\subsubsection{Antecedentes - Tito del Valle}

El sitio Tito del Valle tiene un solo antecedente de investigación reconocido en la bibliografía que es una breve descripción del sitio y el relevamiento del arte rupestre en el marco de la tesis doctoral de la Dra. Natalia Carden 
(Carden 2008). Aquí expondremos brevemente lo que allí se expone.

Se trata de una cueva emplazada en un afloramiento de conglomerados tobáceos de la formación Bajo Pobre (Panza 2001) en un paisaje de lomadas bajas. Este abrigo rocoso ha sido utilizado como refugio de puesteros que trabajaban con ganado ovino de la estancia Bajo Pantano, que da nombre a la localidad arqueológica. En la actualidad la boca de la cueva se encuentra casi completamente cerrada por un muro de adobe construido sobre una base hecha de roca dura. Se han encontrado elementos como frangmentos de metal y un horno hecho de adobe, asi como también estructuras de fogón en la superficie de la cueva. Las paredes están en gran parte cubiertas de hollín como resultado de la actividad de las estructuras mencionadas.

Frente a la cueva corre un pequeño zanjón seco en forma paralela a la entrada de la cueva, el cual desemboca en el Zanjón Blanco. Frente a la cueva, en la margen opuesta de este pequeño zanjón y sobre una lomada se menciona la presencia de una importante concentración de artefactos líticos, entre los que la autora menciona que se encontraron núcleos, desechos de talla e instrumentos coomo puntas, cepillos, raspadores, fragmentos de bolas bifaces y morteros.

En cuanto al arte rupestre, se pudo constatar que se encuentran muy desvaídas y en parte cubiertas por hollín. Más allá de esto, los motivos que se pudieron relevar corresponden a negativos de manos en color rojo desvaído tendiente a rosado, entre las que se reconoció una pertenenciente a un niño pintada 2,3 $\mathrm{m}$ de altura $\mathrm{y}$, manos blancas sobre un fondo previamente pintado de rojo.

La autora plantea que a pesar de no haber sido excavada, la conjunción de arte, material de superficie y la cercanía a un curso de agua permiten suponer que el lugar ha sido ocupado intensamente (Carden 2008:194).

\subsubsection{Antecedentes - Alero el Puesto 1}

La localidad arqueológica Piedra Museo (PM) se ubica en el sector de la cuenca baja de los Zanjones Blanco y Rojo, en la estancia San Miguel, provincia de Santa Cruz, a $47^{\circ} 53^{\prime} 42^{\prime \prime}$ S y $67^{\circ} 52^{\prime} 04^{\prime \prime} \mathrm{O}$ (Figura 4.3). Está integrada por aleros y abrigos rocosos ubicados al borde de una depresión que fue ocupada durante la transición Pleistoceno-Holoceno y posiblemente hasta el Holoceno medio por un lago, actual depresión salina (Miotti 1992; Zárate et al. 2000). 
Se detectaron tres sitios en cuevas y abrigos rocosos que se denominaron Cueva Grande (CG), Alero El Galpón 2 (AEG-2) y Alero El Puesto 1 (AEP-1), labrados en sedimentitas marinas de edad eocena, relicto de una ingresión marina denominada Formación Puesto del Museo (Panza 2001). Estas sedimentitas son psamitas coquinoides de colores gris verdoso amarillento a castaño rojizas, en las que abunda la microfauna como briozooarios, foraminíferos, equinodermos, espículas de esponjas y fragmentos de conchillas (Panza et al. 1998).

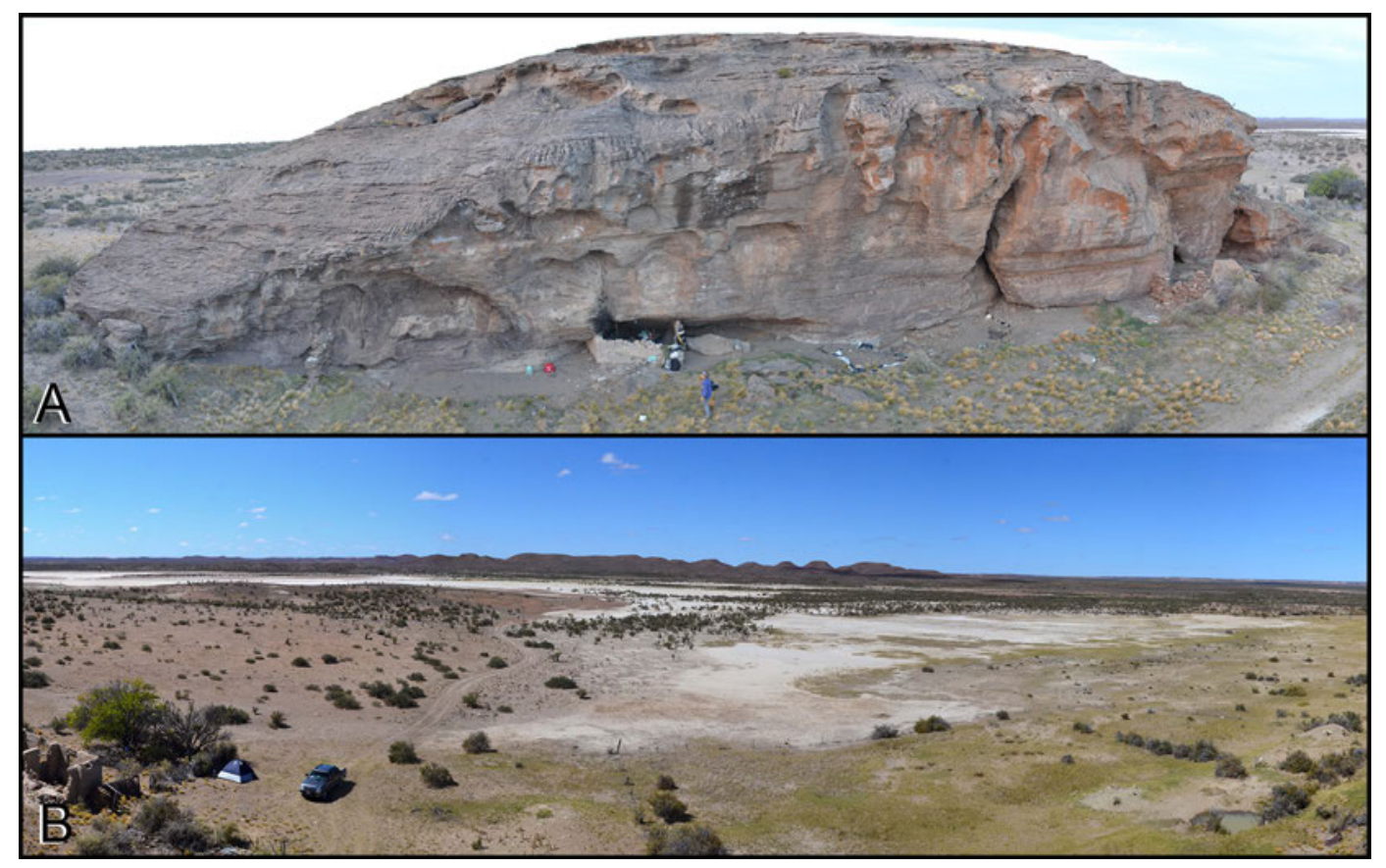

Figura 4.3: Localidad arqueológica Piedra Museo. A. Vista del sitio Alero El Puesto 1 (AEP-1) B. Vista panorámica del paleolago de Piedra Museo (foto tomada desde la cima del afloramiento en el que se emplaza el sitio)

Los sitios AEG-2 y CG fueron analizados por su arte rupestre, mientras que AEP-1 fue excavado en sucesivas campañas arqueológicas entre los años 1990 y 2002, todas ellas bajo la dirección de la Dra. Laura Miotti. Se excavó una superficie total de 41,25 $\mathrm{m}^{2}$ (Figura 4.4).

Durante las excavaciones fueron identificados dos componentes arqueológicos claramente separados por un derrumbe masivo del alero que fue registrado durante las excavaciones realizadas: el superior y el inferior (Miotti et al. 1999). El componente Superior incluye a las Capas 1, 2 y 3 (Miotti 1992; 1996; Miotti et al. 1999) (Figura 4.5). La Capa 1 carece de fechados radiocarbónicos pero es asignable al Holoceno tardío, y la Capa 3 corresponde a un 


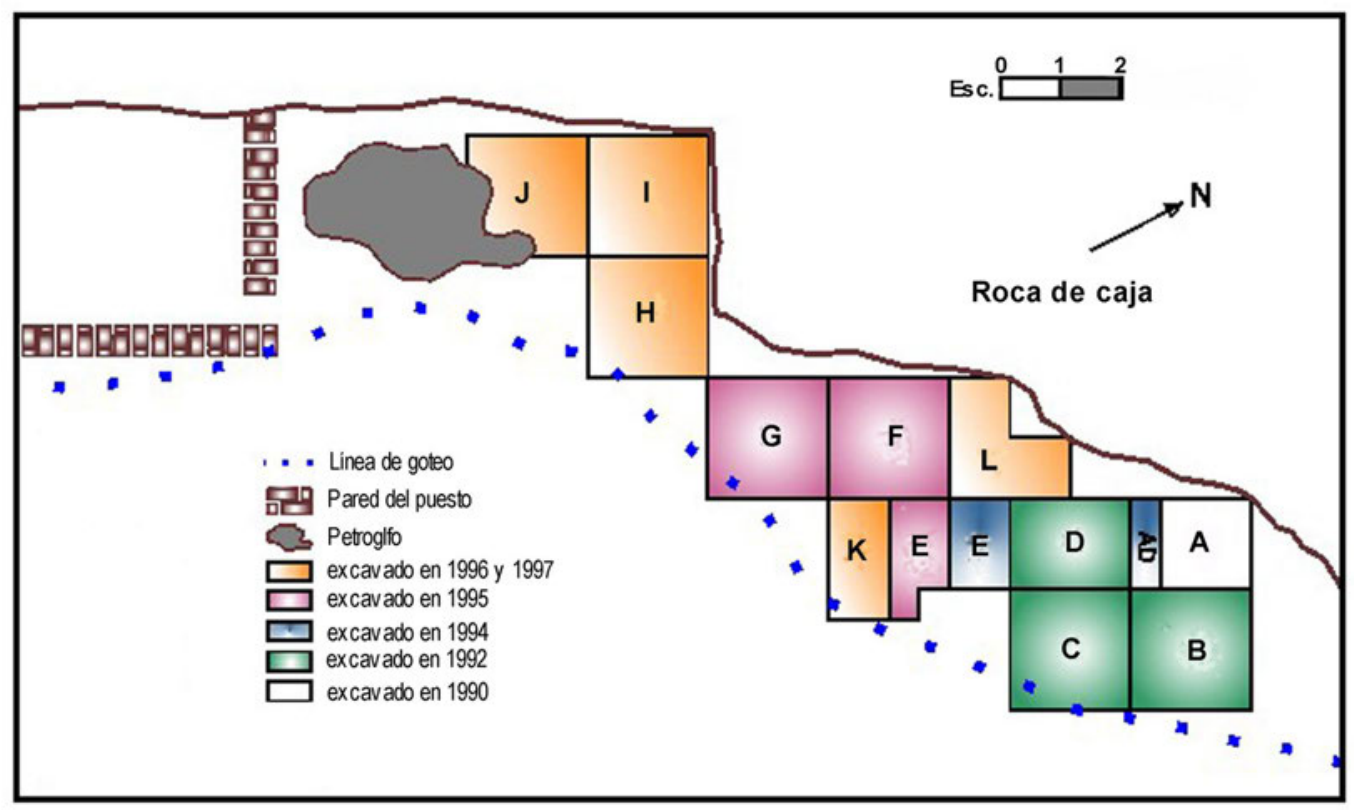

Figura 4.4: Planta de excavación del sitio AEP-1 de Piedra Museo. Tomado de Marchionni 2013

hiato ocupacional. En la Capa 2 se registró la ocupación más tardía del sitio asignada al Holoceno Medio (Miotti et al. 2003).

Por su parte, el componente inferior contiene las Capas 4, 5 y 6, y presenta las ocupaciones más tempranas (Figura 4.5). El derrumbe mencionado fue registrado en la Capa 4, en las cercanías de la línea de goteo del sitio (Miotti et al. 1999). Dentro de este componente se identificaron dos resoluciones arqueológicas, la correspondiente a la Capa 6 por un lado, con fechados radiocarbónicos entre $c a .12 .800$ y 11.000 años AP, y la correspondiente a las Capas 4/5 por el otro, fechadas entre $c a$. 10.500 años AP hasta $c a .9200$ años AP (Miotti et al. 1999; 2003). A continuación se detallan los resultados alcanzados a partir de los distintos análisis y líneas de investigación abordadas en el estudio del sitio: tecnología lítica, tafonomía y zooarqueología.

La información cronológica obtenida en AEP-1 corresponde a un total de 11 dataciones radiocarbónicas (Tabla 4.3) realizadas por método convencional (aquellas cuyo código comienzan con LP) y por AMS. El rango cronológico de ocupación del sitio que muestran estas dataciones es de 12890 \pm 90 hasta $7470 \pm 140$ años ${ }^{14} \mathrm{C}$ AP (15687-7967 años cal AP). 


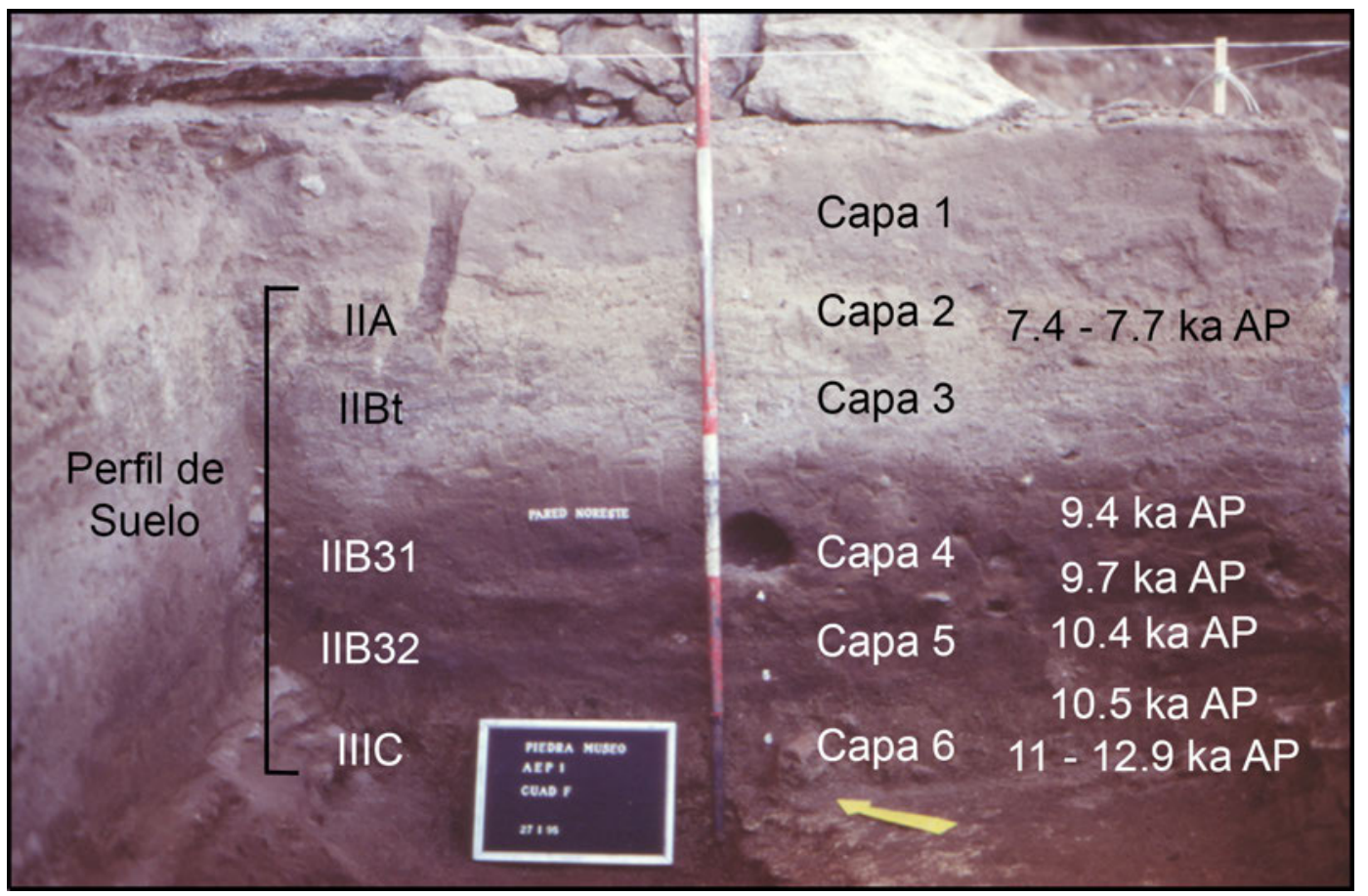

Figura 4.5: Perfil estratigráfico del sitio AEP-1 Tomado de Miotti et al. 2000

\section{Antecedentes geoarqueológicos}

De los tres sitios analizados en esta tesis, AEP-1 es el único que presenta información geoarqueológica previa (Zárate et al. 2000). En dicho trabajo, se realizaron análisis geomorfológicos y sedimentarios que sirvieron para evaluar los agentes intervinientes en la formación del depósito y sus implicancias ambientales. Asimismo, se caracterizaron las capas previamente definidas durante las excavaciones arqueológicas. En la Tabla 4.4 resumimos las características de cada una de ellas.

En el trabajo mencionado, la estratigrafía del sitio fue descripta a partir de un perfil tipo ubicado en la pared NE de la cuadrícula L, en la que se efectuaron además, los muestreos para análisis sedimentológico (Zarate et al. 2000) (Figura 4.5) y polínico (Borromei 2003).

Según los autores, el depósito sedimentario se compone de 6 capas, siendo la 1 uno la que conforma la superficie actual y la 6 la más profunda en contacto con la roca de caja. Se pudo determinar a partir de las características de textura, litología y color, que el conjunto de las capas 2 a 6 corresponden a una secuencia de perfil de suelo, donde cada capa corresponde a un horizonte pedológico (Zárate et al. 2000). Como resultado, se interpretó que la textura sedimentaria de cada capa es resultado por un lado de los aportes 


\begin{tabular}{cccccc}
\hline Código & Años ${ }^{14}$ C AP & Años cal AP & Material & Cuadricula & Capa \\
\hline AA-20125 & $12890 \pm 90$ & $15687-15079$ & Carbón & E & 6 \\
\hline AA-27950 & $11000 \pm 65$ & $12995-12714$ & Idem & C & 6 \\
\hline OXA-8528 & $10925 \pm 65$ & $12932-12685$ & $\begin{array}{c}\text { Óseo } \\
\text { Hippidion } \\
\text { Saldiasi }\end{array}$ & $\mathrm{L}$ & 6 \\
\hline OXA-9249 & $10470 \pm 65$ & $12551-12032$ & Carbón & $\mathrm{L}$ & 6 \\
\hline GRA-9837 & $10470 \pm 60$ & $12549-12039$ & Idem & $\mathrm{L}$ & 6 \\
\hline AA-8428 & $10400 \pm 80$ & $12544-11837$ & Óseo L. & $\mathrm{A}$ & 5 \\
\hline OXA-8527 & $10390 \pm 70$ & $12430-11840$ & Idem & $\mathrm{L}$ & 6 \\
\hline LP859 & $9710 \pm 105$ & $11248-10708$ & Idem & $\mathrm{F}$ & 4 fondo \\
\hline LP949 & $9230 \pm 105$ & $10655-10183$ & Idem & $\mathrm{E}$ & 4 techo \\
\hline LP450 & $7670 \pm 110$ & $8636-8186$ & Idem & $\mathrm{C}$ & 2 fondo \\
\hline NSRL11167 & $7470 \pm 140$ & $8514-7967$ & Idem & & 2 techo \\
\hline
\end{tabular}

Tabla 4.3: Dataciones radiocarbónicas de AEP-1 (Tomadas de Miotti et al. 2003)

durante el proceso acrecional, y por otro, de la reorganización edáfica.

En cuanto a su composición, los autores plantean que el material sedimentario es de procedencia mixta, con una aporte eólico proximal y distal, y un aporte intracuencal resultado de la meteorización de la roca de caja del alero. No se reconocen grandes cambios en cuanto a la composición de las muestras, aunque si se observan variaciones en la importancia relativa en los diferentes aportes a lo largo de la secuencia (Zárate et al. 2000).

\section{Tecnología lítica}

Componente inferior

El número de piezas líticas de estas unidades es relativamente pequeño comparado con los restos óseos recuperados durante las excavaciones realizadas (Miotti 1992, Miotti y Cattáneo 2003; Miotti et al. 1999; Cattáneo 2002), en especial en la Capa 6. Sin embargo, los resultados obtenidos de su análisis, han permitido discutir algunos aspectos de la organización tecnológica, en especial aquéllos vinculados al aprovisionamiento de materias primas y 


\begin{tabular}{|c|c|c|c|c|c|}
\hline Capa & Horizonte & Espesor $(\mathrm{cm})$ & Color & Textura & Caracteristicas Litológicas \\
\hline 1 & $\begin{array}{l}\text { Sin } \\
\text { rasgos } \\
\text { pedoló- } \\
\text { gicos }\end{array}$ & & $\begin{array}{c}10 Y / R \\
5 / 3\end{array}$ & $\begin{array}{l}\text { Arena } \\
\text { Limosa } \\
\text { Gravillo- } \\
\text { sa }\end{array}$ & $\begin{array}{l}\text { Sin rasgos pedológicos. Su } \\
\text { limite inferior es una } \\
\text { discordancia erosiva. }\end{array}$ \\
\hline 2 & IIA & 15 & $\begin{array}{c}10 \mathrm{Y} / \mathrm{R} \\
5 / 4\end{array}$ & $\begin{array}{l}\text { Fango } \\
\text { Arenoso }\end{array}$ & $\begin{array}{l}\text { Truncado parcialmente por } \\
\text { erosión. Su limite inferior va } \\
\text { de claro a gradual sin } \\
\text { evidencias de erosión eólica } \\
\text { o hídrica. }\end{array}$ \\
\hline 3 & IIBt & 20 & $\begin{array}{c}2,5 \mathrm{Y} \\
4,4 \text { a } 10 \\
\mathrm{Y} / \mathrm{R} \\
5 / 3\end{array}$ & $\begin{array}{c}\text { Fango } \\
\text { Arenoso }\end{array}$ & $\begin{array}{c}\text { Limite inferior suave y } \\
\text { gradual. Se observaron } \\
\text { nodulos de calcio y } \\
\text { carbonatación en su base. Se } \\
\text { observaron agrietamientos } \\
\text { verticales en seco. Aporte } \\
\text { coloidal extremadamente } \\
\text { importante. }\end{array}$ \\
\hline 4 & IIB31 & 20 & $\begin{array}{c}10 \mathrm{Y} / \mathrm{R} \\
5 / 3\end{array}$ & $\begin{array}{c}\text { Arena } \\
\text { Fangosa }\end{array}$ & $\begin{array}{l}\text { Limite inferior suave y } \\
\text { gradual. Abundantes } \\
\text { bioturbaciones de } \\
\text { invertebrados y macroporos. } \\
\text { Importante aporte coloidal. }\end{array}$ \\
\hline 5 & IIB32 & 15 & $\begin{array}{c}10 \mathrm{Y} / \mathrm{R} \\
4 / 3\end{array}$ & $\begin{array}{c}\text { Arena } \\
\text { Fangosa }\end{array}$ & $\begin{array}{l}\text { Su limite inferior es gradual } \\
\text { y suave, y en la parte basal } \\
\text { presenta estratificación de } \\
\text { distinta coloración que se } \\
\text { corresponden con uno de los } \\
\text { niveles de ocupación. El } \\
\text { aporte coloidal disminuye. }\end{array}$ \\
\hline 6 & IIIC & & $\begin{array}{c}10 \mathrm{Y} / \mathrm{R} \\
3 / 4\end{array}$ & $\begin{array}{l}\text { Arena } \\
\text { Limosa }\end{array}$ & $\begin{array}{l}\text { Se reconoce en la base una } \\
\text { transición a a la sedimentita } \\
\text { coquinoide de la roca de caja. } \\
\text { Participacion coloidal } \\
\text { insignificante. }\end{array}$ \\
\hline
\end{tabular}

Tabla 4.4: Características sedimentarias y estratigráficas obtenidas en AEP1, extraídas de Zárate et al. 2000. 
estrategias de producción relacionados con la caza y procesamiento primario de presas (Cattáneo 2002; Miotti y Cattáneo 2003; Miotti et al. 2003).

El análisis de distribución de los materiales líticos muestra que la mayoría se encuentran depositados en un sector del alero, principalmente en las cuadriculas $\mathrm{H}$, I y J y que si bien no se reconocieron fogones estructurados para este componente, en las cuadrículas F y G, se habrían identificado sectores de descarte de productos líticos térmicamente alterados (Cattáneo 2002).

\section{Transición Pleistoceno-Holoceno: Capa 6}

Se recuperó un conjunto reducido de instrumentos entre los cuales predominan los artefactos no formatizados con filos largos. Los artefactos con formatización fueron elaborados sobre materias primas de muy buena calidad para la talla, utilizando rocas criptocristalinas o de grano fino (ópalo, xilópalo y calcedonia de coloración blanco translúcido a marrón translúcido). Dentro de este grupo se incluyen 3 raederas de filo lateral largo, 1 artefactos con formatización sumaria y una muesca retocada. El grupo de artefactos no formatizados incluyó 4 cuchillos con filos naturales, confeccionados sobre lascas grandes de adelgazamiento de bifaces (Cattáneo 2002; Lynch 2014).

El análisis funcional realizado a partir de estos materiales arrojó un bajo porcentaje de artefactos con rastros de uso y en su mayoría se pudo observar un grado de alteración alto a moderado, presentando lustre de suelo y abrasión sedimentaria en su superficie. Sin embargo, en aquellas piezas en donde se identificaron rastros diagnósticos del material trabajo se reconoció el empleo de estos artefactos sobre materiales duros (hueso) en acciones de raspado (Lynch 2014; Lynch et al. 2012).

Los trabajos previos realizados para este bloque temporal en Piedra Museo, han mencionado el desarrollo de distintas prácticas tecnológicas, donde la Capa 6 estaría relacionada a la producción de instrumentos generalizados o informales (Cattáneo 2002; 2005) que habrían intervenido en actividades de procesamiento de animales de gran porte, básicamente équidos y camélidos (Miotti y Salemme 1999; 2005).

Sin embargo, a nivel funcional la escasa cantidad de materiales líticos recuperados, sumado a la baja integridad de los artefactos en esta unidad, no serían, por sí solos, indicadores fuertes para sostener la hipótesis del uso de estos artefactos en actividades de procesamiento primario de presas exclusivamente (Lynch et al. 2012). 


\section{Transición Pleistoceno-Holoceno: Capas 4 y 5}

En momentos posteriores (Capa 4/5) se identificaron ocupaciones con fechados de 10400 a 9200 años AP. Los materiales recuperados, están representados por 7 grupos tipológicos de artefactos formatizados, de los cuales el grupo de los raspadores con filos complementarios de raederas es el de mayor frecuencia. En menor medida le siguen el grupo de raederas, artefactos con formatización sumaria, cepillos, muescas retocadas y puntas de proyectil, sumado a una pieza discoidal recuperado de esta capa. La mayoría de estas piezas presentaron tamaños grandes y muy grandes (sensu Aschero 1975; rev. 1983).

Las materias primas utilizadas en su manufactura, en su mayoría corresponden, al igual que la capa anterior, a rocas criptocritalinas o de grano fino de buena calidad para la talla (sílex) y en menor medida la calcedonia, toba silicificada y granito. Estas materias primas son de procedencia local e inmediatamente disponibles, ya que varias fuentes identificadas se encuentran en los alrededores del sitio (sitio cantera-taller 17 de Enero, Cattáneo 2002; 2005). Los dos fragmentos de puntas de proyectil (Miotti 1995; Cattáneo 2005) corresponden a la morfología denominada "Fell I" o "cola de pescado" características de ocupaciones de la transición Pleistoceno-Holoceno en Sudamérica (véase Bird 1946).

El análisis funcional efectuado sobre las piezas de la Capa 4/5 permitió inferir así el desarrollo de distintas actividades. Se reconoció principalmente el raspado sobre material duro (madera o hueso) y en menor medida el raspado sobre hueso y madera. El incremento en la variabilidad de grupos tipológicos y de materiales recuperados en esta capa iría acompañado al uso más repetitivo del sitio (Borrero 1989-1990), que a nivel microscópico estaría expresado a partir del desarrollo de distintas actividades y variedades de los materiales empleados (material duro, madera, hueso y cuero) (Lynch 2014; Lynch et al. 2012).

\section{Componente superior}

\section{Holoceno Medio: Capa 2}

El componente superior, contenido en la Capa 2 y correspondiente al Holoceno medio, muestra que el sitio habría funcionado como lugar de actividades múltiples evidenciando procesamiento de presas, descarte y consumo. 
El conjunto de artefactos líticos recuperados de esta unidad corresponden al bloque temporal del Holoceno medio, con fechados radiocarbónicos de $c a .7700$ y 7400 años AP.

Se registraron 7 grupos tipológicos de los cuales los raspadores estaban mayormente representados en esta unidad. Las materias primas utilizadas en su producción incluyó ignimbritas y riolitas silicificadas y en menor medida otras variedades de rocas criptocristalinas de muy buena calidad para la talla (calcedonia, toba silicificada, xilópalo y obsidiana) (Lynch 2014).

Los resultados obtenidos del análisis funcional reconoció principalmente el trabajo sobre material duro (madera o hueso) en acciones de raspado como de corte; al igual que raspado y corte sobre hueso, a partir de artefactos formatizados como también sin formatización. Esta actividad probablemente haya estado relacionada con el procesamiento de presas hacia el interior del sitio (Lynch 2014). En esta capa se registraron puntas de proyectil (Cattáneo 2002) correspondientes a las morfologías denominadas Magallanes III, Toldenses o "puntas triangulares apedunculadas" (Bird 1946; Cardich et al. 1973; Aschero 1987; Gradin y Aguerre 1994; Aguerre 2003; entre otros) y que vinculan las ocupaciones de la capa 2 de AEP-1 con otros conjuntos del Holoceno temprano y medio de la región (ej. Los Toldos - Cardich et al. 1973; área Río Pinturas - Gradin y Aguerre 1994; La Martita - Aguerre 2003; y Parque Nacional Perito Moreno - Civalero y De Nigris 2005).

Holoceno tardío: Unidad estratigráfica 1

Esta unidad corresponde a la última etapa de ocupación del sitio y se encuentra constituida por los materiales recuperados de la Capa 1. Si bien esta capa no presenta fechados radiocarbónicos, los resultados obtenidos hasta el momento a partir de los materiales recuperados le darían una asignación temporal del Holoceno tardío.La mayoría de las piezas fueron recuperadas de las cuadrículas C y D principalmente hacia el sector Norte.

En cuanto a los AF se reconocieron 7 grupos tipológicos, de los cuales el grupo de los raspadores está mayormente representado; sin embargo también se recuperaron raederas, bifaces, perforadores, puntas de proyectil pedunculadas y muescas. Al igual que en el resto de la secuencia, la producción de estos artefactos evidenció un gran uso de rocas silíceas principalmente de coloración marrón-rojizas y en menor medida el uso de calcedonias, xilópalo y cuarzo. 
De acuerdo a lo observado a nivel microscópico varias piezas de la Capa 1 de Piedra Museo, habrían servido para el trabajo sobre materiales duros (hueso) y blandos (cuero y piel) lo que estaría indicando que para ese entonces, el sitio continuaría siendo utilizado para el desarrollo de actividades domésticas, pero debido a la disminución de materiales recuperados de esta capa, es probable que haya habido un cambio en la distribución del espacio por parte de los grupos que habitaron el alero hacia el Holoceno tardío (Lynch 2014).

Los modelos propuestos para el área de estudio (Borrero 1989-1990; Franco 2002; Miotti 1998; Miotti y Salemme 1999; 2004; 2005; Salemme y Miotti 2008) indican que para estos momentos, habría una mayor densidad de distribución poblacional y cambios en los modos de subsistencia y en las estrategias de apropiación de los recursos, marcado ya desde el Holoceno medio y que se iría acentuado hacia el Holoceno tardío (Miotti 2012).

\section{Tafonomía y Zooarqueología}

Los resultados obtenidos en AEP-1 a partir del desarrollo de estas líneas de investigación proceden de diferentes estudios realizados, en una primera etapa, sobre una parte de los conjuntos correspondientes fundamentalmente al componente inferior: Capa 6 y Capas 4/5 (Giardina et al. 2000; Miotti y Cattáneo 2003; Miotti y Salemme 2005; Miotti et al. 1999); en una segunda etapa, los análisis zooarqueológicos y tafonómicos del componenete inferior consistieron en ampliar la muestra analizada, incluyendo materiales procedentes de las últimas campañas de excavación y en estudiar pormenorizadamente el conjunto correspondiente a la capa 2 del componente superior (Marchionni 2013; 2014; 2015; Marchionni y Vázquez 2012; Marchionni et al. 2010; Miotti y Marchionni 2011).

En esta segunda etapa de análisis, además fueron profundizados los aspectos tafonómicos de los conjuntos con el objetivo de aportar información acerca de la historia tafonómica y formacional del sitio (Marchionni 2013; 2014; 2015).

Con claridad se observa que Lama guanicoe (guanaco) habría sido la especie explotada a lo largo de toda la secuencia del sitio.Se observan cambios en cuanto a cuáles fueron los recursos complementarios en los distintos momentos de ocupación del alero, mientras que en los conjuntos tempranos las especies extinguidas de mamíferos pleistocénicos habrían cumplido un 
rol considerable en la subsitencia juntos con los rheidos, en el componente superior el guanaco adquiere una mayor importancia, notándose un rol menos significativo y complementario de rheidos y aves medianas.

\section{Componente inferior}

\section{Transición Pleistoceno-Holoceno: Capa 6}

Los camélidos, tanto Lama guanicoe como Lama gracilis, constituyen las principales especies aprovechadas por las primeras sociedades que habitaron el sitio. No obstante, en este conjunto no solamente se registra la presencia de otras especies (extinguidas y actuales) sino que además, varias de estas especies presentan claras huellas de procesamiento, indicando que las mismas fueron explotadas en el pasado. Así, además de los camélidos, se observa evidencia de uso antrópico en especímenes de Hippidion saldiasi, Mylodon sp., rheidos y cánidos (Marchionni 2013; Marchionni y Vázquez 2012; Miotti et al. 1999; Miotti y Salemme 1999; Miotti y Cattáneo 2003).

Este patrón diversificado del uso de la fauna refleja tal como lo han propuesto varios autores, una estrategia generalista característica de las primeras etapas del poblamiento de la región (Borrero 1994-95; Marchionni 2013; Miotti y Salemme 1999; 2004).

Los análisis de meteorización realizados indican que ca. el $90 \%$ de los especímenes presentan baja meteorización (estadíos entre 0 y 2 de Behrensmeyer 1978), registrándose escasos restos con mayor deterioro. Esta situación, que caracteriza a la mayoría de los restos de manera homogénea, estaría indicando que el conjunto tuvo un enterramiento relativamente sincrónico (Marchionni 2013).Entre las modificaciones naturales registradas por Marchionni $(2013$; 2015) las manchas de manganeso serían las trazas más recurrentes, estando presentes casi en la mitad de los elementos que conforman el conjunto. Asimismo, se observaron modificaciones producidas por raíces (ca. 13\%) y depósitos de carbonatos (ca. 8\%).

El panorama se completa con un frecuencia muy baja de daño producido por carnívoros $(<3 \%)$ y escasos signos de disolución química $(<2 \%)$. La gran cantidad de elementos con manchas de manganeso posiblemente se deba a las variaciones del nivel freático registradas por Zárate y colaboradores (2000) y a la descomposición de la roca de caja con la que entra en contacto el conjunto, y que también, podría haber sido una fuente de aporte de los carbonatos registrados (Marchionni 2013). La distribución espacial de 
los especímenes con marcas de raíces sugieren la existencia de una cubierta vegetal en el sector más externo del alero, en los momentos en que los conjuntos fueron depositados (Marchionni 2013; 2015).

Entre las modificaciones culturales se registraron huellas de corte, alteración térmica y fracturas antrópicas, tanto en especímenes de taxas actuales como extintas (Marchionni 2013; Marchionni y Vázquez 2012; Miotti 2003; Miotti y Cattáneo 2003; Miotti y Salemme 1999; 2005). Estas marcas sugieren, además de un procesamiento primario como propuso por Miotti et al. (1999), la extracción y consumo de médula ósea de los camélidos, al menos de forma ocasional (Marchionni 2013).

- $\quad$ Transición Pleistoceno-Holoceno: Capas 4 y 5

Este conjunto se encuentra dominado casi exclusivamente por la especie Lama guanicoe (ca. 80 \% NISP), seguida por los rheidos y las aves (Marchionni 2013). A diferencia del conjunto de capa 6 aquí se observa una importante reducción de la diversidad taxonómica, básicamente debida a la ausencia de especies extinguidas, de las cuales solo fueron registrados 3 especímenes de Lama gracilis (Miotti et al. 1999).

Los análisis de la meteorización realizados por Marchionni (2013; 2015) indican un breve tiempo de exposición y un enterramiento relativamente sincrónico de los materiales ( $c a .94 \%$ del conjunto en estadios $\leq 2$ de Behrensmeyer 1978). Entre las modificaciones naturales más sobresalientes se registraron los depósitos de carbonatos en ca.30 \% de los especímenes. Estos minerales se encuentran formando capas finas, que en algunos casos se vuelven espesas y llegan a cubrir más del $70 \%$ de las superficies óseas (Marchionni 2013). El origen de estos carbonatos fue interpretado por Marchionni a partir de la roca del afloramiento y de los bloques de derrumbe que apoyan sobre esta capa y cuya disolución podría haber estado favorecida por los procesos depedogénesis.

También se registraron, en menor proporción, depósitos de manganeso (ca. $17 \%$ ) y marcas de raíces (ca.9\%). Los primeros resultarían de más de un tipo de proceso post-depositacional, posiblemente provengan de la disolución de la roca carbonática pero también de la descomposición de materia orgánica, y por cómo se presentan en los especímenes, se habría depositado primero el manganeso y luego el carbonato (Marchionni 2013).

Sin embargo, y en base a la descripción realizada por Zárate y colaboradores (2000) del perfil del sitio, Marchionni (2013) considera que las man- 
chas de manganeso de los huesos también pueden guardar relación con el moteado observado en el perfil de la capa 4 . El registro de modificaciones antrópicas se remite a la presencia de una baja frecuencia de huellas de corte, puntos de impacto, alteración térmica y fracturas antrópicas (Marchionni 2013).

La frecuencia baja de modificaciones culturales también fue observada por Miotti et al. (1999), y atribuida, en parte, al deterioro de las superficies por alteración química. En este conjunto, asimismo, se recuperó un punzón óseo que evidencia el uso del hueso como materia prima desde los inicios de la ocupación del sitio (Miotti y Marchionni 2014). La baja fragmentación del conjunto, la presencia de partes articuladas y la baja frecuencia de huellas de corte avalan la idea de que en el sitio se desarrollaron actividades limitadas relacionadas fundamentalmente al procesamiento primario de los guanacos y un posible consumo ocasional de médula (Marchionni 2013; Miotti 2003; Miotti y Salemme 2005; Miotti et al. 1999). La alta representación de todas las unidades anatómicas sugiere que los guanacos habrían sido cazados en las cercanías del sitio (Marchionni 2013; Miotti et al. 1999).

Componente superior

\section{Holoceno Medio: Capa 2}

Para el Holoceno medio la especie más representada en el sitio es el guanaco aunque en baja frecuencia también se registran rheidos y aves medianas, asimismo cabe destacar, que para estos momentos, dada la gran fragmentación del conjunto, una frecuencia considerable de especímenes fueron asignados a Mamíferos grandes e indeterminados (Marchionni 2013; Marchionni et al. 2010; Miotti y Marchionni 2011). Los análisis de meteorización indican una buena preservación del conjunto ya que ca. 95 \% de los especímenes mostraron baja meteorización ( $\leq$ estadio 2 de Behrensmeyer 1978).

Entre las modificaciones naturales observadas por Miotti y Marchionni (2011) y Marchionni (2013) se destacan las improntas de raíces (ca. $21 \%$ ) y las manchas de manganeso ( $c a .19 \%$ ). Las primeras fueron interpretadas como resultado de la existencia de una cobertura herbácea en el momento en que los huesos fueron depositados, lo cual fue además vinculado a las características húmicas del horizonte del suelo en que se hallaban contenidos los materiales (Marchionni 2013). Las características de este horizonte, donde se registran niveles elevados de materia orgánica en descomposición, junto 
con los procesos pedogenéticos, podrían ser las que expliquen la frecuencia existente de manchas de manganeso entre los especímenes (Marchionni 2013).

A estas modificaciones naturales se suman, en frecuencias menores, depósitos de carbonatos (ca. $5 \%$ ) -también vinculados a las características del emplazamiento y del depósito-, marcas de roedores y de carnívoros ( $<3 \%)$. La presencia de marcas de procesamiento registradas tanto en elementos axiales como apendunculares indican actividades de procesamiento secundario y consumo de los guanacos. También se registraron modificaciones culturales en especímenes de otras especies como rheidos, cánidos y moluscos, que junto a la presencia de alteración térmica en especímenes de diferentes taxas, y a la presencia de artefactos óseos formales, ponen en clara evidencia el rol humano en la formación del conjunto (Marchionni 2013; Miotti y Marchionni 2011).

Los análisis de distribución de los materiales y rasgos, junto con la presencia de áreas de fogones y los análisis de modificaciones realizados indican que en el sitio se llevaron a cabo actividades domésticas con una posible estructuración del espacio para el desarrollo de actividades más específicas -descarte, procesamiento y consumo-. Los guanacos habrían sido procesados de manera integral no solo para consumo, sino además con otros fines no alimenticios como la manufactura de instrumentos (Miotti y Marchionni 2014), mientras que, las restantes especies con marcas de uso -rheidos, cánidos y moluscos- habrían cumplido un rol complementario en la vida de estas sociedades (Marchionni 2013).

\section{Arte rupestre}

El arte rupestre de Piedra Museo, fue relevada en los sitios AEG-2 y CG. Aquí presentamos una caracterización escueta del arte, para un mayor detalle recomendamos el libro de la Dra. Natalia Carden (2008). En AEG-2 se registraron pinturas rupestres y en techo y paredes y un bloque grabado en posición horizontal (En la Figura 4.4 corresponde al "Petroglifo"). Entre los grabados se identificaron motivos abstractos (curvilíneos, rectilíneos y circulares) y figurativos (pisadas de ave, caballo, guanaco y felino). Este panel tiene una alta densidad de motivos los cuales tienen una conservación diferencial y superposición. Esto permite inferir eventos diferentes de grabado.

En cuanto a las pinturas de AEG-2 presentan una mala conservación, sin 
embargo se pudieron identificarse conjuntos y motivos aislados. Las pinturas consisten en 15 manos negativas la marca de un dedo, una mancha de contorno circular y una línea de puntos. Se pudieron reconocer diferentes manos asignables a niños, lo que es un patrón repetido en diferentes cuevas del área de estudio (Carden 2008).

En CG, que se encuentra a $200 \mathrm{~m}$ de AEP-1, se reconocieron pinturas en techo y paredes y grabados realizados sobre grandes bloques desprendidos del techo. Hay una alta variabilidad de motivos tanto abstractos como figurativos. Entre los abstractos se pudieron observar motivos circulares, curvilíneos, rectilíneos, combinados y puntiformes, mientras que entre los figurativos se registraron manos, pies, rastros de ave y rastreos de felinos. Por su parte, las pinturas consisten en manos en negativo muy desvaídas ( $\mathrm{n}$ = 40) y una línea de puntos.

\section{Proxies Ambientales Biológicos}

Para el sitio AEP-1, contamos con el análisis polínico que ya fue detallado en el capítulo de Paleoambiente (Figura 3.4) y con el análisis de diatomeas realizado por Fernández (2013) en su tesis doctoral.

En el caso de PM, los análisis diatomológicos fueron realizados en el paleolago ubicado frente al sitio. Las especies reconocidas son aerófilas y euterrestres lo que significa que pueden vivir en lugares húmedos o secos). Estos resultados son preliminares ya que no se pudo evaluar si efectivamente el paleolago era un cuerpo lacustre bien constituido para los distintos momentos de ocupación del alero. Los ensambles de diatomeas sugieren un ambiente semi-aéreo de tipo litoral, características de cuerpos de agua que se secan temporalmente.

La ausencia de fechados y materiales datables en el testigo analizado no permitió a la autora realizar una contextualización cronológica absoluta, aunque se sugiere que la columna de $1 \mathrm{~m}$ extraída representaría los últimos mil años. 


\section{Capítulo 5}

\section{Marco teórico metodológico}

Para el desarrollo de esta tesis, partiremos del concepto de geoarqueología en tanto investigación arqueológica que utiliza métodos y conceptos de las ciencias de la tierra (Butzer 1982). Es una disciplina intrínsecamente interdisciplinaria, que busca responder preguntas arqueológicas mediante herramientas relacionadas a la geología. Se vale de técnicas y enfoques utilizados en geomorfología, sedimentología, pedología, estratigrafía, geocronología y micromorfología de suelos para investigar geoformas, sedimentos y suelos de sitios arqueológicos (Courty et al. 1989; Waters 1992; Goldeberg y MacPhail 2006).

Los objetivos generales de esta disciplina están muy bien sintetizados por Waters (1992) quien establece que la geoarqueología tiene como objetivos primarios:

- Ubicar a los sitios y materiales arqueológicos en un contexto temporal relativo y absoluto a través de la aplicación de principios estratigráficos y técnicas de datación absoluta.

- Entender los procesos naturales de formación de sitio, ya que "antes de que los arqueólogos puedan inferir interpretaciones significativas sobre el comportamiento humano a partir del contexto existente, deben saber cómo ese contexto fue creado" (Waters 1992:11).

- Reconstruir el paisaje existente alrededor del sitio o grupo de sitios para el momento en que fue ocupado. Esto permite ubicar las reconstrucciones sobre el pasado humano en un contexto no cultural. 
El proyecto marco en el que se inscribe la presente investigación ${ }^{1}$, se encuentra orientado al estudio del poblamiento inicial de Patagonia y del desarrollo espacio/temporal de las sociedades cazadoras recolectoras que la habitaron. Dicho proyecto se enmarca bajo los lineamientos teóricos de la arqueología del paisaje (Criado Boado 1999), que entiende al paisaje como una construcción ecológico/social donde se conjugan tres tipos de elementos: la matriz medioambiental de la acción humana, el entorno social o medio construido por el ser humano y el espacio en cuanto entorno pensado o medio simbólico.

La contribución de esta Tesis radica principalmente a la comprensión de la matriz medioambiental y de los escenarios naturales en los que se desenvolvieron los cazadores recolectores que ocuparon la región desde fines del Pleistoceno. En este marco, resulta importante destacar que en este trabajo consideraremos a las personas (los grupos cazadores recolectores que aquí estudiamos) no sólo como actores de los sistemas socioculturales del pasado, sino también como agentes geomorfológicos. En este sentido entendemos que ingresan, movilizan y extraen sedimentos de los sitios arqueológicos, deliberadamente o no, pudiendo afectar a las características de los depósitos sedimentarios (Butzer 1982). En suma, nuestro interés mayor responde a comprender en qué medida estos escenarios y cambios ambientales afectaron las decisiones humanas y/o al registro arqueológico.

Para abordar nuestros objetivos, nos valdremos principalmente de los datos generados provenientes de análisis geomorfológicos y sedimentológicos de las cuevas seleccionadas y del entorno de las mismas, buscando complementarlos e integrarlos con datos de proxies ambientales publicados y otros nuevos generados para esta tesis (Borromei 2003; De Porras 2010; De Porras et al. 2009). Asimismo, contamos con abundante información proveniente de los análisis tafonómicos de conjuntos faunísticos (Marchionni 2013, Marchionni et al. 2012), la cual será empleada como evidencia indirecta para evaluar tasas relativas de depositación (Beherensmeyer 1978; Favier Dubois 1997) y la acción de procesos postdepositacionales.

\footnotetext{
${ }^{1}$ Estudio comparativo de los paisajes arqueológicos de los macizos de Somuncurá y del Deseado PICT-2011- 0176 dirigido por la Dra. Laura Miotti.
} 


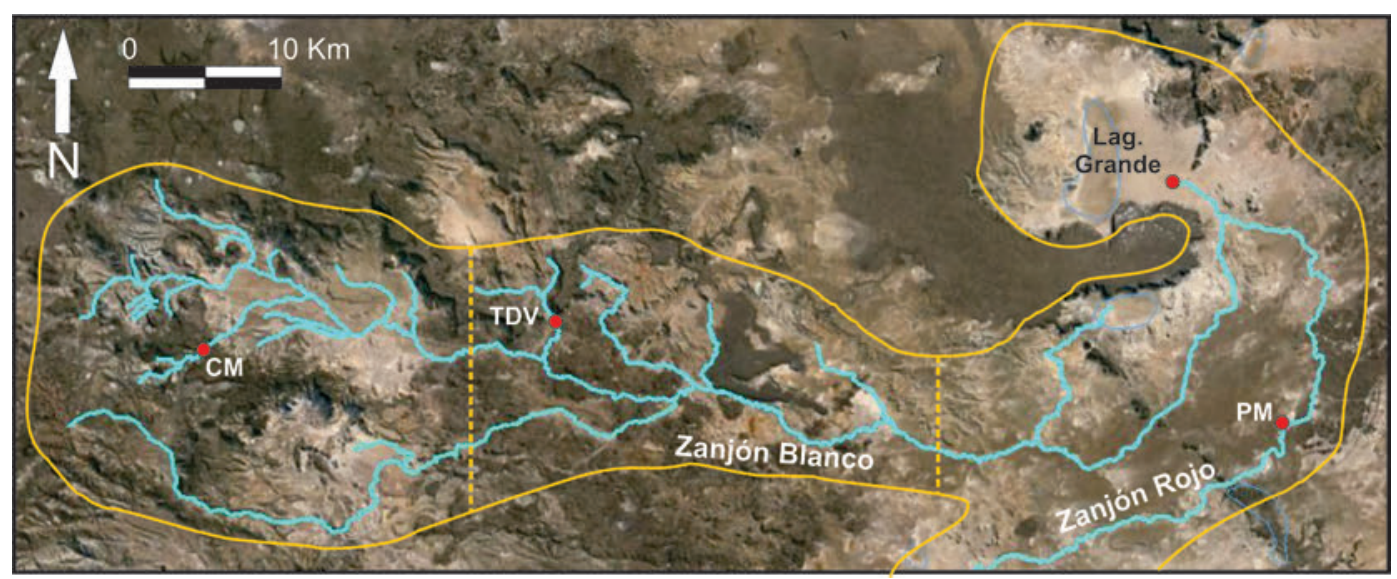

Figura 5.1: División del área de estudio en tres subcuencas. CM: Cueva Maripe, TDV: Tito del Valle, PM: Piedra Museo.

\subsection{Escalas de análisis}

Los alcances de las preguntas y de los resultados obtenidos en la investigación geoarqueológica propuesta en esta tesis, están íntimamente relacionados con las escalas de análisis utilizadas. La geología y la arqueología se manejan en escalas espacio temporales diferentes, por lo que combinarlas para llegar a una buena resolución de los problemas es parte del diálogo interdisciplinario (Favier Dubois 2002; Holliday et al. 1993). En nuestro caso, el área de estudio comprende a la cuenca del Zanjón Blanco y abarca una superficie aproximada de $2400 \mathrm{~km}^{2}$ (Figura 5.1). Tendremos en cuenta la división en subcuencas planteada por Schumm (1977) que plantea que el sistema fluvial se diferencia en una zona de aporte o cuenca alta; una zona de transporte/depositación o cuenca media y una zona de depositación o cuenca baja. El área de estudio fue subdividida, para su análisis arqueológico, teniendo en cuenta dicha propuesta de Schumm.

Si bien adoptamos la clasificación mencionada, cabe notar que en este caso se trata de cauces efímeros en climas secos, los cuales presentan variaciones en cuanto a dinámica hídrica y sedimentaria con respecto a ríos de régimen permanente. En estos casos, los procesos de erosión/sedimentación están regidos por una alternancia entre procesos hídricos, cuando hay transporte de agua, y eólicos cuando los cauces están secos (Bull 1997).

La división del Zanjón Blanco en tres subcuencas (Figura 5.1) queda conformada de la siguiente manera:

1. Cuenca Alta: abarca una superficie aproximada de $730 \mathrm{~km}^{2}$, ubicada 
entre los 800 y los 350 msnm, y conforma la subcuenca "Cuenca Alta" y es la que registra el mayor gradiente (1,55\%). Las divisorias están representadas por mesetas basálticas. Los cauces en este sector son simples presentan diseños variados, sinuosos a rectos, los cuales se han generado principalmente por el escurrimiento de agua de precipitación por lo tanto su caudal es de régimen pluvial. En este sector hemos reconocido numerosos manantiales y mallines de diferente tipo (Figura 2.11) que son una importante fuente de provisión de agua. Estos humedales son concentradores de recursos florísticos y faunísticos (Mazzoni y Rabassa 2013) y muchos de ellos están asociados a sitios arqueológicos (Magnin 2010). Un caso muy importante para esta Tesis es el Cañadón La Primavera que alberga un mallín de valle de 10 $\mathrm{km}$ de longitud en cuyos márgenes se emplaza la Cueva Maripe, entre muchas otras que no han sido excavadas pero en las que se registró arte rupestre (cuevas La Primavera 1, 2, 3 y 5) (Carden 2008). Dentro del Cañadón La Primavera, se realizaron cinco muestreos mediante barreno helicoidal. Las muestras obtenidas, las cuales corrsponden a un total de 60, se utilizaron para análisis sedimentologicos mientras que un testigo fue extraído mediante barreno ruso (Russian peat corer) para análisis polínico. Los muestreos alcanzaron profundidades variadas entre 1.40 y $2.8 \mathrm{~m}$. Como referente arqueológico se analizó la estratigrafía de la Cueva Maripe, que ha sido excavada hasta la roca de caja y cuenta con numerosa información obtenida a partir de los conjuntos analizados (Miotti et al. 2014). El sitio Cueva Maripe y el Cañadón La Primavera, conforman los referentes para el análisis geoarqueológico de la Cuenca Alta.

2. Cuenca Media: la superficie de este sector es de aproximadamente 700 $\mathrm{km}^{2}$, y sus cotas se encuentran entre los 350 y los 150 msnm con un gradiente regional de $0,49 \%$. Los diseños del cauce son sinuosos a meandrosos con tramos que presentan meandros abandonados en lugares donde el ensanchamiento del cauce ha permitido la migración lateral del canal. En uno de los cursos tributarios de este sector se emplaza la cueva Tito del Valle, en la cual realizamos una excavación para obtener un referente estratigráfico de cueva para esta subcuenca. A lo largo de este cauce se pudieron relevar diferentes perfiles estratigráficos, de los cuales tres fueron muestreados para análisis sedimentológicos. En este 
caso, la cueva Tito del Valle y el cauce que corre frente al sitio fueron los lugares seleccionados como referentes de la Cuenca Media.

3. Cuenca Baja: En este sector se encuentra la Laguna Grande del Bosque Petrificado que es el nivel de base de la cuenca de los zanjones Blanco y Rojo. El área abarca $900 \mathrm{~km}^{2}$ aproximadamente y sus cotas se ubican entre 150 y $40 \mathrm{msnm}$ con una pendiente de $0,3 \%$. En cuanto al diseño del cauce del Zanjón Blanco, se reconocen planicies más amplias que en el resto de la cuenca con cauces meandrosos y meandros abandonados. También se pueden reconocer tramos en los que se han ha formado cuerpos de agua. Este es el caso del paleolago de Piedra Museo que se formó en el curso del Zanjón Rojo y en cuyos márgenes se encuentra el sitio arqueológico AEP-1. Los referentes analíticos de la Cuenca Baja son el paleolago de Piedra Museo y AEP-1.

La modalidad de abordaje en la prospección geoarqueológica de las tres localidades analizadas partió del sitio hacia la periferia. En este sentido, las escalas de trabajo utilizadas son inclusivas y jerárquicas, es decir que las micro, meso, y mega escalas (Delcourt y Delcourt 1988) se incluyen unas dentro de las otras integrado los patrones y procesos que ocurren en los niveles jerárquicos menores (Barberena 2008; Delcourt y Delcourt 1988). Nuestras escalas de análisis se compatibilizan con las escalas planteadas por Dincauze (2000), donde la Micro escala corresponde al sitio arqueológico que en nuestro caso al tratarse de cuevas y abrigos rocosos presentan límites determinados. La escala siguiente es la Meso escala que incluye a las escalas Local como pueden ser valles, cañadones o lagos, y Regional, que está representada en nuestro caso por la cuenca del Zanjón Blanco y Rojo. La Macro escala que contiene a las antes mencionadas está representada por el Macizo del Deseado (Tabla 5.1).

\subsection{Diseño de muestreo}

En el caso de los sitios analizados, la estrategia de muestreo apuntó a estudiar los arreglos estratigráficos de las sucesiones sedimentarias y así conocer los eventos depositacionales ocurridos en cada cueva (Stein 1985). En este sentido, se tomaron muestras de cada unidad estratigráfica definida en campo (capas o subcapas). La extracción de muestras se realizó con espá- 


\begin{tabular}{ccc}
\hline $\begin{array}{c}\text { Escala } \\
\text { espacial }\end{array}$ & Área $\left(\mathbf{k m}^{\mathbf{2}}\right)$ & Sectores en esta tesis \\
\hline Macro & Provincia Geológica: $10^{4}-10^{7}$ & Macizo del Deseado \\
\hline & Regional: $10^{2}-10^{2}$ & Cuenca del Zanjón Blanco y Rojo \\
\cline { 2 - 3 } Meso & Local: $1-10^{2}$ & Cañadón La Primavera (Cuenca Alta) \\
\cline { 2 - 3 } & & Cauce sin nombre (Cuenca media) \\
\cline { 2 - 3 } Micro & Sitio: $<1$ & Paleolago (Cuenca alta) \\
\cline { 2 - 3 } & & Cueva Maripe (Cuenca Alta) \\
\hline
\end{tabular}

Tabla 5.1: Escalas de análisis seleccionadas en esta tesis. Adaptación a la propuesta de Dincauze (2000).

tula, en una misma unidad de sedimentación, hasta obtener un mínimo de 200 gr.

El criterio de muestreo dentro de cada sitio consideró a los sectores en los que se excavaron cuadriculas arqueológicas ya que permiten no sólo abordar el análisis del depósito sedimentario sino también de la relación del mismo con los conjuntos arqueológicos. No se realizaron muestreos complementarios dentro de los sitios por fuera de las cuadriculas.

En el sector de la Cuenca Alta, en Cueva Maripe, se realizó un muestreo en las dos cámaras que conforman al sitio para reconocer y correlacionar los eventos de depositación de cada sector y así reconstruir la historia de depositacional de la cueva en su totalidad. Por su parte, en el Cañadón La Primavera los perfiles estratigráficos naturales son escasos, por lo que se optó por un muestreo dentro del mallín que corre en su interior mediante un barreno helicoidal, extrayendo muestras de $20 \mathrm{~cm}$ de potencia (Figura $5.2)$.

De las muestras obtenidas en la Cuenca Alta, 21 corresponden al sitio Cueva Maripe (12 de Cámara Norte y 9 de Cámara Sur). Luego de prospectar los 6 km de longitud del Cañadón La Primavera se seleccionaron cinco puntos de muestreo con barreno que permitieron recuperar columnas sedimentarias de diferente profundidad (entre 180 y $280 \mathrm{~cm}$ ) completando un total de 63 muestras (Tabla 5.2).

En la Cuenca Media, se tomó como referente arqueológico a la cueva Ti- 


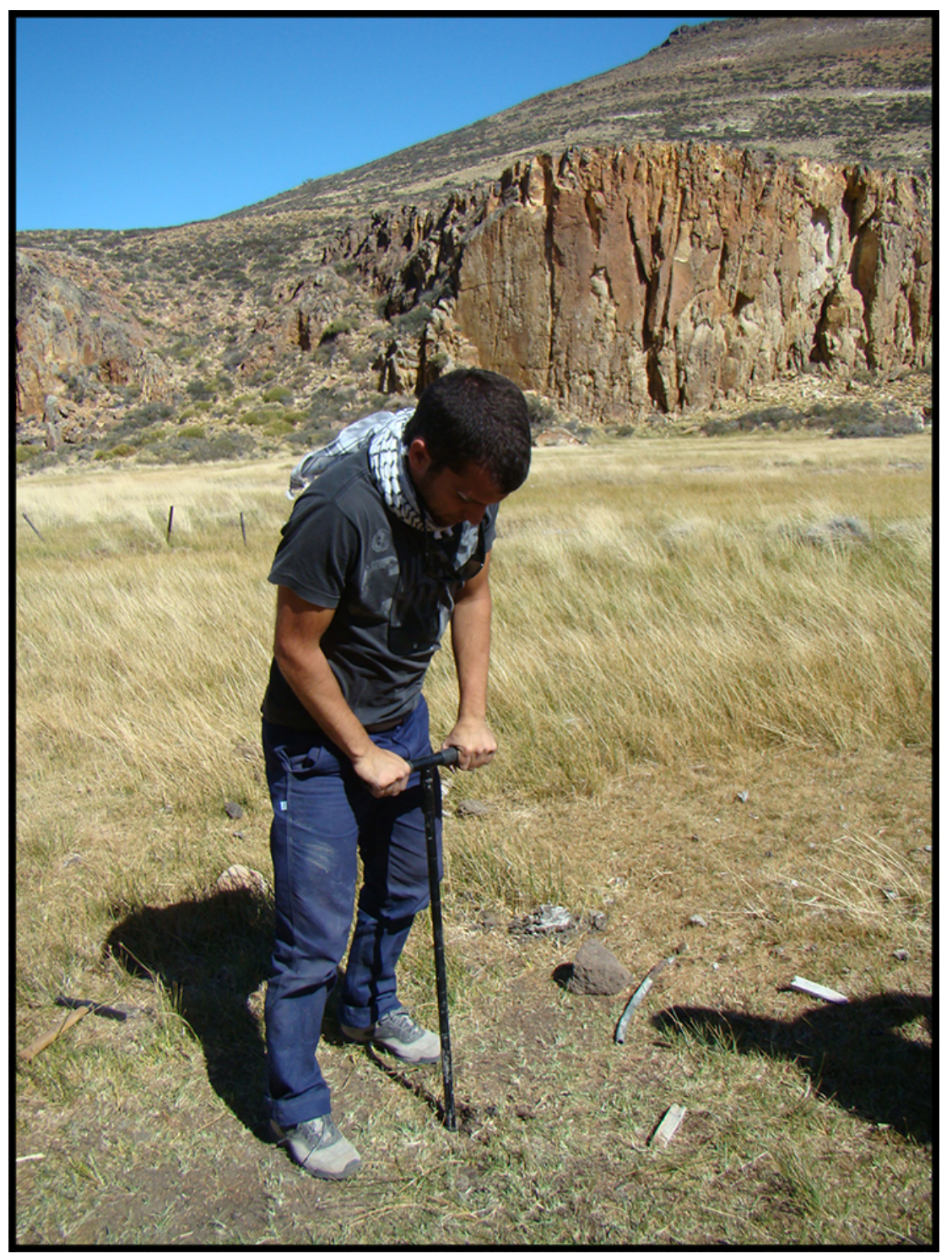

Figura 5.2: Extracción de muestras mediante barreno helicoidal en el Mallín La Primavera. La foto corresponde al muestreo MLP1. 


\begin{tabular}{lcccc}
\hline & Tipo de muestreo & $\begin{array}{c}\text { Profundidad } \\
\text { (en cm) }\end{array}$ & $\begin{array}{c}\text { Cantidad de } \\
\text { muestras }\end{array}$ & $\begin{array}{c}\text { Distancia a } \\
\text { Cueva Maripe } \\
\text { (en metros) }\end{array}$ \\
\hline MLP1 & Barreno en mallín & 180 & 9 & 3112 \\
\hline MLP2 & Barreno en mallín & 280 & 14 & 1853 \\
\hline MLP3 & Barreno en mallín & 220 & 11 & 1829 \\
\hline MLP4 & $\begin{array}{c}\text { Perfil natural } \\
\text { (cárcava) }\end{array}$ & 200 & 10 & 1482 \\
\hline MLP5 & Barreno en mallín & 140 & 7 & 427 \\
\hline MLP6 & Barreno en mallín & 200 & 10 & 50 \\
\hline
\end{tabular}

Tabla 5.2: Testigos sedimentarios obtenidos en el Mallín La Primavera mediante barreno helicoidal.

to del Valle, la cual hasta el momento sólo había sido estudiada por su arte rupestre (Carden 2008). En el marco de esta tesis se practicó una excavación de $1 \mathrm{~m}^{2}$, para obtener un referente estratigráfico en este sector, ya que hasta el momento no hay sitios en cueva que hayan sido excavados en la Cuenca Media. En la excavación no se recuperaron materiales arqueológicos. Aun así, se describieron las 6 unidades estratigráficas reconocidas, las cuales fueron muestreadas y analizadas en laboratorio. En este caso, la cueva se emplaza a la vera de un cauce sin nombre que presenta una serie de cortes estratigráficos que fueron relevados y muestreados (Tabla 5.3). En el margen opuesto del cauce se eleva una lomada sobre la cual se identificó un sitio en superficie compuesto de material lítico. Este sitio fue relevado mediante transectas y analizado para tener una base de información desde los conjuntos arqueológicos, ya que está directamente relacionado con la cueva Tito del Valle.

Los perfiles naturales fueron seleccionados luego de prospectar $3 \mathrm{~km}$ de cauce en los que se reconocieron perfiles naturales. El muestreo con barreno no fue viable, debido a la abundancia de grava en los sectores donde se intentó utilizarlo que impidió la penetración en el suelo. Por lo tanto se tomaron muestras de los 3 de los perfiles relevados y se relevaron 2 más en campo sin realizar el análisis sedimentológico. En uno de ellos (Perfil 3) se reconoció una lente de ceniza volcánica, la cual fue enviada al Dr. Charles Stern de la Universidad de Colorado, Estados Unidos, para realizar análisis geoquímico y reconocer su procedencia. 


\begin{tabular}{ccccc}
\hline muestreo & $\begin{array}{c}\text { Tipo de } \\
\text { del perfil } \\
\text { (en cm) }\end{array}$ & $\begin{array}{c}\text { Cantidad de } \\
\text { muestras/capas }\end{array}$ & $\begin{array}{c}\text { Distancia a } \\
\text { TDV (en } \\
\text { metros) }\end{array}$ \\
\hline Perfil 3 & Perfil de cauce & 196 & 7 & 145 \\
\hline Perfil 4 & Perfil de cauce & 160 & 5 & 350 \\
\hline Perfil 5 & Perfil de cauce & 120 & 7 & 370 \\
\hline
\end{tabular}

Tabla 5.3: Perfiles y muestras relevados en el cauce de Tito del Valle.

La Cuenca Baja, a diferencia de los otros dos sectores, presenta información geoarqueológica previa (Zárate et al. 2000). Por lo tanto, en este caso, se realizó un muestreo del paleolago adyacente a Piedra Museo para poder compararlo con el sitio excavado y se realizó un nuevo muestreo de las capas reconocidas previamente en la estratigrafía de AEP -1 (Miotti 1992; Miotti et al. 1999; 2003; Zárate et al. 2000), para evaluar la composición del depósito. La toma de muestras en el paleolago se realizó con barreno helicoidal. Se logró recuperar un testigo de 0,8 m (4 muestras), ya que se hizo imposible seguir profundizando por la dureza y compactación del sustrato.

Por otro lado, se realizó una prospección de perfiles estratigráficos en diferentes puntos del cauce principal del Zanjón Blanco en los sectores de cuenca alta y media. Esta prospección tuvo como objetivo, reconocer eventos depositacionales, discontinuidades, depósitos de tefra volcánica o cualquier otro indicador que pueda servir para correlacionar eventos de depositación/ no depositación/estabilidad a nivel regional.

\subsection{Perfiles estratigráficos}

El análisis de perfiles estratigráficos se llevó a cabo teniendo en cuenta los rasgos reconocidos en el campo y sus posibles agentes formadores. En el caso de los sitios arqueológicos las unidades analíticas que hemos utilizado para el análisis estratigráfico son las Capas (numeradas en orden creciente de superficie a fondo) y subcapas (designadas con letras) (Stein 1990). La categoría analítica Capa, permite incluir diferentes aspectos del análisis estratigráfico clásico (ej. litoestratigrafía, cronoestratigrafía) en una unidad de análisis acorde a las escalas arqueológicas. En algunos casos, hemos reconocido variaciones internas a las capas que nos han llevado a utilizar una división de menor escala como la subcapa para obtener un análisis de ma- 
yor detalle en cuanto a procesos de depositación. En este sentido, nuestro criterio inicial para la definición de unidades estratigráficas es el litológico, a partir de textura al tacto, color y estructura. En el caso de la Capa 3 de Cámara Sur de Cueva Maripe se detectaron rasgos internos a la capa que no presentaban límites definibles como para diferenciarla en subcapas, por lo que se muestreó de techo a base cada cuatro centímetros. Las estructuras o rasgos reconocidos (fogones, rocas, pozos) fueron registrados como parte de capas, no como rasgos aislados. Nuestro enfoque se aproxima al que ha adoptado Barberena (2008: 118), calificándolo como "minimalista", en el sentido que no busca maximizar el número de unidades estratigráficas (Harris 1991; Fernández 2001) sino otorgar el estatus de unidad estratigráfica a aquellas que sean significativas para el análisis sedimentológico.

A partir de dichos procedimientos, los datos recolectados en campo pudieron ser relacionados con unidades cronológicas y/o culturales, ya que entendemos que cada unidad estratigráfica reconocida responde a diferentes agentes y procesos depositacionales y postdepositacionales entre los que se incluye la actividad humana, que permiten su definición como tal.

\subsection{Análisis sedimentológico}

\subsubsection{Granulométrico}

El análisis granulométrico de las muestras se realizó siguiendo los procedimientos estándares de laboratorio. En primer lugar se tomó el color del sedimento (Munsel Soil Chart) en seco para luego realizar el cuarteo de la muestra para lograr que la porción a analizar sea representativa del total. Una vez separada la muestra, y obtenido unos $30 \mathrm{~g}$, se la trató con peróxido de hidrógeno al $6 \%$ para eliminar partículas pequeñas de materia orgánica, este proceso en algunas muestras requirió varios días y en los casos que presentaban carbonatos se eliminaron con una solución de ácido clorhídrico $(\mathrm{HCl})$ al 10\%. Cuando la muestra dejó de reaccionar se procedió al lavado con agua destilada para llevar el $\mathrm{pH}$ de la solución a valores neutros $(\mathrm{pH}=$ 7) y que de esta manera no se vea afectada la precipitación del sedimento al momento del pipeteo. A la muestras, una vez lavadas, se le agregaron $50 \mathrm{ml}$ de calgón (Hexa metafosfato de sodio) al $4 \%$ de concentración, que actúa como dispersor separando las partículas sedimentarias. Esta solución es ta- 
mizada en húmedo a través de una malla de $4 \varphi$ (límite entre las fracciones psámitica (arena) y pelítica (limo y arcilla) de manera tal que las partículas mayores a $4 \varphi$ (psefitas y psamitas) quedan retenidas en el tamiz, mientras que las de menor tamaño o " pasante" son recogidas en solución en una probeta de $1000 \mathrm{ml}$. El retenido en el tamiz 4 phi es llevado a estufa para su secado, y posterior tamizado.

La separación en fracciones para el análisis granulométrico se realizó mediante el armado de una columna de siete tamices de diferente malla (a un grado de phi), desde $-2 \varphi(4000 \mu \mathrm{m})$ a $4 \varphi(63 \mu \mathrm{m})$ para separar la muestra en tres fracciones: Grava (Finas $-2 \varphi$ y Muy Finas $-1 \varphi$ ), Arena (en sus intervalos de Arena Muy Gruesa -1 a $0 \varphi$, Arena Gruesa 0 a $1 \varphi$, Arena Media 1 a $2 \varphi$, Arena Fina 2 a $3 \varphi$ y Arena Muy Fina 3 a $4 \varphi$ ) y Limo-Arcilla (Figura 5.3). Para la fracción pelítica, la separación se realizó mediante pipeteo. El pipeteo consiste en volcar eli sedimento de la muestra que es más fino que el tamiz de $4 \varphi$ en una probeta de $1000 \mathrm{ml}$. Luego se agita la solución hasta lograr que todo el sedimento de la probeta esté en suspensión y se procede a tomar muestras de $20 \mathrm{ml}$ en intervalos de tiempo establecidos sobre la base de velocidad de caída teórica para esferas de cuarzo de diferentes tamaños (Ley de Stokes). La primera muestra se toma luego de 20 segundos de haber agitado la solución, la que representara el porcentaje en peso de toda la fracción pelítica de la muestra total, y la segunda una hora después en la cual se consigue extraer la alícuota representativa de la fracción arcillosa aun en suspensión $(8 \varphi)$. Luego por diferencia de ambos retenidos, se calcula la fracción de limo de la muestra que se ha sedimentado en el fondo de la probeta (Figura 5.3).

Cada alícuota extraída es colocada en capsulas de porcelana rotulada y llevada a estufa a $<70{ }^{\circ} \mathrm{C}$. Una vez que las muestras se han secado, se procede a pesar cada capsula en balanza analítica. El peso del residuo seco se calcula por diferencia con el peso conocido de la capsula vacía, para posteriormente calcular la representación porcentual en peso de cada intervalo analizado, en nuestro caso $\%$ de limo y \% de arcilla. Con los valores obtenidos porcentuales de contenido de grava, como de arena, limo y arcilla, clasificamos texturalmente las muestras mediante los triángulos de clasificación propuestos por Folk (1957). Este autor propone dos triángulos de clasificación textural de acuerdo a las tres fracciones involucradas en el mismo: triángulo Grava-Arena-Fango (limo + arcilla) y triángulo Arena-Limo- 


\begin{tabular}{|c|c|c|c|c|}
\hline Sedimento & Particula & $\mathrm{mm}$ & & $\phi$ \\
\hline \multirow{6}{*}{ Grava } & Guijarro & 128 & -... & $\begin{array}{l}-8 \\
-7\end{array}$ \\
\hline & \multirow{4}{*}{ Guija } & 64 & -..-- & -6 \\
\hline & & 32 & - & -5 \\
\hline & & 16 & -.-- & -4 \\
\hline & & 8 & -.--- & -3 \\
\hline & Gránulo & 4 & --- & -2 \\
\hline \multirow{5}{*}{ Arena } & Muy Gruesa & & $\cdots$ & -1 \\
\hline & Gruesa & 1 & 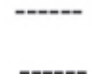 & 0 \\
\hline & Mediana & 0,5 & 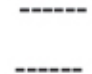 & 1 \\
\hline & Fina & 0,125 & - & 3 \\
\hline & Muy fina & $\begin{array}{l}0,125 \\
0.062\end{array}$ & 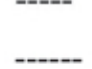 & 4 \\
\hline \multirow{3}{*}{ Limo } & Grueso & & 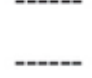 & 5 \\
\hline & \multirow{2}{*}{ Fino } & 0,015 & -.-- & 6 \\
\hline & & 0,008 & -.-- & 7 \\
\hline \multirow{4}{*}{ Arcilla } & & 0,002 & -... & 9 \\
\hline & & 0,001 & --- & 10 \\
\hline & & $\begin{array}{l}0,0005 \\
0,0002\end{array}$ & -.-- & $\begin{array}{l}11 \\
12\end{array}$ \\
\hline & & 0,0001 & ...- & 13 \\
\hline
\end{tabular}

Figura 5.3: Escala granulométrica de Udden-Wentworth.

Arcilla que se utiliza para muestras con menos del 10\% de grava. Para el caso de las muestras provenientes del interior de las cuevas estudiadas se optó por utilizar el que incluye a las gravas para evaluar el rol de la lluvia de detritos (eboulis) generada por la meteorización de la roca de caja.

Si bien en los análisis granulométricos se calculan coeficientes estadísticos de tendencia central como de dispersión que dan cuenta de las características particulares de cada distribución de tamaño, estos pueden ser utilizados con dos motivos:

1. Definir a través de éstos características particulares de cada distribución de tamaños y para cada depósito.

2. Referir estos valores a condiciones particulares del agente de trans- 
porte y depositación. Esto es dar una valoración sobre la dinámica del agente.

Los coeficientes de tendencia central son:

1. Media: no sólo es el promedio de medidas granulométricas, sino que es un parámetro que se relaciona fuertemente con la energía del agente de transporte (Sahu 1964; Blasi 1986).

2. Mediana: es el valor del punto medio de la distribución. En este sentido, responde al tamaño que deja a la mitad (en peso) de la población analizada con tamaños más gruesos y la otra mitad con los tamaños más finos.

3. Moda: Es la clase granulométrica de mayor frecuencia en peso de la muestra. Los histogramas son un medio grafico útil para tener una rápida idea cualitativa de la distribución granulométrica a partir de la cual se puede reconocer si la muestra tiene una moda (la barra de mayor frecuencia) o si es polimodal. Asimismo, si se trata de modas muy desarrolladas o no y donde se ubican sus admixturas proximales de mayor frecuencia en peso.

En tanto los de dispersión son:

1. Selección (Desvío estándar): Es un parámetro que marca la dispersión granulométrica de las partículas que integran el sedimento con respecto a la media. Sirve como indicador de la fluidez del agente a partir del cual se pueden evaluar las fluctuaciones en la energía cinética (Folk 1954).

2. Curtosis: mide la agudeza de la distribución en la curva de frecuencias la cual puede ser de tres tipos básicos: leptokúrtica (curva de cresta aguda), platikurtica (curva de cresta roma) y mesokúrtica (intermedia). La utilizaremos como una característica descriptiva, debido a que su significado en cuanto a dinámica es poco preciso (Spalletti y Mazzoni 1972; Sahu 1964).

3. Asimetría: Relaciona la separación de los extremos ("colas") de la población con la media. Esta relación puede ser una asimetría positiva cuando hay un exceso de partículas finas, o una asimetría negativa 


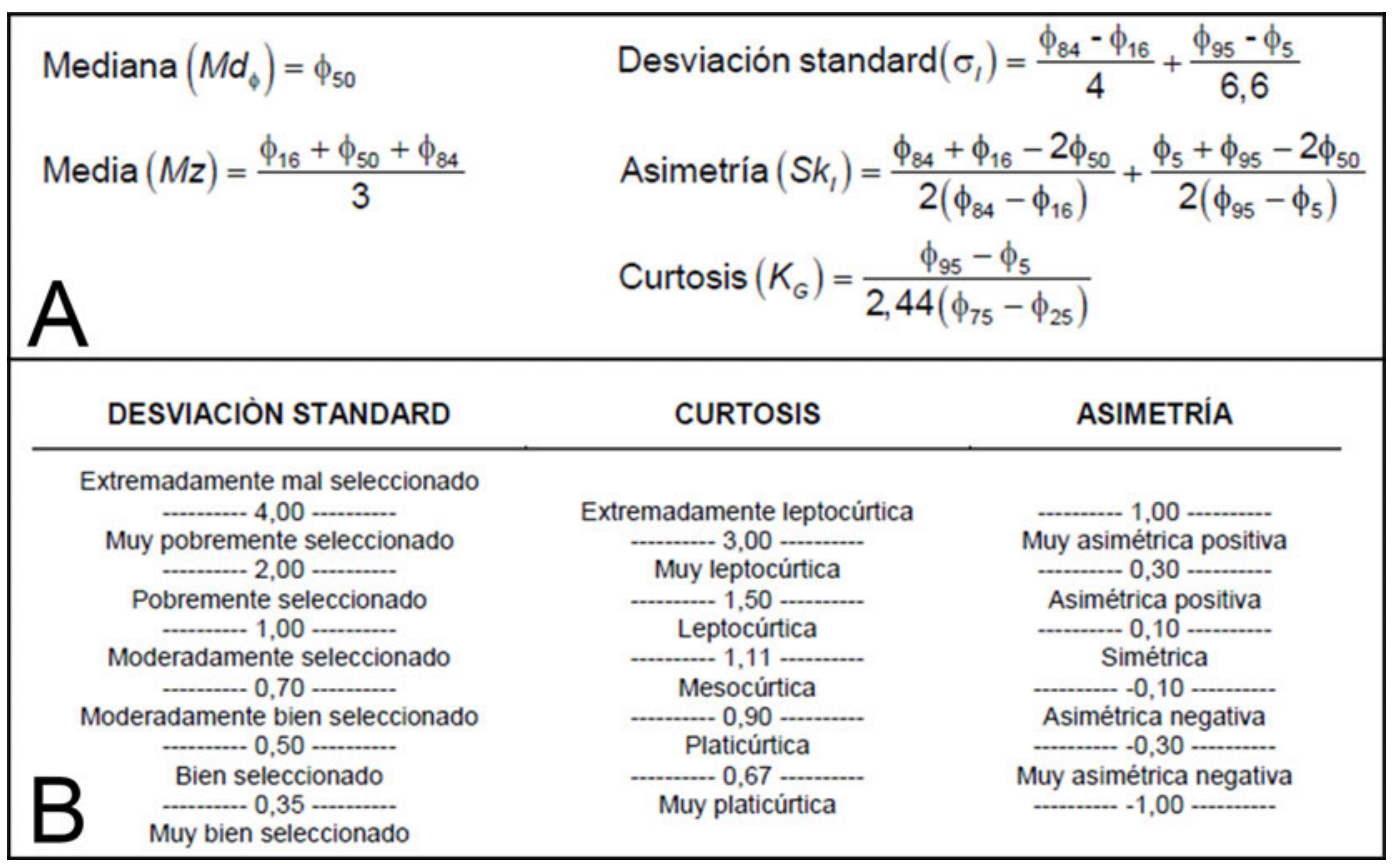

Figura 5.4: Cálculo y valoración de parámetros estadísticos. A. Fórmulas para la obtención de los parámetros estadísticos mediante el método gráfico. B. Valores límites de las categorías de selección, curtosis y asimetría.

cuando el exceso es de partículas gruesas. Es útil para conocer frecuencia y duración de las fluctuaciones de velocidad. Un exceso puede reconocerse por una asimetría positiva o negativa en relación con la velocidad media. También es útil para evaluar la competencia del agente.

Para realizar el cálculo de éstos coeficientes estadísticos primero, se vuelcan los valores porcentuales de cada fracción en papel probabilístico y se desarrolla un grafico de frecuencia acumulada. Posteriormente del grafico obtenido se leen los valores alcanzados por diferentes percentiles y se realizan los cálculos de parámetros propuestos (Figura 5.4).

\subsubsection{Composición y Forma}

Una vez realizado el análisis granulométrico, determinamos otros atributos texturales de los sedimentos epiclásticos: la composición y forma (redondez y esfericidad) de los clastos en las muestras de los sitios excavados.

Las fracciones psefitas y psamitas mayores a $0,250 \mathrm{~mm}(2 \varphi)$ fueron analizadas a través de la observación y conteo de granos (300 x muestra) mediante lupa binocular (Nikon SMZ-445, con base de iluminación por luz 
incidente NI-150).

Para determinar diferencias entre las unidades mecánicas que integran cada muestra obtenida de los perfiles estratigraficos de los sitios arqueológicos, en las fracciones más gruesas que arena fina, se observó el grado de redondeamiento alcanzado como producto de la pérdida por desgaste de aristas y vértices (Powers 1953) (Figura 5.5).

Para conocer las características de los fragmentos producidos por desagregación física de la roca de caja, se procedió a la realización de la molienda de un trozo de la misma. Se separaron distintas fracciones de tamaños y se observaron bajo lupa. En todas las fracciones analizadas registró la composición y se midió el grado de redondeamiento alcanzado por los clastos líticos y monomineraless según escala Powers (1953) (Figura 5.5).

Los clastos psefíticos (>2 $\mathrm{mm}$ ) y psamitas medianas a muy gruesas (2 $0,250 \mathrm{~mm}$ ) fueron observados en las diferentes muestras de la cuevas estudiadas que presentaron ocupaciones arqueológicas en estratigrafía. Dichos clastos fueron reunidos sobre la base de las características de composición y forma en dos grupos: uno atribuible a sedimentos endógenos y otro a los de procedencia exógena (Farrand 1985). El grupo de sedimentos endógenos está conformado por los fragmentos y productos de meteorización de la roca de caja, mientras que en el grupo de los sedimentos exógenos se incluyen los materiales ingresados al sitio por diferentes agentes de transporte ya sea ácueo, eólico, humano, animal, entre otros. Los clastos de carbón fueron considerados como de origen antrópico como producto del ingreso del material combustible (leña). Cabe destacar que no hay evidencias de incendios naturales en este sector del Macizo del Deseado. En este sentido hay estudios realizados en la región del ecotono bosque-estepa en los márgenes de la cordillera santacruceña que señalan una baja posibilidad de dispersión de fuego por incendio en ambientes de estepa arbustiva (Bamonte y Mancini 2011; Sottile et al. 2012) como el que caracterizó al entorno de nuestro sitio durante gran parte del Holoceno (De Porras et al. 2009; Mancini 1998; 2002; Mancini et al. 2013; Páez et al. 1999).

La composición de la fracción arcilla fue determinada tanto para muestras procedentes de la roca de caja como de la estratigrafía del sitio, a partir del análisis de difracción de rayos X (DRX) de muestras orientadas en estado natural, glicoladas y calcinadas. Estos analisis se realizaron para Cueva Maripe y AEP-1. 


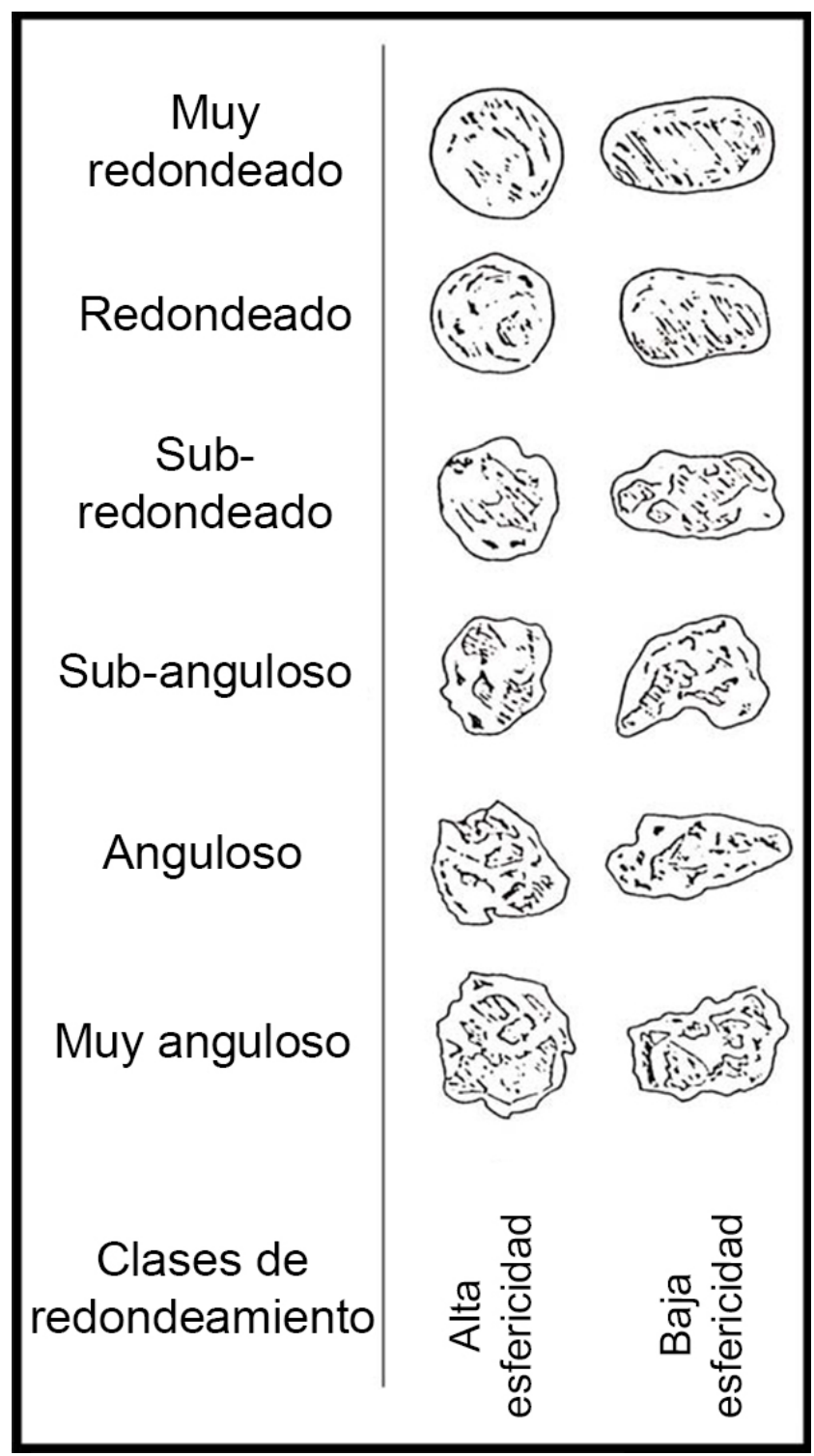

Figura 5.5: Escala de redondeamiento de granos. Tomado de Powers 1953. 
La DRX permite determinar que argilominerales y minerales están presentes en esta fracción. A partir de esto se pueden encontrar similitudes y diferencias en la composición mineralógica de las muestras. El método consiste en realizar un extendido liquido sobre un vidrio/portaobjetos a partir de una suspensión portadora de partículas arcillosas $(<8 \varphi)$ y se deja secar. Así se logra que las los argilominerales (filosilicatos) se depositen durante el tiempo de secado orientadas en la superficie del vidrio según sus caras basales. Esta muestra orientada se lleva al difractómetro de rayos $\mathrm{X}$ para obtener el DRX de Muestra Normal. Luego se expone la muestra a vapores de etil-glicol a $40{ }^{\circ} \mathrm{C}$ durante 24 hs y se lleva nuevamente al difractómetro para obtener el DRX de la muestra glicolada. Por último, la muestra natural, se coloca en una mufla a $550{ }^{\circ} \mathrm{C}$ para proceder a la calcinación, por la cual algunos argilominerales rompen su estructura cristalina. Comparando e interpretando los tres difractogramas de cada muestra, se pueden identificar los minerales de arcilla presentes en cada una de ellas.

En el caso de Cueva Maripe, este análisis se llevó a cabo en el laboratorio de Rayos X del CIG (Centro de Investigaciones Geológicas, UNLPCONICET). Han sido procesadas 17 muestras de las 21 que conforman el total del sitio, puesto que en las restantes 4 solo mostraron valores traza para las especies minerales presentes, por lo que no son incluidas en los gráficos. La semicuantificacion de cada especie mineral se realizó en el CIG. Este análisis de composición no se realizó en las capas 1 y 2 puesto que ambas están formadas por estiércol en diferentes grados de compactación. Este reconocimiento a nivel macroscópico es suficiente para evaluar el proceso de depositación. El análisis pormenorizado de las mismas, desviaría los resultados haciéndolos difíciles de comparar.

Por su parte, en AEP-1 se realizó el DRX de una muestra de cada capa (6 en total), las cuales debido a su alta frecuencia de carbonatos

A partir del conocimiento de la composición argilominerales de la roca de caja y de las muestras obtenidas en la estartigrafia se podrá evaluar la influencia del aporte de la roca de caja en estas fracciones.

\subsubsection{Análisis geoquímicos}

Entre la variedad posible de análisis geoquímicos, en esta tesis hemos optado por dos: análisis de Materia Orgánica (MO) y Carbonatos.

Los análisis de Materia Orgánica son utilizados en arqueología con la 
finalidad de cuantificar el porcentaje de este material en el sedimento muestreado. Las personas que habitan espacios acumulan material orgánico a partir de sus actividades en forma de desechos de alimentos, manufactura de herramientas, armado y utilización de fogones, entre otras. Estas actividades incrementan el porcentaje de MO de la superficie (Stein 1992). En nuestro caso, pretendemos evaluar las variaciones entre capas estratigráficas como un indicador del aporte de material que pudieron haber hecho los humanos al depósito de las cuevas. Estos análisis fueron realizados mediante la técnica de Walckley y Black (1934) en el laboratorio de Sedimentología de la Universidad Nacional de La Pampa.

Por otro lado, se realizó el análisis de proporción de Carbonatos ( \% $\mathrm{CO}_{3}$ ), que son sales presentes en muchos medios naturales. La incorporación de los carbonatos a los suelos y depósitos sedimentarios puede darse por dos vías principales: a través del proceso de carbonatación/ descarbonatación de suelos y por eventos de evaporación de aguas carbonatadas. La carbonatación/ descarbonatación ocurre a partir de la disolución de bicarbonatos solubles y su percolación; luego, cuando las condiciones químicas cambian (disminución de presión de $\mathrm{CO}_{2}$, aumento de $\mathrm{pH}$ ), esos bicarbonatos solubles precipitan y comienzan a formar horizontes cálcicos a una determinada profundidad (son los denominados horizontes $k$, por ejemplo, Bk es un horizonte $\mathrm{B}$ con acumulación de $\mathrm{CaCO}_{3}$ ). La evaluación de los porcentajes de carbonato, permite reconocer procesos edáficos así como también puede ser útil como indicador de climas secos. Los análisis de porcentaje de carbonatos se realizaron en el Laboratorio de Sedimentología de la Facultad de Ciencias Exactas y Naturales de la UNLP, mediante calcímetro digital.

\subsubsection{Información cronológica}

El tratamiento de la información cronológica se realizó a partir de dataciones publicadas, tanto por nuestro grupo de trabajo y en los sitios que nosotros estudiamos, como de sectores adyacentes trabajados por otros equipos de investigación.

El análisis de los fechados radiocarbónicos ha sido ordenado de acuerdo a escalas espaciales de trabajo de menor a mayor con el objetivo de evaluar la información cronológica de nuestra área de estudio y luego compararla a niveles escalares mayores. El objetivo de este abordaje es el de registrar momentos de ocupación y vacíos cronológicos en escalas pequeñas, para luego 
ponerlos a prueba a escalas mayores y así reconocer patrones regionales. Para aportar a una discusión de corte extra regional hemos optado por incluir, en el relevamiento bibliográfico de dataciones, a aquellas provenientes de los sectores de costa y cordillera comprendidos entre los $47^{\circ}$ y $49^{\circ}$ de latitud sur en la provincia de Santa Cruz. Ambos sectores cuentan con una larga tradición de investigaciones en las que se ha generado abundante información cronológica.

Hemos recopilado los fechados radiocarbónicos de sitios arqueológicos estudiados por nuestro equipo de investigación y aquellos publicados en la bibliografía disponible obtenidos en sitios arqueológicos que se ubican entre las latitudes mencionadas. Dentro de la franja latitudinal que constituye la macro-escala, la evidencia fue analizada por separado de acuerdo a una división en tres regiones, concordante con la fisiografía patagónica:

- Sector de Cordillera: Es la franja comprendida entre Bajo Caracoles y el límite con Chile, mientras que los límites norte y sur son los paralelos $47^{\circ}$ y $49^{\circ}$ respectivamente.

- Macizo del Deseado: región comprendida entre los ríos Deseado al norte y Chico al sur, y cuyo límite occidental es el Bajo Caracoles. Hacia el este finaliza a unos $20 \mathrm{~km}$ de la línea de costa actual limitando con la región de Costa.

- Costa: abarca los $20 \mathrm{~km}$ desde la línea alta de mareas hacia el interior del territorio del litoral atlántico patagónico comprendido los $46^{\circ} 30^{\prime}$ de latitud sur, al Norte y la localidad de Bahía Laura al sur, correspondiendo con el área de estudio de la Dra. Alicia Castro (Castro et al. 2003).

Los fechados radiocarbónicos fueron separados por área (Macizo del Deseado, Costa y Cordillera) y por tipo de sitio (Cuevas y aleros, Cielo abierto y Enterratorios) para tener un panorama comparativo dentro de cada región y entre ellas. Con las bases de datos constituidas se procedió a la calibración de las dataciones, para lo cual se utilizó el programa OxCal 4.2 (Bronk Ramsey 2013) y la curva de calibración SHCal 2013 (Hogg et al. 2013). Se tomó la propuesta de metodológica de Rubinos Pérez (2003) de excluir a las dataciones convencionales que tengan errores mayores a 200 años ya que al realizar la calibración y la suma de probabilidades, el fechado abarca lapsos muy grandes haciéndolo inoperante. 
En el marco de esta tesis se obtuvieron tres dataciones radiocarbónicas, dos provenientes del muestreo polínico mencionado previamente en este capítulo y otro obtenido en la base del testigo MLP6, todos ellos dentro del Mallín La Primavera. Las tres dataciones fueron realizadas mediante la técnica Accelerator Mass Spectometry (AMS) en el laboratorio DirectAMS de Seattle, Estados Unidos.

\subsubsection{Cálculo de tasas de depositación}

La acumulación sedimentaria en un sitio arqueológico no es un proceso constante, presenta pulsos o momentos en los que se deposita mayor o menor cantidad de material pudiendo intercalarse con periodos de erosión y/o estabilidad. De esta manera se pueden intercalar momentos de estabilidad y depositación con otros de erosión o falta de depositación, por ejemplo durante un proceso de estabilidad geomorfológica con formación de suelo. El indicador de estas alternancias serán las discontinuidades observadas en el registro sedimentario. Este tipo de dinámica tiene un correlato importante en cuanto registro arqueológico ya que si el registro estratigráfico presenta hiatos, la evidencia cultural presentará de forma discontinua o afectara la resolución temporal de los conjuntos (Farrand 1993).

El cálculo de las tasas de acumulación o depositación sedimentaria permite evaluar la cantidad de sedimento depositado en un determinado periodo de tiempo. Son variables interesantes para el análisis de procesos depositacionales y postdepositacionales, ya que permiten estimar el tiempo involucrado en el proceso de acumulación de la matriz sedimentaria dentro de un sitio arqueológico (Favier Dubois 2001). La velocidad en la depositación influye sobre los procesos de formación de sitio y condicionan la resolución e integridad del registro arqueológico (Binford 1981). Es decir que en situaciones de tasas de acumulación bajas, sería esperable que se dificulte la separación de ocupaciones arqueológicas, lo que si se simplificaría en caso de tener una alta tasa de depositación sedimentaria (Ferring 1986; Waters 1992). Asimismo, un tiempo prolongado de exposición del registro arqueológico a condiciones atmosféricas incrementa las probabilidades de acción de agentes de meteorización reduciendo la integridad del mismo, mientras que tasas de depositación elevadas aíslan a los materiales de la intemperización (Binford 1981; Favier Dubois 2001). En el caso de los análisis tafonómicos de conjuntos zooarqueológicos está ampliamente aceptado el uso 
de los estadios de meteorización planteados por Beherensmeyer (1978) como medida relativa de exposición de los huesos a condiciones atmosféricas. En este sentido, contamos con la información generada por la Dra. Laura Marchionni para su tesis doctoral (Marchionni 2013), que realizó el análisis tafonómico de los sitios Cueva Maripe y AEP-1 de Piedra Museo, así como también de trabajos publicados (Miotti y Marchionni 2011; Marchionni et al. 2012).

Las tasas de depositación se obtienen dividiendo el espesor de sedimento depositado entre dos puntos (en centímetros) por el tiempo involucrado en la depositación (en años). Este método asume que entre los dos puntos la acumulación fue constante. En nuestro caso, adoptamos la propuesta de Stein y colaboradores (2003), que propone dos escalas de análisis: el sitio y la unidad de excavación. En los sitios que analizamos, incluiremos una escala más que es la unidad estratigráfica, que nos permitirá tener una noción de las variaciones en la acumulación sedimentaria en los diferentes sectores de los sitios, como así también en diferentes lapsos temporales.

Para el cálculo de tasas de depositación de un sitio completo o de una capa estratigráfica en los que se cuenta con mas de dos dataciones radiocarbonicas, se utiliza un método simple que consiste en generar un gráfico de distribución que incluye a la profundidad en el eje de las ordenadas y el valor promedio de la datación en el eje de las abscisas. A partir de esta distribución se calculan la ecuación de regresión que describe la relación entre las muestras y el coeficiente de correlación $\left(R^{2}\right)$ describe el grado de ajuste. La pendiente de la ecuación representa la tasa de acumulación en cm/año. En caso de contar sólo con dos fechados se aplica el método que consiste en dividir el espesor depositado por la diferencia en años.

\subsubsection{Los datos tafonómicos como indicadores indirectos de tasas de depositación y procesos postdepositacionales}

Los restos arqueológicos son afectados por múltiples procesos depositacionales y post-depositacionales (Nash y Petraglia 1987). En este sentido, el interés de la tafonomía, radica en entender "los procesos que generan, modifican y destruyen los conjuntos óseos" (O’Connor 2000: 19). Dentro de esta disciplina se han desarrollado diferentes marcos de referencia que permiten evaluar a los agentes involucrados en la formación del registro arqueológico, como la influencia de las condiciones atmosféricas (ej. Estadios de me- 
teorización ósea), modificaciones generadas por las características químicas del depósito (depósitos de carbonatos, depósitos de óxidos manganeso) y otras referidas a aspectos relacionados a la acción de la biota (ej. raíces, marcas de carnívoros) (Behrensmeyer 1978; López González et al. 2006; Lyman 1994; Marchionni 2014).

Los marcos de referencia mencionados son un gran herramienta para utilizar desde un enfoque geoarqueológico, ya que informan sobre diferentes procesos de índole geológica que afectaron específicamente al conjunto óseo. En el caso de los estadios de meteorización (Beherensmeyer 1978), sirven para tener una medida relativa del tiempo que los especímenes óseos estuvieron expuestos a condiciones atmosféricas. En este sentido, las expectativas son que con un enterramiento rápido los estadios de meteorización sean bajos y viceversa. Por otro lado, los depósitos de carbonatos y óxidos de manganeso reconocidos sobre las superficies de los huesos, se dan en situaciones de alternancia de condiciones oxido/reducción entre humedad y sequedad (López Gonzalez et al. 2006). Por último, las marcas de raíces pueden aportar información sobre el desarrollo de vegetación en la superficie que pueden ser utilizados como indicador indirecto de procesos edáficos y desarrollos pedogenéticos.

Desde hace varios años, los estudios tafonómicos han irrumpido en el quehacer arqueológico de manera contundente, llegando a ser muy importantes en cuanto a la construcción del conocimiento arqueológico, principalmente como una parte integral de los estudios zooarqueológicos (Borrero 2011). Acompañando un creciente cúmulo de información zooarqueológica, el análisis tafonómico de restos óseos ha sido ampliamente desarrollado en contextos arqueológicos de la Patagonia tanto en sitios en cuevas como a cielo abierto (Borrero 1989; 2001; Miotti y Marchionni 2011; Bourlot 2010; Marchionni 2013; Marchionni et al. 2012). En nuestra área de estudio, se cuenta con información detallada de las características tafonómicas tanto de Cueva Maripe como de AEP-1 de Piedra Museo, generada por la Dra. Laura Marchionni para su tesis doctoral (Marchionni 2013). Asimismo, se han publicado trabajos al respecto, en algunos de los cuales he colaborado como co-autor (Miotti y Marchionni 2011; Marchionni et al. 2010; 2012). 


\subsubsection{Proxies Ambientales Biológicos}

Si bien consideramos al análisis sedimentológico como un proxy data ambiental, incluimos este apartado para detallar el tratamiento que se dio a los proxies ambientales biológicos que fueron estudiados en el marco de esta tesis: polen y silicofitolitos.

Para llevar a cabo el análisis de polen, se realizó un muestreo específico para este fin utilizando un "barreno ruso" (Russian Peat Corer) que permite extraer muestras sin disturbar. Esta tarea fue realizada en conjunto con el equipo del Laboratorio de Paleoecología y Palinología de la Universidad Nacional de Mar del Plata, dirigido Dra. Virginia Mancini y se obtuvo un perfil de 2,3 $\mathrm{m}$ de potencia en un sector del mallín de muy húmedo a anegado (Mazzoni y Vázquez 2004) ubicado a escasos metros del testigo MLP2 (Figura 5.6). El análisis polínico de este testigo es el primero de una secuencia sedimentaria de mallín dentro del Macizo del Deseado. El objetivo del mismo es ampliar la información polínica disponible para el sector bajo estudio que proviene de AEP-1 (Borromei 2003) y complementarlo con los resultados obtenidos en sitios arqueológicos en cuevas del Macizo del Deseado (Figura 3.3).

Por otro lado, se realizaron análisis de silicofitolitos en el sitio Cueva Maripe y en uno de los testigos recuperados en el Mallín La Primavera (MLP6). Estos estudios fueron realizados por las Dras. Osterrieth y Fernández Honaine del Instituto de Geología de Costas y del Cuaternario de la Universidad Nacional de Mar del Plata, y por la Dra. Georgina Erra de la División Paleobotánica del Museo de Ciencias Naturales de La Plata. Los silicofitolitos son biomineralizaciones de sílice amorfa hidratada ( $\mathrm{SiO} 2 . \mathrm{nH} 2 \mathrm{O})$ formados en espacios inter o intracelulares de tejidos vegetales. Desde el punto de vista taxonómico pueden reconocerse algunos tipos diagnósticos para determinadas familias, como las gramíneas, ciperáceas y palmeras (Twiss et al. 1969). Asimismo, su producción en las plantas es alta, su composición silícea las hace perdurables y poco solubles, por lo que son herramientas muy valiosas para las interpretaciones paleobotánicas, paleoambientales y arqueológicas (Rovner 1971; Alexandre et al. 1997; Barboni et al. 1999; Osterrieth 2000; 2006).

A diferencia del polen que puede ser transportado por el viento a grandes distancias desde su lugar de origen, los fitolitos se depositan en las cercanías del lugar de vida de los vegetales por lo que sus interpretaciones son 
de gran utilidad a escala local y de sitio. Por esta razón, se tomó la decisión metodológica de recuperar tres secuencias de muestras: el Mallín La Primavera mediante barreno helicoidal que servirá de referente natural, y dos secuencias del interior de Cueva Maripe, una secuencia de muestras de sedimento proveniente de Cámara Sur y una secuencia de muestras de estructuras de combustión proveniente de Cámara Norte. En este sentido, el análisis de fitolitos del Mallín La Primavera tuvo como objetivo incluir una línea de evidencia nueva a la reconstrucción paleoambiental y relacionarla con la conformación del depósito de Cueva Maripe. A partir del análisis y comparación de los diferentes muestreos se espera reconocer variaciones espaciotemporales en la estructura florística del sector tanto como respuesta a cambios en el ambiente, así como por el uso que las personas le dieron a los vegetales dentro del sitio. 


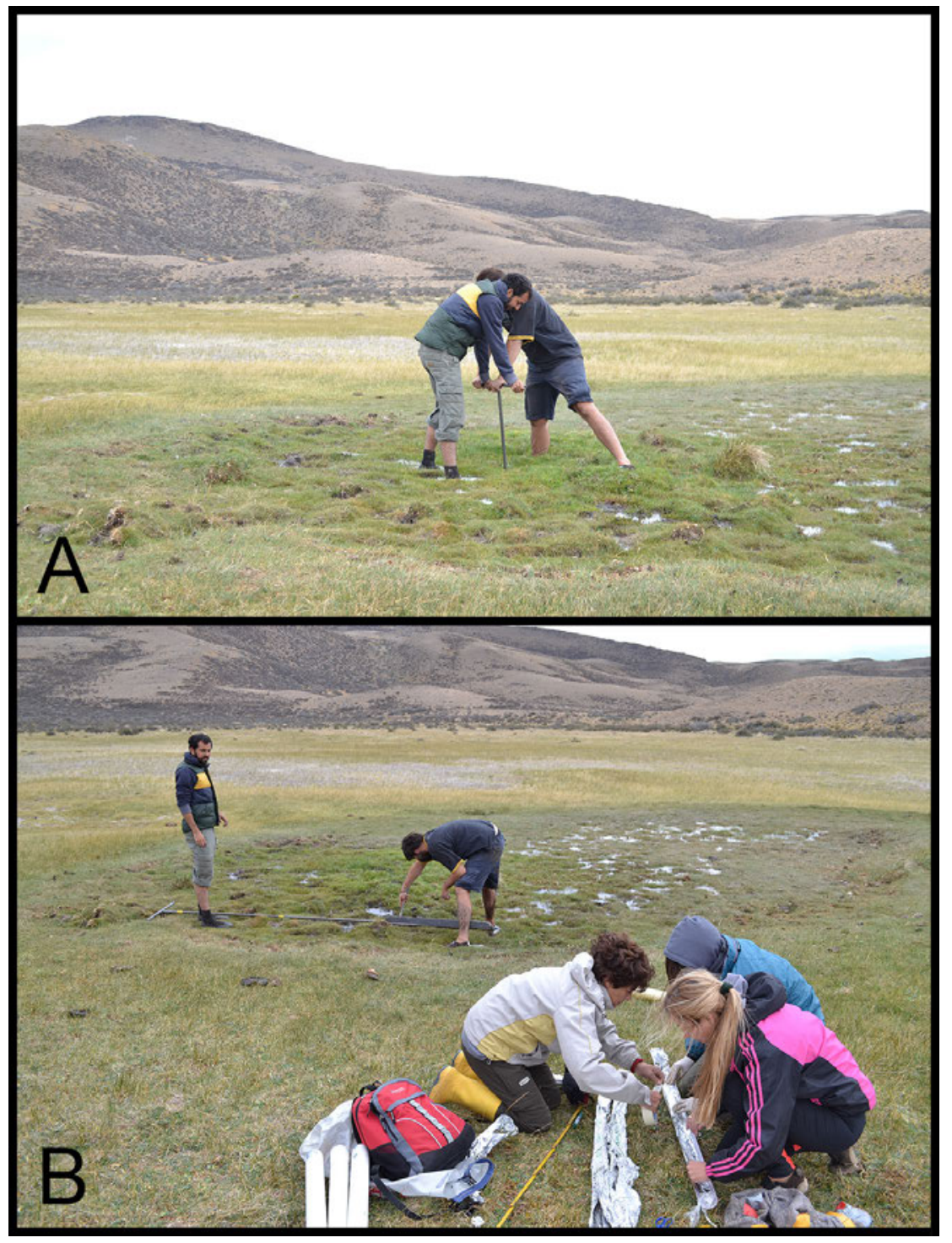

Figura 5.6: A. Extracción de testigos sin disturbar de un sector húmedo del mallín. B. Empaquetamiento de la columna para su transporte al laboratorio. 


\section{Parte II}

\section{Resultados}





\section{Capítulo 6}

\section{Cuenca Alta}

En este capítulo desarrollamos y valoramos los resultados obtenidos en el sector denominado Cuenca Alta y donde se ubica la Cueva Maripe.

En el caso de esta cueva, los resultados se presentan separados en Cámara Norte (CN) y Cámara Sur (CS). Ambos sectores han mostrado diferencias estratigráficas que han dificultado, hasta el momento, la correlación entre ellos (véase Miotti et al. 2014).

En el caso de los materiales arqueológicos recuperados, más allá de las diferencias tecnológicas y funcionales de los conjuntos, la discriminación temporal de los mismos fue más compleja en Cámara Sur, donde la columna estratigrafica se presenta condensada respecto de la de la $\mathrm{CN}$. En el caso de $\mathrm{CN}$, la presencia de una estratigrafía con límites claros entre capas permitió aplicar, en un trabajo previo, una metodología basada en Sistemas de Información Geográfica para agrupar los materiales incluidos en cada capa y analizarlos como subconjuntos (ver Miotti et al. 2014).

Por su parte, en CS, asignar fehacientemente los conjuntos a capas sedimentarias particulares fue una labor más compleja, ya que algunos límites son difusos y no se pudieron seguir en las cuatro paredes de la excavación lo que hizo imposible aplicar la metodología SIG, por lo que se optó por una diferenciación de los conjuntos a partir de niveles artificiales de excavación. La combinación de estas divisiones verticales de los conjuntos de ambas cámaras, fue lo que permitió definir tres componentes arqueológicos como una forma de unificación y relación de los conjuntos de los sectores de Cueva Maripe (Miotti et al. 2014). 


\subsection{Cueva Maripe}

A continuación se describen los resultados obtenidos en los diferentes análisis efectuados. En primer lugar se presentan los datos correspondientes a la roca de caja, ya que la determinación de su litología nos permitirá discriminar los aportes endógenos de los exógenos en cada unidad estratigráfica. Luego se exponen los resultados obtenidos para $\mathrm{CN}$ y finalmente los de CS. La roca de caja fue estudiada a partir de la realización y observación petrográfica de un corte delgado.

\subsubsection{Tipos de aportes sedimentarios: Endógenos y Exógenos}

\section{Aportes endógenos:}

Los clastos de origen Endógeno son los provenientes de la meteorización físico-química de la roca de la cueva. La caída de bloques y detritos más finos del techo de las cuevas es un fenómeno muy frecuente, por lo que el reconocimiento de los materiales que la roca aporta a la estratigrafía interna de la cueva servirá como marco comparativo que permita separar componentes endógenos de exógenos.

La roca de caja fue clasificada mediante petrografía de polarización como una toba lapillítica, la que corresponde a una roca sedimentaria piroclástica, generada por depósitos asociados al vulcanismo explosivo de edad jurásica (Panza 2001). La observación en lupa binocular de diferentes fracciones psefíticas y psamíticas de la muestra molida de la roca de caja nos permitió reconocer que sus componentes son: vidrio volcánico en forma de pómez, trizas vítreas y clastos líticos procedentes de pastas y cuarzo en cristales euhedrales a subhedrales. En tanto, en el estudio de DRX de muestra en polvo de roca total, se reconoció la presencia de cuarzo y zeolita (clinoptilolita), mientras que en el análisis de la fracción arcilla, se reconoció una composición de $90 \%$ caolinita y $10 \%$ illita/esmectita (Figura 6.1)

Por lo tanto, en el caso de Cueva Maripe hemos considerado como de aporte endógeno de cada muestra sedimentaria a los individuos de cuarzo que mantienen cierta forma cristalina, los fragmentos de clastos líticos oscuros angulosos a subangulosos de pómez y de pastas volcánicas. Así como la presencia de clinoptilolita, caolinita e illita/esmectita en los difractogramas 

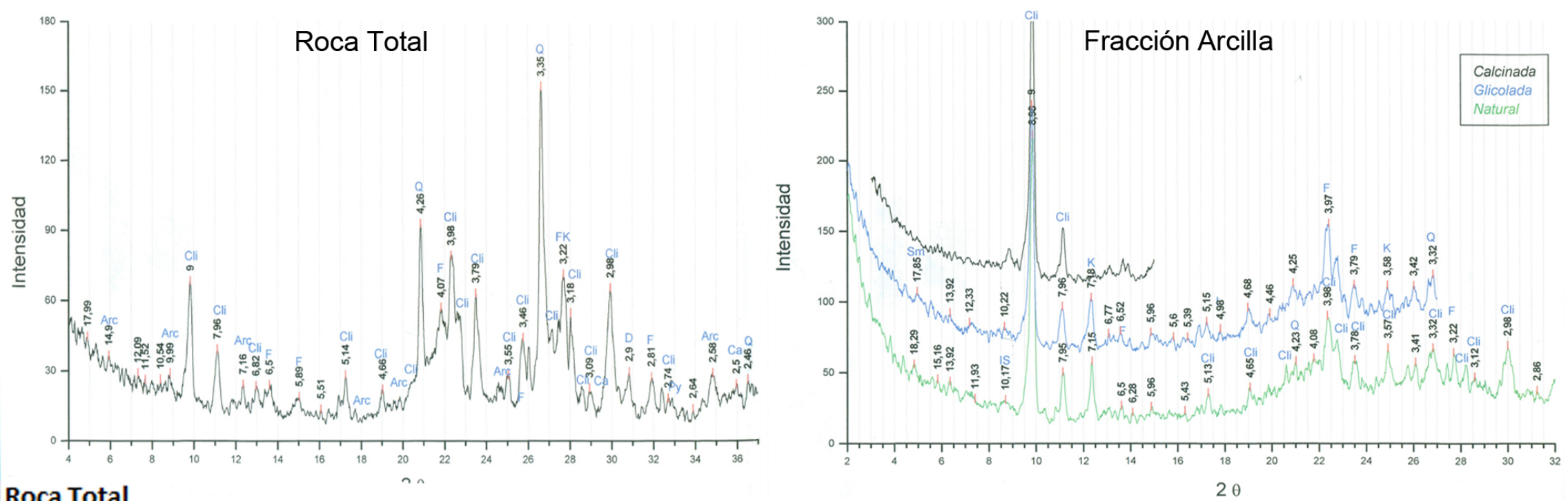

2)

Roca Total

\begin{tabular}{|c|c|c|c|c|c|c|c|c|c|c|c|}
\hline \multirow{2}{*}{ Mineral } & \multirow{2}{*}{ Cuarzo } & \multirow{2}{*}{ Feldespato } & \multirow{2}{*}{ Plagioclasas } & \multirow{2}{*}{ Arcillas } & \multicolumn{3}{|c|}{ Carbonatos } & \multirow{2}{*}{ Zeolitas } & \multirow{2}{*}{ Opalo } & \multirow{2}{*}{ Pirita } & \multirow{2}{*}{ Otros } \\
\hline & & & & & Calcita & Dolomita & Siderita & & & & \\
\hline ounda & Abundante & Escaso & Escaso & Muy Escaso & Trazas & Trazas & $s / d$ & $\begin{array}{c}\text { Abundante } \\
\text { (Clinoptilolita) }\end{array}$ & Escaso & Trazas & \\
\hline
\end{tabular}

\section{Fracción Arcilla}

\begin{tabular}{|l|c|c|c|c|c|c|}
\hline \multirow{2}{*}{ Argilomineral } & \multirow{2}{*}{ Esmectita } & \multirow{2}{*}{ Clorita } & \multicolumn{2}{|c|}{ Interestratificados } & \multirow{2}{*}{ Ilita } & \multirow{2}{*}{ Caolinita } \\
\cline { 4 - 5 } & & & Ilita/Esmectita & Clorita/Esmectita & & \\
\hline Abundancia \% & Trazas & Trazas & 10 & s/d & s/d & 90 \\
\hline
\end{tabular}

Figura 6.1: Resultado de las difractometrías de rayos $\mathrm{X}$ realizadas sobre una muestra de roca de caja. 


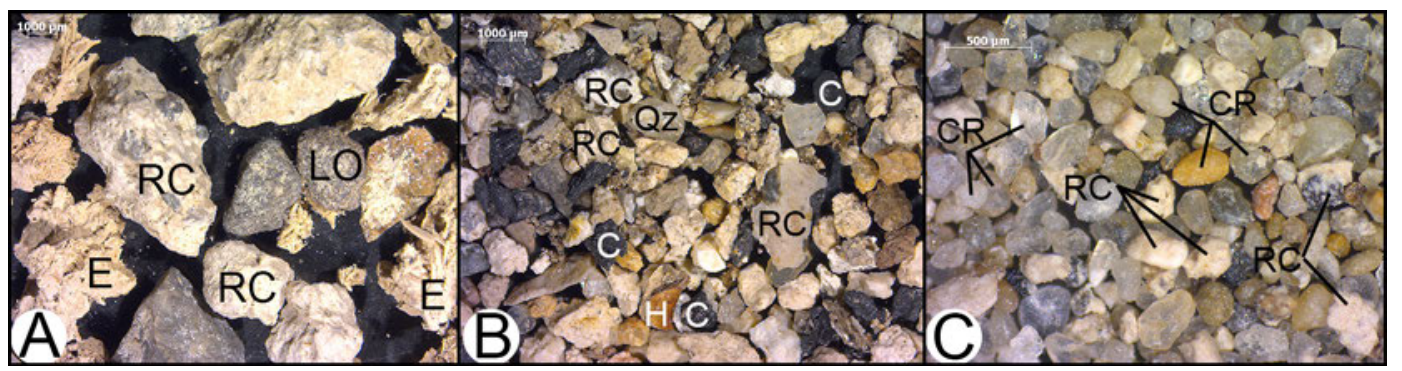

Figura 6.2: Ejemplos de observación y conteo de granos con lupa. A. Capa $3 a$, fracción $-1 \varphi$. B. Capa $4 b$, fracción $1 \varphi$. C. Capa 6 b, fracción $2 \varphi$. Referencias: RC-Roca de Caja; LO - Lítoclasto oscuro; E - Estiércol; Qz - Cuarzo; C Carbón; H - Hueso; CR - Clasto Redondeado.

analizados de las muestras en estratigrafía.

\section{Aportes exógenos:}

Entre los elementos que consideramos de origen Exógeno (ver 5.4.2), que son los provenientes del exterior de la cueva, se incluyeron aquellos introducidos por el accionar de algún agente de transporte.

En el caso de Cueva Maripe, los elementos de aporte Exógeno reconocidos son: estiércol, fibras vegetales, fragmentos de hueso (astillas de huesos grandes y /o huesos de micromamíferos), clastos monominerales (desde blanquecinos, rosados a castaño o gris oscuro) que mostraron un buen a muy buen grado de redondeamiento y carbón (el cual será interpretado como de origen antrópico como se explicó en el Capítulo 5 sección 5.4.2). En la figura 6.2 se ejemplifica la metodología de conteo y casos de diferentes muestras y fracciones vistos en lupa.

\subsubsection{Cámara Norte $(\mathrm{CN})$}

Esta cámara es la más grande del sitio. La superficie excavada en este sector es de $16 \mathrm{~m}^{2}$ correspondiendo a las cuadriculas C5, D5, D6 y P6B, cada una de $2 \times 2 \mathrm{~m}$. Los perfiles utilizados como referente de este sector corresponden a la pared Norte de las cuadriculas C5 y D5, y de la pared Este de D5 (Figura 6.3). En esta cámara la altura de los cortes estratigráficos alcanza los $2 \mathrm{~m}$, lo que representa la mayor potencia reconocida en la cueva hasta el momento. Por otro lado, las características sedimentológicas de la cuadrícula P6B aún se encuentran bajo estudio debido a que no se alcanzó 


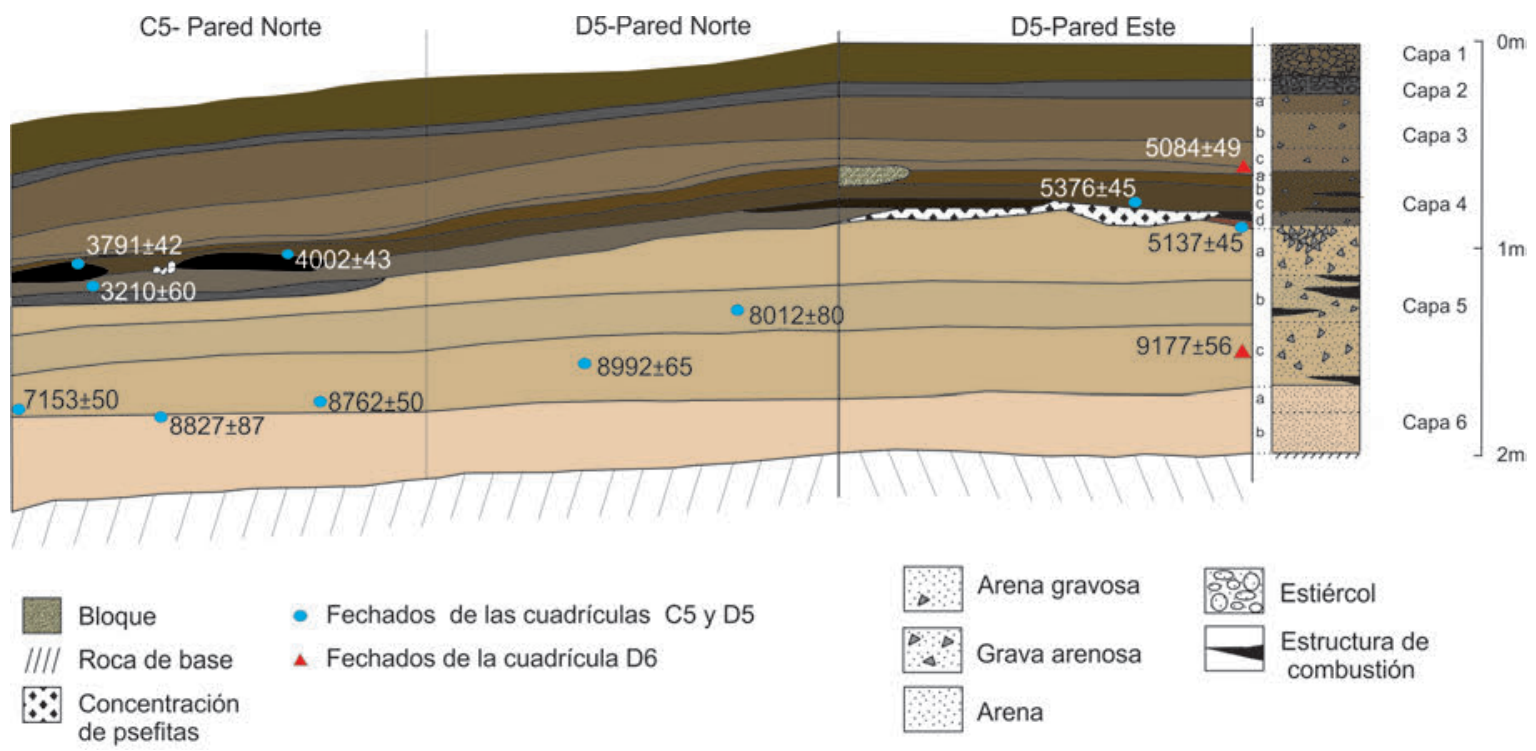

Figura 6.3: Perfil estratigráfico de Cámara Norte.

la roca base en toda su superficie, por lo que nos remitiremos solamente las cuadriculas C5, D5 y D6.

En este sector de la cueva se definieron 6 capas (Rabassa et al. 2007), cada una dividida en subcapas con excepción de las Capas 1 y 2 que corresponden al depósito de estiércol de ganado que conforma la superficie actual del piso de la cueva y a una quemazón previa de dicho estiércol respectivamente.

\subsubsection{Análisis sedimentológico}

Los resultados del análisis textural-granulométrico se resumen en la Tabla 6.1 y se grafican en la Figura 6.5. Por otro lado, los porcentajes de gravaarena-fango se volcaron en el triángulo de clasificación granulométrica de Folk (1954) y se determinaron los tipos texturales dominantes (Figura 6.4). En estos análisis no se incluyeron las capas 1 y 2 compuestas de estiércol de ganado teniendo en cuenta que sabemos su composición, agente de depositación y antigüedad aproximada. Finalmente, los porcentajes individuales de cada fracción fueron volcados en papel probabilístico donde se graficó el diagrama de frecuencia acumulada. La lectura de los diferentes percentiles permitió el cálculo de los coeficientes estadísticos según Folk y Ward (1957) (Tabla 6.1). Cabe destacar que los valores hallados no se utilizaron como indicadores de las condiciones dinámicas del agente de depositación 
por tratarse de un depósito mixto o híbrido. En este sentido, estos depósitos se vinculan a la presencia de dos o más poblaciones clásticas (Blasi et al. 2010).

A partir de los análisis realizados en la estratigrafía de $\mathrm{CN}$, se observa una sección inferior representada por la Capa 6 de $0,5 \mathrm{~m}$ de espesor, compuesta por dos subcapas (6a y 6b). Estos depósitos presentan un arreglo litofacial homogéneo con textura areno-fangosa en su base (6b) de color castaño rosada (5 YR 7/2), mientras que en su techo se reconoció un leve incremento de grava (6a), un cambio de color a castaño claro (10 YR 6/4) (Tabla 6.1) y evidencias de bioturbación por raíces. Como se observa en los histogramas (Figura 6.4), en este caso se trata de muestras unimodales con modas en arena muy fina (6a) y arena fina (6b), con un aporte limo-arcilloso más importante en la superior (6a). El cambio entre las subcapas de la capa 6 es gradual y se diferenciaron en el campo debido principalmente a las evidencias de bioturbación reconocidas en la subcapa 6a y ausentes en la $6 \mathrm{~b}$.

La observación en lupa permitió reconocer que el sedimento que conforma a las muestras está constituido principalmente por clastos redondeados monominerales incoloros translúcidos y clastos líticos opacos con coloraciones rojas, rosas y verdes (ver frecuencias de "Clastos redondeados" en la figura 6.5-A.). ). Estos componentes clásticos se incrementan a medida que disminuye el tamaño de los granos de arena como puede verse en la figura 6.5A.Por su parte, aquellos granos reconocidos en la muestra molida de roca de caja que se observan en las muestras sedimentarias como son los fragmentos de roca de caja (componentes unidos por matriz silícea), los líticos oscuros y cristales de cuarzo euhedrales a subhedrales son mayoritarios en las fracciones psefíticas (mayores a $-1 \varphi$ ) y disminuyen su frecuencia hacia fracciones más finas. En la fracción arcilla de ambas subcapas se reconoció un claro predominio de la esmectita (70\% y $60 \%$ en las capas $6 \mathrm{a}$ y $6 \mathrm{~b}$ respectivamente) por sobre el resto de los argilominerales presentes (Figura 6.5D). Los valores de $\mathrm{MO} \%$ son muy bajos en ambas subcapas $(0,6$ y $0,2 \%)$ como así también los de CaCO3\% $(0,8$ y 0,6).

En la capa 6 (6a y 6b) no se reconocieron restos arqueológicos, lo que evidencia momentos previos a la ocupación humana del sitio.

Se interpreta que la capa 6 está compuesta por un alto porcentaje de material exógeno ( $30 \%$ a $55 \%$ ) sobre la base de una alta presencia de clastos con buen grado de redondeamiento (6.5) distribuciones granulométricas marca- 


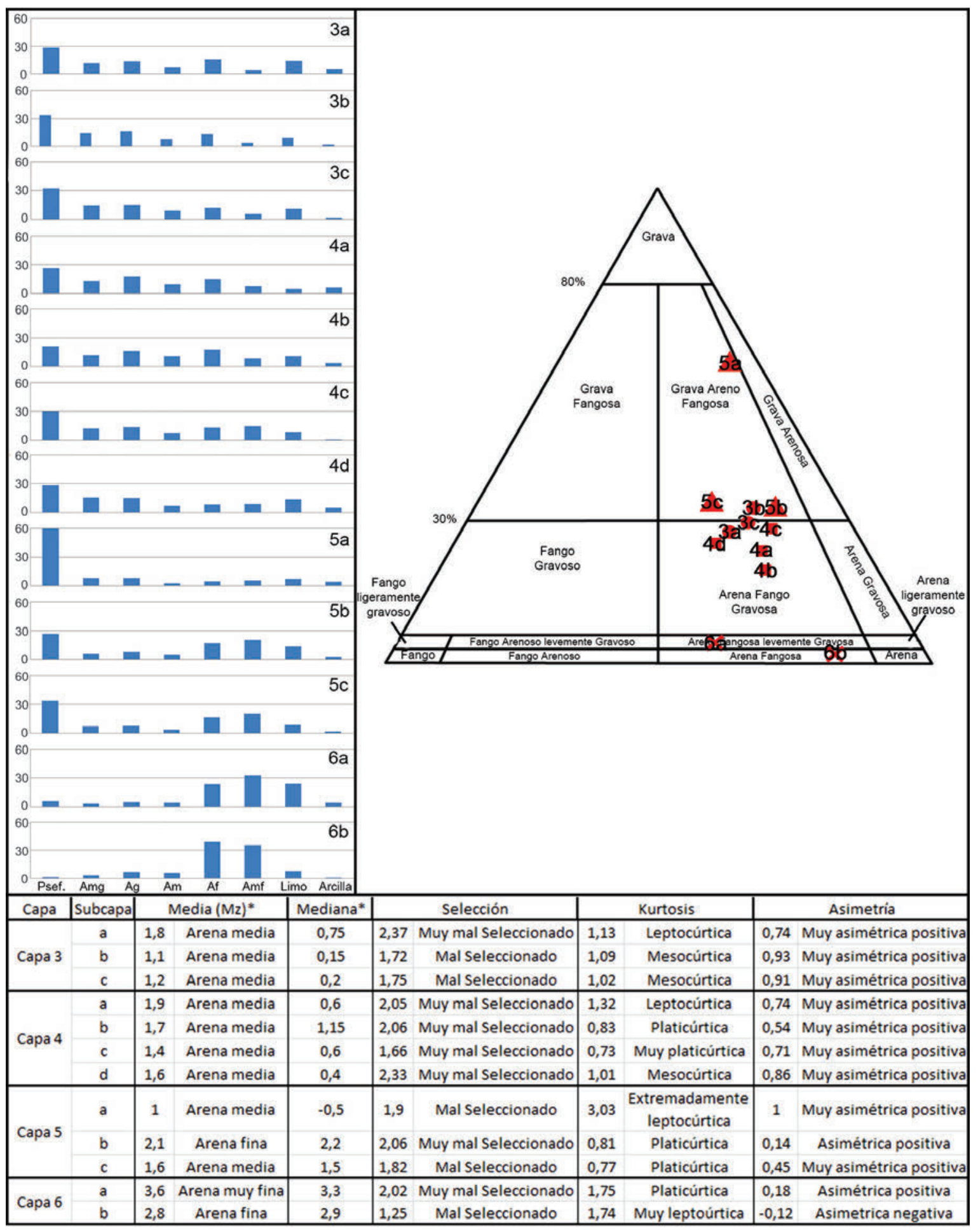

Figura 6.4: Resultados de los análisis textural-granulométricos de Cámara Norte: Histogramas de distribución granulométrica, triangulo de clases texturales y cálculo de coeficientes estadísticos. 


\begin{tabular}{|c|c|c|c|c|c|c|c|c|c|c|c|c|c|}
\hline \multirow[t]{2}{*}{ Capa } & \multirow[t]{2}{*}{ Subcapa } & \multirow{2}{*}{\multicolumn{2}{|c|}{ Color }} & \multicolumn{8}{|c|}{ Granulometría } & \multicolumn{2}{|c|}{ Análisis geoquímicos } \\
\hline & & & & Psef. & Amg & Ag & Am & Af & Amf & Limo & Arcilla & $\%$ MO & $\% \mathrm{CO} 3$ \\
\hline \multirow{3}{*}{3} & a & 5 YR $4 / 2$ & Gris rojo oscuro & 28,5 & 11,5 & 13,6 & 7,3 & 15,8 & 4,2 & 14,2 & 4,9 & 5,03 & 0,2 \\
\hline & $\mathrm{b}$ & 10 YR 5/2 & Castaño Gris & 33,2 & 14,3 & 16,0 & 7,9 & 13,1 & 4,1 & 9,4 & 2,1 & 1,14 & 2 \\
\hline & $\mathrm{c}$ & 7,5 YR $1 / 2$ & Castaño oscuro & 32,1 & 14,5 & 14,9 & 9,0 & 11,7 & 5,5 & 10,7 & 1,5 & 1,94 & 0,3 \\
\hline \multirow{4}{*}{4} & $\mathrm{a}$ & 10 YR 5/1 & Gris & 26,0 & 13,3 & 18,1 & 9,6 & 14,9 & 7,4 & 4,7 & 6,1 & 1,88 & 0,4 \\
\hline & $\mathrm{b}$ & $10 \mathrm{YR} 4 / 2$ & Castaño gris oscuro & 21,0 & 12,0 & 15,7 & 10,8 & 17,2 & 8,6 & 11,0 & 3,7 & 10,06 & 0,4 \\
\hline & $\mathrm{c}$ & 7,5 YR 3/2 & Castaño oscuro & 29,7 & 12,2 & 13,6 & 7,5 & 13,2 & 14,3 & 8,7 & 0,9 & 1,54 & 0,4 \\
\hline & $\mathrm{d}$ & 10 YR 6/1 & Gris & 28,4 & 15,5 & 15,0 & 6,4 & 8,0 & 8,6 & 13,4 & 4,7 & 1,34 & 0,4 \\
\hline \multirow{3}{*}{5} & $\mathrm{a}$ & 5 YR 6/2 & Gris rosado & 59,7 & 7,9 & 7,9 & 2,8 & 4,8 & 5,5 & 7,1 & 4,1 & 0,46 & 0,9 \\
\hline & $\mathrm{b}$ & 7,5 YR 6/2 & Gris rosado & 26,9 & 6,4 & 8,2 & 5,0 & 16,9 & 20,5 & 13,3 & 2,8 & 0,74 & 1,4 \\
\hline & c & 5 YR 6/3 & Gris rosado & 33,8 & 7,3 & 7,9 & 3,9 & 16,3 & 20,3 & 8,6 & 2,0 & 0,47 & 0,7 \\
\hline \multirow{2}{*}{6} & $\mathrm{a}$ & 10 YR 6/4 & Castaño claro & 5,4 & 3,1 & 4,6 & 3,9 & 23,1 & 32,3 & 23,5 & 4,1 & 0,6 & 0,6 \\
\hline & $\mathrm{b}$ & 5 YR 7/2 & Gris rosado & 1,5 & 3,1 & 6,6 & 5,6 & 38,7 & 35,7 & 7,9 & 0,9 & 0,2 & 0,8 \\
\hline
\end{tabular}

Tabla 6.1: Resultados del análisis sedimentológico de Cámara Norte de Cueva Maripe. Características de color, granulometrías y de porcentajes de materia orgánica y carbonatos de calcio. Referencias: Psef.: psefitas, Amg: Arena muy gruesa, Ag: Arena gruesa, Am: Arena mediana, Af: Arena fina, Amf: Arena muy fina. 

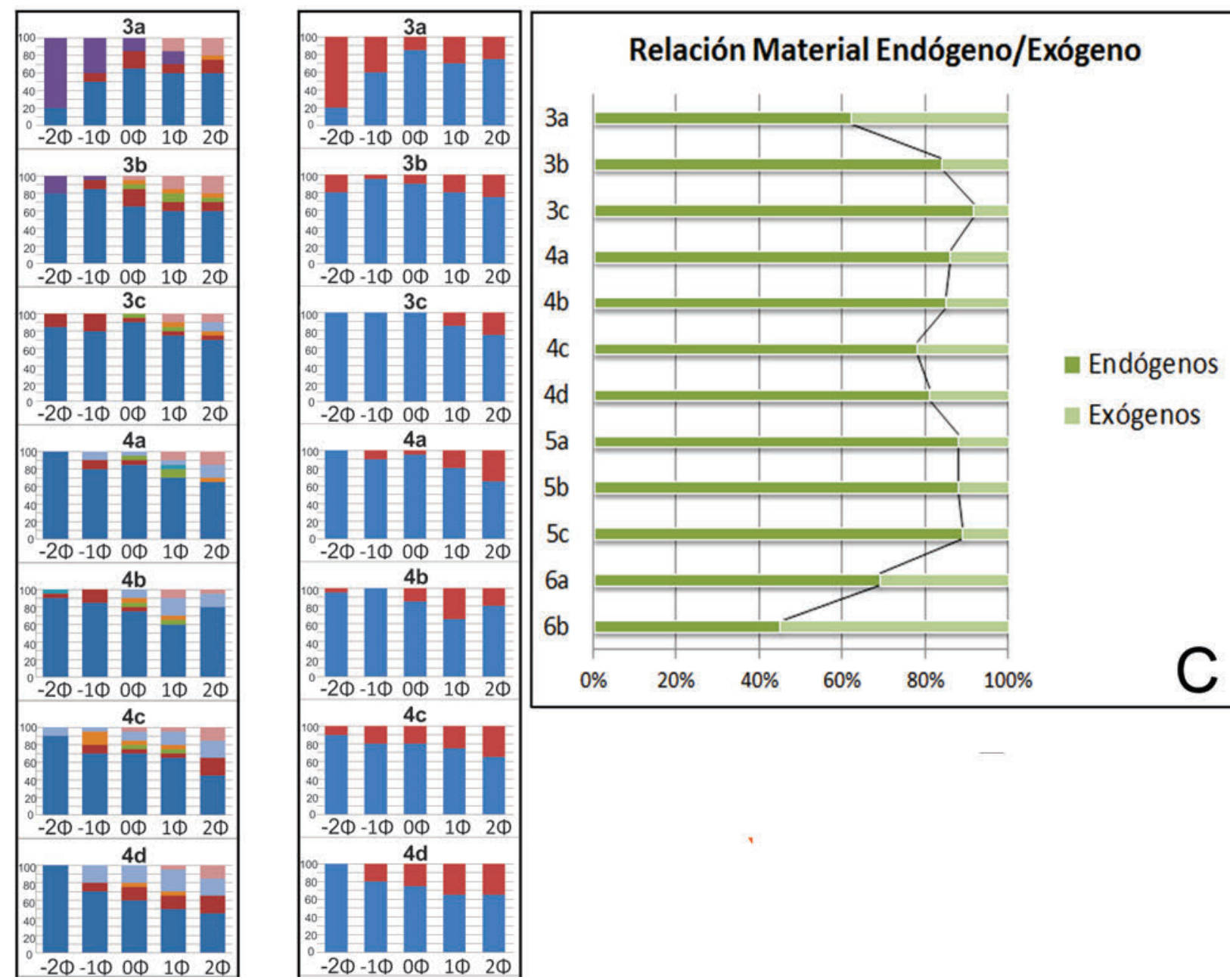

Figura 6.5: Resultados de los análisis de composición sedimentaria de Cámara Norte. A) Porcentajes de componentes reconocidos en las fracciones grava y arena a partir de conteo con lupa binocular. B) Relación de sedimento exógeno y endógeno de cada fracción. C) Relación entre sedimento exógeno y endógeno de la muestra total a partir de la ponderación de los porcentajes de A. D) Composición argilomineral de la fracción arcilla de cada muestra. (Continúa en la siguiente página) 


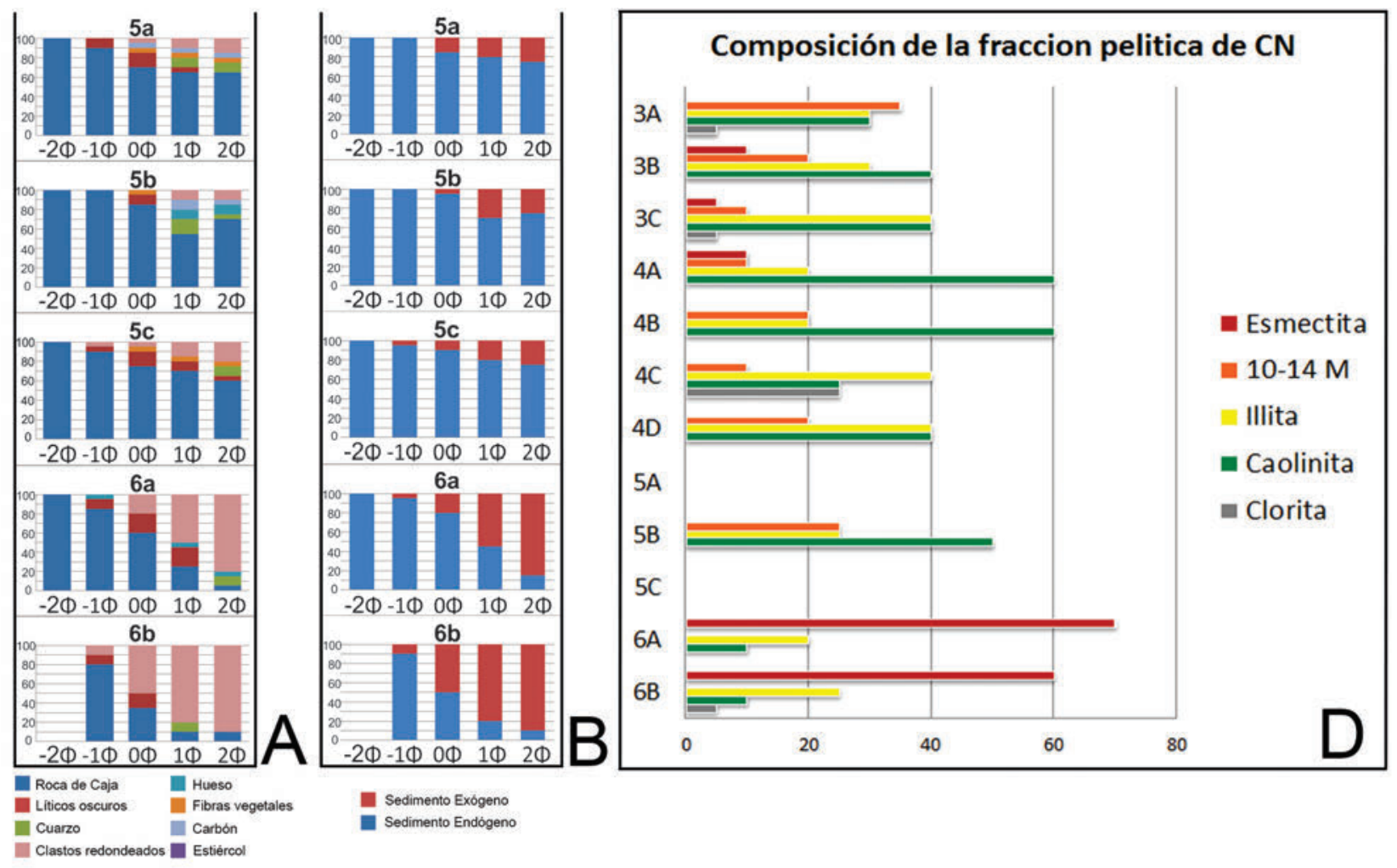

Figura 6.5: continuación.

damente unimodales (si bien se define como "mal seleccionada" presenta el valor mejor de mejor selección de todo perfil, ver Fig. 6.4), y además, se identificó que la esmectita es el argilomineral que presenta mayor frecuencia dentro de la fracción arcilla de esta capa y que no está presente en la roca de caja.

El depósito suprayacente conforma la Capa 5, la cual fue dividida en tres subcapas $(5 \mathrm{a}, 5 \mathrm{~b}$ y $5 \mathrm{c})$ y apoya en contacto claro sobre la Capa 6. La capa 5 marca el comienzo de la ocupación arqueológica de la CN.

Se trata de un depósito de color gris rosado (Tabla 6.1) de textura gravaarena-fangosa donde las subcapas inferiores ( 5 b y $5 \mathrm{c}$ ) presentan una distribución granulométrica bimodal, con la moda principal en la fracción psefítica, mientras que la moda secundaria se ubica en la arena muy fina (Figura 6.4). Este depósito psefítico aparece en el perfil en forma de acumulaciones de geometría lenticular, observándose una textura clasto sostén y presencia de carbones intercalados (Figura 6.6)

Se trata de un depósito de grava-arena-fangosa donde las subcapas inferiores ( 5 b y $5 c$ ) presentan una distribución granulométrica bimodal, con la moda principal en la fracción psefítica, mientras que la moda subordina- 
da (secundaria) se ubica en la arena muy fina (Figura 6.5). Por su parte, la distribución de la subcapa 5 a es unimodal con un alto porcentaje de psefitas (59,7 \%). Este depósito psefítico aparece en el perfil en forma de acumulaciones de geometría lenticular, con carencia de matriz fina observándose una textura clasto sostén y presencia de carbones intercalados, lo que estaría evidenciando lavado de matriz fina causado por la presencia de agua en este momento (Figura 6.6) (Fernández 2013:137; Rabassa et al. 2007). La proporción de grava de la subcapa 5a es la mayor de todo el sitio lo que genera una separación a nivel textural de esta muestra con respecto al resto del depósito (Figura 6.4).

El depósito de la Capa 5 está constituido por un alto contenido en clastos angulosos a subangulosos líticos opácos y cristaloclastos de cuarzo propios de la roca de caja. En menor proporción se observan clastos monominerales translúcidos bien redondeados y fragmentos de carbón en menor proporción (Figura 6.5). La fracción arcilla muestra una composición principalmente caolinítica con presencia en segundo orden de illíta e interestratificados (Figura 6.5D). En cuanto al MO \% en los tres niveles (5a, 5b y 5c) los valores son bajos, quedando por debajo del $1 \%$ (Tabla 6.1).

El material endógeno es el componente mayoritario de las fracciones grava y arena de toda la capa 5 (de $85 \%$ a 90\%), marcando una diferencia clara con la capa 6 . Por su parte el material exógeno está compuesto por clastos redondeados que habrían ingresado desde el exterior por el agente eólico y por carbón el cual fue transportado por el hombre (Figura 6.5). Los argilominerales reconocidos por DRX en la fracción arcilla (Figura 6.5D) muestran predominancia de caolinita (50\%), illita (25\%) y 10-14 M (25\%). Teniendo en cuenta estos valores podemos observar que hay una alta representación de argilominerales procedentes de la roca de caja. Asimismo, los niveles de $\mathrm{MO} \%$ de este depósito son bajos, quedando por debajo del $1 \%$ (Tabla 6.1).

Las seis dataciones realizadas en la Capa 5 (Tabla 4.1) ubican cronológicamente este depósito entre $9177 \pm 56$ y $7153 \pm 50$ años ${ }^{14} \mathrm{C}$ AP $(10496-7858$ cal.AP) (Figura 6.7). De esta manera, teniendo en cuenta la división del Holoceno planteada en el capítulo Marco Teórico Metodológico, la Capa 5 corresponde al Holoceno temprano y el inicio del Holoceno medio.

La Capa 4 fue dividida en cuatro subcapas (4a, 4b, 4c y 4d) que presentaron una textura areno-fango-gravosa y se caracterizaron, a simple vista, por 


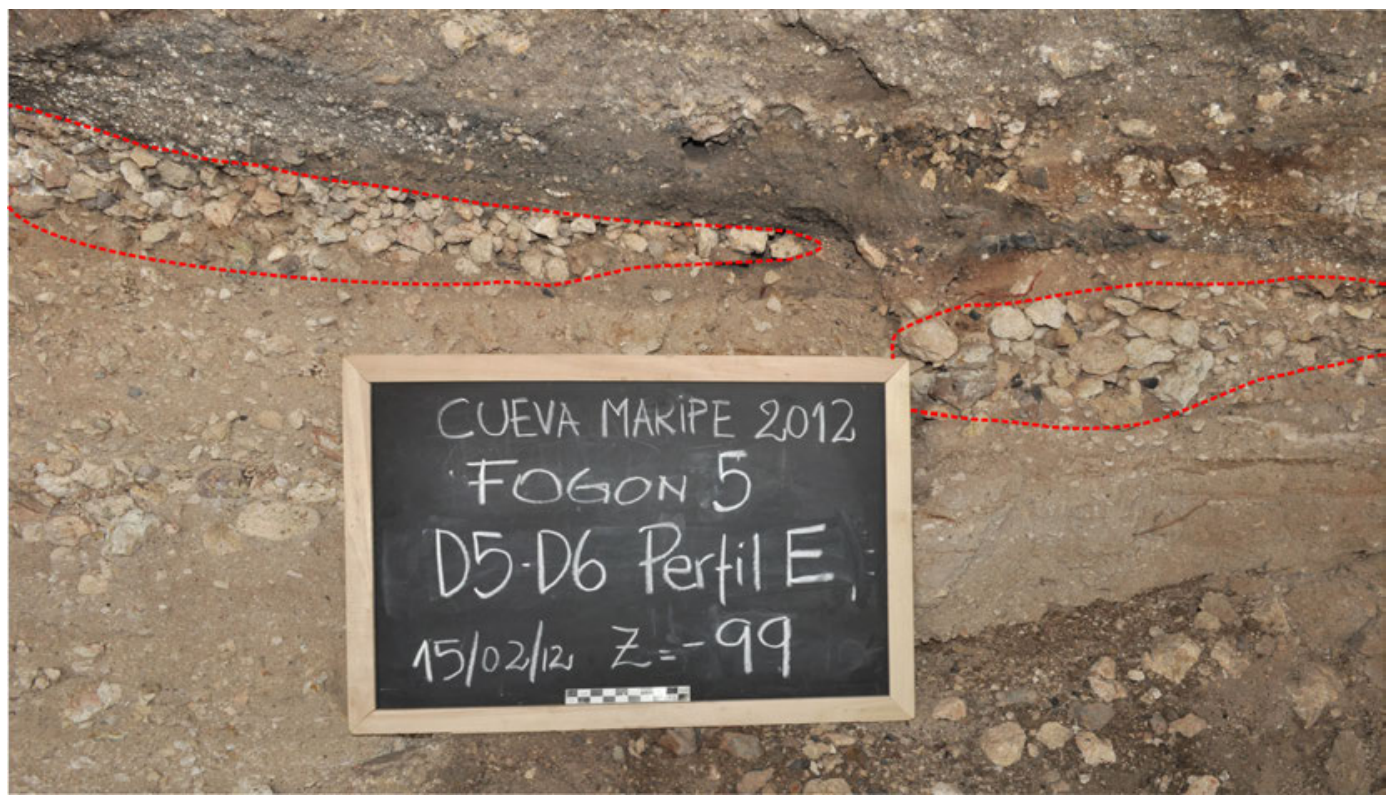

Figura 6.6: Detalle de acumulaciones lentiformes de grava clasto sostén incluidas en la Capa 5a.

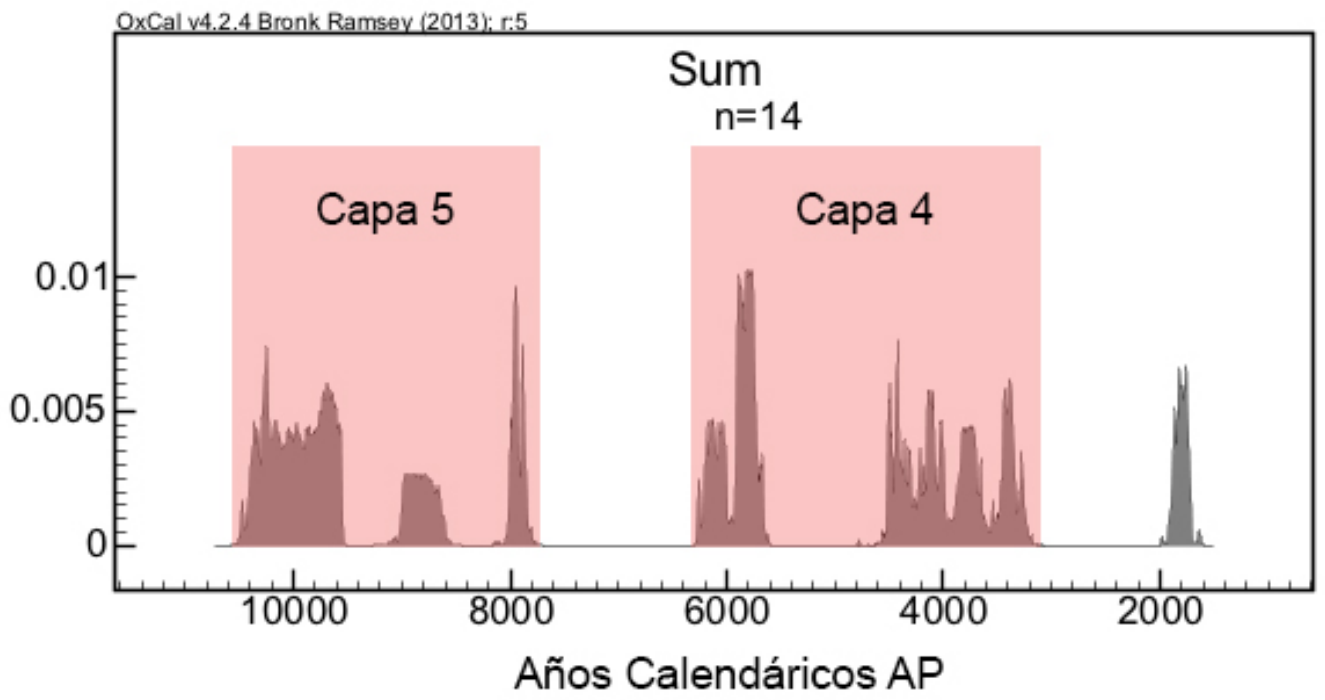

Figura 6.7: Suma de probabilidades de las dataciones radiocarbónicas obtenidas en CS. 
su coloración castaña oscura a gris que la diferencia del resto de la estratigrafía (Tabla 6.1). Las cuatro subcapas presentan distribuciones similares con la moda en la fracción psefítica y tamaño medio de grano en arena media (Figura 6.1). Las subcapas 4c y 4d presentan sección lenticular y un alto contenido de carbón que permite particularizarlas. Dentro de la Capa 4 se han reconocido al menos cinco estructuras de fogón.

La composición sedimentaria de capa 4 presenta como componente principal de la fracción psefítica y arenosa gruesa a clastos angulosos de roca de caja (clastos líticos opacos y oscuros y cristales de cuarzo euhedrales y subhedrales que la componen) (Figura 6.5 B y C). El material exógeno está representado por clastos redondeados, carbón y fibras vegetales (Figura 6.5 A).

Dentro de esta capa se pudo reconocer el aporte exógeno en su formación el cual está constituido en las subcapas $4 \mathrm{c}$ y $4 \mathrm{~d}$ por un porcentaje de material de origen antrópico (carbón) que alcanza entre 10-15\% (Figura 6.5) y por una frecuencia menor de clastos redondeados (Figura 6.5 A). Asimismo, si bien la subcapa $4 \mathrm{~b}$ el porcentaje de carbón es menor que las subcapas $4 \mathrm{c}$ y $4 \mathrm{~d}$, presenta el porcentaje más alto de materia orgánica con un 10,06\%, mientras que el resto de capa 4 presenta valores entre 1,3 y 1,8\% (Tabla 6.1). Estos datos permiten reconocer en este depósito la mayor señal antrópica de $\mathrm{CN}$ a nivel sedimentario.

El incremento de material exógeno reconocido para la Capa 4, tiene una impronta humana en su formación dado que en las subcapas 4c y 4d el porcentaje de material exógeno alcanza un $20 \%$ donde el material de origen antrópico (carbón) alcanza entre 10-15\% (Figura 6.5). Asimismo, si bien la subcapa $4 \mathrm{~b}$ presenta valores menores de porcentaje de carbón y material exógeno en general que $4 c$ y $4 d$, presenta el porcentaje más alto de materia orgánica con un 10,06 \% mientras que el resto de capa 4 presenta valores entre 1,3 y 1,8\% (Tabla 6.1). Estos datos permiten reconocer en este depósito la mayor señal antrópica de $\mathrm{CN}$ a nivel sedimentario.

Las dataciones radiocarbónicas de este depósito presentan valores entre $5376 \pm 45$ y $3210 \pm 60$ años ${ }^{14}$ C AP (6284-3272 años cal. AP) (Figura 6.7), ubicando al depósito en el Holoceno medio y parte del tardío.

La última capa con contenido arqueológico depositada en la CN es la Capa 3, constituida por 3 subcapas areno-fango-gravosas. Presentan variación de color, desde un gris rojo oscuro (30/5 YR 4/2) en su techo, resultado del 
contacto con la quemazón de estiércol que conforma la Capa 2, hacia un castaño oscuro en su base $\left(7,5 \mathrm{YR} \frac{1}{1 / 2}\right)$. Las distribuciones granulométricas son similares a las observadas en capa 4 , con su moda principal en la fracción psefítica y tamaño medio de grano en arena media (Figura 6.4).

En cuanto a la composición de las psefitas de capa 3 se puede observar un alto aporte de estiércol en esta fracción en especial en la subcapa $3 a$ que es la superior y se encuentra en contacto con la capa 2 compuesta por estiércol. El aporte de estiércol disminuye hacia la parte inferior de la capa 3 (subcapas 3 b y $3 c$ ) a medida que toman relevancia los clastos provenientes de la roca de caja y sus componentes (líticos oscuros y cristales de cuarzo euhedrales a subhedrales) (Figura 6.5 A). En la fracción arena de esta capa, el material proveniente del exterior de la cueva está representado por fibras vegetales, clastos redondeados y fragmentos de hueso, los cuales dependiendo la fracción observada, oscilan entre un 10 y $30 \%$ de cada fracción (Figura 6.5 B). Por su parte, los argilominerales de las muestras de capa 3 presentan valores altos de caolinita e illita en las tres muestras mientras que los minerales interestratificados 10-14 M son los más abundantes en la subcapa 3a y disminuyen hacia la base de la capa (Figura 6.5 D).

Al clasificar los componentes de la capa 3 de acuerdo a su origen (endógenos o exógenos) nos encontramos por un lado con aquellos ya mencionados que se depositan por caída directa a partir de la meteorización de la roca de caja, y que hemos identificado previamente en la muestra molida de roca de caja (pómez, trizas vítreas, clastos líticos volcánicos procedentes de pastas y cuarzo en cristales euhedrales a subhedrales). Entonces los materiales exógenos observados están constituidos por: estiércol que ha sido ingresado por animales cuando la cueva fue utilizada como un corral de ganado, fibras vegetales que pudieron ingresar transportadas por viento, por las personas que habitaron el sitio o ser resultado de la desagregación de estiércol y, por último, el carbón, el cual como hemos mencionado habría sido resultado del transporte humano de leña para utilizarlo como combustible.

En este contexto, las arenas de capa 3 muestran un incremento de material exógeno de base a techo donde la subcapa $3 c$ presenta menos de un $10 \%$ de material exógeno, hasta casi un $40 \%$ en la subcapa 3a (Figura 6.5 D). Esa proporción de material exógeno está conformada en el caso de $3 a$ principalmente por estiércol, que es más notorio en las fracciones gruesas, y por sedimento de origen eólico y fibras vegetales (que en este caso pue- 
den ser producto de la disgregación del estiércol) en las fracciones arenosas más finas. La capa $3 \mathrm{~b}$ mantiene la frecuencia de clastos redondeados de origen externo reconocido en la subcapa 3a, aunque disminuye notoriamente el aporte de representado por estiércol. Por otro lado, la subcapa $3 \mathrm{c}$ no muestra evidencias de estiércol, por lo que el aporte exógeno queda principalmente representado por clastos redondeados y el carbón y, las fibras vegetales en segundo lugar. En este la subcapa 3c, la suma de los componentes exógenos no alcanza al $10 \%$ del total de la muestra. Con respecto al porcentaje de $\mathrm{MO}$, el valor más alto es de la subcapa 3 a con un 5,03\%, mientras que el valor de la subcapa $3 b(1,14 \%)$ es menor que la de la 3c (1,94\%) (Tabla 6.1). Dentro de la subcapa 3 a se observaron restos de estiércol de oveja los cuales disminuyen notablemente en la subcapa $3 b$ y desaparecen en la 3c (Figura $6.5 \mathrm{D})$.

En este depósito no se realizaron dataciones radiocarbónicas, sin embargo, en otro sector de $\mathrm{CN}$ (cuadrícula P6B), se realizaron dos dataciones de las cuales una se ubicó en $1907 \pm 48$ años ${ }^{14} \mathrm{C}$ AP (Tabla 4.1). Esto permite insinuar que las ocupaciones posteriores a las de Capa 4 incluidas en la Capa 3 pertenecen al Holoceno tardío (véase Miotti et al. 2014).

La columna estratigráfica culmina con un depósito de estiércol diferenciado en dos capas: la Capa 2 que representa una quemazón de estiércol que se extendió en gran parte de la cueva y que habría sido generada por quienes habitaron la cueva en el siglo XX para limpieza de la misma. La Capa 1 que corresponde a estiércol sin quemar.

\subsubsection{Cálculo de tasas de acumulación sedimentaria (TAS)}

Con el fin de evaluar las relaciones entre eventos de ocupación, sus cronologías y los ritmos de formación de la matriz sedimentaria de la $\mathrm{CN}$ de Cueva Maripe se calcularon las tasas de acumulación sedimentaria. Para realizar dicho cálculo se tomaron como base todos los fechados publicados (ver Tabla 4.1). En este caso no se tuvo consideración sobre la unidad de excavación, ni sobre la ubicación estratigráfica de los mismos, ya que el objetivo fue calcular una tasa promedio para toda la cámara. La pendiente de la ecuación, que representa la tasa de acumulación en cm/año, muestra un valor de 0,0117 cm/año (1,17 cm/100 años) (Figura 6.8). Por su parte, el coeficiente de correlación que permite evaluar el grado de ajuste entre las variables (R2), muestra un valor bajo positivo. Según Stein y colaboradores 


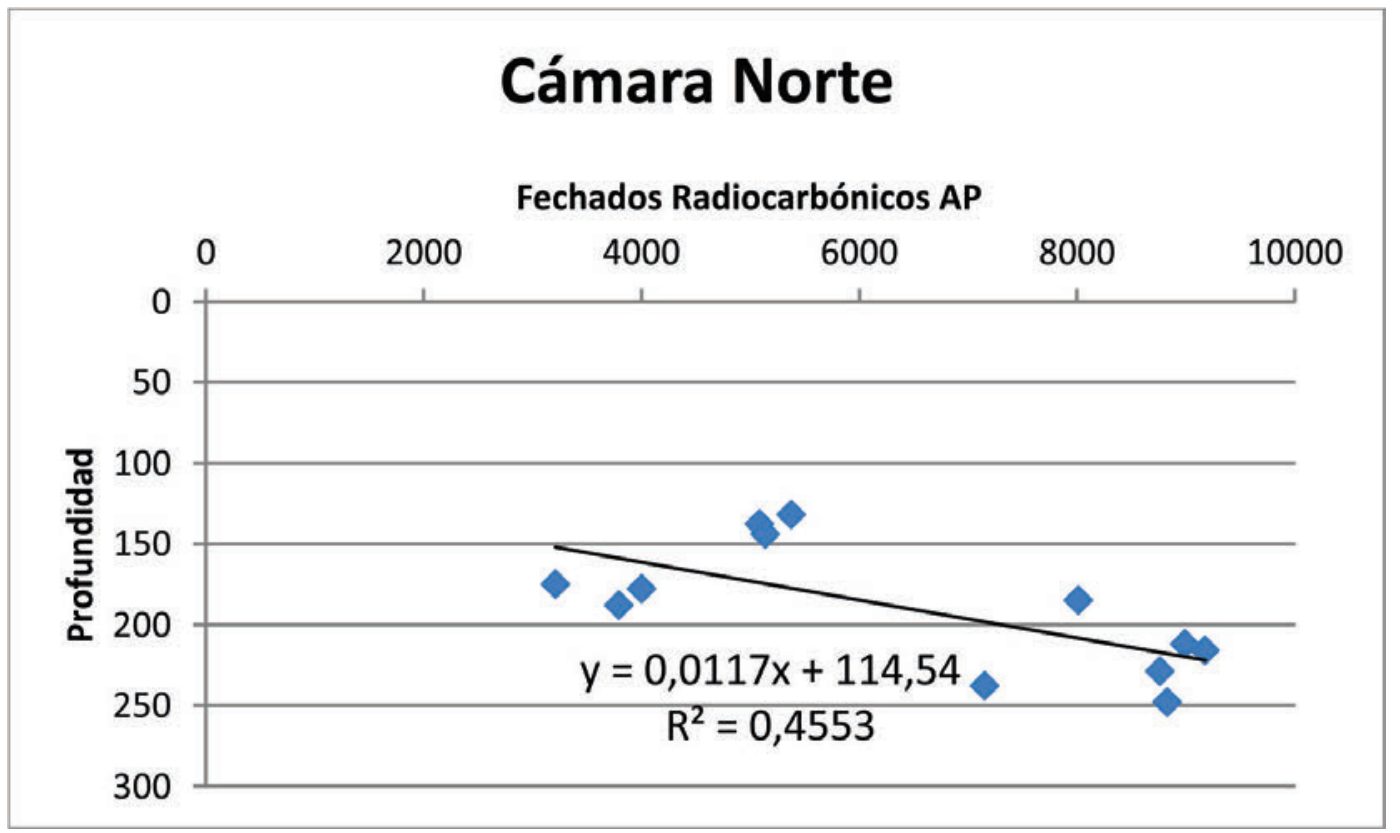

Figura 6.8: Distribución de todos los fechados y cálculo de tasa de acumulación general de la Cámara Norte.

(2003), un R2 bajo da cuenta de tasas de acumulación variables a lo largo de la secuencia.

Pare evaluar la variabilidad en la depositación dentro de CN, hemos analizado las tasas de acumulación de cada unidad de excavación (cuadrícula) por separado mediante dos vías: la ecuación de regresión (método aplicado para todo el sector en figura 6.8) (Stein et al. 2003) y por el método de parejas de fechados (Ferring 1986). Este segundo método nos permite evaluar la variación en la depositación para periodos acotados de tiempo. Como se puede observar en la figura 6.9, las tasas de acumulación de cada cuadricula muestran valores diferentes.

Las tres cuadriculas muestran valores de R2 cercanos a 1 (en el caso de la cuadricula D6 sólo se cuenta con 2 fechados por lo que el valor es 1), por lo que al reducir la escala disminuye la variabilidad de las tasas de depositación. En el caso de C5, que es la que tiene mayor cantidad de fechados $(n=6)$, la TAS general de la cuadricula muestra un valor de $0,0120 \mathrm{~cm} /$ año $(1,2 \mathrm{~cm} / 100$ años), mientras que los valores calculados a partir de pares dan cuenta de una baja depositación entre $8827 \pm 87$ y $7153 \pm 50$ años ${ }^{14} \mathrm{C} \mathrm{AP}$, mientras que es mucho mayor entre $7153 \pm 50$ y $3791 \pm 42$ años ${ }^{14} \mathrm{C}$ AP. Estos valores contrastan con los calculados en la cuadricula D5 donde la tasa general de la unidad alcanza los 0,0189 cm/año (1,89 cm/100años), y las TAS parciales 
calculadas por pares muestran que entre $8992 \pm 65$ y $8012 \pm 80$ años ${ }^{14} \mathrm{C} \mathrm{AP}$ la depositación fue la más rápida de este sector de la cueva $(2,755 \mathrm{~cm} / 100$ años) y, entre $8012 \pm 80$ y $5376 \pm 45$ años ${ }^{14} \mathrm{C}$ AP fue más lenta aunque se mantuvo en valores altos para los calculados en CN (2,011 cm/100 años) (Figura 6.9).

Por último, los dos fechados obtenidos en D6 abarcan el lapso comprendido entre $9177 \pm 56$ y $5084 \pm 49$ años ${ }^{14} \mathrm{C}$ AP para el cual se calculó una TAS de 1,91 cm/100años, similar a la TAS de D5.

\subsubsection{Valoración de los resultados de $\mathrm{CN}$}

Como síntesis podemos decir que en términos generales, los resultados obtenidos mediante observación bajo lupa muestran una predominancia de material endógeno, tanto en la fracción grava como en la de arena. Como excepción a esta tendencia general se encuentra la fracción grava de la subcapa 3a que presenta un alto aporte de estiércol y la fracción arena de la capa 6 (6a y 6b) en la cual el mayor aporte es de clastos redondeados. Sin embargo, al contemplar todas las fracciones juntas (Fig. 6.5 B) solo en el caso de la subcapa 6a los granos provenientes del techo de la cueva son superados por aquellos de un origen exógeno. En el caso de la grava, la roca de caja es el componente casi exclusivo de la fracción, mientras que en las arenas el material exógeno adquiere mayor protagonismo pero sigue teniendo una frecuencia subordinada con respecto al material endógeno. En la CN pudimos reconocer tres momentos con incremento de material exógeno (aparte del depósito de estiércol de ganado): el primero en la Capa 6, el siguiente en las Capas 4c y 4d, y el último en la Capa 3a.

De acuerdo al ordenamiento de las muestras dentro del triángulo de clasificación granulométrica se observó la discriminación de tres áreas de agrupamientos de tipos texturales a lo largo de la estratigrafía (Figura 6.4). El primer agrupamiento corresponde a la arena y arena fangosa de la Capa 6 de génesis predominantemente eólica, y de depositación previa a los ca. $9200{ }^{14} \mathrm{C}$ años AP. La bioturbación reconocida en el techo de esta capa, sumada a la información diatomológica que muestra especies asociadas a vegetación palustre (Fernández 2013) aportan evidencia que permite plantear un incremento en la humedad de $\mathrm{CN}$ que indica la presencia de agua y el desarrollo de vegetación en la cueva antes de la llegada de los primeros humanos al sitio. El segundo agrupamiento corresponde a las arenas fango 


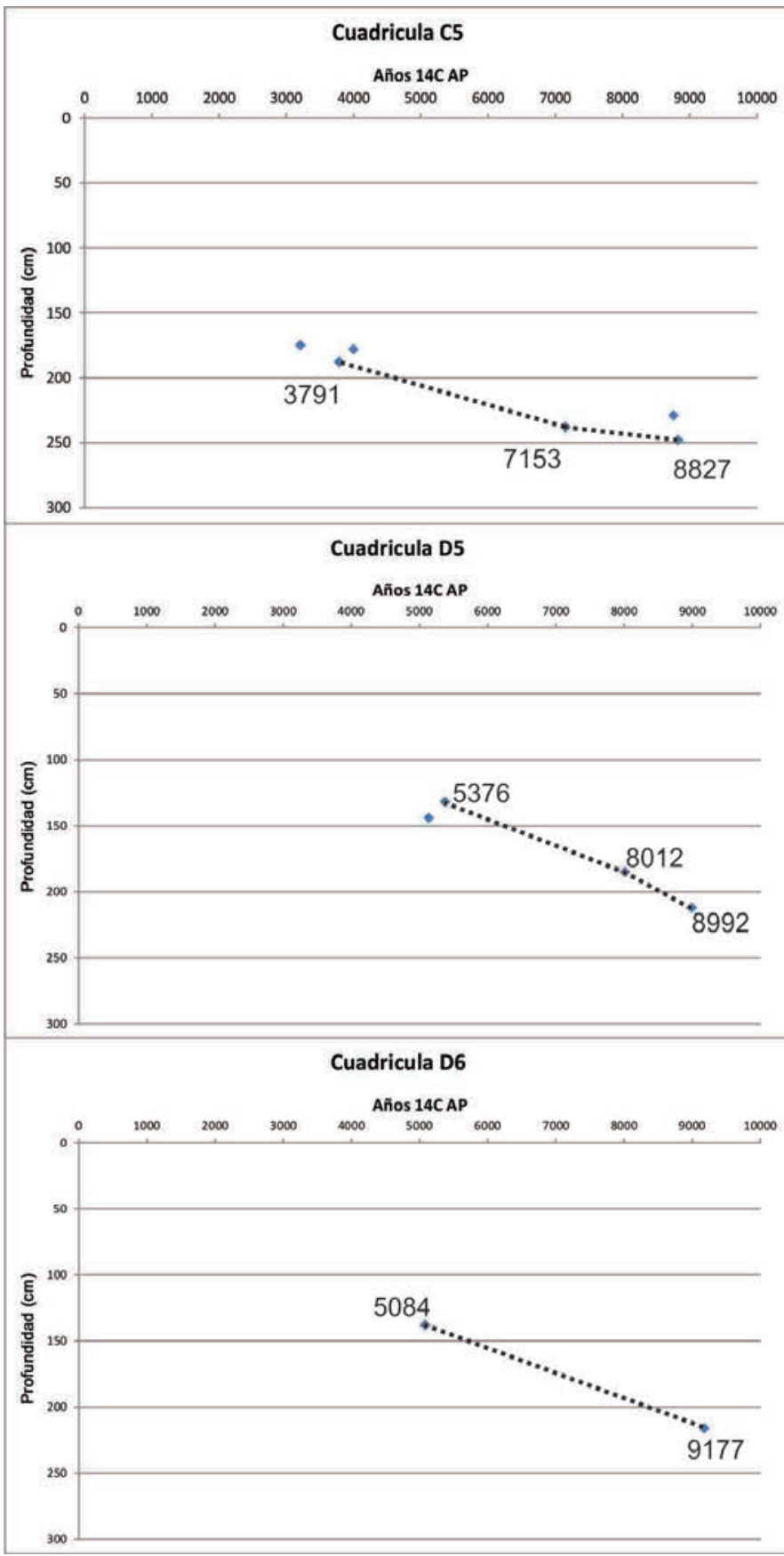

\begin{tabular}{|c|c|c|c|}
\hline Cuadricula & Fechado 14C & Profundidad & $\begin{array}{c}\text { Tasa de } \\
\text { acumulación } \\
\text { (cm/100 años) }\end{array}$ \\
\hline C5 & 3791 & 188 & 1,487 \\
\hline C5 & 7153 & 238 & 7153 \\
8827 & 238 & 0,597 \\
\hline
\end{tabular}

$y=0,0120 x+138,01 R^{2}=0,9052$

\begin{tabular}{|c|c|c|c|}
\hline Cuadricula & Fechado 14C & Profundidad & $\begin{array}{c}\text { Tasa de } \\
\text { acumulación } \\
\text { (cm/100 años) }\end{array}$ \\
\hline D5 & 5376 & 132 & 2,011 \\
\hline D5 & 8012 & 185 & 2012 \\
8992 & 185 & 212 & 2,755 \\
\hline
\end{tabular}

$y=0,0189 x+38,572 R^{2}=0,9578$

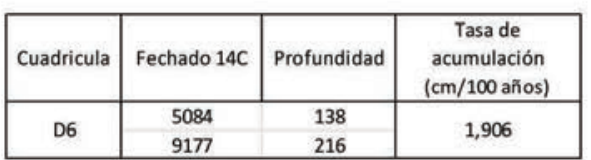

$y=0,0191 x+41,115 R^{2}=1$

Figura 6.9: Cálculo de tasas de acumulación por unidad estratigráfica de Cámara Norte. Las tablas muestran los cálculos por pares y debajo de ellas se incluye el resultado obtenido a partir de la ecuación de regresión (en $\mathrm{cm} /$ año). 
gravosas y gravas fango arenosas de las capas 5 a 3 y que comprende el lapso de la ocupación humana de la cueva. Los depósitos se interpretan como la combinación o mezcla de diferentes agentes de provisión del material. Así, en la acreción del relleno han participado la caída de detritos del techo de la cueva, el aporte de sedimento por parte de las personas que habitaron el sitio y el ingreso de material acarreado por el viento. La capa 4, con fechados entre $3210 \pm 60$ y $5376 \pm 45^{14} \mathrm{C}$ años $\mathrm{AP}$, es la que presenta la mayor señal antrópica en los sedimentos con frecuencias significativas de carbón, la cual es concordante con el conjunto arqueológico más númeroso de la toda la secuencia, tanto de material lítico como zooarqueológico (Miotti et al. 2014). Por último, el tipo arena gravosa perteneciente a la subcapa 5a, corresponde a depósitos con procesos posdepositacionales de lavado de matriz fina (pelítica). Se dataron dos fogones que se encuentran inmediatamente por encima de dos de estos depósitos cuyas edades mostraron valores de $5376 \pm 45$ y $5137 \pm 45$ años ${ }^{14} \mathrm{C}$ AP, por lo que el marco temporal dado para este depósito se podría correlacionar con un episodio de circulación de agua dentro de la cueva durante el Holoceno medio.

El proceso de acreción muestra algunas variaciones en cuanto a las tasas de acumulación calculadas. En este sentido, las TAS calculadas para el Holoceno temprano muestran señales muy diferentes, ya que para ese momento se obtuvo la tasa más alta $(2,755 \mathrm{~cm} / 100$ años) y de la más baja $(0,597$ $\mathrm{cm} / 100$ años). En este caso cabe preguntarse a qué se debe esa polaridad, es decir ¿cuál de ambos cálculos es el más confiable? Las distribuciones verticales de las dataciones de D5 muestran una mayor coherencia estratigráfica, siendo que el fechado de $7153 \pm 50$ años ${ }^{14} \mathrm{C}$ AP presenta un valor muy alejado y una ubicación inferior con respecto a fechados más antiguos que se encuentran por sobre él. No se han reconocido en el sector elementos que permitan hablar de una disminución notable de la depositación (pedogénesis, eventos erosivos) que haya incentivado a un descenso del material datado, aunque si se han reconocido cuevas de animales cavadores en las cercanías del sector del que se obtuvo el fechado (ver Marchionni 2013) por lo que, a priori, el cálculo realizado en base a los dos fechados más antiguos de D5 asoma como el más confiable.

Por su parte, para momentos posteriores, entrando en el Holoceno Medio, los cálculos realizados en C5 y D5 muestran valores más coherentes entre sí que correspondientes a momentos previos. Teniendo en cuenta que 
para el Holoceno temprano consideramos que la tasa de D5 es la más confiable, hacia el Holoceno medio la velocidad de acumulación promedio disminuye. De esta manera sería esperable una menor resolución temporal de los conjuntos para el Holoceno medio de $\mathrm{CN}$ en relación con el resto de la secuencia.

\subsubsection{Cámara Sur (CS)}

La Cámara Sur (CS) ocupa una superficie más pequeña que la Cámara Norte, aproximadamente la mitad. En este sector se excavaron cuatro cuadriculas de 2 × 2 m (A11, A12, B12, E11) y una media cuadrícula 2 × $1 \mathrm{~m}$ (AA12) completando un total de $18 \mathrm{~m}^{2}$. El referente estratigráfico de este sector es la pared Sur de las cuadriculas A12 y B12. La altura de estos cortes estratigráficos es de $1 \mathrm{~m}$ lo que muestra una estratigrafía mucho menos potente que en $\mathrm{CN}$. Las cuadriculas que utilizaremos como referentes de este sector son la A12 y la B12, fueron excavadas hasta la roca base y sus materiales ya han sido analizados por miembros del equipo.

En esta cámara también se definieron 6 capas, aunque con características macroscópicas diferentes a las de $\mathrm{CN}$. Solo la capa 5 fue dividida en subcapas, mientras que en la capa 3 que presentaba rasgos heterogéneos al interior de la misma, se optó por un muestreo cada cuatro centímetros. Las Capas 1 y 2 corresponden al depósito de estiércol de ganado que conforma la superficie actual del piso de la cueva y a una quemazón de dicho estiércol, como sucede en CN. Sin embargo, aquí se distinguen rasgos de oxidación en la base de Capa 1 que marcan la presencia de humedad.

\subsubsection{Análisis sedimentológico}

Los resultados textural-granulométricos han sido volcados en la tabla 6.2, y se grafican en la figura 6.11. Asimismo, siguiendo la metodología explicada previamente, se calcularon los parámetros estadísticos de tendencia central y dispersión (Figura 6.11).

La secuencia estratigráfica de CS, comienza con la Capa 6 que apoya sobre la roca de caja. Se trata de un depósito areno fango gravoso de color castaño claro (10 YR 7/3) con unos $10 \mathrm{~cm}$ de potencia en el sector más cercano a la boca de la cueva, mientras que hacia el fondo se acuña y desaparece en concordancia con la posición más elevada de la roca de caja. La 


\begin{tabular}{|c|c|c|c|c|c|c|c|c|c|c|c|c|c|}
\hline \multirow[t]{2}{*}{ Capa } & \multirow[t]{2}{*}{ Subcapa } & \multirow{2}{*}{\multicolumn{2}{|c|}{ Color }} & \multicolumn{8}{|c|}{ Granulometría } & \multicolumn{2}{|c|}{ Análisis geoquímicos } \\
\hline & & & & Psef. & Amg & $\mathrm{Ag}$ & Am & Af & Amf & Limo & Arcilla & $\% \mathrm{MO}$ & $\% \mathrm{CO} 3$ \\
\hline \multirow{5}{*}{3} & $0-4 \mathrm{~cm}$ & $2,5 Y 3 / 2$ & $\begin{array}{l}\text { Castaño grisáceo } \\
\text { muy oscuro }\end{array}$ & 12,17 & 8,11 & 11,27 & 6,76 & 11,72 & 9,91 & 24,06 & 16,00 & 6,7 & 1,7 \\
\hline & $4-8 \mathrm{~cm}$ & 7,5 YR 5/2 & Castaño & 7,94 & 1,59 & 4,23 & 3,18 & 8,47 & 7,41 & 36,07 & 31,12 & 1,41 & 0,4 \\
\hline & $8-12 \mathrm{~cm}$ & $10 \mathrm{YR} 5 / 1$ & Gris & 6,77 & 5,32 & 10,16 & 9,68 & 18,87 & 6,77 & 20,78 & 21,63 & 0,6 & 0,6 \\
\hline & $12-16 \mathrm{~cm}$ & $2,5 \mathrm{YR} 3 / 2$ & Rojo oscuro & 20,82 & 3,79 & 6,15 & 4,26 & 7,57 & 6,62 & 22,69 & 28,11 & 1,34 & 0,5 \\
\hline & $16-20 \mathrm{~cm}$ & $2,5 Y 3 / 0$ & $\begin{array}{l}\text { Gris muy } \\
\text { oscuro }\end{array}$ & 18,69 & 8,63 & 11,50 & 10,06 & 16,53 & 10,06 & 7,48 & 17,04 & 7,04 & 0,7 \\
\hline 4 & & $5 \mathrm{YR} 3 / 2$ & $\begin{array}{l}\text { Marrón rojizo } \\
\text { oscuro }\end{array}$ & 9,63 & 7,93 & 13,03 & 7,37 & 13,03 & 7,93 & 24,25 & 16,83 & 2,75 & 0,6 \\
\hline \multirow{2}{*}{5} & $\mathrm{a}$ & $2,5 Y 3 / 2$ & $\begin{array}{l}\text { Castaño grisaceo } \\
\text { muy oscuro }\end{array}$ & 15,11 & 6,61 & 11,65 & 9,13 & 21,40 & 16,05 & 11,05 & 9,00 & 4,69 & 0,9 \\
\hline & $\mathrm{b}$ & 7,5 YR 6/2 & Gris rosado & 15,48 & 8,33 & 10,32 & 9,13 & 28,17 & 14,68 & 2,66 & 11,23 & 1,34 & 0,4 \\
\hline 6 & & $10 \mathrm{YR} 7 / 3$ & Castaño claro & 13,21 & 15,53 & 19,16 & 10,90 & 17,51 & 7,60 & 5,67 & 10,42 & 0,4 & 0,3 \\
\hline
\end{tabular}

Tabla 6.2: Resultados del análisis sedimentológico de Cámara Sur de Cueva Maripe. Características de color, granulometrías y de porcentajes de materia orgánica y carbonatos de calcio. Referencias: Psef.: psefitas, Amg: Arena muy gruesa, Ag: Arena gruesa, Am: Arena mediana, Af: Arena fina, Amf: Arena muy fina 


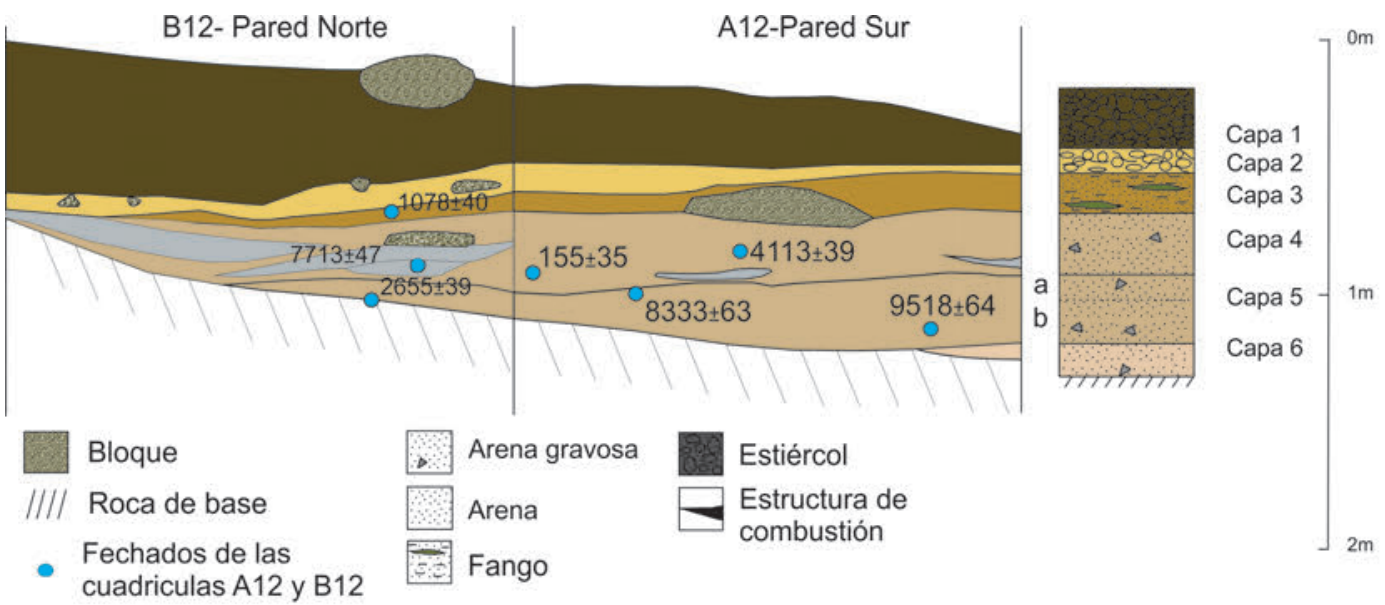

Figura 6.10: Perfil estratigráfico de Cámara Sur.

muestra presenta una distribución granulométrica polimodal (Figura 6.11) con un tamaño medio de grano en arena media $(1,5 \varphi)$ la cual en campo se observa como un sedimento suelto principalmente arenoso y sin estructura. A diferencia del depósito basal de $\mathrm{CN}$ (Capa 6) la composición de grava y arena de Capa 6 de CS presenta un aporte minoritario de material exógeno (24\%) (Figura 6.12-C). Por su parte, los análisis de DRX sólo mostraron valores traza de algunos minerales, por lo que no se consideran para el análisis de composición. Asimismo, los porcentajes de $\mathrm{MO}$ y $\mathrm{CaCO}_{3}$ son muy bajos (Tabla 6.2). Este depósito es arqueológicamente estéril.

La Capa 5, apoya sobre la Capa 6 y en algunos sectores directamente sobre la roca de caja. Este depósito fue dividido en dos subcapas (a y b) a partir de su coloración y de una aparente diferencia textural reconocida en campo (Rabassa et al. 2007). Sin embargo, ambas son definidas texturalmente como arena fango gravosa. La subcapa $5 \mathrm{~b}$ presenta un color gris rosado (7,5 YR 6/2) con una distribución que si bien es polimodal, presenta una moda principal en arena fina y un tamaño medio de grano en arena media $(1,7 \varphi)$. El porcentaje medido de $\mathrm{MO}$ es de $1,34 \%$ y el de $\mathrm{CaCO}_{3}$ es de $0,4 \%$. Por su parte, la subcapa 5 a es de color castaño grisáceo muy oscuro $(2,5 \mathrm{Y}$ $3 / 2$ ) con una distribución polimodal similar a la de la subcapa 5b, también con su moda principal en arena fina, aunque su media granulométrica se ubica en arena fina $(2,2 \varphi)$. El valor de $\mathrm{MO} \%$ muestra una clara diferencia con respecto a la subcapa 5 b, con un valor de $4,69 \%$, siendo uno de los más altos de la secuencia, mientras que el porcentaje de $\mathrm{CaCO}_{3}$, se mantiene por debajo del $1 \%$. Los análisis de composición muestran frecuencias similares 


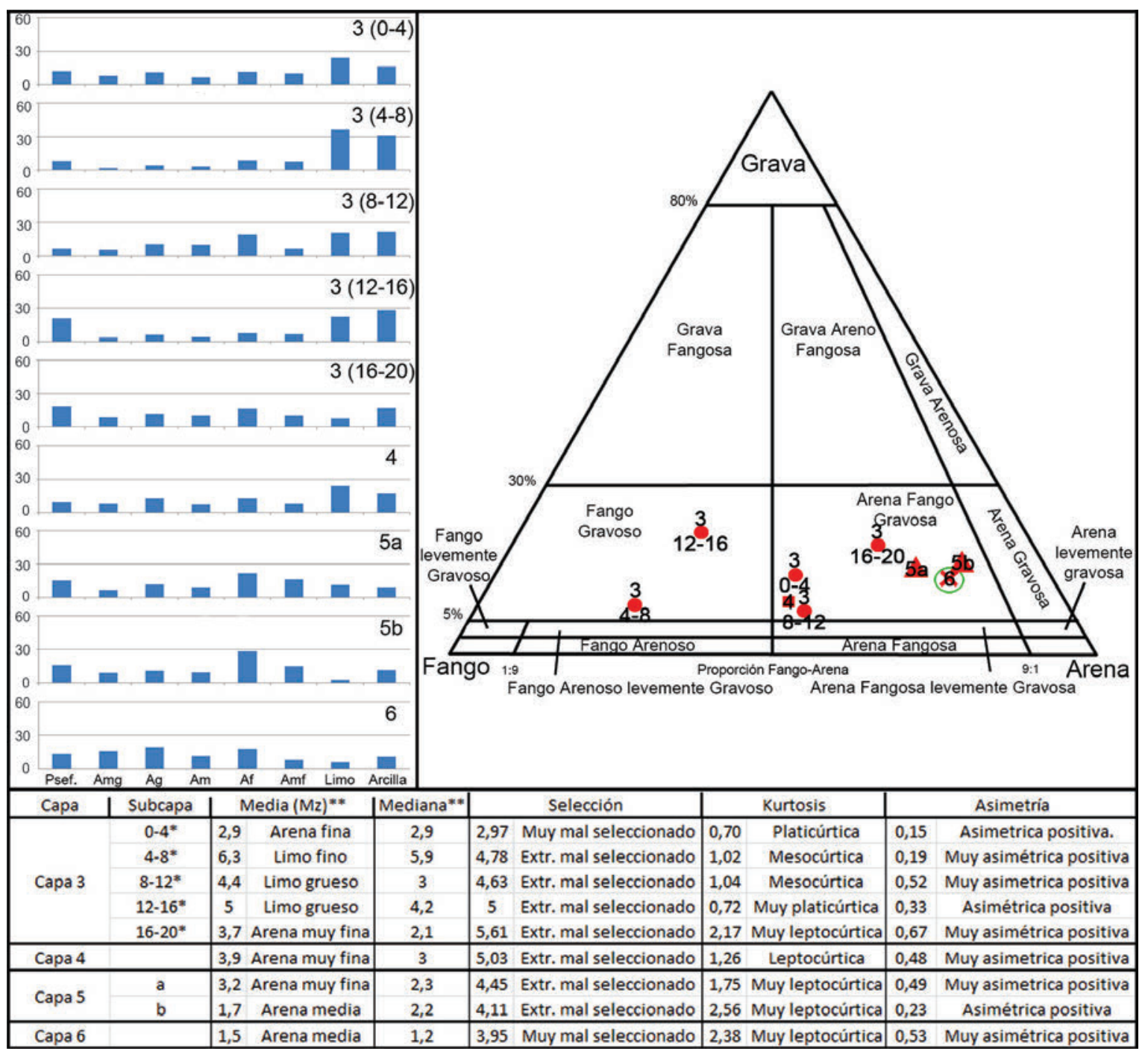

Figura 6.11: Resultados de los análisis textural-granulométricos de Cámara Sur: Histogramas de distribución granulométrica, triangulo de clases texturales y cálculo de coeficientes estadísticos. 
de material endógeno y exógeno en ambas subcapas con valores cercanos al $20 \%$ de exógeno (Figura 6.12-C). En ambos casos el aporte de material exógeno de la fracción arena está dado principalmente por sedimento eólico y hueso, con la diferencia de que en la subcapa 5 a aparecen evidencias de carbón (Figura 6.12-A). Por otro lado, en cuanto a la composición argilomineral las pelitas, solo pudo cuantificarse en la muestra $5 b$, la cual está representada principalmente por illita $(60 \%)$ y caolinita $(30 \%)$ y bajas cantidades de esmectita (5\%) y minerales interestratificados 10-14 M (5\%). Los fechados radiocarbónicos obtenidos en la capa 5 son tres: dos de ellos son coherentes con la secuencia estratigráfica y cultural $\left(8333 \pm 63\right.$ y $9518 \pm 64$ años ${ }^{14} \mathrm{C} \mathrm{AP}$; 11102-9136 años cal. AP), mientras que el tercero $\left(2655 \pm 39\right.$ años ${ }^{14} \mathrm{C}$ AP 2849-2736 años cal. AP) fue considerado un valor anómalo con respecto a los demás fechados de la secuencia en cuanto a su posición estratigráfica (Miotti et al. 2014) (Figura 6.13).

Sobre la Capa 5 se reconoció la Capa 4, de textura areno fango gravosa y color castaño rojizo oscuro (5 YR 3/2). Presenta una distribución polimodal, con su moda principal en la fracción limo, y su media granulométrica en arena muy fina $(3,6 \varphi)$. En cuanto a su composición, los análisis muestran un incremento de material exógeno con respecto a las capas inferiores alcanzando un $35 \%$, el cual está representado principalmente por hueso y carbón y, en menor medida, por clastos redondeados de origen eólico. La composición de la fracción pelítica muestra una proporción mayoritaria de ilíta (50\%), seguida por caolinita ( $25 \%$ ) y minerales intersestratificados $10-14 \mathrm{M}$ (25\%). El MO \% se mantiene en niveles relativamente altos con un 2,75\%, mientras que el $\mathrm{CaCO}_{3}$ sigue mostrando porcentajes muy bajos (0,6\%) (Tabla 6.2). En esta capa también se obtuvieron tres fechados que ubican al depósito entre $7713 \pm 47$ y $4113 \pm 47$ años AP (8584-4522 años cal. AP) (Figura 6.13), mientras que el tercero muestra un valor anómalo con respecto a los otros dos fechados y a su posición estratigráfica con un valor de 155 \pm 35 (285 años cal. AP) (Miotti et al. 2014).

La Capa 3 corresponde al último depósito sedimentario con restos arqueológicos previo a los depósitos de estiércol de ganado que conforman la porción superior de la estratigrafía. Es una capa de $20 \mathrm{~cm}$ de potencia máxima y está compuesta por sedimentos oscuros con estructura laminar y presencia de moteados castaño-rojizos que le otorgan heterogeneidad interna. Tal heterogeneidad nos llevó a realizar un muestreo más detallado 

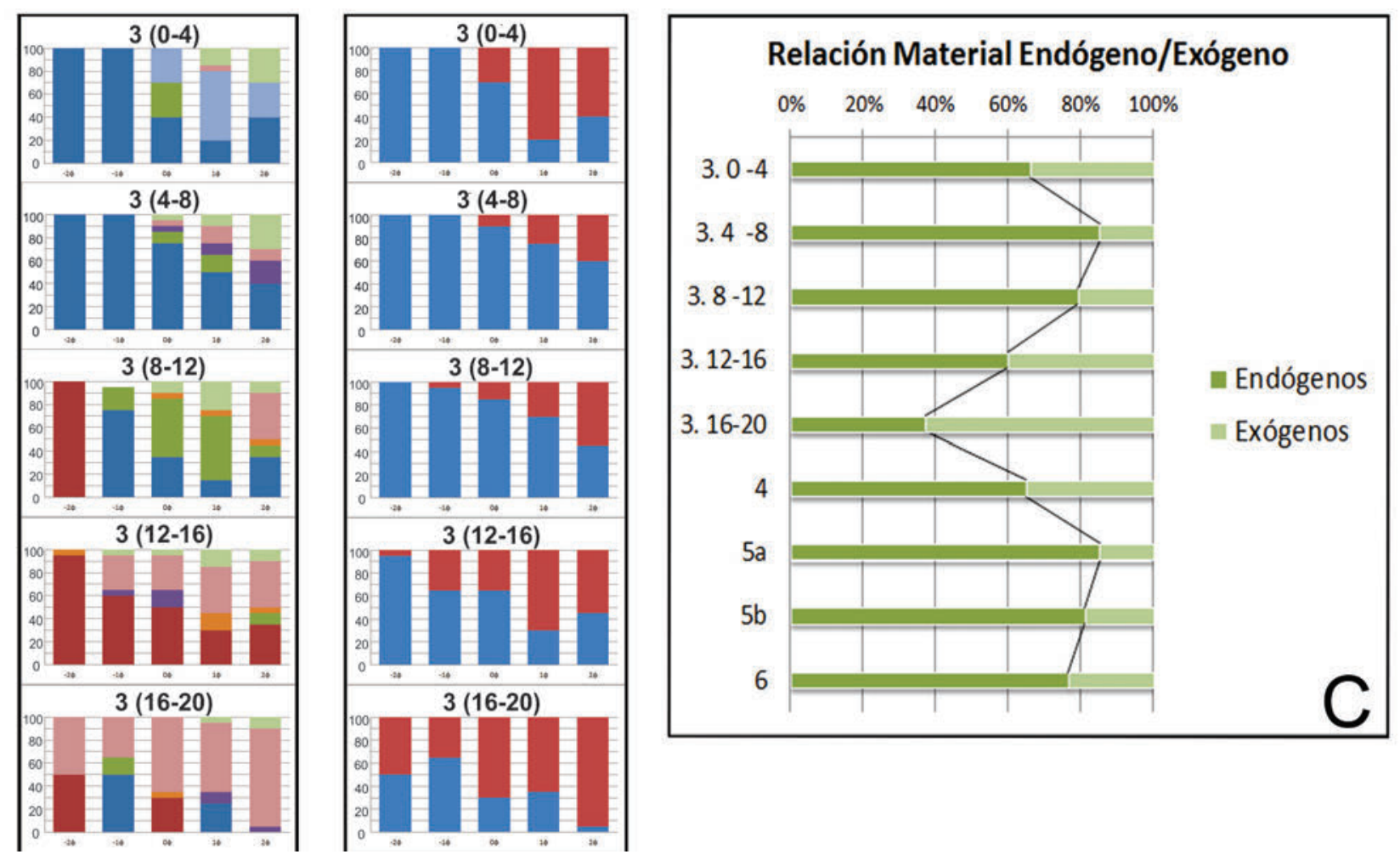

Figura 6.12: Resultados de los análisis de composición sedimentaria de Cámara Sur. A) Porcentajes de componentes reconocidos en las fracciones grava y arena a partir de conteo con lupa binocular. B) Relación de sedimento exógeno y endógeno de cada fracción. C) Relación entre sedimento exógeno y endógeno de la muestra total a partir de la ponderación de los porcentajes de A. D) Composición argilomineral de la fracción arcilla de cada muestra. (Continúa en la siguiente página) 

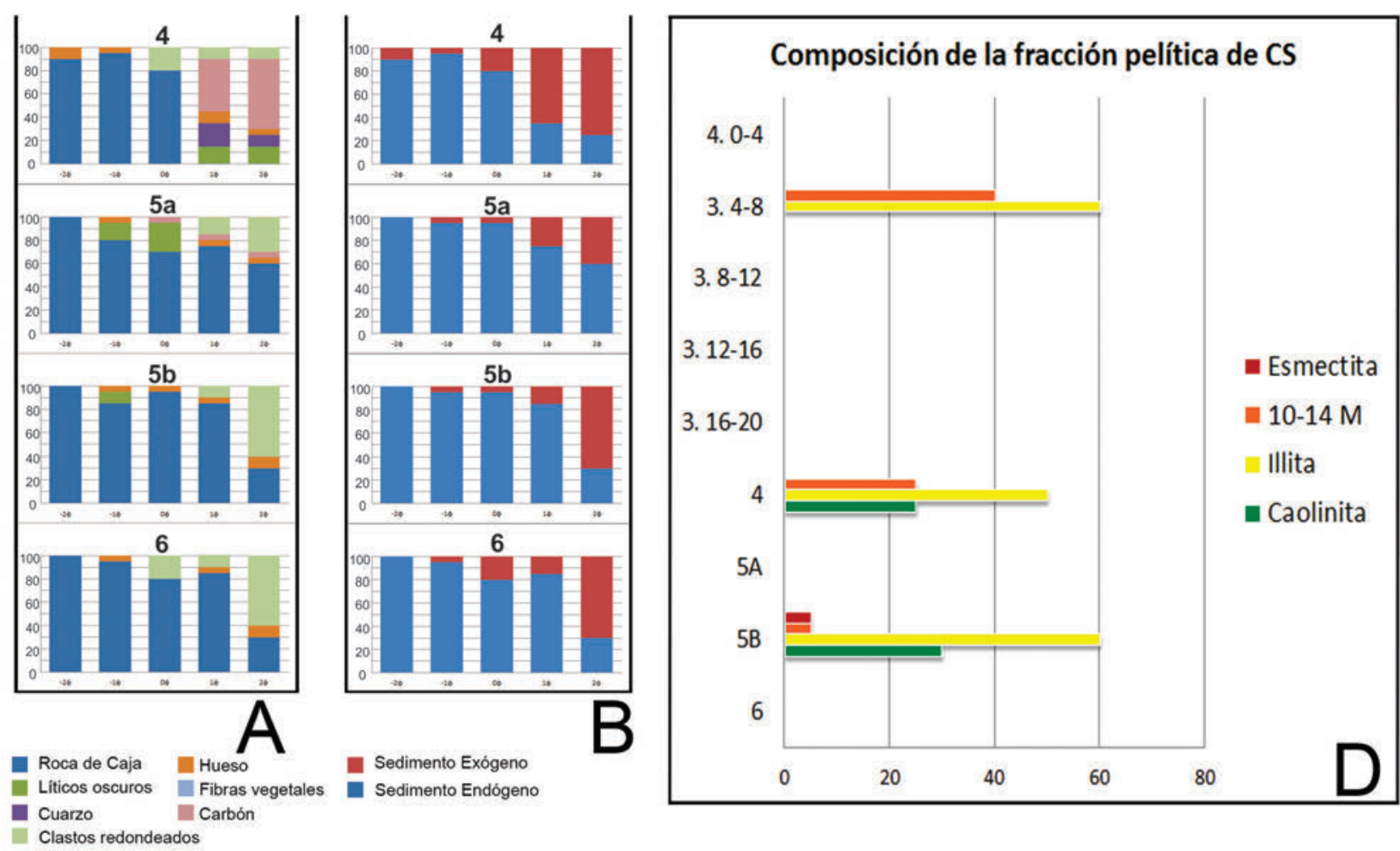

Figura 6.12: continuación.

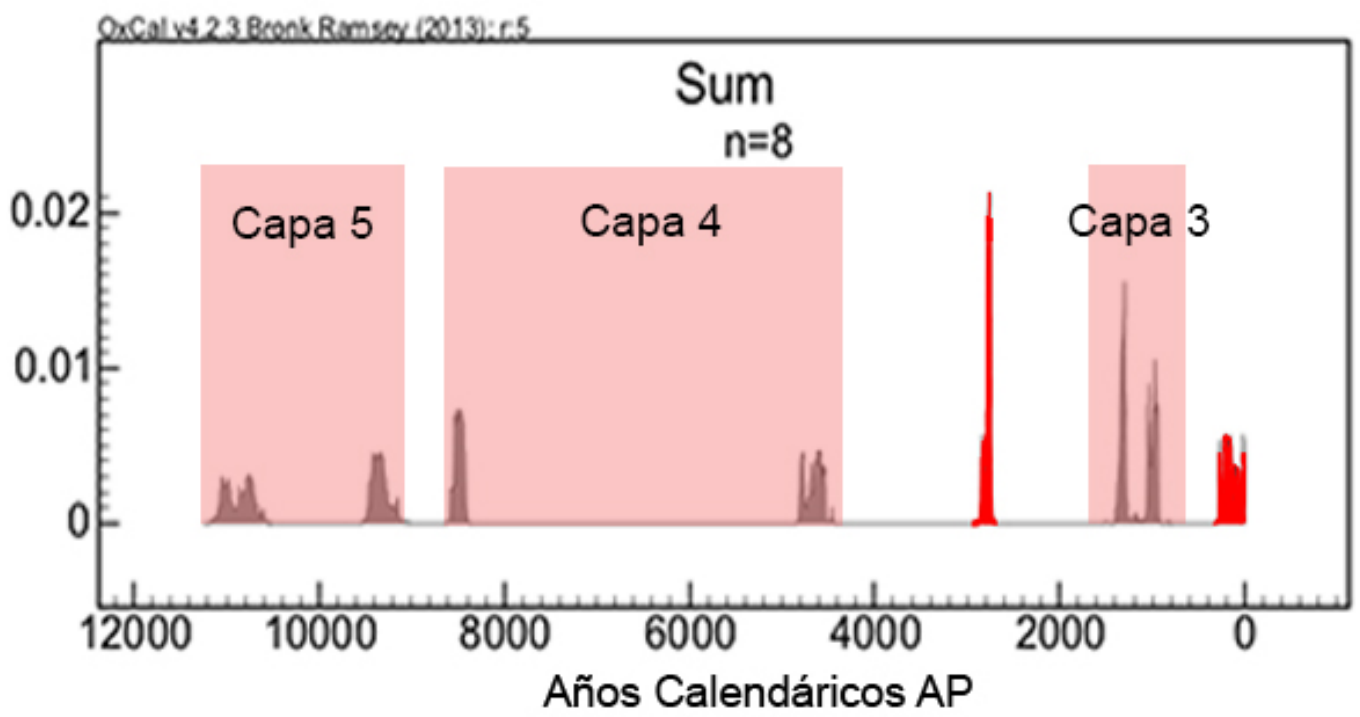

Figura 6.13: Suma de probabilidades de las dataciones radiocarbónicas obtenidas en CS. Las dos curvas pintadas de rojo corresponden a los fechados que presentan valores anómalos. 
tomando muestras cada $4 \mathrm{~cm}$ (Tabla 6.2). La capa está compuesta por una alternancia de sedimentos areno fango gravosos y fango gravosos, donde todas las muestras presentan distribuciones polimodales y medias granulométricas variadas (ver 6.11). En cuanto a la composición sedimentaria, las fracciones psefíticas y arenosas presentan variaciones dentro de la capa. La muestra de la base $(316-20 \mathrm{~cm}$ ) alcanza un $63 \%$ de material exógeno, compuesto principalmente por carbón y bajos porcentajes de hueso y clastos redondeados (Figura 6.12-A). En la muestra $312-16 \mathrm{~cm}$ se reconocieron los mismos componentes, aunque disminuye el porcentaje de material exógeno total llegando a un $42 \%$. En esta muestra hay una alta recurrencia de roca de caja quemada dentro de los materiales endógenos (Figura 6.12-A). La muestra 3 8-12 cm continúa con la tendencia a la disminución del aporte material exógeno que en este caso alcanza un $26 \%$ y está compuesto por carbón, clastos redondeados y huesos. La muestra $34-8 \mathrm{~cm}$ presenta el porcentaje más bajo de material exógeno de la capa 3 con un $15 \%$ representado por carbón y clastos redondeados (Figura 6.12-A). Por último, en la sección superior de la capa representada por la muestra $30-4 \mathrm{~cm}$ el porcentaje de material exógeno vuelve a incrementarse hasta alcanzar un $34 \%$, que en este caso en particular, a diferencia del resto de la secuencia corresponde mayoritariamente a fibras vegetales. Esta muestra corresponde al techo de la capa 3 que se encuentra en contacto con la capa 2 formada por estiércol. En cuanto a la composición argilomineral, solo la muestra 3 4-8 cm permitió realizar una cuantificación, ya que las muestras restantes arrojaron valores traza. Los argilominerales reconocidos están compuestos por un $60 \%$ de illita y un $40 \%$ de minerales interestratificados 10-14M (Figura 6.12). Los porcentajes de $\mathrm{MO}$ son altos en la muestra de la base de la capa $(7,04 \%)$ y en la muestra de la cúspide $(6,7 \%)$, en tanto que los valores disminuyen hacia el centro del depósito alcanzando su menor porcentaje en la muestra $38-12 \mathrm{~cm}$ $\left(0,6 \%\right.$ ) (Ver Tabla 6.2). Los valores de porcentaje de $\mathrm{CaCO}_{3}$ se mantienen por debajo del $1 \%$ con excepción de la muestra $30-4 \mathrm{~cm}$ que alcanza un 1,7\%. Se obtuvo un fechado de este depósito el cual lo ubica en $1078 \pm 40$ años ${ }^{14} \mathrm{C}$ AP (1061-928 años cal. AP) (Miotti et al. 2014).

Las capas 1 y 2, como en el caso de la CN están formadas por estiércol de ganado. En este caso presentan algunas características diferentes en Capa 2 ya que si bien se reconoce la quemazón observada en $\mathrm{CN}$, en el caso de CS hay sectores con rasgos de acción hídrica, como lixiviación y oxidación de 


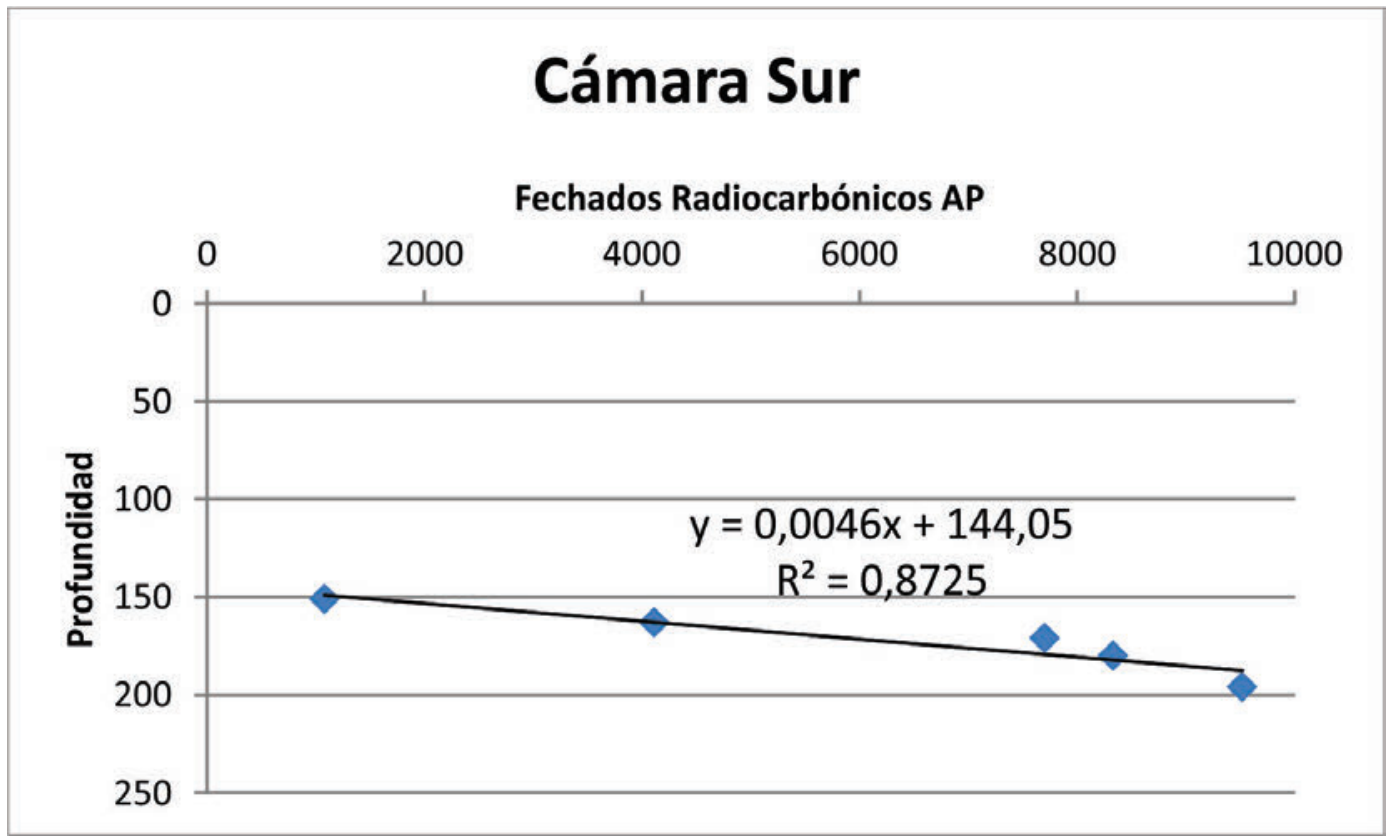

Figura 6.14: Distribución de todos los fechados y cálculo de tasa de acumulación general de la Cámara Sur.

estiércol.

\subsubsection{Cálculo de tasas de acumulación sedimentaria (TAS)}

El valor calculado de TAS para toda la CS es de 0,0046 cm/año (0,46 $\mathrm{cm} / 100$ años) con un valor de $\mathrm{R}^{2}=0,8725$, lo que muestra poca variación a lo largo de la distribución (Figura 6.14).

Al calcular de manera pormenorizada las tasas en cada unidad de excavación pudimos reconocer algunas diferencias. Por un lado, en la cuadricula A12 la TAS calculada para toda la unidad muestra un valor de 0,0056 $\mathrm{cm} /$ año $(0,56 \mathrm{~cm} / 100$ años) similar al calculado para toda CS (ver Fig.TasaCS). Sin embargo, el cálculo por pares de fechados muestran claras diferencias. Durante el Holoceno temprano, entre $9518 \pm 64$ y $8333 \pm 63$ años ${ }^{14} \mathrm{C}$ AP la TAS es de 1,350 cm/100 años, mientras que entre $8333 \pm 63$ y $4113 \pm 39$ años ${ }^{14} \mathrm{C}$ AP este valor disminuye notablemente hasta una depositación promedio de 0,403 cm/100 años (Figura 6.15).

En el caso de la cuadricula B12 solo se cuenta con dos dataciones la más antigua de $7703 \pm 47$ años ${ }^{14} \mathrm{C}$ AP y la más reciente de $1078 \pm 40$ años ${ }^{14} \mathrm{C} \mathrm{AP}$, entre las cuales se calculó una TAS de 0,302 cm/100 años. Este es el valor más bajo del sector, sin embargo es cercano al calculado en A12 para el lapso 


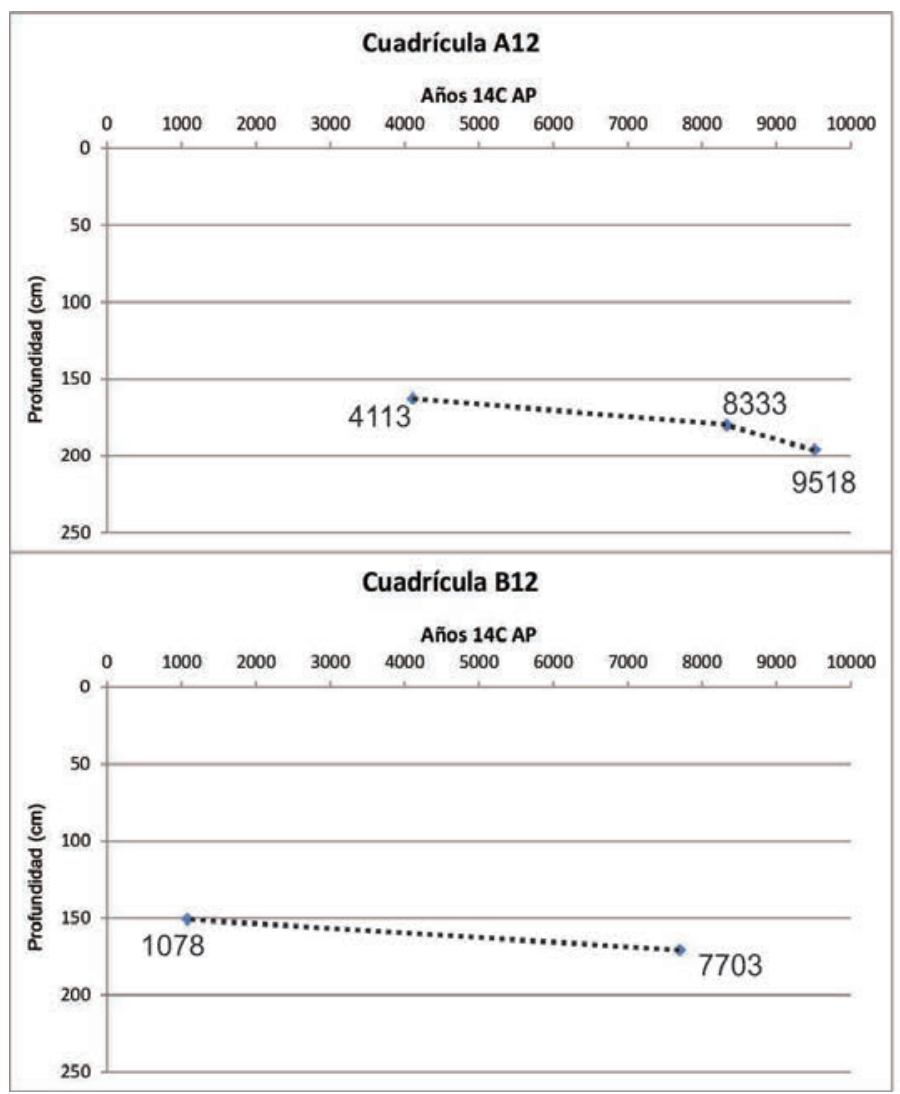

\begin{tabular}{|l|r|r|c|}
\hline Cuadricula & Fechado 14C & $\begin{array}{c}\text { Profundidad } \\
\text { (cm) }\end{array}$ & $\begin{array}{c}\text { Tasa de } \\
\text { acumulación } \\
\text { cm/100 años }\end{array}$ \\
\hline A12 & 4113 & 163 & 0,403 \\
\hline A12 & 8333 & 180 & 180 \\
\hline A12 & 8333 & 1,350 \\
\hline A12 & 9518 & 196 & \\
\hline
\end{tabular}

$y=0,0056 x+138,99 R^{2}=0,9149$

\begin{tabular}{|c|c|c|c|}
\hline Cuadricula & Fechado 14C & $\begin{array}{c}\text { Profundidad } \\
\text { (cm) }\end{array}$ & $\begin{array}{c}\text { Tasa de } \\
\text { acumulación } \\
\text { cm/100 años }\end{array}$ \\
\hline B12 & 1078 & 151 & 0,302 \\
\hline B12 & 7703 & 171 & 0,302 \\
\hline
\end{tabular}

$y=0,003 x+147,75 R^{2}=1$

Figura 6.15: Cálculo de tasas de acumulación por unidad estratigráfica de Cámara Sur. Las tablas muestran los cálculos por pares y debajo de ellas se incluye el resultado obtenido a partir de la ecuación de regresión.

temporal que se solapa (entre $8333 \pm 63$ y $4113 \pm 39$ años ${ }^{14} \mathrm{C}$ AP) (Figura 6.15).

\subsubsection{Valoración de los resultados de CS}

A nivel general, el material endógeno es el principal componente de la estratigrafía de CS, aunque se observan algunas variaciones a lo largo del depósito. En el caso de la fracción psefítica la roca de caja es el componente casi exclusivo, mientras que en la fracción arena hay una mixtura entre endógenos y exógenos. En este caso, se reconocieron dos incrementos principales de material exógeno: el primero entre la base de Capa 3 y Capa 4, y el segundo en el techo de Capa 3, que de acuerdo a los fechados obtenidos, se ubican en el Holoceno medio y tardío respectivamente.

Los arreglos texturales de las muestras de CS presentan valores de psefitas bajos y ubican a la mayoría de ellas dentro del triángulo de textura en arena fango gravosa. Solo dos muestras correspondientes a la Capa 3 salen 
de esa categoría y caen en fango gravoso. En este sentido, en la distribución de las muestras no se reconocen agrupamientos claros, con excepción de las capas 5 y 6 que son contiguas y presentan granulometrías semejantes. Estas capas presentan composiciones similares con cerca de un $20 \%$ de material exógeno en cada una de ellas compuesto principalmente por clastos redondeados y huesos y fueron depositadas durante el Holoceno temprano en el caso de Capa 5 y previo a la ocupación humana en el caos de Capa 6.

En las Capas 3 y 4 el aporte humano a la conformación sedimentaria de CS es muy marcado. En Capa 4 se reconocen altos porcentajes de carbón y presencia de clastos de origen eólico, mientras que en la base de capa 3 aumenta sustancialmente el contenido de carbón acompañado de bajos porcentajes de hueso. Esto coincide con que el conjunto arqueológico recuperado en Capa 3, que se incluye en el componente arqueológico 1 (Miotti et al. 2014), es el más numeroso de la CS.

Un rasgo muy importante es la presencia del manantial que surge en las paredes del fondo de CS. Este manantial generó modificaciones postdepositacionales en la Capa 3 que han sido mencionadas y se reflejan en el conjunto zooarqueológico. Un gran número de especímenes óseos presenta depósitos de óxidos de $\mathrm{Mn}$ y $\mathrm{CaCO}_{3}$ y un muy alto porcentaje de especímenes fue determinado en la categoría "teñidos", ya que presentan superficies oscurecidas pero que no responden claramente a las características de los depósitos de MN o de huesos quemados (Marchionni 2013). En este sentido, la dinámica hídrica de CS combinada con el alto contenido de carbón reconocido en estos depósitos podrían dar cuenta de estas modificaciones.

Las tasas de acumulación calculadas para CS permite inferir una acreción relativamente rápida $(1,350 \mathrm{~cm} / 100$ años $)$ durante el Holoceno temprano, mientras que entre el Holoceno medio y tardío son sustancialmente más lentas $(0,302 \mathrm{~cm} / 100$ años y 0,403 cm/100 años). En este sentido, los conjuntos tempranos presentan potencialmente una mejor resolución temporal.

La tasa de depositación más lenta hacia el Holoceno medio y tardío, involucra momentos en los que el sector estuvo bajo la influencia del agua de manantial el cual habría influido en forma de encharcamientos. Esto es lo que permitió la depositación de sedimentos fangosos y el desarrollo de rasgos hidromórficos (moteados, oxidación, laminación). La acción del agua en CS se inicia durante el Holoceno medio ca. 4100 años ${ }^{14} \mathrm{C}$ AP momento 
para el cual podemos confirmar una mayor actividad del manantial en este sector y en la cueva en general durante el Holoceno medio en vistas de las evidencias de $\mathrm{CN}$.

\subsubsection{Integración de resultados de Cueva Maripe}

En primer lugar, la evidencia radiocarbónica nos permite afirmar que el sitio comienza a ser ocupado por humanos durante el Holoceno temprano, periodo en el cual los fechados permiten inferir una ocupación recurrente (Figura 6.16). Durante el Holoceno medio, entre los fechados se reconocen vacíos cronológicos de hasta 1500 años cal. AP; y durante el Holoceno tardío, los fechados se distribuyen con cierta homogeneidad. La presencia de hiatos cronológicos es esperable a escala de sitio, por lo que más adelante discutiremos su persistencia o no, en escalas mayores.

A partir de los análisis sedimentológicos y composicional-mineralógicos desarrollados se puede reconocer que los depósitos basales, previos a la ocupación humana, que caracterizan a CN (capa 6) están formados por un marcado aporte exógeno de origen eólico. En el techo de este depósito se reconoce bioturbación por raíces para un momento en el que desde los análisis diatomológicos, se infiere que la CN "podría haber estado inundada por aguas someras y quietas antes de su primera ocupación" (Fernández 2013:137). En CS, la capa 6 presenta poca potencia y es difícil de reconocer, en este sentido la $\mathrm{CN}$ al presentar su piso relativamente más bajo que CS, permitió una mayor acumulación en este sector durante los momentos iniciales.

Por encima de esta capa, en la capa 5, comienza la ocupación humana durante el Holoceno Temprano, tanto en CN como en CS, con fechados de ca. 9200 y 9500 años AP (Miotti et al. 2014), respectivamente. A partir de este momento hay un cambio notorio en cuanto a los agentes de depositación, ya que disminuye el aporte de arena de origen eólico y aumenta el porcentaje de detritos desprendidos del techo en las muestras analizadas en $\mathrm{CN}$, mientras que en CS este proceso no es tan claro. Por su parte, que no se haya reconocido este cambio en el depósito sedimentario de CS aporta evidencia que avala la interpretación de un escaso desarrollo de la capa 6 en este sector, que asociamos con la diferencia de altura de la roca de base. Por otro lado, las tasas de acumulación sedimentaria para este momento (Holoceno temprano) son relativamente altas en ambas cámaras con valores de 1,3 cm/ 100 años para CS y 2,75 cm/100 años para CN. 

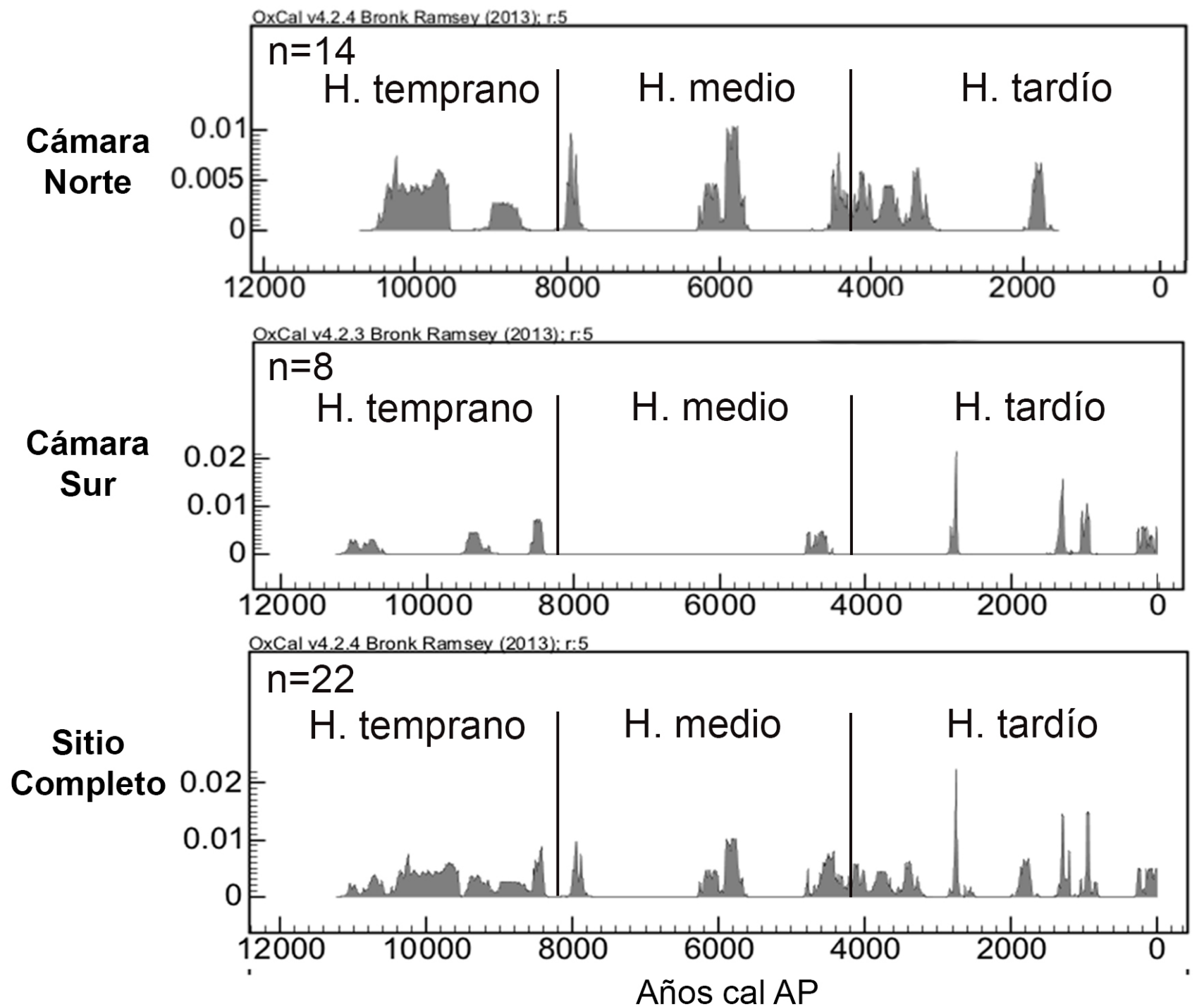

Figura 6.16: Fechados calibrados y suma de probabilidades de Cueva Maripe. 
Hacia el Holoceno medio, en ambas cámaras hay un incremento notorio en el aporte de material de origen antrópico, principalmente evidenciado en la capa 4 de CN y en la capa 4 y base de capa 3 de CS. Para el caso de $\mathrm{CN}$, estos picos de ingreso de material antrópico, reconocidos tanto con lupa binocular como por el análisis de \%MO, se registran entre los fechados de $5376 \pm 45$ y $3210 \pm 60$ años ${ }^{14} \mathrm{C}$ AP (Miotti et al. 2014). De esas capas se ha extraído la mayor cantidad de material arqueológico, considerando especímenes faunísticos y artefactos líticos (Lynch 2014; Marchionni 2013; Miotti et al. 2014). Asimismo, la distribución granulométrica de sedimentos se mantiene dentro de los parámetros observados en capa 5 con identidades texturales similares, por lo que no se puede plantear una diferencia clara desde el punto de vista de los agentes naturales de depositación pero sí desde su composición, donde la intervención humana se hace notoria. De esta manera, podemos corroborar que el Holoceno medio es el lapso temporal con mayor señal arqueológica de CN. Por su parte, en CS el incremento de sedimento de origen antrópico ocurre también durante el Holoceno medio ca. 4100 años ${ }^{14} \mathrm{C}$ AP. Durante el Holoceno medio, las tasas de depositación disminuyen en ambos sectores (1,48 y 2,01 cm/100 años en CN; 0,43 cm/100 años en CS) con respecto al Holoceno temprano, con una acumulación mucho más lenta en CS lo que resulta en una potencia menor en este sector.

En un trabajo previo se pudo determinar que en CS la mayor frecuencia de especímenes óseos proviene del conjunto del Holoceno tardío (ca. 1080 años $\mathrm{AP}$ ), mientras que el conjunto del Holoceno medio es el segundo en importancia en cuanto a frecuencia de estos hallazgos se refiere (Marchionni 2013; Miotti et al. 2014). Sin embargo, el conjunto lítico de artefactos formatizados es más numeroso en el depósito del Holoceno Medio (Lynch 2014). En este caso, la baja tasa de acumulación sedimentaria contribuyó a una escasa separación vertical de materiales de diferentes ocupaciones.

En ambas cámaras se pudo determinar la presencia de agua en el pasado, influyendo en la formación del depósito. Actualmente, en $\mathrm{CN}$ la filtración de agua de manantial es mínima y se restringe sólo al fondo de la cueva, sin tener incidencia sobre los sectores excavados. En $\mathrm{CN}$ se reconocieron en el perfil sectores con acumulación de grava con lavado de matriz fina, estructura laminar y formas de canales someros y el análisis textural muestra claras diferencias con respecto al resto de la secuencia. Sumado a esto, el conjunto zooarqueológico de las capas que subyacen estos sectores en los 
que actuó el agua, muestra un alto porcentaje de especímenes con manchas de manganeso y depósitos de carbonatos (Marchionni 2013), que son rasgos tafonómicos asociados a la actividad hídrica (Courty et al. 1989; Karkanas et al. 2000; Gutiérrez 2004). Este agente habría actuado en forma de escorrentías de muy baja energía o estancamientos durante diferentes momentos del Holoceno medio en $\mathrm{CN}$, principalmente en la primera mitad generando las modificaciones mencionadas sin desplazar los materiales.

Por su parte, en CS la presencia de agua es observable en la actualidad escurriendo desde el fondo de la cueva. Durante las excavaciones se registró sedimento húmedo en esta cámara y se observaron sectores del perfil con rasgos de acción hídrica (Rabassa et al. 2007), los cuales pueden ubicarse temporalmente en la segunda mitad del Holoceno medio, luego de los $4113 \pm 39$ años ${ }^{14} \mathrm{C}$ AP (Miotti et al. 2014) (Figura 6.17). En coincidencia con estos rasgos, en el conjunto zooarqueológico de este sector se reconocieron huesos con manchas de manganeso y carbonato de calcio, así como también un alto porcentaje de huesos ennegrecidos en los que no se logró determinar si son resultado de manganeso o combustión (Marchionni 2013; Marchionni et al. 2012). Sin embargo, pudo haber sucedido que el agua haya humedecido sedimentos carbonosos como los presentes en capa 3, y que este proceso haya contribuido a teñir los huesos contenidos en ella y en la capa subyacente.

La alternancia del escurrimiento de agua entre cámaras, observada para momentos del Holoceno medio habría afectado la disponibilidad de superficies para ser ocupadas en cada cámara y en diferentes momentos, lo que aporta evidencia en favor de la hipótesis planteada en trabajos previos sobre la utilización alternada de ambos sectores (Miotti y Marchionni 2009).

Por último, en la secuencia cronológica de CS se obtuvieron dos fechados (155 \pm 35 y $2655 \pm 39$ años AP) que fueron definidos como outliers por su valor incongruente con la posición estratigráfica y con los demás fechados. Ambas dataciones fueron realizadas sobre carbón, y las muestras han sido recolectadas de sectores de excavación contiguos (SE de A12 y SW de B12) distanciadas por $70 \mathrm{~cm}$. Dado que se cuenta con otros cinco fechados que son congruentes entre sí, el interrogante se centra en qué es lo que pudo haber ocurrido en el sector particular de la excavación del cual provienen estas dos dataciones anómalas. En este sentido, se han registrado una serie de procesos bioestratinómicos que afectaron a los sectores en cuestión, co- 


\section{Cámara Norte}

Cámara Sur

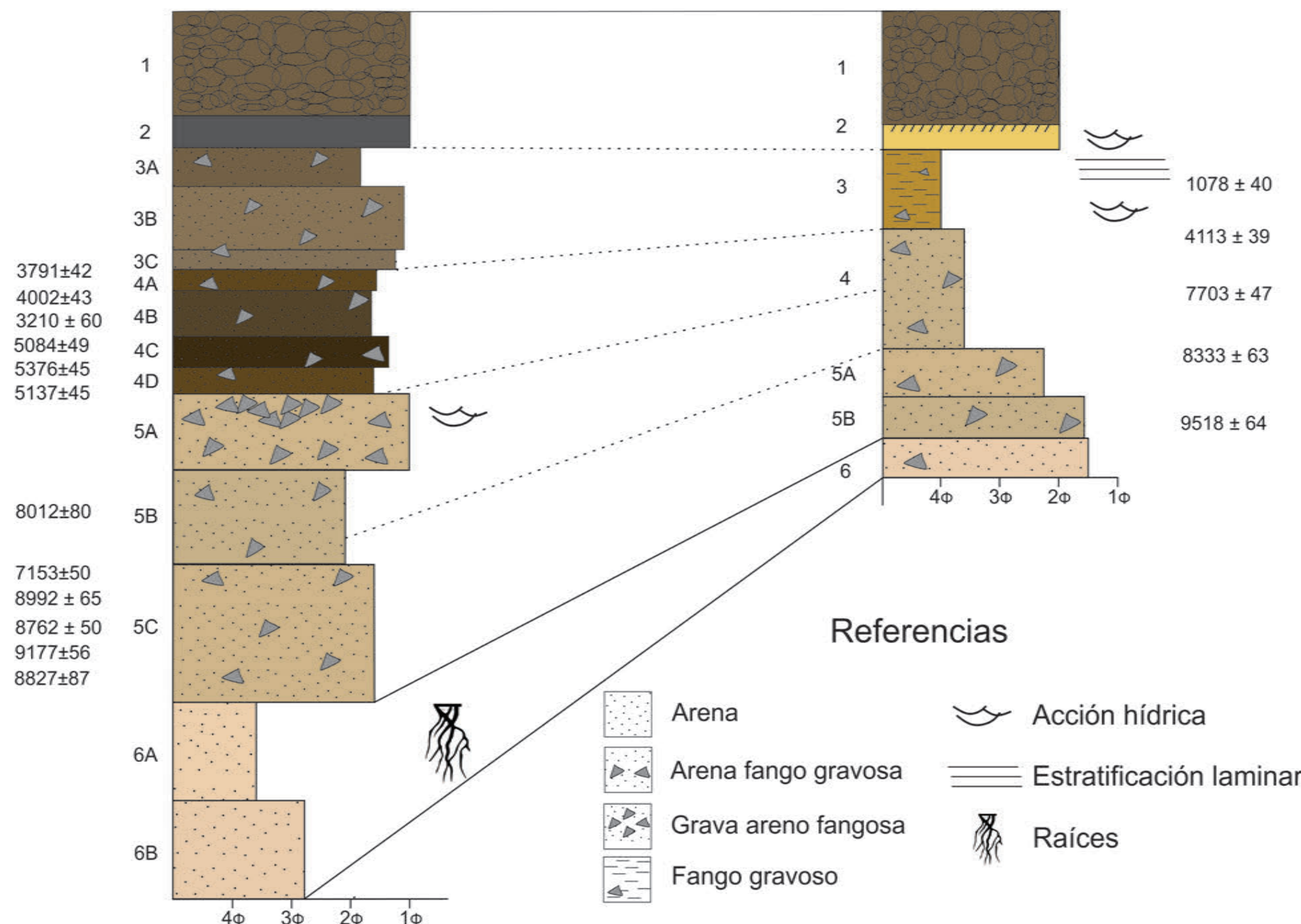

2)

(210 \pm 60

$5137 \pm 45$

$\begin{array}{llll}4 \Phi & 3 \Phi & 2 \Phi & 1 \Phi\end{array}$

Fango gravoso

Figura 6.17: Correlación estratigráfica entre las dos cámaras de Cueva Maripe. Los colores asigados a las capas responden a diferencias colorimétricas comparadas con la Munsell Color Chart 
mo raíces y cuevas de animales cavadores. A priori, son las raíces las que pudieron haber influido en las muestras que se discuten, ya que las cuevas de roedores que se han detectado y mapeado no afectan específicamente a los lugares de donde se extrajeron estos carbones. Por otro lado, no se descarta un posible enriquecimiento de carbono por procesos edáficos incipientes que se relacionen con la presencia de agua registrada en CS. Si bien los porcentajes de carbonato en las muestras de sedimento son bajos, en el registro zooarqueológico se observaron depósitos de carbonato y manganeso en frecuencias mayores que las marcas de raíces. En definitiva, hasta el momento no se han definido cuáles fueron los procesos bioestratinómicos que afectaron al sector de la excavación en cuestión y del cual proceden los fechados considerados como anómalos, y que abren interrogantes sobre los materiales obtenidos en esta porción de CS.

\subsection{Mallín La Primavera}

Las características propias de los mallines fueron descriptas en el capítulo Área de Estudio. Para analizar esta geoforma, que conforma el entorno inmediato de Cueva Maripe, se seleccionaron diferentes puntos de muestreo. En algunos casos se buscó intervenir directamente el mallín en sectores semihúmedos donde fue posible utilizar el barreno helicoidal, es decir, sectores en los cuales la vegetación se mantiene verde. Estos son los casos de los muestreos MLP-1, MLP-2 y MLP-6. Para complementar la información proveniente de los muestreos mencionados se seleccionaron sectores adyacentes al mallín para verificar la continuidad o no de los depósitos sedimentarios. Por un lado en asociación con el muestreo MLP-2, a unos 200 $m$ de distancia se extrajo el testigo MLP-3, en el borde del mallín donde previamente se reconoció y se analizó un sitio arqueológico de superficie denominado La Playita (Magnin y Blanco 2006; Magnin 2010). Por otro lado, el testigo MLP-5 fue obtenido sobre la ladera del cañadón, a unos $400 \mathrm{~m}$ aguas arriba de la Cueva Maripe y el barreno MLP-6 (Figura 6.18). Se seleccionó este sector debido a que allí se reconocieron cuatro surgentes de agua actualmente activas en asociación con un extenso sitio de superficie denominado La Quinta, en el cual se practicó un sondeo estratigráfico pudiendo datar un fragmento de hueso en $939 \pm 59$ años ${ }^{14}$ C AP (Magnin 2010). 


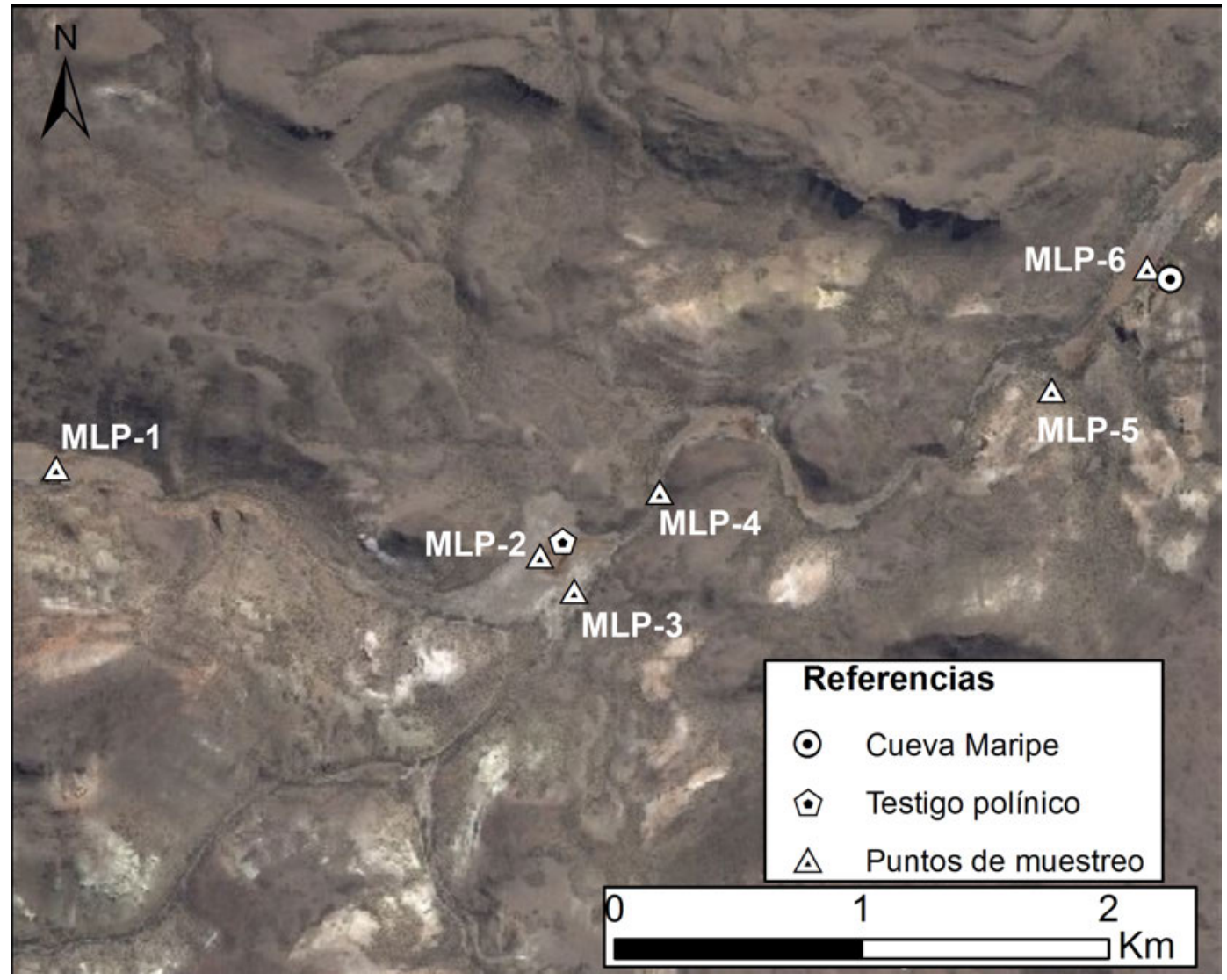

Figura 6.18: Ubicación de los muestreos realizados a lo largo del Mallín La Primavera. 


\subsubsection{MLP-1}

Este testigo se extrajo de un sector semi húmedo del mallín, en las cabeceras del cañadón La Primavera (Ver Figura 5.2). El arreglo litológico muestra dos secciones, diferenciándose los $0,4 \mathrm{~m}$ superiores del resto de la secuencia. Las dos muestras superiores $(0-20$ y $20-40 \mathrm{~cm})$ son de color gris castaño $(2,5$ YR 4/2) con presencia de raíces, la media granulométrica se ubica en la fracción limo fino y, en la base, se puede observar sedimento húmedo y presencia de moteados negros. El resto del testigo, desde los 0,4 m hasta la base muestra una continuidad litológica muy marcada con un alto porcentaje de arcilla y limo. En la muestra $100-120 \mathrm{~cm}$ se comienza a observar la aparición de moteados de color verde, hasta los 140-160 cm donde definitivamente las muestras se tornan de color verde. Las medias granulométricas de las muestras entre $0,4 \mathrm{~m}$ y $2 \mathrm{~m}$ (todas ubicadas en la fracción arcilla), los histogramas de distribución granulométrica, sumado a los valores de simetría que caen en la categoría simétrica en su mayoría y a los valores constantes de curtosis, dan cuenta de la homogeneidad litológica mencionada (Figura 6.19).

\subsection{2. $\quad$ MLP-2}

El testigo MLP-2 se recuperó en un sector del mallín en el que el cañadón se ensancha y sus márgenes forman un contorno semicircular del cual también se obtuvo el testigo para análisis polínico (ver Figuras 6.20 y 6.27). Este muestreo es el más largo de los obtenidos en el Mallín La Primavera con una profundidad total de 2,8 m. En este caso, del total de las muestras recuperadas (14) se procesó la mitad y de manera intercalada, lo que deja un total de siete muestras procesadas. En términos generales la textura sedimentaria es relativamente uniforme, con sedimentos principalmente arcillosos y fangosos (Figura 6.21). La sucesión sedimentaria de este muestreo se inicia con un nivel arcillo arenoso de color castaño (7,5 YR 5/2) que presenta el mayor porcentaje de arena de las muestras obtenidas $(240-280 \mathrm{~cm})$ con una media granulométrica ubicada en la fracción limo fino $(7,7 \varphi)$ y una distribución bimodal en arcilla y arena fina (Figura 6.21). Entre los 200 y $240 \mathrm{~cm}$ las muestras se tornan de color verde (5 Y 6/4) con algunos moteados de color negro y restos vegetales en descomposición, con moda y medias granulométricas en la fracción arcilla $(10,2 \varphi)$. La sección media del testigo, entre 80 


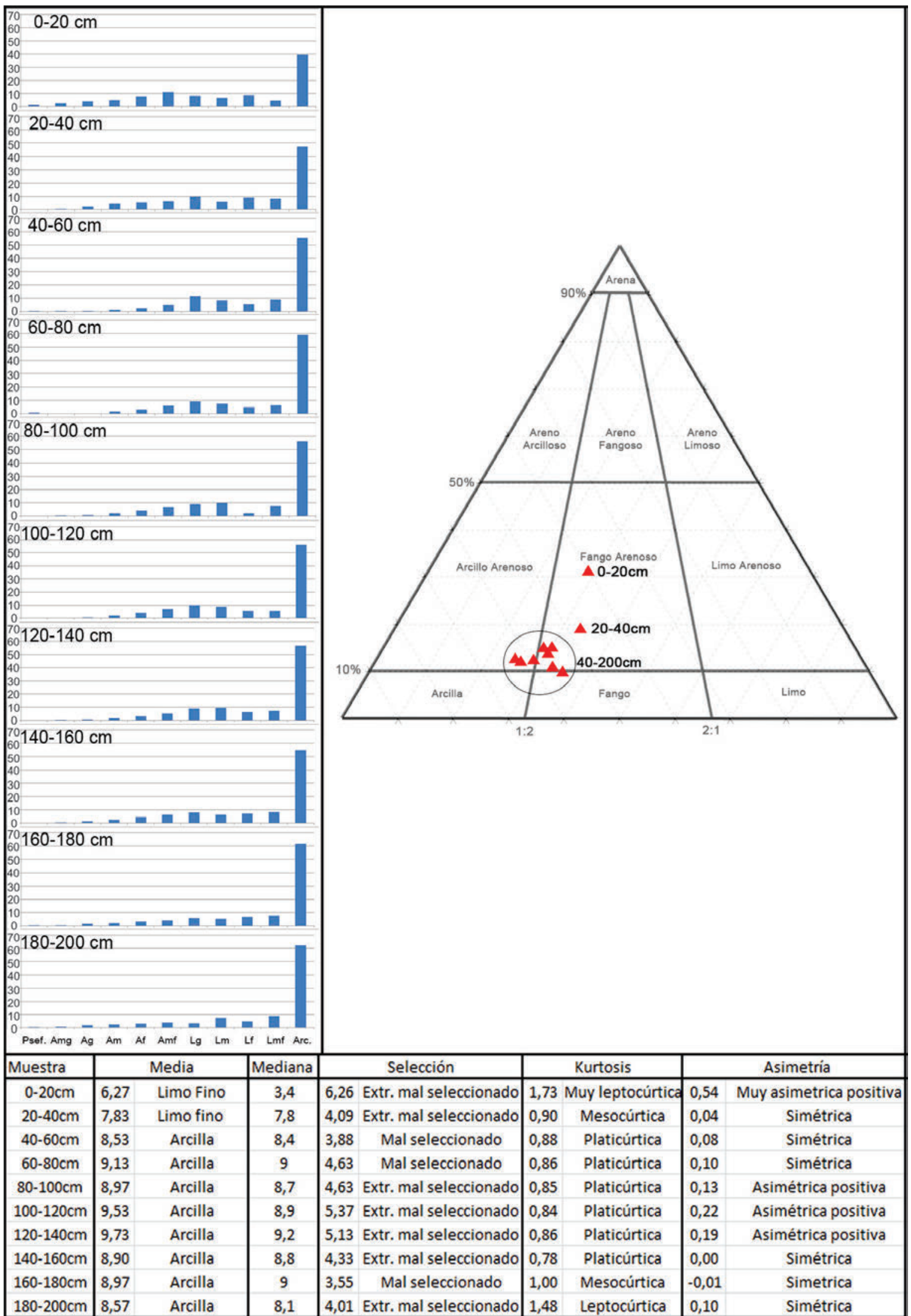

Figura 6.19: Caracterización sedimentaria de las muestras del testigo MLP1. 
y $200 \mathrm{~cm}$ presenta en la base sedimento húmedo de color verde que hacia la superficie va adquiriendo color negro en forma de moteados hasta alcanzar una coloración negra total en la muestra $80-100 \mathrm{~cm}$. Estas muestras mantiene sus valores de moda y media granulométrica en la fracción arcilla (8,8 $10,2 \varphi)$. Este tramo presenta un fuerte olor pútrido y fragmentos vegetales en degradación. En la sección superior $(0-80 \mathrm{~cm})$ las muestras son arcillo limosas, de color negro (5 YR 4/1), con moda y media granulométrica en la fracción arcilla $(8,8-9,5 \varphi)$ (Figura 6.21).

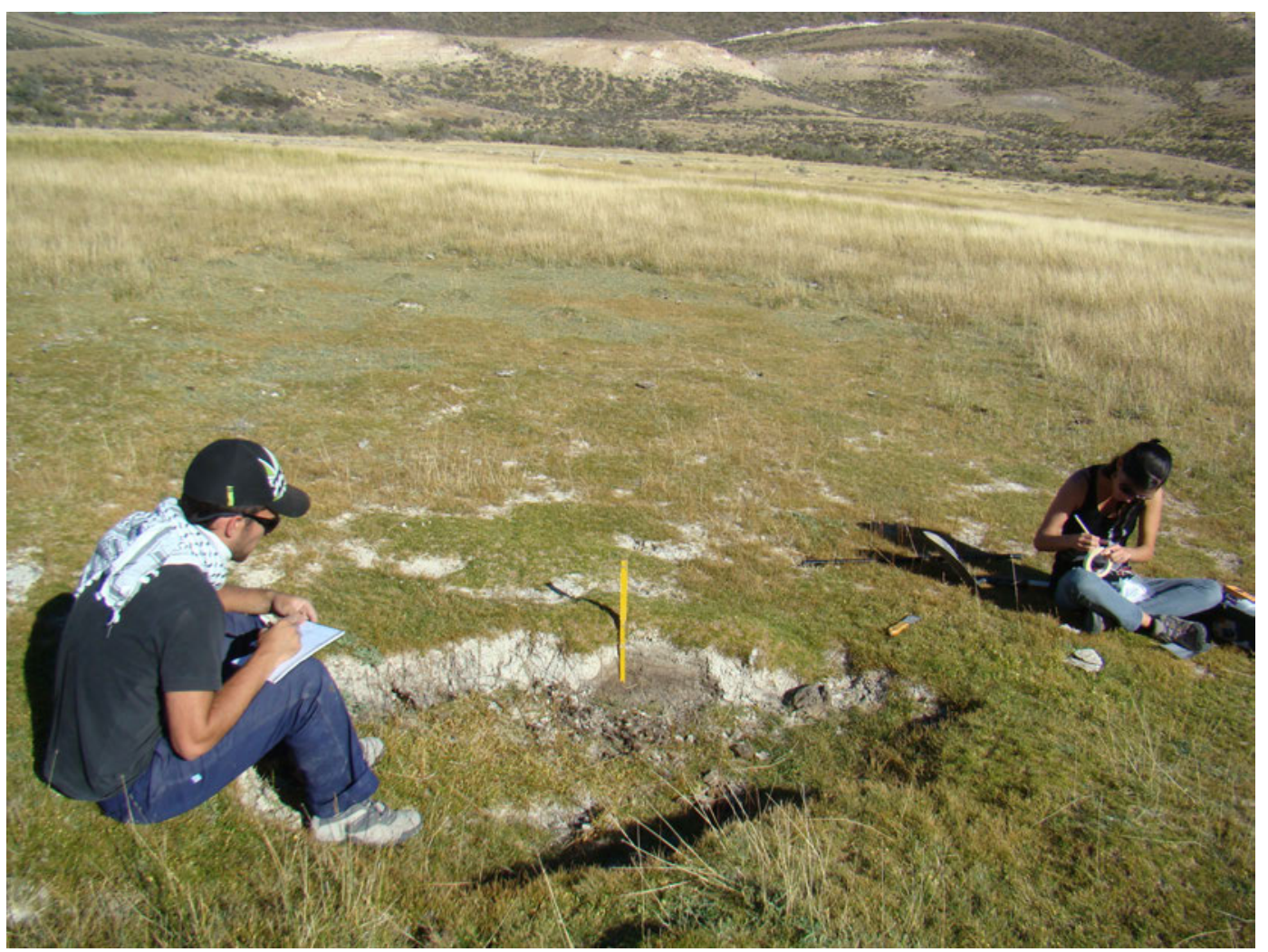

Figura 6.20: Imagen del entorno del que se obtuvo el testigo MLP-2 dentro del Mallín La Primavera.

\subsubsection{MLP-3}

Este testigo, a diferencia de los dos anteriores, no fue realizado directamente sobre el mallín sino sobre uno de sus márgenes. Este sector se caracteriza por un cambio florístico claro, donde la cobertura graminosa propia del mallín es desplazada por una en la que prevalece la arbustiva (Figura 6.22). Se escogió un punto en el que se relevó un sitio en superficie denominado La Playita (Magnin y Blanco 2006; Magnin 2010). El testigo obtenido 


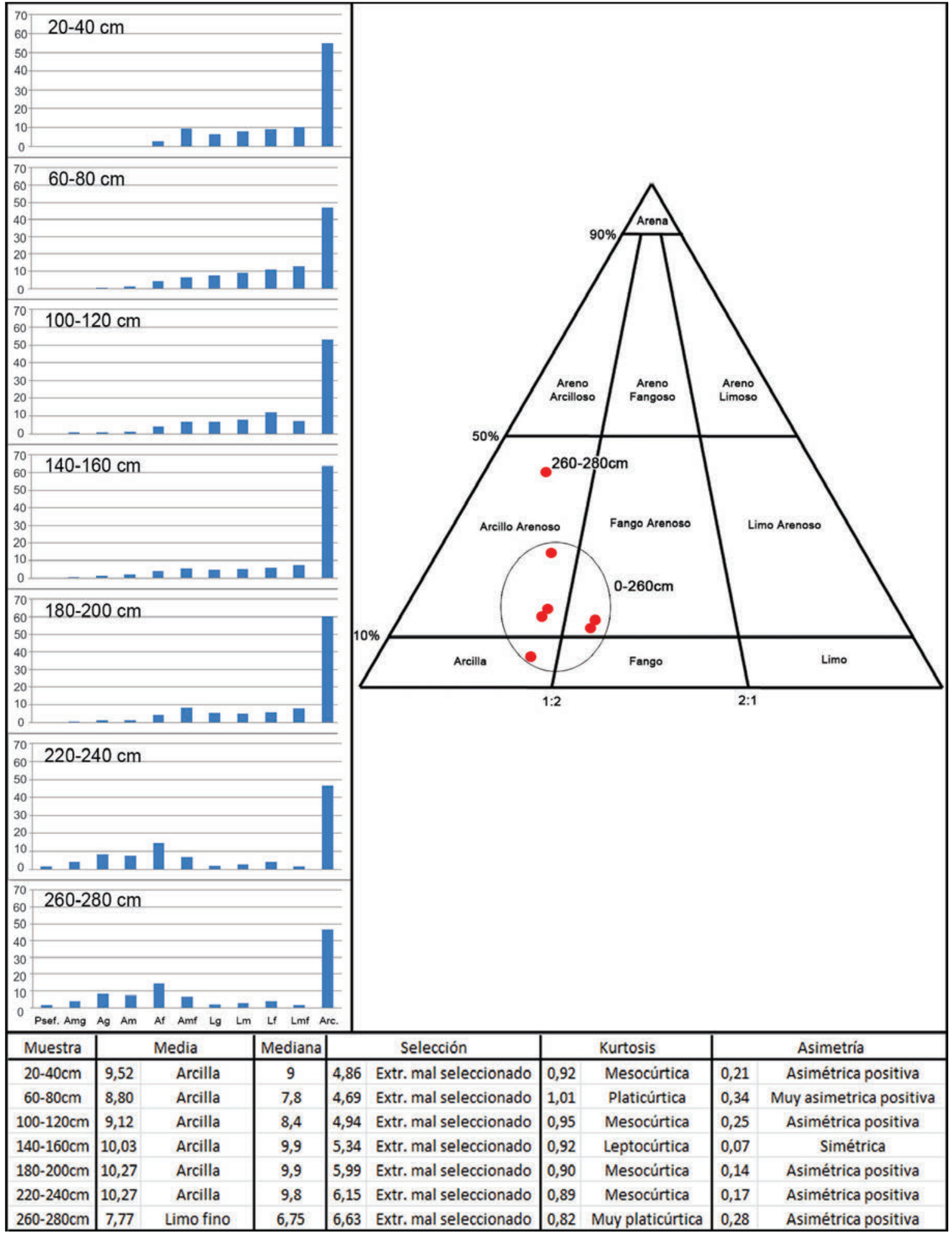

Figura 6.21: Caracterización sedimentaria de las muestras del testigo MLP2. 
alcanzó 2,2 m, totalizando 11 muestras.

Los análisis realizados muestran tres agrupamientos texturales. El primero de estos agrupamientos está conformado por las cinco muestras que componen el metro basal $(120-220 \mathrm{~cm})$ que son de color verde (5 YR 5/1). Se caracteriza por una textura areno arcillosa con medias granulométricas en la fracción limo grueso (entre 4,07 y 4,83 $\varphi$ ), las distribuciones granulométricas son bimodales con una moda principal entre arena media y fina, y la otra en la fracción arcilla (Figura 6.22). Por encima de esta sección se reconoce el segundo agrupamiento textural que incluye a las muestras comprendidas entre los 40 y $120 \mathrm{~cm}$. Esta sección presenta una textura fango arenosa de color gris claro (5 Y 7/1), con distribuciones granulométricas polimodales con modas en arcilla, arena fina y psefitas. Los tamaños promedio de granos se ubican en limo grueso y limo fino $(4,77-6,27 \varphi)$. El segmento superior del testigo está formado por el agrupamiento de las dos muestras más superficiales. Estas son muestras areno limosas y en la superior $(0-20 \mathrm{~cm})$ hay un aporte de grava superior al 10\%. A diferencia del resto del testigo, las medias granulométricas se ubican en la fracción arena fina y media $(2,77$ $1,8 \varphi)$ (Figura 6.22).

\subsubsection{MLP-5}

Este muestreo se realizó en la ladera del cañadón La Primavera, a 400 m de Cueva Maripe y del testigo MLP-6. En este sector se recuperó un sitio en superficie denominado La Quinta (Magnin 2010). El punto de extracción del testigo se encuentra a unos $4 \mathrm{~m}$ sobre la superficie actual del mallín y a unos $3 \mathrm{~m}$ de una surgente de agua. Este muestreo presentó complicaciones para su obtención ya que el sustrato era muy duro y de hecho en el proceso de perforación se quebró la punta del barreno quedando enterrada a 1,6 m de profundidad.

El testigo completo presenta una profundidad máxima de 1,4 m. A diferencia de los muestreos ya presentados, en este caso cobra relevancia la fracción grava, por lo que se utilizó el triángulo grava-arena-fango para caracterizar las muestras.

Las muestras son fango gravosas, de color castaño y sin evidencia de bioturbación. Entre los 40 y $100 \mathrm{~cm}$ las muestras presentan concreciones carbonáticas. En cuanto a su textura, presentan distribuciones polimodales con su moda principal en la fracción arena fina. Los valores de media granulo- 


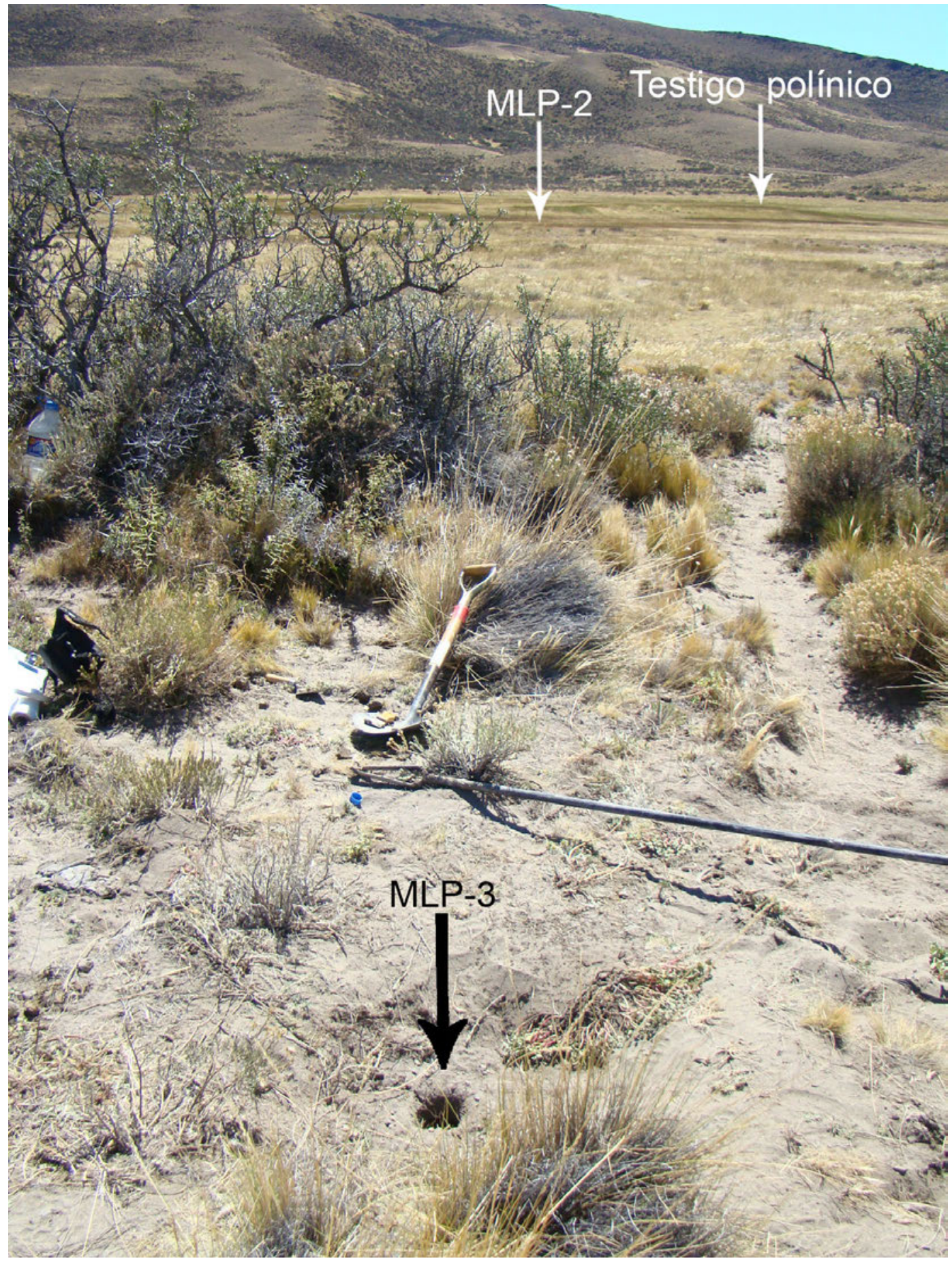

Figura 6.22: Sector de la extracción del testigo MLP-3 en relación con los muestreos polínico y MLP-2. 


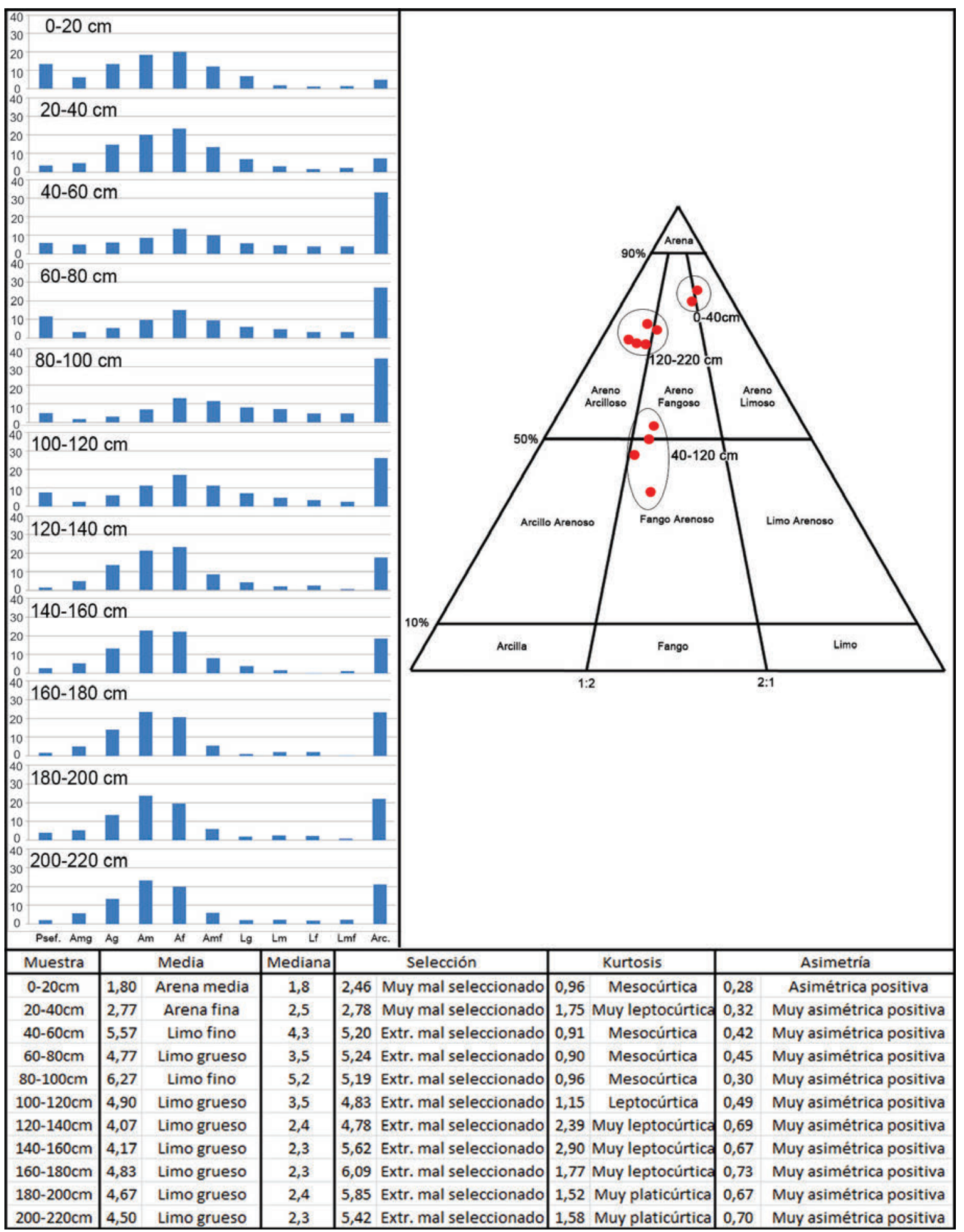

Figura 6.23: Caracterización sedimentaria de las muestras del testigo MLP3. 
métrica se ubican en arena media y fina (entre 1,93 y 3,3 $\varphi$ ) (Figura 6.25).

\subsubsection{MLP-6}

Este muestreo fue obtenido en el mallín La Primavera, frente a la Cueva Maripe (Figura 6.24). Se seleccionó un sector semihúmedo del mallín en el cual se extrajeron $2 \mathrm{~m}$ de testigo.

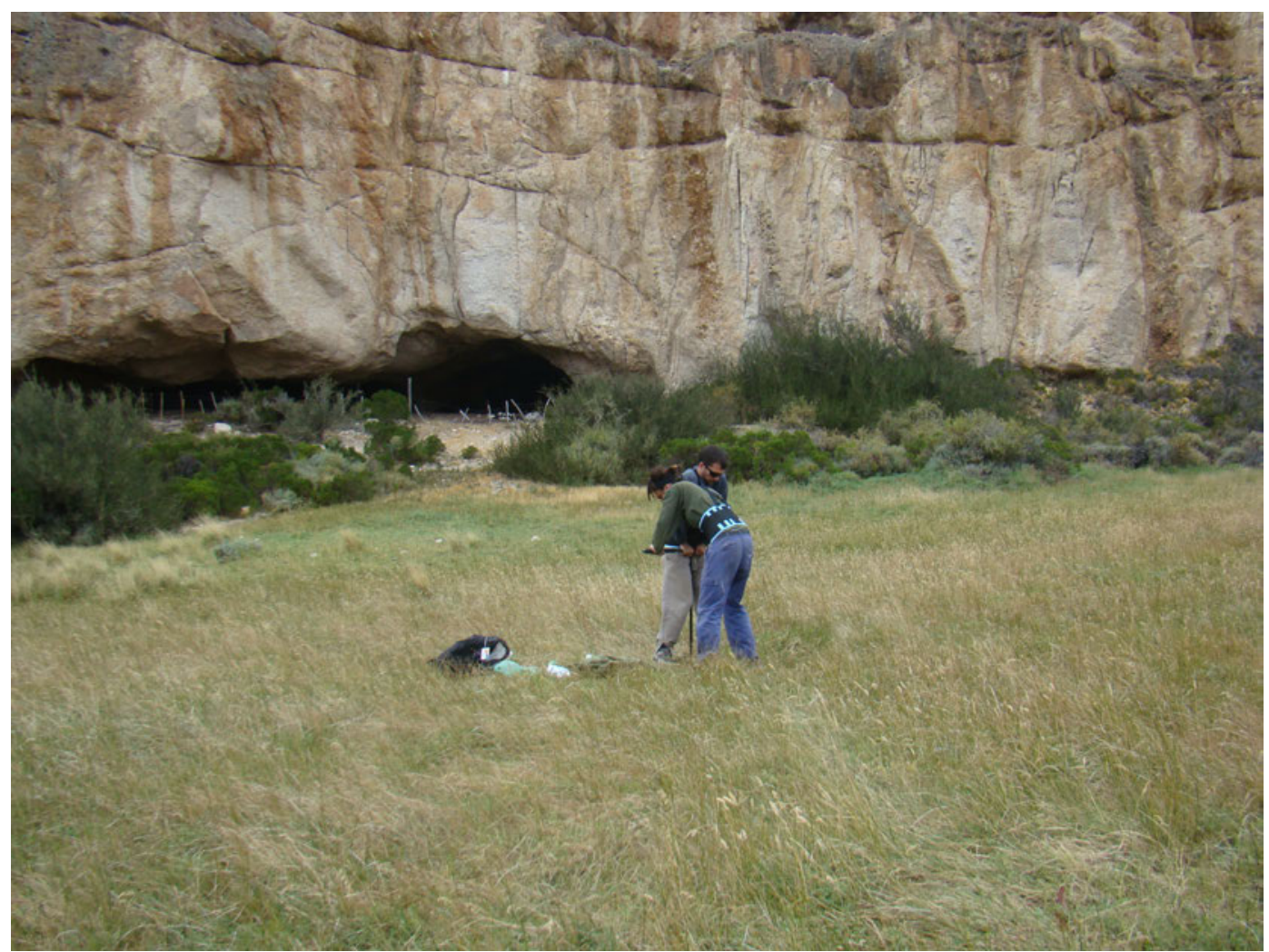

Figura 6.24: Extracción del testigo MLP-6 sobre el Mallín La Primavera. En el fondo se observa la Cueva Maripe.

Las muestras de este testigo se clasifican texturalmente como arcilla, fango y fango arenoso, con bajo aporte de arena. Las dos muestras que presentan mayor porcentaje de arena y se alejan de las demás son las correspondientes a la base de la columna sedimentaria.

El arreglo litológico de este testigo está conformado por $40 \mathrm{~cm}$ basales $(160-200 \mathrm{~cm})$ de fango arenoso de color verde (5 YR 6/4). Estas muestras presentan distribuciones bimodales, con su moda principal en la fracción arcilla y una moda secundaria en arena fina, mientras que sus medias granulométricas e ubican en la fracción limo (5,8-6,93 $\varphi)$. Se envió a datar una 


\begin{tabular}{lcccc}
\hline \multirow{2}{*}{ Código } & \multirow{2}{*}{ Edad ${ }^{14}$ C AP (1 $\left.\sigma\right)$} & \multicolumn{2}{c}{ Edad cal. AP } & \multirow{2}{*}{ Material } \\
\cline { 3 - 4 } & & Desde & Hasta & \\
\hline D-AMS 007083 & $4910 \pm 28$ & 5711 & 5591 & Sedimento \\
\hline
\end{tabular}

Tabla 6.3: Datación radiocarbónica obtenida en el testigo MLP6.

muestra de sedimento de la extracción correspondiente a 160-180 cm, cuyo resultado fue $4910 \pm 28$ años ${ }^{14} \mathrm{C}$ AP (Tabla 6.3).

El segmento superior de la secuencia que abarca desde 1,6 m de profundidad hasta la superficie, está conformado por sedimentos arcillosos a fango arenosos de color negro (2,5 Y 4/0). En este tramo se registró la presencia de raíces. Las distribuciones granulométricas presentan una moda principal en la fracción arcilla y una secundaria en la fracción limo, y sus tamaños de grano medio (Figura 6.28).

\subsubsection{Valoración de resultados}

El análisis sedimentológico del Mallín La Primavera muestra que el arreglo litológico de los tres testigos realizados en el fondo del mallín (MLP-1, MLP-2 y MLP-6) presenta claras similitudes (Figura 6.26). Las texturas predominantes, son arcillo arenosas y fango arenosas principalmente En los casos que hay muestras que se separan del resto, se trata de las que provienen del techo o de la base del testigo (ver Figuras 6.28, 6.19 y 6.21). El color ha sido una característica común a los tres testigos ya que se ha podido reconocer una base de tonalidad verde y por sobre esa capa una sección de color oscuro. Este cambio es gradual, ya que entre ambos depósitos se observan moteados. Estos rasgos hidromórficos permiten inferir el sector del testigo en el cual oscila el nivel freático. Las medias granulométricas y las distribuciones responden a ambientes de muy baja energía, con estancamientos de agua y/o de flujos muy débiles. La presencia de raíces en descomposición es casi constante en estos muestreos marcando una continuidad en la cobertura vegetal de estos ecosistemas, a no ser que el mallín se encuentre degradado.

Por otro lado, el testigo recuperado en el margen del mallín (MLP-3) con una leve diferencia de altura sobre el mismo (aproximadamente $1 \mathrm{~m}$ ), presenta un desarrollo textural con granulometrías más gruesas que las reconocidas en el fondo del mallín con tres agrupamientos claros. En este tes- 


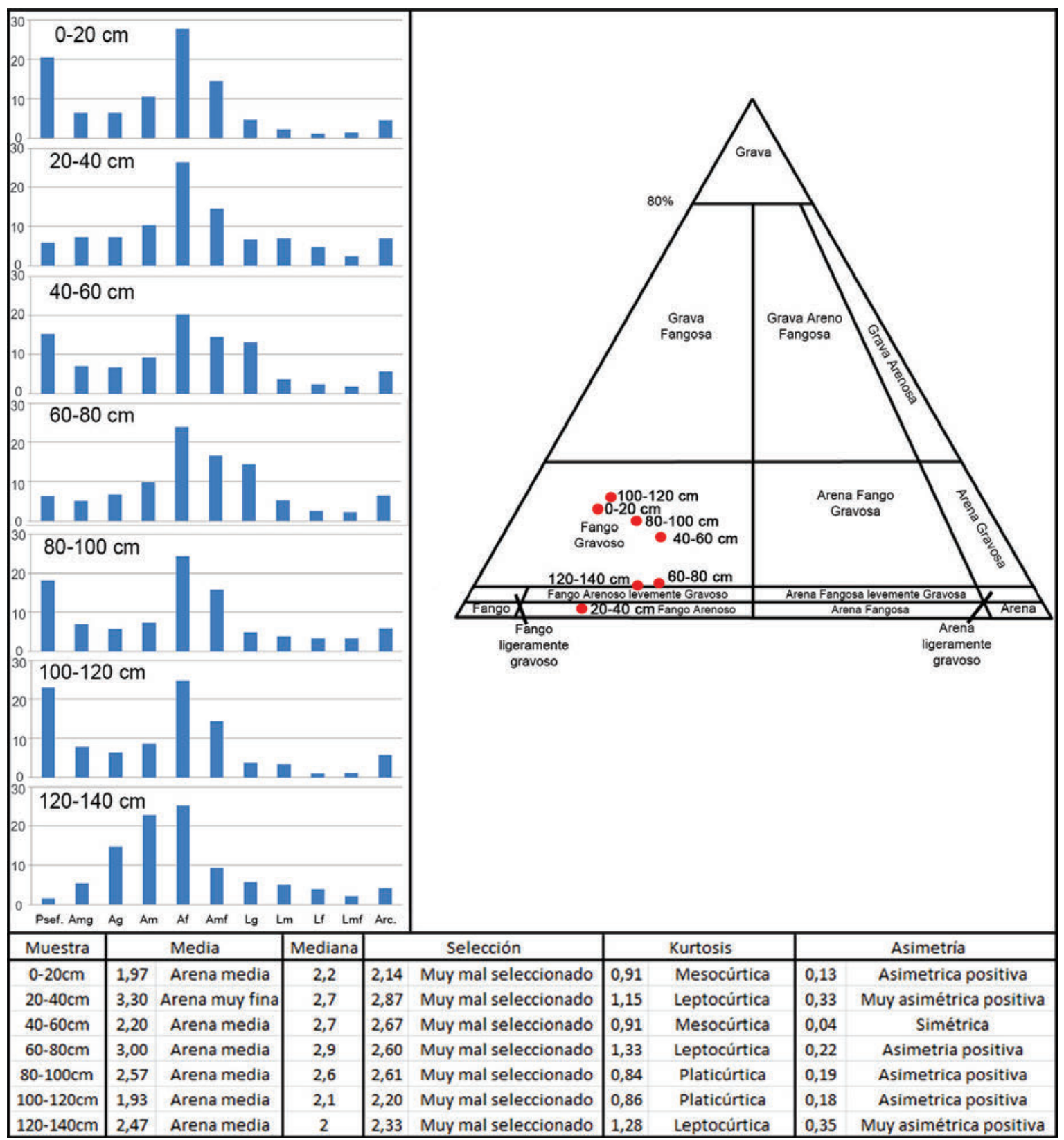

Figura 6.25: Caracterización sedimentaria de las muestras del testigo MLP5. 
tigo no se reconoció claramente la secuencia con rasgos hidromórficos que pudieron caracterizarse en los mallines, lo que permite inferir que el mallín no se habría expandido lateralmente. El barreno realizado en la ladera del cañadón (MLP-5) responde a un perfil totalmente diferente al resto, con sedimentos gravosos y sectores de roca semiconsolidada, posiblemente resultado de depósitos coluviales.

El fechado obtenido en MLP-6 nos permite establecer una edad mínima para la base de este testigo $\left(4910 \pm 20\right.$ años ${ }^{14} \mathrm{C}$ AP) en el Holoceno medio, lo que resulta interesante también desde el punto de vista de la potencia sedimentaria con 1,8 m depositados durante los últimos ca. 5000 años ${ }^{14} \mathrm{C}$ AP. Esto contrasta fuertemente con las tasas de depositación reconocidas en Cueva Maripe y nos permite contar con información comparativa para el Holoceno. Los datos sedimentológicos de este testigo, marcan un cambio textural entre momentos previos a la datación y momentos posteriores con una prevalencia de la fracción arena en la base y una mayor importancia de la fracción arcilla en el segmento superior.

\subsection{Análisis de proxies ambientales}

\subsubsection{Polen}

La reconstrucción de asociaciones polínicas del sector de la Cuenca Alta, fue realizada a partir de un muestreo sin disturbar obtenido en el mallín La Primavera (Figuras 6.27 y 5.6). Este análisis es el primero que se realiza en un mallín dentro del Macizo del Deseado.

Con la intención de ubicar cronológicamente los cambios polínicos a lo largo del testigo hemos realizado dos fechados radiocarbónicos (Tabla 6.4). Estos fechados presentan una inversión cronológica y están separados por una distancia de 0,5 m. A pesar de esto, la diferencia cronológica entre ambos es relativamente pequeña (623 años $\left.{ }^{14} \mathrm{C} \mathrm{AP}\right)$, lo que nos permite ubicar al muestreo con una antigüedad que al menos llega al Holoceno Medio.

Las asociaciones polínicas reconocidas, muestran algunas variaciones a lo largo del testigo. Previamente al fechado de $6920 \pm 33$ años ${ }^{14} \mathrm{C}$ AP, predomina el estrato herbáceo representado tanto por poáceas como por cyperáceas siendo estas últimas las más abundantes con frecuencias mucho mayores que el resto de la secuencia. En cuanto a los arbustos y subarbus- 
Testigos extraidos del mallin

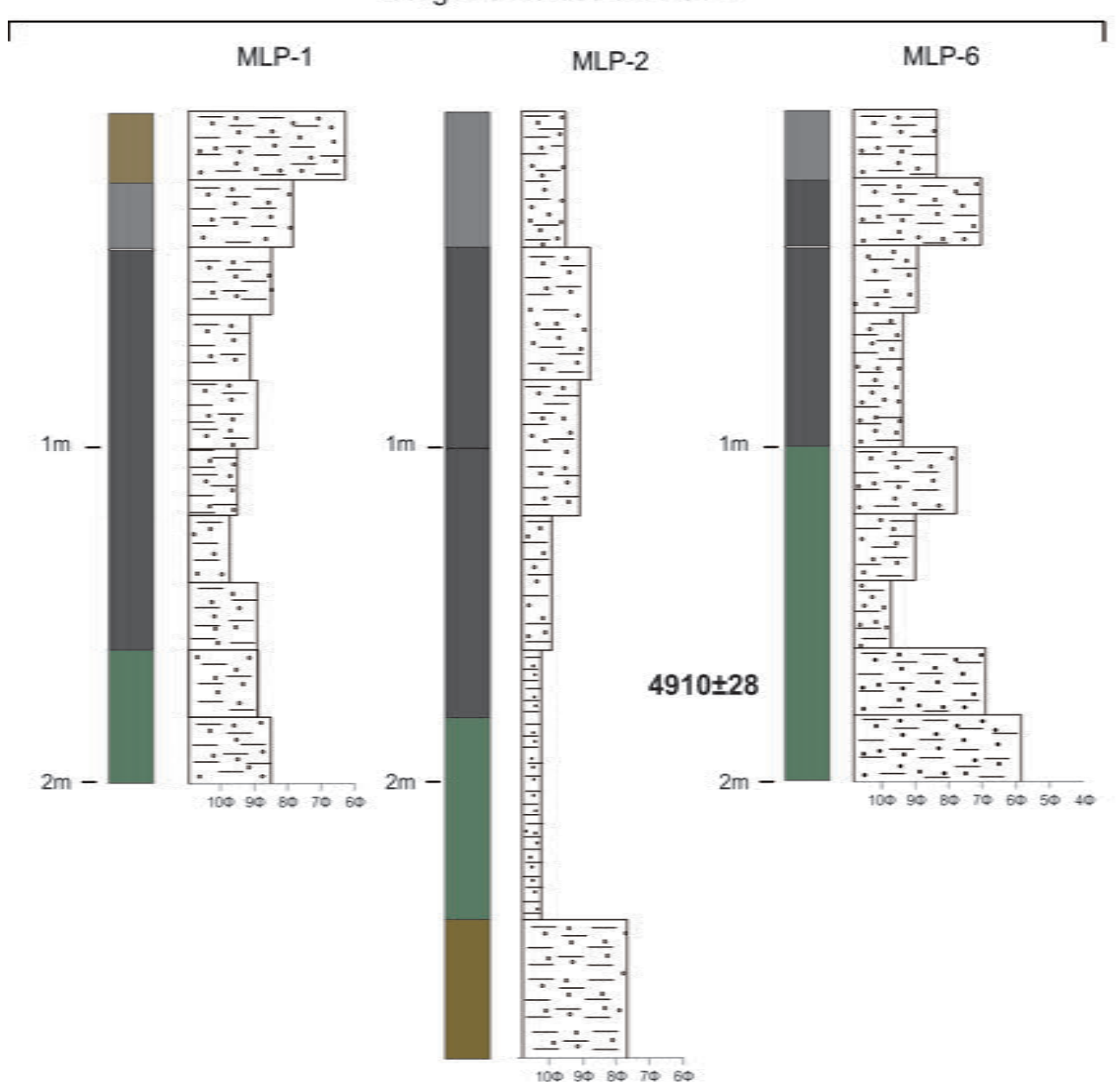

Margen del mallín y ladera

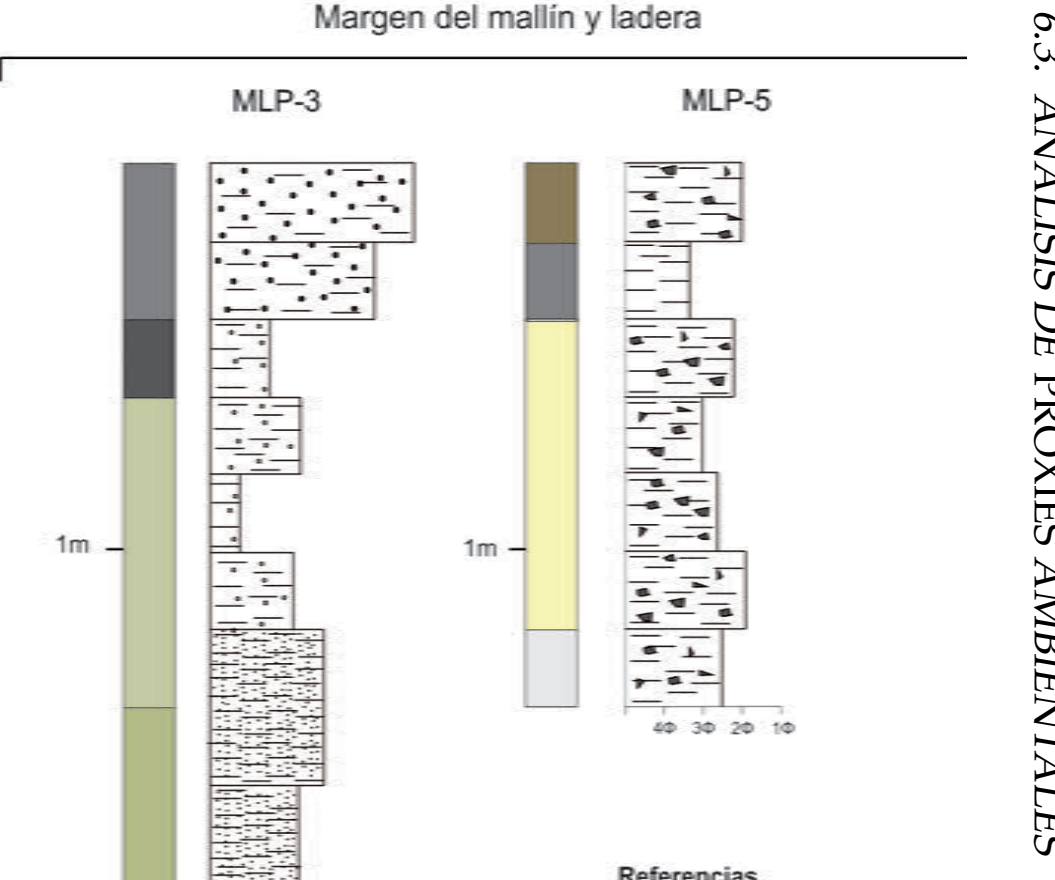

Referencias

Figura 6.26: Columnas estratigráficas de los barrenos realizados en el Mallín La Primavera y sectores aledaños. 


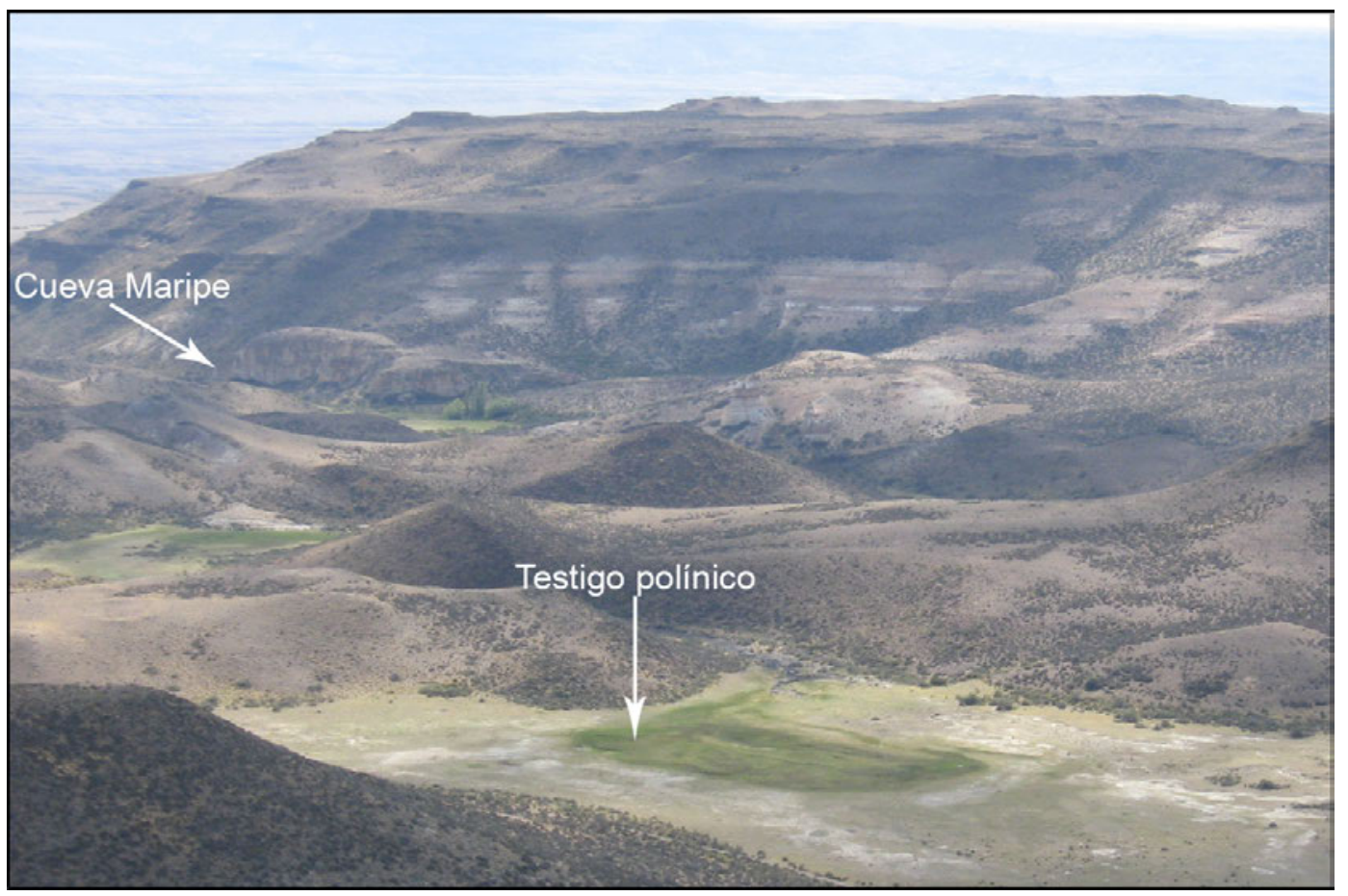

Figura 6.27: Vista del Mallín La Primavera mostrando la ubicación del muestreo polínico y su relación con el Cueva Maripe. La foto está tomada desde las cabeceras del cañadón en dirección NE pudiendo observar, en el fondo de la misma, el bajo en el que corre el Zanjón Blanco.

tos, hay mayor variabilidad que en el resto de la secuencia, entre las que se registró Ast. Asteroideae, Nassauvia, Ephedra, Azzorella y Chenopodiineae entre los más frecuentes. Por su parte los porcentajes de polen de larga distancia, como Nothofagus y Podocarpus son muy bajos.

Entre los fechados $7543 \pm 34$ y $6920 \pm 33$ años ${ }^{14} \mathrm{C}$ AP hay un aumento considerable de gramíneas de la familia poaceae pero disminuyen notablemente las cyperaceae. El polen de arbustos y subarbustos de Ephedra, Nassauvia y Chenopodiineae disminuyen sus frecuencias mientras que Ast. asteraceae mantiene frecuencias similares y se observa un aumento muy importante

\begin{tabular}{lcccc}
\hline \multirow{2}{*}{ Código } & \multirow{2}{*}{ Edad ${ }^{14}$ C AP (1 $\left.\sigma\right)$} & \multicolumn{2}{c}{ Edad cal. AP } & \multirow{2}{*}{ Material } \\
\cline { 3 - 4 } & & Desde & Hasta & \\
\hline D-AMS 007081 & $7543 \pm 34$ & 8391 & 8201 & Carbón \\
\hline D-AMS 007082 & $6920 \pm 33$ & 7794 & 7619 & Carbón \\
\hline
\end{tabular}

Tabla 6.4: Dataciones radiocarbónicas del testigo polínico obtenido en el Mallín La Primavera. 
de un hongo del género Glomus, el cual se asocia a pastizales y se relaciona con pérdidas de humedad de los suelos (Chmura et al. 2006).

En el tramo ubicado por encima del fechado de $7543 \pm 34$ años ${ }^{14} \mathrm{C}$ AP disminuyen considerablemente la frecuencia de poáceas, mientras que las cyperáceas prácticamente desaparecen, y se observa un incremento en la frecuencia de polen de arbustos Ast. Asteroideae (el mayor de la secuencia hasta el momento), mientras que los valores de Glomus disminuyen, pero manteniéndose en niveles altos.

\subsubsection{Fitolitos}

Los estudios de silicofitolitos provenientes de sitios arqueológicos son escasos en la región patagónica, por lo que la inclusión de estos análisis en la tesis aporta información de escala local, tanto de Cueva Maripe como del Mallín La Primavera, y representa información de base para los posteriores análisis de este tipo que puedan desarrollarse en la región. Los análisis e interpretaciones de los datos se están realizando en conjunto con la Dra. Margarita Osterrieth y su equipo del Instituto de Geología de Costas y del Cuaternario de la Universidad Nacional de Mar del Plata, por lo que aquí presentamos un avance parcial de dichos análisis (Osterrieth et al. 2015). La estrategia de muestreo consistió en obtener, por un lado, una secuencia de fogones para cuyo fin se seleccionó la $\mathrm{CN}$, que es el sector de la cueva en el que se registró la mayor cantidad de estructuras formales de fogón (Figura 6.30). De esta manera fueron seleccionadas seis muestras de fogones de distintos perfiles y una muestra de la capa más superficial (capas 1) formada por estiércol de ganado que selló la secuencia. Por otro lado, en CS se seleccionaron muestras de todas las capas que componen la secuencia estratigráfica complementando y relacionándolas con las de $\mathrm{CN}$. Por su parte, se realizó el muestreo sobre el mallín La Primavera con barreno helicoidal a $50 \mathrm{~m}$ de la línea de goteo de la cueva donde se obtuvo un testigo de $2 \mathrm{~m}$ de altura correspondientes a diez muestras de $20 \mathrm{~cm}$ de espesor cada una.

Por último, se analizaron dos muestras de suelo de los 0-10 cm superficiales correspondientes al sector de mallín y a la cueva, sin evidencias de acción antrópica. Además, se analizaron pellets provenientes de ganado que actualmente pastorea en el área como vaca (Bos taurus) y oveja (Ovis aries). Estas muestras fueron utilizadas como parámetro actualístico. 


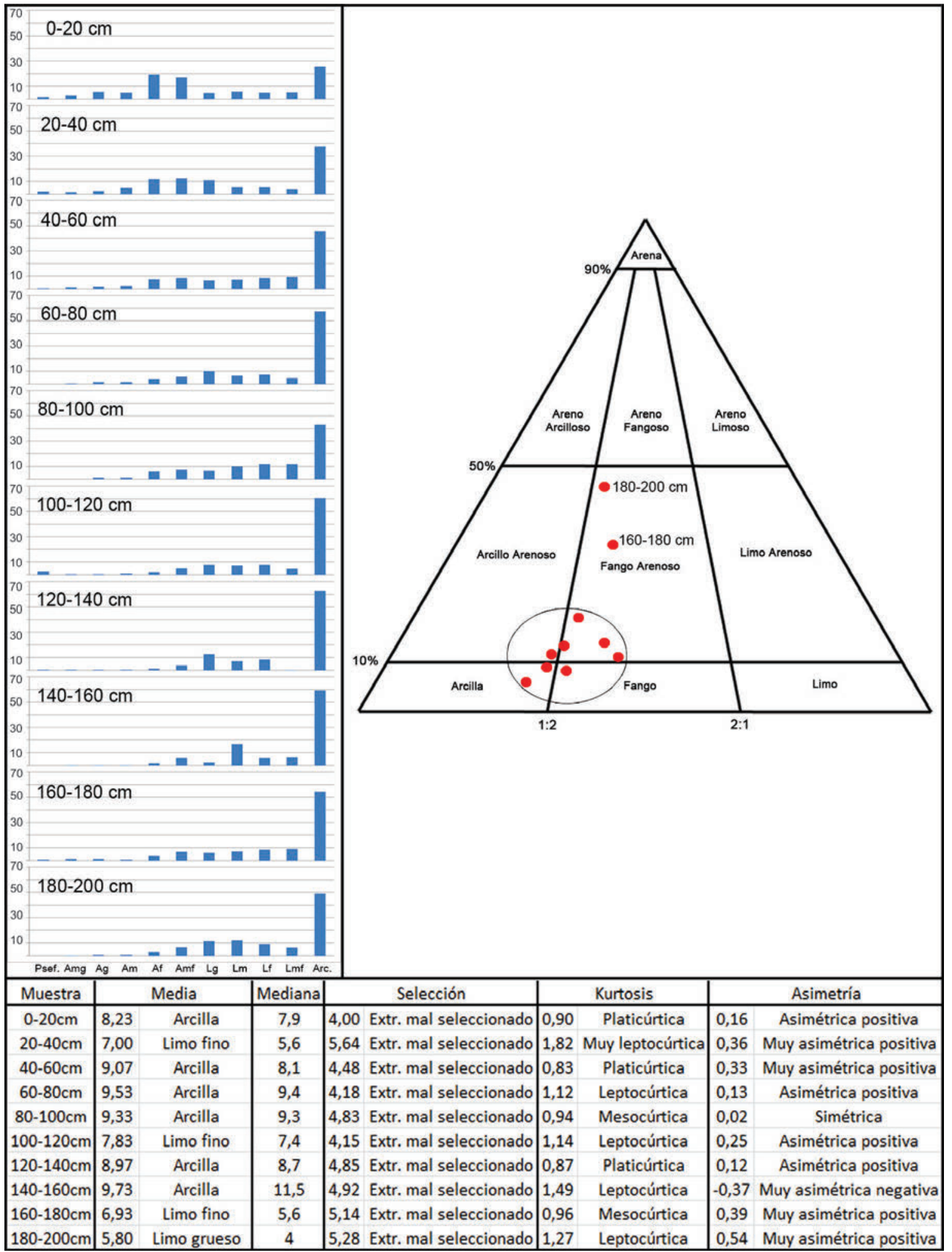

Figura 6.28: Resultados del análisis sedimentológico de las muestras del testigo MLP-6. 


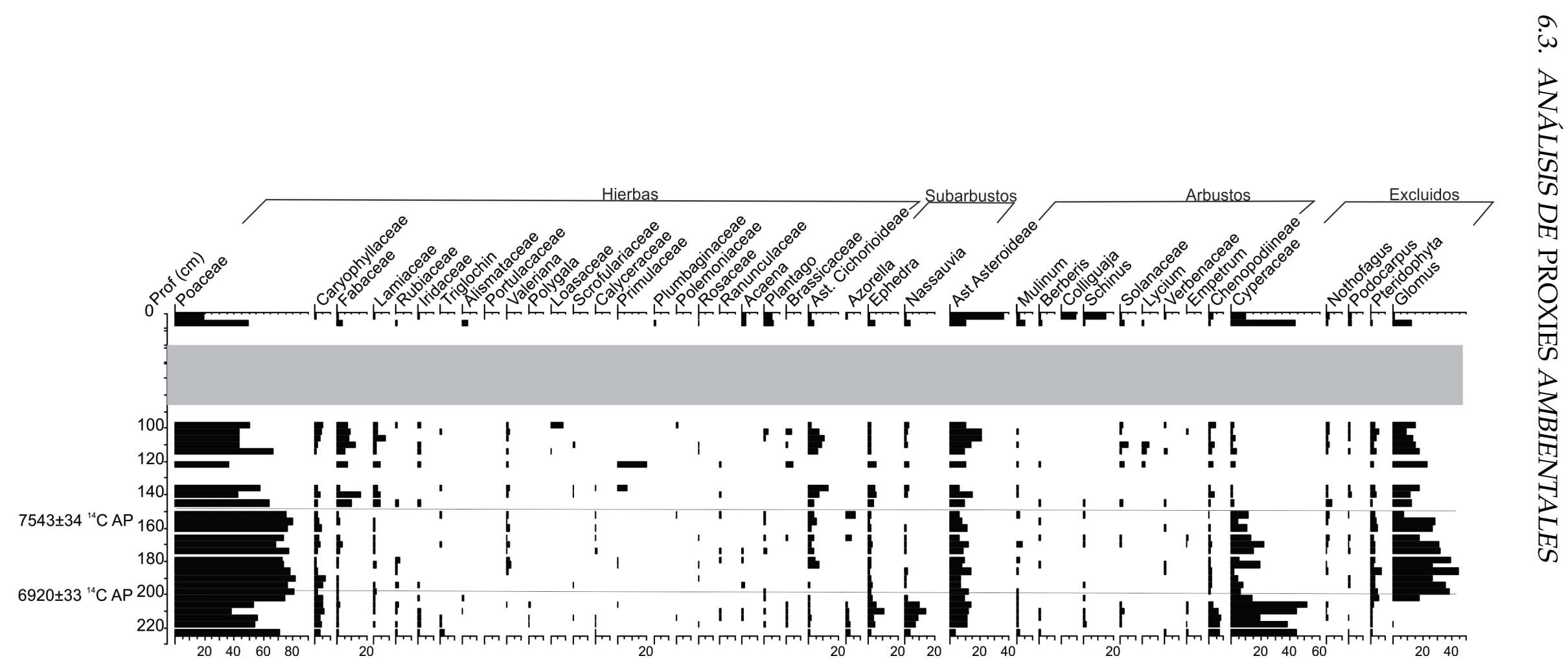

Figura 6.29: Diagrama polínico del testigo extraído del Mallín La Primavera. 
Cámara Norte

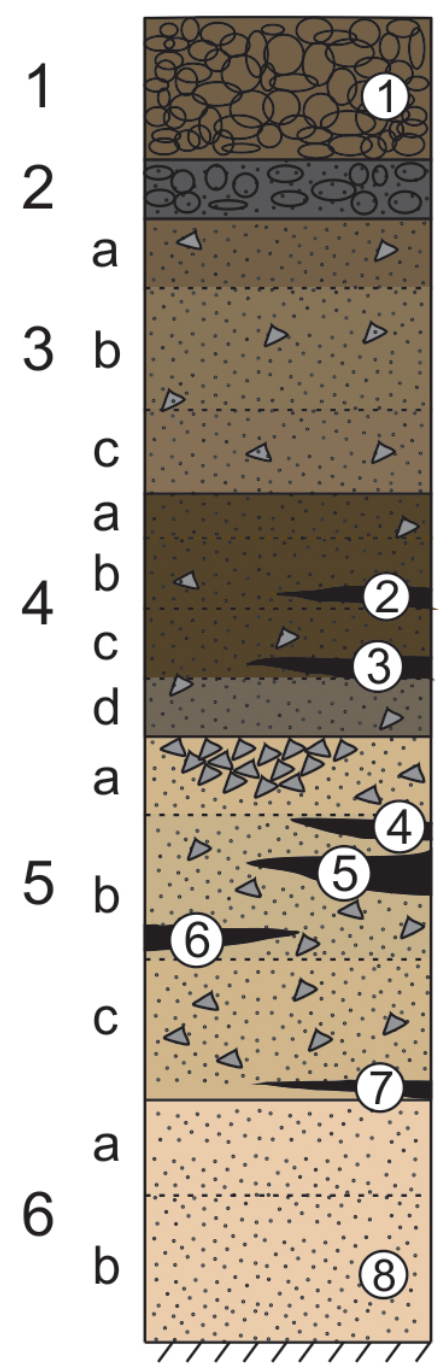

Cámara Sur

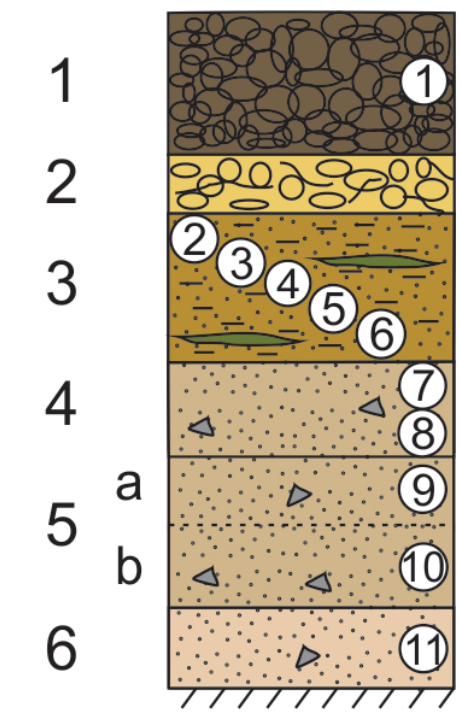

Arena gravosa

Grava Arenosa

Arena

Estiércol quemado

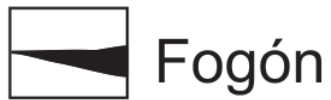

Fango con laminación

(1) Muestra de fitolitos

Figura 6.30: Perfiles esquemáticos de Cámara Norte y Cámara Sur que señalan el lugar de procedencia de las muestras. 


\subsubsection{Cámara Norte}

En el caso de Cámara Norte, los fitolitos completan entre 40 y $80 \%$ del total de las partículas contabilizadas en cada muestra.

En este sector las muestras provienen de fogones, y predominan las morfologías rondel (Pooide) y los elongate (tanto psilate como crenate), los cuales en conjunto alcanzan entre el 40 y el $60 \%$ del total de morfologías. Los elongates se pueden asignar a un amplio espectro de familias de monocotiledóneas (gramíneas, ciperáceas y juncáceas) y dicotiledóneas, por lo que su potencial diagnóstico es muy bajo. Los rondels por su parte, son asignados principalmente a Pooideae y Stipoideae, mientras que en el perfil también se han reconocido bajos porcentajes de otras morfologías de gramíneas como bilobate y saddle, presentes en Poaceae. Los bilobate pueden ser producidos por especies de Panicoideae (Bilobate panicoid, polylobate, simple lobate), Stipoidea (Stipa bilobate, simple lobate) y Chloridoideae (Saddle).

De las muestras analizadas, solo dos muestran variaciones en cuanto las morfologías predominantes (Figura 6.31): la muestra 1 (depósito de estiércol histórico) y la muestra 2 que proviene de un fogón datado en $3781 \pm 42$ años ${ }^{14} \mathrm{C}$ AP. En el caso de la muestra 1 se observa un aumento en las poáceas (simple lobate y papillae) y en dicotiledóneas (tabular), lo que en este caso se asume como resultado de la selección que el ganado hace de la vegetación para comer. Por su parte, la muestra 2 presenta diferencias con el resto de los fogones, con una disminución marcada de simple lobate y un incremento de Stipa lobate, lo que señala un cambio en las gramíneas utilizadas ya que en todas las muestras la frecuencia de los distintos tipos de bilobates y polilobates es constante y uniforme (Figura 6.31).

En la Cámara Sur, las muestras rondan entre el 40 y $90 \%$ de fitolitos por muestra. Las muestras inferiores presentan incrementos en los fitolitos bilobates marcan una clara presencia de gramíneas de las subfamilias Panicoideae y Stipoideae, acompañados por bulliform phytoliths (de gramíneas) y tabular phytoliths (de dicotiledóneas) (Figura 6.32). Hacia la parte superior de la estratigrafía se puede reconocer una clara diferencia entre las muestras de Capa 3 (muestras 2 a 6) y el resto de la secuencia. En este segmento se reconoce una alta abundancia de elongates y rondel, acompañados de trapeziform crenate, que en conjunto con rondel caracterizan a las gramíneas Pooideae. Además, la presencia de fitolitos articulados y de ciperáceas, los cuales son susceptibles a la degradación, indicaría cierta estabilidad en este 


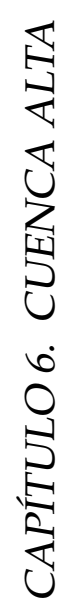

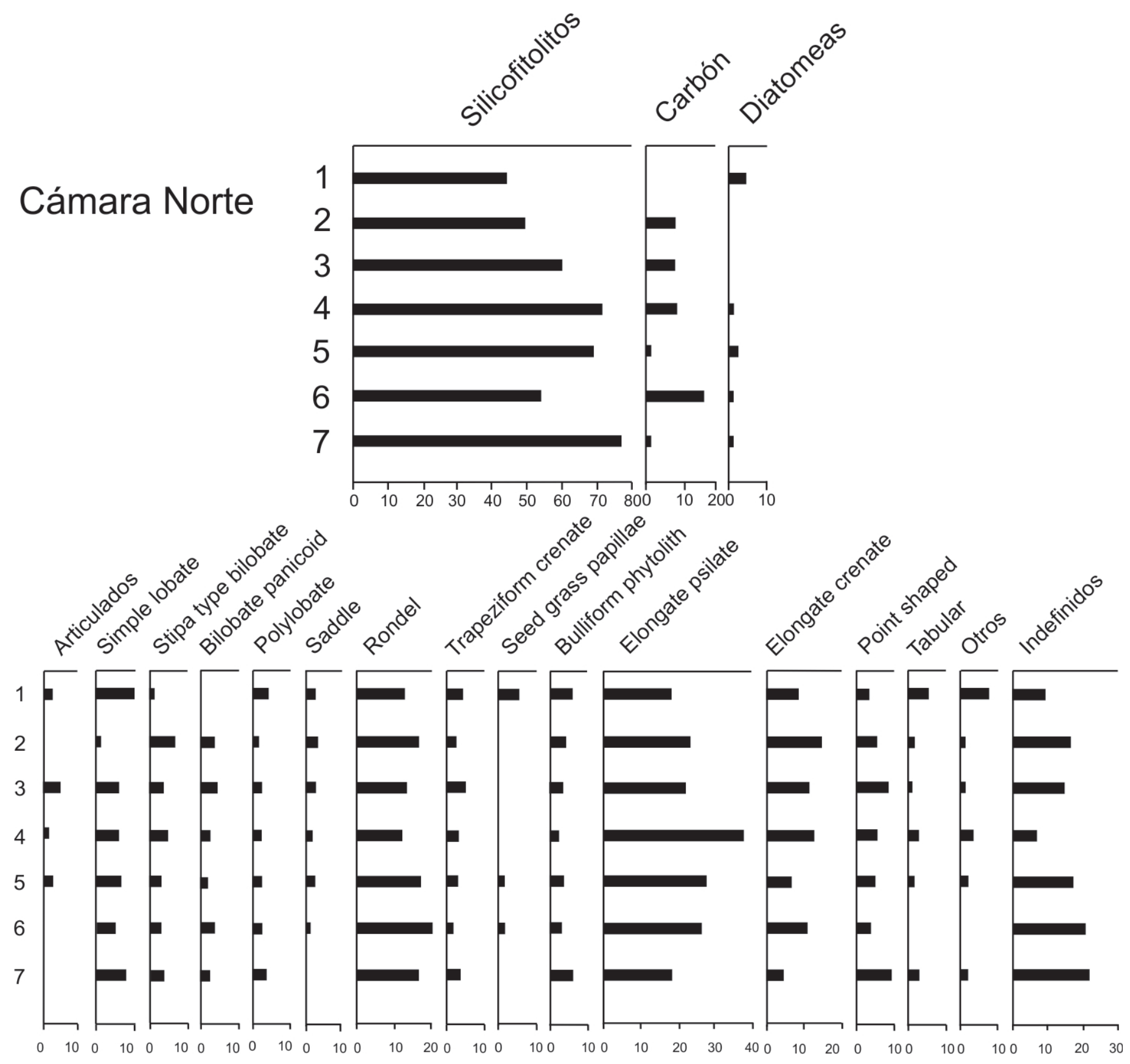

Figura 6.31: Diagrama porcentual de fitolitos de las muestras de Cámara Norte. 


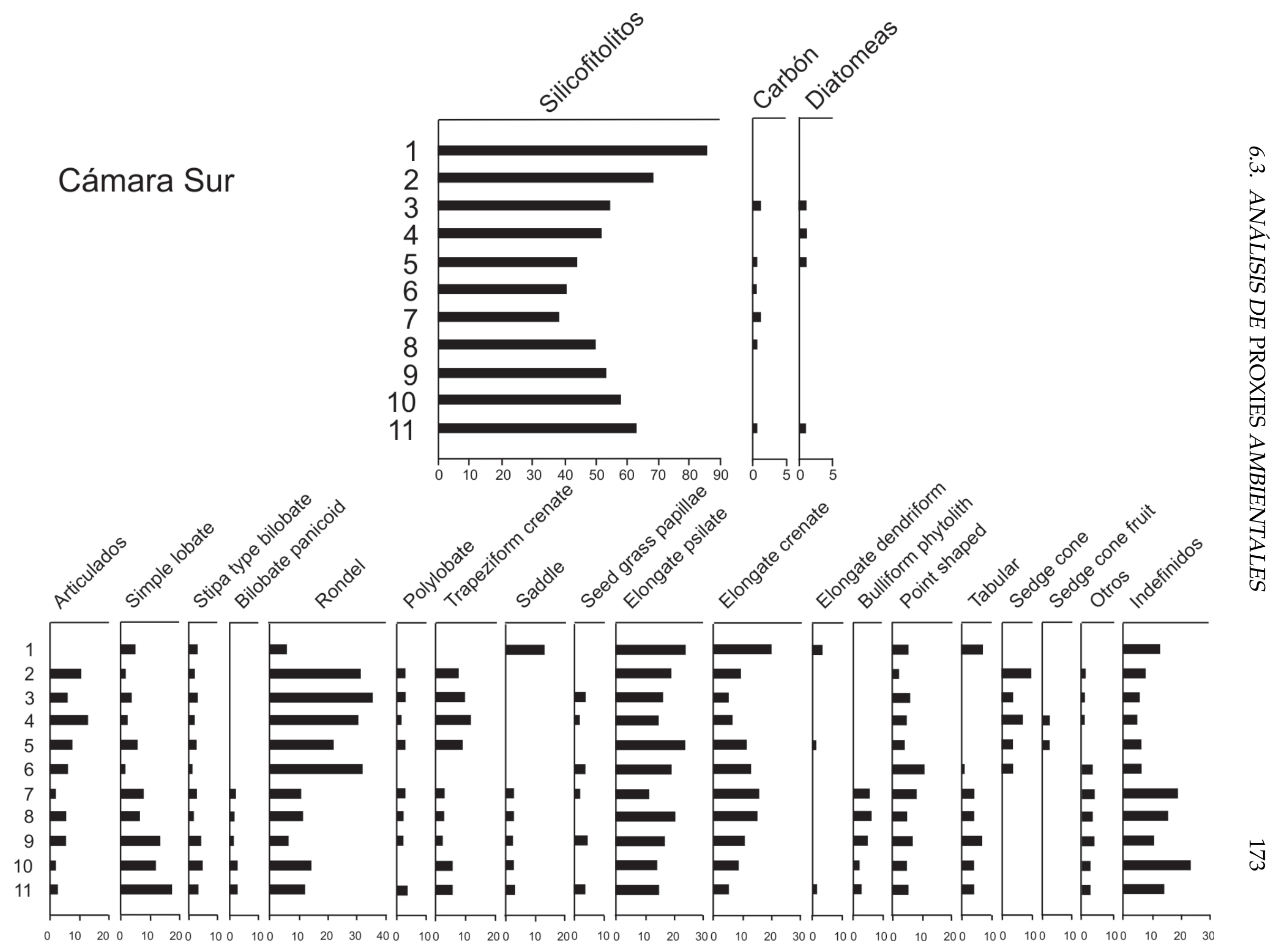

Figura 6.32: Diagrama porcentual de fitolitos de las muestras de Cámara Sur. 
sector. Por lo tanto en la capa 3, se reconoce un cambio claro en la estructura florística.

\subsubsection{Mallín La Primavera}

Las muestras utilizadas son las provenientes del muestreo MLP-6. Los porcentajes de silicofitolitos con respecto al total de partículas de cada muestra ronda entre 13 y $49 \%$ (Figura 6.33), lo que muestra porcentajes mucho menores que los contabilizados dentro de ambas cámaras de Cueva Maripe. Para obtener un referente cronológico del testigo se envió a datar por AMS una muestra de la base (nivel 160-180). Este fechado arrojó una datación de $4910 \pm 28{ }^{14}$ C AP (D-AMS 007083).

Las frecuencias de fitolitos muestran que los rondel, asignados a gramíneas de las subfamilias Pooideae y Stipoideae, y los elongates (sin poder diagnóstico), constituyen las morfologías dominantes en todas las muestras. En sólo dos muestras fueron observados fitolitos articulados $(40-60$ y 60-80 cm) en muy baja proporción $(<2 \%)$.

Entre otros tipos de fitolitos, los trapeziform crenates fueron los dominantes (4-9\%, a excepción del nivel 140-160 cm donde el porcentaje fue nulo). Estos morfotipos son producidos por gramíneas Pooides principalmente. Los fitolitos simple lobate y Stipa type bilobate, producidos por gramíneas Panicoides y Stipoides, presentaron valores muy bajos. Los fitolitos polilobados (subfamilias Panicoideae y Stipoideae) se observaron sólo en los niveles comprendidos entre 0 y $120 \mathrm{~cm}$. Por último, se destaca la importancia de los fitolitos indefinidos, cuyos porcentajes oscilaron entre 1 y $31 \%$, siendo el nivel 180-200 cm el que presentó el valor más elevado.

\subsubsection{Valoración de resultados}

Los análisis de fitolitos nos permiten ahondar en aspectos paleoambientales locales del pasado de Cueva Maripe y del Mallín La Primavera. En este sentido, realizamos tres muestreos para poder recabar información paleoambiental a partir de la inferencia de la estructura vegetal (Cámara Sur y Mallín La Primavera) y por otro lado, interpretar posibles usos de estos vegetales por parte de las poblaciones cazadoras recolectoras.

En este sentido, los análisis de los sedimentos de fogones de $\mathrm{CN}$, muestran una constancia en cuanto a las morfologías de fitolitos presentes. Sólo 


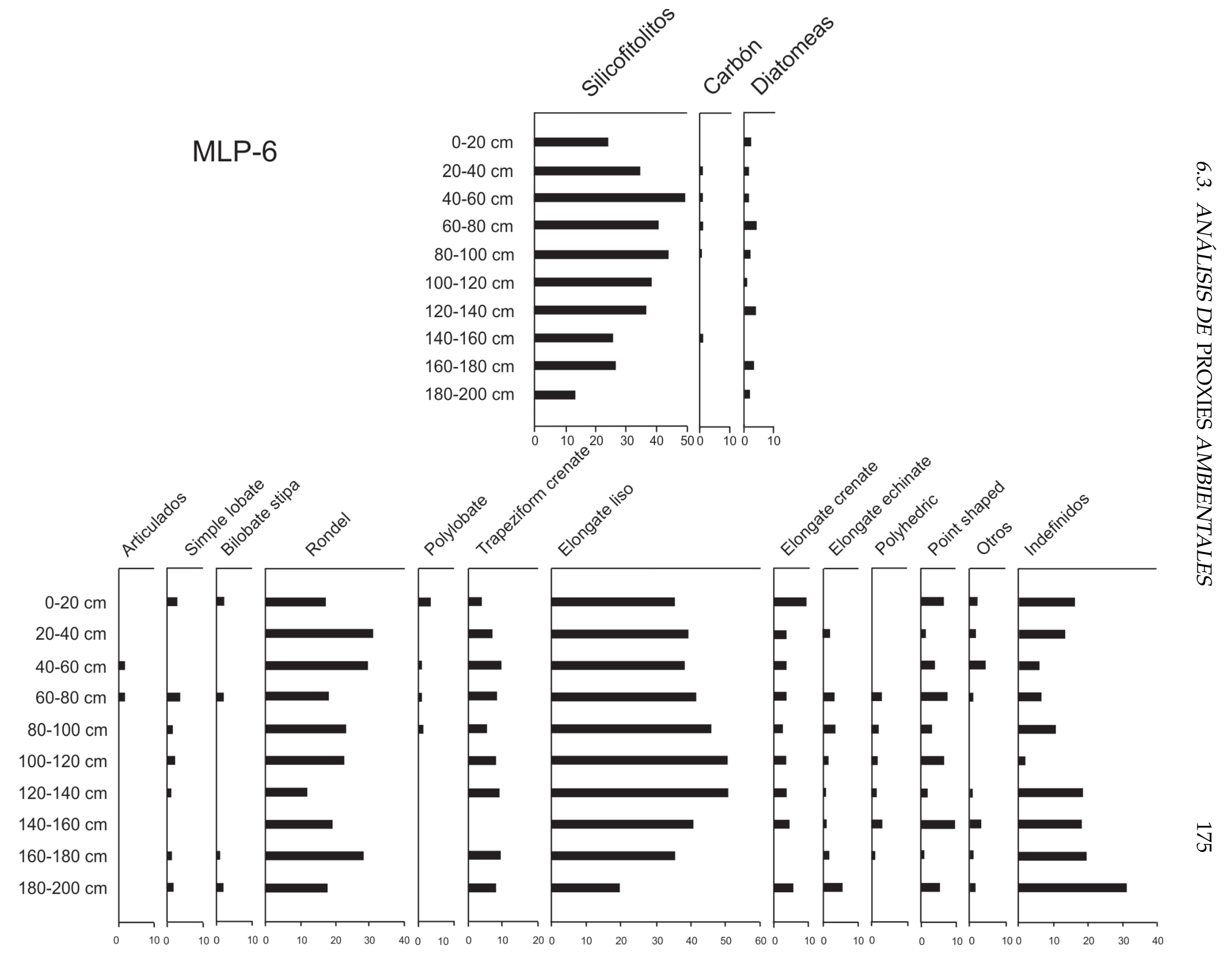

Figura 6.33: Diagrama porcentual de fitolitos de las muestras de MLP6. 
se reconoció una variación en el fogón de la muestra 2, datado en $3781 \pm 42$ años ${ }^{14} \mathrm{C} \mathrm{AP}$, donde la frecuencia de stipa lobate disminuye y se incrementa stipa bilobate. Más allá de este cambio leve, la secuencia presenta valores casi similares en las morfologías y los tipos representados.

Por otro lado, en CS, a partir de un muestreo diferente al de CN que apuntó a recuperar una secuencia sedimentaria respetando la estratigrafía, se pudo reconocer un cambio en la estructura vegetal. En este sentido, el segmento inferior de la estratigrafía se caracteriza por frecuencias relativamente altas de morfologías asignables a Panicoideae y Stipoideae (Simple lobate, stipa bilobate, bilobate panicoid), a otras gramíneas (Bullyform phitolyth) y a dicotiledóneas (Tabular). Mientras que en el segmento superior representado por la capa 3, hay un cambio notorio, ya que disminuyen fuertemente las morfologías mencionadas para el segmento inferior y hay un claro aumento de las morfologías perteneciente a la subfamilia Pooideae (Rondel, trapeziform crenate), de los fitolitos articulados y de morfologías asignables a ciperáceas (sedge cone).

La asociación de fitolitos hallada en la capa 3, apunta a un incremento en la humedad de este sector, el cual en este caso también se ve avalado por la presencia de diatomeas. La alta frecuencia fitolitos articulados indica una cierta estabilidad de este sector. Los fechados radiocarbónicos ubican a la base de esta capa en ca. 4100 años ${ }^{14} \mathrm{C}$ AP.

Por último, los datos provenientes del testigo obtenido en el mallín, permitieron reconocer que la base del depósito tiene una antigüedad de 4910 \pm 28 ${ }^{14} \mathrm{C}$ AP. En cuanto a la reconstrucción de la estructura vegetal generada desde los fitolitos se puede mencionar en primer lugar que las muestras presentan valores porcentuales de fitolitos por muestra menores a los obtenidos en la cueva y presenta una cantidad más baja de morfologías. Más allá de esto, predominan los fitolitos de la subfamilia Pooideae (Rondel, trapeziform crenates) $y$, en este caso, los elongates que pueden ser de mono o dicotiledóneas, al no encontrarlos asociados a fitolitos tabulares (dicotiledóneas) se infiere que pertenecen a monocotiledóneas. En todas las muestras se registraron diatomeas en bajos porcentajes.

Dentro del mallín, la presencia de fitolitos indicadores de condiciones ambientales templadas fríos (gramíneas de las subfamilias Pooideae y Stipoideae) sumado a la ausencia de aquellos indicadores de condiciones cálidas (gramíneas de las subfamilias Chloridoideae y Panicoideae), y ausencia de fi- 
tolitos indicadores de dicotiledóneas y ambientes boscosos, evidenciaría un paisaje de pastizal abierto compuesto por gramíneas de ruta metabólica C3 con esporádicos cuerpos de agua que albergarían diatomeas y darían lugar al desarrollo de Cyperaceas. 


\section{Capítulo 7}

\section{Cuenca Media}

\subsection{Sitio Tito del Valle}

El sitio Tito del Valle (TDV) es una cueva ubicada a la vera de un cauce efímero sin nombre ( $47^{\circ} 50^{\prime} 04$ "S $\left.68^{\circ} 34^{\prime} 55^{\prime \prime} \mathrm{O}\right)$, tributario por margen norte del Zanjón Blanco. Dicho cauce corre en sentido N-S y desemboca en el sector de cuenca media del Zanjón Blanco. Las dimensiones de la cueva son de $12,5 \times 3 \mathrm{~m}$, su boca abre al oeste y la diferencia de altura entre la superficie de la cueva y la base del cauce es de aproximadamente $1 \mathrm{~m}$. El afloramiento rocoso en el que se emplaza la cueva pertenece a la unidad litoestratigráfica Formación Bajo Pobre que consiste en basaltos, andesitas y aglomerados volcánicos básicos (Panza 2001).

Hasta el momento sólo se cuenta con información publicada proveniente del arte rupestre (Carden 2008) ya que no se habían practicado excavaciones o estudios de otros materiales. Tito del Valle presenta un interesante potencial arqueológico debido a la presencia de arte rupestre, al abundante material arqueológico de superficie registrado en una loma ubicada al frente de la cueva cruzando el cauce. Además, se detectó una serie de elementos que evidencia un uso relativamente reciente de la misma. La boca de la cueva se encuentra cerrada casi completamente mediante una pared de adobe y en su interior se pudieron registrar diferentes estructuras de combustión, en forma de acumulaciones de carbon en la superficie asi como una estructura de adobe de forma rectangular con cabón en su interior (Figura 7.1). Además, un rasgo que resalta en el interior de la cueva es el depósito en forma de pequeño mónticulo compuesto por ceniza proveniente de la erupción del volcán Hudson del año 1991 (Figura 7.1). 


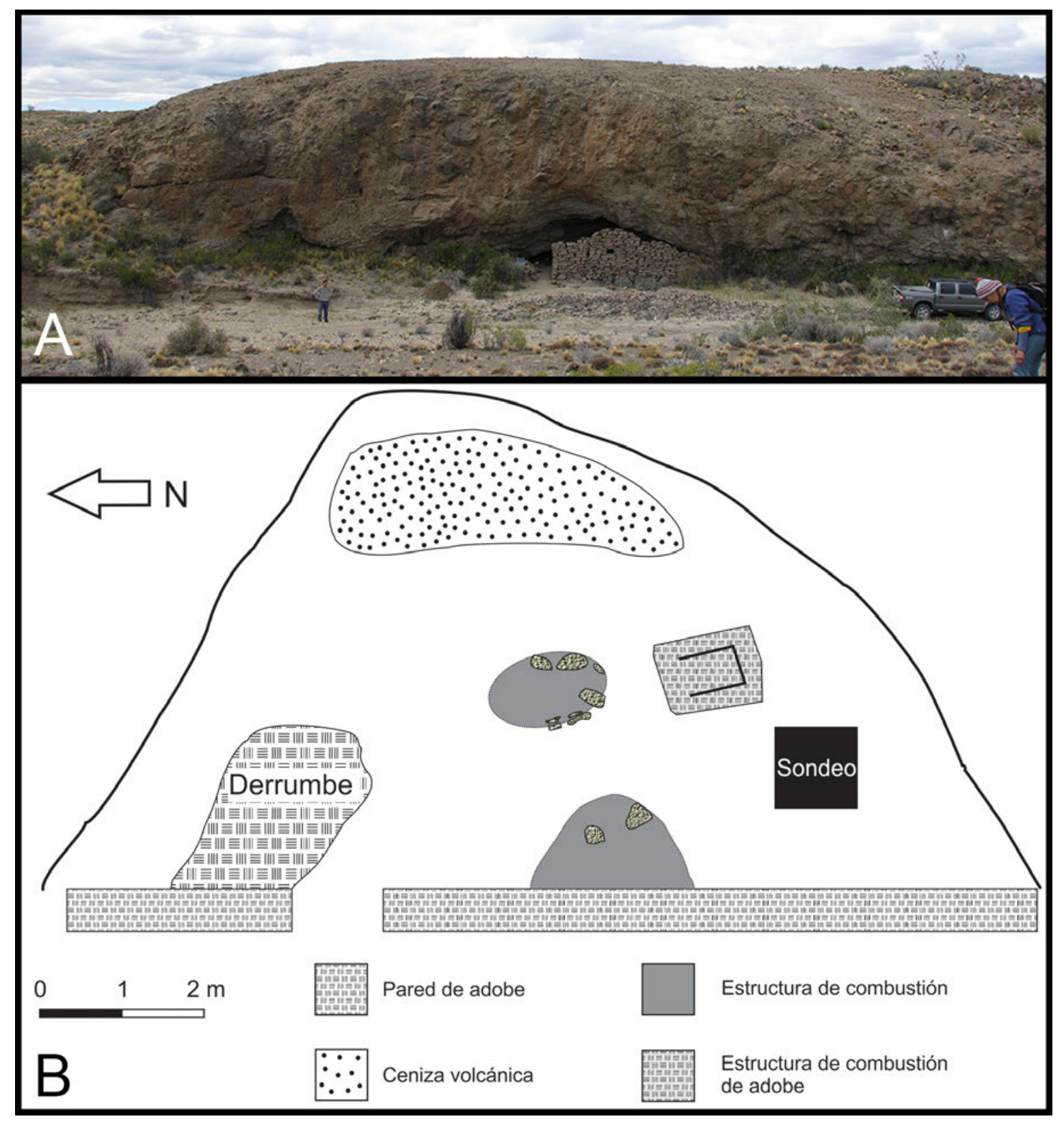

Figura 7.1: Planta de la cueva Tito del Valle. 


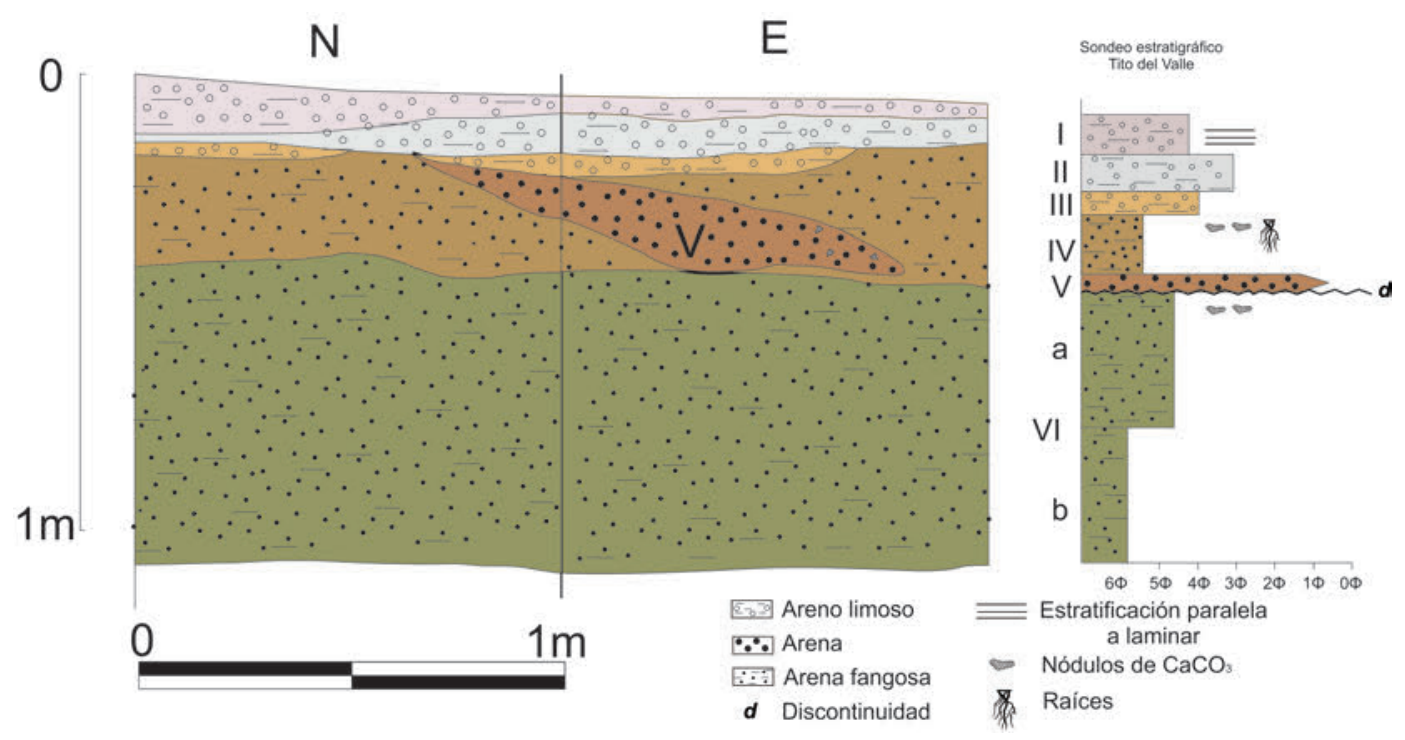

Figura 7.2: Estratigrafía del sondeo de la cueva Tito del Valle.

En el marco de esta tesis se realizó un sondeo estratigráfico de 1 x $1 \mathrm{~m}$ para obtener material arqueológico en estratigrafía y para analizar el depósito sedimentario de la cueva. En la excavación no se hallaron materiales arqueológicos, por lo que el análisis de este sitio será exclusivamente sedimentológico.

\subsubsection{Análisis sedimentológico}

Teniendo en cuenta que no se reconocieron pisos de ocupación con material arqueológico, consideramos al depósito sedimentario de este sitio como un depósito natural. Por lo tanto, en este caso no evaluamos la influencia humana en la conformación del mismo en términos de material exógeno y endógeno como en AEP-1 y en Cueva Maripe. No obstante, a partir del análisis de los perfiles reconocidos en el cauce que corre frente al sitio y de la poca diferencia de altura entre la superficie del sitio y la base del cauce, podemos estudiar la estratigrafía del sitio como parte de la dinámica sedimentaria de la localidad.

La estratigrafía del sitio está compuesta por 6 capas de la cuales se obtuvo una muestra de cada una y dos muestras de capa VI (a y b) que es la capa basal dividida en subcapas (Figura 7.2). La potencia total de la excavación es de $1,3 \mathrm{~m}$.

La estratigrafía de la cueva comienza con la denominada capa VI, que es un depósito areno fangoso (Figura 7.3) de color verde pálido (5 Y 6/4) con 
presencia de moteados oscuros, aspecto masivo, y en el que se reconocieron concreciones de $\mathrm{CaCO}_{3}$ alineadas en el techo de la capa. El sedimento se presenta húmedo. En la capa VI se analizaron 2 muestras debido a que se reconoció un cambio en la textura sedimentaria hacia la base del depósito con una granulometría fango arenoso más fino que el techo de la misma. Ambas muestras, tienen medias granulométricas en la fracción limo y distribuciones unimodales, donde las modas se ubican en limo para la muestra VIb y en arena fina para la muestra VIa (Figura 7.3).

En la pared E del perfil, sobre la capa VI apoya la capa V que es un depósito lenticular arenoso con un leve aporte de gravas finas que se reconoce en la pared $\mathrm{E}$ y $\mathrm{N}$ de la excavación y también se observa otra acumulación lenticular más pequeña en la pared $\mathrm{S}$. Es de color castaño (7,5 YR 5/2) aunque si se observa con detalle los granos que la forman presentan variación de composición y color. La distribución granulométrica es unimodal centrada en la fracción arena gruesa y el tamaño medio de grano se ubica en arena media $(\varphi$ 0,57). Durante la excavación se pudo determinar que ambos lentes reconocidos en el perfil forman parte de la misma acumulación, la cual por su forma en planta y perfil y su granulometría, se asemeja a las barras laterales (depósitos de márgenes expuestos) reconocidas en el cauce que corre frente a la cueva. La capa $\mathrm{V}$ se incluye dentro de la capa IV, como una cambio litofacial lateral de una misma facies sedimentaria. Ambos depósitos apoyan sobre la capa VI (Figura 7.2).

La capa IV es un depósito areno fangoso de color castaño (7,5 YR 5/2) presenta estructura prismática, evidencias de bioturbación por raíces y abundantes concreciones de $\mathrm{CaCO}_{3}$. Su histograma muestra una distribución unimodal con moda en arena fina, y una media granulométrica en limo fino $(\varphi$ 5,4) (Figura 7.3). Este depósito presenta en su techo un contacto neto con las capas II y III, y apoya en límite difuso sobre la capa VI.

La capa III es un depósito areno limoso de color castaño rojizo (5 YR 6/4). Presenta sección lenticular y aspecto masivo uniforme. Su distribución granulométrica es unimodal en arena muy fina con la media ubicada en arena muy fina $(4 \varphi)$ (Figura 7.3). Esta capa lentiforme se presenta en forma discontinua, estando ausente en la pared $S$ de la cuadrícula y apoyan en contacto claro sobre la capa V y en contacto difuso sobre la capa IV (Figura 7.2).

La capa II responde a un depósito poco potente $(5 \mathrm{~cm})$ de arena limo- 


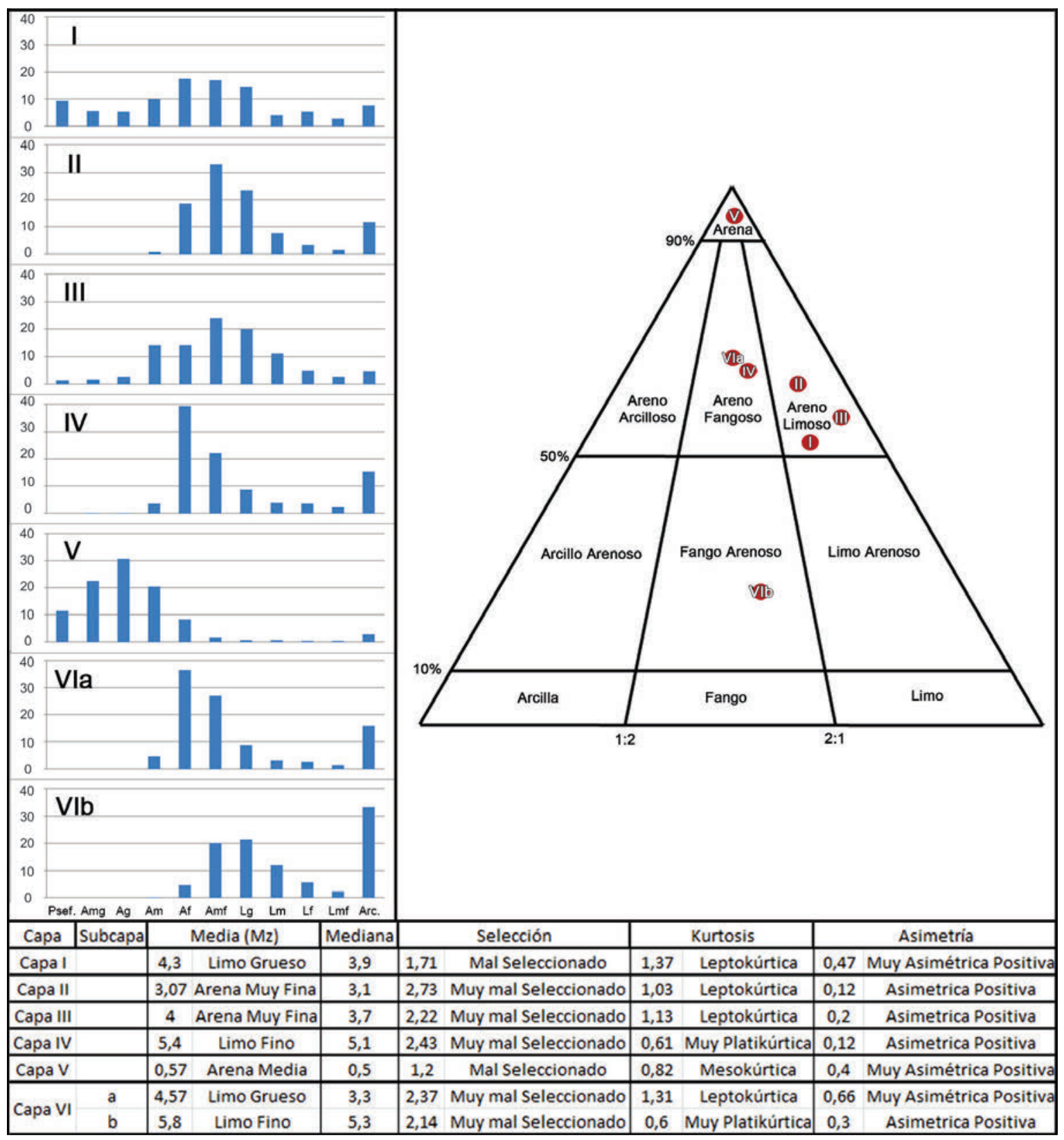

Figura 7.3: Histogramas de distribución granulométrica, triángulo de clasificación y coeficientes estadísticos de las capas que conforman el depósito sedimentario de la cueva Tito del Valle. 
sa de color gris (10 YR 5/1) con moteados carbonosos. La distribución es unimodal, con su moda en arena muy fina, y con una media granulométrica ubicada en arena muy fina $(\varphi 3,07)$. Este es el único depósito de toda la secuencia en el que se reconocieron restos de actividad humana como son carbones, pequeños fragmentos de huesos quemados y fragmentos de vidrio de botella. Su límite con respecto a la capa inferior es fácilmente reconocible.

Por último, la capa I que corona la estratigrafía de la cueva, es un depósito areno limoso de color gris (7,5 YR 6/2) que presenta estructura laminada. Su distribución es bimodal, y el tamaño medio de grano se ubica en la fracción limo grueso $(\varphi 4,3)$. No presenta evidencias de bioturbación y se apoya en límite neto sobre la capa II. Esta capa corresponde a la superficie del piso actual de la cueva.

En la excavación realizada no hemos hallado ningún tipo de evidencia arqueológica que nos permita evaluar la ocupación de la cueva. Los pocos restos de carbón y pequeños fragmentos de hueso provenientes de la Capa II se encontraban muy deteriorados impidiendo su identificación, y en su asociación con fragmentos de botellas de vidrio, lo que indica que corresponde a tiempos recientes.

\subsubsection{Cauce Sin Nombre de Tito del Valle}

El cauce sin nombre que corre frente a la cueva TDV a un nivel topográfico de cerca de $0,7 \mathrm{~m}$ más bajo que el piso de la cueva, corresponde a un curso de agua efímero que corre con orientación N-S y presenta un diseño sinuoso (meandroso). Por tramos su cauce se encuentra limitado por barrancas de diferente desarrollo vertical. Se recorrieron a pie $3,5 \mathrm{~km}$ a lo largo del cauce para observar la estratigrafía de las barrancas desarrolladas a lo largo del mismo. En este recorrido se escogieron secciones estratigráficas en el sector aguas arriba de la cueva (norte), donde se relevaron y realizaron muestreos. Por su parte, hacia el sur de la cueva (aguas abajo) las secciones reconocidas son muy poco potentes o no presentaron cortes verticales. Por lo tanto, para el análisis estratigráfico se seleccionaron secciones en las que se observaban claramente superficies limitantes o discontinuidades. Los depósitos de ceniza volcánica fueron elegidos especialmente para su análisis, ya que su potencial de inferencia cronológica es muy alto.

En total se relevaron siete perfiles estratigráficos de los cuales se eligie- 


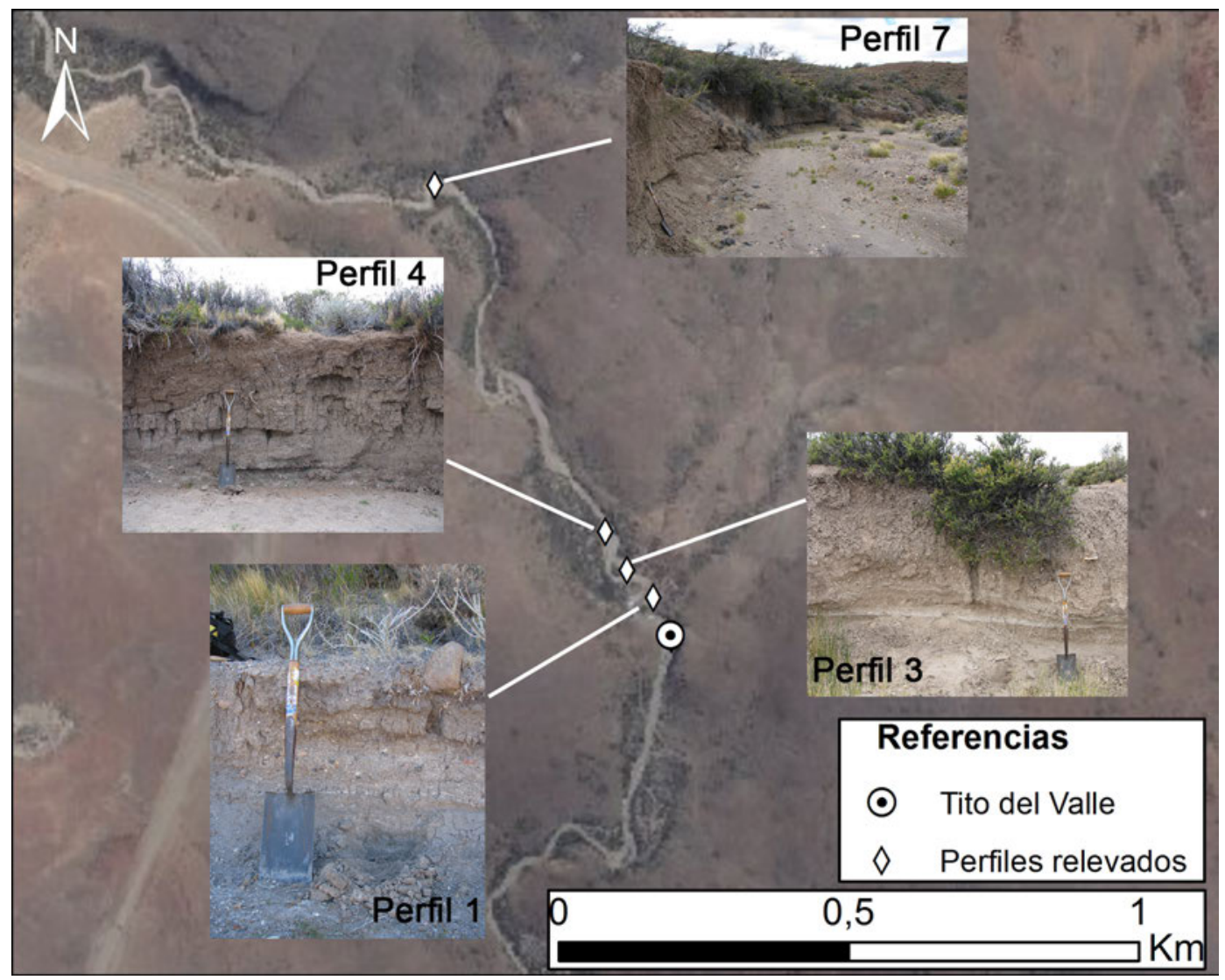

Figura 7.4: Sector del cauce sin nombre relevado en el sector Cuenca Media. Se señalan diferentes sectores del recorrido que muestran diferentes secciones estratigráficas a lo largo del cauce.

ron tres para el análisis sedimentológico (perfiles 3, 4 y 5). Los perfiles 4 y 5 se encuentran en el mismo sector del cauce pero en márgenes opuestos, mientras que el perfil 3 se encuentra a unos $100 \mathrm{~m}$ hacia el norte de la cueva (Figura 7.4).

En los tres perfiles mencionados se realizó el análisis sedimentológico para complementar con las observaciones geomorfológicas realizadas en el campo. Y a continuación los presentamos comenzando por el más alejado de la cueva.

\section{- Perfil 5}

Esta columna estratigráfica presenta una potencia aproximada de 1,6 m, se ubica frente al perfil 4 , y en el sector interno de un pequeño meandro (Figura 7.5).

El perfil 5 muestra un arreglo litofacial heterogéneo compuesto por cua- 

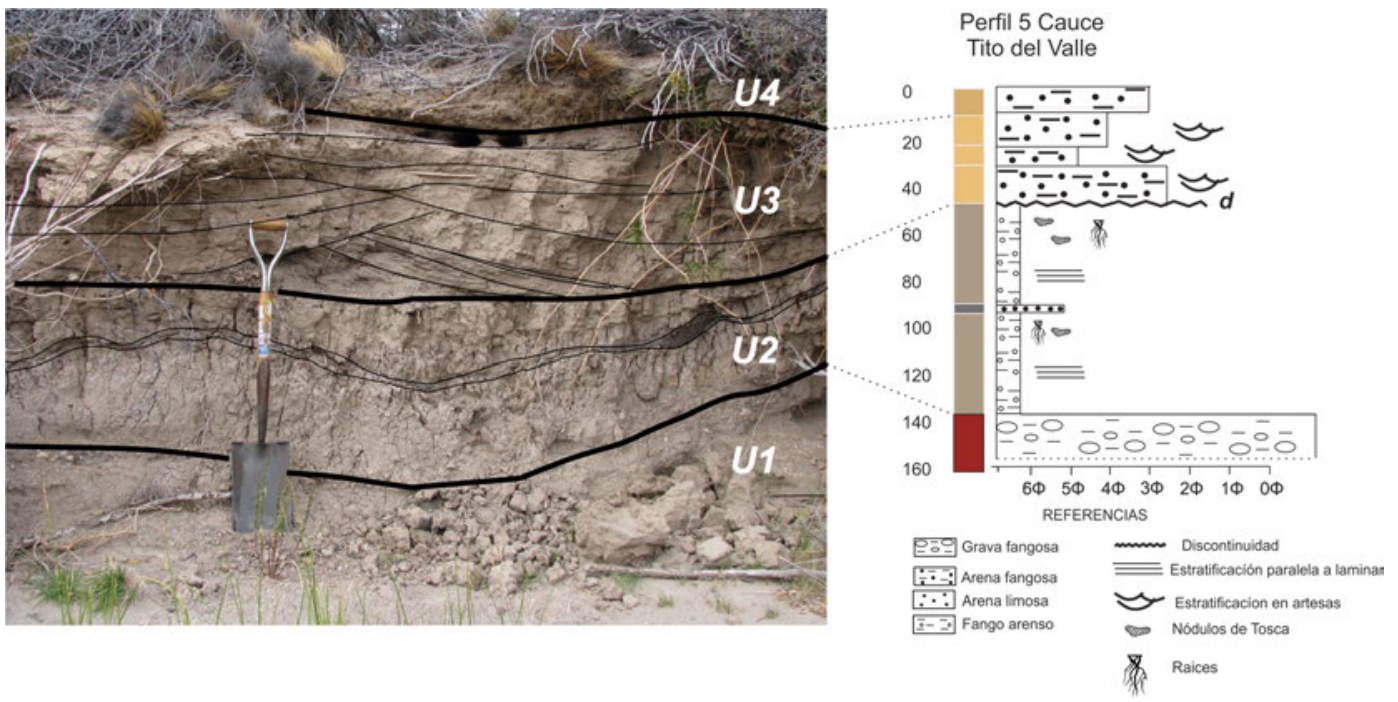

Figura 7.5: Imagen de la sección muestreada y columna estratigráfica.

tro unidades estratigráficas. La unidad basal (U1) solo se describió en campo, debido a su composición gruesa de gravas medias en matriz arenosa. Se observan lentes de acumulación gravosa. El depósito siguiente responde a la denominada Unidad 2, en la que observamos 3 sectores. El inferior (U2a) tiene $40 \mathrm{~cm}$ de potencia y está conformado por un fango arenoso de color gris (5 Y 6/1) con estructura prismática que dificulta la observación de la laminación; se reconoció la presencia de raíces y de carbonatos, en especial en la porción superior. Sobre éste y en contacto neto se ubica un estrato muy delgado (U2b) que es un depósito de muy poca potencia $(1 \mathrm{~cm}$, aunque en sectores se ensancha alcanzando los $5 \mathrm{~cm}$ ) conformado por arena fangosa de color gris oscuro a negro (5 YR 3/1) compuesta por una gran cantidad de carbón y materia orgánica. Esta Unidad finaliza en un sector superior (2c) de unos $30 \mathrm{~cm}$ de espesor, formado por fango arenoso de color gris (10 YR $6 / 1$ ) y en el que se pudo reconocer que el material parental se encuentra estratificado en láminas al que por procesos postdepositacionales se le sobre impuso un arreglo columnar. Los resultados de los análisis se presentan en la figura 7.6.

La Unidad 2 finaliza con una discordancia erosiva que interrumpe la continuidad del depósito. Por encima de esta discordancia apoya la Unidad estratigráfica 3 que también se diferencia en 3 sectores. Los estratos inferior (U3a) y superior (U3c) son depósitos de arena fangosa suelta de color castaño (7,5 YR 5/2) con estructura de estratificación entrecruzada en artesas, entre estos dos depósitos se diferenció un sector intermedio que presenta es- 


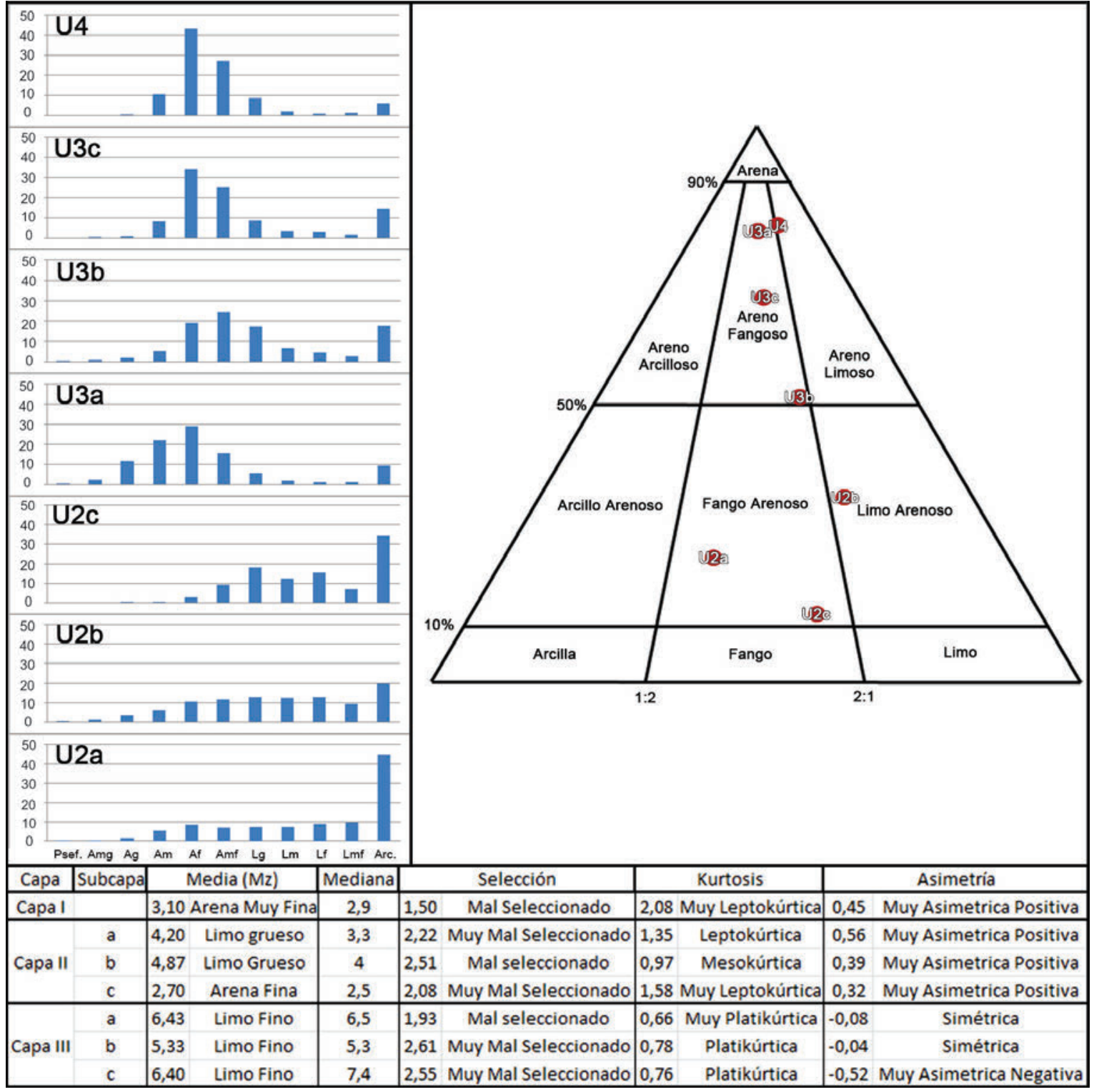

Figura 7.6: Histogramas de distribución granulométrica, triángulo de clasificación sedimentaria y parámetros estadísticos de las capas que conforman el Perfil 5. 


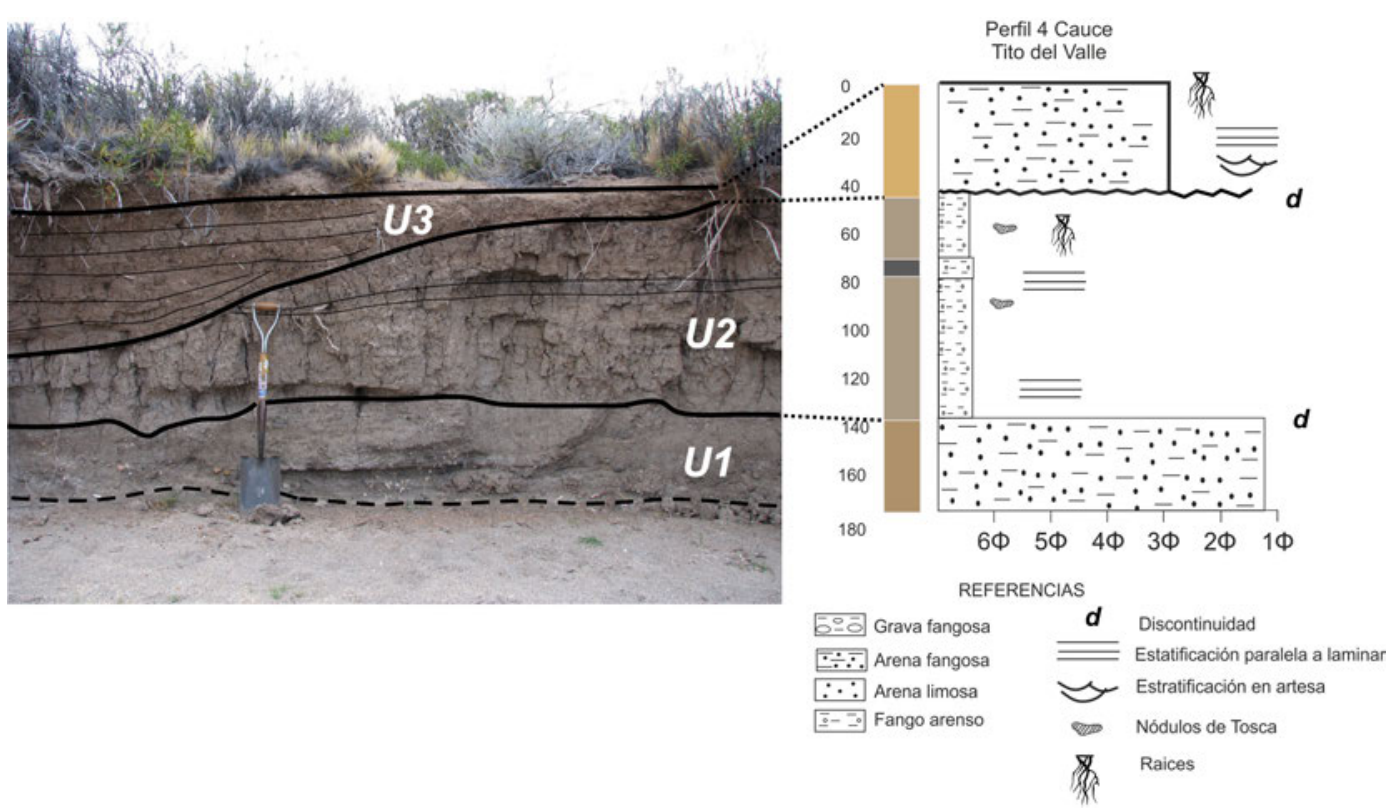

Figura 7.7: Estratigrafía del perfil 4.

tratificación como el resto de la capa pero con carbonatación lo cual contribuyó a generar un sector con mayor cementación que el resto de la unidad. La secuencia estratigráfica termina con la Unidad 4, la cual es un depósito arenoso similar al de Unidad 3, sólo que sobre esta se observa el desarrollo de vegetación actual.

\section{- Perfil 4}

Este perfil, ubicado frente al perfil 5 en la margen opuesta del cauce, presenta expuesto 1,4 $\mathrm{m}$ de potencia (Figura 7.7). En él se reconocieron tres unidades estratigráficas dentro de las cuales sólo la Unidad II fue subdividida para su análisis en laboratorio a partir de sus diferencias internas.

En la base del corte se observa un depósito de gravas con matriz arenosa. Sobre este depósito se desarrolla la estratigrafía que relevamos, comenzando con la Unidad 1 la cual está conformada por sedimento areno fangoso de color castaño oscuro (10 YR 4/3) con laminación difusa. Dentro de la capa se pudo reconocer una sucesión de pequeños depósitos de arena y limo arcilla intercalados, evidenciando variaciones internas. Sin embargo, la distribución observada en el histograma granulométrico de este estrato es unimodal centrada en la fracción arena gruesa, con una media granulométrica arena fina $(2,9 \varphi)$ (Figura 7.8).

La Unidad 2 apoya sobre la 3 en contacto claro. Como se observa en el 


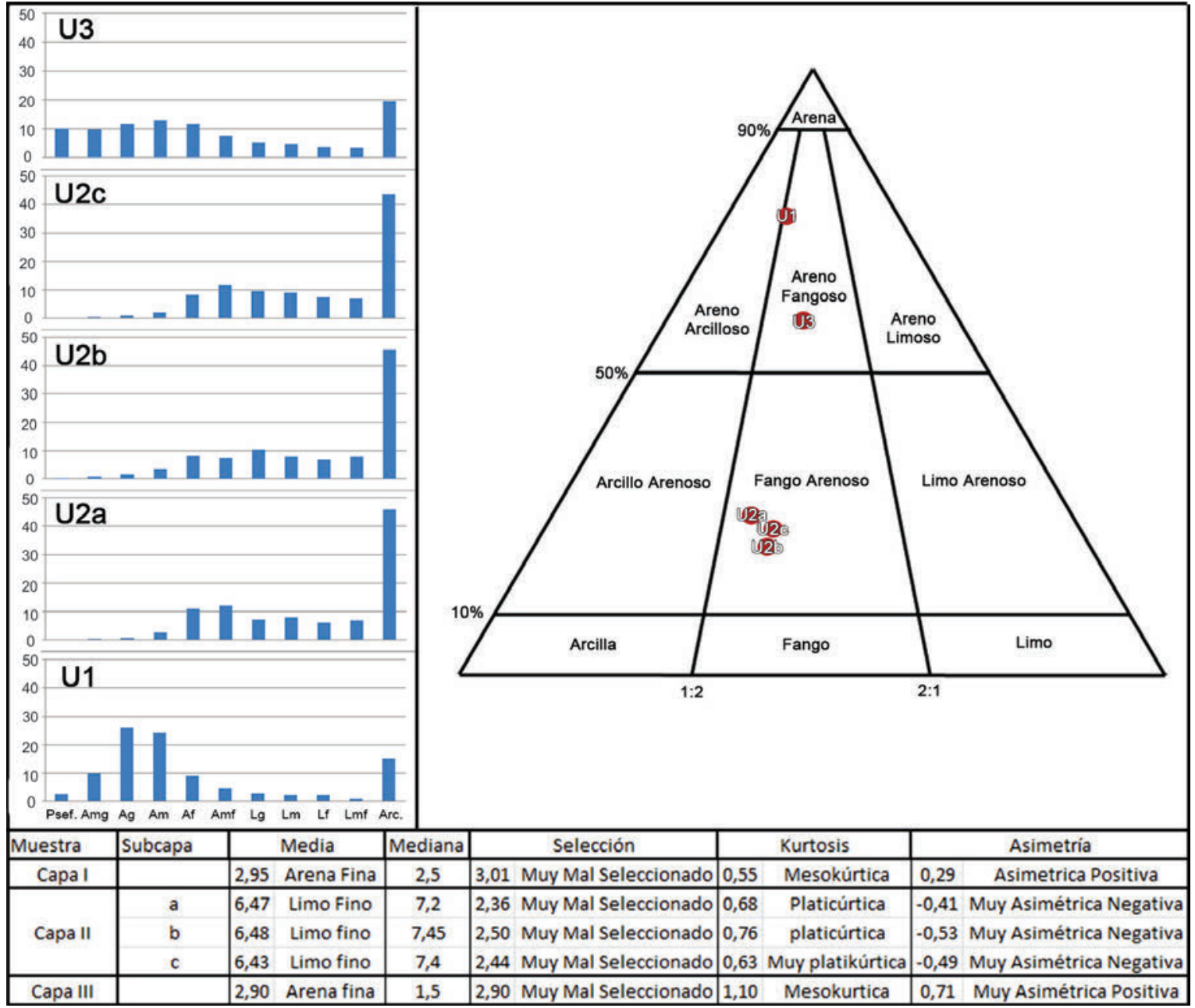

Figura 7.8: Histogramas de distribución granulométrica, triángulo de clasificación sedimentaria y parámetros estadísticos de las capas que conforman el Perfil 4. 
triángulo de clasificación (Figura 7.8) las tres muestras de la Unidad 2 corresponden a fango arenoso. El sector superior (U2c) e inferior (U2a) son similares, de color castaño (7,5 YR 5/2) con agregación prismática dentro de la cual se pueden reconocer alternancia de pequeñas lentes arenosas y limo-arcillosas. El inferior a diferencia del superior, se distingue por una recurrencia de concreciones carbonáticas. Entre estos dos sectores se diferenció un estrato intermedio que se distingue por una coloración castaña gris oscura (2,5 YR 4/2) dentro del arreglo sedimentario común a toda la Unidad 2, lo que podría estar indicando un aumento de materia orgánica. En cuanto a sus características texturales la Unidad 2 presenta homogeneidad, tanto en su distribución como en el tamaño medio de grano (Figura 7.8). Esta unidad finaliza con una discordancia erosiva.

Sobre la discordancia mencionada se depositó la Unidad 3 sobre la cual se generó el suelo actual. Se trata de una acumulación de sedimento areno fangoso de color castaño oscuro (10 YR 4/3) con una distribución granulométrica que la diferencia del resto de la secuencia (Figura 7.8). Es una capa con aporte tanto de material fino como grueso, y conforma la única muestra con una frecuencia significativa de psefitas y una alta presencia de raíces a lo largo de la misma.

\section{- Perfil 3}

En este caso, la descripción se realizó a partir de dos sectores contiguos (Figura 7.9) de un perfil que tiene 1,8 m de potencia máxima. Estos dos sectores se relacionan espacialmente y en cada uno de ellos se pudieron reconocer capas con diferente grado de claridad por lo que se optó por la realización de un perfil esquemático que incluya a ambos.

Hemos reconocido cinco unidades estratigráficas en el perfil 3. La base de la misma corresponde a la Unidad 1, constituida por sedimento fango gravoso de color castaño a verde (7,5 YR 4/2). Es un depósito que aparece húmedo, en el que se reconoce laminación de sedimentos finos y moteados de Fe-Mn como resultado de procesos hidromórficos. Su distribución sedimentaria unimodal y la media granulométrica se ubica en arena media $(\varphi$ 1,72).

En la Unidad estratigráfica 2 se obtuvieron tres muestras. El depósito inferior (U2a) se reconoce como un estrato fangoso de color grisáceo $(7,5 \mathrm{YR}$ $6 / 2$ ), con una distribución granulométrica similar a la de Unidad 1 aunque 


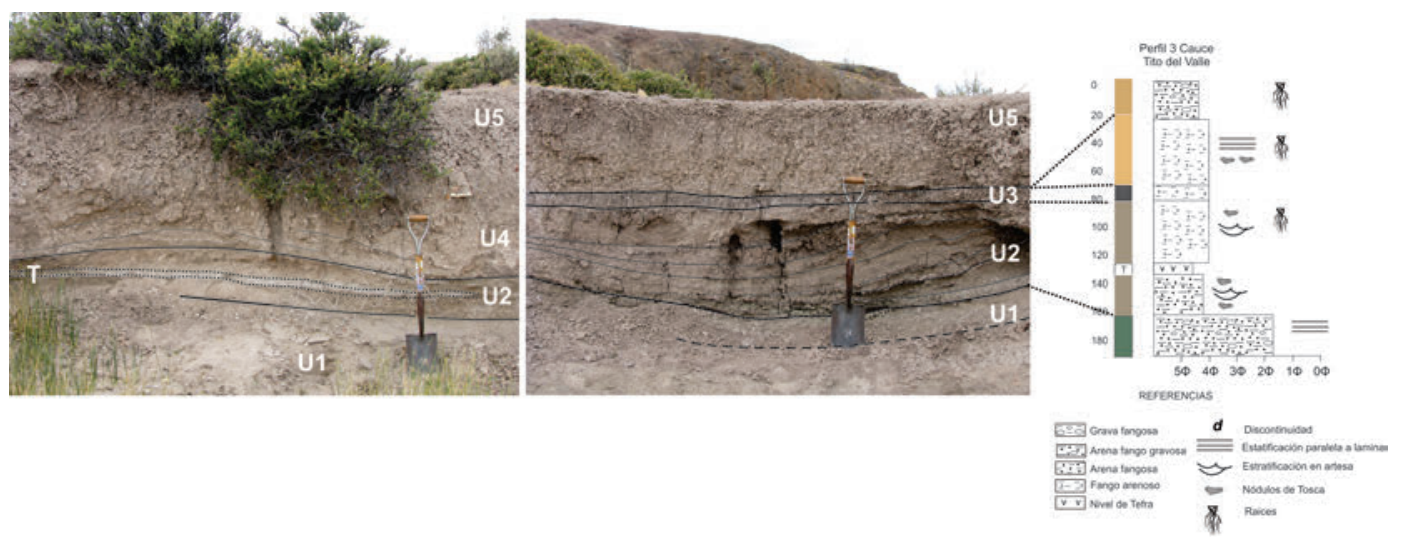

Figura 7.9: Imágenes de la estratigrafía del perfil 3. En la foto A se puede observar la capa clara de ceniza volcánica la cual en el análisis sedimentológico se denomina Capa V. En la foto B, se ve con claridad la capa oscura que conforma la Capa III.

la media granulométrica es más fina, por lo que se ubica dentro de la categoría arena muy fina $(3,85 \varphi)$. En ella se reconocen depósitos carbonaticos muy frecuentes en forma de concreciones.

Sobre este estrato, en contacto neto se reconoció un depósito de ceniza volcánica $(\mathrm{T})$, discontinuo en sentido lateral, de sección lenticular y color blanco (5 Y 8/1) que tienen unos $7 \mathrm{~m}$ de largo y $8 \mathrm{~cm}$ de espesor (Figura 7.9 A). La distribución granulométrica es bimodal con modas en las fracciones limo medio/fino y arena fina, mientras que el tamaño medio de grano en la muestra es de $4,43 \varphi$, coincidiendo con la fracción limo grueso. Para conocer a qué erupción pertenece este depósito de tefra, enviamos una muestra a la Universidad de Colorado, donde el Dr. Charles Stern realizó el análisis de elementos químicos mediante la técnica de Espectrometría de Masas con Plasma Acoplado Inductivamente (ICP-MS) (Tabla 7.1 y Figura 7.10). Los resultados químicos muestran que su composición es coincidente con la de la erupción H2 datada en ca. 4050 años cal. AP (Naranjo y Stern 1998).

Por sobre la ceniza se reconoció un depósito (U2c) de textura fango arenosa de color gris claro (2,5 Y 7/2). La misma se presenta como arena con cierto grado de compactación, con concreciones carbonáticas y evidencias de bioturbación por raíces. Asimismo, su base es cóncava y los depósitos de carbonato se presentan alineados con la base. El histograma de granulometría muestra una distribución unimodal con una media en arena muy fina $(3,93 \varphi)$.

La secuencia continúa con la Unidad 3, la cual se reconoce por su colo- 


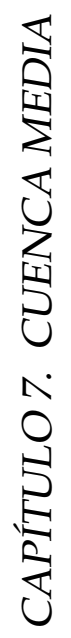

\begin{tabular}{|c|c|c|c|c|c|c|c|c|c|c|c|c|c|c|c|c|c|}
\hline Elemento & Ti & $\mathbf{V}$ & $\mathbf{C r}$ & $\mathbf{M n}$ & $\mathbf{C o}$ & $\mathbf{N i}$ & $\mathbf{C u}$ & $\mathbf{Z n}$ & $\mathbf{R b}$ & $\mathbf{S r}$ & $\mathbf{Y}$ & $\mathbf{Z r}$ & $\mathbf{N b}$ & $\mathbf{C s}$ & $\mathbf{B a}$ & $\mathbf{L a}$ & $\mathbf{C e}$ \\
\hline $\mathrm{ppm}$ & 3980 & 151 & 8 & 629 & 18 & 5 & 7 & 104 & 67 & 162 & 34 & 375 & 27 & 2,1 & 576 & 49,5 & 114 \\
\hline Elemento & $\mathbf{P r}$ & $\mathbf{N d}$ & $\mathbf{S m}$ & $\mathbf{E u}$ & $\mathbf{G d}$ & $\mathbf{T b}$ & $\mathbf{D y}$ & $\mathbf{H o}$ & $\mathbf{E r}$ & $\mathbf{T m}$ & $\mathbf{Y b}$ & $\mathbf{L u}$ & $\mathbf{H f}$ & $\mathbf{T a}$ & $\mathbf{P b}$ & $\mathbf{T h}$ & $\mathbf{U}$ \\
\hline $\mathrm{ppm}$ & 13,2 & 49,5 & 9,29 & 2,25 & 14,8 & 1,34 & 6,44 & 1,26 & 4,13 & 0,54 & 3,74 & 0,59 & 10,95 & 15,34 & 10,50 & 11,49 & 2,33 \\
\hline
\end{tabular}

Tabla 7.1: Resultado del análisis ICP-MS realizado sobre la muestra de tefra que conforma el depósito de capa V del perfil 3. 

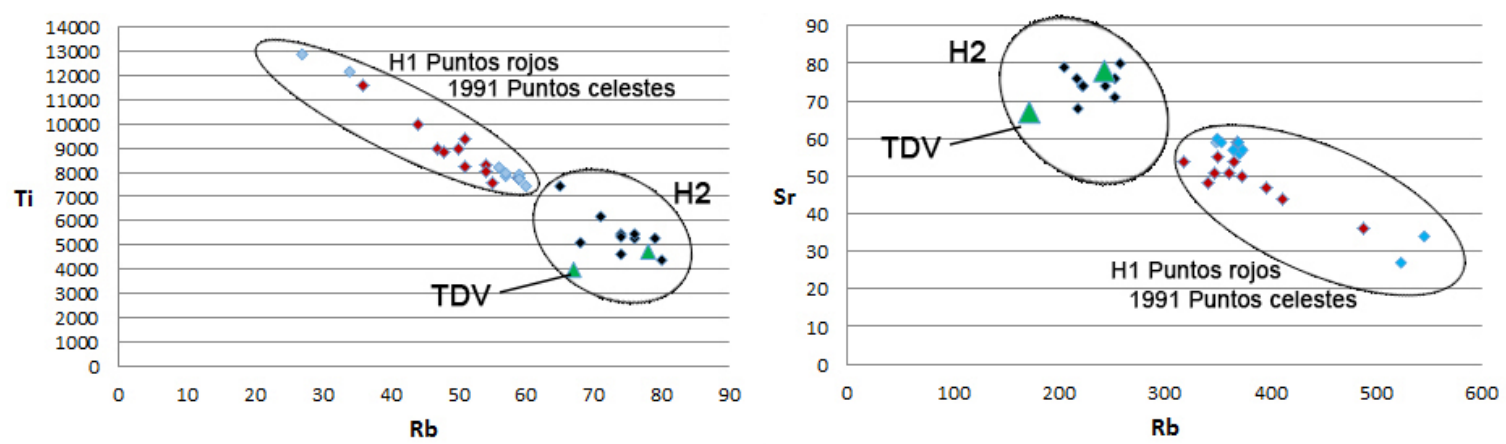

Figura 7.10: Relación Ti-RB y Sr-Rb de la muestra de ceniza recuperada en el perfil 3 en relación con otras muestras de la región de procedencia conocida. Se grafican las erupciones H1, H2 y 1991 del volcán Hudson. Los datos comparativos fueron extraídos de Naranjo y Stern 1998 y Kratzmann et al. 2010.

ración gris oscura (10 YR 5/4) que la diferencia de las capas que la rodean (Figura 7.9 B). Se trata de un sedimento fango arenoso con una distribución unimodal ubicada en la fracción arcilla, si bien esta fracción representa todo el sedimento de tamaño menor a 8 phi, se presume que la moda se encuentra en esa fracción, diferenciándola del resto de la secuencia. La media granulométrica en este caso se ubica en la fracción limo grueso con un valor de $4,02 \varphi$. En el sector del perfil que incluye el depósito de ceniza volcánica esta capa es mucho menos potente. Como se describió para el caso del estrato medio de la Unidad 2 del perfil 4, ésta tonalidad más oscura es interpretada como una mayor presencia de materia orgánica.

La Unidad 4 alcanza unos $40 \mathrm{~cm}$ de espesor y se encuentra entre los depósitos más potentes registrados en este sector de la cuenca. Está conformada por sedimento areno fangoso con un leve aporte de grava, que muestra una distribución polimodal con una media granulométrica en arena muy fina $(3,3 \varphi)$. Es de color gris (10 YR 6/1) y en ella se reconoce una abundante depositación de carbonatos en forma de concreciones, las cuales son claramente visibles en la figura 7.9.

La estratigrafía culmina con la Unidad 5 que conforma la superficie actual del terreno, y corresponde a un sedimento polimodal (Figura 7.11) fango gravoso de color gris rosado (7,5 YR 6/2) con una media granulométrica ubicada en arena muy fina $(3,65 \varphi)$. Se presenta como sedimento suelto en el cual se desarrollan raíces de la vegetación actual. 


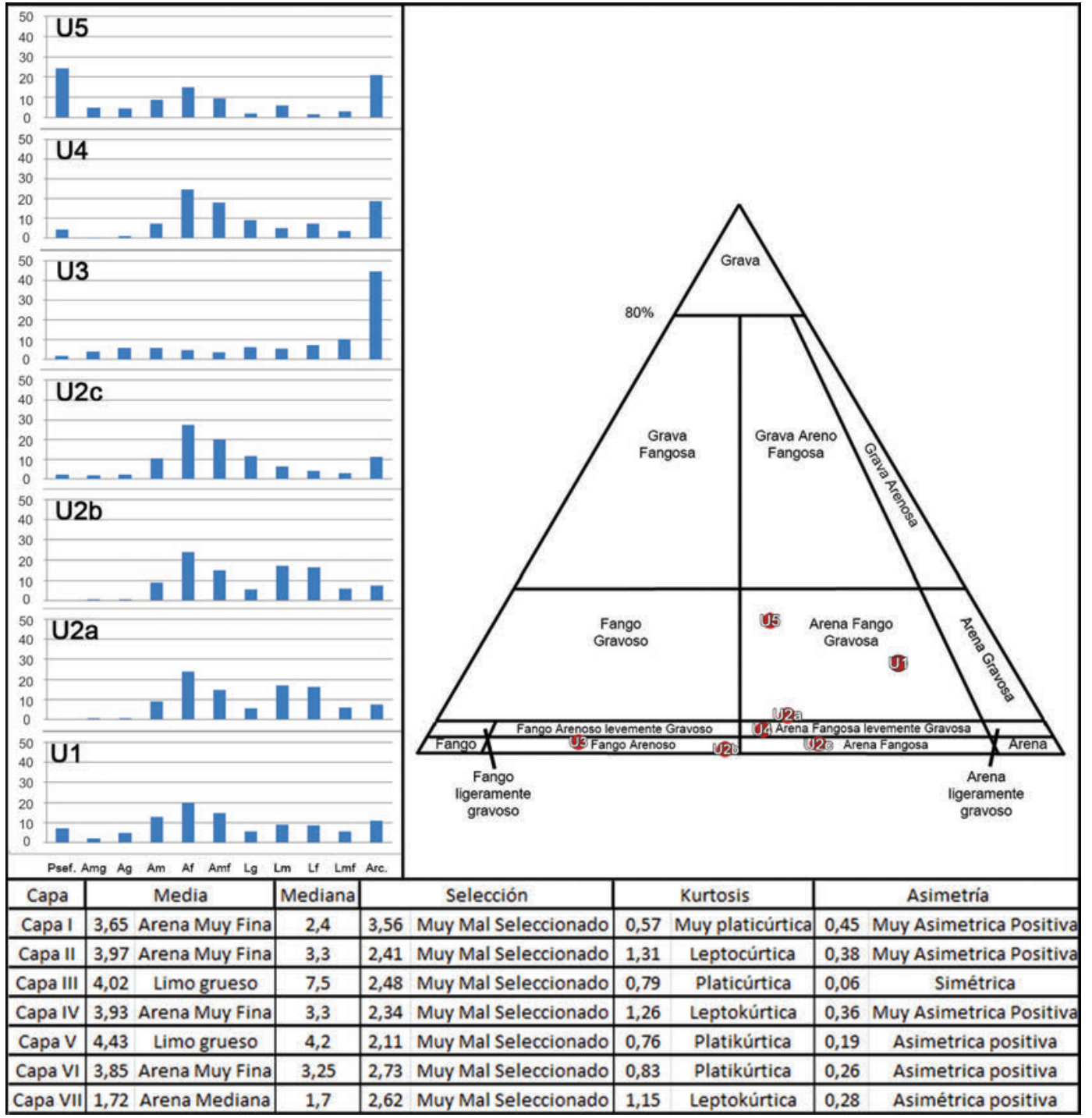

Figura 7.11: Histogramas de distribución granulométrica, triángulo de clasificación sedimentaria y coeficientes estadísticos de las capas que conforman el Perfil 5. 


\subsection{Valoración de resultados}

Las secciones estratigráficas relevadas en la Cuenca Media, más precisamente en el cauce efímero sin nombre, muestran un arreglo vertical complejo y discontinuo en los diferentes sectores estudiados.

En el perfil 5, el depósito basal, presenta gruesa de gravas medias en matriz arenosa, por lo que lo consideramos como un depósito de canal que fue generado por una escorrentía corriente de alta energía. Sobre esta unidad se reconoció un depósito fango arenoso a arena fangosa (Unidad 2). Estos corresponderían a depósitos aluviales de baja energía, depósitos de encharcamientos en depresiones del lecho (nivel límnico de U2b) con retrabajo eólico de los materiales aluviales en momentos de déficit hídrico. Las presencia de marcas de raíces, concreciones carbonaticos y la presencia de estructura columnar, indicaría el soporte de una cubierta vegetal y procesos postdepositacionales de reorganización pedogenética. La unidad 2 está truncada en su techo por una discordancia erosiva, resultado de un cambio en el ambiente. Sobre esta discordancia se depositó la Unidad 3, de granulometría arenosa y con estructura entrecruzada en artesa en artesas que permite definirla como un depósito de canal de menor energía que el de la sección basal.

En el perfil 4 el depósito areno fangoso que conforma a la Unidad 1, fue interpretado como un depósito de canal de arena y pelitas similar al reconocido en la U3 del perfil 5. La Unidad 2 de este perfil corresponde a depósitos aluviales de baja energía en la que se reconoce un nivel límnico oscuro que podría indicar encharcamientos en depresiones del lecho (similar la Unidad 2 del Perfil 5). La estructura columnar reconocida en este depósito, junto con las evidencias de raíces y las concreciones carbonáticas observadas, evidencian el soporte de una cubierta vegetal y un proceso de reorganización pedogenética. La Unidad 2 finaliza con una discordancia erosiva que marca un cambio climático. Sobre la base erosiva que conforma la discordancia se observa un depósito de canal que conforma la Unidad 3.

Por último, el perfil 3 comienza con un depósito de canal fluvial bajo condiciones de alta energía de transporte (U1) sobre el que apoya un depósito de canal fluvial que condiciones hidrodinámicas de escasa energía y episódicas (U2). En la U2 alternan depósitos aluviales con retrabajo eólico, entre los que se encuentra un nivel lenticular de ceniza volcánica y, niveles límnicos de encharcamiento. La U3 corresponde a uno de estos niveles 
limnicos. El depósito correspondiente a la U4 es similar a la U2, aunque las evidencias de concreciones carbonáticas y raíces permiten reconocer una reorganización pedogenética. La secuencia termina con la U5 que conforma la superficie actual del terreno, con desarrollo de vegetación.

Así, los flujos más caudalosos y competentes tienen lugar durante las épocas de deshielo y luego de lluvias torrenciales, que se dan en estos regímenes áridos. Los escurrimientos son breves o temporarios y las acumulaciones de sedimento que tienen lugar durante estos lapsos, son muy variados de acuerdo a los múltiples tipos o modelos de flujo que se dan dentro del cauce. Por otro lado, en épocas secas los cauces están secos, los flujos se ven interrumpidos y la acción eólica re-trabaja y deposita el material fluvial depositado previamente. En algunos tramos y durante periodos secos, pueden quedar subambientes "encharcados" en depresiones del canal e influenciados por el aporte de agua freática o de manantiales (Figura 7.13).En las barrancas, las diferentes facies fluviales reconocidas, reflejan los diferentes regímenes hidrodinámicos de los flujos durante cada evento depositacional. Por ejemplo, la U1 de los perfiles 4 y 5 es un depósito de material grueso, entre psefítico y arenoso (arena gruesa) con una matriz limosa, que a lo largo del cauce pudo observarse en varios sectores conformando la base de las barrancas. Esta litofacies reflejan momentos en los que la corriente ha tenido caudal y energía relativamente alta, para permitir la generación de depósitos de barra (Figura 2.9-D).

Por su parte, en el perfil 3, la base está conformada por un depósito más fino (arena fina a limo) y se emplaza en un sector en el que aflora el nivel freático en la base del cauce humedeciendo los sedimentos (Figura 7.12). Esto explicaría sus características de ámbito palustre como es el color verde pálido (hidromorfismo) con moteados oscuros de Fe-Mn.

Asimismo, se han reconocido litofacies areno limosas y fango arenosas (U2 perfil 4 y U2, U3 y U4 del perfil 3) con abundantes concreciones carbonáticas, presencia de raíces y en algunos casos con estructura prismática. Estas tres características permiten inferir cierto grado de reorganización postdepositacional de estos depósitos. Sin embargo, hacia el interior de estas capas se pudieron reconocer pequeñas acumulaciones laminadas que no modificaron su estructura original, lo que nos da la pauta de que tal reordenamiento es aún incipiente. Estas acumulaciones pueden ser el resultado de la acumulación de material fino en cuerpos de agua tranquilos y someros, 


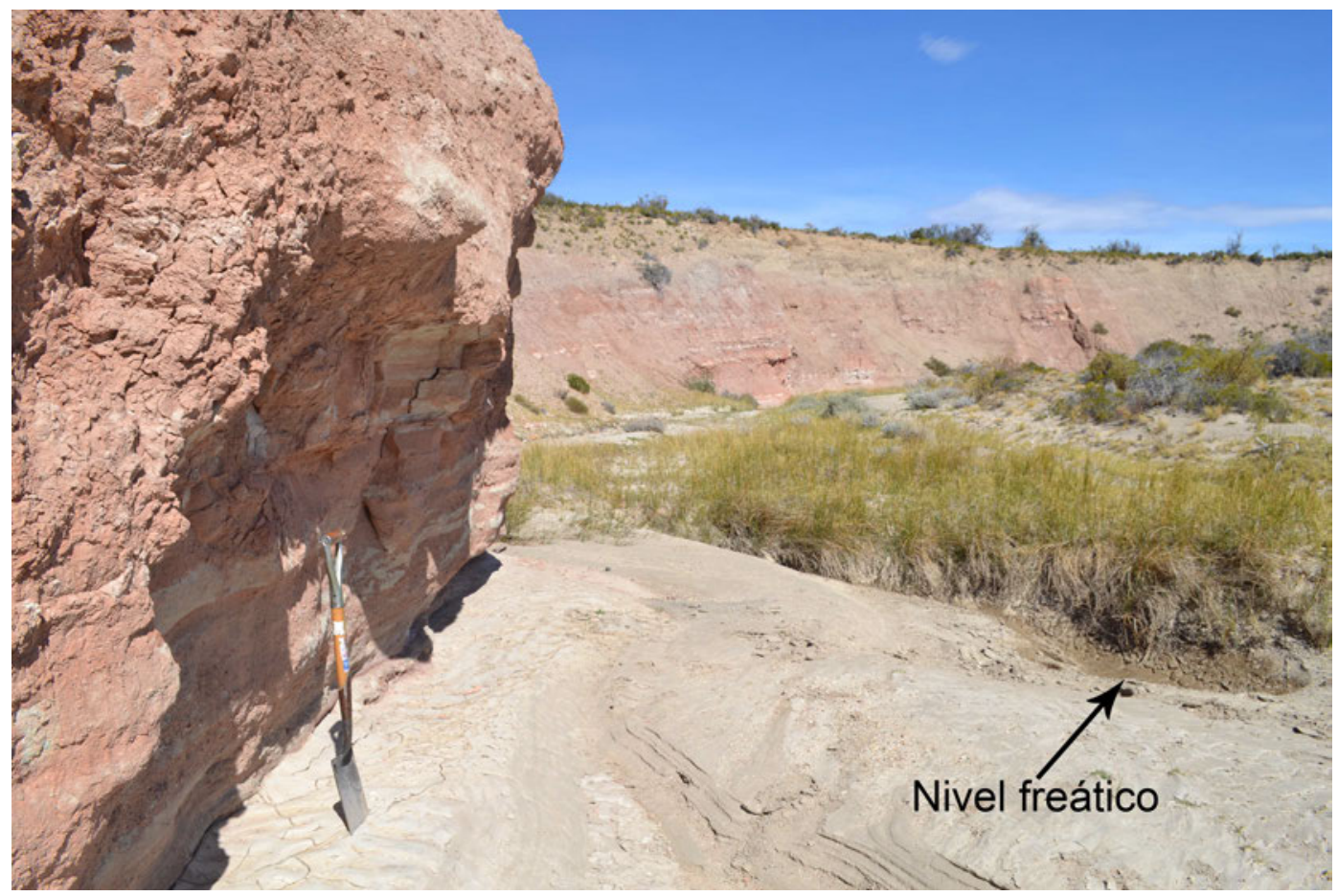

Figura 7.12: Ejemplo de afloramiento del nivel freático en la base de los cauces de los zanjones secos.

generados dentro del cauce ya sea por estancamientos en depresiones luego de lluvias intensas y/o por la efluencia de aguas subterráneas o manantiales (Figura 7.13). Estos rasgos del paisaje resultan interesantes en ambientes áridos como los que caracterizan a nuestra área de estudio, ya que ofrecen fuentes temporales de agua. En este sentido pueden concentrar flora y fauna, lo que en consecuencia las vuelve potenciales sectores a ser explotados por cazadores-recolectores.

Es interesante el hallazgo de una capa de ceniza volcánica asignable sobre la base de su composición geoquímica a la erupción H2 del Volcán Hudson, datada en 3600 años ${ }^{14} \mathrm{C}$ AP (ca. 4050 años cal. AP) (Naranjo y Stern 1998). Con esta referencia podemos ubicar a las facies en un marco temporal aproximado. Sobre este depósito de tefra se reconocen facies que debido a sus características litológicas podrían ser asignados a depósitos coluviales. En los perfiles 4 y 5 tales litofacies finalizan en una discordancia erosiva con forma cóncava sobre la que apoyan facies fluviales y coluviales. Este evento erosivo, por lo tanto, habría tenido lugar en el Holoceno tardío.

La observación de los depósitos que constituyen las barrancas refleja marcadas diferencias en la dinámica de los flujos del agua encauzados en 


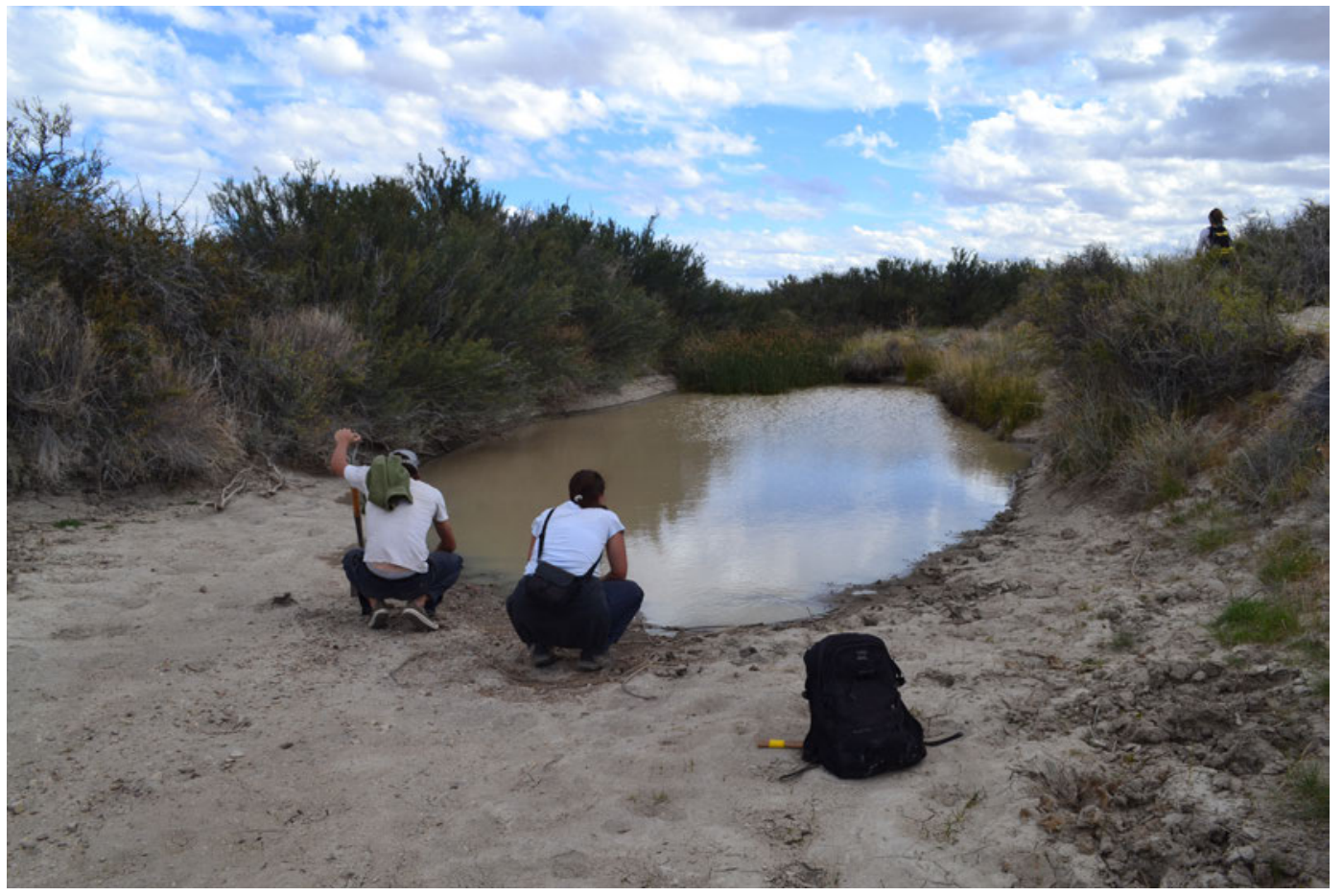

Figura 7.13: Ejemplo de un cuerpo de agua formado en una depresión en un cauce efímero.

los diferentes momentos, hasta la ausencia de éstos en algunos intervalos. Se considera que este cauce ha tenido su mayor desarrollo a lo largo del Holoceno y con el carácter de un "arroyo" efímero o temporario (Antevs 1952).

La estratigrafía del sondeo de Tito del Valle presenta rasgos hidromórficos en la sección inferior (Capa VI). Estas características permiten inferir que el nivel freático oscila dentro de estos depósitos que se encuentran en niveles aproximados a la base del cauce. Sin embargo, la Capa V, por su granulometría, diseño del depósito y contacto discordante con la capa VI nos permite inferir que responde a un depósito de barra, resultado de un flujo de agua con una competencia alta que corrió dentro de la cueva durante el Holoceno tardío. De esta manera, en caso de que se hubiesen depositado materiales arqueológicos es muy probable que hayan sido afectados por la mencionada corriente de agua movilizándolos y sacándolos de la cueva. Los depósitos superiores (Capas I, II y III) responden a flujos de menor energía, en los que el agente eólico habría participado en el retrabajo y depositación de material arenoso. Como hemos mencionado, a estos depósitos se les asigna una cronología reciente, de tiempos históricos, por lo que pueden ser 
contemporáneos o posteriores a la construcción de la pared de adobe que actualmente cierra a la cueva y protege a su interior de eventuales flujos de agua. De esta manera la cueva se encuentra protegida ante la dinámica fluvial del cauce, y esta sería la razón por la cual los depósitos superiores no han sido modificados por agua, así como tampoco las estructuras de fogón superficiales ni los materiales reconocidos en Capa II. 


\section{Capítulo 8}

\section{Cuenca Baja}

Como hemos mencionado antes, Piedra Museo es la única localidad de las estudiadas en esta tesis que cuenta con información geoarqueológica previa (Zárate et al. 2000). En este sentido, hemos realizado un nuevo muestreo de la estratigrafía de AEP-1 a partir de las capas reconocidas por Zárate y colaboradores (2000) para realizar el análisis de composición. Para la descripción textural hemos utilizado los datos publicados en dicho trabajo y a partir de ellos calculamos los coeficientes estadísticos. Además calculamos las tasas de acumulación sedimentaria del sitio. Tanto el análisis de composición como el cálculo de coeficientes estadísticos y de tasas de acumulación, sirvieron para unificar criterios metodológicos con respecto a Cueva Maripe. Por otro lado, hemos complementado esta información con la inclusión del análisis de un testigo sedimentario recuperado en el paleolago de Piedra Museo.

\subsection{Sitio AEP-1}

El sitio AEP-1 corresponde a un alero, que se abre en la base de una sedimentita relicto de una ingresión marina denominada Fm Puesto El Museo cuya extensión se reduce a este afloramiento (Panza 2001). El sitio forma parte de la localidad arqueológica Piedra Museo, junto con la Cueva Grande, emplazada en otro sector del afloramiento. Por su situación topográfica, se destaca sobre la planicie circundante y sirve como un lugar estratégico desde el que se pueden divisar los movimientos de tropillas de animales provenientes de diversos lugares hacia el bajo donde existen manantiales y ojos de agua (Figura 8.1). Su altura sobre la antigua línea de costa del exten- 
so paleolago es de $4 \mathrm{~m}$.

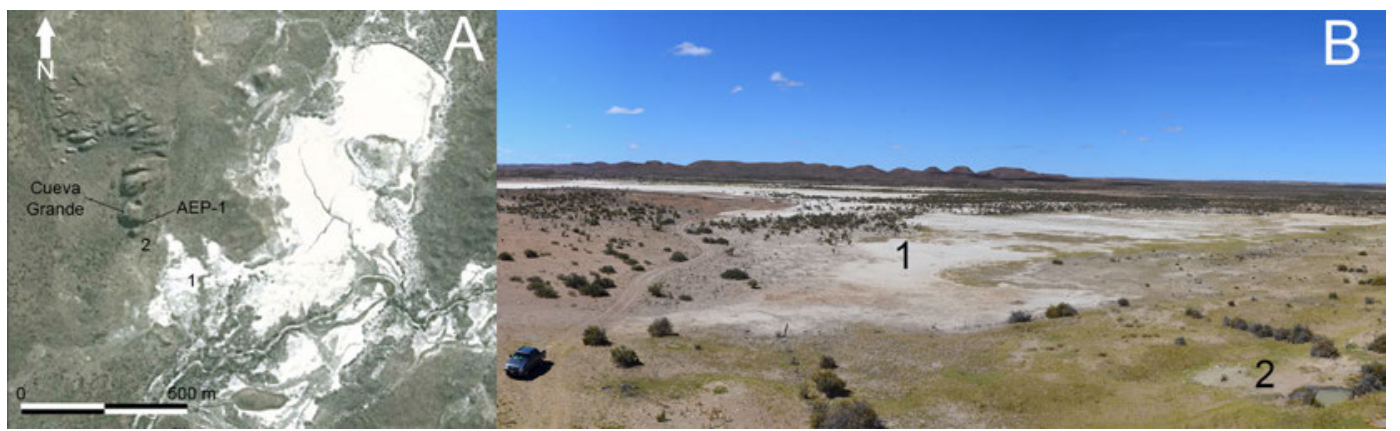

Figura 8.1: A. Imagen satelital de la localidad arqueológica Piedra Museo. B. Panorama visual del paleolago desde el techo del afloramiento de la Formación Puesto el Museo. Referencias: 1. Lugar de extracción del testigo sedimentario del paleolago. 2. Manantial.

\subsubsection{Tipos de aportes sedimentarios: Endógenos y Exógenos}

\section{Aportes endógenos:}

El sitio AEP-1 se emplaza en un afloramiento de la Fm Puesto El Museo, definida como una sedimentita coquinoide de origen marino (Panza 2001). $\mathrm{Al}$ igual que en Cueva Maripe, en primer lugar realizamos el análisis de la composición de la roca de caja. Para tal fin se observaron con lupa binocular las fracciones psefitas y psamitas (mayores a $2 \varphi$ ) de una muestra de roca molida.

Los clastos aportados por la roca del abrigo al relleno sedimentario de la cueva son: clastos carbonáticos angulosos de tonalidades rosadas a blanquecinas y brillo mate (fragmentos de micrita, subesparita a esparita), granos de cuarzo hialinos subredondeados, frecuentemente con fracturas cóncavas y brillo vítreo muy marcado y, fragmentos de roca de caja (fragmentos de valvas ligados a clastos de cuarzo por cemento carbonatico) (Figura 8.2). La presencia de estos componentes en el registro sedimentario de AEP- 1 indica aporte propio de la roca de caja. Estos componentes de la roca de caja, son los que al ser observados en las muestras sedimentarias de la estratigrafía del sitio serán considerados como aportes endógenos. 


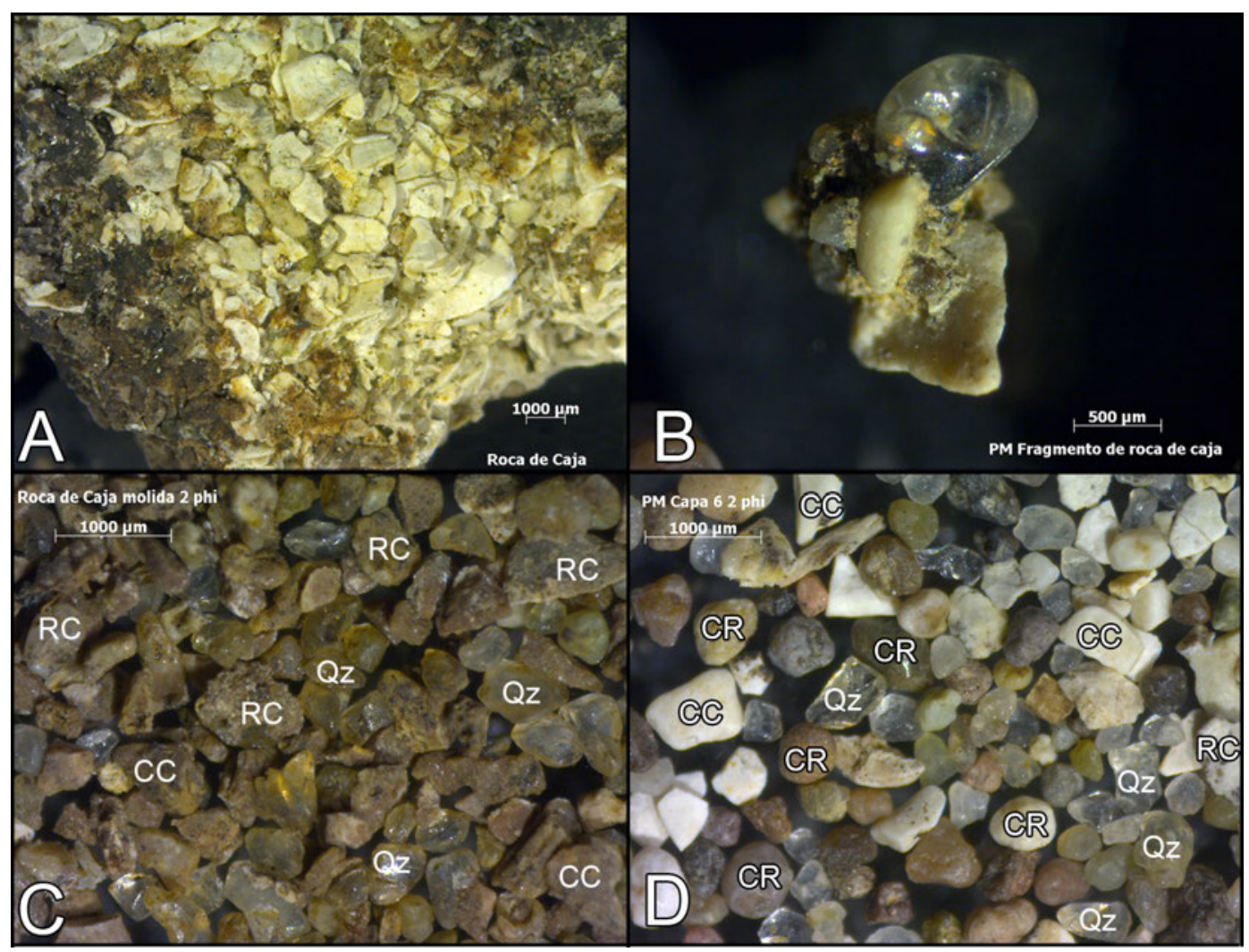

Figura 8.2: Imágenes de muestras de roca de caja y de sediemento del sitio AEP-1 . A) Concentración de valvas en la roca de caja. B) Detalle de componentes de la roca, una valva cementada junto a un grano redondeado de cuarzo C) Muestra de roca de caja molida y reconocimiento de sus componentes D) Muestra sedimetaria de Capa 6. Referencias: RC-Roca de caja; CR-Clasto redondeado; CC-Clasto carbonático; Qz-Cuarzo 


\section{Aportes exógenos:}

Entre los componentes de las muestras sedimentarias que fueron ingresados al sitio por diversos agentes de transporte podemos mencionar fragmentos de hueso, carbón y clastos redondeados a muy redondeados (Figura 5.5) de diferentes tonalidades de brillo graso a mate (clastos líticos volcánicos oscuros, clastos de minerales opacos y clastos silicoclásticos translucidos) (Figura 8.2). Estas características de los clastos redondeados, posibilitaron la diferenciación de clastos provenientes del exterior respecto de los de cuarzo aportados por la roca de caja (Figura 8.2).

Por otro lado, al igual que en Cueva Maripe el carbón y los fragmentos de hueso, fueron interpretados como ingresados por las personas que habitaron el sitio.

\subsubsection{Análisis sedimentológico}

En AEP-1 en particular, las valvas de moluscos son un componente importante de la roca de caja y al ser de composición carbónatica se desintegran ante un ataque con ácido clorhídrico (ver 5.4). Teniendo en cuenta esto, para realizar el análisis de composición no hemos tratado a la muestra con ácido. Esta práctica ha generado que tampoco se desintegre el cemento carbonático que liga los granos permitiendo la presencia de pequeños litoclastos de tamaño psefítico. De esta manera, como se podrá ver en el cuadro de composición (Figura 8.4) están representadas las psefitas, mientras que en el análisis textural, no (Figura 8.3).

En principio, los análisis de porcentaje de materia orgánica mostraron valores muy bajos, de hecho solo el de capa 4 superó el 1 \% (ver 8.1). Por otro lado, si bien en la figura de análisis de composición (Figura 8.4) no hemos incluido a los análisis de composición argilomineral mediante DRX, estos han sido realizados. En este caso optamos por no agregarlos ya que todas las muestras presentaron un alto contenido de carbonatos, lo que genera que los picos indicadores de la presencia de cada argilomineral no tuvieran el desarrollo esperado ante la presencia de carbonato.

La estratigrafía de AEP-1 comienza con un estrato de arena suelta de color castaño claro (10 YR 3/4) en contacto con la roca de caja que corresponde al horizonte pedológico IIIC, según lo propuesto por Zárate y colaboradores (2000). En cuanto a textura, se trata de un sedimento areno limoso de 
distribución bimodal muy leptocúrtica. La media granulométrica se ubica en arena fina $(2,53 \varphi)$ (Figura 8.3). El análisis de composición de la capa 6 muestra que los fragmentos de roca de caja y clastos carbonaticos son los componentes exclusivos de la fracción psefítica. En las fracciones arenosas hay un notorio aporte de clastos muy redondeados no reconocidos en la roca de caja (entre 20 y $40 \%$ ), mientras que el resto de la muestra se compone de fragmentos de roca de caja, clastos carbonáticos y granos de cuarzo hialino subredondeados (Figura 8.4). Las dataciones radiocarbónicas obtenidas previamente en este depósito son cinco y ubican entre $12890 \pm 90$ y $10390 \pm 70$ años ${ }^{14} \mathrm{C}$ AP (15687-11840 años cal. AP) (Figura 8.5).

Por encima, la capa 5 (horizonte pedológico IIB32 -Zárate et al. 2000-) es un depósito de color castaño oscuro (10 YR 4/3) que apoya en límite gradual sobre la capa 6 . Su textura es areno limosa, muy mal seleccionada con distribución granulométrica polimodal platicúrtica. Estas características marcan una clara diferencia de este depósito con respecto la capa subyacente. El valor de media granulométrica es de 4,6 $\varphi$ que corresponde a la fracción limo grueso (Figura 8.3). En cuanto a la composición, las fracciones psefíticas presentan como componentes exclusivos a fragmentos de roca de caja o alguno de sus componentes (Figura 8.4). En tanto que en la fracción arenosa disminuye la proporción de clastos muy redondeados con respecto a la capa 6 ubicándose entre 10 y $25 \%$. Asimismo, la proporción de granos de cuarzo sub redondeado asignables a la roca de caja alcanza su mayor frecuencia en la fracción $2 \varphi$ con un $25 \%$ (Figura 8.4). Solo se reconocieron escasos restos de hueso en la fracción arena muy gruesa. La capa 5 cuenta con dos dataciones de $10400 \pm 80$ y $10470 \pm 65$ años ${ }^{14}$ C AP (12544-11837 años cal. AP) (Figura 8.5).

La capa 4 (horizonte pedológico IIB31-Zárate et al. 2000-) apoya en limite gradual sobre la capa 5. Es un depósito fango arenoso de color castaño grisáceo (10 YR 5/3) en el que se reconocen evidencias de bioturbación. La distribución granulométrica es bimodal. La media granulométrica de este depósito se ubica en la fracción limo grueso $(4,93 \varphi)$. Los coeficientes de dispersión, indican que la muestra está muy mal seleccionada y presenta una distribución muy platicúrtica (Figura 8.3). De acuerdo a los análisis de composición, los componentes exclusivos de los clastos psefiticos son los fragmentos de roca de caja. Por su parte, en las fracciones arena se mantiene una tendencia similar donde la mayor proporción de cada fracción está 


\begin{tabular}{|c|c|c|c|c|c|c|c|c|c|c|c|c|c|c|c|}
\hline \multirow[t]{2}{*}{ Capa } & \multirow{2}{*}{$\begin{array}{l}\text { Horizonte } \\
\text { pedológico }\end{array}$} & \multirow{2}{*}{\multicolumn{2}{|c|}{ Color }} & \multicolumn{11}{|c|}{ Granulometría } & \multirow[b]{2}{*}{$\% \mathrm{MO}$} \\
\hline & & & & Psef. & Amg & Ag & Am & Af & Amf & Lg & Lm & Lf & Lmf & Arcilla & \\
\hline $\begin{array}{l}1 \\
2\end{array}$ & IIA & $\begin{array}{l}10 \text { YR } 5 / 3 \\
10 \text { YR } 5 / 4\end{array}$ & $\begin{array}{l}\text { Castaño grisáceo } \\
\text { Castaño amarillento }\end{array}$ & $\begin{array}{c}10 \\
0\end{array}$ & $\begin{array}{l}0,85 \\
0,87\end{array}$ & $\begin{array}{l}1,88 \\
2,27\end{array}$ & $\begin{array}{c}16 \\
4,74\end{array}$ & $\begin{array}{c}0,1 \\
6,54\end{array}$ & $\begin{array}{c}33,83 \\
5,02\end{array}$ & $\begin{array}{c}11,64 \\
6,69\end{array}$ & $\begin{array}{c}5,48 \\
11,68\end{array}$ & $\begin{array}{c}3,9 \\
13,53\end{array}$ & $\begin{array}{c}4,67 \\
12,71\end{array}$ & $\begin{array}{l}11,68 \\
35,95\end{array}$ & $\begin{array}{l}0,7 \\
0,7\end{array}$ \\
\hline 3 & IIBt & 10 YR $5 / 3$ & Castaño grisáceo & 0 & 1,13 & 0,84 & 3,5 & 6,15 & 8,09 & 7,38 & 3,64 & 5,4 & 11 & 53,24 & 0,7 \\
\hline 4 & IIB31 & 10 YR 5/3 & Castaño grisáceo & 0 & 1,3 & 1,88 & 11,08 & 16,63 & 16,32 & 11,31 & 4,2 & 4,24 & 8,81 & 24,22 & 1,06 \\
\hline 5 & IIB32 & $10 \mathrm{YR} 4 / 3$ & Castaño oscuro & 0 & 0,39 & 2,13 & 18,81 & 14,45 & 15,95 & 12,95 & 7,85 & 3,59 & 7,56 & 16,31 & 0,37 \\
\hline 6 & IIIC & 10 YR 3/4 & Castaño claro & 0 & 2,8 & 7,62 & 31,28 & 30,94 & 11,12 & 3,54 & 1,44 & 1,94 & 3,91 & 5,4 & 0,03 \\
\hline
\end{tabular}

Tabla 8.1: Resultados del análisis sedimentológico de AEP-1. 
constituida por fragmentos de roca de caja, clastos carbonáticos y clastos de cuarzo hialino subredondeados. El resto de los componentes se presentan en valores extremadamente bajos y sólo en algunas fracciones (Figura 8.4). Las dataciones publicadas de este depósito lo ubican entre $9230 \pm 105$ y $9710 \pm 105$ años ${ }^{14} \mathrm{C}$ AP (11248-10183 años cal. AP) (Figura 8.5).

La capa 4 (horizonte pedológico IIB31-Zárate et al. 2000-) apoya en limite gradual sobre la capa 5. Es un depósito fango arenoso de color castaño grisáceo (10 YR 5/3) en el que se reconocen evidencias de bioturbación. La distribución granulométrica es bimodal. La media granulométrica de este depósito se ubica en la fracción limo grueso $(4,93 \varphi)$. Los coeficientes de dispersión, indican que la muestra está muy mal seleccionada y presenta una distribución muy platicúrtica (Figura 8.3). De acuerdo a los análisis de composición, los componentes exclusivos de los clastos psefíticos son los fragmentos de roca de caja. Por su parte, en las fracciones arena se mantiene una tendencia similar donde la mayor proporción de cada fracción está constituida por fragmentos de roca de caja, clastos carbonáticos y clastos de cuarzo hialino subredondeados. El resto de los componentes se presentan en valores extremadamente bajos y sólo en algunas fracciones (Figura 8.4). Las dataciones publicadas de este depósito lo ubican entre $9230 \pm 105$ y $9710 \pm 105$ años ${ }^{14} \mathrm{C}$ AP (11248-10183 años cal. AP) (Figura 8.5).

La capa 3 (horizonte pedológico IIBt -Zárate et al. 2000-) corresponde a un depósito fango arenoso de color castaño oliva (10 YR 5/3) que apoya en limite gradual sobre la capa 4 . Los histogramas muestran una distribución bimodal y un tamaño de media granulométrica en limo fino $(6,87 \varphi)$. Los coeficientes estadísticos dan cuenta de sedimentos muy mal seleccionados con una distribución platicúrtica y asimetría negativa (Figura 8.3). Su alto contenido de arcilla, define su identidad pedológica y se reconoce en esta capa una abundante presencia de carbonatos. En cuanto a su composición, en las fracciones psefitas podemos observar que continúan predominando los fragmentos de roca de caja como el principal componente, pero en este caso re reconoció un aporte de fragmentos de hueso que alcanza el $20 \%$ de la fracción $-1 \varphi$ (Figura 8.4). En la fracción arena, los fragmentos de roca de caja o componentes de la misma (clastos carbonáticos y de cuarzo hialino subredondeado) conforman más del $89 \%$ de todas las fracciones mientras que el porcentaje restante se compone de carbón y fragmentos de hueso (Figura 8.4). La capa 3 ha sido determinada como arqueológicamente estéril 


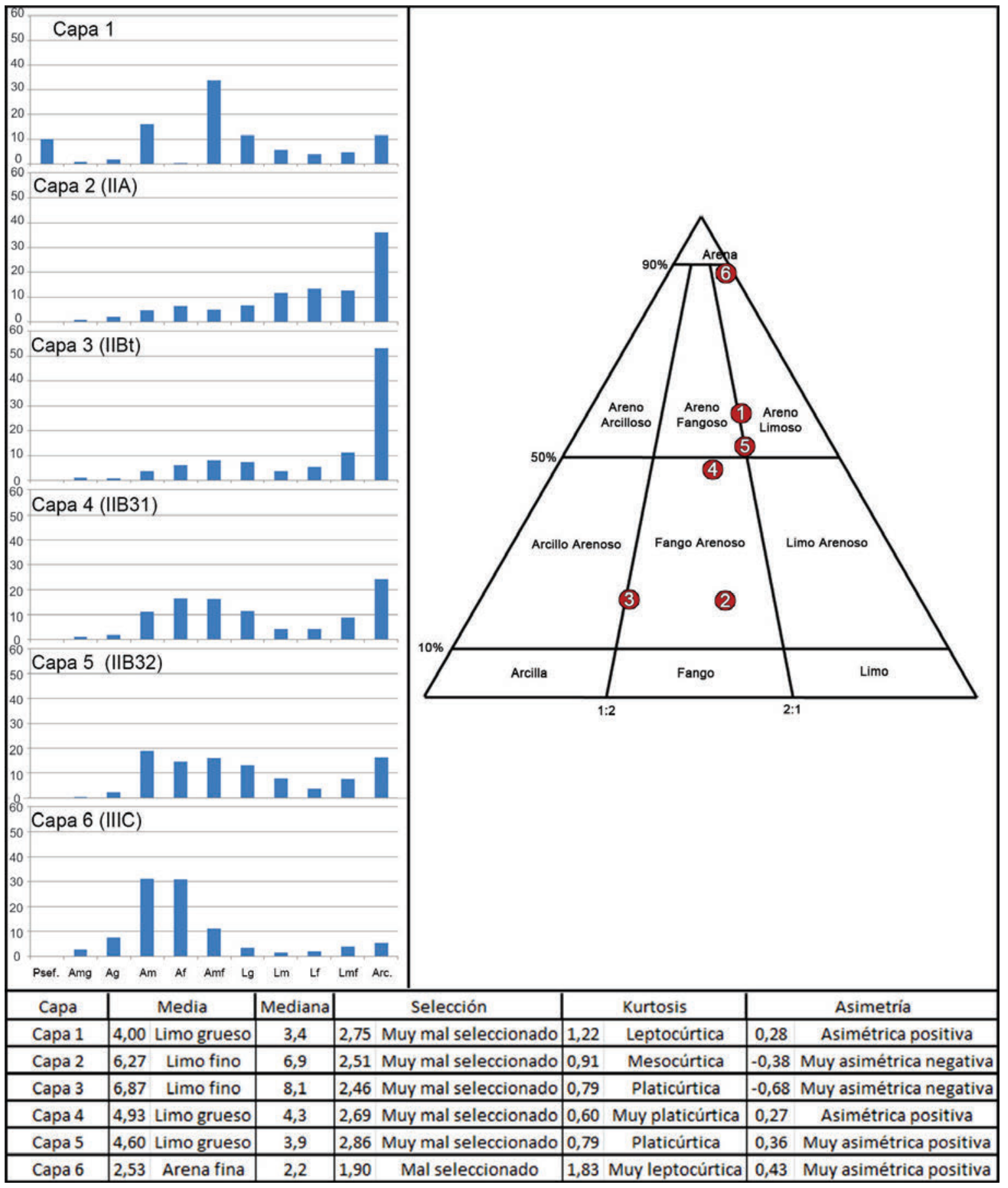

Figura 8.3: Histogramas de distribución granulométrica, triángulo de clasificación y coeficientes estadísticos de las capas que conforman el depósito sedimentario de AEP-1. 
y no presenta dataciones radiocarbónicas. El contacto entre las capas 2 y 3 es variable, pudiendo encontrarse como superficies abruptas y onduladas o como límite gradual.

La capa 2 presenta un arreglo textural areno fangoso de color castaño amarillento (10 YR 5/4), con distribución bimodal, donde la moda principal se ubica en limo fino y una moda secundaria en arena fina. La media granulométrica de esta muestra es similar a la de capa 3 y se ubica en limo fino $(6,27 \varphi)$ (Figura 8.3). En cuanto a la composición sedimentaria, la capa 2 presenta el porcentaje más alto de material exógeno del sitio alcanzando el $22 \%$. Entre los componentes exógenos se observan huesos principalmente en las fracciones más gruesas y clastos redondeados en las más finas (Figura 8.4). La información radiocarbónica de esta capa consta de dos dataciones que la ubican en $7470 \pm 140$ y $7670 \pm 110$ años ${ }^{14} \mathrm{C}$ AP (8636-7967 años cal. AP) (Figura 8.5).

La capa 2 (horizonte pedológico IIA -Zárate et al. 2000-) presenta un arreglo textural areno fangoso de color castaño amarillento (10 YR 5/4) con distribución bimodal. La media granulométrica de esta muestra es similar a la de capa 3 y se ubica en limo fino $(6,27 \varphi)$. Como en el caso de la Capa 3, los coeficientes estadísticos dan cuenta de sedimentos muy mal seleccionados y con una distribución muy asimétrica negativa y mesocúrtica (Figura 8.3). En cuanto a la composición sedimentaria, la capa 2 presenta un alto porcentaje de fragmentos de hueso en la fracción psefítica ( $40 \%$ ), aunque los fragmentos roca de caja y los clastos carbonáticos siguen siendo mayoritarios (suman el $60 \%$ ). Entre los componentes de la fracción arena se reconoce una alta frecuencia de fragmentos de roca de caja y sus componentes tales como clastos carbonaticos, en la fracción $2 \varphi$, cobran relevancia los clastos de cuarzo hialino subredondeados presentes en la roca de caja. Asimismo, se observa un incremento en la frecuencia de clastos redondeados de composición variada a medida de que disminuye el tamaño de la fracción con un $5 \%$ en $0 \varphi$ y alcanzando el $20 \%$ en $2 \varphi$ (Figura 8.4). La información radiocarbónica de esta capa consta de dos dataciones que la ubican en $7470 \pm 140$ y $7670 \pm 110$ años ${ }^{14} \mathrm{C}$ AP (8636-7967 años cal. AP) (Figura 8.5).

Las unidades pedológicas culminan con una discordancia erosiva sobre la que se deposita la capa 1. Esta capa está compuesta por arena de color castaño (10 YR 5/3) que texturalmente se define como arena limosa. Su distribución es polimodal y su media granulométrica se ubica en limo grue- 


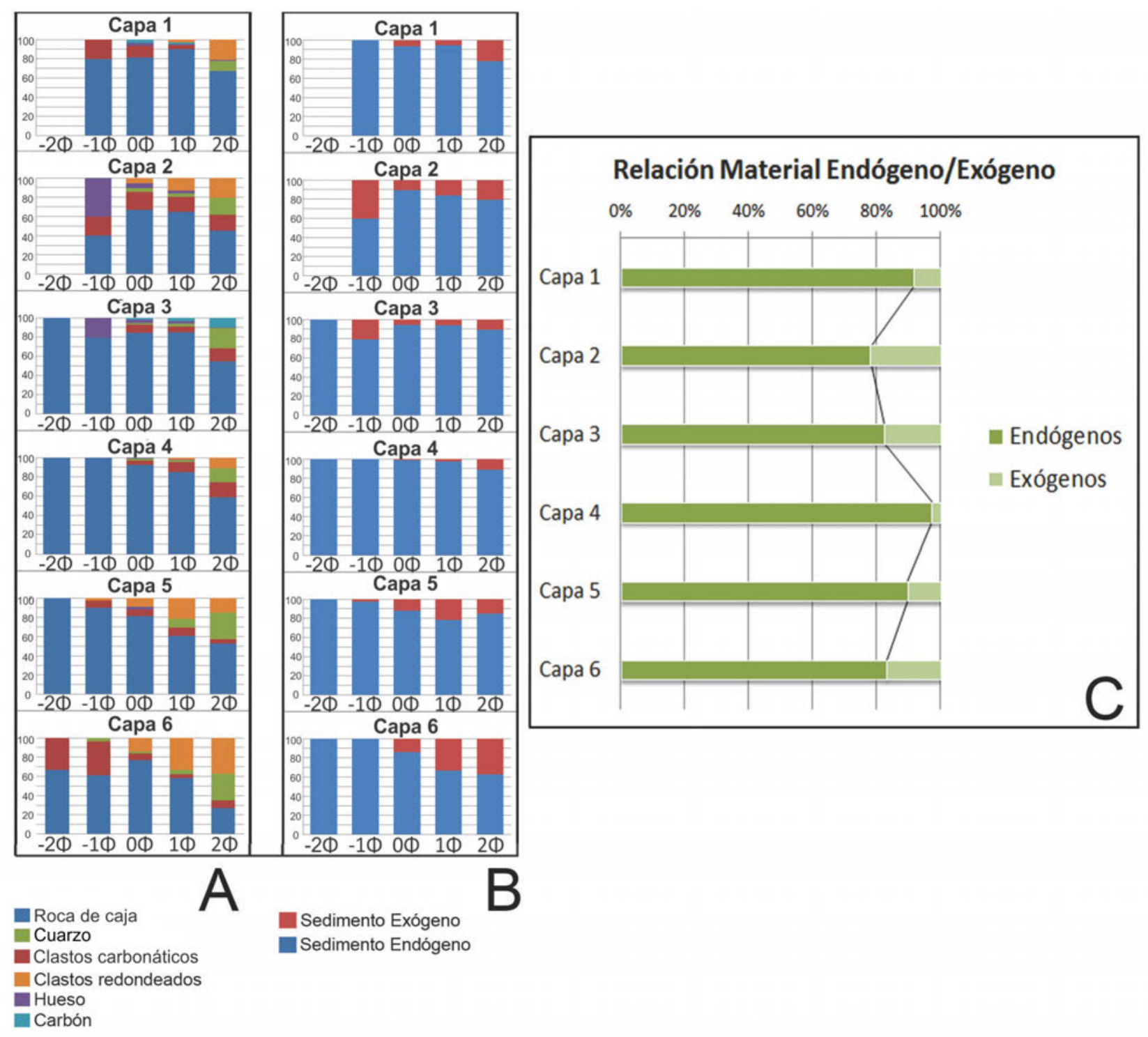

Figura 8.4: Resultados de los análisis de composición sedimentaria de AEP1. A) Porcentajes de componentes reconocidos en las fracciones grava y arena a partir de conteo con lupa binocular. B) Relación de sedimento exógeno y endógeno de cada fracción. C) Relación entre sedimento exógeno y endógeno de la muestra total a partir de la ponderación de los porcentajes de A. 


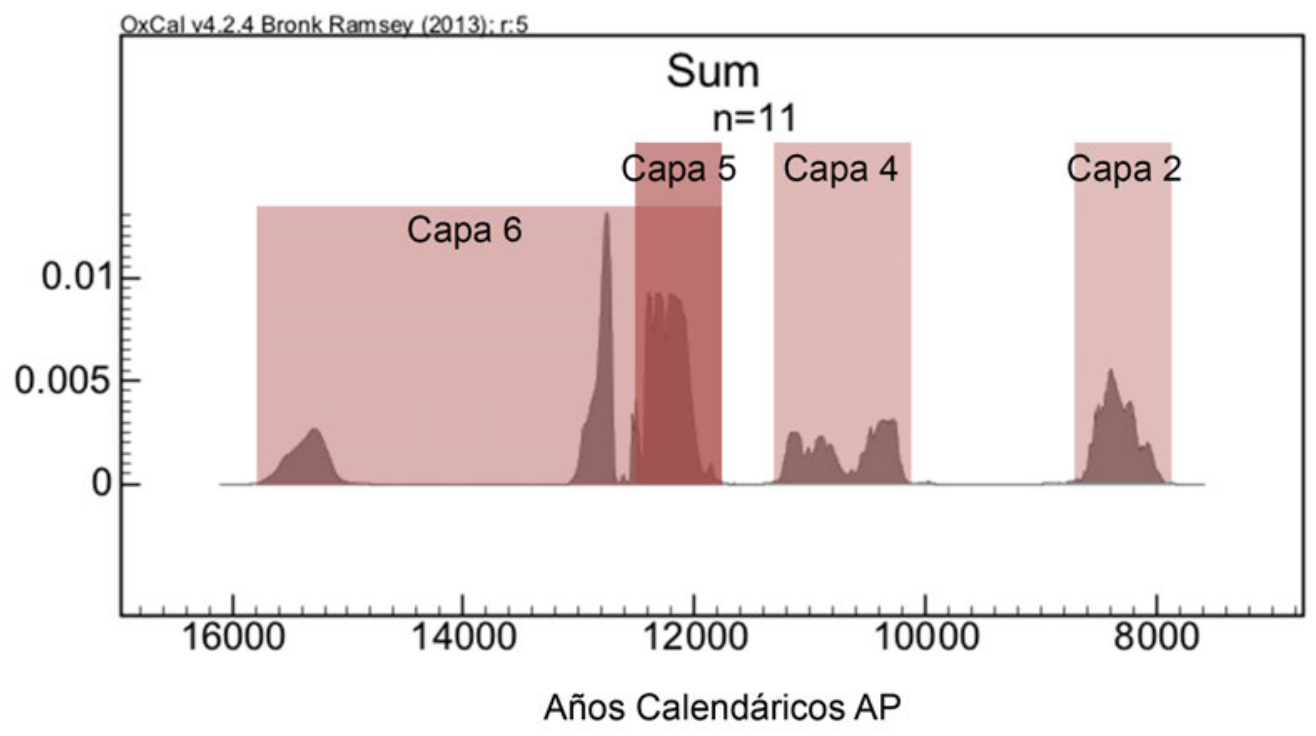

Figura 8.5: Calibración y suma de probabilidades las dataciones provenientes de AEP-1. Nótese que hay una superposición cronológica de dataciones provenientes de Capa 5 y Capa 6.

so $(4 \varphi)$. No presenta estructura. Los análisis de composición muestran un aporte endógenos del $92 \%$ y que el material exógeno predominante son los clastos redondeados de origen eólico (Figura 8.4).

Las unidades pedológicas culminan con una discordancia erosiva sobre la que se deposita la capa 1. Esta capa está compuesta por arena de color castaño (10 YR 5/3) que texturalmente se define como arena limosa. Su distribución es polimodal y su media granulométrica se ubica en limo grueso (4f). No se observa estructura sedimentaria ni rasgos pedogenéticos. Los análisis de composición muestran que los fragmentos de roca de caja y sus componentes son exclusivos en la fracción psefítica y, en las arenas representan, en conjunto, entre el 70 y $95 \%$ de cada fracción. Las observaciones realizadas permitieron reconocer que los fragmentos de hueso y carbón son muy escasos (menos del $5 \%$ de cada fracción) y que los clastos redondeados de composición diferente al cuarzo alcanzan un $20 \%$ en el fracción arena media $(2 \varphi)$ (Figura 8.4).

\subsubsection{Calculo de tasas de acumulación sedimentaria (TAS)}

Hemos calculado la TAS general de AEP-1 a partir de todos los fechados radiocarbónicos obtenidos en el sitio, la que dio como resultado 0,0141 


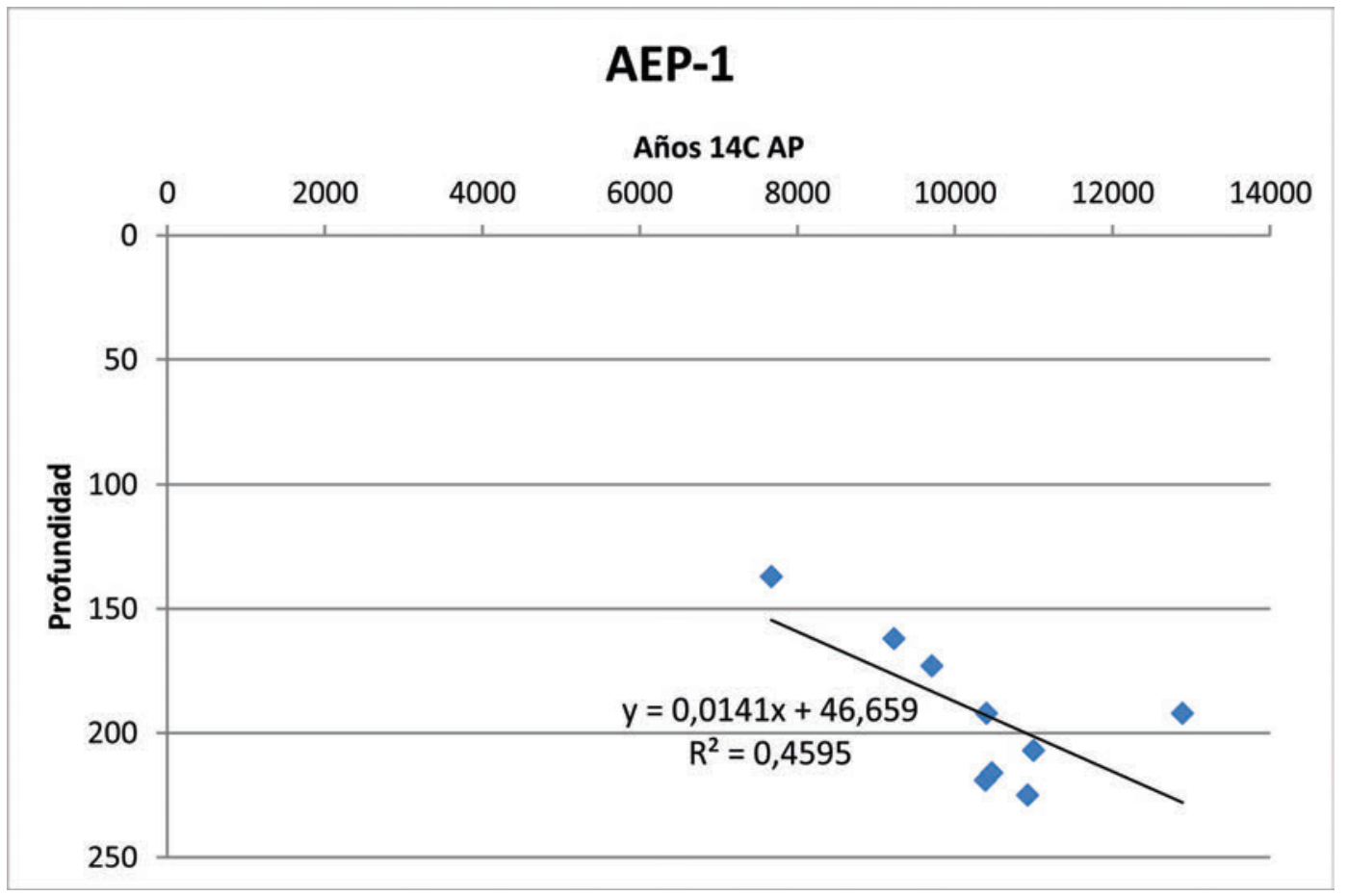

Figura 8.6: Distribución de todos los fechados y cálculo de tasa de acumulación general del sitio AEP-1.

cm/año (1,41 cm/100 años) (Figura 8.6). Si tenemos en cuenta el valor de $\mathrm{R}^{2}$ $=0,4595$, podemos reconocer que no hay un ajuste claro entre las variables, por lo que sería esperable una variación de las tasas de depositación a lo largo de la secuencia.

A diferencia de lo que ocurre en Cueva Maripe, a la hora de realizar el cálculo de la TAS por unidad de excavación nos encontramos con que sólo la cuadricula L presenta más de dos fechados. Por su parte, la cuadricula E presenta dos dataciones entre las que se incluye $12890 \pm 90$ años ${ }^{14} \mathrm{C}$ AP. Esta datación presenta algunas objeciones, ya que se separa del resto de los fechados de la Capa 6 por lo que puede ser considerado un outlier (Steele y Politis 2009, Marchionni 2013). Debido a esto, hemos optado por no incluirlo en los cálculos de TAS y hemos relacionado el fechado restante de esta cuadrícula con uno proveniente de la cuadricula $\mathrm{F}$ adyacente a la cuadricula $\mathrm{E}$ (ver Figura 4.4).

El hecho de no contar con cuadrículas con más de dos fechados con separaciones temporales que permitan reconocer variaciones en la velocidad de acumulación, disminuye las chances de ver variaciones a lo largo del tiempo. Sin embargo, en AEP-1, los lapsos temporales abarcados por las datacio- 
nes de cada cuadricula se complementan y permiten abarcar prácticamente todo el lapso de ocupación arqueológica.

Los fechados de la cuadrícula L permiten estimar una TAS de 1,97 cm/100 años, para el lapso comprendido entre 10925 y 10390 años ${ }^{14} \mathrm{C}$. Si bien uno de los cálculos parciales arroja un valor de $-3,75 \mathrm{~cm} / 100$ años entre los fechados de $10390 \pm 70$ y $10470 \pm 65$ años ${ }^{14} \mathrm{C}$ AP (Figura 8.7), lo que significaría una acumulación negativa, la cercanía de los valores de los fechados nos llevó a realizar un test de significancia t utilizando el programa CALIB 6.0, que confirmó que ambas datación son estadísticamente iguales. En este sentido podemos interpretar que pertenecen al mismo evento de ocupación. Basándonos en estos datos podemos tomar como válido para este momento la TAS de 1,97 cm/100 años (Figura 8.7).

En las cuadriculas E-F se obtuvieron dos fechados que permitieron calcular la TAS para el lapso $9230 \pm 105-9710 \pm 105$ años ${ }^{14} \mathrm{C}$ AP. El resultado de este cálculo es de 2,29 cm/100 años que es un valor mayor al obtenido en la cuadricula L para momentos previos (Figura 8.7).

Por último, las dos dataciones recuperadas en la cuadricula $\mathrm{C}$, abarcan un periodo temporal amplio desde $11000 \pm 65$ años ${ }^{14} \mathrm{C}$ AP hasta $7670 \pm 110$ años ${ }^{14} \mathrm{C}$ AP (Figura 8.7). En este lapso se incluyen los de las cuadrículas analizadas previamente y se extiende hasta el Holoceno medio. El valor calculado para esta TAS es de 2,1cm/100 años, manteniéndose en valores similares a los obtenidos previamente (Figura 8.7).

\subsection{Paleolago de Piedra Museo}

La geoforma más relevante ubicada en las cercanías de AEP-1 es el denominado paleolago de Piedra Museo. En la búsqueda de relacionar su depósito sedimentario con el de AEP-1, realizamos un muestreo con barreno sobre el lecho del mismo a unos $200 \mathrm{~m}$ del sitio en dirección SSE del cual se obtuvo un testigo completo de $0,8 \mathrm{~m}$, que por la dureza del sustrato se hizo imposible profundizar más (Figura 8.8). Ante este panorama, intentamos otro muestreo en un punto alejado de este testigo, pero el resultado fue el mismo.

El análisis textural muestra que la base del testigo $(60-80 \mathrm{~cm})$ está conformada por sedimentos areno arcilloso de color gris rosado (7,5 YR 6/2) en el que se reconoce una distribución granulométrica bimodal centrada en 

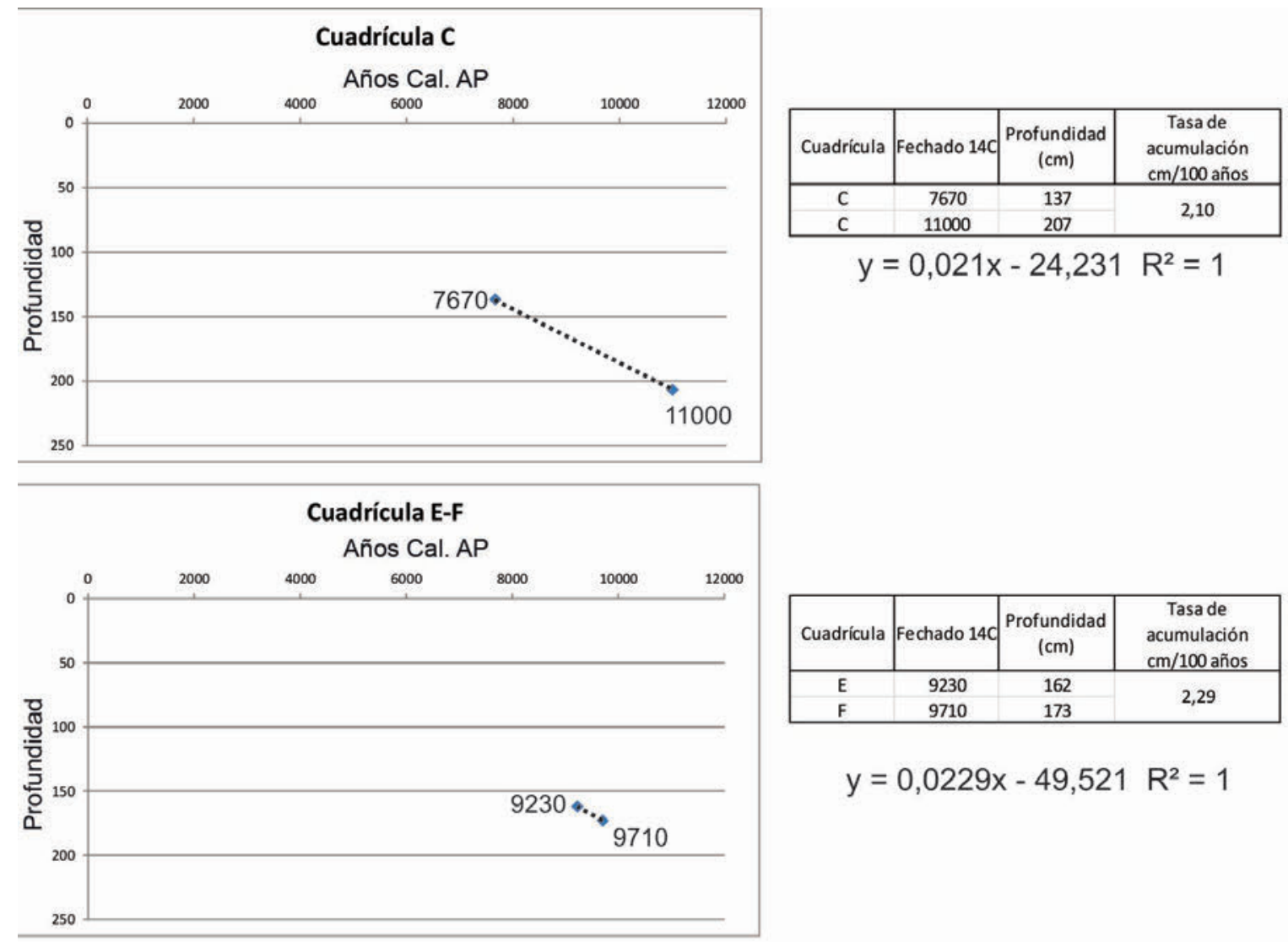

$$
y=0,0229 x-49,521 R^{2}=1
$$

\section{Cuadrícula L}

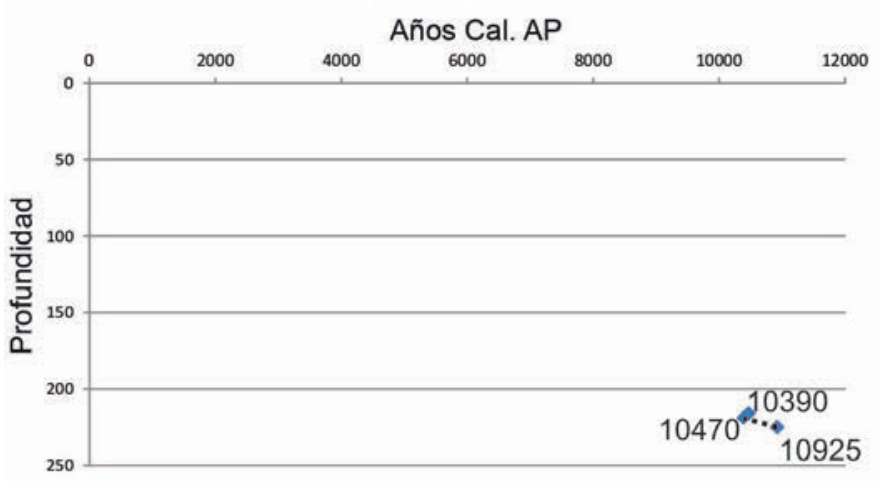

\begin{tabular}{|c|c|c|c|}
\hline Cuadrícula & Fechado $14 \mathrm{C}$ & $\begin{array}{c}\text { Profundidad } \\
(\mathrm{cm})\end{array}$ & $\begin{array}{c}\text { Tasa de } \\
\text { acumulación } \\
\mathrm{cm} / 100 \text { años }\end{array}$ \\
\hline L & 10390 & 219 & $-3,75$ \\
\hline L & 10470 & 216 & \multirow{2}{*}{1,978021978} \\
\hline L & 10925 & 225 & \\
\hline
\end{tabular}

Figura 8.7: Cálculo de tasas de acumulación por unidad de excavación de AEP-1. Las tablas muestran los cálculos por pares y debajo de ellas se incluye el resultado obtenido a partir de la ecuación de regresión (en cm/año). 


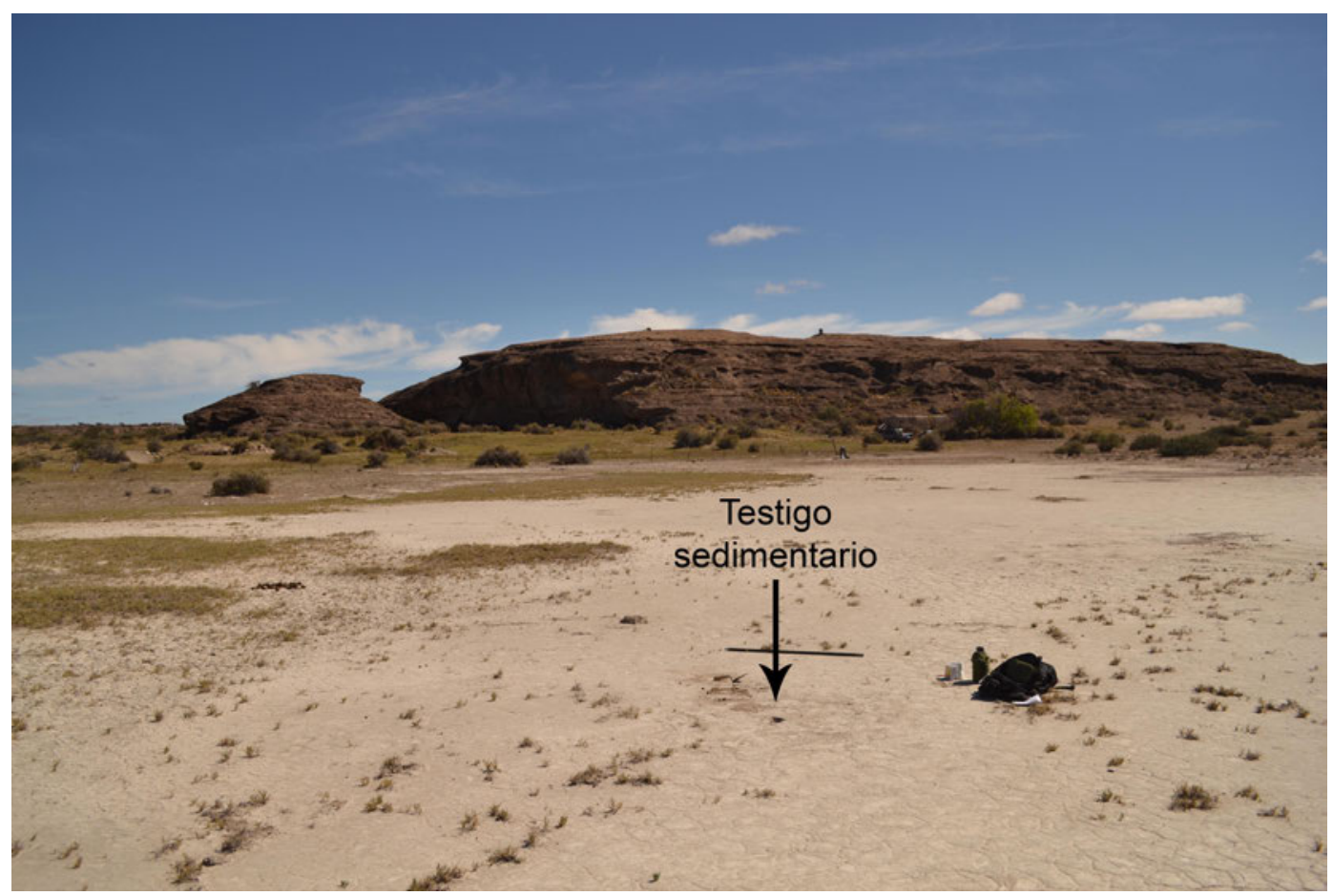

Figura 8.8: Sector de extracción del testigo del Paleolago de Piedra Museo. $\mathrm{Al}$ fondo se puede observar el afloramiento de la Fm. El Museo en el que se ubica el sitio AEP-1.

la fracciones arena fina y arcilla (Figura 8.9). El tamaño de grano promedio para esta muestra se ubica en limo grueso $(5,6 \varphi)$. Por su parte, los coeficentes estadísticos indican una muestra extremadamente mal seleccionada, con una distribución mesocúrtica y muy asimétrica positiva. No se reconocieron raíces ni restos vegetales.

En la muestra 40-60 cm, aumenta la fracción arcilla y disminuye la arenosa. Presenta color gris rosado (7,5 YR 6/2) y una textura arcillo arenosa. La media granulométrica es más fina que en el nivel inferior con un valor de $7,4 \varphi$, que la ubica en limo muy fino. Los coeficentes estadísticos clasifican a la muestra como muy mal seleccionada, con una distribución platicúrtica y asimetría positiva. La distribución en este caso podemos asumirla como polimodal con la moda principal en la fracción arcilla, ya que esta fracción reúne al $48 \%$ de la muestra y secundariamente en arena fina y limo fino (Figura 8.9).

Siguiendo hacia la superficie, en la muestra $40-20 \mathrm{~cm}$ los porcentajes de las fracciones arena y arcilla presentan leves variaciones, aunque se incrementa la proporción de limo. De esta manera se llega a una textura fango arenosa con distribución polimodal como en la muestra anterior, y con mo- 
das granulométricas en arena fina, limo muy fino y arcilla (Figura 8.9). A pesar de estas variaciones, el tamaño promedio de grano se mantiene en $7,4 \varphi$ (limo muy fino). Asimismo, los coeficentes estadísticos son similares a los de la muestra anterior clasificandola como extremadamente mal seleccionada, con una distribución platicúrtica y asimétrica positiva (Figura 8.9).

La muestra más superficial mantiene el alto porcentaje de arcilla reconocido en las dos muestras anteriores. Es un sedimento de gris rosado (7,5 YR $6 / 2$ ) y textura fango arenosa (Figura 8.9). Como suceden en muestras anteriores, la distribución granulométrica es polimodal, con modas en arena fina, limo muy fino y arcilla, y con una media granulométrica que se ubica en la fracción limo muy fino 7,9 9 . Los coeficientes estadísticos permiten reconocer una muestra muy mal seleccionada, con una distribución platicúrtica y cuyo valor de asimetría la establece como una distribución simétrica (Figura 8.9).

\subsection{Valoración de los resultados de la Cuenca Baja}

A continuación haremos una interpretación de los datos que hemos mostrado aquí para integrarlos con aquellos publicados en trabajos previos realizados en el sitio.

La composición sedimentaria del perfil estratigráfico de AEP-1 fue evaluada comparando los elementos reconocidos en las muestras sedimentarias con aquellos componentes clásticos que aporta la roca de caja a partir de su meteorización (ver detalle en punto (8.1.1)).

Los elementos que no pudieron ser asignados a las categorías mencionadas de aporte endógeno, se asumieron como exógenos dado que al no estar presentes en la roca de caja su procedencia es del exterior de la cueva. Entre estos encontramos al carbón, fragmentos de hueso, y clastos muy redondeados. Como en Cueva Maripe, en el caso del carbón se consideró que ingresó al sitio como resultado del transporte humano como leña (ver Capítulo 5), los fragmentos de hueso pudieron ingresar como resultados del transporte humano y también animal y, por último los clastos muy redondeados son resultado del transporte eólico. El grado de redondeamiento de éste material exógeno, fue considerado como producto de un transporte prolongado, en un ciclo o más de sedimentación. 


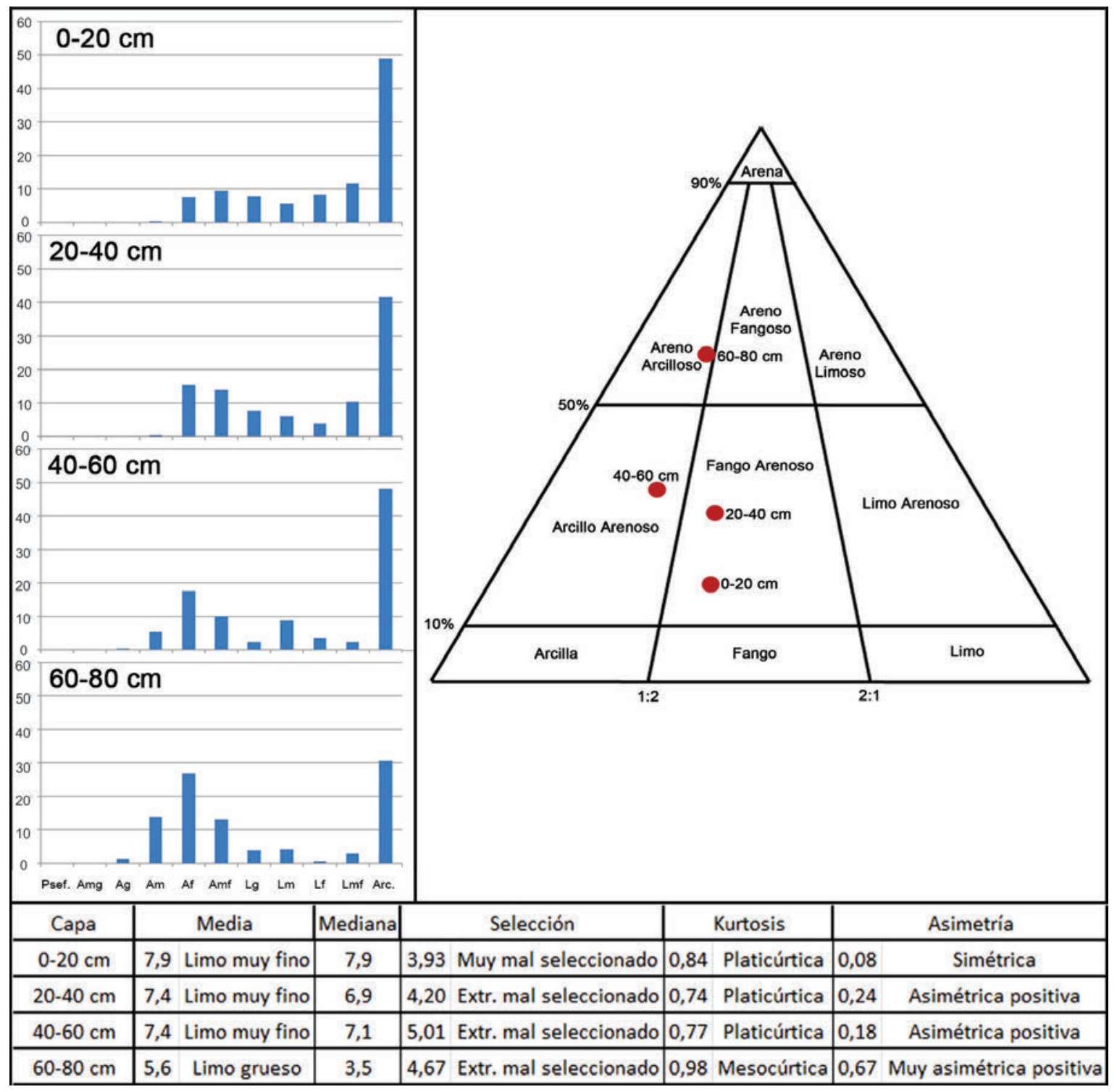

Figura 8.9: Histogramas de distribución granulométrica, triángulo de clasificación y coeficientes estadísticos del registro sedimentario de un testigo del Paleolago de Piedra Museo. 
Nuestros análisis indican que los aportes de origen endógeno son mayoritarios en todas las muestras analizadas de la secuencia del sitio AEP-1 y son resultado de la caída de detritos desde el techo (ver Figura 8.4 B y C). Esto significa que la caída de detritos del techo es un proceso de aporte sedimentario con clara presencia en todas las capas con valores totales mayores al 78 \% (ver Figura 8.4 B y C). Por su parte, los materiales exógenos, son minoritarios en todas las muestras y presentan valores entre $22 \%$ (en Capa 2) y $5 \%$ (en capa 4 ) (ver Figura 8.4 B y C). Esto da como resultado un depósito sedimentario de composición mixta que conjuga aportes principalmente endógenos y en segundo lugar aportes de origen exógeno.

Si bien en el análisis textural la roca de caja no está representada la fracción psefítica (ver explicación en el primer párrafo del apartado Análisis sedimentológico en este capítulo), al analizar la muestra sin tratar con ácido clorhídrico pudimos observar que su participación en la muestra es escasa. De esta manera, si tenemos en cuenta la alta proporción de material endógeno que constituye a las muestras de sedimento, entendemos que la fragilidad de la roca de caja no permitió la persistencia en el tiempo de clastos grandes. No obstante, si bien el registro de la caída de detritos dentro del alero pudo verse modificado, en AEP-1 se reconoció un derrumbe del techo que apoya en la capa 4, es decir que habría ocurrido con una cronología posterior a los ca. 9200 años ${ }^{14} \mathrm{C}$ AP (ver Tabla 4.3).

La capa 6, que conforma el depósito basal y se ubica temporalmente en el Pleistoceno final, presenta como principal componente, dentro del material exógeno, a los clastos redondeados de origen eólico. Los estudios polínicos muestran una asociación de estepa arbustiva características de climas secos con precipitaciones menores a $200 \mathrm{~mm}$ anuales (Borromei 2003). Esta condición climática, habría permitido una mayor disponibilidad de sedimento en los alrededores del sitio para su transporte. Las tasas de acumulación sedimentaria calculadas entre fechados provenientes de este depósito muestran valores relativos altos $(1,97 \mathrm{~cm} / 100$ años) que se condicen con la buena preservación del conjunto zoarqueológico en el que predominan los estadios de meteorización 1 y 2 (Marchionni 2013). Asimismo, son abundantes los depósitos de óxidos de $\mathrm{Mn}$ y $\mathrm{CaCO}_{3}$ que evidencian por un lado la acción hídrica sobre los especímenes óseos donde la fluctuación del nivel freático podría haber tenido un papel preponderante y por otro, un proceso de carbonatación. 
Las capa 4 y 5 presentan características texturales similares y en cuanto a composición hay una continua disminución del aporte exógeno con respecto a capa 6, el cual está siempre constituido por clastos redondeados (Figura 8.11). Considerando la información polínica, en estas capas los datos apuntan una configuración florística de estepa graminosa, que indica condiciones de mayor humedad relativa (Borromei 2003). Este cambio habría contribuido a una menor disponibilidad de material para el transporte eólico. La velocidad de agradación en ambas capas se mantiene en valores similares a los de capa 6, y tal como sucede en ese depósito, los análisis tafonómicos de las capas 4 y 5 muestran estadios de meteorización bajos ( 1 y 2), sin embargo, hay un claro cambio en cuanto a las modificaciones naturales encontradas en las superficies óseas ya que, con respecto a capa 6 se invierten las frecuencias de materiales con marcas de $\mathrm{Mn} \mathrm{y} \mathrm{CaCO}_{3}$, siendo estos últimos los más frecuentes (Marchionni 2013).

La capa 3 corresponde a un hiato ocupacional, sin embargo hemos hallado pequeños restos de hueso y carbón en la muestra de sedimento que son los que representan el aporte exógeno de este depósito. Esta capa a nivel pedológico conforma el horizonte IIBt, con un alto contenido de arcilla resultado de la acumulación por proceso de iluviación. Por lo que la acción postdepositacional (pedogénesis) fue la que conformó el arreglo sedimentológico de este depósito y habría incorporado los pequeños restos de hueso y carbón de la capa superior. Los datos palinológicos aportan en este sentido, marcando un contexto de estepa arbustiva en el que la aparición de Chenopodiineae, sumados a Plumbaginaceae y Caryophillaceae indican la presencia de comunidades desarrolladas en depresiones de escaso drenaje (Borromei 2003).

La capa 2 por su parte contiene a las ocupaciones del sitio asignables al Holoceno medio. El techo de este depósito está marcado por una discontinuidad. Durante a exavación se pudo reconocer que ésta discontinuidad corresponde a una superficie ondulada con cierto grado de consolidación por carbonatos formada por pequeñas cubetas, que evidencian una superficie mal drenada (Figura 8.10). De acuerdo a nuestros análisis es la capa con mayor aporte de material exógeno de toda la secuencia. Este aporte se compone de hueso y clastos redondeados principalmente, evidenciando que fueron los humanos el principal agente de transporte y depositación de material exógeno. El análisis polínico evidencia un ambiente de estepa ar- 
bustiva de Ephedra y Asteroidea típica de ambientes muy áridos (Borromei 2003). La tasa de acumulación sedimentaria que se calculó para este tramo de la secuencia se asemeja a las calculadas para el resto de la estratigrafía. Sin embargo, como incluye en un segmento temporal amplio (11000 \pm 65 $7670 \pm 110$ años ${ }^{14} \mathrm{C} \mathrm{AP}$ ) puede suceder que se estén enmascarando algunos cambio en la velocidad de depositación. En este sentido, el proceso pedogenético descripto para el sitio permite, al menos, estimar una disminución en la velocidad de acreción sedimentaria hacia el Holoceno medio. El proceso de carbonatación muy evidente en las capas 2 y 3 aporta datos en cuanto a estabilidad de la superficie, como así también de la aridez del ambiente. Resulta interesante que el conjunto zoarqueológico presenta estadios de meteorización bajos, al igual que el resto de la secuencia. Sin embargo, hay un cambio en cuanto a las modificaciones naturales reconocidas en las superficies óseas ya que cobran relevancia las marcas de raíces acompañadas de los depósitos de Mn en segundo lugar (Marchionni 2013). Estas marcas son coherentes con un contexto pedológico de un horizonte IIA enterrado como el que representa la capa 2, y el cual luego de su depositación recibió un marcado aporte de agua que genero modificaciones sobre la superficie y favoreció el proceso de iluviación (Figura 8.11).

Los análisis realizados sobre las muestras del paleolago muestran en principio una continuidad litoestratigráfica. En este sentido, los $80 \mathrm{~cm}$ recuperados están compuestos por dos fracciones modales principales, arena fina y arcilla. Esto marca una un ambiente de muy baja energía con depositación por decantación. Es probable que parte de las arcillas se hayan depositado por floculación o agregación en un cuerpo de agua somero.

En un trabajo previo se analizó la flora diatomológica de la cubeta del paleolago a partir de un testigo similar al obtenido por nosotros. La asociación de diatomeas está representada por especies aerófilas y euterrestres, por lo que pueden encontrarse en ambientes húmedos o secos. Los resultados de estos análisis no alcanzaron interpretaciones definitivas, por lo que solo se pudo inferir una alternancia entre episodios de llenado de la cubeta del lago con momentos de sequía (Fernández 2013).

El testigo recuperado no muestra cambios significativos de ningún tipo, ni texturales, ni en cuanto a flora diatomológica ni tampoco pudo ser relacionado fehacientemente con la estratigrafía del sitio AEP-1, por lo que asumimos que este depósito corresponde a una cronología tardía y que si bien 


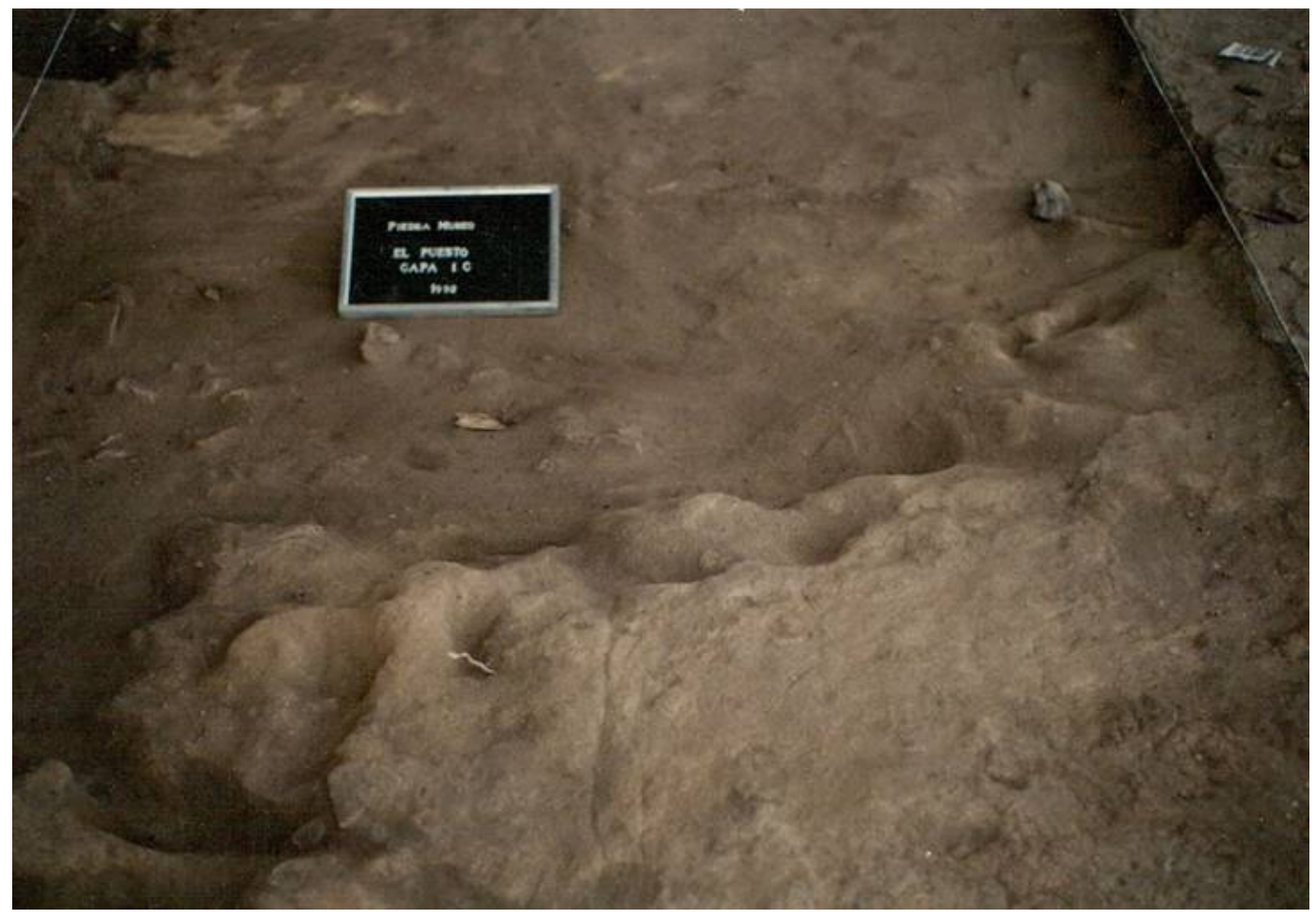

Figura 8.10: Techo de Capa 2 de AEP-1. Superficie ondulada que marca la discordancia observada en la estratigrafía (fotografía, Miotti y Marchionni 2011). 


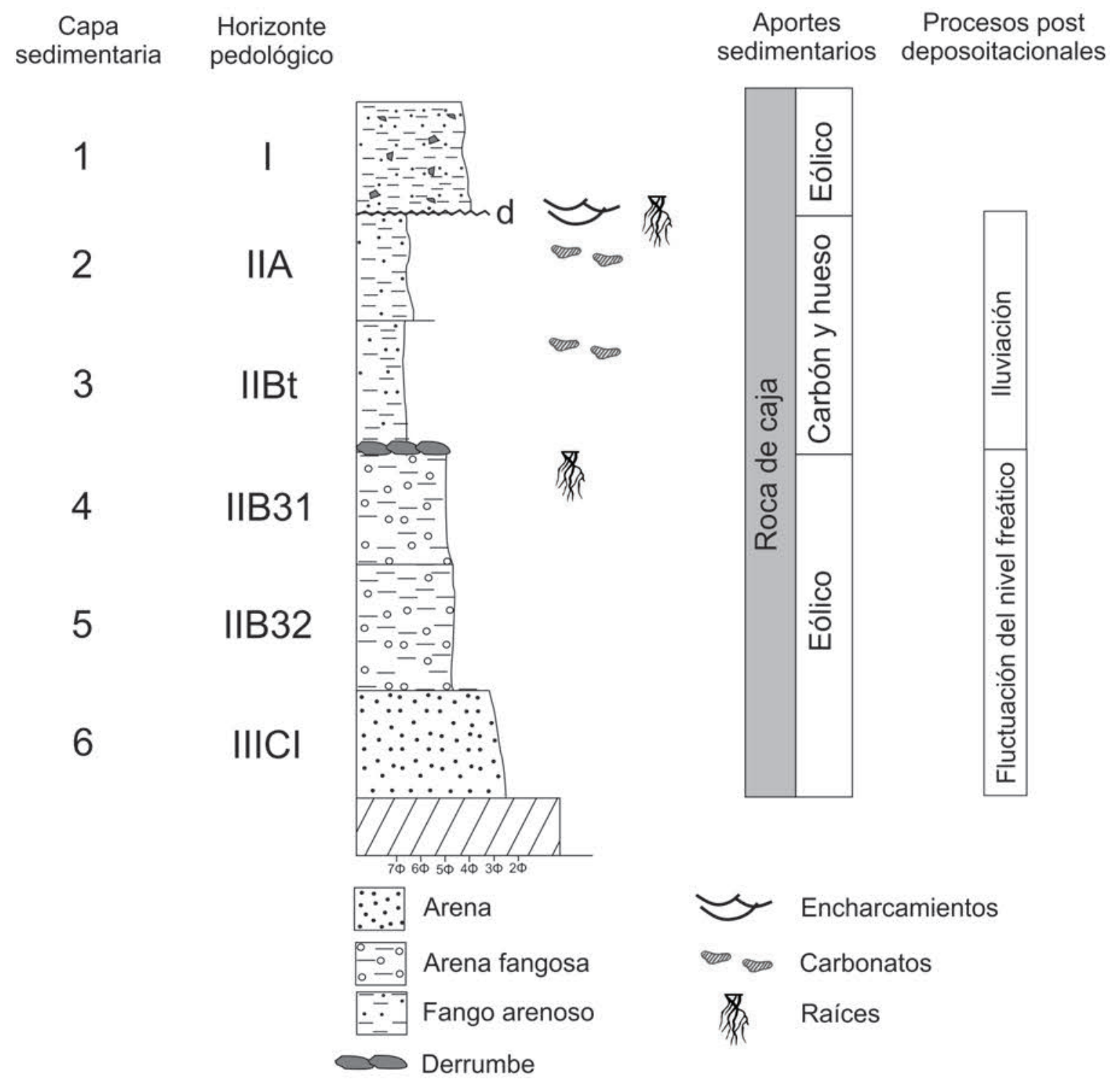

Figura 8.11: Estratigrafía de AEP-1 con caracterización general de los aportes sedimentarios y modificaciones postdepositacionales (modificado de Zárate et al. 2000). 
no se condice con un comportamiento de aguas someras como el esperable en un paleolago, representa condiciones de mayor o menor acumulación de agua dependiendo del régimen pluvial, tal como sucede en la actualidad. 


\section{Capítulo 9}

\section{Marco cronológico de las ocupaciones humanas}

A lo largo de los años de trabajo arqueológico en nuestra área de estudio y en sectores aledaños, se ha generado un gran cúmulo de información fechados radiocarbónicos. A continuación presentamos los resultados que hemos obtenido a partir del relevamiento bibliográfico de las dataciones publicadas provenientes de nuestra área de estudio, del Macizo del Deseado y de regiones aledañas como son la costa y la cordillera. A la base de datos que hemos generado, la cual recopila a todas las dataciones de las regiones mencionadas, la hemos "tamizado" a partir del filtro metodológico que explicamos en la seeción 5.4.4. De esta manera quedaron fuera de análisis cinco fechados del Macizo del Deseado entre los que se incluyen tres dataciones ob-

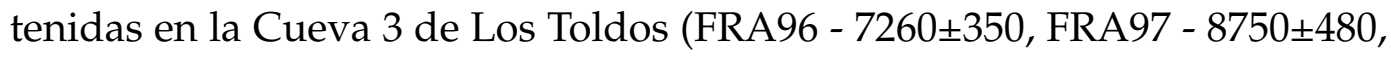

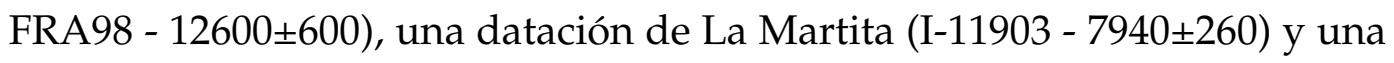

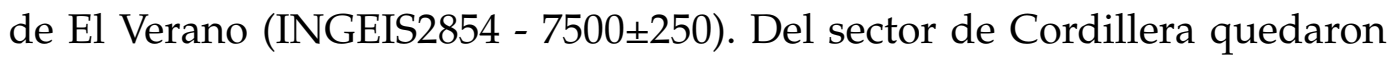
fuera de análisis un total de nueve fechados: cuatro fechados del sector del Lago Cardiel de los cuales dos provienen del sitio Alero del León (UGA8714 - 6550 \pm 440 , UGA-8713 - 1170 \pm 290 ), uno de Alero Manuk I (UGA-8707

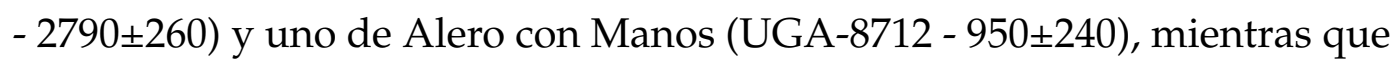
del Parque Nacional Perito Moreno (PNPM) se excluyeron dos del Alero

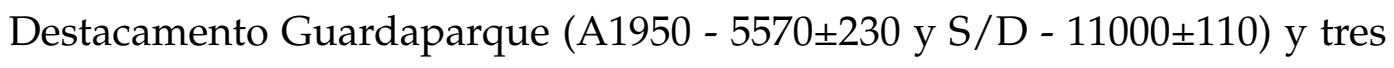
de CCP7 de los cuales uno no cumple con el límite estipulado para el desvío (UGA-7382 - 8460 \pm 400 ) y los otros porque en el trabajo original se aclara

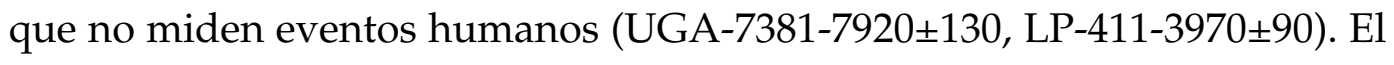
sector de Costa no presenta fechados con errores de mas de 200 años radio- 
carbonicos.

La calibración de estos fechados y su inclusión en un gráfico de suma de probabilidades nos permite reconocer continuidades y discontinuidades cronológicas. El tamaño de la muestra puede condicionar la lectura que hacemos del grafico de suma de probabilidades, y es por esto que utilizaremos diferentes escala de análisis de menor a mayor: 1) Cuenca de los zanjones Blanco y Rojo, 2) Macizo del Deseado y 3) Macizo-Costa-Cordillera para poder observar si las discontinuidades responden a fenómenos particulares de escalas pequeñas.

\subsection{Cuenca de los Zanjones Blanco y Rojo}

En la cuenca de los zanjones Blanco y Rojo se han obtenido 34 fechados radiocarbónicos (ver Tabla 9.1) de 5 sitios arqueológicos, tres de ellos en cuevas (Cueva Maripe, AEP-1 y Cueva Mora), un enterratorio (El Sargento) y un sitio a cielo abierto (La Quinta). De esta manera, la muestra quedó conformada por una gran mayoría correspondiente a cuevas y aleros rocosos $(\mathrm{n}=32)$ y los dos restantes a sitios a cielo abierto.

El gráfico de suma de probabilidades marca el inicio de la señal cronológica en este sector hacia los 15700 años cal. AP, con una débil señal establecida por un solo fechado proveniente de AEP-1 (15687-15079 años cal. AP). Luego de este fechado se reconoce el primer hiato cronológico hasta los ca. 13000 años cal. AP, momento en que se incrementa la señal demostrando una clara ocupación humana que se mantiene hasta los ca. 7800 años cal. AP. (Figura 9.1). El lapso abarcado desde el inicio de las ocupaciones hasta los 7800 años cal. AP está constituido por dataciones que provienen de AEP-1 y de Cueva Maripe. En el caso de AEP-1, este lapso incluye a todas las dataciones del sitio.

Durante el Holoceno medio, entre los $7153 \pm 50$ y los $5376 \pm 45$ años ${ }^{14} \mathrm{C}$ AP (7828-6275 años cal. AP) hay un vacío de evidencia cronológica, esto constituye el segundo hiato cronológico y el más extenso de los reconocidos. Asimismo, se distingue otro vacío cronológico entre los 5660 y 4810 años cal. AP. Por último, en el Holoceno tardío se reconoce un hiato cronológico entre los 3200 y 1900 años cal. AP. 


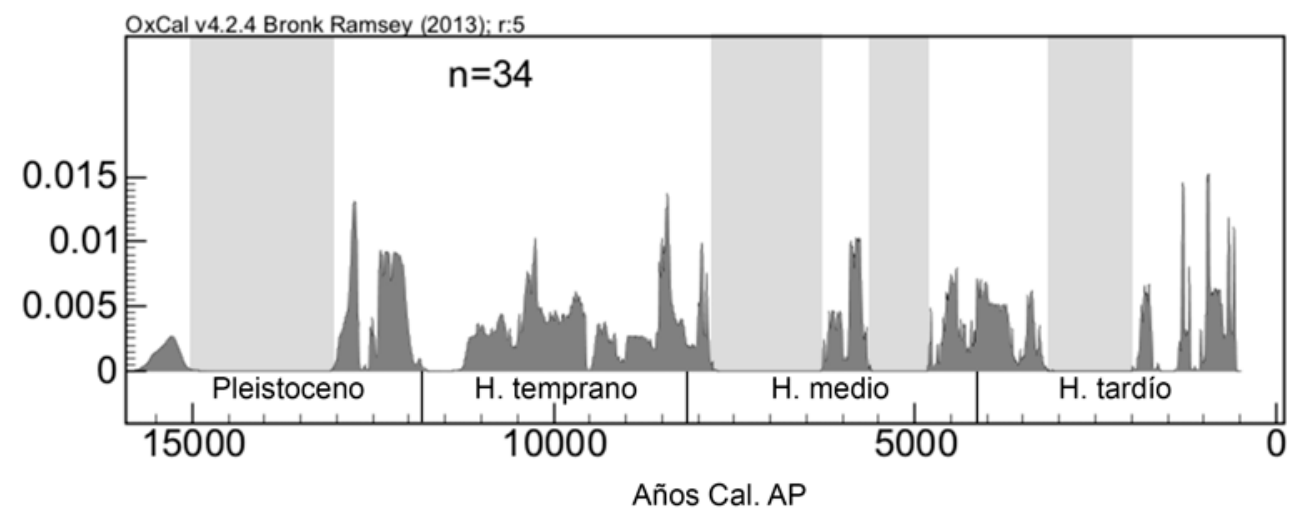

Figura 9.1: Suma de probabilidades de los fechados de la cuenca del Zanjón Blanco y cuenca baja del Zanjón Rojo. Las sombras rectangulares grises marcan los vacíos cronológicos mencionados en el texto.

Tabla 9.1: Fechados radiocarbónicos de sitios arqueológicos en Cuevas del Macizo del Deseado. En la tabla se incluyen los sitios ubicados en la Cuenca de los zanjones Blanco y Rojo.

\begin{tabular}{|c|c|c|c|c|}
\hline Localidad/Area & Sitio & Código & Edad & Cita \\
\hline \multirow{12}{*}{$\begin{array}{l}\text { Cerro } \\
\text { Tres Tetas }\end{array}$} & \multirow{12}{*}{ Cueva 1} & LP-770 & $830 \pm 60$ & \multirow{12}{*}{ Paunero 2000; 2003} \\
\hline & & LP-1180 & $1340 \pm 50$ & \\
\hline & & LP-1187 & $1740 \pm 60$ & \\
\hline & & LP-541 & $2190 \pm 70$ & \\
\hline & & LP-538 & $5220 \pm 70$ & \\
\hline & & LP- 800 & $10260 \pm 110$ & \\
\hline & & LP-781 & $10850 \pm 150$ & \\
\hline & & AA-39366 & $10853 \pm 70$ & \\
\hline & & OxA-9244 & $10915 \pm 65$ & \\
\hline & & AA-39368 & $11015 \pm 66$ & \\
\hline & & AA-22233 & $11100 \pm 150$ & \\
\hline & & LP-525 & $11560 \pm 140$ & \\
\hline \multirow{12}{*}{ La María } & \multirow{4}{*}{$\begin{array}{l}\text { Casa del } \\
\text { Minero } 1\end{array}$} & LP-1552 & $5190 \pm 80$ & \multirow{10}{*}{ Frank 2011} \\
\hline & & AA-45705 & $10250 \pm 110$ & \\
\hline & & AA-37208 & $10967 \pm 55$ & \\
\hline & & AA-37207 & $10999 \pm 55$ & \\
\hline & \multirow{6}{*}{$\begin{array}{l}\text { Cueva } \\
\text { Tunel }\end{array}$} & AA-81417 & $4177 \pm 43$ & \\
\hline & & AA-81423 & $5577 \pm 44$ & \\
\hline & & LP-1965 & $10420 \pm 180$ & \\
\hline & & AA-82496 & $10510 \pm 100$ & \\
\hline & & AA-71147 & $10408 \pm 59$ & \\
\hline & & AA-71148 & $10400 \pm 100$ & \\
\hline & \multirow[b]{2}{*}{ La Mesada } & Beta-135964 & $4500 \pm 40$ & \multirow[b]{2}{*}{ Paunero 2000} \\
\hline & & Beta-135963 & $9090 \pm 40$ & \\
\hline
\end{tabular}




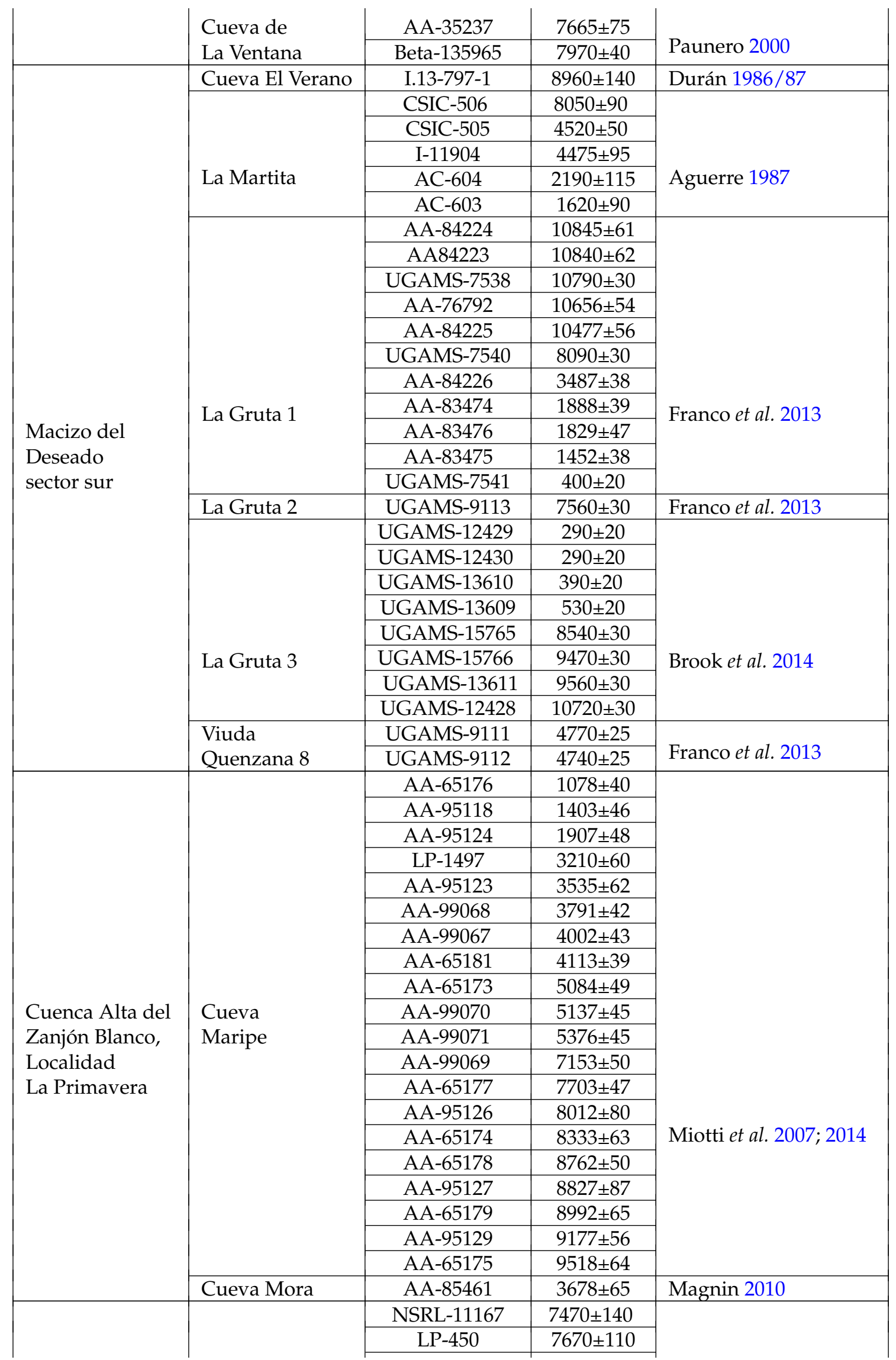




\begin{tabular}{|c|c|c|c|c|}
\hline \multirow{9}{*}{$\begin{array}{l}\text { Cuenca Alta del } \\
\text { Zanjón Rojo, } \\
\text { Localidad } \\
\text { Piedra Museo }\end{array}$} & \multirow{9}{*}{ AEP-1 } & LP-949 & $9230 \pm 105$ & \multirow{9}{*}{ Miotti et al. 2003} \\
\hline & & LP-859 & $9710 \pm 105$ & \\
\hline & & OXA-8527 & $10390 \pm 70$ & \\
\hline & & AA-8428 & $10400 \pm 80$ & \\
\hline & & GRA-9837 & $10470 \pm 60$ & \\
\hline & & OXA-9249 & $10470 \pm 65$ & \\
\hline & & OXA-8528 & $10925 \pm 65$ & \\
\hline & & AA-27950 & $11000 \pm 65$ & \\
\hline & & AA-20125 & $12890 \pm 90$ & \\
\hline \multirow{2}{*}{$\begin{array}{l}\text { Aguada } \\
\text { del Cuero }\end{array}$} & Cueva Moreno & OS-23754 & $3000 \pm 11$ & \multirow[b]{2}{*}{ Miotti et al. 2005} \\
\hline & $\begin{array}{l}\text { Cueva } \\
\text { La Hacienda }\end{array}$ & OS-23753 & $2250 \pm 70$ & \\
\hline \multirow{5}{*}{ Los Toldos } & \multirow{3}{*}{ Cueva 13} & LP-1516 & $2390 \pm 80$ & \multirow{3}{*}{ De Porras et al.2009 } \\
\hline & & LP-1524 & $3750 \pm 80$ & \\
\hline & & Beta183025 & $3380 \pm 40$ & \\
\hline & Cueva 1 & Beta183024 & $1410 \pm 40$ & De Porras et al.2009 \\
\hline & Cueva 3 & LP-136 & $4850 \pm 90$ & Cardich 1984/1985 \\
\hline \multirow{33}{*}{ Rio Pinturas } & \multirow{6}{*}{$\begin{array}{l}\text { Cueva de } \\
\text { las Manos }\end{array}$} & CSIC-137 & $430 \pm 50$ & \multirow{6}{*}{ Gradín et al. $1976 b$} \\
\hline & & NOVA-115 & $1610 \pm 60$ & \\
\hline & & NOVA-116 & $3380 \pm 90$ & \\
\hline & & NOVA-117 & $7280 \pm 60$ & \\
\hline & & CSIC-385 & $9300 \pm 90$ & \\
\hline & & CSIC-138 & $9320 \pm 90$ & \\
\hline & \multirow{14}{*}{$\begin{array}{l}\text { Cueva Grande } \\
\text { del } \\
\text { Arroyo Feo }\end{array}$} & CSIC-524 & $1170 \pm 50$ & \multirow{14}{*}{ Alonso et al. 1984-1985 } \\
\hline & & CSIC-399 & $1660 \pm 50$ & \\
\hline & & CSIC-523 & $1880 \pm 50$ & \\
\hline & & CSIC-398 & $3330 \pm 50$ & \\
\hline & & CSIC-520 & $4050 \pm 50$ & \\
\hline & & CSIC-521 & $4480 \pm 60$ & \\
\hline & & CSIC-397 & $4900 \pm 50$ & \\
\hline & & CSIC-519 & $5550 \pm 50$ & \\
\hline & & CSIC-518 & $6000 \pm 90$ & \\
\hline & & CSIC-396 & $9330 \pm 80$ & \\
\hline & & CSIC-516 & $8410 \pm 70$ & \\
\hline & & CSIC-514 & $9410 \pm 70$ & \\
\hline & & CSIC-5I5 & $8610 \pm 70$ & \\
\hline & & CSIC-522 & $3260 \pm 50$ & \\
\hline & \multirow{4}{*}{$\begin{array}{l}\text { Alero } \\
\text { Cárdenas }\end{array}$} & AC-497 & $7750 \pm 125$ & \multirow{4}{*}{ Alonso et al. 1984-1985 } \\
\hline & & AC- 499 & $7300 \pm 200$ & \\
\hline & & AC- 498 & $3450 \pm 110$ & \\
\hline & & AC-500 & $1180 \pm 85$ & \\
\hline & \multirow{5}{*}{$\begin{array}{l}\text { Alero } \\
\text { del Búho }\end{array}$} & CSIC-511 & $1520 \pm 50$ & \multirow{5}{*}{ Alonso et al. 1984-1985 } \\
\hline & & CSIC-512 & $1450 \pm 50$ & \\
\hline & & CSIC-513 & $1170 \pm 50$ & \\
\hline & & CSIC-584 & $960 \pm 50$ & \\
\hline & & CSIC-545 & $900 \pm 50$ & \\
\hline & \multirow{2}{*}{$\begin{array}{l}\text { Alero } \\
\text { Charcamata }\end{array}$} & CSIC-800 & $5290 \pm 60$ & \multirow{4}{*}{ Gradin y Aguerre 1994} \\
\hline & & CSIC-801 & $5040 \pm 60$ & \\
\hline & \multirow{2}{*}{$\begin{array}{l}\text { Alero } \\
\text { Rosamel }\end{array}$} & CSIC-799 & $1590 \pm 70$ & \\
\hline & & CSIC-798 & $1570 \pm 50$ & \\
\hline
\end{tabular}




\subsection{Macizo del Deseado}

Al incluir a todos los fechados de sitios arqueológicos del Macizo del Deseado, la base de datos aumenta sustancialmente llegando a un total de 130 dataciones radiocarbónicas, provenientes de 25 sitios en cuevas y abrigos rocosos (Tabla 9.1), 3 dataciones de 2 entierros humanos (Tabla 9.3) y la datación restante que se obtuvo en un sitio a cielo abierto (Tabla 9.2) (Figura 9.2).

El efecto de la expansión de la base de datos sobre la suma de probabilidades es que los vacíos cronológicos que observamos en la cuenca del zanjón Blanco y Rojo desaparecen o disminuyen su rango. En este sentido, durante el Holoceno tardío prevalece un vacío de aproximadamente 300 años calendáricos en (3005-2710 años cal. AP). Por su parte durante el Holoceno medio, no hay registros cronológicos durante un lapso de casi 700 años calendáricos (7828-7151 años cal. AP) y lo que resulta llamativo es que uno de los límites de este vacío está dado por un solo fechado proveniente de área del Río Pinturas (CSIC-518 - 6000 \pm 90 años ${ }^{14}$ C AP), en el límite oeste del macizo. Sin ese fechado, el vacío cronológico sería de aproximadamente 1400 años calendáricos (7828-6434 años cal. AP). El lapso sin dataciones reconocido durante el Pleistoceno final en la cuenca de los zanjones, se mantiene a escala del Macizo del Deseado con una amplitud de cercana a los 2000 años calibrados AP (15687 - 13696 años cal. AP). En este caso, sólo se modifica uno de sus límites con la inclusión de dataciones de más de 11000 años ${ }^{14} \mathrm{C}$ AP -sitio Cerro Tres Tetas- (Tabla 9.1), mientras que el límite más antiguo del lapso sigue siendo el fechado se $12890 \pm 90$ años ${ }^{14} \mathrm{C}$ AP proveniente de AEP-1.

Tabla 9.2: Fechados de sitios a cielo abierto de la cuenca de los zanjones Blanco y Rojo.

\begin{tabular}{|l|l|c|c|l|}
\hline Localidad/Area & Sitio & Código & Edad & Cita \\
\hline $\begin{array}{l}\text { Cuenca alta del } \\
\text { Zanjón Blanco }\end{array}$ & La Quinta & AA- 85460 & $939 \pm 59$ & Magnin 2010 \\
\hline
\end{tabular}



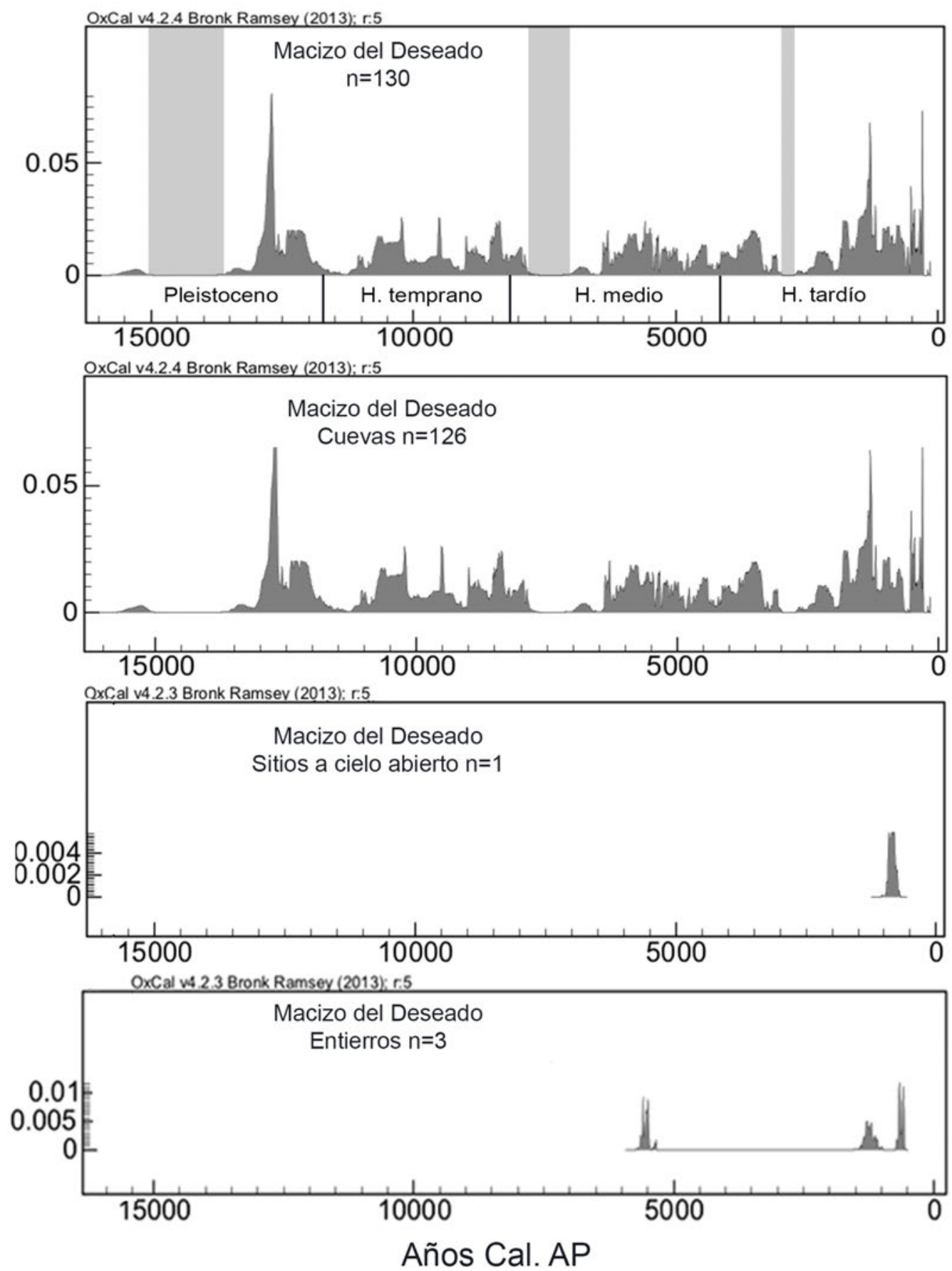

Figura 9.2: Suma de probabilidades de los fechados provenientes de diferentes contextos arqueológicos del Macizo del Deseado. Las sombras rectangulares grises marcan los vacíos cronológicos mencionados en el texto. 
Tabla 9.3: Fechados de entierros humanos del Macizo del Deseado.

\begin{tabular}{|l|l|c|c|l|}
\hline Localidad/Area & Sitio & Código & Edad & Cita \\
\hline $\begin{array}{l}\text { Área } \\
\text { Rio Pinturas }\end{array}$ & Puesto el Rodeo & AC-943 & $1380 \pm 90$ & Gradin y Aguerre 1994 \\
\cline { 3 - 4 } $\begin{array}{l}\text { Cuenca baja del } \\
\text { Zanjón Blanco }\end{array}$ & El Sargento & AA-6518 & $4860 \pm 50$ & \\
\hline
\end{tabular}

\subsection{Escala extra-regional: Sectores de costa y cordillera}

A los fines de evaluar el alcance de los tres vacíos cronológicos reconocidos en el Macizo del Deseado, evaluamos la suma de probabilidades de los fechados recuperados en los sectores de Costa y Cordillera de la provincia de Santa Cruz, entre los paralelos $47^{\circ}$ y $49^{\circ} \mathrm{S}$, que son los que incluyen al Macizo del Deseado. Hemos elegido estas regiones por ser sectores adyacentes a nuestra región de estudio y en las que se desarrolla investigaciones arqueológicas sistemáticas desde hace años (ver citas en Tablas 9.4, 9.5, 9.6, 9.7, 9.8 y 9.9), por lo que se presentan como buenos referentes comparativos.

Para generar la base de datos de las dataciones recuperadas en el sector de Costa, se utilizaron los fechados publicados en un trabajo de síntesis reciente (Zubimendi et al. 2015). Las dataciones utilizadas alcanzan un total de 74, de las cuales 18 corresponden a cuevas (Tabla 9.4), 39 a sitios a cielo abierto (en este caso son sitios tipo conchero) (Tabla 9.5) y las 17 restantes provienen de entierros humanos (Tabla 9.6). Sólo un fechado fue desafectado de nuestro análisis por tener un desvío mayor a 200 años (Cabo Tres Puntas, LP-1647 - 5480 \pm 808 ).

La señal cronológica de este sector comienza durante el Holoceno medio con un fechado radiocárbónico de $6930 \pm 100$ años ${ }^{14} \mathrm{C}$ AP (LP-2318, 79347577 años cal AP), proveniente del sitio Alero El Oriental. Esta señal se mantiene durante el Holoceno medio hasta ca. 5500 años cal. AP (Figura 9.3). A partir de este momento se reconoce un vacío cronológico amplio, hasta los ca. 3600 años cal. AP donde reaparece la señal cronológica con más intensidad y se incrementan, no sólo las dataciones sino la variedad contextos de los cuales se obtuvieron (entierros humanos).

En el caso de la Cordillera, a partir de la revisión bibliográfica de datacio- 
nes radiocarbónicas, completamos una base de datos total de 179 fechados siendo la más numerosa de las tres regiones. Del número total, 120 fechados fueron obtenidos en sitios arqueológicos en cuevas (Tabla 9.7), 28 en sitios a cielo abierto (Tabla 9.8) y 31 en entierros humanos (chenques) (Tabla 9.9). El inicio de la señal radiocarbónica en este sector comienza con una datación de $10690 \pm 72$ años ${ }^{14}$ C AP (UGA-873; 12714-12435 años cal. AP) procedente del sitio Cerro Casa de Piedra 7. Esta datación es un caso aislado separado por un vacío cronológico de 1180 años calendáricos y la señal comienza nuevamente hacia los $9730 \pm 100$ años ${ }^{14} \mathrm{C}$ AP (11255-10725 años cal. AP). Posteriormente a esta cronología se pudo reconocer el último vacío cronológico de la región que abarca un lapso de 751 años cronológicos entre 8777 y 8026 años cal. AP (UGA-864 813 \pm 52 y LP-397 7060 \pm 105 años ${ }^{14}$ C AP) (Figura 9.4). Las dataciones radiocarbónicas realizadas en este sector, muestran que las ocupaciones correspondientes al Holoceno medio y momentos previos, fueron obtenidas casi exclusivamente en contextos en cuevas y aleros rocosos.

Tabla 9.4: Fechados radiocarbónicos de las Cuevas de la Costa Norte de Santa Cruz.

\begin{tabular}{|c|c|c|c|c|c|}
\hline \multicolumn{2}{|c|}{ Localidad/Area } & Sitio & Código & Edad & Cita \\
\hline \multirow{18}{*}{ 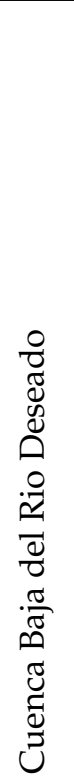 } & \multirow{4}{*}{$\begin{array}{l}\text { Margen Norte } \\
\text { de la } \\
\text { Ria Deseado }\end{array}$} & Cueva de los Leones & $S / D$ & $480 \pm 30$ & \multirow{6}{*}{ Zubimendi et al. 2015} \\
\hline & & Cueva del indio & $\mathrm{S} / \mathrm{D}$ & $1680 \pm 25$ & \\
\hline & & Cañadon Torcido & LP-2908 & $1690 \pm 90$ & \\
\hline & & Alero 4 & LP-2762 & $2760 \pm 70$ & \\
\hline & \multirow[t]{2}{*}{ Rio Deseado } & \multirow[t]{2}{*}{ Cueva Marsicano } & AA80415 & $6853 \pm 48$ & \\
\hline & & & AA80414 & $6684 \pm 48$ & \\
\hline & \multirow{12}{*}{$\begin{array}{l}\text { Bahía del } \\
\text { Oso Marino }\end{array}$} & \multirow[t]{5}{*}{ Alero El Oriental } & LP-2318 & $6930 \pm 100$ & \multirow{5}{*}{ Ambrústolo et al. 2012} \\
\hline & & & LP-2311 & $5150 \pm 80$ & \\
\hline & & & LP-2310 & $5860 \pm 90$ & \\
\hline & & & LP-2218 & $5810 \pm 110$ & \\
\hline & & & LP-2267 & $1530 \pm 60$ & \\
\hline & & \multirow[t]{6}{*}{ Cueva del Negro } & LP-2071 & $1730 \pm 80$ & \multirow{6}{*}{ Zubimendi et al. 2011} \\
\hline & & & LP-2320 & $1390 \pm 70$ & \\
\hline & & & LP-2279 & $1290 \pm 50$ & \\
\hline & & & LP-2047 & $1220 \pm 80$ & \\
\hline & & & LP-2290 & $1170 \pm 110$ & \\
\hline & & & LP-2065 & $1340 \pm 60$ & \\
\hline & & Peñon Azopardo & LP-2560 & $1690 \pm 60$ & Zubimendi et al. 2015 \\
\hline
\end{tabular}



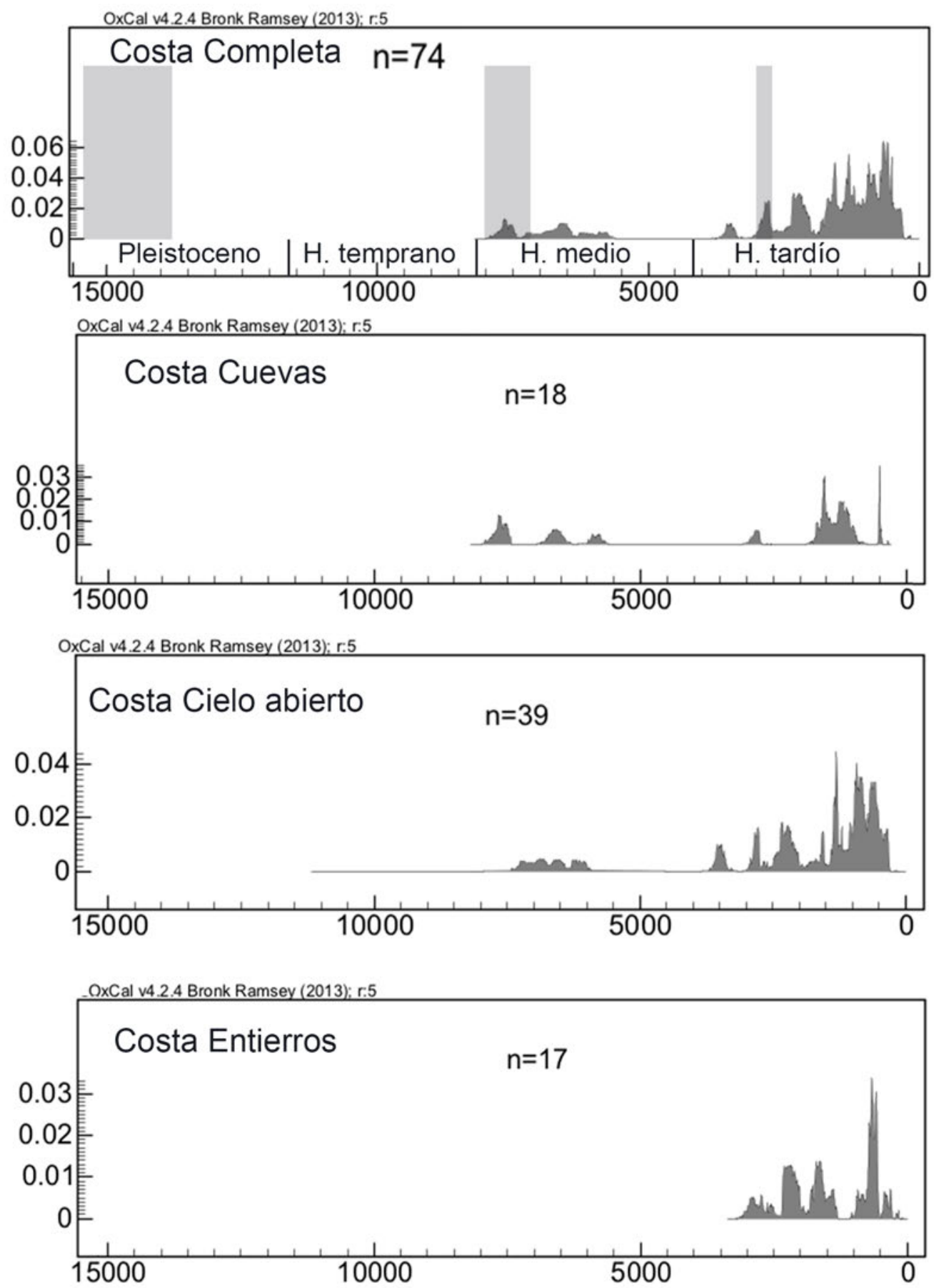

Figura 9.3: Suma de probabilidades de los fechados de la costa atlántica entre los paralelos $47^{\circ}$ y $49^{\circ} \mathrm{S}$. Las sombras grises marcan los vacíos cronológicos reconocidos en el Macizo del Deseado. 

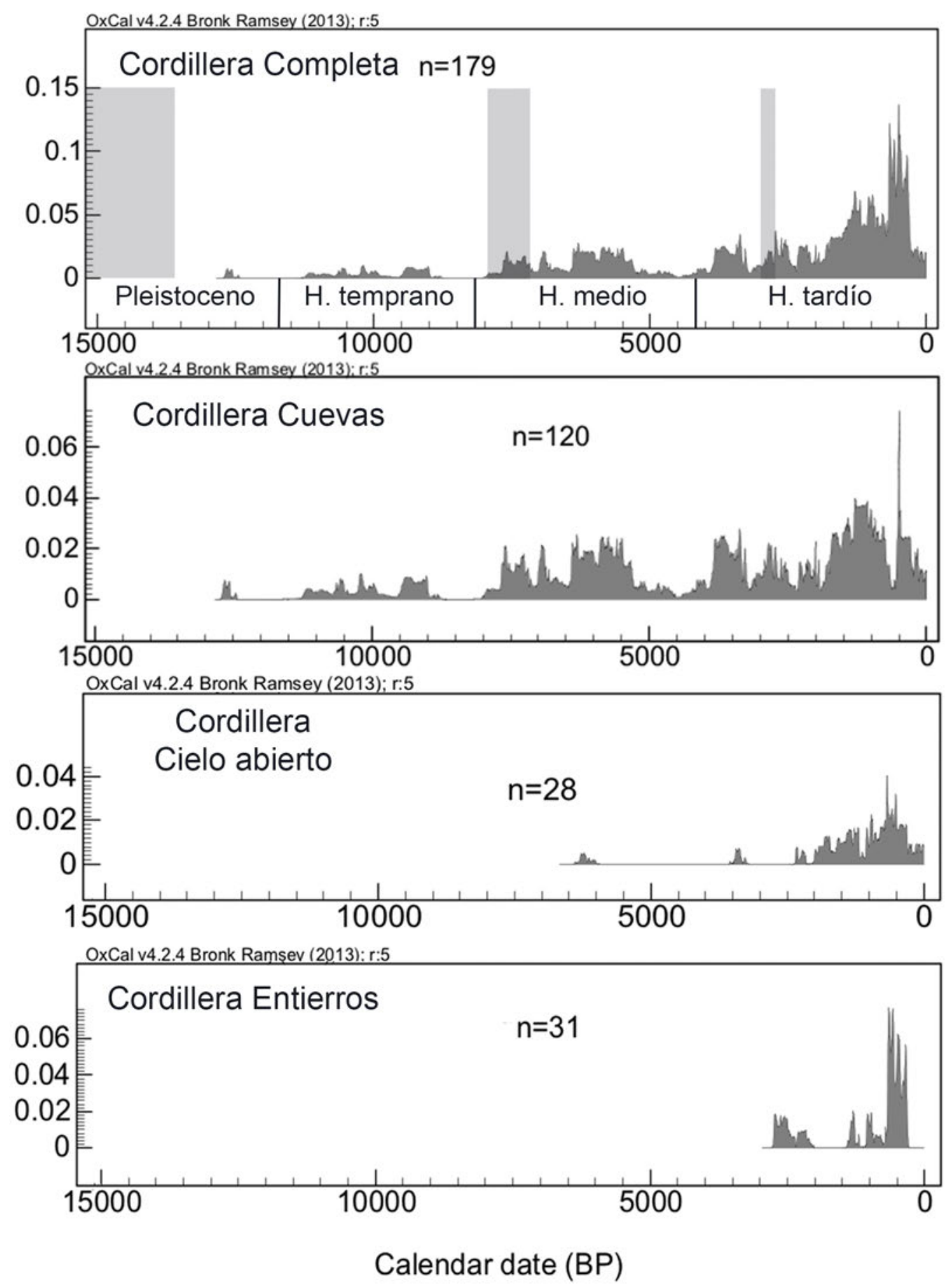

Figura 9.4: Suma de probabilidades de los fechados del sector Cordillerano entre los paralelos $47^{\circ}$ y $49^{\circ} \mathrm{S}$. Las sombras grises marcan los vacíos cronológicos reconocidos en el Macizo del Deseado. 
Tabla 9.5: Fechados radiocarbónicos de sitios tipo concheros de la Costa Norte de Santa Cruz.

\begin{tabular}{|c|c|c|c|c|c|}
\hline \multicolumn{2}{|c|}{ Localidad/Area } & Sitio & Código & Edad & Cita \\
\hline \multirow{14}{*}{ 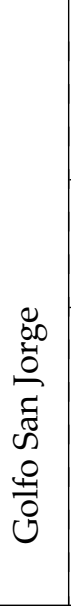 } & \multirow{4}{*}{$\begin{array}{l}\text { Golfo } \\
\text { San Jorge } \\
\text { Centro }\end{array}$} & Palo Alto & LP-2280 & $690 \pm 90$ & \multirow{4}{*}{$\begin{array}{l}\text { Moreno y Castro 1995, } \\
\text { Zubimendi et al. } 2010\end{array}$} \\
\hline & & Palo Caído & LP-2275 & $560 \pm 60$ & \\
\hline & & Sitio & LP-206 & $2720 \pm 50$ & \\
\hline & & Moreno & $1063 \mathrm{cSM}$ & $3290 \pm 90$ & \\
\hline & \multirow{3}{*}{$\begin{array}{l}\text { Golfo } \\
\text { San Jorge } \\
\text { Sur }\end{array}$} & Cabo Tres Puntas 1 & AA-13663 & $6060 \pm 70$ & \multirow{3}{*}{$\begin{array}{l}\text { Castro y Moreno 1996-1998, } \\
\text { Zubimendi et al. } 2005\end{array}$} \\
\hline & & Cabo Tres Puntas (3) & LP-1647 & $5480 \pm 80$ & \\
\hline & & Cabo Tres Puntas (2) & LP-1692 & $5420 \pm 80$ & \\
\hline & \multirow{7}{*}{$\begin{array}{l}\text { Cabo } \\
\text { Blanco }\end{array}$} & Cabo Blanco 1 & Beta 134598 & $1700 \pm 30$ & \multirow{7}{*}{$\begin{array}{l}\text { Castro et al. 2007, } \\
\text { Moreno 2008, } \\
\text { Zubimendi } 2010\end{array}$} \\
\hline & & & Beta 134597 & $1420 \pm 50$ & \\
\hline & & Cabo Blanco 2 & LP-992 & $3310 \pm 50$ & \\
\hline & & & Beta 134599 & $960 \pm 60$ & \\
\hline & & El Piche & LP-2027 & $1850 \pm 90$ & \\
\hline & & Laguna del Telégrafo & LP-1677 & $2380 \pm 60$ & \\
\hline & & La Estrella & LP-2096 & $690 \pm 70$ & \\
\hline \multirow{10}{*}{ 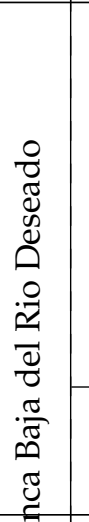 } & \multirow{7}{*}{$\begin{array}{l}\text { Margen Norte } \\
\text { de la } \\
\text { Ria Deseado }\end{array}$} & $\begin{array}{l}\text { Cañadón } \\
\text { del Puerto }\end{array}$ & LP-1298 & $1040 \pm 40$ & \multirow{10}{*}{$\begin{array}{l}\text { Castro et al. 2007, } \\
\text { Hammond y Zubimendi 2013, } \\
\text { Iantanos 2004, } \\
\text { Moreno y Videla 2008, } \\
\text { Schellmann y Radtke 2010, } \\
\text { Zubimendi et al. } 2015\end{array}$} \\
\hline & & Cañadon Giménez & LP-1800 & $1070 \pm 70$ & \\
\hline & & Sitio UNPA & LP-2891 & $970 \pm 50$ & \\
\hline & & & LP-2896 & $690 \pm 70$ & \\
\hline & & Conchero 1 & $\mathrm{~s} / \mathrm{d}$ & $476 \pm 59$ & \\
\hline & & $\mathrm{Pa} 02 / 19$ & $\mathrm{~s} / \mathrm{d}$ & $800 \pm 40$ & \\
\hline & & & $\mathrm{s} / \mathrm{d}$ & $1437 \pm 49$ & \\
\hline & \multirow{3}{*}{$\begin{array}{l}\text { Margen Sur } \\
\text { de la } \\
\text { Ria Deseado }\end{array}$} & Puerto Jenkins 2 & LP-2630 & $690 \pm 60$ & \\
\hline & & Punta Guanaco 91 & LP-1694 & $2280 \pm 70$ & \\
\hline & & Punta Guanaco 97 & LP-1648 & $1480 \pm 70$ & \\
\hline \multirow{7}{*}{$\stackrel{\Xi}{\Xi}$} & \multirow{7}{*}{$\begin{array}{l}\text { Bahía del } \\
\text { Osos Marino }\end{array}$} & La Cantera & LP-2041 & $1170 \pm 60$ & \multirow{7}{*}{$\begin{array}{l}\text { Hammond y Zubimendi 2013, } \\
\text { Zubimendi et al. 2005; 2015, } \\
\text { Zubimendi y Hammond 2009, } \\
\text { Zubimendi } 2010\end{array}$} \\
\hline & & Las Hormigas & LP-2504 & $370 \pm 40$ & \\
\hline & & Los Albatros & LP-2012 & $1070 \pm 80$ & \\
\hline & & & LP-2067 & $1040 \pm 80$ & \\
\hline & & Playa del Negro & LP-2682 & $1450 \pm 60$ & \\
\hline & & Médano Alto & LP-1579 & $5790 \pm 80$ & \\
\hline & & Sitio 112 & LP-2541 & $2770 \pm 60$ & \\
\hline \multirow{9}{*}{ 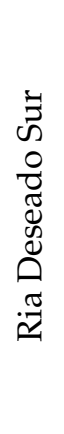 } & \multirow{9}{*}{ Punta Medanosa } & Médano 1 & LP-1544 & $6300 \pm 90$ & \multirow{9}{*}{$\begin{array}{l}\text { Hammond y Zubimendi 2013, } \\
\text { Zubimendi et al. 2005; } 2015\end{array}$} \\
\hline & & & LP-1536 & $2390 \pm 90$ & \\
\hline & & & LP-2501 & $2140 \pm 60$ & \\
\hline & & Médano 3 & LP-1532 & $2240 \pm 80$ & \\
\hline & & Médano 4 Baliza & LP-1344 & $920 \pm 40$ & \\
\hline & & $\begin{array}{l}\text { Médanos del } \\
\text { Canal } 196\end{array}$ & LP-1522 & $2280 \pm 70$ & \\
\hline & & Puesto Baliza 2 & LP-2732 & $1290 \pm 60$ & \\
\hline & & Punta Buque 1 & LP-2724 & $1070 \pm 60$ & \\
\hline & & Sitio 160 & LP-2507 & $370 \pm 50$ & \\
\hline
\end{tabular}


Tabla 9.6: Fechados radiocarbónicos de entierros humanos de la Costa Norte de Santa Cruz.

\begin{tabular}{|c|c|c|c|c|c|}
\hline \multicolumn{2}{|c|}{ Localidad/Area } & Sitio & Código & Edad & Cita \\
\hline \multirow{10}{*}{$\begin{array}{l}\text { Golfo } \\
\text { San Jorge }\end{array}$} & \multirow[t]{9}{*}{ Centro } & $\begin{array}{c}\text { Puerto Caleta } \\
\text { Paula }\end{array}$ & LP-2695 & $1040 \pm 60$ & \multirow{10}{*}{$\begin{array}{l}\text { Zilio 2013a; 2015, } \\
\text { Zilio et al. 2013, } \\
\text { Zubimendi et al. 2011b }\end{array}$} \\
\hline & & Sitio Heupel & LP-2393 & $730 \pm 60$ & \\
\hline & & Bahía Lángara 1 & LP-2713 & $320 \pm 50$ & \\
\hline & & Bahía Lángara 2 & LP-2700 & $1820 \pm 60$ & \\
\hline & & Bahía Lángara 5 & LP-2705 & $2170 \pm 50$ & \\
\hline & & Cantera Morales 2 & LP-2692 & $1820 \pm 60$ & \\
\hline & & $\begin{array}{c}\text { Cañadón del } \\
\text { Algarrobo }\end{array}$ & LP-2689 & $2300 \pm 50$ & \\
\hline & & El Zanjón 1 & LP-2443 & $2130 \pm 90$ & \\
\hline & & El Zanjón 2 & LP-2461 & $2250 \pm 60$ & \\
\hline & $\begin{array}{l}\text { Golfo } \\
\text { San Jorge Sur }\end{array}$ & $\begin{array}{c}\text { Cañadón del } \\
\text { Duraznillo }\end{array}$ & LP-2668 & $640 \pm 50$ & \\
\hline $\begin{array}{l}\text { Cuenca Baja } \\
\text { del } \\
\text { Rio Deseado }\end{array}$ & $\begin{array}{l}\text { Margen Norte } \\
\text { de la } \\
\text { Ria Deseado }\end{array}$ & Sitio Carsa & LP-2088 & $1740 \pm 60$ & $\begin{array}{l}\text { Zubimendi et al. } 2015 \\
\text { Zilio } 2015\end{array}$ \\
\hline \multirow{6}{*}{$\begin{array}{l}\text { Ria Deseado } \\
\text { Sur }\end{array}$} & \multirow{3}{*}{$\begin{array}{l}\text { Bahía del } \\
\text { Oso Marino }\end{array}$} & Punta Norte-2 & LP-2558 & $770 \pm 60$ & \multirow{3}{*}{$\begin{array}{l}\text { Zilio 2015, } \\
\text { Zilio et al. 2013, } \\
\text { Zubimendi et al. } 2015\end{array}$} \\
\hline & & Playa Castillo-37 & LP-2523 & $730 \pm 60$ & \\
\hline & & $\begin{array}{l}\text { Medano Alto } \\
\text { Oeste }\end{array}$ & LP-2551 & $1570 \pm 50$ & \\
\hline & \multirow{3}{*}{$\begin{array}{l}\text { Punta } \\
\text { Medanosa }\end{array}$} & $\begin{array}{l}\text { Campo de } \\
\text { Chenques }\end{array}$ & LP-2778 & $830 \pm 60$ & \multirow{3}{*}{$\begin{array}{l}\text { Zilio 2013a; 2015, } \\
\text { Zubimendi et al. } 2015\end{array}$} \\
\hline & & El Amanecer & LP-2747 & $2850 \pm 60$ & \\
\hline & & Shag & LP-2755 & $2620 \pm 70$ & \\
\hline
\end{tabular}

\subsection{Valoración de los resultados del análisis de fechados radiocarbónicos}

E1 97\% de las dataciones radiocarbónicas obtenidas en contextos arqueológicos del Macizo del Deseado corresponden a sitios en cuevas y abrigos rocosos. Esto marca un sesgo en cuanto al análisis de la información, ya que estamos perdiendo la dimensión cronológica que aportan otros tipos de sitios. Sin embargo, este desbalance en cuanto a tipos de sitio permite un análisis más profundo de los abrigos rocosos y de sus continuidades y discontinuidades ocupacionales a lo largo de la historia humana en la región.

De acuerdo a nuestros datos, se pueden reconocer 3 vacíos cronológicos dentro del Macizo del Deseado. El más temprano de ellos, no lo reconoceremos como tal, ya que su límite inicial está marcado por una sola datación (AA-20125 - 12890ะ90 años ${ }^{14} \mathrm{C}$ AP; $15687-15079$ años cal AP) que no tiene soporte en ningún otro dato a nivel regional o extraregional. Si bien hay 
trabajos en los que se explicita y se corrobora la ausencia de errores metodológicos y de procesos contaminantes en torno a este fechado (Miotti. et al. 2000; 2003), su amplia separación cronológica en relación a otros fechados tanto del sitio como de la región, mantiene un manto de duda sobre esta datación. En este sentido, tomaremos una postura conservadora respecto de su utilización y por el momento lo consideraremos como un fechado anómalo hasta tanto se encuentren fechados similares en la región. A los fines de nuestras investigaciones, el inicio de las ocupaciones humanas en la región ocurrió ca. 11000-11500 años ${ }^{14} \mathrm{C}$ AP. (13696-12714 años cal. AP).

Durante el Holoceno medio, se reconoce un vacío cronológico claro. Durante un lapso de aproximadamente 700 años calendáricos la distribución de probabilidades es nula y sólo se ve interrumpida por una datación. A modo ilustrativo, para marcar esta disminución de la señal, imaginemos que esa datación, proveniente del límite Macizo-Cordillera, no existiera: el lapso sin dataciones sería de 1400 años calendáricos (7828-6434 años cal. AP). Esto es equivalente al $10 \%$ del tiempo que nuestra región de estudio estuvo ocupada por humanos y sucede en momentos donde la ocupación del espacio era casi total. En este sentido, son varias las razones que podrían generar un vacío de este tipo: error de muestreo, discontinuidad de uso de la región o un uso marginal de la misma, y el sesgo tafonómico. Más adelante discutiremos la prevalencia de cada una de estas opciones. Este vacío cronológico desaparece al incluir las regiones de costa y cordillera. En el caso de la cordillera, durante el Pleistoceno final y Holoceno temprano la suma de probabilidades es baja y la señal cronológica desaparece durante casi 1000 años calendáricos entre fines del Holoceno temprano e inicios del Holoceno medio (Figura 9.5). El momento en que la señal reaparece ( $c a .8000$ años cal. AP) coincide con el inicio del hiato cronológico del Macizo del Deseado. Algo similar ocurre en la costa, donde las dataciones más tempranas que marcan el inicio de la ocupación humana de este sector, son sincrónicas con el hiato en cuestión (Figura 9.5).

Por último, hemos reconocido un vacío cronológico de casi 300 años calendáricos (3005-2710 años cal. AP) en el Holoceno tardío. Este es un periodo breve de ausencia de datos y se reconoce en un momento en el que hay una alta frecuencia de dataciones previa y posteriormente al mismo. En la Cordillera, este momento se incluye en un periodo de continuidad de la señal cronológica, mientras que en la Costa corresponde a un momento en 
el que comienza a incrementarse la señal radiocarbónica (Figura 9.5). Este incremento ha sido interpretado como resultado de una redundancia ocupacional en algunas localidades o sitios específicos de la Costa (Zubimendi et al. 2005; 2015).

Tabla 9.7: Fechados radiocarbónicos de sitios arqueológicos en cuevas del sector cordillerano seleccionado.

\begin{tabular}{|c|c|c|c|c|}
\hline Localidad/Area & Sitio & Código & Edad & Cita \\
\hline \multirow{14}{*}{$\begin{array}{l}\text { Lago } \\
\text { Pueyrredón }\end{array}$} & \multirow{4}{*}{$\begin{array}{l}\text { Cueva Milodon } \\
\text { Norte } 1\end{array}$} & UGA-16707 & $2470 \pm 170$ & \multirow[t]{14}{*}{ Aschero et al. 2009} \\
\hline & & $\mathrm{R}-2677$ & $4829 \pm 43$ & \\
\hline & & UGA-1654 & $5060 \pm 50$ & \\
\hline & & R-2681 & $5086 \pm 42$ & \\
\hline & $\begin{array}{l}\text { Cueva Milodon } \\
\text { Norte } 2\end{array}$ & UGA-1656 & $1140 \pm 40$ & \\
\hline & \multirow{3}{*}{$\begin{array}{l}\text { Estancia } \\
\text { Pueyrredón } 1\end{array}$} & R-2679 & $2213 \pm 40$ & \\
\hline & & UGA-1657 & $5050 \pm 60$ & \\
\hline & & R-2680 & $5358 \pm 42$ & \\
\hline & $\begin{array}{l}\text { Estancia } \\
\text { Pueyrredón } 2\end{array}$ & UGA-1655 & $3490 \pm 60$ & \\
\hline & Alero Colgado & UGA-16706 & $350 \pm 170$ & \\
\hline & Alero Inclinado & UGA-16708 & $1780 \pm 140$ & \\
\hline & Bajo Laguna 2 & $\mathrm{R}-2678$ & $142 \pm 35$ & \\
\hline & \multirow{2}{*}{ Cerro Cuadrado 3} & $\mathrm{~S} / \mathrm{D}$ & $460 \pm 20$ & \\
\hline & & $\mathrm{S} / \mathrm{D}$ & $2080 \pm 20$ & \\
\hline \multirow{18}{*}{$\begin{array}{l}\text { Lago } \\
\text { Posadas }\end{array}$} & \multirow{18}{*}{$\begin{array}{l}\text { Cerro de los } \\
\text { Indios I }\end{array}$} & AC-1099 & $990 \pm 110$ & \multirow[t]{18}{*}{ De Nigris et al. 2004} \\
\hline & & LP-1079 & $1170 \pm 60$ & \\
\hline & & LP-689 & $1250 \pm 50$ & \\
\hline & & LP-687 & $1290 \pm 50$ & \\
\hline & & LP-1059 & $1410 \pm 60$ & \\
\hline & & CSIC-394 & $1420 \pm 50$ & \\
\hline & & UGA-9856 & $1590 \pm 26$ & \\
\hline & & LP-1067 & $1630 \pm 60$ & \\
\hline & & LP-679 & $1660 \pm 60$ & \\
\hline & & LP-493 & $1790 \pm 50$ & \\
\hline & & LP-708 & $1810 \pm 60$ & \\
\hline & & AC-1098 & $3150 \pm 90$ & \\
\hline & & LP-369 & $3230 \pm 120$ & \\
\hline & & CSIC-395 & $3320 \pm 50$ & \\
\hline & & LP-378 & $3350 \pm 110$ & \\
\hline & & LP-480 & $3400 \pm 90$ & \\
\hline & & UGA-9857 & $3570 \pm 79$ & \\
\hline & & LP-455 & $3860 \pm 90$ & \\
\hline & CCP7 & LP-279 & $3460 \pm 70$ & Aschero 1996, \\
\hline & & LP-294 & $3480 \pm 70$ & Aschero et al. 1992; 2005, \\
\hline & & LP-440 & $4270 \pm 90$ & Civalero y De Nigris 2005, \\
\hline & & Beta-59926 & $5120 \pm 80$ & Velázquez et al. 2010 \\
\hline & & LP-282 & $5310 \pm 110$ & \\
\hline & & UGA-872 & $5319 \pm 67$ & \\
\hline
\end{tabular}




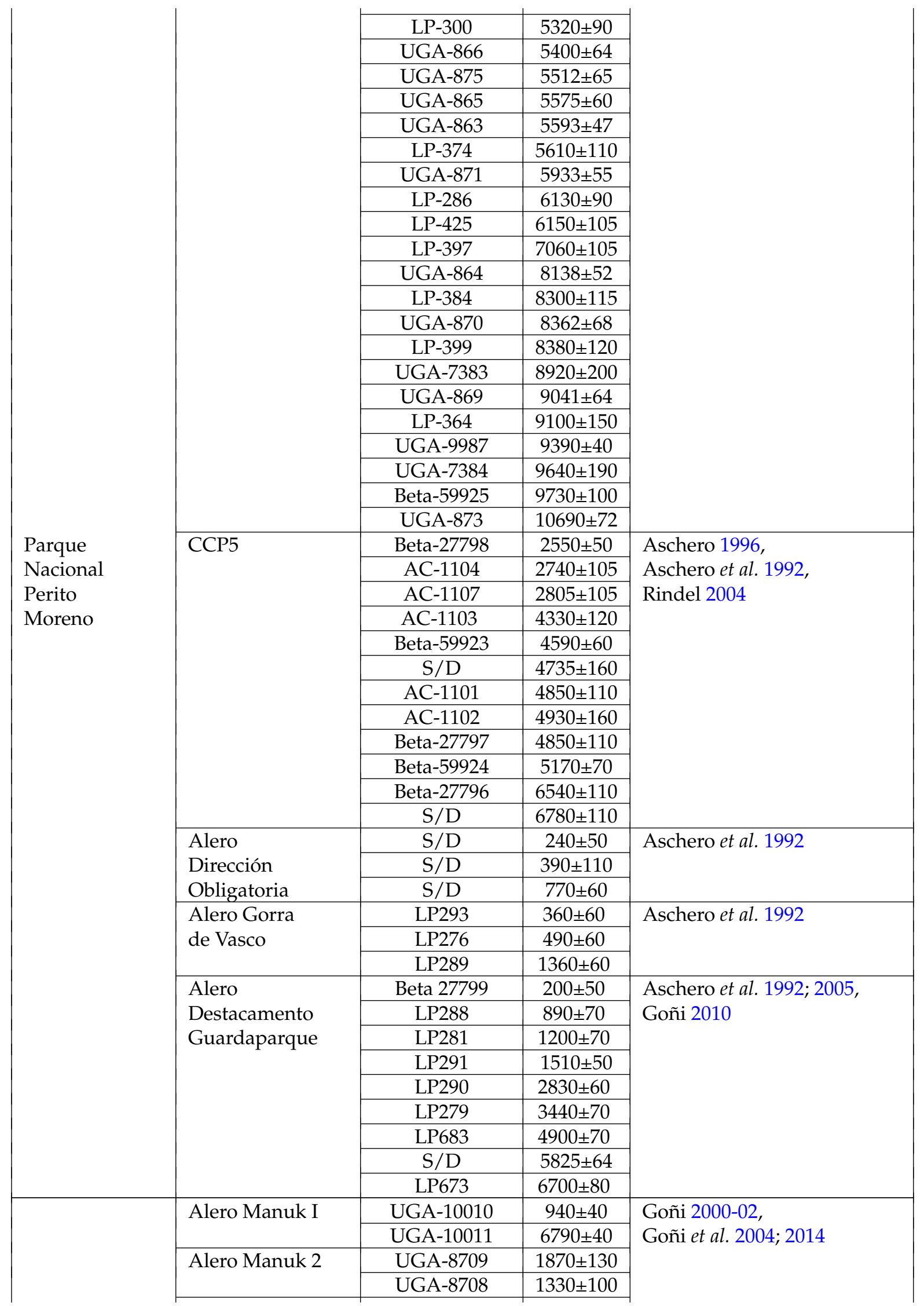




\begin{tabular}{|c|c|c|c|c|}
\hline \multirow{12}{*}{$\begin{array}{l}\text { Lago } \\
\text { Cardiel }\end{array}$} & \multirow[t]{3}{*}{ Alero del León } & UGA-10007 & $290 \pm 40$ & \\
\hline & & UGA-10009 & $2190 \pm 50$ & \\
\hline & & UGA-10008 & $3560 \pm 40$ & \\
\hline & \multirow[t]{2}{*}{ Alero sin manos } & AC-1573 & $1680 \pm 120$ & \\
\hline & & AC-1574 & $1840 \pm 115$ & \\
\hline & Alero Gerasín I & UGA-10016 & $3760 \pm 40$ & \\
\hline & Alero Gerasín II & UGA-10017 & $1580 \pm 40$ & \\
\hline & GSLN I Alero & UGA-8711 & $520 \pm 60$ & \\
\hline & Alero Manguera & UGA-8710 & $1360 \pm 70$ & \\
\hline & \multirow{3}{*}{$\begin{array}{l}\text { Alero Los } \\
\text { Guanacos } 1\end{array}$} & AA96300 & $6498 \pm 74$ & \\
\hline & & AA87698 & $6387 \pm 66$ & \\
\hline & & AA96302 & $6367 \pm 46$ & \\
\hline \multirow{17}{*}{$\begin{array}{l}\text { Los Antiguos, } \\
\text { Paso Roballos }\end{array}$} & \multirow[t]{3}{*}{ Mauricio II } & UGAMS-01297 & $930 \pm 40$ & \multirow{17}{*}{$\begin{array}{l}\text { Figuerero Torres y } \\
\text { Mengoni Goñalons 2007, } \\
\text { Mengoni Goñalons 1988, } \\
\text { Mengoni Goñalons et al. } 2009\end{array}$} \\
\hline & & UGAMS-01298 & $1000 \pm 40$ & \\
\hline & & UGAMS-3175 & $2590 \pm 25$ & \\
\hline & \multirow[t]{9}{*}{ Sol de Mayo I } & UGAMS-3176 & $370 \pm 25$ & \\
\hline & & UGAMS-3705 & $1060 \pm 30$ & \\
\hline & & UGAMS-3706 & $1210 \pm 30$ & \\
\hline & & LP-1652 & $1780 \pm 70$ & \\
\hline & & UGAMS-3176 & $2790 \pm 25$ & \\
\hline & & UGAMS-7604 & $2960 \pm 25$ & \\
\hline & & UGAMS-5031 & $3200 \pm 30$ & \\
\hline & & UGAMS-7348 & $6100 \pm 30$ & \\
\hline & & UGAMS-8762 & $6120 \pm 30$ & \\
\hline & \multirow[t]{3}{*}{ Colmillo Sur I } & UGAMS-00934 & $1212 \pm 55$ & \\
\hline & & UGAMS-00935 & $2209 \pm 58$ & \\
\hline & & UGAMS-8762 & $3160 \pm 25$ & \\
\hline & Lago Columna I & AA65131 & $1293 \pm 36$ & \\
\hline & Las Cuevas 2 & S/D & $2510 \pm 110$ & \\
\hline
\end{tabular}

Tabla 9.8: Fechados radiocarbónicos de sitios arqueológicos a cielo abierto del sector cordillerano seleccionado.

\begin{tabular}{|c|c|c|c|c|}
\hline Localidad/Area & Sitio & Código & Edad & Cita \\
\hline \multirow{9}{*}{ Cardiel } & Solís & UGA-10018 & $1140 \pm 40$ & \multirow{9}{*}{$\begin{array}{l}\text { Goñi 2000-02, } \\
\text { Goñi et al 2004, } \\
\text { Rindel 2004, } \\
\text { Stine y Stine } 1990\end{array}$} \\
\hline & GSLN 2 Médano & CAMS-71154 & $2310 \pm 50$ & \\
\hline & Médanos Margen Sur. M4 & UGA-10015 & $1860 \pm 40$ & \\
\hline & Médanos sector sur & CAMS71155 & $970 \pm 40$ & \\
\hline & Rio Cardiel Margen derecha & LDGO1714P & $1900 \pm 60$ & \\
\hline & La Siberia. Sector este Lag. & UGA-10012 & $160 \pm 40$ & \\
\hline & \multirow[t]{2}{*}{ La Siberia 2 Sondeo 3} & UGA-10013 & $1100 \pm 40$ & \\
\hline & & UGA-10014 & $1710 \pm 40$ & \\
\hline & Bayo 1 & $\mathrm{~S} / \mathrm{D}$ & $348 \pm 42$ & \\
\hline \multirow{5}{*}{$\begin{array}{l}\text { Pampa del } \\
\text { Asador }\end{array}$} & Cerro Pampa 2A Parapeto 2 & $\mathrm{~S} / \mathrm{D}$ & $310 \pm 40$ & \multirow{5}{*}{$\begin{array}{l}\text { Cassiodoro 2008, } \\
\text { Goñi 2000-02, } \\
\text { Goñi 2010, } \\
\text { Re et al. } 2010\end{array}$} \\
\hline & \multirow[t]{2}{*}{ Cerro Pampa 2A Parapeto 4} & $\mathrm{~S} / \mathrm{D}$ & $170 \pm 40$ & \\
\hline & & $\mathrm{S} / \mathrm{D}$ & $2010 \pm 50$ & \\
\hline & \multirow[t]{2}{*}{ Cerro Pampa 2C Parapeto 3} & $\mathrm{~S} / \mathrm{D}$ & $662 \pm 42$ & \\
\hline & & $\mathrm{S} / \mathrm{D}$ & $1498 \pm 44$ & \\
\hline
\end{tabular}




\begin{tabular}{|c|c|c|c|c|}
\hline & Cerro Pampa 2B Ojo de agua & AA77135 & $1582 \pm 46$ & \\
\hline & Lago Guitarra Parapeto 2 & $\mathrm{~S} / \mathrm{D}$ & $507 \pm 43$ & \\
\hline & \multirow[t]{2}{*}{ Lago Guitarra Parapeto 4} & S/D & $401 \pm 42$ & \\
\hline & & S/D & $894 \pm 44$ & \\
\hline & Lomadas del Este de ADG & $\mathrm{S} / \mathrm{D}$ & $5471 \pm 78$ & \\
\hline \multirow{3}{*}{$\begin{array}{l}\text { Meseta del } \\
\text { Strobel }\end{array}$} & Don Edmundo & $\mathrm{S} / \mathrm{D}$ & $3214 \pm 51$ & \\
\hline & \multirow[t]{2}{*}{ Itsmo Lago Belgrano } & S/D & $1360 \pm 45$ & \\
\hline & & $\mathrm{S} / \mathrm{D}$ & $1328 \pm 43$ & \\
\hline \multirow[t]{3}{*}{ Lago Posadas } & MLP Médano 1 & $\mathrm{~S} / \mathrm{D}$ & $770 \pm 30$ & \multirow{6}{*}{$\begin{array}{l}\text { Cassiodoro 2008, } \\
\text { Goñi 2000-02 }\end{array}$} \\
\hline & MLP Médano 2 & S/D & $560 \pm 90$ & \\
\hline & LPEH & $\mathrm{S} / \mathrm{D}$ & $660 \pm 180$ & \\
\hline \multirow[t]{3}{*}{ Salitroso } & SAC 3 & $\mathrm{~S} / \mathrm{D}$ & $960 \pm 125$ & \\
\hline & SAC 11 & S/D & $750 \pm 60$ & \\
\hline & SAC 25 & S/D & $1600 \pm 100$ & \\
\hline
\end{tabular}

Tabla 9.9: Fechados radiocarbónicos de entierros humanos del sector cordillerano seleccionado.

\begin{tabular}{|c|c|c|c|c|}
\hline Localidad/Area & Sitio & Código & Edad & Cita \\
\hline \multirow{30}{*}{$\begin{array}{l}\text { Lago Salitroso } \\
\text { y Lago Posadas- } \\
\text { Sierra Colorada }\end{array}$} & SAC 1-1-3 & AA38555 & $352 \pm 40$ & \multirow{30}{*}{$\begin{array}{l}\text { Cassiodoro 2008, } \\
\text { Cassiodoro y García 2009, } \\
\text { García Guraieb 2006, } \\
\text { Goñi et al. 2000-02, } \\
\text { Goñi y Barrientos } 2004\end{array}$} \\
\hline & SAC 30-1-1 & AA77147 & $361 \pm 45$ & \\
\hline & SAC 20-3-2 & UGA10623 & $380 \pm 40$ & \\
\hline & SAC 1-2-2 & AA38552 & $389 \pm 40$ & \\
\hline & SAC 1-2-1 & AA38553 & $418 \pm 40$ & \\
\hline & SAC 1-4-1 & AA38564 & $424 \pm 39$ & \\
\hline & SAC 22-2-1 & AA87702 & $432 \pm 43$ & \\
\hline & SAC 8-3-2 & AA77145 & $435 \pm 46$ & \\
\hline & SAC 2-4-1 & AA81451 & $486 \pm 43$ & \\
\hline & SAC 1-6-3 & AA38558 & $539 \pm 46$ & \\
\hline & SAC 1-1-B & AA38560 & $622 \pm 57$ & \\
\hline & SAC 10-2-1 & AA77149 & $637 \pm 47$ & \\
\hline & SAC 10-1-1 & AA38569 & $662 \pm 43$ & \\
\hline & SAC 10-1-4 & AA38570 & $687 \pm 43$ & \\
\hline & SAC 1-6-2 & AA38557 & $690 \pm 40$ & \\
\hline & SAC 22-1-1 & AA77150 & $704 \pm 42$ & \\
\hline & SAC 4-1-1 & AA38565 & $728 \pm 39$ & \\
\hline & SAC 1-6-1 & AA38556 & $756 \pm 32$ & \\
\hline & SAC 2-5-4 & AA77148 & $758 \pm 51$ & \\
\hline & SAC 1- 7-2 & AA38561 & $1142 \pm 42$ & \\
\hline & SAC 1-7-1 & AA38559 & $1147 \pm 37$ & \\
\hline & SAC 3-1-1 & AA77151 & $1408 \pm 44$ & \\
\hline & SAC 3-1-2 & AA81450 & $1486 \pm 45$ & \\
\hline & SAC 1-11-1 & AA81448 & $2208 \pm 48$ & \\
\hline & SAC 4-2-3 & AA38566 & $2274 \pm 41$ & \\
\hline & SAC 1-8-2 & AA38562 & $2494 \pm 43$ & \\
\hline & SAC 4-N1-1 & AA38567 & $2520 \pm 40$ & \\
\hline & SAC 1-8-1 & AA38563 & $2532 \pm 41$ & \\
\hline & SAC 4-N6-3 & AA77146 & $2586 \pm 54$ & \\
\hline & SAC 4-N2-1 & AA38568 & $2607 \pm 41$ & \\
\hline
\end{tabular}




\begin{tabular}{|l|l|l|l|l|}
\hline $\begin{array}{l}\text { Los Antiguos - } \\
\text { Paso Roballos }\end{array}$ & Lago Ghio I & CAMS-71700 & $970 \pm 40$ & Mengoni Goñalons et al. 2009 \\
\hline
\end{tabular}



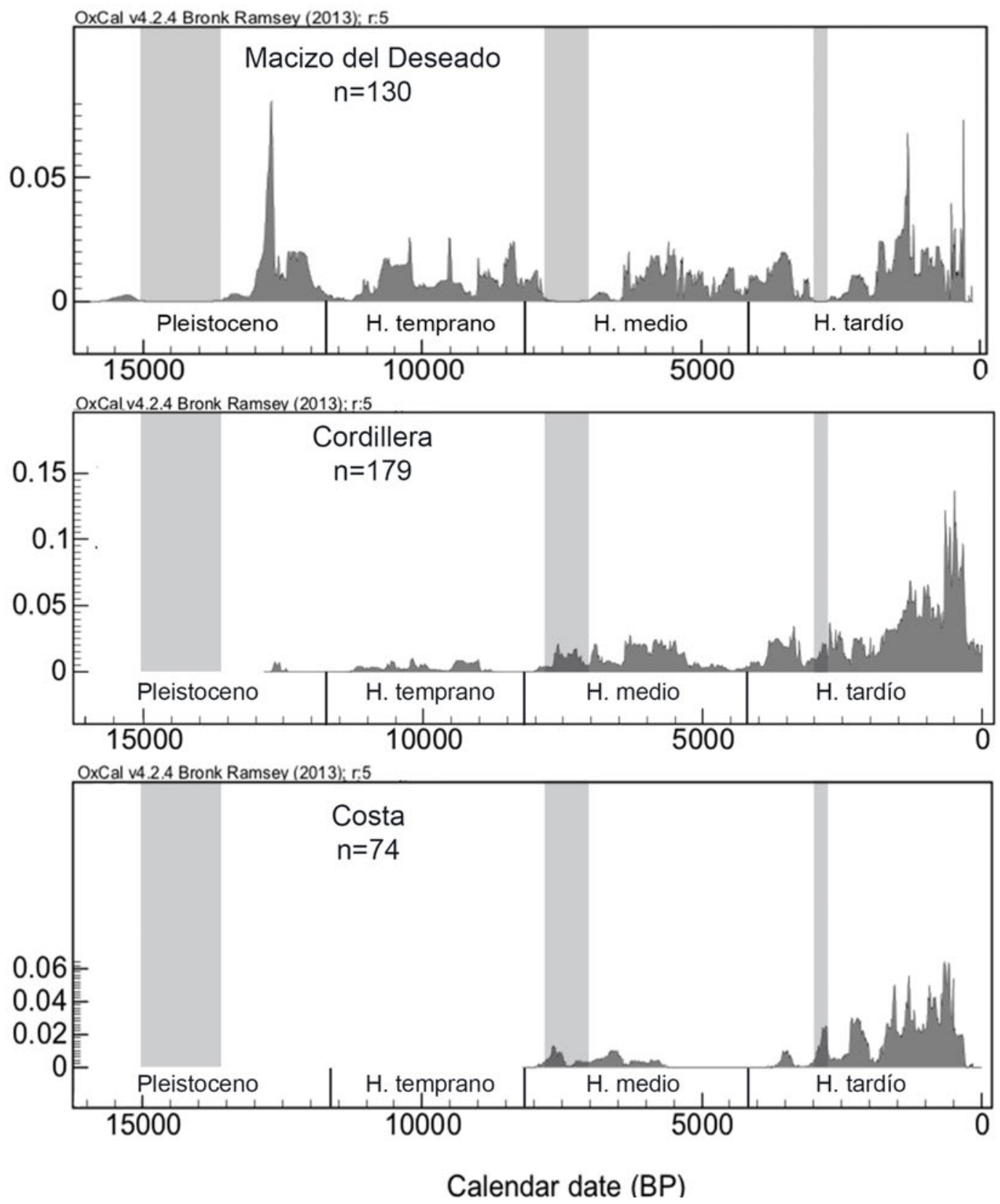

Figura 9.5: Sumas de probabilidades de las dataciones radiocarbónicas obtenidas en cada área. Las sombras grises marcan los hiatos reconocidos en el Macizo del Deseado. 


\section{Parte III}

\section{Discusión y Conclusiones}





\section{Capítulo 10}

\section{Discusión}

Los estudios de depósitos sedimentarios y proxies ambientales realizados en esta Tesis, así como las revisiones bibliográficas que permitieron la descripción del área de estudio, del paleoambiente y de la cronología humana en la región, tuvieron como finalidad última indagar e interpretar la variabilidad en la dinámica de los cazadores recolectores de nuestra área de estudio en relación a los cambios ambientales. Como se pudo apreciar en la sección Resultados, hemos realizado valoraciones sobre los datos recabados a escala de sitio y de las geoformas seleccionadas a modo de breves discusiones que le permitan al lector incorporar la información generada. De esta manera, comenzaremos a relacionar los datos a escala regional, elevando el nivel inferencial de nuestra discusión.

Como principal referente empírico, hemos utilizado sitios arqueológicos en cuevas las cuales son trampas sedimentarias que permiten albergar material arqueológico e información paleoambiental en estratigrafía , los cuales en sitios a cielo abierto de Patagonia meridional son difíciles de hallar, especialmente para momentos tempranos (Colcutt 1979). Este tipo de sitio, si bien permite la formación de contextos en estratigrafía, la preservación del material arqueológico está lejos de representar una suerte de "premisa de Pompeya" (Miotti 2010). De hecho, algunas investigaciones realizadas sobre depósitos de cuevas y abrigos rocosos han mostrado que en estos depósitos la continuidad en las ocupaciones y en la depositación sedimentaria es aparente y que sólo contamos con representaciones de periodos cortos ("snapshots" -fotografías-) intercalados con vacíos ("gaps") del tiempo involucrado en la estratigrafía (Farrand 1993).

En nuestros estudios hemos podido aseverar la discontinuidad intrín- 
seca en estos depósitos, en primer lugar porque las tres cuevas analizadas aquí presentan rangos cronológicos diferentes (AEP-1 12995- 7967 años cal. AP, Tito del Valle sin dataciones se estima Holoceno medio a tardío, Cueva Maripe 11102-928 años cal. AP). En algunos casos, como AEP-1 y Tito del Valle se registraron discontinuidades, y por último, los análisis de fechados muestran que tanto en la cuenca de los zanjones estudiados como en la macro área de estudio hay momentos que no están representados ya sea por sedimentos o por material arqueológico (ver Figura 9.1). Teniendo en cuenta esto, abordaremos la discusión de acuerdo a bloques temporales, los cuales están representados diferencialmente, tanto en las secuencias sedimentarias de los sitios arqueológicos, como en las secuencias no arqueológicas. Para cada momento buscaremos articular la información que hemos generado en el marco de la tesis, con los datos paleoambientales y arqueológicos disponibles hasta el momento.

En términos generales podemos afirmar que los despósitos sedimentarios analizados son fuentes importantes de información paleoambiental. Por un lado, si bien las cuevas y abrigos rocosos son depósitos discontinuos que pudieron verse afectados no sólo por situaciónes propias del ambiente, sino tambien por al accionar de las personas que las habitaron, permiten una estrecha relación entre el deposito sedimentario (y la información paleoambiental) y los conjuntos arqueológicos que contienen. En el Macizo del Deseado, la mayor fuente de información paleoambiental de fines del Pleistoceno y el Holoceno proviene de los análisis polínicos realizados en cuevas, lo que presenta ventajas y desventajas ya que el registro es discontinuo y de un ambiente muy particular como es el de estas trampas sedimentarias. Pero también contamos con un gran número de cuevas analizadas por lo que las características de la muestra permiten un corpus sólido de información paleoambiental que permite elevar la escala de las inferencias.

En esta tesis hemos resaltado la importacia de los mallines como fuentes de agua y concentradores de recursos, pero también hemos podido verificar su potencialidad como reservorios de información paleoambiental. Las altas tasas de depositación de estas geoformas, sumadas a la buena conservación de proxies ambientales los ubican como sectores muy importantes para el análisis paleoambiental, en especial para el Holoceno. La complementariedad de la información proveniente de estos depósitos con la de las cuevas permiten un conocimiento más acabado de los diferentes paisajes del pasa- 
do y contribuyen a indagar cuestiones arqueológicas como por ejemplo los vacíos cronológicos del área.

En el caso del estudio de lagunas secas como el paleolago de Piedra Museo, tuvimos dificultades en cuanto al muestreo de campo dado que la dureza del sustrato permitió la obtención de testigos sedimentarios muy cortos por lo que se hace necesario indagar en otras metodologías de perforación para poder lograr mejores muestreos.

\subsection{Consideraciones sobre los sitios arqueológicos estudiados en la cuenca de los zanjones Blanco y Rojo}

Para abordar los objetivos de esta tesis, hemos seleccionado tres sitios en cuevas y abrigos rocosos, cada uno ubicado dentro de un subsector diferente de la cuenca en estudio y en relación con diferentes geoformas. Esto nos permitió abarcar una interesante variabilidad de casos, los cuales nos permitieron abordar diferentes aspectos de los ambientes sedimentarios desarrollados en cuevas. La escala temporal abarcada es amplia en términos arqueológicos, ya que se estudiaron depósitos asignables al final del Pleistoceno y a distintos momentos del Holoceno. De esta manera, continuaremos la discusión de acuerdo a un orden cronológico, relacionando y discutiendo la información que hemos generado para esta tesis de acuerdo a los bloques temporales. Si bien en la bibliografía arqueológica el Holoceno temprano generalmente es analizado conjuntamente con el Pleistoceno final dentro del periodo denominado Transición Pleistoceno-Holoceno, aquí hemos optado por utilizar, como se explicó en el Capítulo 3, la división del Holoceno publicada por Walker y colaboradores (2012). Es una división de corte geológico, que se basa en cambios ambientales reconocidos a nivel global, por lo que tener en mente esos límites nos permitirá contextualizar variaciones climáticas a gran escala y su repercusión en nuestra propia escala de estudio (Figura 10.2). 


\subsection{Pleistoceno final (13500 - 11700 años cal. AP - 11500-10000 años ${ }^{14}$ C AP)}

Palabras clave: Aridez y Frio/Depósitos eólicos en cuevas/Baja cobertura vegetal/Alta tasa de acumulación/Inicio de la ocupación humana/Younger Dryas/Estrategia generalizada (megafauna)/Locus de actividades limitadas/Exploración

Este lapso está definido por el inicio de la ocupación humana en el Macizo del Deseado, la cual comienza hacia fines del Episodio Frio Reverso Antártico -EFRA- (Brook et al. 2013), y por el final del Younger Dryas que es el evento que marca el final de la última glaciación (Walker et al. 2009). Tomamos a los 13500 años cal. AP como inicio de la ocupación humana ya que es en ese momento cuando las sumas de probabilidades empiezan a marcar una tendencia clara en cuanto a la ocupación de la región (Figura 10.2). Anteriormente hemos planteado algunas reservas en cuanto a la aceptación del fechado más temprano de AEP-1 y del Macizo del Deseado (AA-20125

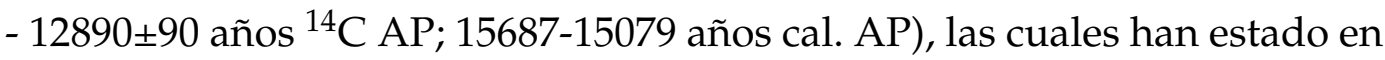
sintonía con lo sugerido por otros autores quienes, a partir de la imposibilidad de datarlo nuevamente o hallar un fechado similar que lo respalde, lo consideran como un "outlier sin explicación" (Prates et al. 2013; Steele y Politis 2009).

Los depósitos pertenecientes a esta época están representados en AEP-1 por las capas 5 y 6, las cuales según las dataciones de contextos arqueológicos se ubican entre 12995 y 11840 años cal. AP, mientras que en Cueva Maripe, si bien no hay dataciones para este momento, la Capa 6, arqueológicamente estéril, se depositó en momentos previos a los 11102 años cal AP $\left(9518 \pm 64\right.$ años ${ }^{14} \mathrm{C}$ AP) y podría corresponderse con aquél lapso.

Entre los depósitos basales mencionados en ambos sitios, pueden reconocerse algunas similitudes tales como la presencia de materiales de procedencia exógena. Estas están representadas principalmente por arenas de origen eólico. En la Cámara Norte de Cueva Maripe este aporte muestra predominio respecto de los restantes (endógenos), teniendo en cuenta que la porción basal de ésta capa (subcapa 6b) está compuesta por más de un $50 \%$ de arenas eólicas. A partir del análisis de las distribuciones granulométricas de la capa basal observamos que el material arenoso habría sido movilizado en saltación durante el transporte eólico hasta su depositación en el sitio. 
La composición argilomineral de naturaleza esmectítica, en el depósito basal avala la procedencia exógena del material de relleno de la cueva en este lapso. Por su parte, en la capa 6a se incrementa la fracción pelítica, característica que ha sido vinculada a depositación en un ambiente "encharcado" en momentos previos a la ocupación humana (Fernández 2013). A nivel arqueológico, este contexto depositacional haría de la cueva un espacio poco propicio para su ocupación, o al menos para la ocupación y/o desarrollo de actividades en los sectores encharcados, lo que emerge como una explicación posible de por qué esta cueva no fue ocupada en momentos previos cuando hay evidencias claras de ocupaciones más tempranas en sitios cercanos (Miotti et al. 2014; 2015). Por otro lado, en la Cámara Sur este depósito tiene una expresión difusa. En este sentido, en CN la roca base se encuentra en una posición topográfica más baja que en CS, por lo tanto el inicio de la acumulación de sedimentos, se dio en la cámara Norte. Con el correr del tiempo la acumulación niveló la altura del piso, entre ambas cámaras, permitiendo que la acumulación posterior fuera similar en ambos sectores.

Por su parte, en AEP-1, los depósitos sedimentarios de este lapso, constituidos por las Capas 6 y 5, muestran que el aporte exógeno está conformado por arena de origen eólico, pero a diferencia de lo que sucede en Cueva Maripe, estos alcanzan sólo un $17 \%$. No obstante, es la frecuencia de material eólico más alta de todo el sitio. Por otro, lado en la capa 5 se reconoce una composición similar sólo que disminuye la frecuencia del material eólico $(10 \%)$, y la fracción modal sigue ubicándose en las arenas y aumentan la frecuencia de pelitas. Esta tendencia es similar a la observada en la capa 6 de Cueva Maripe, aunque aquí no se han reconocido evidencias de bioturbación.

Hemos calculado las tasas de acumulación sedimentaria como un dato de referencia y de comparación intrasitio e intersitio. Los únicos fechados radiocárbonicos con los que contamos para realizar el cálculo de este periodo, provienen de AEP-1 que si bien mostraron un valor levemente menor a los demás realizados en el sitio $-1,97 \mathrm{~cm} / 100$ años- (Figura 10.1), son valores relativamente altos a escala de la cuenca. En otra unidad de excavación se calculó una tasa de 2,1 cm/100 años, sin embargo abarca un lapso muy amplio (entre 11000 y 7676 años ${ }^{14} \mathrm{C}$ AP) lo que le otorga más confiabilidad a la mencionada anteriormente. En relación a esto, hemos hablado en el Capítulo 5 de la utilidad que los estadios de meteorización ósea pro- 
puestos por Behrensmeyer (1978) presentan como indicador indirecto de tasas de acumulación. Los conjuntos óseos recuperados en capa 6 de AEP-1 presentan estadios de meteorización bajos ( 0 a 2 ) con una muy baja representación de estadio 3. Estos datos indican un enterramiento relativamente rápido, ya que los pocos especímenes que presentan estadios más altos de meteorización son casos de baja densidad ósea (Marchionni 2013). Asimismo, se reconoció un alto porcentaje de especímenes óseos con depósitos de Mn principalmente que alcanza a la mitad del conjunto lo que constituye la modificación natural más relevante ya que la proporción de huesos con marcas de raíces y $\mathrm{CaCO}_{3}$ es muy baja. Estas concordancias entre TAS y conservación ósea, nos permiten decir, que la sección inferior de la estratigrafía se vio afectada postdepositacionalmente por la oscilación del nivel freático. En última instancia, la alta tasa de acumulación contribuyó a una baja meteorización de las superficies óseas y a una buena resolución arqueológica (sensu Binford 1981).

Las características sedimentológicas registradas para el Pleistoceno final señalan por un lado un aporte eólico proximal, representado por las arenas medias a muy finas las cuales son transportadas por mecanismos de saltación, mientras que la fracción limosa más propensa al transporte por suspensión, presenta una frecuencia subordinada. Una dinámica de este tipo requiere disponibilidad de arena a escala local con áreas susceptibles de ser deflacionadas y una escasa o nula cobertura vegetal En este sentido, a partir de la información paleoambiental sintetizada en el Capítulo 3, sabemos que las asociaciones polínicas encontradas en los sitios cercanos a nuestra área de estudio (i.e. La María, Los Toldos) y en AEP-1, la estructura florística era principalmente arbustiva (Ephedra y Asteroideae) y refleja condiciones frías y áridas entre ca. 14000 y 13000 años cal. AP (ca. 12000-11000 años ${ }^{14} \mathrm{C}$ AP) (De Porras 2010, Mancini et al. 2005; Mancini et al. 2013; Páez et al. 1999) coincidiendo con los momentos previos a la ocupación humana de Cueva Maripe y con las primeras ocupaciones de AEP-1. En el caso de AEP-1, luego de los 13000 años cal. AP (11000 años ${ }^{14} \mathrm{C}$ AP) según los registros polínicos de AEP-1 prolifera la estepa graminosa en respuesta a un incremento de la humedad por un aumento en las precipitaciones bajo condiciones frías, cambio que también se reconoce en Los Toldos y en La Gruta, respetivamente al norte y al sur de nuestra área de estudio (Borromei 2003; Mancini et al. 2013; Páez et al. 1999) (Figura 10.2). Es en este momento cuando comienza el 


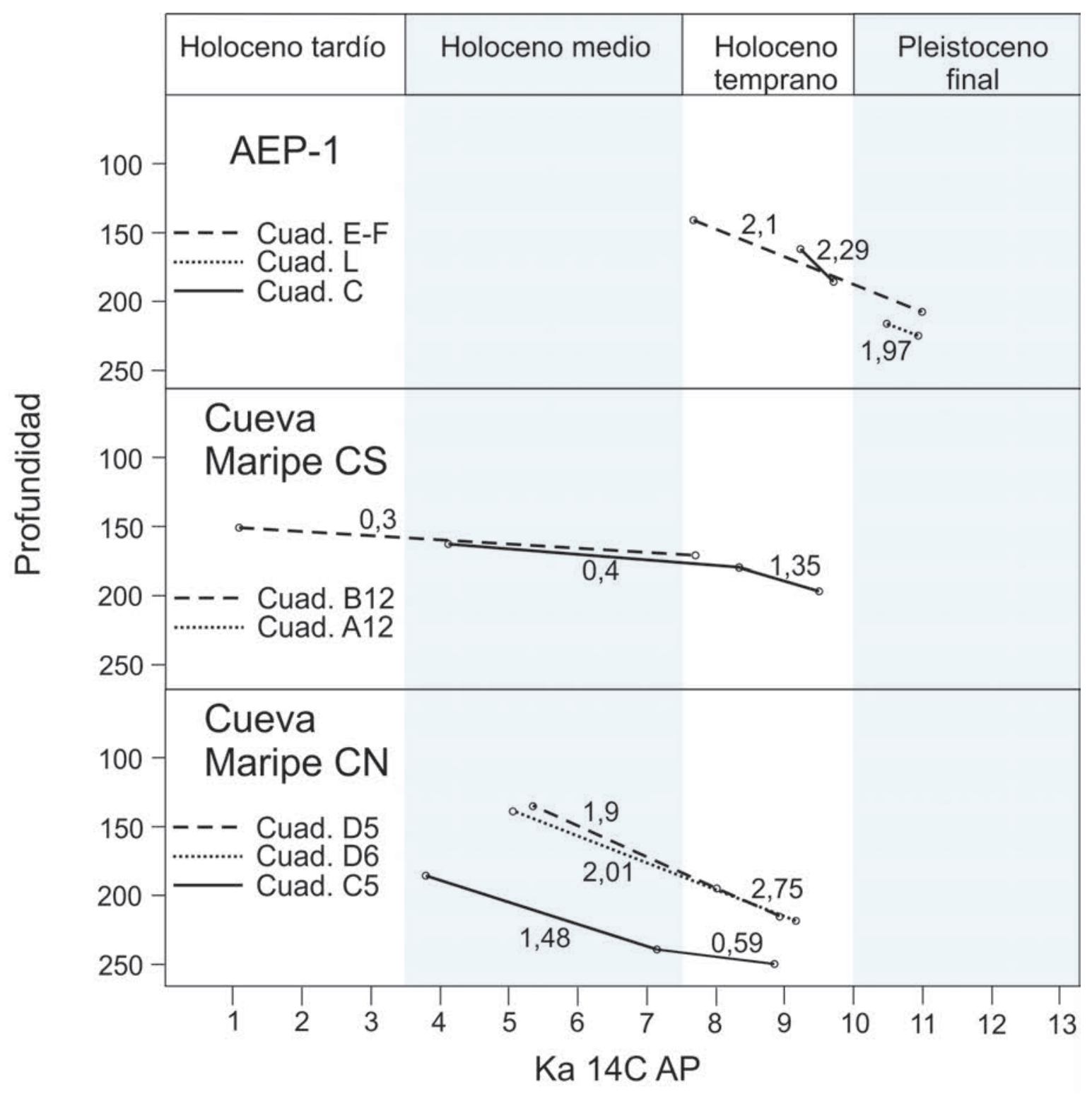

Figura 10.1: Cuadro comparativo de las tasas de acumulación sedimentaria de AEP-1 y Cueva Maripe. Los valores que acompañan a las rectas responden al valor calculado en cm/100 años presentado en el Capítulo 6. 
proceso de acreción que forma a la capa 5 de AEP-1 donde el aporte eólico decrece debido a que la cobertura vegetal y el aumento en la humedad disminuyeron la disponibilidad de arenas y sesgaron su transporte. Asimismo, en Cueva Maripe, este cambio en las condiciones climáticas habría generado los encharcamientos en $\mathrm{CN}$ y habría contribuido a la formación de una cobertura vegetal dentro de la cueva (capa 6a).

Tengamos en cuenta que este momento de mayor humedad coincide con la cronozona Younger Dryas, lapso en el que la temperatura del hemisferio sur se encuentra en ascenso (Brook et al. 2013; Shakun y Carlson 2010) generando una disminución en los glaciares y aumentando el agua en superficie. Este proceso es muy claro en el Lago Cardiel, donde el nivel se encuentra en ascenso y alcanza su pico máximo ( $55 \mathrm{~m}$ sobre la cota actual) hacia los 10800 años cal AP (9780 \pm 80 años ${ }^{14}$ C AP) (Ariztegui et al. 2014; Stine y Stine 1990). En este contexto ambiental, y tomando en consideración los rasgos de encharcamiento y cobertura vegetal reconocidos en el techo de capa 6 de Cueva Maripe, proponemos que la mayor disponibilidad de agua habría tenido su efecto en la recarga de los acuíferos permitiendo el crecimiento y proliferación de manantiales y mallines, dentro de los cuales pueden incluirse el manantial que brota dentro de Cueva Maripe así como también el Mallín La Primavera.

Contamos con un único conjunto arqueológico correspondiente al Pleistoceno final que fue recuperado en la Capa 6 de AEP-1. Las características de esta ocupación incluyen un número bajo de instrumentos líticos, confeccionados principalmente sobre materias primas no locales y una muestra zooarqueológica de baja frecuencia que responden a un locus de actividades limitadas de procesamiento primario de presas (Miotti et al. 1999; Marchionni 2013) en el que el guanaco (Lama guanicoe) fue principal recurso explotado y los megamamíferos tuvieron un rol complementario en la dieta (Miotti et al. 1999; Miotti y Salemme 2005). Es decir que la tasa de depositación de artefactos líticos (ver Franco 2002) y especímenes óseos (Marchionni 2013) fue baja, en un contexto de dinámica poblacional que utiliza rangos de acción amplios (materias primas no locales). Teniendo en cuenta esta conjunción, se cumplen las expectativas arqueológicas para una etapa de exploración planteada por Borrero (1994-95) o de la Fase de Colonización Inicial (Miotti y Salemme 1999; véase asimismo Miotti et al. 2015). Nuestros datos muestran que las tasas de acumulación sedimentaria calculadas pa- 
ra este momento dentro de la cuenca presentan valores relativamente altos por lo que la separación vertical de este conjunto con respecto al superior (capa 4/5) (mayor resolución arqueológica) habría sido resultado de una baja redundancia ocupacional pero también de una rápida depositación de sedimentos.

A escala macro regional, dentro del Macizo del Deseado, desde el análisis sedimentológico se pudieron reconocer casos similares a los de AEP-1 en cuanto a cambios en los mecanismos de depositación y en la redundancia ocupacional. En el caso de la localidad arqueológica La Gruta, se observa un cambio en los mecanismos de depositación entre las unidades estratigráficas datadas en Pleistoceno final con respecto a las del Holoceno temprano tanto en el sitio La Gruta 3 (LG3) como en La Gruta 1 (LG1) (Brook et al. 2015). Las características de estos cambios sedimentológicos son diferentes a los de los sitios estudiados en esta tesis, puesto que por ejemplo, en LG1 el depósito que contiene las ocupaciones humanas del Pleistoceno (Unidad A) presenta altas frecuencias de grava como resultados de un colapso del techo o meteorización por cuñas de hielo (Brook et al. 2015). Sin embargo, coincidentemente con lo que planteamos para la Capa 6 de Cueva Maripe, se observa en su techo rasgos que permiten inferir un período de mayor humedad y estabilidad de la superficie (Brook et al. 2015).

En el caso de LG3, el depósito basal se presenta como un estrato arenoso a limoso en el que el transporte eólico fue un mecanismo preponderante, y que responde a condiciones de depositación similares a las inferidas para AEP-1 y Cueva Maripe durante el Pleistoceno final, donde las arenas y limo estaban disponibles localmente (recordemos que La Gruta se encuentra asociada a una laguna actualmente seca). Los autores sugieren que durante el Pleistoceno final las ocupaciones humanas del sitio fueron ocasionales y discontinuas. La presencia de artefactos líticos de obsidiana (materia prima alóctona) así como de materias primas locales, avala la utilización de rangos de acción de diferentes extensión para los primeros cazadores recolectores (Cattáneo 2002, Franco et al. 2011). Características similares en cuanto a las primeras ocupaciones humanas se pueden observar en Cerro Tres Tetas y en sitios de la Localidad La María como Cueva del Minero 1 y Cueva Túnel, en los que los conjuntos pleistocénicos son asignados a una fase colonizadora (Frank 2011 y bibliografía allí citada). 


\subsection{Holoceno Temprano (11700 - 8200 años cal. $\mathrm{AP}$ - ca. 10000 - 7500 años ${ }^{14} \mathrm{C}$ AP)}

Palabras clave: Frío seco/Alta tasa de acumulación/Aumento de meteorización física en cuevas/Derrumbes/escaso eólico/humedad/recarga de acuíferos/Suelos/Estrategia centralizada en el guanaco/Líticos locales/Exploración-colonización inicial de espacios

El inicio del Holoceno temprano está definido por el final del Younger Dryas y su final por el evento climático $8.2 \mathrm{ka}$ cal. AP (ca. $7.4{ }^{14} \mathrm{C}$ AP) (ver 3.1). La utilización de divisiones temporales como Pleistoceno y Holoceno temprano en lugar de una Transición Pleistoceno-Holoceno que abarque ambos, nos permitió un acercamiento de mayor detalle, ya que el final del Younger Dryas responde al mayor cambio climático que afectó a la región desde que está ocupada por humanos. Más allá de las características globales que presenta este evento, en la región patagónica se reconocen evidencias que dan cuenta de la magnitud de los cambios ocurridos durante este evento climático y momentos posteriores. En este sentido, el Lago Cardiel muestra una facie de desecación hacia 11200 años ${ }^{14} \mathrm{C}$ AP, mientras que dentro de la cronozona Younger Dryas tiene lugar la Reversión Fría HuelmoMascardi que marca las condiciones frías y áridas de ese momento en la región. Luego de los 10000 años ${ }^{14} \mathrm{C}$ AP (final del Younger Dryas) diferentes registros muestran un aumento en la humedad, entre estos podemos mencionar el mayor nivel alcanzado por el Lago Cardiel hacía los ca. 9700 años ${ }^{14} \mathrm{C}$ AP (Stine y Stine 1990), así como también la inferencia desde análisis multyproxy que hacen Markgraf y colaboradores (2003) a partir de la cual reconocer que en la banda latitudinal $43^{\circ}-52^{\circ} \mathrm{S}$, la cual abarca al Lago Cardiel y a nuestra región de estudio, muestra niveles de humedad relativamente altos entre los 10000 y 8500 años ${ }^{14} \mathrm{C} \mathrm{AP}$, al tiempo en que en las bandas latitudinales adyacentes superior e inferior los ambientes son más áridos.

En la cuenca de los zanjones Blanco y Rojo, la muestra de conjuntos arqueológicos es más amplia para este periodo. En Cueva Maripe, los fechados obtenidos se extienden a lo largo de todo el Holoceno temprano, abarcando el lapso 11102 - 7858 años cal. AP $\left(9518 \pm 64-7153 \pm 50\right.$ años ${ }^{14} \mathrm{C}$ AP). En el caso de la Cámara Sur, los materiales arqueológicos fueron agrupados 
por niveles artificiales en Unidades Analíticas (Miotti et al. 2014), debido a la complejidad y compactación del registro. En este sentido, el Componente arqueológico 1 de Cueva Maripe (el más temprano del sitio) corresponde a ocupaciones del Holoceno temprano, y está conformado por la Unidad Analítica 3 de CS y la Capa 5 de CN (Miotti et al. 2014; Hermo y Lynch 2015).

Las características sedimentológicas de estos depósitos muestran cambios con respecto a momentos previos. En Cueva Maripe se puede reconocer un cambio claro con respecto a la depositación de la capa subyacente sobre todo en $\mathrm{CN}$, mientras que en CS presenta características diferentes. Por un lado, en la capa 5 de CN es notorio el incremento de la "lluvia de detritos" en relación al depósito previo donde el aporte de grava del techo es casi inexistente. La fracción arenosa tiene una representación menor que en el depósito basal, por lo que el transporte eólico disminuyó notoriamente. Este cambio en el ambiente sedimentario se da junto con el inicio de las ocupaciones humanas del sitio las cuales además de ingresar material pudieron haber afectado la estabilidad de la roca de caja con su actividad (i.e. fogones, movimiento de personas dentro del sitio, etc.), aumentando la meteorización física y beneficiando el desprendimiento de detritos (Farrand 1985). En la sección superior de la capa 5 (subcapa 5a, fines del Holoceno temprano), la frecuencia de la roca de caja en la fracción psefítica es la más alta de todo el sitio la cual, en combinación con la forma y estructuración de tales acumulaciones, permitieron inferir la acción del agua en forma de escorrentías de muy baja energía en este sector que lavó la matriz fina contribuyendo a la concentración de gravas (Rabassa et al. 2007; Mosquera 2015). De esta manera, la acción hídrica repite su acción en este sector luego de los encharcamientos ocurridos en capa 6. Los conjuntos zooarqueológicos de capa 5 muestran cerca de un $30 \%$ de especímenes con manchas de óxidos de Mn (Marchionni 2013), lo que avala la acción postdepositacional del agua. En este sentido, el agua subterránea es la responsable de disolver al Mn que al unirse con $\mathrm{CO} 2$ forman bicarbonato de $\mathrm{Mn}$ soluble $-\mathrm{Mn}(\mathrm{HCO} 3) 2$-; posteriormente, la perdida de $\mathrm{CO}^{2}$, la oxidación y la evaporación en la cueva concentra al Mn que luego precipita (López-González et al. 2006). Asimismo, en un $10 \%$ de los especímenes se reconocieron depósitos de $\mathrm{CaCO}_{3}$ los cuales se acumulan por procesos mediados por agua.

En el caso de CS, el paso de la capa 6 a la 5 no muestra diferencias claras 
entre los depósitos, en principio por la depositación diferencial de la Capa 6 que en este sector tiene muy poca potencia y un porcentaje mayor de grava con respecto a $\mathrm{CN}$ y, en segundo lugar, porque no se reconoció una diferencia marcada en cuanto al aporte eólico previo a la ocupación humana y al aporte detrítico reconocido en $\mathrm{CN}$ en tiempos de ocupación humana.

En el caso de AEP-1, el Holoceno temprano corresponde a la capa 4 (Horizonte IIB31) que cuenta con dos dataciones, ambas incluidas en este periodo (Tabla 4.3). Nuestros análisis muestran una composición casi exclusiva de material endógeno, con un aporte eólico y antrópico muy bajo. La distribución granulométrica muestra un alto aporte de arena fina y muy fina, pero que responden a un proceso de aporte interno de la cueva, no como sucede en capa 6 donde la fracción arenosa modal representa un aporte eólico importante. Por otro lado, las fracciones arcilla y limo muy fino se concentran en este depósito como resultado del reordenamiento pedogenético que caracteriza a la estratigrafía del sitio (Zárate et al. 2000). En este sentido, las modificaciones naturales registradas en el conjunto zooarqueológico muestran una preponderancia de los depósitos de $\mathrm{CaCO}_{3}$ sobre las manchas de óxidos de manganeso. Podemos inferir entonces que este depósito se vio afectado por un proceso de carbonatación propio del desarrollo pedogenético mencionado previamente, y por otro lado, la influencia de la fluctuación del nivel freático fue menor que en la capa subyacente (Marchionni 2013). Asimismo, la influencia de las raíces en esa capa es clara, ya que se reconocieron marcas en las superficies óseas del conjunto, así como también poros en el sedimento. Por lo tanto, las modificaciones postdepositacionales de la capa son de naturaleza diversa y están signadas por el proceso pedogenético y la formación de cobertura vegetal asociada a él. A partir del evento de derrumbe que se reconoció en el techo de la capa, se desprende que luego de los ca. 9200-9700 años ${ }^{14} \mathrm{C}$ AP tuvo lugar una meteorización física, más intensa de la roca de caja, generando el mencionado derrumbe y la consecuente modificación de la superficie habitable. Este proceso de derrumbes ha sido reconocido en otros sitios del macizo y de otras regiones en diferentes sitios en cuevas con cronologías cercanas a los 9000 años ${ }^{14} \mathrm{C}$ AP como son la Cueva 7 de El Ceibo (Cardich et al. 1981-82); CCP7; Arroyo Feo 1 (Aschero 1996); Cueva de Las Manos (Gradín et al. 1976a) y Las Buitreras (Sanguinetti 1976). Se requerirán estudios a futuro para determinar si esta situación es mas que una coincidencia y depende de factores ambientales 
regionales.

Las tasas de acumulación sedimentaria calculadas para ambos sitios mostraron valores de acumulación relativamente altos. Los valores absolutos entre sitios, así como entre las cámaras de Cueva Maripe son diferentes. Sin embargo, dentro de cada estratigrafía, los valores de TAS de este periodo son los más altos de cada secuencia. Sólo hay una excepción en CN de Cueva Maripe $(0,59 \mathrm{~cm} / 100$ años $)$ sobre la cual hemos puesto algunos reparos en cuanto a una de las dataciones implicadas en el cálculo (ver sección 6.1.5). Es decir que para este momento calculamos tasas de acumulación altas para periodos cortos, en tanto las dataciones implicadas no superan los 1000 años ${ }^{14} \mathrm{C}$ de diferencia entre ellas. Por lo tanto, afirmamos que durante el Holoceno temprano la depositación sedimentaria fue alta. Siempre tengamos en cuenta que, como hemos explicado en el Capítulo 5, estos cálculos asumen una depositación constante por lo que pueden estar encubriendo momentos de estabilidad, sin embargo, por el momento no tenemos evidencias de que hayan ocurrido periodos de estabilidad sostenidos. En este caso, los resultados fueron calculados para periodos cortos y en sitios diferentes por lo que muestran consistencia temporal y a escala de la cuenca.

En este contexto sedimentario los conjuntos arqueológicos recuperados muestran que los obtenidos en Cueva Maripe atribuibles al Holoceno temprano (Componente 1) pueden asignarse en cuanto a su tecnología lítica a momentos de exploración/colonización inicial de espacios con una baja frecuencia artefactual, uso de materias primas preferentemente locales con excepciones de casos de aprovisionamiento regional (obsidiana), y módulos muy espesos. Los instrumentos más característicos son puntas de proyectil triangulares apedunculadas, cepillos y raederas. La ocurrencia de estos grupos tipológicos y morfologías se da asimismo en otros contextos del norte de la provincia de Santa Cruz, que han sido incluidos en entidades (o tradiciones) culturales como la "industria Toldense" o el Nivel cultural Río Pinturas I (véase Cardich et al. 1973; Gradin y Aguerre 1994). Por su parte, la apropiación de la fauna se focalizó en el guanaco, en un contexto de disminución de la variabilidad taxonómica debido a la extinción de la mayoría de las especies de megafauna. Si bien hay evidencias de la persistencia de la megafauna a lo largo del Holoceno temprano, la estrategia de subsistencia adoptada estuvo focalizada casi exclusivamente en el guanaco (Marchionni 2013, Miotti et al. 2014) (Figura 10.2). 
Por su parte, el conjunto de AEP-1 asignable a este periodo está distribuido en dos unidades estratigráficas que conforman la Unidad 4/5. Esta unidad arqueológica, de acuerdo a las dataciones obtenidas abarca desde finales del Pleistoceno hasta momentos del Holoceno temprano. El remontaje entre piezas de las unidades 4 y 5 dan la pauta de que se trata de una única resolución arqueológica la cual mediada por una alta tasa de depositación se presenta distribuida verticalmente y con baja meteorización de las superficies óseas. Esto evidencia que ha habido una reutilización del alero como locus de actividades limitadas referidas al faenamiento de presas y reactivación de filos de corte con áreas de actividad marcadas por la acumulación de huesos en pilas (Miotti et al. 1999). La caza estuvo centrada en el guanaco, y en segundo lugar en las aves corredoras (Rhea americana y Pterocnemia pennata), marcando uno de los últimos registros de Rhea americana en la región. Esta especie se retrajo hacia el norte patagónico durante el Holoceno, por lo que se ha planteado que su convivencia con megamamifeos pastadores como Hippidion sp. y Lama gracilis suponen un ecosistema de estepa graminosa (Alberdi et al. 2001; Miotti y Salemme 2005; Miotti y Tonni 1996; Miotti et al. 1999).

Los datos polínicos obtenidos en AEP-1 marcan la presencia de una estepa arbustiva en un contexto paleoambiental de menor humedad relativa (Borromei 2003) mientras que los registros polínicos del Macizo presentan señales disimiles. Por ejemplo, en sitios del sector central como Los Toldos y AEP-1, al inicio del Holoceno temprano (fin del Younger Dryas) se registran asociaciones de estepa arbustiva (Borromei 2003; Páez et al. 1999), mientras que en el sector sur en La Gruta y La Martita, se reconoce una asociación de estepa graminosa casi hasta el final del periodo. Esto muestra una distribución vegetal en parches dentro del Macizo del Deseado en la que se reconocen sectores de estepa graminosa, de arbustos y de arbustos enanos como la que se reconoce en la actualidad (Mancini et al. 2013). De acuerdo a los análisis de fitolitos realizados en esta tesis, los resultados obtenidos en CS muestran que la vegetación estaba compuesta por gramíneas de las subfamilias Stipoideae y Pooideae, de ruta metabólica C3, que permiten inferir condiciones ambientales templadas frías (Osterrieth et al. 2015). 


\subsection{Holoceno Medio (8200-4200 años cal. AP - $c a$. 7500 -3500 años ${ }^{14}$ C AP)}

Palabras clave: Cálido seco/Intensificación de los westerlies/Baja tasa de acumulación/ Hiato cronológico/ Escorrentías interiores en las cuevas/Stress ambiental/ Tecnología de hojas / Nuevos sistemas de armas/ Potenciación en el uso del guanaco

Entre los ca. 8000 y 4000 años ${ }^{14} \mathrm{C}$ AP se registra un aumento de temperatura a nivel global, denominado Hipsitermal u Óptimo Climático del Holoceno. Este periodo es coincidente en gran parte con los límites del Holoceno Medio que usamos aquí. A nivel regional, este lapso está caracterizado por erupciones del volcán Hudson (H1 y H2) (Naranjo y Stern 1998), elevación del nivel del mar (Codignotto et al. 1992), fortalecimiento de los westerlies (Gilli et al. 2005), así como también condiciones climáticas más cálidas y secas que llegaron a un punto de máxima aridez hacia los 6000 años ${ }^{14} \mathrm{C}$ AP (Markgraf et al. 2003).

La información arqueológica de este segmento del Holoceno en nuestra región de estudio proviene tanto de Cueva Maripe como de AEP-1. Las dataciones radiocarbónicas obtenidas en estos sitios muestran discontinuidad cronológica dentro del periodo con la presencia de dos vacíos cronológicos (ver Figura 9.1). Sin embargo, al contrastarlas con el resto de los sitios del Macizo del Deseado, hemos podido confirmar la presencia de un único hiato cronológico que abarca casi 700 años calendáricos (7828-7151 años cal. AP

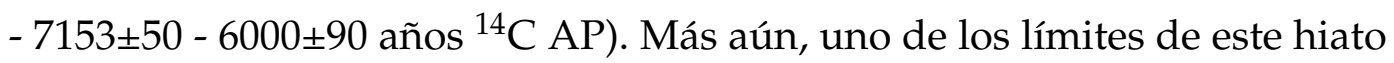
está dado por un único fechado (CSIC-518 - 6000ะ90 años ${ }^{14} \mathrm{C}$ AP) obtenido en el área del Río Pinturas, en el límite oeste del macizo, sin el cual la ausencia de fechados alcanzaría aproximadamente 1400 años calendáricos (7828-6434 años cal. AP - 7153 $\pm 505577 \pm 44$ años ${ }^{14} \mathrm{C}$ AP). Por lo tanto, no hay información radiocarbónica proveniente de sitios arqueológicos durante 1400 años calendáricos en la mayor parte del Macizo del Deseado (Ver 10.2).

Las razones de las discontinuidades cronológicas pueden ser variadas, y en términos generales podemos mencionar tres: 1) error de muestreo, 2) sesgo tafonómico y/o de depositación y, 3) cambios en la dinámica social (i.e. abandono de la región, modificación en los hábitos de uso de las cuevas, 
véase Hermo 2008) que pudieron estar motivados por cambios ambientales o sociales. En este sentido, los fechados analizados en el Macizo del Deseado provienen casi exclusivamente de sitios en cuevas y abrigos rocosos, por lo que han sido obtenidos en ambientes de depositación con modos tafonómicos similares. A escala de sitio, la ocupación de los mismos puede verse afectada por procesos geológicos de diferente índole que generan cambios tanto en la morfología de la cueva como en la superficie plausible de ser ocupada, como derrumbes del techo y colmatación sedimentaria (Borrero 2001; Borrero et al. 2007; Miotti 2010). Dentro de los sitios analizados en esta tesis, hemos podido reconocer diferentes procesos geológicos que contribuyeron a la ausencia de información radiocarbónica para el hiato mencionado del Holoceno Medio. En el caso de Cueva Maripe, las escorrentías superficiales inferidas en $\mathrm{CN}$ disminuyeron el espacio habitable en algún momento entre los 8152-6004 años cal. AP (7153 $\pm 50-5376 \pm 45$ años $\left.{ }^{14} \mathrm{C} \mathrm{AP}\right)$. Sin embargo, las evidencias en CS pueden marcar una situación de falta de disponibilidad de espacio son posteriores a los $4821-4522$ años cal. AP $\left(4113 \pm 39\right.$ años ${ }^{14} \mathrm{C}$ AP) por lo que los procesos de este tipo explican la falta de evidencia sólo para $\mathrm{CN}$, impidiendo generalizarlo a todo el sitio.

La cueva Tito del Valle, fue afectada por procesos de agentes ácueos de diferente energía que actuaron dentro de la cueva. En la base de la estratigrafía las características sedimentarias permitieron reconocer un ambiente similar al de los mallines y en el cual posteriormente fluctuó el nivel freático, mientras que en la parte superior se reconocen momentos de flujos de mayor energía. Esto tiene una doble implicancia arqueológica: por un lado, la presencia de agua dentro del sitio, lo habría hecho inhabitable, y por otro, los materiales depositados en momentos en los cuales pudo ser ocupada habrían sufrido transporte y/o retrabajo por movilización en momento de flujos de energía media a alta como muestran por ejemplo las capas II y $\mathrm{V}$ (Figura 7.2).

Por último, en el caso de AEP-1, la secuencia pedológica descripta para el sitio presenta una discordancia erosiva en el techo de capa 2 poniendo fin al perfil de suelo (Zárate et al. 2000). Esta capa ha sido datada en 8636-7967 años cal. AP $\left(7470 \pm 140-7670 \pm 110\right.$ años $\left.{ }^{14} \mathrm{C} A P\right)$, por lo que la discordancia fue posterior a estos fechados. En este sentido, la combinación de la estabilidad de la superficie que permitió el desarrollo pedológico, sumado al proceso erosivo que actuó en el techo de capa 2 generaron un contexto 
tafonómico de baja preservación de los conjuntos que pudieron haber sido depositados luego de los ca. 7500 años ${ }^{14} \mathrm{C}$ AP. Esta es una de las razones por la cual AEP-1 no presenta cronologías posteriores a los fechados mencionados, y que resulta en un aporte a local a la discusión sobre la falta de dataciones que conforman el hiato mencionado del Holoceno Medio.

El testigo polínico recuperado en el mallín La Primavera tiene su base cronológica en $6920 \pm 33$ años ${ }^{14} \mathrm{C}$ AP (7794-7619 años cal. AP) mientras se recuperó otro de $7543 \pm 34$ años ${ }^{14} \mathrm{C}$ AP (8391-8201 años cal. AP) a 0,5 m por encima del anterior. Esto marca una inversión cronológica, sin embargo, la distancia temporal entre ambos es cercana a los 600 años ${ }^{14} \mathrm{C}$ por lo que en definitiva estamos ubicados siempre dentro del Holoceno Medio. La asociación polínica reconocida entre los fechados mencionados, muestran una tendencia a condiciones más áridas, donde desaparecen las ciperáceas lo que indica una marcada disminución de la humedad del mallín y aumenta sustancialmente la frecuencia de Glomus, que es un género de micorrizas arbusculares y se considera un buen indicador de condiciones de aridez y ambientes estresados (Limaye et al. 2007) que en general se relaciona con disminuciones de humedad del suelo (Chmura et al. 2006) (ver Figura 6.29). En este caso es notorio el cambio entre momentos previos, donde había abundancia de ciperáceas y una casi total ausencia de Glomus generando un contraste entre momentos de mayor humedad previos a los $6920 \pm 33$ años ${ }^{14} \mathrm{C}$ AP y momentos más áridos con posterioridad a esa datación. Luego, las asociaciones inferidas en el testigo ubicado sobre el fechado de $7543 \pm 34$ años ${ }^{14} \mathrm{C} \mathrm{AP}$, muestran una fuerte disminución de pastos. En este sentido, el bajísimo porcentaje de ciperáceas y el aumento de arbustos para este momento indican condiciones más secas que las actuales y que las precedentes. Este sería el momento más seco de la secuencia. Esos nuevos datos permiten inferir que los mallines de la cuenca del Zanjón Blanco habría sufrido una disminución en el aporte de agua, lo que en consecuencia generó una menor disponibilidad ambiental y una disminución de la productividad de los mismos, pudiendo conformarse mallines secos o degradados (Mazzoni y Vazquez 2004). Por otro lado, en el caso del análisis de fitolitos del mallín a partir de otro testigo cuya base fue datada en $4910 \pm 28{ }^{14} \mathrm{C}$ AP, hemos podido inferir que luego de esa datación la estructura vegetal graminosa no muestra cambios abruptos y estaría en consonancia con la actividad de un mallín semihúmedo, similar a las condiciones actuales del sector del cual 
se extrajo este testigo. En este sentido, la composición vegetal es de gramíneas de ruta metabólica C3 con la eventual incorporación de Ciperáceas, en momentos en que el mallín fue ocupado por eventuales cuerpos de agua permitiendo también el desarrollo de diatomeas.

Estas evidencias a escala de sitio y localidad tienen su correlato con otras a escala regional provenientes del Macizo del Deseado. Luego un periodo de mayor humedad a nivel regional como sucedió a finales del Holoceno Temprano, el aumento de la temperatura que caracterizó al Holoceno Medio repercutió en el Macizo del Deseado generando un ambiente más seco que, según algunos autores, alcanzó su mayor aridez en momentos previos a los 6500 años cal. AP (ca. 5700 años ${ }^{14}$ C AP) (Brook et al. 2015). Para estos momentos, las evidencias de tal disminución de la humedad pueden reconocerse en el Lago Cardiel, donde se registran los niveles de costa más bajos en estos momentos (Stine y Stine 1990). Asimismo, Markgraf y colaboradores (2003) plantean que entre los 6000 y 5000 años ${ }^{14} \mathrm{C}$ AP la región se vio afectada por una extensa aridez, algo que también sucedió en otros sectores de Sudamérica. En el sector de La Gruta, los estudios sedimentológicos en las cuencas lagunares, muestran que previamente a la depositación sedimentaria que comenzó hacia los 6500 años cal. AP (ca. 5700 años ${ }^{14} \mathrm{C}$ $\mathrm{AP}$ ), ocurrió un periodo de deflación en un contexto de alta aridez como el que describimos previamente (Brook et al. 2015). Este lapso se corresponde temporalmente con la falta de evidencia de ocupaciones humanas en este sector, por lo que el uso de este área por los cazadores-recolectores cambió con respecto a momentos previos en los que la humedad era mucho mayor (Brook et al. 2015; Mancini et al. 2013).

Cabe preguntarse en este contexto paleoambiental de una alta disminución de la humedad, si tales cambios podrían haber repercutido en una suerte de colapso del ecosistema del Macizo del Deseado (Borrero 2001: 824), que haya motivado a los cazadores-recolectores de esta región a discontinuar la ocupación del mismo generando el hiato cronológico mencionado para el Holoceno Medio (ver Figura 9.5). Dentro de esta posibilidad, el hiato cronológico en el macizo ocurre en sincronía con la señal de primeras ocupaciones en el sector de la Costa y con la reocupación de algunos sectores cordilleranos (ver Figuras 9.3 y 9.4). En este sentido hay evidencias desde el Holoceno temprano de una integración de la cordillera, el macizo y la costa atlántica (véase Miotti 2006a; Hermo y Miotti 2011), dentro de los rangos de movi- 
lidad de los cazadores-recolectores, por lo que es posible que durante un periodo de stress ambiental como el que planteamos para el momento del hiato cronológico, el Macizo del Deseado haya sido un espacio de menor jerarquía. Un rasgo a destacar que resulta interesante, es que la erupción H1 (se estima que fue la más importante de este volcán y una de las más grandes de la región) es sincrónico con el comienzo del hiato mencionado (Figura 10.2). A partir de esto es factible preguntarse si este evento tuvo relación con la ausencia posterior de fechados. Si bien resulta sugestivo como un factor explicativo, no puede ser directamente relacionado con la ausencia de fechados debido a que no se han detectado depósitos asignables a esta erupción dentro del Macizo del Deseado. Solo se cuenta con evidencias de estas cenizas en el Lago Cardiel y en Tierra del Fuego y sur de Chile (Gilli et al. 2005; Stern 2008). De hecho, para el caso del sur de Chile, se ha propuesto que esta erupción pudo haber sido un detonante para el desarrollo de poblaciones marinas (canoeros) a partir de cazadores recolectores terrestres (Prieto et al. 2013).

Por otro lado, a partir de los sitios estudiados aquí, en algunos casos como Tito del Valle o AEP-1 se puede explicar la ausencia de fechados y ocupaciones humanas en el lapso 7828-6434 años cal. AP, a partir de procesos geomorfológicos de erosión hídrica (ie. Capa V de TDV, techo de Capa 2 de AEP-1). En el caso de Cueva Maripe no se reconocen superficies discordantes que puedan significar la erosión y destrucción o transporte de cualquier evidencia depositada en esos momentos. En este sentido, la falta de depositación sedimentaria parece ser una opción válida para explicar la falta depósitos asignables al lapso mencionado, algo que fue propuesto para los casos de La Gruta 1 y 3 (Brook et al. 2015). Por lo tanto, en estos casos, la ausencia de fechados radiocarbónicos de materiales arqueológicos tiene un correlato geoarqueológico en la ausencia de depósitos sedimentarios que los contengan (Figura 10.2).

Para realizar los cálculos de tasas de acumulación sedimentaria para este lapso sólo contamos con fechados de Cueva Maripe, donde los resultados mostraron valores menores que en momentos previos en ambas cámaras, por lo que la tasa de acumulación fue menor durante el Holoceno Medio que durante el Holoceno Temprano. En el caso de Cámara Sur, las tasas calculadas para este lapso son las más bajas de toda la cuenca. Si bien estos datos no son excluyentes, ya que presentan valores diferentes en todos los casos 
y bajas diferencias con respecto a momentos previos, aportan evidencia a la hipótesis de una baja depositación durante el lapso del hiato cronológico.

No encontramos una única línea de evidencia para explicar el hiato cronológico del Holoceno Medio para el Macizo del Deseado, sino que consideramos que las evidencias que contribuyen a explicar este fenómeno son variadas. Por un lado, el factor climático generó un ambiente de alta aridez que afectó la disponibilidad de agua en la región en general y particularmente en los mallines, que son fuentes de agua previsibles en un ambiente semi árido como el de la Patagonia Extraandina (Mazzoni y Vázquez 2004). Esto habría establecido un contexto desfavorable para la ocupación humana, motivando cambios en la dinámica de las poblaciones humanas durante el Holoceno Medio las cuales habrían modificado el uso permanente del macizo, por uno más esporádico de paso o para tareas específicas. Por otro lado, la conformación estratigráfica de Tito del Valle y AEP-1 dan la pauta de procesos geomorfológicos actuantes a escala de sitio que obliteraron los contextos arqueológicos de este momento.

Por último, en el caso de Cueva Maripe, la presencia de agua generó cambios en la disponibilidad de espacios internos de la cueva afectando su posible ocupación en algún momento entre 8152-6004 años cal. AP (7153 \pm 50 - 5376 \pm 45 años ${ }^{14} \mathrm{C} \mathrm{AP}$ ). En relación con esto, el fechado obtenido a 0,3 $\mathrm{m}$ de la base del testigo MLP-6 frente a Cueva Maripe, se ubica en ca. 5000 años ${ }^{14} \mathrm{C} \mathrm{AP}$, lo que indica que el proceso de acreción sedimentaria propio de la actividad del mallín es cercana a esta datación. En este sentido podemos proponer que la actividad hídrica del manantial que surge dentro de la cueva y afectó a la Cámara Norte, estuvo en relación con una mayor presencia de agua en el cañadón La Primavera, que permitió la conformación del mallín y habría sido posterior al hiato cronológico en momentos de aumento de humedad no sólo a nivel local, sino regional (Stine y Stine 1990). El registro polínico muestra cambios en este sentido. Por un lado, en La Martita se observa un cambio ambiental de corto plazo en respuesta a condiciones de mayor precipitación que las actuales hacia ca. 5000 años ${ }^{14} \mathrm{C}$ AP (Mancini 1998), mientras que para Los Toldos y La María, De Porras (2010) plantea que hay un incremento en la temperatura bajo condiciones de precipitación similares a las actuales.

Los conjuntos arqueológicos presentan algunas variaciones con respecto momentos previos. En principio, en el caso de la capa 2 de AEP-1, se ob- 
serva una clara diferencia con los conjuntos más tempranos, donde la dieta se centra casi exclusivamente en el guanaco y es complementada con aves y moluscos. Además, si bien la meteorización del conjunto es baja, presenta una alta fragmentación como resultado de fractura intencional para el aprovechamiento de médula en un contexto procesamiento intensivo de las presas (Marchionni et al. 2010). A partir de este conjunto se interpreta que el sitio fue utilizado como locus de actividades múltiples, es decir que durante el Holoceno Medio cambia su funcionalidad con respecto a conjuntos previos. Los conjuntos líticos también van en esta dirección ya que se recuperaron artefactos de diferentes grupos tipológicos y muestran rastros de uso de raspado y corte sobre hueso (Lynch 2014). Un rasgo tecnológico interesante es la presencia de puntas triangulares apedunculadas tipo toldense que vinculan a estas ocupaciones con sitios de otros sectores del macizo así como también de áreas cercanas a la cordillera (ej. Los Toldos - Cardich et al. 1973; área Río Pinturas - Gradin y Aguerre 1994; La Martita - Aguerre 2003; y Parque Nacional Perito Moreno - Civalero y De Nigris 2005).

Las modificaciones naturales del conjunto zooarqueológico muestran en primera instancia bajos estadios de meteorización con más del $95 \%$ de los especímenes por debajo del estadio 2, lo que permite estimar un rápido enterramiento de los huesos. Además las marcas de raíces son las más abundantes dentro del conjunto (22\%) acompañadas en segundo lugar por los depósitos de óxidos de Mn (19\%). Si bien, para esta capa no se pudo calcular la tasa de depositación, estos indicadores indirectos permiten estimar que el proceso acresional pudo darse de forma rápida y posteriormente se estabilizó la superficie, permitiendo el desarrollo de vegetación y la aparición de consecuentes marcas de raíces. Luego, la presencia de agua que generó la discordancia erosiva y el ambiente pantanoso en el techo de capa 2, estableció las condiciones de humedad que permitieron la ocurrencia de precipitados de Mn.

En Cueva Maripe, los conjuntos correspondientes al Holoceno Medio conforman el Componente Arqueológico 2 (Miotti et al. 2014). El conjunto zooarqueológico muestra que el recurso principal continúa siendo el guanaco, sin embargo cambia la forma de aprovechamiento con una tendencia a su mayor procesamiento. Además, se registró la presencia de cáscaras de huevo de rheidos, lo que podría relacionarse con un posible uso estacional del sitio y una potenciación del recurso para momentos de estrés ambiental 
como el que planteamos arriba (Miotti et al. 2014).

Desde el punto de vista tafonómico más del $95 \%$ de los especímenes se incluyen por debajo del estadio 2, principalmente en el estadio 1 . Por otro lado, las modificaciones naturales registradas son pocas, donde la más frecuente son los depósitos de óxidos de Mn con un $6 \%$ de representación.

La tecnología lítica del Componente 2 correspondiente al Holoceno medio, presenta mayor frecuencia y diversidad morfológica de artefactos formatizados, representando un uso del espacio para actividades múltiples. Si bien las materias primas locales son predominantes, se reconoció un incremento en el uso de xilópalo y de obsidiana. Los rangos de movilidad hacia regiones vecinas como la cordillera para aprovisionamiento de la obsidiana, así como el registro a nivel regional de ítems de origen marino (Barberena 2008; Miotti 2008; Goñi 2010) avalaría la idea de los cambios de circuitos de movilidad presentada arriba. Para el norte santacruceño se han señalado diferentes cambios en la tecnología durante el Holoceno medio, algunos de los cuales indican diferencias en el uso de las materias primas y en las formas de captura de del guanaco, elementos que inciden en la discusión sobre la movilidad de los grupos cazadores-recolectores. Diferentes autores señalan que la tecnología de hojas comienza a ser más frecuente en los contextos del Holoceno medio (véase Hermo y Magnin 2012 para más detalles), lo que implica un aprovechamiento particular de las rocas aptas para la talla. Por otro lado, la aparición de bolas de boleadora, ha sido observado como indicador de un nuevo sistema de armas, lo que implicó nuevas organizaciones de los recursos líticos, topográficos y humanos involucrados en las actividades cinegéticas (véase Hermo 2008; Torres Elgueta 2009).

Teniendo en cuenta las particularidades de los contextos culturales y del registro paleoambiental, así como la distribución de sitios arqueológicos en espacios no ocupados previamente, podemos plantear que durante el periodo de mayor stress ambiental se habría discontinuado el uso del Macizo del Deseado, el cual devino en un lugar poco frecuentado y hasta evitado por los cazadores-recolectores (Borrero 2001; Miotti y Salemme 2004) por lo que posteriormente, al mejorar las condiciones ambientales, fue reocupado adoptando nuevas estrategias de explotación de fauna y de aprovechamiento de materias primas. 


\subsection{Holoceno Tardío (4200-0 años cal. AP - ca. 3500 años ${ }^{14} \mathrm{C} \mathrm{AP}$ - presente)}

Palabras Clave: Expansión territorial/Potenciación en el uso del guanaco /Eventos erosivos en cauces / Intensificación de los westerlies / Actividad del manantial en Cueva Maripe

El último bloque temporal analizado es el Holoceno Tardío, el cual está delimitado a nivel global por el "evento 4.2 ka años AP" (Walker et al. 2012). Este fenómeno climático se refleja en registros proxy de Norteamérica, Medio oriente, China, África y Sudamérica y Antártida (Mayewski et al. 2004; Staubwasser y Weiss 2006). En el caso de Sudamérica, se expresa en algunas regiones como un desplazamiento a condiciones áridas. En este sentido, este evento se condice con la tendencia a condiciones áridas establecida desde el Holoceno Medio en la Patagonia y que, durante el Holoceno Tardío, con la intensificación de los southern westerlies winds (ca. 1800 años AP; Gilli et al. 2001) alcanzaron momento de "sequías épicas" a nivel regional (Stine 1994). En el Macizo del Deseado y sectores aledaños se registra un rasgo que sirve como referente estratigráfico del límite Holoceno Medio/Tardío: los depósitos de tefra de la erupción del volcán Hudson H2 que fue datada en 3600 años ${ }^{14}$ C AP (ca. 3800 años cal. AP) (Naranjo y Stern 1998) (Ver 10.2).

Los fechados radiocarbónicos obtenidos dentro de la cuenca de los zanjones Blanco y Rojo para el Holoceno tardío (Figura 9.1) muestran un hiato cronológico que desaparece al analizar la muestra a escala regional (Macizo del Deseado), por lo que sería esperable que tal ausencia de fechados responda a una sesgo en las series de dataciones obtenidas por los distintos equipos de investigación, más que a un cambio en las dinámicas sociales de ocupación del norte santacruceño.

Las evidencias arqueológicas y paleoambientales del Holoceno Tardío obtenidas en el marco de esta tesis provienen de los sectores de Cuenca Alta y Cuenca Media. El conjunto arqueológico de referencia, con respaldo de dataciones radiocarbónicas, corresponde al Componente Arqueológico 3 de Cueva Maripe (Miotti et al. 2014). Como hemos explicado anteriormente, en el caso de AEP-1, los fechados más tardíos son del Holoceno Medio y marcan el final de la secuencia arqueológica, mientras que en el sector de Tito del Valle, la presencia de cenizas de la erupción H2 permitió ubicar 
temporalmente algunos de los perfiles relevados.

En la Cámara Norte de Cueva Maripe, las dataciones obtenidas en la base de este depósito nos permiten ubicarlo temporalmente en una edad mínima de ca. 3200-3700 años ${ }^{14} \mathrm{C}$ AP, mientras que la datación de $1907 \pm 48$ años ${ }^{14} \mathrm{C}$ AP obtenida en la cuadricula $\mathrm{P} 6 \mathrm{~B}$, cuyos materiales aún se encuentran bajo análisis, permite inferir que las ocupaciones continuaron durante el Holoceno tardío en $\mathrm{CN}$.

El depósito sedimentario del Holoceno tardío de Cueva Maripe, presenta características diferentes entre las cámaras que componen al sitio. Por un lado, los agentes intervinientes en la conformación de este depósito son similares a los reconocidos para el Holoceno Medio marcando una continuidad en los mecanismos de transporte y depositación, aunque en términos composicionales disminuye la participación del material ingresado por los humanos. A diferencia de momentos previos, en los que se reconoció la incidencia del agua en este sector, durante el Holoceno Tardío no se registra la actividad del manantial en CN. Esta situación se contrapone con lo observado en Cámara Sur, donde los depósitos sedimentarios muestran incidencia del agua entre los $4113 \pm 39$ y $1078 \pm 40$ años ${ }^{14} \mathrm{C} \mathrm{AP}$, con rasgos de acumulación de tipo palustre, por lo que el manantial estuvo activo en este sector e influyó sobre los materiales depositados previamente.

Las modificaciones naturales reconocidas sobre los conjuntos zooarqueológicos van en consonancia con la diferencia mencionada en cuanto a la presencia de agua en cada cámara. Mientras que en Cámara Norte se reconocieron manchas de $\mathrm{Mn}$ en menos del 5\% y ausencia de depósitos de $\mathrm{CaCO}_{3}$ sobre las superficies óseas, en CS, donde hubo incidencia hídrica, los depósitos de Mn alcanzan al 10\% de los especímenes y se reconoció un $2 \%$ de huesos con depósitos de $\mathrm{CaCO}_{3}$. Además en CS, se contabilizó un $10 \%$ de especímenes óseos dentro de la categoría teñidos, que es una categoría que incluye huesos en los que no se pudo determinar fehacientemente si su tonalidad más oscura se debe a depósitos de Mn o alteración térmica (Marchionni et al. 2012; Marchionni 2013). En cuanto a los huesos teñidos, podemos sugerir que las modificaciones de este tipo respondan una característica propia, determinada por un contexto como el que se plantea para el depósito de CS en el que sedimentos con altas frecuencias de carbón, al humedecerse, generen una solución que oscurece a la superficie de los huesos. Esta hipótesis deberá ser contrastada pero sirve de punto de partida para 
explicar este tipo de modificaciones.

Teniendo en cuenta estas evidencias, la alternancia en la presencia del agua en las dos cámaras podría estar marcando una variación en la disponibilidad de espacio interno de la cueva durante la ocupación humana. En este sentido, las escorrentías estructurarían el espacio interno de la cueva, tornando habitable una cámara mientras la otra estaba colmada de humedad. Este comportamiento intrasitio del manantial podría fundamentar la hipótesis de uso alternado de las cámaras propuesta en trabajos anteriores (Miotti et al. 2007; 2014; Carden 2008; Hermo 2008; Marchionni 2013; Lynch 2014).

Por otro lado, contamos con sólo un cálculo de acumulación sedimentaria que involucra al Holoceno tardío, pero que responde a un rango de 6600 años radiocarbónicos y que abarca también al Holoceno medio (entre $1078 \pm 40$ y $7703 \pm 47$ años ${ }^{14} \mathrm{C}$ AP) (Figura 10.1). Este cálculo fue realizado en CS y su valor es de $0,3 \mathrm{~cm} /$ año, por lo que refleja una velocidad de depositación muy lenta. En este sentido, el conjunto zooarqueológico de este sector presenta estadios de meteorización entre 1 y 3 (donde el estadio 3 alcanza el $12 \%$ de los especímenes) lo que muestra una meteorización más intensa que en los conjuntos de momentos previos tanto en este sitio como en AEP-1 (Marchionni 2013). Esta característica coincide con un contexto de depositación lenta acorde al valor de la tasa de acumulación.

En contraste, la meteorización de los especímenes óseos de $\mathrm{CN}$ es mucho más baja, donde más del $70 \%$ del conjunto presenta estadios muy bajos $(0$ y 1) y menos de un $5 \%$ presentan estadio 3 . En este sentido, en términos relativos se puede inferir una depositación más rápida en $\mathrm{CN}$ que en CS durante el Holoceno medio. Por lo tanto, la variabilidad tafonómica dentro de la cueva refleja un proceso de acreción diferente entre las cámaras, donde las velocidades de depositación inferidas muestran una acumulación más rápida en $\mathrm{CN}$ y una acumulación más lenta y por lo tanto menor potencia sedimentaria en CS.

En los testigos del Mallín La Primavera sobre los que se realizó el análisis polen y fitolitos, los fechados radiocarbónicos realizados no permiten una ubicación temporal certera de los depósitos que puedan ser asignados al Holoceno tardío. Las tres dataciones obtenidas se ubican en el Holoceno medio, por lo tanto, si bien no se reconocen sobre estas dataciones cambios claros en las asociaciones tanto polínicas como de fitolitos, no podemos te- 
ner certezas sobre cuáles son las que responden al lapso que tratamos en este apartado.

Los datos estratigráficos generados en la Cuenca Media pudieron ser referenciados cronológicamente a partir de un depósito de tefra de la erupción H2 del volcán Hudson - ca. 3600 años ${ }^{14}$ C AP - (Naranjo y Stern 1998) en la base de uno de los perfiles relevados. En este sentido, las características de los cortes estratigráficos del cauce analizados en el Capítulo 7, nos permiten inferir que durante el Holoceno tardío, en el sector aledaño a la cueva Tito del Valle, se sucedieron depósitos de diferente naturaleza: coluviales, fluviales (playa, barras) y eólicos. También identificamos sectores en los que estos depósitos se encontraban truncados por discontinuidades erosivas, lo que determina la incidencia de eventos fluviales de alta energía en momentos del Holoceno tardío.

Las corrientes efímeras como son los cursos hídricos de nuestra región de estudio, presentan características que los diferencian de los modelos clásicos de dinámica fluvial y que generan una gran variedad de litofacies en los cortes estratigráficos del cauce. Estos depósitos sedimentarios muestran una alternancia en la dinámica del cauce entre episodios de erosión y acreción que son resultado de momentos de transporte de agua a partir de precipitaciones o deshielo, y de momentos en que el cauce está seco en los que cobra relevancia el agente eólico (Bull 1997; Miall 2016). En ambientes semi áridos y con baja cobertura vegetal, se dan crecidas rápidas que transportan gran carga de sedimentos, y generan litofacies mal seleccionadas, que pueden presentar estructuras laminadas y entrecruzadas, y superficies de erosión (Miall 2016), como las que se detallaron en los perfiles del Cauce Sin Nombre en la Cuenca Media. Este arreglo litológico indica la ocurrencia de flujos poco profundos y de alta energía los cuales, con su actividad modifican el diseño del cauce y generan variación lateral de tales depósitos, pudiendo encontrar depósitos de barra y de planicie de inundación.

La dinámica fluvial mencionada tuvo implicancias importantes en cuanto a los procesos de formación de sitio. En el caso de la cueva Tito del Valle, el Cauce Sin Nombre corre a $4 \mathrm{~m}$ de distancia de la línea de goteo y la superficie del sitio se ubica a $1 \mathrm{~m}$ sobre la base el cauce. En este contexto, los eventos de flujos de alta energía como el que se infiere para la Capa V, afectaron al sitio, movilizando y eliminando evidencia arqueológica en caso de que haya sido depositada previamente. Además, las evidencias sedimento- 
lógicas de la Capa VI muestran que, previamente a la incidencia de corrientes de alta energía, en el interior de la cueva se desarrolló un ambiente de tipo mallín en el que fluctuó el nivel freático. Por ende, la presencia de agua impidió la instalación humana en los primeros momentos de depositación, y posteriormente cualquier evidencia arqueológica pudo ser eliminada por corrientes de agua de alta energía.

Dentro del área de estudio, el único de los sitios analizados que cuenta con conjuntos datados correspondientes al Holoceno tardío es Cueva Maripe. Estos materiales se encuentran incluidos en el Componente arqueológico 3 conformado por los conjuntos tardíos provenientes de Cámara Norte y de Cámara Sur. Los trabajos publicados sobre el análisis de ambos conjuntos permitieron, por un lado, diferenciar espacios de actividad dentro de la cueva y, por otro contribuir a al conocimiento de los sistemas de subsitencia del Holoceno tardío.

La tecnología lítica muestra en principio una clara diferencia en cuanto a la frecuencia de artefactos formatizados recuperados en cada sector con una presencia mucho mayor en $\mathrm{CS}(\mathrm{CN} \mathrm{n}=26 ; \mathrm{CS} n=110)$. En estos conjuntos las hojas son la forma base principal para la manufactura de diferentes grupos tipológicos (i.e. raspadores, filos laterales retocados, muescas), y presentan una tendencia al diseño de artefactos formatizados de tamaños menores que en los componentes anteriores (Hermo y Lynch 2015). Estas características del conjunto tecnológico son concordantes con las registradas en otros sitios a nivel regional (Aschero 1987; Yacobaccio y Guráieb 1994; Orquera 1999). En la CS se reconocieron once grupos tipológicos entre los que predominan los raspadores, que superan el $70 \%$ de los artefactos recuperados en el sector, y las formas de filos largos como artefactos de filo sumario, láminas retocadas, raederas y bifaces. Además se hallaron dos puntas de proyectil: una triangular con aletas y pedúnculo irregular sobre obsidiana y la otra responde a un ápice de sílice. Por su parte, en el conjunto de $\mathrm{CN}$, se identificaron sólo cinco grupos tipológicos de los cuales el más representado también es el de los raspadores, seguido por las láminas retocadas, los filos no diferenciados y las muescas. Finalmente, se observa para este momento la utilización de materias primas tanto locales como alóctonas, estas últimas representadas principalmente por la obsidiana. Hermo y Lynch (2015) interpretan que el conjunto lítico del Componente 3 de Cueva Maripe refleja la utilización de $\mathrm{CN}$ de Cueva Maripe, como parte del proceso de expansión 
territorial de los grupos cazadores-recolectores durante el Holoceno tardío.

En cuanto a los conjuntos faunísticos, como venía sucediendo en momentos más tempranos, el guanaco se mantiene como el recurso central de la dieta de los cazadores recolectores. Los rheidos y las aves medianas aparecen en un rol complementario y en CS se registraron especies introducidas en tiempos históricos como Ovis Aries. Además en CS es mucho mayor el número de especímenes óseos con alteración térmica. Estas diferencias entre los conjuntos marcan una estructuración del espacio con actividades múltiples en CS y actividades más puntuales y específicas en $\mathrm{CN}$, donde también, en el sector de la cuadricula P6B en el fondo de $\mathrm{CN}$, se pudo determinar $a$ priori (los materiales están siendo analizados) un sector de descarte. Al respecto, planteamos que la presencia de agua superficial durante el Holoceno tardío debió jugar un rol relevante en la selección de sectores internos de la cueva para el desarrollo diferencial de dichas actividades, estructurando la distribución de los restos óseos durante este lapso.

Se ha planteado que a partir de las condiciones ambientales áridas establecidas durante el Óptimo Climático Medieval - entre 1021-1228 años DC - (Stine 1994; 2000), se produjo un cambio en la movilidad y la subsistencia de los cazadores recolectores de la región cordillerana. Se propuso que tales condiciones de aridez plantearon una distribución más puntual del recurso hídrico, permitiendo que las cuencas de los lagos Cardiel, Posadas y Salitroso, fueran sectores preferidos para la instalación humana en un contexto de fuerte disminución de la movilidad residencial (Goñi 2010). Nuestros datos no muestran cambios en la señal cronológica que puedan marcar una interrupción de las ocupaciones, a diferencia de lo que hemos propuesto para el Holoceno medio ante el establecimiento de condiciones áridas. La información sedimentaria tampoco muestra cambios en el proceso de acreción que puedan ser correlato de un momento de stress ambiental, por lo que nuestro análisis al respecto todavía es de grano muy grueso.

Si bien las evidencias arqueológicas y paleoambientales obtenidas en nuestra área de estudio son escasas en parte por su ausencia real como sucede en AEP-1 y, por otro lado, por falta de evidencias cronológicas, podemos brindar un aporte a discusiones de escala regional. En este sentido, los conjuntos arqueológicos descriptos arriba permitieron plantear que, teniendo en cuenta que los restos de guanaco presentan alto grado de fragmentación, alta frecuencia de huesos quemados (especialmente en CS) y un uso com- 
plementario de otros taxa (huevos de rheidos y Ovis Aries), la estrategia de subsistencia estuvo centrada en la potenciación del recurso guanaco con la existencia de una mayor inversión de trabajo para la obtención de nutrientes y productos de los recursos tradicionalmente explotados (Miotti 1998; 2012). Este tipo de explotación faunística se reconoce en otros sitios de Patagonia centro-meridional, donde los conjuntos presentan baja riqueza taxonómica y los especímenes hallados se centran en el guanaco, tendencia que se insinuaba desde el Holoceno medio. En este escenario, habrían jugado un papel preponderante los cambios tecnológicos y organizacionales en torno a las actividades cinegéticas, tales como la aparición del sistema de armas de arco y la flecha, y la implementación de estrategias de acecho y cacería que involucran topografías y estructuras particulares (vg. parapetos) (véase Magnin et al. 2012).

A modo de síntesis final de los datos analizados y de los resultados obtenidos en esta tesis, presentamos la Figura 10.2, en el cual se integra la información geoarqueológica, paleoambiental y cultural que caracterizan los momentos de ocupación humana en el área de estudio, desde hace ca. 15000 años cal. AP. 


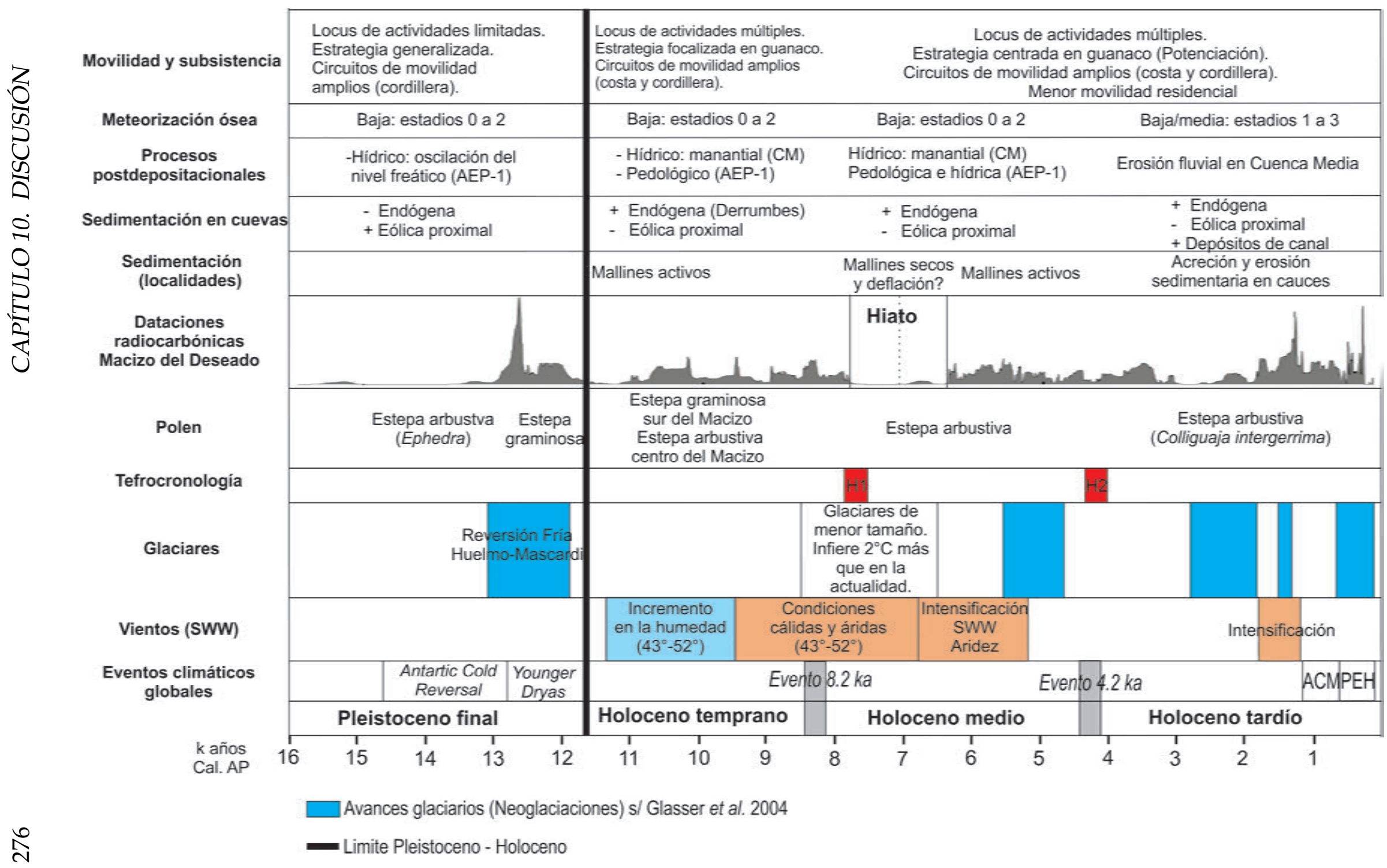

Figura 10.2: Cuadro de síntesis de información generada y recopilada tratada en esta tesis. 


\section{Capítulo 11}

\section{Conclusiones}

A lo largo de la Tesis, hemos abordado diferentes temas de competencia geoarqueológica a partir de un enfoque que se basó en el análisis sedimentológico, en la búsqueda de relacionar datos proxy nuevos con la información arqueológica y cronológica disponible. Esto genera un nuevo escenario en el conocimiento de las relaciones entre los grupos humanos, su cultura material y los ambientes, ya que es el primer trabajo (o tesis doctoral) con base geoarqueológica realizado para la región del Macizo del Deseado. Por lo tanto, es esperable que además de generar información nueva, se proponga una agenda de trabajos futuros tendientes a responder las nuevas inquietudes que se desprenden de la presente tesis.

La metodología aplicada y las escalas de trabajo elegidas fueron pertinentes para abordar los objetivos que guiaron este trabajo y contrastar las hipótesis planteadas. Si bien en la región son escasos los antecedentes de estudios sistemáticos de depósitos sedimentarios (tanto de abrigos rocosos como de las geoformas presentes en el entorno), consideramos que este trabajo presenta un aporte interesante y de alta potencialidad informativa para el estudio del ambiente y las poblaciones humanas del pasado. En tal sentido, hemos abordado los objetivos planteados por lo que a continuación presentamos las conclusiones a las que arribamos.

Las tres cuevas analizadas presentan una clara variabilidad estratigráfica. La conformación sedimentaria de Cueva Maripe y AEP-1, que son los sitios en los que se registraron ocupaciones arqueológicas, muestra una preponderancia de material endógeno aportado por la cueva, lo que lo constituye en el principal componente de los depósitos sedimentarios. Sin embargo, hemos podido determinar momentos en los que cobraron relevancia otros 
componentes de origen exógeno: entre los $9710 \pm 105$ y $11000 \pm 65$ años ${ }^{14} \mathrm{C}$ AP (12995-10708 años cal. AP) en AEP-1, y antes de los $9518 \pm 64$ años ${ }^{14} \mathrm{C}$ AP (11102-10594 años cal. AP) en Cueva Maripe se estableció un ambiente sedimentario eólico en un contexto más frio y árido que el presente y de baja cobertura vegetal (De Porras 2010; Mancini et al. 2013), que permitió la deflación de sedimentos de sectores cercanos a los sitios y la subsecuente acumulación de arena con tasas de depositación relativamente rápidas en el interior de estos sitios.

La ocupación humana de estos sitios se desarrolló en AEP-1 durante el final del Pleistoceno, mientras que en Cueva Maripe comenzó una vez iniciado el Holoceno. En el caso de Maripe, la presencia de agua en forma de encharcamientos para momentos previos a la ocupación humana, habría condicionado el uso de la cueva por parte de los primeros pobladores. Tales episodios estarían relacionados con un aumento en la humedad a nivel regional (ej. máximo nivel del Lago Cardiel, predominio de estepa graminosa), la cual habría tenido su efecto en la recarga de los acuíferos que generó una mayor actividad de los manantiales en el Macizo de Deseado. Este cambio ambiental en cuanto a la humedad, sumado a la llegada de los primeros grupos humanos que habitaron la cueva indujo modificaciones en los agentes implicados en la acreción sedimentaria tanto de Cueva Maripe como de Piedra Museo, donde la "lluvia de detritos" del techo de las cuevas se hizo más intenso. En este sentido, la mayor meteorización de la roca de caja responde a un cambio en el ambiente, el cual en otros sitios de la región se expresa como derrumbes del techo, que pudieron servir de sello para ocupaciones preexistentes y que posteriormente condicionaron el espacio habitable dentro de esas cuevas.

Los cazadores recolectores que ocuparon los sitios, tuvieron la mayor incidencia en la depositación sedimentaria en la Cámara Norte de Cueva Maripe durante el Holoceno Medio, entre los 5376 \pm 45 y $3210 \pm 60$ años ${ }^{14} \mathrm{C}$ AP (6284-3272 años cal. AP), mientras que en la Cámara Sur, la mayor frecuencia de sedimentos de origen antrópico, ocurrió ca. 4100 años ${ }^{14} \mathrm{C}$ AP. De esta manera, en Cueva Maripe, la depositación del Holoceno medio estuvo signada por el aporte atrópico (componentes sedimentarios y porcentaje de materia orgánica) en ambas cámaras, y esta intervención tiene su correlato en la alta frecuencia de materiales arqueológicos de este depósito con respecto a momentos previos. Durante el Holoceno Medio, también se recono- 
ció la incidencia esporádica del agua dentro de cada cámara, durante algún momento previo a los 5376 \pm 45 años ${ }^{14} \mathrm{C}$ AP (6284-6004 años cal. AP) en CN $\mathrm{y}$, con posterioridad a los $4113 \pm 39$ años ${ }^{14} \mathrm{C}$ AP (4821-4522 años cal. AP) en CS. Estos cambios en la presencia de agua en cada sector funcionaron como estructuradores del espacio interno de la cueva, lo que generó ocupaciones alternadas entre las cámaras. Esta situación también pudo influir en las actividades realizadas en cada una, dado que mientras CS habría funcionado como el espacio habitacional, $\mathrm{CN}$ conformaría un espacio de uso alternativo destinado a actividades especiales (Miotti et al. 2007; 2014; Carden 2008; Hermo 2008; Marchionni 2013; Lynch 2014).

En AEP-1 y Tito del Valle, también se reconoció la influencia del agua en la estratigrafía. En el primer caso generó una discordancia erosiva y un ámbito palustre mal drenado luego de los 7470 \pm 140 (8514-7967 años cal. AP), mientras que en Tito del Valle se pudo establecer la presencia de agua aportada por el nivel freático en los depósitos basales y con posterioridad, en el Holoceno tardío, el flujo del Cauce Sin Nombre movilizo depósitos sedimentarios preexistentes y deposito nuevos. Este caso constituye un claro ejemplo de cómo la acción de los agentes naturales actúa en sectores discretos y acotados del espacio: por un lado, alterando los espacios disponibles para la ocupación humana y, por otro, causando la remoción del registro arqueológico.

Las tasas de acumulación sedimentaria calculadas, tienden a valores altos durante el Pleistoceno y el Holoceno Temprano, y valores relativamente más bajos durante el Holoceno medio y Tardío. A priori, esta situación debería tener un correlato en cuanto a tafononomía de los conjuntos óseos (estadios de meteorización bajos antes del Holoceno medio, y estadios más altos desde el Holoceno medio en adelante) (Behrensmeyer 1978). Sin embargo, en los conjuntos analizados predominan los estadios bajos (Marchionni 2013). En este sentido, la aplicación del modelo de Behrensmeyer (el cual fue generado a partir de elementos óseos expuestos a condiciones atmosféricas) presentan una sensibilidad diferente como estimador de tasas de acumulación en contextos de cuevas y abrigos rocosos.

La recopilación, calibración y cálculos de suma de probabilidades realizados sobre las dataciones radiocarbónicas publicadas dentro del Macizo del Deseado, nos permitió reconocer una cierta continuidad ocupacional a lo largo de los últimos 13500 años cal. AP. En este sentido, observamos y 
delimitamos un periodo de ausencia de fechados radiocarbónicos existente para dicha región durante el Holoceno medio. Este hiato o vacío cronológico abarca en la mayor parte del macizo, el lapso comprendido entre $7153 \pm 50$ y 5577 \pm 44 años ${ }^{14} \mathrm{C} \mathrm{AP} \mathrm{(7828-6434} \mathrm{años} \mathrm{cal.} \mathrm{AP).} \mathrm{Sólo} \mathrm{una} \mathrm{datación} \mathrm{obtenida}$ en el área del Rio Pinturas, con un valor $6000 \pm 90$ años ${ }^{14} \mathrm{C}$ AP, acorta el hiato mencionado a $c a .700$ años calendáricos. Consideramos que por estar en los límites del área analizada no le quita significancia al vacío cronológico reconocido en el resto del Macizo, donde en definitiva sólo se cuenta con una datación dentro del lapso de 1400 años calendáricos.

El Holoceno medio fue un periodo de aumento global de la temperatura. En nuestra región esta tendencia se pudo reconocer en la estructura florística, la cual adopta características de estepa arbustiva a medida que los cañadones se colmataban de sedimento (De Porras 2010; Mancini et al. 2005). Asimismo, se ha planteado que hacia los 6000 años ${ }^{14} \mathrm{C}$ AP la aridez afectó gran parte de sudámerica (Markgraf et al. 2003), y nuestra región no estuvo ajena a esta tendencia. Los datos generados para esta tesis muestran, a partir de los análisis de polen del Mallín La Primavera, que desde los 6920ะ33 años ${ }^{14} \mathrm{C}$ AP (7794-7619 años cal. AP) y dentro del lapso abarcado por el hiato cronológico mencionado, prevalecieron condiciones de alta aridez que afectaron significativamente la humedad del mallín y por ende su productividad. Sumado a estas evidencias, las tasas de acumulación sedimentaria de Cueva Maripe muestran valores más bajos que en momentos previos por lo que, a priori el proceso de acreción fue más lento. El desarrollo pedogenético reconocido en AEP-1, que evidencia un periodo de estabilidad de la superficie, contribuye a esta afirmación.

Consideramos entonces que en este momento, los cambios ambientales tendientes a condiciones más áridas afectaron la productividad del Mallín La Primavera, lo que potencialmente pudo incidir de igual manera en otros mallines de la región. Esta situación disminuyó la disponibilidad de agua y la productividad del entorno, generando una situación de stress ambiental que provocó, un uso menos frecuente del área de estudio, y a mayor escala, del Macizo del Deseado. Las características de los conjuntos arqueológicos muestran para el Holoceno medio, tanto antes como después del vacío cronológico, la adopción de una estrategia tendiente a la potenciación en el uso del guanaco, con un aprovechamiento integral de los individuos y un uso más intensivo de sus partes que en momentos previos (ie. ma- 
yor fragmentación intencional para acceso a la medula, mayor cantidad de marcas de procesamiento, manufactura de artefactos óseos), (García Añino et al. 2014; Marchionni 2013; Miotti 2012). Asimismo, los conjuntos líticos muestran tendencias distintas a las de momentos previos ya que hay un incremento en la frecuencia de raspadores, las hojas son las formas bases predominantes y se agregan nuevas tecnologías como son las bolas (Hermo 2008; Hermo y Magnin 2012). Además, los conjuntos arqueológicos presentan una mayor densidad artefactual, algo que se repite en otros sectores de la región (Aschero 1987) e indicaría una mayor concentración de gente debido a la disminución de la movilidad residencial (véase Hermo y Magnín 2012; Hermo y Lynch 2015).

Los depósitos sedimentarios estudiados datados radiocarbónicamente en el Holoceno tardío provienen de Cueva Maripe. Asimismo, a partir de la identificación de un depósito de tefra de la erupción $\mathrm{H} 2$ del volcán Hudson, asignamos parte de las estratigrafías relevadas en la Cuenca Media a este periodo, y aportamos nueva evidencia sobre la extensión de dicha erupción. La estratigrafía del Cauce Sin nombre estudiado en la Cuenca Media nos dio la pauta de la dinámica variante de los cursos fluviales que predominan en el área de estudio. La alternancia de los agentes de transporte implicados en su formación, los eventos estacionales en los que el agua fluye por estos cauces, la variedad de energía con la que se dan estas escorrentías en relación con la intensidad de nevadas y precipitaciones imperantes terminaron por configurar una estratigrafía de depósitos con poca continuidad lateral y una alta variabilidad estratigráfica dentro de los cauces. En este sentido, generar expectativas de hallazgo arqueológico a cielo abierto en estos cauces asoma como una tarea muy difícil. Los datos que hemos recopilado muestran que la cueva Tito del Valle entró en la dinámica del cauce, lo que generó momentos en el que el sustrato interno de la cueva estaba húmedo por ser parte del fondo del cauce en el que puede aflorar el nivel freático, y posteriormente las corrientes erosionaron parte de la estratigrafía y generaron depósitos de barra.

En los depósitos sedimentarios de Cueva Maripe correspondientes al Holoceno tardío se reconocieron los mismos agentes de acumulación principales que imperaron durante todo el Holoceno (roca de caja, aporte eólico, aporte antrópico), aunque la influencia del aporte antrópico es notablemente menor que durante el Holoceno Medio. No hemos registrado señales que 
respondan a los eventos climáticos reconocidos a escala global para este periodo, como la Anomalía Climática Medieval y la Pequeña Edad del Hielo. Según las investigaciones llevadas a cabo en las cuencas lacustres del sector cordillerano, estos fenómenos climáticos repercutieron notablemente en la movilidad y subsistencia de los cazadores recolectores de la región (Goñi 2010), por lo que asoma como una vía de investigación interesante para nuestra área de estudio. Sin embargo, nuestros datos presentan aún una baja resolución cronológica tanto en los sitios que hemos investigado como en los testigos sedimentarios estudiados, por lo que su abordaje quedará como una tarea futura.

Para finalizar, podemos decir que a lo largo de la Tesis hemos contrastado las hipótesis planteadas, con diferentes grados de profundidad:

Hipótesis 1: Las estratigrafías de los sitios arqueológicos en cuevas analizados, reflejan los cambios ambientales ocurridos desde el Pleistoceno Tardio hasta la actualidad, debido a su cualidad de ser trampas sedimentarias efectivas.

- Si bien las cuevas son "trampas sedimentarias", el principal componente de las estratigrafías analizadas es el material aportado por la roca de caja, el cual tiene representación en todas las fracciones granulométricas. Los cambios ambientales ocurridos en la región presentan registros diferenciales en los abrigos rocosos dado que no siempre quedan registrados en las cuevas. Los depósitos arenosos de edad pleistocena son un ejemplo de registros ambientales. Asimismo, los depósitos de tefra que sólo se registran en algunas cuevas, dan la pauta de las particularidades de cada cueva como un ambiente de acumulación específico, dado que sabemos que el área se vio afectada por diferentes erupciones a lo largo del tiempo y sin embargo su registro es relativamente escaso.

Hipótesis 2: La variabilidad arqueológica y tafonómica entre los sitios en cuevas abrigos rocosos en los tres sectores seleccionados de la cuenca son resultado de diferencias paleoambientales locales.

- Hemos corroborado la variabilidad existente en los rasgos tafonómicos de los conjuntos arqueológicos recuperados en las cuevas así como también en su registro estratigráfico. Además, el estudio de dos sectores en Cueva Maripe permitió reconocer variabilidad interna dentro de las capas que componen el sitio y en las que se desarrollaron 
ambientes de depositación diferentes. Estos afectaron a los conjuntos arqueológicos, incidieron en los rasgos tafonómicos registrados y condicionaron la ocupación de algunos sectores diferentes momentos. En el caso de Tito del Valle, pudimos confirmar la ausencia de evidencia arqueológica debido a la acción del agua que fluye estacionalmente en el cauce adyacente.

Hipótesis 3: La presencia de hiatos arqueológicos y cronológicos en distintos momentos del pasado, tanto en cuevas como en sitios a cielo abierto, se debe a la acción de procesos geomorfológicos actuantes a diferentes escalas, los cuales impidieron su preservación.

- El hiato cronológico que hemos discutido aquí y que indica un lapso sin dataciones a de casi 1400 años calibrados durante el Holoceno Medio, presenta en nuestra región de estudio evidencias que avalan parcialmente esta hipótesis. La discordancia erosiva de AEP-1 y las bajas tasas de depositación durante el Holoceno medio son las evidencias a escala local que podemos esgrimir en ese sentido. Sin embargo, los datos disponibles en la bibliografía, sumados a los generados en esta tesis que nos informan sobre un periodo de mucha aridez durante este momento, dan la pauta de que hay otras variables explicativas en juego. Asimismo, sólo como un punto de partida de análisis a futuro, podemos mencionar la sincronía de la erupción H1 del volcán Hudson con el inicio del vacío cronológico. Esta erupción que fue las más potente de este volcán (5 veces mayor que la del año 1991) y no se hallaron por el momento evidencias de que haya afectado al Macizo del Deseado, ya que al este de los Andes sólo se identificó en el Lago Cardiel.

Hipótesis 4: La dinámica social de los cazadores recolectores de la región se vio afectada por cambios ambientales ocurridos desde el Pleistoceno final, generando modificaciones en la presencia y características del registro arqueológico recuperado en las cuevas.

- El registro arqueológico de los sitios estudiados evidencia cambios en cuanto a tecnología y subsistencia en diferentes momentos. En este sentido, a partir del análisis de fechados radiocarbónicos realizado para el Macizo del Deseado, la Costa y la Cordillera, sumado a las 
características y composición de los conjuntos arqueológicos, podemos plantear que desde el inicio del Holoceno medio las condiciones tendientes a mayor aridez generaron cambios en las pautas de subsistencia de los cazadores recolectores. Esto llevo a un ajuste en las estrategias de explotación de la fauna que en AEP-1 y Cueva Maripe se expresan mediante la potenciación del recurso guanaco. Luego, las condiciones se tornan más áridas hasta llegar a un momento de stress ambiental como el ocurrido entre ca. 6900 y 6000 años ${ }^{14} \mathrm{C}$ AP, en el que los mallines y manantiales, principal fuente de agua de la región pierden productividad. Esta situación motivó a discontinuar la ocupación en la cuenca de los zanjones Blanco y Rojo, y posiblemente en todo el Macizo del Deseado, mientras que en el caso de la costa se reconocen las primeras ocupaciones del sector y en la cordillera se ocupan sectores que no tenían ocupaciones previas (véase Miotti y Salemme 2004). Entonces el Macizo del Deseado pudo pasar a ser un área de menor jerarquía, de paso o utilizada incursiones esporádicas. Luego de la ausencia de dataciones, comienza la reocupación del área ca. 5500 años ${ }^{14} \mathrm{C}$ AP próximo a los fechados en los que se establecen las condiciones climáticas actuales en la región.

Como corolario de este trabajo rescatamos el aporte realizado en cuanto a la metodología aplicada, y a una aproximación multiproxy como la que hemos llevado a cabo. La región del Macizo del Deseado adolece de análisis sistemáticos de proxies ambientales (el registro polínico es una excepción), y gran parte de ellos provienen de sitios en cuevas que proveen estratigrafías que permiten abordar lapsos temporales amplios. La inclusión de los mallines en este tipo de estudios es un avance en este sentido, dado que permiten contrastar la información proveniente de las cuevas y suministran un contexto de estudio directamente relacionado con la disponibilidad de agua en la región. Además la falta de estudios desde la Geología del Cuaternario para las problemáticas propias del Macizo del Deseado como pueden ser los modelos de drenaje de los cauces efímeros, o el estudio estratigráfico de lagunas secas con equipos de perforación acordes a estos sustratos, muestran un contexto de trabajo en el que avanzamos, pero en el que queda mucho por hacer. La aplicación de esta metodología, con el objetivo de homologar las muestras de perfiles sedimentarios y de proxies a escala del área de estudio, permitirán ajustar el grado de resolución temporal y espacial y así 
vincular con mayor detalle los eventos paleambientales y culturales acaecidos en la región. 


\section{Bibliografía}

A., Borrero L. 2015. "Con lo mínimo: los debates sobre el poblamiento de. América del Sur. Foro de Discusión." Intersecciones en Antropología 16:5-38.

Aguerre, A. 1987. "Investigaciones arqueológicas en el Area de La Martita, Departamento Magallanes, Provincia de Santa Cruz." Primeras Jornadas de Arqueología de la Patagonia, Serie Humanidades, 2:11-26.

Aguerre, A. 2003. Arqueología y paleoambiente en la Patagonia Santacruceña Argentina.

Alberdi, M. T. y J. L. Prado. 1993. "Review of the genus Hippidion Owen, 1869 (Mammalia: Perissodactyla) from the Pleistocene of South America." Zoological Journal of the Linnean Society, 108(1):1-22.

Alberdi, M. T., L. Miotti y J. L. Prado. 2001. "Hippidion saldiasi Roth, 1899 (Equidae, Perissodactyla), at the Piedra Museo Site (Santa Cruz, Argentina): Its implication for the regional economy and environmental reconstruction." Journal of Archaeological Science, 28(4):411-419.

Alexandre, A., J. D. Meunier, A. M. Lezine, A. Vincens y D. Schwartz. 1997. "Phytoliths: indicators of grassland dynamics during the late Holocene in intertropical Africa." Palaeogeography, Palaeoclimatology, Palaeoecology, 136(1):213-229.

Alonso, F., C. Gradín, C. Aschero y A. Aguerre. 1984-1985. “Algunas consideraciones sobre dataciones radiocarbónicas para el área del Río Pinturas." Relaciones de la Sociedad Argentina de Antropología, 16:275-285.

Ambrústolo, P., M. A. Zubimendi y C. Stern. 2012. “Explotación de obsidiana negra en la costa norte de Santa Cruz (Patagonia Argentina)." Cazadores Recolectores del Cono Sur, 13:409-421. 
Andreis, R. 2007. "Estudio composicional de los sedimentos de la Gruta del Indio, Rincón del Atuel, departamento de San Rafael, Mendoza." Revista de la Asociación Geológica Argentina, 62:30-34.

Antevs, E. 1952. "Arroyo-cutting and filling." The Journal of Geology, 6:375385.

Ariztegui, D., A. Gilli, F. S. Anselmetti y V. Markgraf. 2014. Limnogeología del Lago Cardiel y la reconstrucción de cambios ambientales desde el Pleistoceno tardío. En: Arqueología de los Lagos Cardiel y Strobel. POblamiento Humano y Paleoambientes en Patagonia., editado por R. Goñi, J. B. Belardi, G. Cassiodoro y A. Re. Editorial Aspha.

Aschero, C. 1975. “Ensayo para una clasificación morfológica de artefactos líticos aplicada a estudios tipológicos comparativos." Informe al CONICET. $M S$.

Aschero, C. 1987. Tradiciones culturales en la Patagonia Central-una perspectiva arqueológica. En: Comunicaciones 1ras. Jornadas de Arqueología de la Patagonia. Gobierno del Chubut, serie Humanidades. Vol. 2 pp. 17-33.

Aschero, C. 1996. El área Río Belgrano - Lago Posadas (Santa Cruz): problemas y estado de problemas. En: Arqueología: Solo Patagonia, editado por J. Gómez Otero. Puerto Madryn: Centro Nacional Patagónico (CONICET). pp. pp. 17-26.

Aschero, C. A. 1983. Arqueología del Chubut: el valle de Piedra Parada. Dirección Provincial de Cultura.

Aschero, C. A., C. Bellelli, M. T. Civalero, R. Goñi, A. G. Guraieb y R. Molinari. 1992. "Cronología y tecnología en el Parque Nacional Perito Moreno (PNPM): ¿Continuidad o reemplazos?" Arqueología, 2:89-106.

Aschero, C. A., D. Bozzuto, M. T. Civalero, M. De Nigris, A. Di Vruno, V. Dolce, N. Fernández y P. Limbrunner. 2009. El registro arqueológico de la costa noreste del Lago Pueyrredón-Cochrane (Santa Cruz, Argentina). En: Arqueología de la Patagonia. Una mirada desde el último confín, editado por M. Salemme, F. Santiago, M. Álvarez, E. Piana, M. Vázquez y E. Mansur. Vol. 2 Ushuaia, Editorial Utopías. pp. 919-926. 
Aschero, C. A., R. Goñi, M. T. Civalero, R. Molinari, S. L. Espinosa, A. G. Guraieb y C. Bellelli. 2005. "Holocenic Park: Arqueología del PNPM." Anales de la Administración de Parques Nacionales, 17:71-119.

Bamonte, F. P. y M. V. Mancini. 2009. Características ambientales del ecotono Bosque Estepa durante el Holoceno medio (Santa Cruz, Argentina). En: Arqueología de Patagonia: una mirada desde el último confín, editado por $\mathrm{F}$. M. Salemme, M Santiago, E. Alvarez, M. Piana, Vázquez y M. E. Mansur. Utopías, Ushuaia. pp. 881-892.

Bamonte, F. P. y M. V. Mancini. 2011. "Palaeoenvironmental changes since Pleistocene-Holocene transition: Pollen analysis from a wetland in southwestern Patagonia (Argentina)." Review of Palaeobotany and Palynology, 165(1):103-110.

Barberena, R. 2008. Arqueología y biogeografía humana en Patagonia meridional. Sociedad Argentina de Antropología.

Barberena, R. 2014. Discordancias y discontinuidades en Patagonia septentrional: Crono-estratigrafía de Cueva Huenul 1 (Neuquén, Argentina). En: Arqueología en ambientes de altura en Mendoza y San Juan. pp. 203-219.

Barberena, R., A. Blasi y C. Castiñeira. 2006. “Geoarqueología en Pali Aike: Cueva Orejas de Burro 1 (Patagonia, Argentina)." Magallania, 34(1):103122.

Barberena, R., A. Blasi y C. Castiñeira. 2007. Geoarqueología y Biogeografía: el registro de cuevas en Pali Aike. En: Arqueología de Fuego-Patagonia. Levantando piedras, desenterrando huesos... y develando arcanos., editado por F. Morello, M. Prieto y G. Bahamondes. Punta Arenas, Ediciones CEQUA.

Barboni, D., R. Bonnefille, A. Alexandre y J. D. Meunier. 1999. “Phytoliths as paleoenvironmental indicators, west side Middle Awash Valley, Ethiopia." Palaeogeography, Palaeoclimatology, Palaeoecology, 152(1):87-100.

Behrensmeyer, A. K. 1978. “Taphonomic and ecologic information from bone weathering." Paleobiology, 4:150-162.

Bellelli, C. 1991. Campo Moncada 2 (CM2): Momentos tempranos de ocupación del Valle de Piedra Parada (Chubut, República Argentina). En: Actas 
del X Congreso Nacional de Arqueología Chilena, Santiago de Chile. pp. 225235.

Binford, L. 1981. Bones: ancient men and modern myths. Academic Press.

Binford, L. R. 1980. "Willow smoke and dogs tails: hunter-gatherer settlements sistems and archaeological site formation." American Antiquity, 45(1):4-20.

Bird, J. 1938. "Antiquity and migrations of the early inhabitants of Patagonia." The Geographical Review, 28:250-275.

Bird, J. 1946. The archaelogy of Patagonia. En: Handbook of South American Indians. Vol. 1 Washington D. C. pp. 17-24.

Blanco, R. 2014. El arte rupestre en los macizos del Deseado y Somuncurá: la producción de grabados y pinturas entre cazadores-recolectores desde el Holoceno medio. Tesis doctoral FCNyM, Universidad Nacional de La Plata.

Blanco, R. V. y V. Lynch. 2011. “Experimentos replicativos de grabados en piedra. Implicancias en el arte rupestre de la localidad Arqueológica de Piedra Museo (Santa Cruz, Argentina)." Boletín Museo Chileno de Arte Precolombino, 16:9-21.

Blasi, A., C. Castiñeira Latorre, L. Del Puerto, A. Prieto, E. Fucks, C. De Francesco, P. Hanson, F. García-Rodriguez, R. Huarte, J. Carbonari y A. Young. 2010. “Paleoambientes de la Cuenca Media del Río Luján (Buenos Aires, Argentina) durante el Último Período Glacial (Eio 4-2)." Latin American Journal of Sedimentology and Basin Analysis, 17(2):85-111.

Blasi, A., J. Rabassa, R. Cattaneo y L. Miotti. 1997. Investigación geoarqueológica en la localidad Piedra Museo. En: Resúmenes XII Congreso Nacional de Arqueología Argentina.

Blasi, A. M. 1986. Sedimentología del río Colorado. Tesis doctoral FCNyM, Universidad Nacional de La Plata.

Blasi, A. M. 2008. “El aporte de la Geología en investigaciones arqueológicas multidisciplinarias e interdisciplinarias: casos de estudio." Terrae Didatica, 3(1):36-49. 
Blasi, A. M., G. Politis y C. Bayon. 2013a. “Environmental reconstruction of a La Olla, pre-ingressive early-middle Holocene archaeological site in the Pampean coast (Argentina)." Journal of Archeological Science, 40:1554-1567.

Blasi, A. M. y M. A. Zárate. 2002. Sedimentación y pedogénesis en un alero rocoso (Piedra Museo, Santa Cruz). En: IX Reunión Argentina de Sedimentología. Córdoba, 21, Mayo, 2002. Asociación Argentina de Sedimentología (AAS).Argentina. Bol. Resúmenes. Vol. 1 p. 81.

Blasi, Adriana, Gustavo Politis y Cristina Bayón. 2013b. "Palaeoenvironmental reconstruction of La Olla, a Holocene archaeological site in the Pampean coast (Argentina)." Journal of Archaeological Science, 40(3):15541567.

Blunier, T., J. Schwander, B. Stauffer, T. Stocker, A. Dallenbach, A. Indermuhle, J. Tschumi, J. Chappellaz, D. Raynaud y J. M. Barnola. 1997. “Timing of the Antarctic Cold Reversal and the atmospheric CO 2 increase with respect to the Younger Dryas event." Geophysical Research Letters, 24(21):26832686.

Borrero, L. A. 1984. "The archaeology of continental Patagonia." Trabajo presentado al 45th Annual Meeting of the Soviety for American Archaeology, Portland, .

Borrero, L. A. 1989. "Replanteo de la arqueología patagónica." Interciencia, XIV(3):127-135.

Borrero, L. A. 1989-1990. "Evolución cultural divergente en la Patagonia Austral." Anales del Instituto de la Patagonia, 19:133-140.

Borrero, L. A. 1994-95. "Arqueología de la Patagonia. Palimpsesto." Revista de Arqueología, 4:9-69.

Borrero, L. A. 2001. El poblamiento de la Patagonia: Toldos, milodones y volcanes. Emecé.

Borrero, L. A. 2009. The elusive evidence: The archaeological record of the South American extinct megafauna. En: American Megafaunal Extinctions at the end of the Pleistocene,, editado por G. Haynes. Springer Science pp. 145168. 
Borrero, L. A. 2011. "La función transdisciplinaria de la arqueozoología en el siglo XXI: restos animales y más allá." Antipoda. Revista de Antropología y Arqueología, 13:267-274.

Borrero, L.; Franco, N. 1997. "Early Patagonian hunter-gatherers: subsistence and technology." Journal of Anthropological Research, 53:219-239.

Borrero, L., R. Barberena, F. Martin, K. Borrazzo, M. Kornfeld, V. Sergey y L. Miotti. 2007. Collapsed rockshelters in Patagonia. En: On Shelter's Ledge: Histories, Theories and Methods of Rockshelter Research. BAR, International Series Oxford pp. 135-139.

Borromei, A. M. 2003. "Palynology at Piedra Museo locality, Santa Cruz Province, Argentina." Where the South Winds Blow, pp. 113-119.

Bourlot, T. 2010. Zooarqueología de sitios a cielo abierto en el lago Cardiel, Provincia de Santa Cruz: fragmentación ósea y consumo de grasa animal en grupos cazadores-recolectores del Holoceno tardío. Tesis doctoral FFyL, Universidad de Buenos Aires.

Bozzuto, D. L. 2011. Cazadores, lugares y movilidad en Patagonia. Análisis de conjuntos líticos de superficie en el norte del Lago PueyrredónCochrane, Argentina. En: Más allá de los chenques .. . Registro arqueológico a cielo abierto en la cuenca de los lagos Salitroso y Posadas Pueyrredón.

Bronk Ramsey, C. y S. Lee. 2013. "Recent and planned developments of the program OxCal." Radiocarbon, 55:3-4.

Brook, G. A., M. V. Mancini, N. V. Franco, F. Bamonte y P. Ambrústolo. 2013. "An examination of possible relationships between paleoenvironmental conditions during the Pleistocene-Holocene transition and human occupation of southern Patagonia (Argentina) east of the Andes, between $46^{\circ}$ and 52 ${ }^{\circ}$ S." Quaternary International, 305:104-118.

Brook, G. A., M. V. Mancini, N. V. Franco, F. Bamonte y P. Ambrústolo. 2014. "An examination of possible relationships between paleoenvironmental conditions during the Pleistocene-Holocene transition and human occupation of southern Patagonia (Argentina) east of the Andes, between $46^{\circ}$ and 52 S." Quaternary International, 305:104-118. 
Brook, G. A., N. V. Franco, P. Ambrústolo, M. V. Mancini, L. Wang y P. M. Fernandez. 2015. "Evidence of the earliest humans in the Southern Deseado Massif (Patagonia, Argentina), Mylodontidae, and changes in water availability." Quaternary International, 363:107-125.

Bull, W. B. 1997. "Discontinuous ephemeral streams." Geomorphology 19:227-276.

Butzer, Karl W. 1982. Archaeology as Human Ecology: Methods and Theory for a Contextual Approach. Cambridge: Cambridge University Press.

Cabrera, A. 1976. Regiones fitogeográficas argentinas. Vol. 1, Editorial Acme.

Cabrera, A. y J. Yepes. 1940. Mamíferos Sudamericanos. Vida, costumbres y descripción. Companía Argentina de Editors, Buenos Aires.

Cabrera, A. L. y A. Willink. 1980. Biogeografía de América latina. En: Programa regional de desarrollo científico y tecnológico-OEA, Washington.

Carden, N. 2008. Imágenes a través del tiempo: arte rupestre y construcción social del paisaje en la Meseta Central de Santa Cruz. Sociedad Argentina de Antropología.

Cardich, A. 1984/1985. “Una fecha radiocarbónica más de la cueva 3 de Los Toldos (Santa Cruz, Argentina)." Revista Relaciones de la Sociedad Argentina de Antropología, Nueva Serie, 16:269-273.

Cardich, A. 1987. "Arqueología de Los Toldos y El Ceibo (Provincia de Santa Cruz, Argentina)." Investigaciones Paleoindias al sur de la línea ecuatorial, Estudios Atacameños, 8:98-117.

Cardich, A., E. Mansur-Franchomme, M. Giesso y V. Durán. 1981-82. "Arqueología de las Cuevas de El Ceibo (Provincia de Santa CruzArgentina)." Relaciones de la Sociedad Argentina de Antropología, XIV(2):173209.

Cardich, A y L. Miotti. 1983. "Recursos faunísticos en la economía de los cazadores recolectores de Los Toldos (provincia de Santa Cruz, Argentina)." Revista Relaciones, pp. 147-157. 
Cardich, A. R., L. A. Cardich y A. Hajduk. 1973. “Secuencia arqueológica y cronológica radiocarbónica de la cueva 3 de Los Toldos (Santa Cruz, Argentina)." Relaciones de la Sociedad Argentina de Antropología, 7.

Cardich, A., R. S. Paunero y A. Castro. 1994. "Análisis de los conjuntos líticos de la Cueva 2 de Los Toldos (Santa Cruz, Argentina)." Anales del Instituto de la Patagonia, 22:149-173.

Cassiodoro, G. 2008. Movilidad y uso del espacio de cazadores-recolectores del Holoceno tardío: estudio de la variabilidad del registro tecnológico en distintos ambientes del noroeste de la provincia de Santa Cruz (Argentina). Tesis doctoral FFyL, Universidad de Buenos Aires.

Cassiodoro, G., A. Aragone y A. Re. 2004. Más allá de los chenques... Registro arqueológico a cielo abierto en la cuenca de los lagos Salitroso y Posadas Pueyrredón. En: Contra Viento y Marea. Arqueología de Patagonia, editado por M. T. Civalero, P. Fernández y A. G. Guraieb. pp. 325-328.

Cassiodoro, G. y S. García Guraieb. 2009. Análisis del registro tecnológico y osteológico de los entierros humanos del Holoceno tardío del lago Salitroso (Santa Cruz): un aporte al estudio del comportamiento mortuorio de cazadores-recolectores. En: Arqueología de Patagonia: una mirada desde el último confin, editado por M Salemme, F. Santiago, M. Álvarez, E. Piana, M. Vázquez y M. E. Mansur. Utopías, Ushuaia, pp. 613-628.

Castiñeira, C., A. M. Blasi, M. Bonomo, G. Politis y E. Apolinaire. 2014. "Modificación antrópica del paisaje durante el holoceno tardío: las construcciones monticulares en el delta superior del río Paraná." Revista de la Asociación Geológica Argentina, 71(1):33-47.

Castiñeira, C., M. Cardillo, J. Charlin y J. Baeza. 2012. “Exploring Morphometric Variations in Fishtail Porjectile Points from Urugay, Pampa, and Patagonia." Current Research in the Pleistocene, Special Edition, pp. 57-61.

Castro, A. y J. E. Moreno. 1996-1998. “Un sitio del Holoceno medio en la Costa Norte de Santa Cruz." Palimpsesto, 5:135-137.

Castro, A., J. E. Moreno, M. A. Andolfo, R. Giménez, C. Peña, L. Mazzitelli, M. A. Zubimendi y P. Ambrústolo. 2003. "Análisis distribucionales en la costa de Santa Cruz (Patagonia Argentina): alcances y resultados." Magallania, 31:69-94. 
Castro, A., J. E. Moreno, M. A. Zubimendi, M. A. Andolfo, B. Videla, P. Ambrústolo, L. Mazzitelli y S. Bogan. 2007. Cronología de la ocupación humana en la Costa Norte de Santa Cruz: Actualización de datos radiocarbónicos. En: Arqueología de Fuego-Patagonia. Levantando piedras, desenterrando huesos... y develando arcanos, editado por F. Morillo, M. Martinic, A. Prieto y G. Bahamonde. CEQUA, pp. 527-539.

Cattáneo, R. 2005. "Tecnología lítica en la localidad arqueológica Piedra Museo (Santa Cruz, Argentina)." Relaciones, 30:79-103.

Cattáneo, R. G. 2002. Una aproximación a la organización tecnología lítica entre los cazadores recolectores del holoceno medio/pleistoceno final en la Patagonia austral. Tesis doctoral FCNyM, Universidad Nacional de La Plata.

Chmura, G. L., P. A. Stone y M. S. Ross. 2006. "Non-pollen microfossils in Everglades sediments." Review of Palaeobotany and Palynology, 141:103-119.

Civalero, M. y M. De Nigris. 2005. “Explotación de fauna y tecnología lítica en Cerro Casa de Piedra 7 (Santa Cruz, Argentina)." Relaciones, XXX:105122.

Civalero, M. T. 2000. "Circulación, aprovechamiento de recursos líticos y estrategias de diseño en el sur patagónico." Arqueología, 10:135-152.

Civalero, M. T. y N. F. Franco. 2003. “Early Human Occupations at the West of Santa Cruz Province. Southern end of South America." Quaternary International, 109:77-86.

Codignotto, J. O. 1997. "Geomorfología y Dinámica Costera." El Mar Argentino y Sus Recursos Pesqueros. Instituto Nacional de Investigación y Desarrollo Pesquero, pp. 89-105.

Codignotto, J. O., R. R. Kokot y S. Marcomini. 1992. "Neotectonism and sealevel changes in the coastal zone of Argentina." Journal of Coastal Research, 8:125-133.

Colcutt, S. N. 1979. "The Analysis of Quaternary Cave Sediments." World Archaeology, 10:290-301. 
Coronato, A. y J. Rabassa. 2007. Late Quaternary glaciations in South America. En: Encyclopedia of quaternary science, editado por S. Elias. Vol. 2, Amsterdam. Elsevier pp. 1101-1108.

Coronato, A., M. Salemme y J. Rabassa. 1999. "Palaeoenvironmental conditions during the early peopling of Southernmost South America (Late glacial-Early Holocene, 14-8 ka BP)." Quaternary International, 53:77-92.

Courty, M., P. Goldberg y R. Macphail. 1989. Soils and Micromorphology in Archaeology. Cambridge University Press, Cambridge.

Criado Boado, F. 1999. "Del terreno al espacio: planteamientos y perspectivas para la arqueología del paisaje." CAPA, Grupo de Investigación en Arqueología, Universidad de Santiago de Compostela, (6):1-82.

Cruzate, G., L. González y J. Panigatti. 2007. “Mapa de Suelos y Ambientes. Santa Cruz, Argentina.".

De Barrio, R. 1993. “El vulcanismo ácido jurásico en el noroeste de Santa Cruz, Argentina." Actas XII Congreso Geológico Argentino IX, pp. 189-198.

De Giusto, J. M., C. A. Di Persia, E. Pezzi y J. Turner. 1980. “Nesocratón del Deseado." Geología Regional Argentina, 2:1389-1430.

De Nigris, M. E., M. J. Figuerero Torres, A. G. Guraieb y G. L. Mengoni Goñalons. 2004. Nuevos fechados radiocarbónicos en la localidad de Cerro de los Indios 1 (Santa Cruz) y su proyección areal. En: Contra viento y marea: arqueología de Patagonia., editado por M. T. Civalero, P. M. Fernández y A. G. Guraieb. INAPL, Buenos Aires. pp. 537-544.

De Porras, M. E. 2010. Dinámica de la vegetación de la Meseta Central de Santa Cruz durante los últimos 11.000 años a partir del análisis polínico: forzantes bióticos y abióticos. Tesis doctoral Facultad de Ciencias Exactas y Naturales- Universidad Nacional de Mar Del Plata, Mar del Plata.

De Porras, M. E., M. V. Mancini y A. R. Prieto. 2009. “Vegetation changes and human occupation in the Patagonian steppe, Argentina, during the late Holocene." Vegetation history and archaeobotany, 18(3):235-244.

Delcourt, H. R. y P. A. Delcourt. 1988. “Quaternary landscape ecology: Relevant scales in space and time." Landscape Ecology, 2(1):23-44. 
Dincauze, D. 2000. Environmental Archaeology. Principles and Practice. Cambridge: Cambridge University Press.

Durán, V. 1986/87. "Estudio tecno-tipológico de los raspadores del sitio El Verano, Cueva 1. Patagonia Centro Meridional, Santa Cruz, Argentina." Anales de Arqueología y Etnografía, Arqueología y Etnología Universidad Nacional de Cuyo, pp. 41-42, 129-163.

Durán, V. 1990. "Estudio tecno-tipológico de los raspadores del sitio El Verano. Cueva 1 (Área de La Martita), Provincia de Santa Cruz." Anales de Arqueología y Etnología, 41-42:129-163.

Durán, V., A. Gil, G. Neme y A. Gasco. 2003. El Verano: ocupaciones de 8900 años en la Cueva 1 (Santa Cruz, Argentina). En: Arqueología y Paleoambiente en la Patagonia Santacruceña Argentina:, editado por A. Aguerre. Buenos Aires, Ediciones del autor. pp. 93-120.

Erlandson, J. M. 2001. “The Archaeology of Aquatic Adaptations: Paradigms for a New Millennium." Journal of Archaeological Research, 9:287-350.

Espinosa, S. y R. Goñi. 1999. Viven: una fuente de obsidiana en la provincia de Santa Cruz. En: Soplando en el Viento. Actas de las Terceras Jornadas de Arqueología de la Patagonia. Vol. 1 Universidad Nacional del Comahue e Instituto Nacional de Antropología y Pensamiento Latinoamericano, Neuquén-Buenos Aires. pp. 177-188.

Etchichury, M. C. 1976. "Sedimentología de la Cueva de las Manos, estancia Alto río Pinturas (provincia de Santa Cruz)." Relaciones de la Sociedad Argentina de Antropología, X:251-260.

Eugenio, E. 1999. “Geoarqueología de la cueva de Las Buitreras (Provincia de Santa Cruz, Argentina)." Praehistoria, 3:135-147.

Farrand, W. R. 1985. "Rockshelter and cave sediments." Archaeological sediments in context, pp. 21-39.

Farrand, W. R. 1993. "Discontinuity in the stratigraphic record: snapshots from Franchthi Cave." Formation processes in archaeological context 17:85-96.

Favier Dubois, C. 1997. "Indicadores de tasas de depositación relativas en el registro arqueológico, su aplicación en sitios de Fuego Patagonia." Arqueología, pp. 51-75. 
Favier Dubois, C. 1998. “Dinámica sedimentaria y cambios ambientales en relación al registro arqueológico y tafonómico del Cerro Cabeza de León, Bahía San Sebastián (Tierra del Fuego, Argentina)." Anales del Instituto de la Patagonia, 26:137-152.

Favier Dubois, C. 2001. Análisis geoarqueológico de los procesos de formación del registro, cronología y paleoambientes en sitios arqueológicos de Fuego Patagonia Tesis doctoral FFyL, Universidad de Buenos Aires.

Favier Dubois, C. 2002. “Un suelo referible al periodo cálido medieval en Patagonia Austral y Tierra del Fuego (Argentina). Aspectos cronológicos y paleoclimáticos." Estudios Geológicos, 58:95-102.

Favier Dubois, C. 2003. "Late Holocene climatic fluctuations and soil genesis in southern Patagonia: effects on the archaeological record." Journal of ArchaeologicalScience, 30:1657-1664.

Favier Dubois, C. 2004. Fluctuaciones climáticas referibles al Período Cálido Medieval en Fuego-Patagonia. Indicadores indirectos y el aporte de modelos climáticos. En: En Contra Viento y Marea, Arqueología de Patagonia. Instituto Nacional de Antropología y Pensamiento Latinoamericano, Buenos Aires. pp. 545-556.

Favier Dubois, C. 2006. “Dinamica fluvial, paleoambientes y ocupaciones humanas en la localidad arqueológica Paso Otero, río Quequén Grande, provincia de Buenos Aires." Intersecciones en Antropología, (7):109-127.

Favier Dubois, C. 2009. "Valores de efecto reservorio marino para los últimos 5.000 años obtenidos en concheros de la costa atlántica norpatagónica (golfo San Matías, Argentina)." Magallania, 37(2):139-147.

Favier Dubois, C. 2014. ¿Quiénes y para qué hacemos geoarqueología en Latinoamérica? En: VII Reunión de Teoría Arqueológica de América del Sur (TAAS). Libro de resúmenes. San Felipe, Chile.

Favier Dubois, C.; Bonomo, M. 2008. “Geoarqueología en la Localidad Nutria Mansa (Pdos. De Gral. Alvarado y Lobería, Provincia de Buenos Aires)." Revista Comechingonia, 11:9-28. 
Favier Dubois, C. y F. Borella. 2007. "Consideraciones acerca de los procesos de formación de concheros en la costa Norte del golfo San Matías (Río Negro, Argentina)." Cazadores-recolectores del Cono sur, 2:151-165.

Favier Dubois, C. y F. L. Scartascini. 2012. "Intensive fishery scenarios on the North Patagonian coast (Río Negro, Argentina) during the MidHolocene." Quaternary International, 256:62-70.

Favier Dubois, C. y M. Bonomo. 2008. “Geoarqueología en la Localidad Nutria Mansa (Pdos. de Gral. Alvarado y Loberia, provincia de Buenos Aires)." Comechingonia, 11:9-28.

Favier Dubois, C. y R. Kokot. 2011. “Changing scenarios in Bajo de la Quinta (San Matías Gulf, Northern Patagonia, Argentina): Impact of geomorphologic processes in subsistence and human use of coastal habitats." Quaternary International, 245(1):103-110.

Fernández, M. 2013. Los paleoambientes de Patagonia meridional, Tierra del Fuego e Isla de los Estados en los tiempos de las primeras ocupaciones humanas Tesis doctoral FCNyM, Universidad Nacional de La Plata.

Fernández, M. M. 2001. "La Casa de Piedra de Ortega (Pcia. de Río Negro)." Relaciones de la Sociedad Argentina de Antropología, 26.

Fernández, P. M., M. Carballido Calatayud, C. Bellelli y M. Podestá. 2013. Tiempo de cazadores. Cronología de las ocupaciones humanas en el valle del río Manso inferior (Río Negro). En: Tendencias teórico-metodológicas y casos de estudio en la arqueología de Patagonia. MHNSR-SAA-INAPL Buenos Aires pp. 167-175.

Ferring, C. R. 1986. "Rates of Fluvial Sedimentation: Implications for Archaeological Variability." Geoarchaeology: An International journal, 1(3):259274 .

Feruglio, E. 1949. “Descripcion geologica de la Patagonia: direccion general de Yacimientos Petroliferos Fiscales, Buenos Aires." Coni, 1.

Figuerero Torres, M. y G. L. Mengoni Goñalons. 2007. Cronología del area de Monte Zeballos-Los Antiguos y Paso Roballos (Santa Cruz, Argentina). En: Resúmenes Extendidos XVI Congreso Nacional de Arqueología Argentina,. Number III pp. 371-372. 
Fitzhugh, B., S. C. Phillips y E. Gjesfjeld. 2011. Modeling Hunter-Gatherer Information Networks: An Archaeological Case Study from the Kuril Islands. En: Information and Its Role in Hunter-Gatherer Bands,, editado por A. L.; Hitchcock R. K. Whallon, R.; William. Ideas, Debates, and Perspectives 5, Cotsen Institute of Archaeology Press: Los Angeles. pp. 85-115.

Flegenheimer, N., L. Miotti y N. Mazzia. 2013. Rethinking early objects and landscape in the Southern Cone: Fishtail point concentrations in the Pampas and northern Patagonia. En: In Paleoamerican Odyssey,, editado por G. Kelly, C. Ketron y M. R. Waters. College Station: Center for the Study of First Americans, Texas A\&M University pp. 359-376.

Fletcher, M. y P. Moreno. 2012. "Have the Southern Westerlies changed in a zonally symmetric manner over the last 14,000 years. A hemisphere-wide take on a controversial problem." Quaternary International, 253:32-46.

Folk, R. 1954. "The distinction between grain size and mineral composition in sedimentary rock nomenclature." Journal of Geology, 62:344-359.

Folk, R. y W. Ward. 1957. "Brazos river bar: a study in the significance of grain size parameters." Journal of Sedimentary Petrology, 37(2):514-521.

Franco, N. 2002. “ ¿Es posible diferenciar los conjuntos líticos atribuídos a la exploración de un espacio de los correspondientes a otras etapas del poblamiento? El caso del extremo sur de Patagonia." Revista Werken, 3:119132.

Franco, N. V., N. Cirigliano, L. Vetrisano y P. Ambrústolo. 2015b. “Raw material circulation at broad scales in Southern Patagonia (Argentina): the cases of the Chico and Santa Cruz river basins." Quaternary International 375:72-83.

Franco, N. V., N. Cirigliano y P. Ambrústolo. 2011. Semejanzas en tecnologías, diseños y prácticas funerarias al sur de la cuenca superior del río Santa Cruz: algunos ejemplos correspondientes al Holoceno tardío. En: Bosques, Montañas y Cazadores. Investigaciones Arqueológicas en Patagonia Meridional, editado por L. A. Borrero y K. Borazzo. CONICET-IMHICIHU, Buenos Aires, pp. 155-178.

Franco, N. V., P. Ambrústolo, A. Acevedo, N. Cirigliano y M. Vommaro. 2013. Prospecciones en el sur del Macizo del Deseado (provincia de Santa 
Cruz). Los casos de La Gruta y Viuda Quenzana. En: Tendencias teóricometodológicas y casos de estudio en la Arqueología de la Patagonia. Museo de Historia Natural de San Rafael., editado por A. F. Zangrando, R. Barberena, A. Gil, G. Neme, M. Giardina, L. Luna, C. Otaola, S. Paulides, L. Salgán y A. Tívoli. Altuna Impresores, Buenos Aires, pp. 371-378.

Franco, N. V., P. Ambrústolo y L. Vetrisano. 2015a. “Materias primas líticas y su utilización en las cuencas de los ríos Chico y Santa Cruz (provincia de Santa Cruz, Patagonia argentina)." Intersecciones en Antropología 16:113123.

Frank, A. D. 2011. Tratamiento térmico y manejo del fuego en sociedades cazadoras-recolectoras de la Meseta Central de Santa Cruz. Tesis doctoral FCNyM, Universidad Nacional de La Plata.

García Añino, E., Marchionni L. y L. Miotti. 2014. The processing of guanaco in Extra-Andean Patagonia over time. En: Trabajo presentado en la $12^{\circ} \mathrm{ICAZ}$. San Rafael, Argentina.

García Guraieb, S. 2006. "Salud y enfermedad en cazadores recolectores del Holoceno tardío en la cuenca del lago Salitroso (Santa Cruz)." Intersecciones en Antropología, 7:37-48.

Giardina, M., D. Hermo, L. Miotti y M. Vásquez. 2000. “Resolución e integridad arqueológica del Componente Inferior de Piedra Museo." Taller Internacional del INQUA, pp. 81-87.

Gilli, A., D. Ariztegui, F. S. Anselmetti, J. A. McKenzie, V. Markgraf, I. Hajdas y R. D. McCulloch. 2005. "Mid-Holocene strengthening of the southern westerlies in South America sedimentological evidences from Lago Cardiel, Argentina (49 S)." Global and Planetary Change, 49(1):75-93.

Gilli, A., F. S. Anselmetti, D. Ariztegui, J. P. Bradbury, K. R. Kelts, V. Markgraf y J. A. Mckenzie. 2001. "Tracking abrupt climate change in the Southern Hemisphere: a seismic stratigraphic study of Lago Cardiel, Argentina (495)." Terra Nova, 13:443-448.

Gilli, A. P. 2003. Tracking late Quaternary environmental change in southernmost South America using lake sediments of Lago Cardiel (49 S), Patagonia, Argentina Tesis doctoral Doctoral dissertation, Eidgenossische Technische Hochschule ETH Zurich. 
Gladfelter, B. G. 1977. “Geoarchaeology: The geomorphologist and archaeology." American Antiquity, 42:519-538.

Gómez Otero, J. y C. Stern. 2005. “Circulación, intercambio y uso de obsidianas en la costa de la provincia del Chubut (Patagonia, Argentina) durante el Holoceno tardío." Intersecciones en Antropología, 6:93-108.

Goñi, R. 2010. Cambio climático y poblamiento humano durante el Holoceno tardío en Patagonia Meridional. Una perspectiva arqueológica. Tesis doctoral FFyL, Universidad de Buenos Aires.

Goñi, R. y G. Barrientos. 2004. Poblamiento tardío y movilidad en la cuenca del lago Salitroso. En: Contra Viento y Marea. Arqueología de Patagonia, editado por T. Civalero, P. Fernández y G. Guraieb. INAPL-SAA, Buenos Aires, pp. 313-324.

Goñi, R., G. Barrientos y G. Cassiodoro. 2000-02. “Condiciones previas a la extinción de las poblaciones humanas del sur de Patagonia: una discusión a partir del análisis del registro arqueológico de la cuenca del lago Salitroso." Cuadernos del Instituto Nacional de Antropología y Pensamiento Latinoamericano, 19:249-266.

Goñi, R., G. Barrientos, M. J. Figuerero, G. L. Mengoni, F. Mena, V. Lucero y O. Reyes. 2004. “Distribución Espacial de entierros en la cordillera de Patagonia centro-meridional (Lago Salitroso-Paso Roballos ARG/Entrada Baker-Río Chacabuco CH)." Chungará, 36:1101-1107.

Goñi, R., J. B. Belardi, G. Cassiodoro, D. Ridel, S. García Guraieb y T. Bourlot. 2014. Registro arquelógico y cronología de las ocupaciones cazadoras recolectoras en la cuenca del Lago Cardiel. En: Arqueología de las cuencas de los lagos Cardiel y Strobel. Poblamiento humano y paleoambientes en Patagonia., editado por R. Goñi, J. B. Belardi, G. Cassiodoro y A. Re. Aspha Ediciones.

Goldberg, P. y R. Macphail. 2006. Practical and Theoretical Geoarchaeology. Blackwell Publishing.

González Loyarte, M. 1995. “La diagonale aride argentine: une realite écologique oscillante." Sécheresse, 1(6):35-44.

Gradin, C. y A. Aguerre. 1994. Contribución a la Arqueología del Río Pinturas. Concepción del Uruguay: Ediciones Búsqueda de Ayllu. 
Gradin, C., C. Aschero y A. Aguerre. 1976a. "Investigaciones arqueológicas en la Cueva de Las Manos, Estancia Alto Río Pinturas (Provincia de Santa Cruz)." Relaciones de la Sociedad Argentina de Antropología, X:201-250.

Gradin, C., C. Aschero y A. Aguerre. 1976b. "Investigaciones arqueológicas en la Cueva de Las Manos, Estancia Alto Río Pinturas (Santa Cruz)." Relaciones, 10:201-250.

Gradín, C., C. Aschero y A. Aguerre. 1987. "Primeros niveles culturales en el área río Pinturas (Provincia de Santa Cruz, Argentina)." Estudios Atacameños, 8:118-141.

Grimm, E. C., S. Lozano García, H. Behling, V. Markgraf y V. Markgraf. 2001. "Holocene vegetation and climate variability in the Americas." Interhemispheric Climate Linkages. Academic Press, San Diego, pp. 325-370.

Guido, D., M. Escayola, R. de Barrio, I. Schalamuk y G. Franz. 2006. “La Formación Bajo Pobre (Jurásico) en el este del Macizo del Deseado, Patagonia: vinculación con el Grupo Bahía Laura." Revista de la Asociación Geológica Argentina, 61(2):187-196.

Gutiérrez, M. A. 2004. Análisis tafonómicos en el área Interserrana (provincia de Buenos Aires). Tesis doctoral FCNyM, Universidad Nacional de La Plata.

Gutiérrez, M. y G. Martínez. 2008. “Trends in the faunal human exploitation during the late Pleistocene and early Holocene in the Pampean region (Argentina)." Quaternary International, 191:53-68.

Haberzettl, T., H. Corbella, M. Fey, S. Janssen, A. Lücke, C. Mayr, C. Ohlendorf, F. Schäbitz, G. H. Schleser, M. Wille, S. Wulf y B. Zolitschka. 2007. "Lateglacial and Holocene wet-dry cycles in southern Patagonia: chronology, sedimentology and geochemistry of a lacustrine record from Laguna Potrok Aike, Argentina." The Holocene, 17(3):297-310.

Hajdas, I., G. Bonani, P. I. Moreno y D. Ariztegui. 2003. “Precise radiocarbon dating of Late Glacial cooling in mid-latitude South America." Quaternary Research, 59(1):70-78.

Hammond, H. y M. A. Zubimendi. 2013. Estudio de la composición de sitios concheros en la Costa Norte de Santa Cruz (Patagonia Argentina). 
En: Tendencias teórico metodológicas y casos de estudio en la Arqueología de la Patagonia, editado por A. F. Zangrando, R. Barberena, A. Gil, G. Neme, M. Giardino, L. Luna, C. Otaola, L. Paulides, L. Salgán y A. Tívoli. Altuna, Buenos Aires, pp. 405-415.

Harris, E. C. 1991. Principios de Estratigrafía Arqueológica. Editorial Crítica, Barcelona.

Hermo, D. 2008. Los cambios en la circulación de las materias primas líticas en ambientes mesetarios de Patagonia. Una aproximación para la construcción de los paisajes arqueológicos de las sociedades cazadorasrecolectoras Tesis doctoral FCNyM, Universidad Nacional de La Plata.

Hermo, D, E. Terranova y L. Miotti. 2015. “Tecnología y uso de materias primas en puntas cola de pescado de la Meseta de Somuncurá (Provincia de Río Negro, argentina)." Chungara, Revista de Antropología Chilena, 47(1):101-115.

Hermo, D. y L. Magnin. 2012. "Blade and bifacial technology in MidHolocene occupations at Deseado massif, Santa Cruz province, Argentina." Quaternary International, 256:71-77.

Hermo, D. y L. Miotti. 2011. La obsidiana en el Nesocraton del Deseado (Santa Cruz, Argentina): extractos de una oscura biografía. En: Biografías de paisajes y seres: visiones desde la arqueología sudamericana, Encuentro Grupo Editor. Facultad de Humanidades, Universidad Nacional de Catamarca. pp. 111131.

Hermo, D. y V. Lynch. 2015. “Core technology from Maripe Cave site (Santa Cruz, Argentina): Implications for rocks provisioning processes and lithic." Quaternary International, 375:135-144.

Hogg, A. G., Q. Hua, P. G. Blackwell, M. Niu, C. E. Buck, T. P. Guilderson, T. J. Heaton, J. G. Palmer, P. J. Reimer, R. W. Reimer, C. S. M. Turney y S. R. H. Zimmerman. 2013. "SHCal13 Southern Hemisphere calibration, 0-50,000 cal yr BP." Radiocarbon, 55(4):1889-1903.

Hoguin, R. y F. Restifo. 2012. “Middle Holocene archaeology: Dynamics of environmental and socio-cultural change in South America." Quaternary International, 256. 
Holliday, V. T., C. R. Ferring y P. Goldberg. 1993. The scale of soil investigations in archaeology. En: Effects of Scale on Archaeological and Geoscientific Perspectives, editado por J. K. Stein y A. R. Linse. Number 283 Geological Society of America, Boulder, Colo. pp. 29-37.

Horovitz, I. 2003. "Restos faunísticos de La Martita y nuevo registro biogeográfico de Lestodelphys halli (Didelphidae, Mammalia)." Arqueología y paleoambiente en la Patagonia Santacrucena Argentina, pp. 87-91.

Iantanos, N. 2004. Dinámica sedimentaria de la ría del Deseado, Provincia de Santa Cruz. Tesis doctoral inédita para optar al grado en doctor en geología FCN, Universidad Nacional de la Patagonia San Juan Bosco, Comodoro Rivadavia.

Johnson, Eileen, Vance T Holliday, Gustavo Martínez, María Gutiérrez y Gustavo Politis. 2012. “Geochronology and landscape development along the middle Río Quequén Grande at the Paso Otero locality, Pampa Interserrana, Argentina." Geoarchaeology, 27(4):300-323.

Karkanas, P., O. Bar-Yosef, P. Goldberg y S. Weiner. 2000. “Diagenesis in prehistoriccaves: the use of minerals that form in situ to assess the completeness of thearchaeological record." Journal of Archaeological Science, 27:915-929.

Kratzmann, David J, Steven Carey, Roberto A Scasso y Jose-Antonio Naranjo. 2010. "Role of cryptic amphibole crystallization in magma differentiation at Hudson volcano, Southern Volcanic Zone, Chile." Contributions to Mineralogy and Petrology 159(2):237-264.

Kuhn, S. L. 2004. “Upper Paleolithic raw material economies at Ucagizli cave, Turkey." Journal of Anthropological Archaeology, 23(4):431-448.

León, R. J. C., D. Bran, M. Collantes, J. M. Paruelo y Soriano. A. 1998. “Grandes unidades de vegetación de la Patagonia extra andina." Ecología Austral, 8:125-144.

Limaye, R. B., K. P. N. Kumaran, K. M. Nair y D. Padmalal. 2007. “Nonpollen palynomorphs as potential palaeoenvironmental indicators in the Late Quaternary sediments of the west coast of India." Current Science, 92(10):1370-1382. 
López González, F. y A. Grandal d'Anglade y J. R. Vidal-Romani. 2006. "Deciphering bone dopositational sequences in caves trought the study of manganese coatings." Journal of Archaeological Science, 33:707-717.

Lyman, R. L. 1994. “Quantitative units and terminology in zooarchaeology.” American Antiquity, 59:36-71.

Lynch, V. 2013. Análisis morfológico-funcional de raspadores líticos del sitio Cueva Maripe (Santa Cruz, Argentina). En: Tendencias teórico-metodológicas y casos de estudio en la arqueología de Patagonia, editado por F. Zangrando, R. Barberena, A. Gil, G. Neme, M. Giardina, L. Luna, C. Otaola, S. Paulides, L. Salgán y A. Tivoli. Buenos Aires: Sociedad Argentina de Antropología, Instituto Nacional de Antropología y Pensamiento Latinoamericano Museo de Historia Natural de San Rafael. pp. 406-416.

Lynch, V. 2014. Estudio comparativo de la producción y uso de artefactos líticos en el Macizo del Deseado (Santa Cruz, Argentina). Tesis doctoral FCNyM, Universidad Nacional de La Plata.

Lynch, V. y D. Hermo. 2015. "Evidence of hafting traces on lithics endscrapers at Maripe cave site (Santa Cruz, Argentina)." Lithic Technology, 40(1):68-79.

Lynch, V., D. Hermo y M. Álvarez. 2012. The use of the form: Functional analysis of lower component artifacts from Piedra Museo (Santa Cruz, Argentina). En: Southbound: Late Pleistocene Peopling of Latin America,, editado por L. Miotti, M. Salemme y Goebel T. Flegenheimer, N. Center for the Study of the First Americans, Texas A\&M University, College Station. pp. 133-37.

Lynch, V. y L. Miotti. 2015. “Morphological And Functional Variability On The Endscrapers In Cueva Maripe Site (Santa Cruz Province, Argentina)." Lithic Technology, p. En prensa.

Magnin, L. 2010. Distribuciones arqueológicas en la meseta central de Santa Cruz. Implicancias para los estudios de uso del espacio y movilidad de sociedades cazadoras recolectoras. Tesis doctoral FCNyM, Universidad Nacional de La Plata. 
Magnin, L. A. 2015. "Hunter-gatherer provisioning strategies in a landscape with abundant lithic resources (La Primavera, Santa Cruz, Argentina)." Quaternary International 375:55-71.

Magnin, L., D. Hermo y C. Weitzel. 2012. Aproximación a las estrategías dde caza en la localidad arqueológica de La Primavera, Santa Cruz (Argentina). Análisis de visibilidad y accesibilidad mediante el SIG. En: XIX Congreso Nacional de Arqueologia Chilena.Sociedad Chilena de Arqueología. Arica.

Magnin, L. y R. Blanco. 2006. Análisis espacial de artefactos líticos dentro de un conjunto de recolección superficial. Sitio arqueológico La Playita, Cañadón de La Primavera, Santa Cruz. En: Libro de Resúmenes de las VII Jornadas de Jóvenes Investigadores en Ciencias Antropológicas, Buenos Aires, Instituto Nacional de Antropología y Pensamiento Latinoamericano. pp. 46-47.

Maldonado, M. G., L. del Valle Neder, J. Roldán y M. M. SampietroVattuone. 2009. "Procesos de formación de sitios en el sector meridional de las Selvas Occidentales (sitio STucYeb 2 "Horco Molle", Yerba Buena, Tucumán, Argentina)." Anales de Arqueología y Etnología, .

Mancini, M. V. 1998. "Vegetational changes during the Holocene in Extra Andean Patagonia, Santa Cruz Province, Argentina." Palaeogeography, Palaeoclimatology, Palaeoecology, 138(1):207-219.

Mancini, M. V. 2002. "Vegetation and climate during the Holocene in Southwest Patagonia, Argentina." Review of Palaeobotany and Palynology, 122(3):101-115.

Mancini, M. V. 2009. "Holocene vegetation and climate changes from a peat pollen record of the forest steppe ecotone, Southwest of Patagonia (Argentina)." Quaternary Science Reviews, 28(15):1490-1497.

Mancini, M. V., A. R. Prieto, M. M. Paez y F. Schabitz. 2008. "Late Quaternary vegetation and climate of Patagonia." Late Cenozoic of Patagonia and Tierra del Fuego. Developments in Quaternary Sciences Elsevier. 11:351-367.

Mancini, M. V., M. M. Paez, A. R. Prieto, S. Stutz, M. Tonello y I. Vilanova. 2005. "Mid-Holocene climatic variability reconstruction from pollen records (32-52 S, Argentina)." Quaternary International, 132(1):47-59. 
Mancini, M. V. y M. Trivi de Mandri. 1994. Vegetación en el área del río Pinturas: análisis polínico del Alero Cárdenas. En: Contribución a la arqueología del río Pinturas, editado por C. J. Gradin y A. M. Aguerre. Utopías, Ushuaia, Concepción del Uruguay, pp. 48-62.

Mancini, M. V., N. V. Franco y G. A. Brook. 2013. "Palaeoenvironment and early human occupation of southernmost South America (South Patagonia, Argentina)." Quaternary International, 299:13-22.

Mansur Franchomme, M. E. 1983. Traces dŽutilisation et technologie lithique: exemples de la Patagonie. Tesis doctoral Tesis doctoral de la Universidad de Bordeaux I. Francia.

Marchionni, L. 2013. Comparación de las distintas historias tafonómicas en conjuntos zooarqueológicos provenientes de la Meseta Central de la provincia de Santa Cruz Tesis doctoral FCNyM, Universidad Nacional de La Plata.

Marchionni, L. 2014. “Taphonomic study in Argentinian Patagonia: analysis of variability through time and space in the Central Plateau (Santa Cruz Province)." Archaeological and Anthropological Sciences, pp. 1-15.

Marchionni, L. 2015. “Taphonomic study in Argentinian Patagonia: analysis of variability through time and space in the Central Plateau (Santa Cruz Province)." Archaeological and Anthropological Sciences, pp. 1-15.

Marchionni, L., B. Mosquera y E. García Añino. 2012. “Analysis of zooarchaelogical and taphonomical variability from Maripe Cave site, Santa Cruz province, argentinian Patagonia." Quaternary International, 278:1221.

Marchionni, L., L. Miotti y B. Mosquera. 2010. El uso de la fauna entre el Pleistoceno Final y el Holoceno medio en la Patagonia extra-andina. En: Zooarqueología a principio del S. XXI: aportes teóricos,metodológicos y casos de estudio, editado por M. De Nigris, P. M. Fernández, M. Giardina, A. F. Gil, M. A. Gutiérrez, A. I. Izeta, G. Neme y H. D. Yacobaccio. Ediciones del Espinillo, Malargüe, Mendoza. pp. 259-271.

Marchionni, L. y M. Vázquez. 2012. “New data on exploited Pleistocene fauna at Piedra Museo (central plateau of Santa Cruz Province, Argentina)." Curr Res Pleistocene, pp. 139-142. 
Markgraf, V., J. Bradbury, A. Schwalb, S. Burns, C. Stern, D. Ariztegui, A. Gilli, F. Anselmetti, S. Stine y N. Maidana. 2003. "Holocene palaeoclimates of southern Patagonia: limnological and environmental history of Lago Cardiel, Argentina." The Holocene, 13(4):581-591.

Martinez, G. A., D. L. Mazzanti, C. Quintana, A. Zucol, M. Colobig, G. S. Hassan, M. Brea y E. Passeggi. 2013. “Geoarchaeological and Paleoenvironmental context of the human settlement in the Eastern Tandilia Range, Argentina." Quaternary International, 299:23-37.

Mayewski, P.: Rohling, E., J. Stager, W. Karlén, K. Maasch, L. Meeker, E. Meyerson, F. Gasse, S. van Kreveld y K. Holmgren. 2004. "Holocene climate variability." Quaternary research, 62(3):243-255.

Mazzanti, DL, G Martínez, M de los M Colobig, AF Zucol, E Passeggi, M Brea, GF Bonnat, G Hassan, JL Soria, JA Vera et al. 2013. “Avances en los estudios arqueologicos, geoarqueologicos y paleoambientales en las Sierras Orientales de Tandilia. Resultados preliminares de los sitios Alero El Mirador y Abrigo La Grieta." Revista del Museo de La Plata, 13(87):59-76.

Mazzanti, DL.;, GA.; Martínez y CA. Quintana. 2015. “Asentamientos del Holoceno medio en Tandilia oriental. Aportes para el conocimiento de la dinámica poblacional de la región pampeana, Argentina." Relaciones de la Sociedad Argentina de Antropología, 40(1).

Mazzoni, E. 2001. Distribución espacial y caracterización geomorfológica de bajos sin salida de la Patagonia Austral Extracordillerana. En: Anales del Instituto de la Patagonia. Serie Ciencias Naturales. Vol. 29, pp. 5-24.

Mazzoni, E. y J. Rabassa. 2013. “Types and internal hydro-geomorphologic variability of mallines (wet-meadows) of Patagonia: Emphasis on volcanic plateaus." Journal of South American Earth Sciences, 46:170-182.

Mazzoni, E. y M. Vázquez. 2004. Ecosistemas de mallines y paisajes de la Patagonia Austral (Provincia de Santa Cruz). Buenos Aires: INTA.

Mazzoni, E., M. Vázquez y E. Ruiz Posse. 2002. "Dinámica geomorfológica de depósitos eólicos asociados a bajos sin salida de la Patagonia austral." Actas IV Jornadas Nacionales de Geografía Física. Universidad Nacional de Mar del Plata. Mar del Plata, pp. 165-176. 
McCulloch, R. D., C. J. Fogwill, D. E. Sugden, M. J. Bentley y P. W. Kubik. 2005. "Chronology of the last glaciation in central Strait of Magellan and Bahía Inútil, southernmost South America." Geografiska Annaler. Series A. Physical Geography, pp. 289-312.

McDonald, J. y P. Veth. 2011. Information Exchange amongst HunterGatherers of the Western Desert of Australia. En: Information and Its Role in Hunter-Gatherer Bands,, editado por A. L. H. R. K. Whallon, R.; William. Ideas, Debates, and Perspectives 5, Cotsen Institute of Archaeology Press, Los Ángeles. pp. 221-233.

Mehl, A. y N. Franco. 2009. Cambios en la morfología de los reparos rocosos: el caso de los sitios arqueológicos Chorrillo Malo 2 y Río Bote 1 (pcia. de Santa Cruz, Argentina). En: Arqueología de Patagonia: una mirada desde el último confin, editado por M. Salemme, F. Santiago, M. Álvarez, E. Piana, M Vazquez y M. Mansur. Number 2 Editorial Utopia pp. 893-900.

Menghin, O. 1957. "Estilos del arte rupestre de Patagonia." Acta Praehistorica, 1:57-87.

Mengoni Goñalons, G. L. 1976. “Los materiales oseos de la Cueva 2 de Los Toldos (Expedicion Menghin), y una aproximacion a la metodologia de analisis de restos faunisticos." Runa, 13(1-2):59-68.

Mengoni Goñalons, G. L. 1983. "Prehistoric utilization of faunal resources in arid Argentina." Animals and Archaeology: I. Hunter and their prey. British Archaeological Reports, 163:325-335.

Mengoni Goñalons, G. L. 1988. El Estudio de huellas en arqueofaunas. Una vía para reconstruir situaciones interactivas en contextos arqueológicos. Aspectos teóricos-metodológicos y técnicas de análisis. En: De procesos, contextos y otros huesos., editado por A. Haber y N. Ratto. Facultad de Filosofía y Letras, Universidad de Buenos Aires, pp. 17-28.

Mengoni Goñalons, G. L., M. J. Figuerero Torres, M. V. Fernández y P. V. Chávez. 2009. Carácter de las ocupaciones humanas en el área de Los Antiguos-Monte Zeballos y Paso Roballos (Santa Cruz, Argentina). En: Arqueología de Patagonia: una mirada desde el último confín, editado por M. Salemme, F. Santiago, M. Álvarez, E. Piana, M. Vázquez y M. E. Mansur. Ushuaia, Editorial Utopías. pp. 1061-1074. 
Miall, A. D. 2016. Facies Models. En: Stratigraphy: A Modern Synthesis. Springer pp. 161-214.

Miotti, L. 1992. "Paleoindian occupation at Piedra Museo Locality, Santa Cruz Province, Argentina." Current Research in the Pleistocene, 9:30-32.

Miotti, L. 1995. "Piedra Museo locality: a special place in the New World." Current Research in the Pleistocene, 12:37-40.

Miotti, L. 1996. "Piedra Museo (Santa Cruz), nuevos datos para la ocupación Pleistocénica en Patagonia." Actas de las Segundas Jornadas de la Arqueología de la Patagonia, pp. 27-38.

Miotti, L. 1998. “Zooarqueología de la meseta central y costa de Santa Cruz. Un enfoque de las estrategias adaptativas aborígenes y los paleoambientes." Revista del Museo de Historia Natural de San Rafael, 10(1/4):1-306.

Miotti, L. 2003. "South America. A paradox for building images of the colonization of the New World." Quaternary International, 109-110:147-173.

Miotti, L. 2006a. La fachada atlántica, como puerta de ingreso alternativa de la colonización humana de América del Sur durante la transición PleistocenoHoloceno. En: II Simposio Internacional El Hombre Temprano En América, editado por J. C. Jiménez y S. González. México, INAH, Museo del Desierto de Coahuila, UNAM. pp. 155-188.

Miotti, L. 2006b. "Paisajes domésticos y sagrados desde la arqueología de los cazadores-recolectores en el Macizo del Deseado, Provincia de Santa Cruz." Cazadores Recolectores del Cono Sur, pp. 13-42.

Miotti, L. 2008. "Household and sacred landscapes among Holocene huntergatherers of Patagonias Central Plateau." Before Farming, 3:5-44.

Miotti, L. 2010. Cuevas y abrigos rocosos: nudos de las redes sociales entre los cazadores-recolectores del Macizo del Deseado, Patagonia extraandina. En: III Simposio Internacional (2008) El Hombre Temprano en América,, editado por Jiménez. J. C., C. Serrano, A. González y F. Aguilar. UNAMInstituto de Investigaciones Antropológicas-INAH, México pp. 147-174.

Miotti, L. 2012. "El uso de los recursos faunísticos entre los cazadoresrecolectores de Patagonia: tendencias espacio/temporales de las estrate- 
gias durante el Holoceno." Archaeofauna: International Journal of archaeozoo$\log y_{,}(21): 137-160$.

Miotti, L., D. Hermo, E. Terranova y R. Blanco. 2015. “Edenes en el desierto. Señales de caminos y lugares en la historia de la colonización de Patagonia Argentina." Antípoda. Revista de Antropología y Arqueología, (23):161-185.

Miotti, L., D. Hermo, L. Magnin, N. Carden, L. Marchionni, A. Alcaráz, B. Mosquera, E. Terranova y Mónica Salemme. 2007. "Resolución e Integridad Arqueológica en la Cueva Maripe (Santa Cruz, Argentina)." Arqueología de Fuego-Patagonia: levantando piedras, desenterrando huesos y develando arcanos, Ediciones CEQUA. Punta Arenas, Chile, pp. 555-569.

Miotti, L. y E. Terranova. 2015. “A Hill Plenty of Points in Terra Incognita from Patagonia: Notes and Reflections for Discussing the Way and Tempo of the Initial Peopling." PaleoAmerica Maney publish, 1(2):181-196.

Miotti, L. y E. Tonni. 1996. Rheidos del sitio arqueológico AEP-1 de Piedra Museo y la meseta central de Santa Cruz y sus implicancias paleoambientales. En: Póster inédito presentado en las III Jornadas de Arqueología de Patagonia, Bariloche.

Miotti, L. y L. Marchionni. 2009. Procesando huesos: entre la Etnografía y la Arqueología. En: Arqueología de la Patagonia. Una mirada desde el confin del mundo, editado por M. Salemme, F. Santiago, M. Álvarez, E. Piana, M. Vázquez y M. Mansur. Editorial Utopía, Ushuaia pp. 787-799.

Miotti, L. y L. Marchionni. 2011. "The study of archaeofauna at middle Holocene in AEP-1 rockshelter, Santa Cruz, Argentina: Taphonomic implications." Quaternary International, 245(1):148-158.

Miotti, L. y L. Marchionni. 2014. "Autopodios de guanacos en sitios arqueológicos: equifinalidad entre lo palatable y lo preservado." Revista Chilena de Antropología, 29(1):122-129.

Miotti, L., L. Marchionni, B. Mosquera, D. Hermo y A. Ceraso. 2014. “Fechados radiocarbónicos y delimitación temporal de los conjuntos arqueológicos de Cueva Maripe, Santa Cruz (Argentina)." Relaciones de la Sociedad Argentina de Antropología, 39:509-537. 
Miotti, L., M. Osterrieth, L. Marchioni, R. Blanco y J. Rabassa. 2008. First contributions of Phytolithic studies to the paleoenvironmental recostruction of the maripe Cave Site, Santa Cruz. En: 7thInternational Meeting of Phytolith research, 4th Southamerican Meeting on Phytolith research. Libro de resúmenes. Mar del Plata, Universidad Nacional de Mar del Plata,, editado por M. Osterrieth, M. Fernández Honaine y N. Borrelli. pp. 69-70.

Miotti, L. y M. Salemme. 1999. “Biodiversity, taxonomic richness and specialists-generalists during late Pleistocene early Holocene times in Pampa and Patagonia (Argentina, southern South America)." Quaternary International, 53:53-68.

Miotti, L. y M. Salemme. 2004. "Poblamiento, movilidad y territorios entre las sociedades cazadoras recolectoras de Patagonia." Complutum, 15:177206.

Miotti, L. y M. Salemme. 2005. Hunting and butchering events at the Pleistocene/Holocene transition in Piedra Museo: an example of adaptation strategies of the first colonizers of Patagonia. En: Paleoamerican origins: beyond Clovis, editado por R. Bonnichsen. Center for the Studies of first Americans-Texas A\&M University Press, College Station pp. 209-220.

Miotti, L., M. Salemme y A. Menegaz. 1988. El manejo de los recursos faunísticos durante el Pleistoceno final y Holoceno temprano en Pampa y Patagonia. En: Actas del IX Congreso Nacional de Arqueología Argentina. Instituto de Ciencias Antropológicas, Facultad de Filosofía y Letras- UBA, Buenos Aires. pp. 102-118.

Miotti, L., M. Salemme, D. Hermo, M. Vázquez, N. Carden, M. Giardina y L. Magnin. 2005. Aguada del Cuero, un nuevo escalón en la arqueología de la Meseta Central de Santa Cruz. En: Actas XIII Congreso Nacional de Arqueología Argentina, editado por E. Berberián. Vol. 4 Universidad Nacional de Córdoba, Córdoba. pp. 55-62.

Miotti, L., M. Salemme y J. Rabassa. 2000. Cronología radiocarbónica. En: Guía de Campo de la visita a las Localidades arqueológicas. Taller Internacional La colonización del Sur de América durante la transición Pleistoceno/Holoceno," editado por L. Miotti, R. Paunero, M. Salemme y R. Cattáneo. Servicoop, La Plata. pp. 83-85. 
Miotti, L., M. Salemme y J. Rabassa. 2003. "Radiocarbon chronology at Piedra Museo locality." Where the south winds blow, pp. 99-104.

Miotti, L., M. Vázquez y D. Hermo. 1999. “Piedra Museo: un yamnagoo pleistocénico de los colonizadores de la meseta de Santa Cruz. El estudio de la arqueofauna." Actas de las III Jornadas de Arqueología de la Patagonia, pp. 113-136.

Miotti, L. y R. Cattáneo. 2003. Pleistocene/Holocene transition at Piedra Museo and surrounding region. En: Where the south winds blow: ancient evidence of paleo South Americans., editado por L. Miotti, M. Salemme y N. Flegenheimer. Center for the Studies of the First Americans- Texas A\&M University Press, Texas. pp. 105-113.

Moreno, E. y A. Castro. 1995. "Sitio Moreno: Datos preliminares de un sitio chico en la Costa Norte de Santa Cruz, Argentina." Anales del Instituto de la Patagonia (Serie Ciencias Humanas), 23:143-149.

Moreno, E. y B. Videla. 2008. "Rastreando ausencias: la hipótesis del abandono del uso de los recursos marinos en el momento ecuestre en la Patagonia continental." Magallania, 36(2):91-104.

Moreno, J. E. 2008. Arqueología y etnohistoria de la Costa Patagónica Central en el Holoceno Tardío. Fondo Editorial Provincial, Secretaría de Cultura del Chubut.

Mosquera, B. 2014. Análisis geoarqueológico del sitio cueva Maripe, Macizo del Deseado (Santa Cruz, Argentina). En: Entre pasados y presentes IV. Estudios contemporáneos en ciencias antropológicas., editado por A. Castro Esnal, M. L. Funes, G. Grosso, N. Kuperszmit, A. Murgo y G. Romero. Buenos Aires, AINA. pp. 641-660.

Mosquera, B. 2015. "Geoarqueología del sitio Cueva Maripe, Macizo del Deseado, provincia de Santa Cruz." Comechingonia, 19(1):155-182.

Mosquera, B. y C. Castiñeira. 2014. La Georqueología en Actas. Aportes en el desarrollo de las investigaciones del cuaternario en los últimos 20 años en Argentina. En: VII Reunión de Teoría Arqueológica de América del Sur (VII TAAS) desarrollado en la ciudad de San Felipe (Chile) del 6 al 10 de octubre de 2014, tuvo lugar el Simposio Teoría y práctica de la geoarqueología en Latinoamérica. 
Naranjo, J. A. y C. R. Stern. 1998. "Holocene explosive activity of the Hudson volcano, southern Andes." Bulletin of Volcanology, 59:291-306.

Nash, D. T. y M. D. Petraglia. 1987. Natural formation processes and the archaeological record. Vol. 352 BAR.

O Connor, T. 2000. The Archaeology of Animal Bones. Sutton Publishing, Great Britain.

Ogg, J. 2008. "Request for IUGS Ratification of the GSSP defining the base of the Holocene Series/Epoch of the Quaternary System/Period.".

Oliva, G., L. González y P. Rial. 2001. El ambiente en la Patagonia Austral. En: Ganadería sustentable en la Patagonia Austral, editado por P. Borrelli y G. Oliva. INTA, pp. 17-80.

Orquera, L. A. 1984-85. “Tradiciones culturales y evolución en Patagonia." Relaciones de Sociedad Argentina de Antropología, 16:249-267.

Orquera, L. A. 1999. Acerca de tendencias temporales en la arqueología de Patagonia. En: Actas de las Terceras Jornadas de Arqueología de la Patagonia. Bariloche, Neuquén. pp. 515-522.

Osterrieth, M. 2000. "Silicofitolitos una herramienta para la comprensión de procesos pedológicos del Cuaternario." Actas XVII Cong. Arg. de la Ciencia del Suelo, 21.

Osterrieth, M., B. Mosquera, M. Fernandez Honaine, L. MIotti, J. Rabassa, L. Marchionni, Blanco. R. y G. Erra. 2015. "Analsis de fitolitos de Cueva Maripe y Mallín La Primavera: Inferencias paleoambientales. Ms.".

Osterrieth, M. L. 2006. Ciclo biogeoquimico del Silicio: Biomineralizaciones silíceas. En: Medioambiente en Iberoamérica II, editado por J. Gallardo Lancho. pp. 583-590.

Paez, M. M., A. R. Prieto y M. V. Mancini. 1999. “Fossil pollen from Los Toldos locality: a record of the Late glacial transition in the Extra Andean Patagonia." Quaternary International, 53:69-75.

Pankhurst, R., C. Rapela y M. Márquez. 1993. "Geocronología y petrogénesis de los granitoides jurásicos del noreste del Macizo del Deseado." Actas del XII Congreso Geológico Argentino, 4:134-141. 
Panza, J., C Náñez y N. Malumian. 1998. Afloramientos y foraminíferos eocenos en el Macizo del Deseado, Provincia de Santa Cruz. En: Paleógeno de América del Sur y de la Península Antartica, editado por S. Casadío. Vol. 5 Asociación Paleontológica Argentina, Publicación Especial pp. 95-107.

Panza, J., G. Náñez, N. Malumian y S. Casadío. 1996. “Afloramientos y foraminíferos eocenos en el Macizo del Deseado, Provincia de Santa Cruz." Ameghiniana, 33:231.

Panza, J. L. 1982. “Descripción geológica de las hojas 53e Gobernador Moyano y 54e Cerro Vanguardia. Servicio Geológico Nacional, 197 págs. Inédito. Buenos Aires.".

Panza, J. L. 2001. Hoja Geológica 4769-IV Monumento Natural Bosques Petrificados 1:250.000. Provincia de Santa Cruz. SEGEMAR.

Paruelo, J., A. Beltran, E. Jobbagy, O. E. Sala y R. A. Golluscio. 1998. “The climate of Patagonia: general patterns and controls on biotic." Ecología Austral, 8:85-101.

Paruelo, J. M.M., R. A. Golluscio, E. G. Jobbágy, M. Canevari, M. R. Aguiar, A. Brown, U. Martínez Ortiz, M. Acerbi y J. Corcuera. 2005. “Situación ambiental en la estepa patagónica." La situación ambiental Argentina, pp. 302320.

Paunero, R. 2000. "Localidad arqueológica Cerro Tres Tetas." Guía de Campo de la Visita a las Localidades Arqueológicas, pp. 89-100.

Paunero, R. 2003. The presence of a Pleistocenic colonizing culture in La Maria archaeological locality: Casa del Minero 1. En: Where the South Winds Blow: Ancient Evidence of Paleo South Americans, editado por L. Miotti, M. Salemme y N. Flegenheimer. pp. 127-132.

Paunero, R. 2010. La extinción de Hippidion saldiasi y su relación con el paleoambiente y los grupos humanos que colonizaron Patagonia. Nuevos datos provenientes de Cerro Bombero, Santa Cruz. En: Zooarqueología a principios del Siglo XXI: Aportes teóricos, metodológicos y casos de estudio. Ediciones del Espinillo, Buenos Aires pp. 297-306.

Paunero, R. S. 2009. La Colonización Humana de La Meseta Central de Santa Cruz durante el Pleistoceno Final: indicadores arqueológicos, referentes 
estratigráficos y nuevas evidencias. En: Arqueología de Patagonia: una mirada desde el último confin ,, editado por F.; Álvarez M.; Piana E.; Vázquez M.; Mansur M. E. Salemme, M. C.; Santiago. Vol. 1 Editorial Utopías Ushuaia pp. 85-100.

Paunero, R. S. y A. M. Blasi. 2009. “Geoarqueología de la Cueva 2 Los Toldos, Santa Cruz, Argentina." IV Congreso de Geomorfología y Geología del Cuaternario. La Plata, .

Paunero, R. S., G. Rosales, J. L. Prado y M. T. Alberdi. 2008. “Cerro Bombero: registro de Hippidion saldiasi Roth, 1899 (Equidae, Perissodactyla) en el Holoceno temprano de Patagonia (Santa Cruz, Argentina)." Estudios Geológicos, 64(1):89-98.

Paunero, R. S., P. Albertengo, M. Cueto, A. Dávila, A. Frank, A. Olivera y C. Piva. 2007. Sitio Casa del Minero 1, localidad arqueológica La María: nuevas evidencias sobre ocupación humana pleistocénica en Santa Cruz. En: Arqueología Argentina en los inicios de un nuevo siglo, editado por F. Oliva. Laborde Editor. pp. 337-344.

Politis, G. 1984. Arqueología del área Interserrana Bonaerense. Tesis doctoral Tesis doctoral inédita de la Facultad de Ciencias Naturales- Universidad Nacional de La Plata.

Politis, G. y P. G. Messineo. 2008. “The Campo Laborde site: New evidence for the Holocene survival of Pleistocene megafauna in the Argentine Pampas." Cuaternary International, 191:98-114.

Ponce, J. F., J. Rabassa, A. Coronato y A. Borromei. 2011. “Palaeogeographical evolution of the Atlantic coast of Pampa and Patagonia from the last glacial maximum to the Middle Holocene." Biological Journal of the Linnean Society, 103(2):363-379.

Powers, M. C. 1953. "A new roundness scale for sedimentary particles." Journal of Sedimentary Petrology 23:117-119.

Prates, L.; Politis, G.; Steele J. 2013. "Radiocarbon chronology of the early human occupation of Argentina." Quaternary International, 301:104-122. 
Prieto, A., C. R. Stern y J. E. Estévez. 2013. “The peopling of the FuegoPatagonian fjords by littoral huntere gatherers after the mid-Holocene $\mathrm{H} 1$ eruption of Hudson Volcano." Quaternary International, 317:3-13.

Rabassa, J. 1987. The Holocene of Argentina: a review. En: Quaternary of South America and Antarctic Peninsula. Vol. 5, pp. 269-290.

Rabassa, J., C. J. Heusser y N. Rutter. 1989. "Late Glacial and Holocene of Argentine Tierra del Fuego." Quaternary of South America and Antarctic Peninsula, 7:327-351.

Rabassa, J., L. Miotti, R. Blanco, L. Marchionni y M. Salemme. 2007. “Informe decampaña arqueológica Cueva Maripe. Ms.".

Raedecke, K. 1978. El guanaco de Magallanes, Chile. Su distribución y biología. En: Corporación Nacional Forestal. Publicación Técnica $N^{\circ} 4$. Ministerio de Agricultura, Chile.

Rapp, G. Jr. y C. Hill. 1998. Geoarchaeology. The Earth-science Approach to Archaeological Interpretation. Yale.

Re, A., R. Goñi, J. B. Belardi y F. Guichón. 2010. Evidencias de contacto en el arte rupestre de la Meseta del Strobel (Patagonia austral argentina),. En: Global Rock Art. Anais do Congresso Internacional de Arte Rupestre IFRAO. Fundhamentos IX (1) Piauí (Brasil), Fundação Museu do Homen Americano. CD-Rom,. Vol. 97 Artigo pp. 1319-1330.

Renfrew, C. 1976. Archaeology and the earth sciences. En: Geoarchaeology: Earth Science and the Past., editado por D. A. Davidson y M. L. Shackley. Duckworth, London pp. 1-5.

Rindel, D. 2004. Patrones de procesamiento faunístico en el sitio Alero Destacamento Guardaparque durante el Holoceno medio. En: Contra viento y marea. Arqueología de la Patagonia., editado por Fernández P. Civalero, M. T. y A. G. Guráieb. Buenos Aires, SAA y AINA. pp. 263-276.

Roig, F. A. 1998. La vegetación de la Patagonia. En: Colección Científica INTA. Vol. 1.

Rovner, I. 1971. "Potential of opal phytoliths for use in paleoecological reconstruction." Quaternary Research, 1:343-359. 
Rubin de Rubin, J. 2013. "Algunos Desafíos a la Arqueologia y la Geoarqueologiafrente los Procesos Naturales y Antropogénicos." Conferencia en I Taller de Suelos en Arqueología. Grupo de estudios Geoarqueológicos de América Latina, .

Rubinos Pérez, A. 2003. Recopilación y análisis de las fechas Carbono-14 del Norte de Santa Cruz. En: Arqueología y Paleoambiente en la Patagonia Santacruceña Argentina, editado por A. Aguerre. pp. 1-25.

Sahu, B. K. 1964. "Depositional mechanisms from the size analysis of clastic sediments." Journal of Sedimentary Research, 34(1):73-83.

Salemme, M. C. y L. Miotti. 1987. Zooarchaeology and palaeoenvironments: some examples from the Patagonian and Pampean regions (Argentina). En: INQUA international congress. pp. 33-57.

Salemme, M. y L. Miotti. 2008. Archeological hunter-gatherer landscapes since the latest Pleistocene in Fuego-Patagonia. En: The late cenozoic of $\mathrm{Pa}-$ tagonia and Tierra del Fuego, editado por J. Rabassa. Elsevier Nueva York pp. 437-483.

Sampietro, M. M. 2001. “Geoambientes y sitios arqueológicos formativos en el valle de Tafí (Noroeste-República Argentina)." Cuadernos del Instituto de Antropología y Pensamiento Latinoamericano, 19:599-611.

Sampietro, M. M. 2010. Espacio, ambiente y los inicios de la agricultura indígena en el Noroeste argentino: Un enfoque geoarqueológico. JAS Arqueología.

Sampietro, M. M. y J. M. Sayago. 1996. “Aproximación Geoarqueológica al conocimiento del sitio arqueológico Río Blanco", valle de Tafí, Tucumán (Argentina)." Cuadernos del Instituto Nacional de Antropología y Pensamiento Latinoamericano, 17:257-273.

Sanguinetti, A. 1976. "Excavaciones prehistóricas en la cueva de Las Buitreras (provincia de Santa Cruz)." Relaciones de la Sociedad Argentina de Antropología, pp. 271-292.

Scasso, R. y E. Eugenio. 1999. "Estudio sedimentológico de la cueva Las Buitreras (Provincia de Santa Cruz, Argentina)." Praehistoria, 3:147-161. 
Schabitz, F., M. M. Paez, M. V. Mancini, F. Quintana, M. Wille, H. Corbella, T. Haberzettl, A. Lucke, A. R. Prieto, N. Maidana, C. Mayr, C. Ohlendorf, G. H. Scheleser y B. Zolitschka. 2003. “Estudios paleoambientales en lagos volcánicos en la Región Volcánica de Pali Aike, sur de Patagonia (Argentina): palinología." Revista del Museo Argentino de Ciencias Naturales Nueva Serie 5:301-316.

Schellmann, G. y U. Radtke. 2010. “Timing and magnitude of Holocene sea-level changes along the middle and south Patagonian Atlantic coast derived from beach ridge systems, littoral terraces and valley-mouth terraces." Earth-Science Reviews, 103(1):1-30.

Schumm, S. A. 1977. The Fluvial System. John Wiley and Sons, Inc., New York.

Shakun, J. y A. Carlson. 2010. "A global perspective on Last Glacial Maximum to Holocene climate change." Quaternary Science Reviews, 29(15):1801-1816.

Skarbun, F. 2011. La organización tecnológica en grupos cazadores recolectores desde las ocupaciones del Pleistoceno final al Holoceno tardio, en la Meseta Central de Santa Cruz, Patagonia. BAR International Series 2307. Archaeopress. Publish of British Archaeological Reports, Oxford.

Skarbun, F. y A. D. Frank. 2011. “Organización espacial intrasitio durante el pleistoceno final en la meseta central de Santa Cruz." Relaciones de la Sociedad Argentina de Antropología, 36.

Skarbun, F. y G. Páez. 2012. “Análisis de secciones delgadas de materias primas provenientes de la Localidad Arqueológica La María, Meseta Central de Santa Cruz, Argentina." Comechingonia, 16:247-260.

Soriano, A., C. P. Movia y R. J. C. León. 1983. Deserts and semideserts of Patagonia: Vegetation. En: Temperate Deserts and Semi-deserts., editado por N. E. West. Elsevier, Amsterdam pp. 423-460.

Sottile, G., F. Bamonte y Mancini M. y M. Bianchi. 2012. "Insights into Holocene vegetation and climate changes at the southeast of the Andes: Nothofagus forest and Patagonian steppe fire records." The Holocene, 22(11:):1309-1322. 
Spalletti, L. A. y M. M. Mazzoni. 1975. “Estudio sedimentológico de la cueva de Los Toldos, Pcia. de Santa Cruz." Revista Asociación Argentina Mineralogía, Petrología y Sedimentología, 5:18-26.

Spalletti, L. A. y M. Mazzoni. 1972. “Paleocorrientes del Miembro Medio de la Formación Yacimiento Los Reyunos, Sierra Pintada, Pcia. de Mendoza, República Argentina." Revista de la Asociacion Argentina de Mineralogia, Petrologia y Sedimentologia, 3:77-90.

Staubwasser, M: Weiss y H. 2006. "Holocene climate and cultural evolution in late prehistoric-early historic West Asia." Quaternary Research, 66(3):372-387.

Steele, J.; Politis, G. 2009. "AMS 14 C dating of early human occupation of southern South America." Journal of Archaeological Science, 36(2):419-429.

Stein, J. K. 1985. Archaeological sediments in context. Vol. 1 Center for the Study of the First.

Stein, J. K. 1990. "Archaeological stratigraphy." Archaeological Geology of North America, Geological Society of North America, Centennial Special, 4:513523.

Stein, J. K. 1992. "Organic matter in archaeological contexts." Soils in Archaeology, pp. 193-216.

Stein, J. K., J. N. Deo y L. S. Phillips. 2003. "Big sites-short time: accumulation rates in archaeological sites." Journal of Archaeological Science, 30(3):297-316.

Stein, J. K. y W. R. Farrand. 1985. Context and geoarchaeology: An introduction. En: Archaeological Sediments in Context. Peopling of the Americas,, editado por J. Stein y W. Farrand. Vol. 1 Center for the Sutdy of Early Man Institute for Quaternary Studies, University of Maine at Orono, U.S.A, pp. 1-3.

Stern, C. 1999. Black obsidian from central-south Patagonia: chemical characteristics, sources and regional distribution of artifacts. En: Soplando en el viento. Actas de las III Jornadas de Arqueología de la Patagonia. pp. 221-234.

Stern, C. R. 2004. "Active Andean volcanism: its geologic and tectonic setting." Revista geológica de Chile, 31(2):161-206. 
Stern, C. R. 2008. "Holocene tephrochronology record of large explosive eruptions in the southernmost Patagonian Andes." Bulletin of Volcanology, 70(4):435-454.

Stine, S. 1994. "Extreme and persistent drought in California and Patagonia during mediaeval time." Nature, 369(6481):546-549.

Stine, S. 2000. "On the Medieval Climatic Anomaly." Current Anthropology, 41(4):627-628.

Stine, S. y M. Stine. 1990. "A Record from Lake Cardiel of Climate Change in Southern South America." Nature, 345(6277):705-707.

Sugden, D., M. Bentley, C. Fogwill, N. Hulton, R. McCulloch y R. Purves. 2005. "Late glacial glacier events in southernmost south america: a blend of northern and southern hemispheric climatic signals." Geografiska Annaler: Series A, Physical Geography, 87(2):273-288.

Tambussi, C. y E. P. Tonni. 1985. “Aves del sitio Arqueológico Los Toldos, cañadón de las Cuevas, Provincia de Santa Cruz (República Argentina)." Ameghiniana, 22(1-2):69-74.

Torres Elgueta, J. 2009. Bolas líticas y sus procesos de manufactura, en contextos de cazadores recolectores terrestres del norte de Tierra del Fuego. Evidencias desde el Holoceno Medio hasta 1500 años AP. En: Arqueología de la Patagonia, Una Mirada desde el último confín., editado por M. Salemme, F. Santiago, M. Álvarez, E. Piana, M. Vázquez y M. E. Mansu. Vol. 1 Editorial Utopías. Ushuaia. pp. 393-412.

Triveri, F. 2008. “La región del volcán Hudson, luego de la erupción de 1991.".

URL: $\quad$ http://blog.nuestroclima.com/blog/2008/05/15/la-region-del-volcanhudson-luego-de-la-erupcion-de-1991/

Twiss, P. C., E. Suess y R. M. Smith. 1969. "Morphological classification of grass phytoliths." Soil Science Society of America Journal, 33(1):109-115.

Velázquez, N. J., L. S. Burry, M. V. Mancini y M. H. Fugassa. 2010. “Coprolitos de camélidos del Holoceno como indicadores paleoambientales." Magallania, 38(2):213-229. 
Walker, M. J. C., M. Berkelhammer, S. Bjorck, L. C. Cwynar, D. A. Fisher, A. J. Long, J. J. Lowe, R. M. Newnham, S. O. Rasmussen y H. Weiss. 2012. "Formal subdivision of the Holocene Series, Epoch: a Discussion Paper by a Working Group of INTIMATE (Integration of ice-core, marine and terrestrial records) and the Subcommission on Quaternary Stratigraphy (International Commission on Stratigraphy)." Journal of Quaternary Science, 27(7):649-659.

Walker, M., J. Sigfus, R. Sune, P. Trevor, J. Steffensen, P. Gibbard, W. Hoek, J. Lowe, J. Andrews y S. Bórck. 2009. “Formal definition and dating of the GSSP (Global Stratotype Section and Point) for the base of the Holocene using the Greenland NGRIP ice core, and selected auxiliary records." Journal of Quaternary Science, 24(1):3-17.

Walkley, A. y I. A. Black. 1934. "An examination of the Degtjareff method for determining soil organic matter, and a proposed modification of the chromic acid titration method." Soil science, 37(1):29-38.

Waters, M. R. 1992. Principles of geoarchaeology: a North American perspective. University of Arizona Press.

Yacobaccio, H. y G. Guráieb. 1994. Tendencia temporal de contextos arqueológicos: Área del Río Pinturas y zonas vecinas. En: Contribución a la Arqueología del Río Pinturas. Provincia de Santa Cruz., editado por C. Gradín y A. Aguerre. Concepción del Uruguay, Búsqueda de Ayllu. pp. 13-28.

Zilio, L. 2013a. "Chenques en Patagonia Centro-meridional: análisis de los patrones de distribución espacio-temporales." Comechingonia, 17(2):237254.

Zilio, L. 2015. Prácticas mortuorias en la costa norte de Santa Cruz: arqueología de sociedades cazadoras recolectoras en paisajes costeros de la Patagonia argentina Tesis doctoral FCNyM, Universidad Nacional de La Plata.

Zilio, L., M. A. Zubimendi y H. Hammond. 2013. "Chenques en un paisaje costero: análisis espacial de estructuras de entierro en Punta Medanosa." Anuario de Arqueología, 5:253-267.

Zárate, M. A. 1993. La geología del cuaternario y la arqueología. En: Actas del Curso de Postgrado Introducción al estudio del Cuaternario. 14 a 19 de junio, Santa Rosa, La Pampa. 
Zárate, M. A. 1994. Geoarqueología. En: Jornadas de Arqueología e Interdisciplina, Programa de Estudios Prehistóricos, CONICET. Buenos Aires. pp. 21-33.

Zárate, M. A. 1997. "Late Pleistocene geoarchaeology of the southern pampas, Buenos Aires, Argentina." Anthropologie, XXXV:197-205.

Zárate, M. A., A. M. Blasi y J. Rabassa. 2000. Geoarqueología de la localidad Piedra Museo. En: Guía de Campo de la visita a las localidades arqueológicas., editado por L. Miotti, R. Paunero, M. Salemme y G. R. Cattáneo. Taller Internacional del INQUA, La Colonización del Sur de América durante la Transición Pleistoceno/Holoceno. La Plata, Santa Cruz. pp. 56-64.

Zárate, M. A., G. Neme y A. Gil. 2005. “Mid Holocene paleoenvironments and human occupation in southern South America." Quaternary International, 132(1):1-3.

Zubimendi, M. A. 2010. Estrategias de uso del espacio por grupos cazadores recolectores en la costa norte de Santa Cruz y su interior inmediato. Tesis doctoral FCNyM, Universidad Nacional de La Plata.

Zubimendi, M. A., A. Castro y J. E. Moreno. 2005. “Procesos de ocupación de la Costa Norte de Santa Cruz (Argentina)." Relaciones de la Sociedad Argentina de Antropología, 30:225-233.

Zubimendi, M. A. y H. Hammond. 2009. Análisis de los restos malacológicos en el sitio Los Albatros, Bahía del Oso Marino (Provincia de Santa Cruz). En: Arqueología de la Patagonia: una mirada desde el último confín, editado por M. Salemme, F. Santiago, M. Álvarez, E. Piana, M. Vázquez y M. Mansur. Utopías, Ushuaia, pp. 865-878.

Zubimendi, M. A., L. Mazzitelli, A. Navarro, L Zilio y H. Hammond. 2010. Primeras excavaciones en el sitio Palo Alto, Bahía Lángara, Costa Norte de Santa Cruz. En: Arqueología Argentina en el Bicentenario de la Revolución de Mayo, Facultad defilosofía y Letras, Universidad Nacional de Cuyo, CONICET, Mendoza, Argentina, editado por J. R. Bárcena y H. Chiavazza. Vol. 5 pp. 2011-2016.

Zubimendi, M. A., L. Zilio, H. Hammond y C. Gribaudo. 2011b. Rescate arqueológico en la localidad El Zanjón: primeros estudios sobre las prácticas mortuorias en el Golfo San Jorge, Costa Norte de Santa Cruz. En: 
Simposio Muerte, Sociedad y Cultura, editado por M. A. Caggiano y M. C. Sempé. Instituto Municipal de Investigaciones Antropológicas de Chivilcoy (IMIACH) y FCNyM-UNLP, pp. 29-43.

Zubimendi, M. A., P. Ambrústolo, L. Zilio y A. Castro. 2015. “Continuity and discontinuity in the human use of the north coast of Santa Cruz (Patagonia Argentina) through its radiocarbon record." Quaternary International, 356:127-146.

Zubimendi, M. A., P. Ambrústolo, M. Beretta, L. Mazzitelli, M. L. Ciampagna, H. Hammond, L. Zilio, M. Plischuk y A. Castro. 2011. “Sitio Cueva del Negro: Un caso de aprovechamiento intensivo de los recursos marinos en la Costa Norte de Santa Cruz (Patagonia Argentina)." Revista de Estudios Marítimos y Sociales, 4:51-62. 